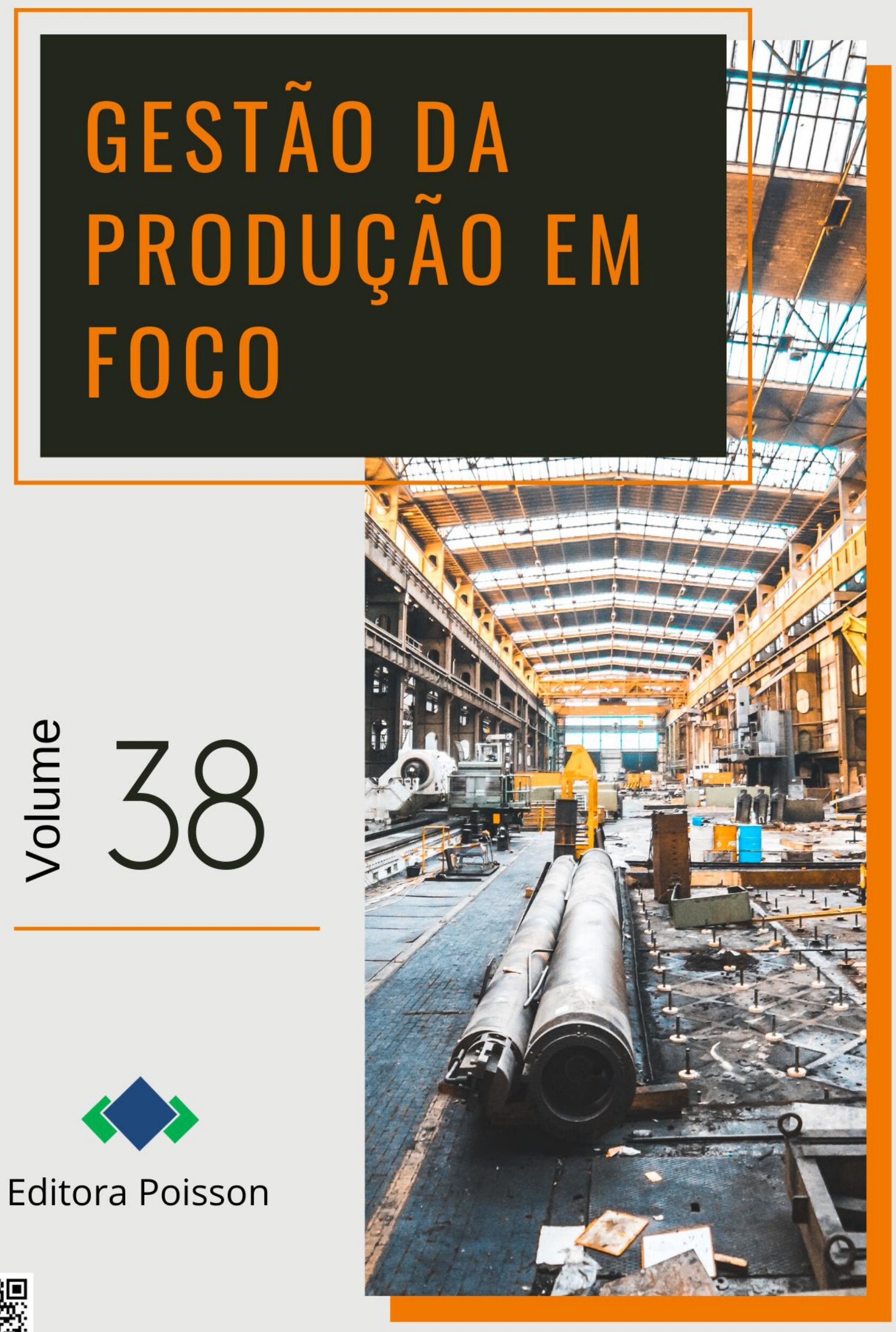


Editora Poisson

\title{
Gestão da Produção em Foco Volume 38
}

\author{
1a Edição
}

Belo Horizonte

Poisson

2019 
Editor Chefe: Dr. Darly Fernando Andrade

\section{Conselho Editorial}

Dr. Antônio Artur de Souza - Universidade Federal de Minas Gerais

Ms. Davilson Eduardo Andrade

Dra. Elizângela de Jesus Oliveira - Universidade Federal do Amazonas

MS. Fabiane dos Santos

Dr. José Eduardo Ferreira Lopes - Universidade Federal de Uberlândia

Dr. Otaviano Francisco Neves - Pontifícia Universidade Católica de Minas Gerais

Dr. Luiz Cláudio de Lima - Universidade FUMEC

Dr. Nelson Ferreira Filho - Faculdades Kennedy

Ms. Valdiney Alves de Oliveira - Universidade Federal de Uberlândia

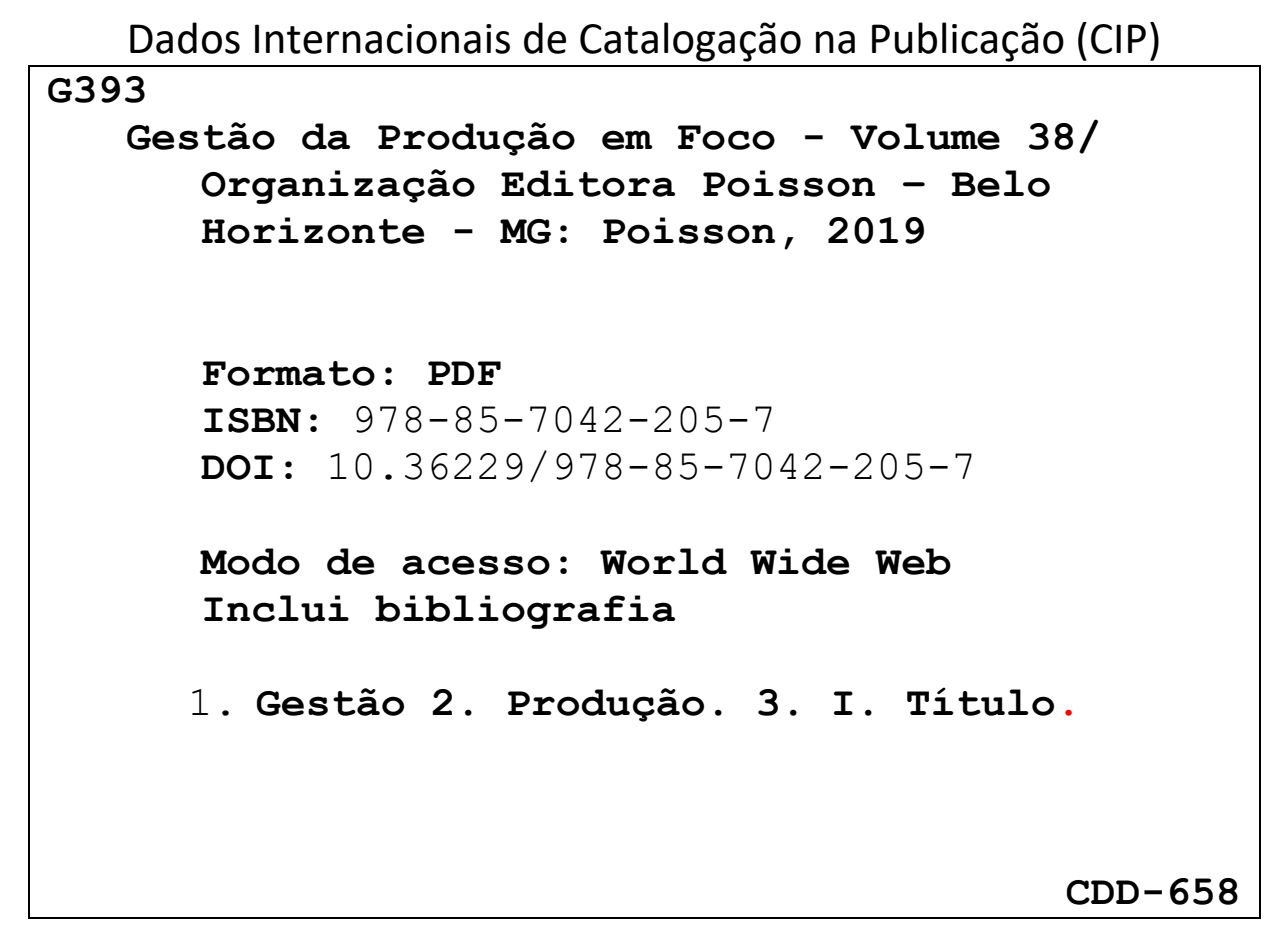

O conteúdo dos artigos e seus dados em sua forma, correção e confiabilidade são de responsabilidade exclusiva dos seus respectivos autores.

Baixe outros títulos gratuitamente em www.poisson.com.br contato@poisson.com.br 


\section{SUMÁRIO}

Capítulo 1: Implantação do Sistema Kanban no Setor de Solda de uma Indústria Metalúrgica de Pequeno Porte do Interior do Estado de São Paulo

Aline dos Reis Cordeiro, Ethel Cristina Chiari da Silva, Roberta Pinheiro Bortolassi, Isabel Cristina Ravazzi Fernandes Nogueira

DOI: 10.36229/978-85-7042-205-7.CAP.01

Capítulo 2: Aplicação da ferramenta FMEA em uma Indústria Têxtil de Pequeno Porte

Laíne de Cássia Teixeira, Shirley Lima Silva, Estefânia Paula da Silva

DOI: $10.36229 / 978-85-7042-205-7 . C A P .02$

Capítulo 3: Planejamento de manutenção para uma Empresa Siderúrgica na Produção de Cal. 25

Vinícius Pimentel Martins, Bernardo Duarte Tofano, Manuel Antonio Molina Palma, Kelly Alonso Costa DOI: $10.36229 / 978-85-7042-205-7 . C A P .03$

Capítulo 4: Implementação do processo de PCP em uma Empresa de Pequeno Porte

Lenita Duarte, Macáliston Gonçalves da Silva, Rafael Maciel da Silva

DOI: $10.36229 / 978-85-7042-205-7 . C A P .04$

Capítulo 5: Um estudo sobre planejamento e controle da qualidade e desenvolvimento de software através do enfoque meta-analítico 52

David de Almeida Moysés, Alexandre Bonfim Martins, Leonardo Daniel Straub, Patrícia Mota Milhomem, Edgard Costa Oliveira

DOI: $10.36229 / 978-85-7042-205-7 . C A P .05$

Capítulo 6: Corrosão em próteses implantadas cirurgicamente 62

Leonardo Rodrigues

DOI: $10.36229 / 978-85-7042-205-7 . C A P .06$

Capítulo 7: Modelo de Matriz de Diagnóstico e Avaliação de Desempenho de Sistemas de Gestão Integrados (SGI) da Qualidade, Meio Ambiente, Segurança e Saúde no Trabalho

Raymundo Jorge de Sousa Mançú, Luís Manuel Borges Gouveia, Silvério dos Santos Brunhoso Cordeiro DOI: $10.36229 / 978-85-7042-205-7 . C A P .07$

Capítulo 8: Gestão de processos aplicado no planejamento de Call Center enfatizando a previsão de demanda - Estudo de caso em Empresa de Seguros 95

Nelson Antonio de Mello Silva Junior, Nicolas André Alves da Silva, Yuri Faro DOI: $10.36229 / 978-85-7042-205-7 . C A P .08$ 


\section{SUMÁRIO}

Capítulo 9: Proposta de melhoria no gerenciamento de projetos inovadores em startup de base tecnológica utilizando modelo híbrido de gestão de projeto

Gustavo de Souza, Isotilia Costa Melo, Karoline Arguelho da Silva, Diogo Ferraz, Daisy Aparecida do Nascimento Rebelatto

DOI: $10.36229 / 978-85-7042-205-7 . C A P .09$

Capítulo 10: Inovações na manufatura aditiva

Júlia Estefane Gonçalves, Lisley Panfilo Santos, Marcelo Franca Alves Júnior, Roberto Guzman Sanchez DOI: $10.36229 / 978-85-7042-205-7 . C A P .10$

Capítulo 11: Industry 4.0: Is there any impact on worker's health and safety? - A literature review

Jessica Alves Justo Mendes, Carlos Alberto Chaves

DOI: $10.36229 / 978-85-7042-205-7 . C A P .11$

Capítulo 12: Gestão de estoque: A previsão de demanda aplicada em uma Distribuidora de Frangos

Kelly Vanessa Barbosa Conceição, Marco André Matos Cutrim, Antonilton Serra Sousa Junior, Luidson Coelho Fernandes, Cássio Ricelly Souza Costa

DOI: 10.36229/978-85-7042-205-7.CAP.12

Capítulo 13: Uma revisão sistemática da literatura sobre tecnologias da gestão de documentos

David de Almeida Moysés, Brenda Baumann Gewehr, Isabella Helena Tavares de Morais, Ari Melo Mariano, Edgard Costa Oliveira

DOI: $10.36229 / 978-85-7042-205-7 . C A P .13$

Capítulo 14: Gestão das Relações Interorganizacionais na Cadeia de Suprimentos Convencional da Construção Civil: Uma revisão sistemática

Christiane Wagner Mainardes Krainer, Jefferson Augusto Krainer, Daniel Getúlio Fernandes Ribeiro, Alfredo Iarozinski Neto, Cezar Augusto Romano

DOI: $10.36229 / 978-85-7042-205-7 . C A P .14$

Capítulo 15: Estudo da pegada hídrica para gestão dos recursos hídricos em Região Semiárida Brasileira

Rodolfo José Sabiá, Thais Aparecida Ribeiro Clementino, Luis Gabriel de Alencar Alves, Caio Vinicius de Araujo Ferreira Gomes, Pedro Eugênio Sabiá DOI: $10.36229 / 978-85-7042-205-7 . C A P .15$ 


\section{SUMÁRIO}

Capítulo 16: Análise da influência da roteirização de veículos na performance térmica da distribuição de produtos da cadeia do frio. 168

Gabriel Alexandre Müller, Vanina Macowski Durski Silva, Diogo Lôndero da Silva DOI: 10.36229/978-85-7042-205-7.CAP.16

Capítulo 17: A concepção do biodigestor para produção de biogás na agroindústria, utilizando o Sistema de Automação Industrial para controle das variáveis de processo

Adão Robson Vieira da Cruz, Alexandre Gaspary Haupt

DOI: $10.36229 / 978-85-7042-205-7 . C A P .17$

Capítulo 18: Análise dos pré-tratamentos de resíduos vegetais na produção de metano em reatores de Biodigestão Anaeróbia

Arthur Ribeiro Torrecilhas, Marcio Ronald Sella, Flávio Augusto Carraro, Juliana Alberton Frias, Ana Carla Viotti

DOI: $10.36229 / 978-85-7042-205-7 . C A P .18$

Capítulo 19: Estudo bibliográfico sobre Estações de Recarga de Veículos Elétricos .204 Matheus Binotto Francescatto, Anderson Felipe Habekost, Cristiano Roos DOI: 10.36229/978-85-7042-205-7.CAP.19

Capítulo 20: As dificuldades enfrentadas na concessão de crédito pelos empreendedores de Bonfinópolis de Minas.

Jorge Luiz Andrade Ramos, Raquel Aparecida Alves, Gevair Campos, Rosimeire Fernandes Cruz Pereira DOI: $10.36229 / 978-85-7042-205-7 . C A P .20$

Capítulo 21: Um estudo comparativo entre as diferentes propostas metodológicas no desenvolvimento de um sistema de mobilidade para equoterapia.

Guilherme Neto Ferrari, Paula Conceição Rocha de Oliveira, Bruno Isamu Obana, Maria de Lourdes Santiago Luz

DOI: $10.36229 / 978-85-7042-205-7 . C A P .21$

Capítulo 22: Um estudo comparativo da eficiência do desempenho acadêmico à luz da aplicação de metodologias inovadoras 232

Ivonalda Brito de Almeida Morais, Eldelita Aguida Porfírio Franco, Genyvana Criscya Garcia Carvalho, Manoel Eulálio Neto, Oduvaldo Vendrametto

DOI: $10.36229 / 978-85-7042-205-7 . C A P .22$ 


\section{Capítulo 1}

Implantação do Sistema Kanban no Setor de Solda de uma Indústria Metalúrgica de Pequeno Porte do Interior do Estado de São Paulo

\section{Aline dos Reis Cordeiro \\ Ethel Cristina Chiari da Silva \\ Roberta Pinheiro Bortolassi \\ Isabel Cristina Ravazzi Fernandes Nogueira}

Resumo: Em uma organização, o bom desempenho do Planejamento e Controle da Produção (PCP) pode proporcionar atendimento à demanda com redução de estoques. Por outro lado, quando o planejamento e controle da produção SÃO DEFICIENTES ISTO pode gerar altos índices de estoques de peças em processo, aumento de custos, parada de linha, altos índices de refugo, entre outros problemas. o sistema Kanban que é foco deste trabalho, se trata de um sistema de informação que controla a produção dos itens necessários, na quantidade necessária e no tempo certo, faz parte, portanto do Sistema toyota de produção ou produção enxuta. 0 objetivo deste trabalho é apresentar a implantação do sistema kanban no setor de solda MAG de uma empresa de pequeno porte do setor metal mecânico a fim de melhorar o planejamento e controle da produção. Para tanto, o trabalho se apoia em uma revisão bibliográfica e em uma pesquisa-ação na empresa citada. Ao final, FORAM CONSTATADOS resultados qualitativos como a melhor organização do setor e aumento do envolvimento dos funcionários e resultados quantitativos como a redução de custos no processo de fabricação devido a diminuição de máquinas e funcionários parados.

Palavras-chaves: Kanban; Pesquisa-Ação; Just in Time; Planejamento e Controle da Produção; Produção Enxuta. 


\section{INTRODUÇÃO}

Segundo Vollmann et al. (2006,p. 30) "um Planejamento e Controle da Produção (PCP) inadequado ou ineficaz são a maldição de muitos gerentes. Na verdade, um desempenho pobre do PCP tem sido a maior causa de falência das firmas".

A estrutura de decisão do PCP é bastante complexa e envolve decisões e planejamento nos níveis estratégico, tático e operacional. Esse trabalho vai tratar especificamente do nível operacional envolvendo o estudo do sistema Kanban.

Ao abordar o sistema Kanban, vale contextualizar que este se trata uma ferramenta do sistema Just-inTime (JIT) que é um dos pilares da manufatura enxuta ou lean manufacturing.

Ghinato (2000) coloca que o Sistema Toyota de Produção (STP) passou a ser referenciado como "Sistema de Produção Enxuta" e que este se trata de uma filosofia de gerenciamento que procura otimizar a organização de forma a atender as necessidades do cliente no menor prazo possível, com qualidade e ao menor custo, ao mesmo tempo em que aumenta a segurança e moral dos trabalhadores e ainda, envolve a integração tanto da manufatura quanto das outras partes da organização.

Quanto ao sistema Kanban, Rahman; Sharif; Esa (2013) afirmam que o sistema Kanban é uma ferramenta relacionada à manufatura enxuta que ajuda a melhorar a produtividade da empresa e, ao mesmo tempo, minimiza os desperdícios da produção.

0 ambiente desse estudo se trata de uma empresa do segmento metal mecânico classificada de pequeno porte segundo a lei complementar 123/2006 conhecida como a lei principal e geral da micro e pequena empresa (BRASIL, 2006).

A empresa atende o mercado automobilístico de carros, ônibus e caminhões. A empresa possui os seguintes processos de fabricação: estampagem que se trata da conformação de materiais planos através de um molde; solda MAG que se trata de um processo de fabricação no qual há a união de diversos tipos de materiais e é muito utilizado nas industrias; solda brasagem trata-se do processo de fabricação de união de diversos materiais; solda ponto/projeção trata-se da união de porcas e/ou parafusos em materiais planos; corte guilhotina/serra; montagem. E além disso os tratamentos de superficie que são a pintura eletrostática, a pintura KTL, a zincagem, a decapagem e o fosfato.

O setor escolhido para essa pesquisa foi o da Solda MAG, pois é o setor que mais ocasionava paradas de linha de produção, um setor de alto custo para a empresa, o setor com grandes problemas de organização no seu layout. Além disso, para poder fazer o tratamento de superfície das peças, estas peças devem estar já soldadas, ou seja, os processos de fabricação de tratamento de superficie são dependentes do setor de Solda MAG.

Os principais problemas desse setor podem ser sumarizados em: (a) organização ou falta de peças, (b) falta de informações seguras e (c) alto índice de refugo de peças.

Diante do exposto o objetivo deste trabalho é implantar o sistema Kanban como uma ferramenta auxiliar na melhoria do planejamento e controle da produção no setor de solda MAG de uma empresa de pequeno porte do setor metal mecânico, localozada no interior do estado de São Paulo.

Para atingir o objetivo proposto o trabalho se baseou em pesquisa bilbiográfica que forneceu o suporte teórico para o desenvolvimento de uma pesquisa-ação na empresa citada.

0 texto foi organizado em cinco seções mais as referências, sendo a primeira a introdução que apresenta o trabalho; a segunda a manufatura enxuta e o sistema kanban que apresenta o referncial teórico de suporte dessa pesquisa; a terceira o método da pequisa que apresenta a classificação metodológica da pesquisa e as etapas para sua excecução, a quarta a pesquisa-ação na empresa que detalha a intervenção realizada; a quinta conclusões e considerações finais que encerra o trabalho e destaca alguns pontos dessa pesquisa e, por fim as referências.

\section{MANUFATURA ENXUTA E O SISTEMA KANBAN}

Womack e Jones (1998) definiram a produção enxuta como uma nova abordagem, segundo a qual, sempre existe uma melhor forma de organizar e gerenciar os relacionamentos de uma empresa com os clientes, a cadeia de fornecedores, o desenvolvimento de produtos e as operações da produção. 
A produção enxuta, conforme Chase et al. (2006) foi desenvolvida com a finalidade de melhorar a qualidade e a produtividade, e está baseado em duas filosofias centrais: (a) a eliminação de perdas; (b) respeito pelas pessoas.

Ghinato (2000) coloca que o JIT significa que cada processo deve ser suprido com os itens certos, no momento certo, na quantidade certa e no local certo.

0 JIT baseia-se em três frentes:

- Conjunto de técnicas: são técnicas centrais do sistema JIT utilizadas para atacar todas as fontes e causas de desperdícios;

- Participação de todos: o JIT é um sistema que propicia excelência na manufatura. Isto significa que todas as pessoas e todos os processos devem ser incluídos;

- Melhoramento contínuo (Kaizen): a filosofia JIT enfatiza conceitos ideais em muitas áreas, tais como zero defeito, zero estoque. Portanto, o JIT propõe o que se pode chamar de a "jornada sem fim".

Portanto, ao se analisar o JIT como uma filosofia de produção, três objetivos se destacam:

- Eliminação dos desperdícios;

- Envolvimento de todos;

- Aprimoramento contínuo.

Ao se analisar como um conjunto de técnicas e conceitos pode-se destacar: (a) Programação nivelada; (b) troca rápida de ferramentas; (c) programas de manutenção preventiva; (d) layout celular; (e) operador multifuncional; (f) melhoria no manual de operações e padronização das operações; (g) qualidade por toda empresa; (h) sistema kanban; (i) sistema de fornecedores.

O foco deste trabalho está no sistema Kanban, lembrando que, para seu bom fincionamento, necessita de um ambiente JIT.

Abordando agora o sistema Kanban, Moura (2007, p. 25) coloca que,

Kanban é uma técnica de gestão de materiais e de produção no momento exato ("Just in Time"), que é controlado através do movimento do cartão (Kanban). 0 sistema Kanban é um método de "puxar" as necessidades de produtos acabados e, portanto, é oposto aos sistemas de produção tradicionais. É um sistema simples de auto-controle a nível de fábrica, independente de gestões paralelas e controles computacionais.

Na visão de Tubino (2009, p.142), "Kanban é um sistema puxado, os cartões Kanban têm a função, conforme a finalidade para que se destinam, de substituírem as ordens de produção, de montagem, de compra ou movimentação".

Segundo Slack, Chambers e Johnston (2007, p.494), "o controle Kanban é um método de operacionalizar o sistema de planejamento e controle puxado".

Segundo Corrêa e Gianesi (1993, p. 91)

Kanban é o termo japonês que pode significar cartão. Este cartão age como disparador da produção de centros produtivos em estágios anteriores do processo produtivo, coordenando a produção de todos os itens de acordo com a demanda de produtos finais.

Segundo Pace (2003, p. 8)

Sistema Kanban consiste no emprego de cartões, tanto para requisitar material de um centro produtor para um centro consumidor, quanto para ordenar o centro produtor a produzir determinado produto em determinado momento. Visa à redução dos estoques em processo a limites mínimos e à produção somente quando necessária. 
Conforme as definições citadas pode-se dizer que o Kanban é uma ferramenta que faz parte do sistema JIT e tem por função auxiliar o planejamento e controle da produção por meios de cartões ou qualquer dispositivo visual que tem a função de "ordenar" a produção mostrando qual é a prioridade na fabricação.

Segundo Schonberger (1987), o Kanban só funcionará bem no contexto do sistema JIT, este por sua vez, pode fucionar sem um subsistema Kanban, mas faltará sentido ao Kanban que for operado independente do JIT.

Para realizar o propósito do sistema JIT, o kanban deve ser usado com as seguintes regras, conforme Monden (1981):

- 0 processo posterior deve retirar somente os itens necessários do processo anterior, nas quantidades necessárias e no momento certo;

- O processo posterior deve produzir seus itens nas quantidades requisitadas pelo processo posterior;

- 0 produto disponibilizado no supermercado tem qualidade assegurada;

- $\quad 0$ número de kanbans deve ser minimizado.

O cálculo do número de kanbans pode ser feito pela seguinte fórmula, conforme Monden (1981):

$$
y=\frac{(\bar{D} L+w)}{a}(1)
$$

Onde:

y - número de kanbans;

$\overline{\mathrm{D}}$ - demanda média esperada por unidade de tempo;

$\mathrm{L}$ - Lead time

w - índice de segurança (não mais que $10 \%$ do DL)

a - capacidade do contenedor

Tem-se que o sincronismo da produção por kanban pode adaptar-se somente a pequenas flutuações da demanda. 0 sistema kanban apresenta uma grande flexibilidade com relação as prioridades e uma flexibilidade limitada com relação ao volume.

No sistema Kanban, utiliza-se o Painel Porta-Kanbans, que tem como objetivo a sinalização da produção, pois nele estão os cartões Kanban, no qual possui todas as informações. Esses painéis normalmente ficam próximos aos "supermercados" espalhados pela produção. O lugar onde o painel Kanban fica deve ser estratégico, pois é através dele que sinaliza o fluxo de movimentação, o consumo dos itens em processo e a matéria-prima que deve ser adquirida. Segundo Moura (2007, p.80), "o Painel Porta-Kanbans é um método que utiliza um quadro colorido na célula ou estação de produção para indicar o fluxo de consumo de cada item. 0 quadro é pintado de verde, amarelo e vermelho, de baixo para cima".

Segundo Tubino (2009, p.146)

Essas três faixas são utilizadas para seqüenciar de forma visual a reposição dos supermercados. Para administrar esse seqüenciamento, sempre que os clientes desse supermercado forem retirando os contenedores com os lotes dos itens, os cartões Kanban correspondentes devem ser afixados da faixa verde para a vermelha.

A Figura 1 mostra um painel porta-kanbans e uma analogia entre o controle do sistema kanban com a política de reposição de estoques acionada pelo ponto de pedido. 
Figura 1 - Painel porta-kanbans. Fonte: Moura (2007, p. 81).

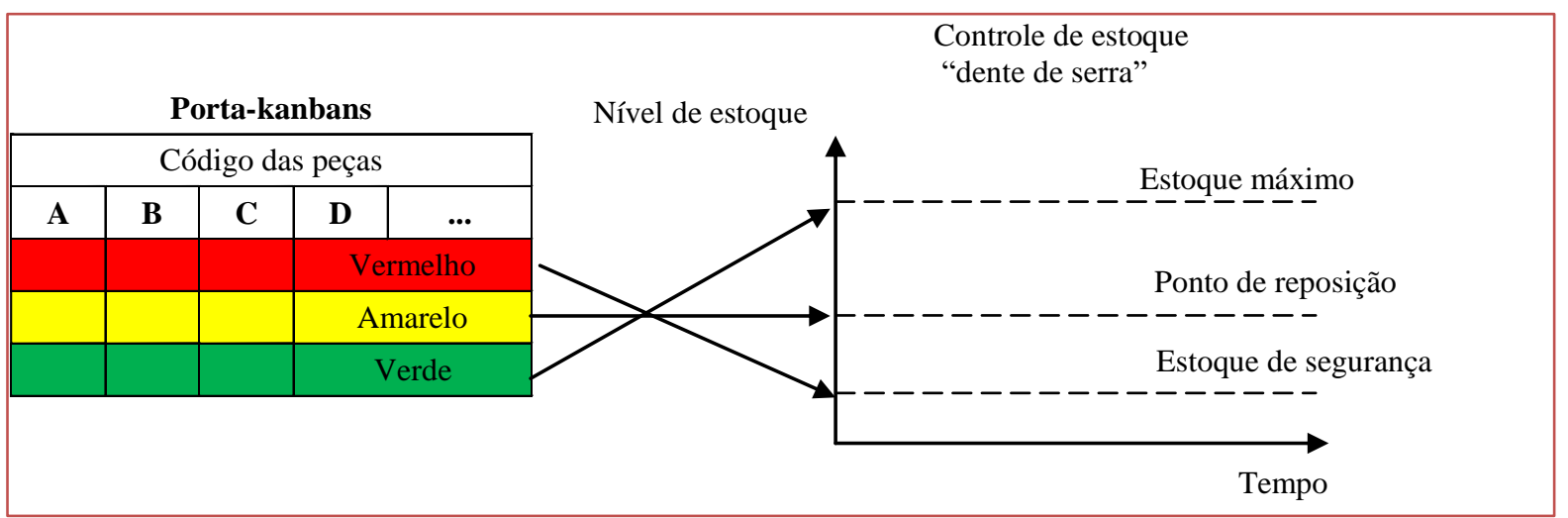

\section{MÉTODO DA PESQUISA}

0 trabalho foi desenvolvido por meio de pesquisa bibliográfica e também por meio de uma pesquisa em uma empresa pequeno porte do setor metal mecânico. A pesquisa na empresa caracteriza-se como uma pesquisa-ação, pois segundo Tripp (2005) esta é caracterizada por agir no campo da prática e investigar de maneira teórica a respeito dela.

Para Thiollent (1997 apud Miguel, 2007), a pesquisa-ação pode ser definida como a pesquisa com base empírica que é concebida e realizada em estreita associação com uma ação ou com a resolução de um problema coletivo e na qual os pesquisadores da situação ou do problema estão envolvidos de modo cooperativo ou participativo. A pesquisa-ação segue um ciclo de investigação que com a prática vai se aprimorando. Segundo Tripp (2005), esse ciclo segue o raciocino: planeja-se, implementa-se, descreve-se e avalia-se uma mudança para a melhora de sua prática, aprendendo mais, no correr do processo, tanto a respeito da prática quanto a própria investigação. Normalmente o ciclo de melhoria contínua também é desta forma. A figura 2 mostra de maneira clara as fases do ciclo da pesquisa-ação.

Figura 2 - Representação em quatro fases do ciclo básico da investigação-ação. Fonte: Tripp (2005, p. 446).

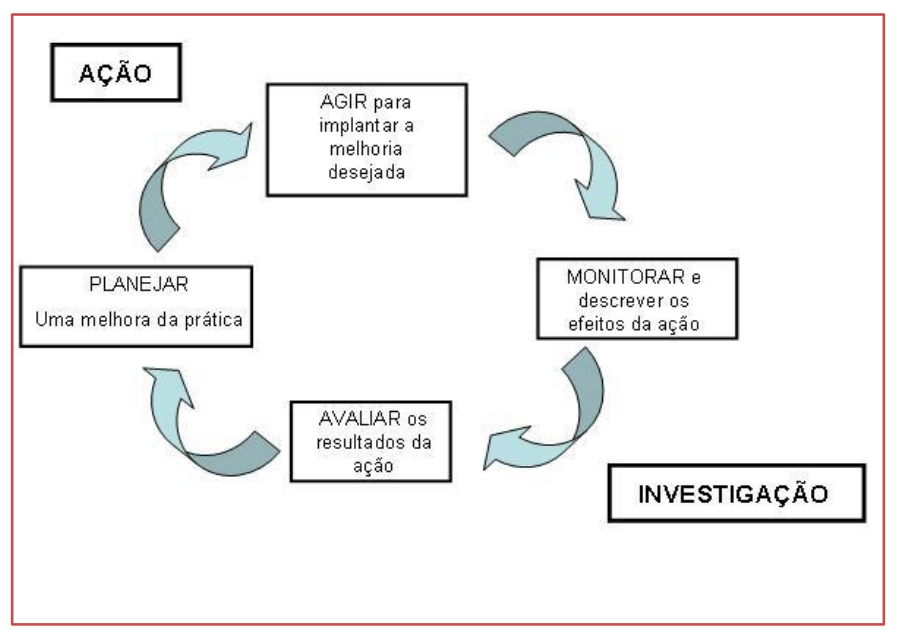

A solução dos problemas começa com a sua identificação. Identificado o problema é feito um planejamento para buscar as hipóteses de solução, sua implementação, seu monitoramento e a avaliação de sua eficácia (Tripp, 2005). 


\subsection{FASES DO DESENVOLVIMENTO DA PESQUISA-AÇÃO DESSE ESTUDO}

A seguir no Quadro 1, pode-se observar as fases da pesquisa-ação e o que foi feito no trabalho aqui relatado.

Quadro 1 - Fases da pesquisa-ação e o detalhamento de procedimentos do presente estudo. Fonte: os próprios autores.

\begin{tabular}{|c|c|}
\hline Fases da pesquisa-ação & Procedimentos do presente estudo \\
\hline Planejamento & $\begin{array}{l}\text { Nesta fase fez-se um estudo a fundo do setor e coletou-se dados em relação a } \\
\text { custos. Fez um acompanhamento na produção em um período de quinze dias, } \\
\text { analisando funcionários e máquinas paradas. }\end{array}$ \\
\hline Ação & Realizou-se um passo-a-passo da implantação do sistema Kanban no setor \\
\hline Resultados & $\begin{array}{c}\text { Após a implantação do Kanban, em um período de } 15 \text { dias novamente foi } \\
\text { coletado dados da produção em relação a funcionários e máquinas paradas e } \\
\text { analise dos resultados. }\end{array}$ \\
\hline Avaliação & Foi realizado um gráfico comparativo do antes e depois do sistema Kanban \\
\hline
\end{tabular}

\section{A PESQUISA-AÇÃO NA EMPRESA DO ESTUDO}

\subsection{CARACTERIZAÇÃO DA EMPRESA E DO AMBIENTE DO ESTUDO}

A empresa estudada atende ao mercado automobilistico desde o ano de 1970, mercado este muito exigente em relação a cumprimento de prazo de entrega, qualidade em seus produtos e seus processos de fabricação. 0 setor de Solda MAG, possui 7 máquinas de solda e 14 funcionários.

O setor de solda MAG funciona da seguinte forma:

- Em cada máquina há uma dupla de funcionários, um é o alimentador da linha e o outro o soldador;

- $\quad$ alimentador da linha coloca as peças a serem soldadas na máquina e faz toda a preparação para o soldador fazer os cordões de solda;

- Cada peça dependendo de seu formato passa por uma "dupla" em uma máquina ou em todas as "duplas" percorrendo todas as máquinas;

- Em cada "dupla" de máquina para fazer a solda e necessário no mínimo duas peças para ser soldadas, caso contrário, não se realiza a operação.

No setor tem as peças para serem soldadas e também as peças finalizadas que são encaminhadas para o processo seguinte, que é o tratamento de superfície.

A Figura 3 mostra o setor de Solda MAG da empresa.

Figura 3 - Setor de Solda MAG.

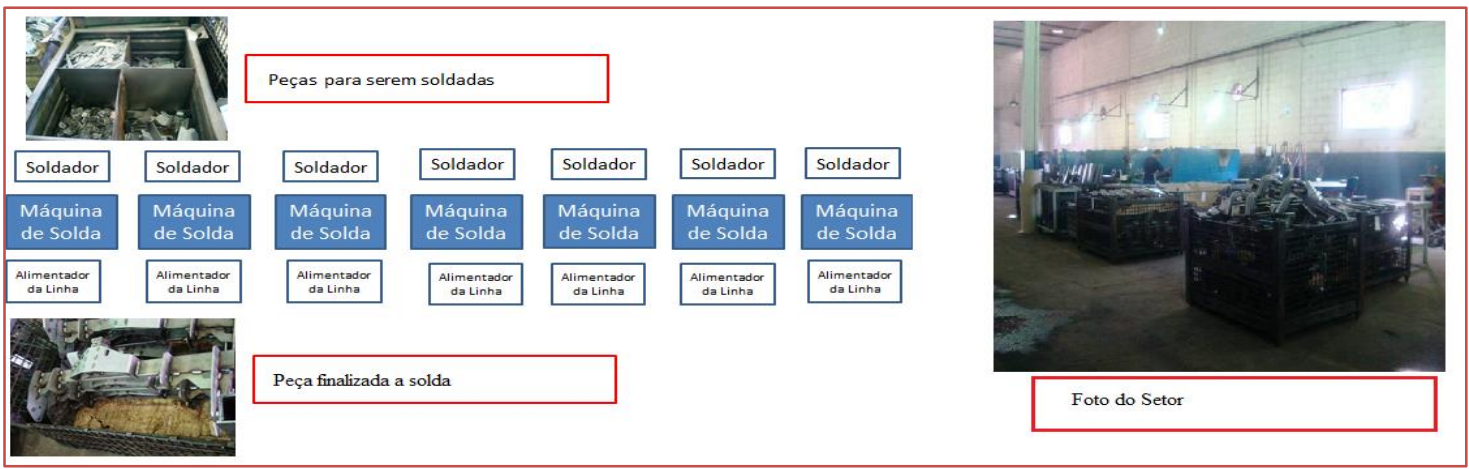

Fonte: A empresa do estudo. 


\subsection{A FASE DE PLANEJAMENTO}

Nesta fase de planejamento, inicialmente foi coletado os dados antes da implantação do Kanban, com relação:

\section{a) Dados em Relação ao Custo}

- Custo da hora do funcionário do setor de solda MAG. 0 setor atualmente possui 7 máquinas de solda MAG e 14 funcionários no setor.

- Custo da hora/máquina.

Os valores não serão apresentados para não expor a empresa do estudo.

Em seguida foi acompanhado em um período de quinze dias no qual houve produção das peças soldadas e os resultados foram os seguintes:

\section{b) Dados em Relação a Produção}

Dos 15 dias acompanhando a produção, em 11 dias houve máquinas paradas devido à falta de peças para a realização da soldagem.

Dos 15 dias acompanhando a produção, 10 dias os processos de tratamento superficial ficaram parados por no mínimo uma hora, aguardando as peças soldadas para serem pintadas.

Um dia crítico em que 5 máquinas e 10 funcionários ficaram parados devido as peças que estavam em estoque para serem soldadas foram refugadas devido ao longo período de estocagem.

Aproximadamente $10 \%$ de todo o estoque de peças a serem soldadas refugadas devido ao longo período de armazenagem.

\subsection{A FASE DE AÇÃO}

A implantação do Kanban foi realizada da seguinte forma:

10 Passo - Levantamento de todas as peças que passam pelo setor de solda MAG, com a finalidade de ter conhecimento do volume mensal de rotatividade de peças no setor, a partir disso é possível se ter um parâmetro de verificação de níveis aceitáveis de estoque para as futuras conferências.

2o Passo - Organização do setor através da mudança do layout. O setor de solda MAG não possuía inicialmente espaço físico suficiente para qualquer tipo de reorganização, foi necessário estudar e reorganizar os setores próximos a fim de disponibilizar um local para o armazenamento dos componentes que não estavam em processo de fabricação naquele setor no momento. Com isso, uma grande área do setor da solda MAG foi liberada. Foi desenvolvido também a "Prateleira Kanban", cuja finalidade é o armazenamento das peças pequenas, e as demais peças de tamanho maior ficaram armazenados em caçambas, mas de maneira padronizada.

3o Passo - Foi realizado um inventário no setor para saber as reais quantidades de peças. Durante esta etapa foi constatado o problema que já era previsto pela gestão, as quantidades de peças descritas no cartão de identificação eram diferentes da física, que era a principal causa dos problemas de parada de linha no setor. Foi averiguada também a mistura de peças em uma mesma embalagem, bem como identificado a existência de quantidades de peças desconhecidos pelo líder de produção. Além disso, todas as peças foram devidamente identificadas.

4o Passo - Foi realizado um treinamento com os funcionários com o objetivo de mostrar a proposta do projeto Kanban, as melhorias que proporcionariam a partir dessa mudança e funcionamento do mesmo. Também foi definido neste momento um funcionário que seria responsável pelo controle das entradas e saídas das peças na área reservada para o Kanban.

5o Passo - Identificação com a classificação de prioridades de acordo com a demanda de cada peça: baseado em um histórico de saídas foi definido o estoque de segurança para cada peça.

\subsection{RESULTADOS}

A Figura 4 mostra os ganhos qualitativos em relação a implantação do sistema Kanban, mostrando uma cronologia do antes e do depois da implantação, é nítido observar no que diz respeito a melhoria na 
organização, um melhor ambiente de trabalho e resolução de pequenos problemas de identificação incorreta além de proporcionar segurança na informação.

Após a implantação do Kanban, novamente em um período de quinze dias foi feito um acompanhamento da produção em relação a máquinas e funcionários, e os resultados encontrados foram os seguintes:

- Diminuição no estoque de peças a serem soldadas em 35\%.

- Não houve peças a serem soldadas refugadas devido ao longo tempo de estocagem.

- Dos 15 dias, em apenas 4 dias houve 1 máquina e 2 funcionários parados.

o Tratamento de Superfície não ficou nenhum dia parado devido falta de peças.

Figura 4 - Imagens Antes e Depois da Implantação do Kanban - Ganhos Qualitativos - no setor de solda MAG. Fonte: a empresa do estudo.

Antes da implantação do sistema kanban.

\subsection{AVALIAÇÃO}

Após as fases de planejamento, ação e os resultados encontrados pode-se avaliar por meio de gráficos o quanto benefico foi à implantação do Sistema Kanban no setor de Solda MAG. A Figura 5 mostra através de um gráfico a quantidade de máquinas e funcionários parados antes da aplicação do Kanban. Pode-se observar que em um período de 15 dias, somente em 4 dias não houve parada de máquinas e funcionários. No dia 14, teve 5 máquinas e 10 funcionários parados. Tratando-se de produtividade, esses números são muito alto e deixa a produtividade do setor baixa. 
Figura 5 - Gráfico quantidade de funcionários e máquinas paradas antes da aplicação do Kanban

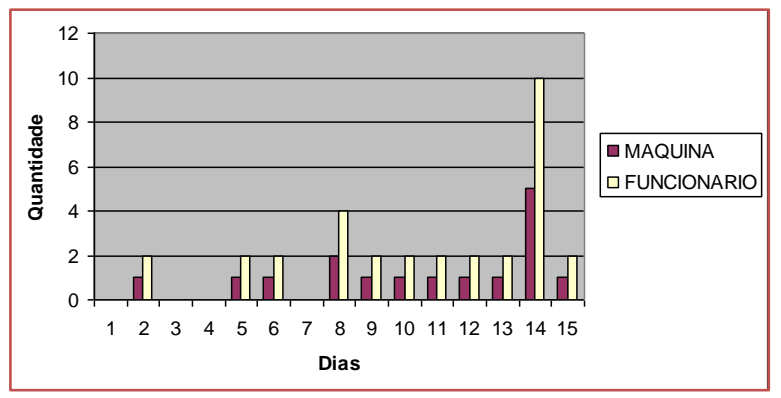

Fonte: Os próprios autores.

A Figura 6 amostra através de um gráfico a quantidade de máquinas e funcionários parados depois da aplicação do Kanban. Observa-se que somente em 4 dias houve 1 máquina e 2 funcionários parados.

Figura 6 - Gráfico quantidade de funcionários e máquinas paradas após a aplicação do Kanban

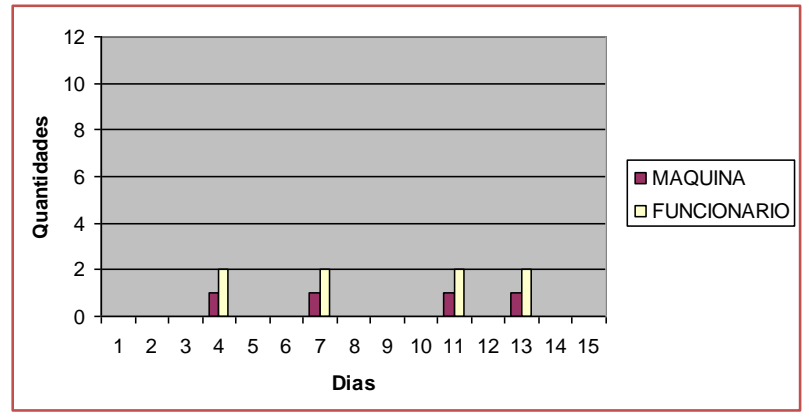

Fonte: Os próprios autores.

Os gráficos mostram visualmente a grande mudança no setor após a aplicação do Kanban em relação a máquinas e funcionários parados. Observa-se que houve aumento da produtividade devido à dimunição de dias com máquinas e funcionários parados no setor de solda MAG. A empresa fez um estudo em relação ao custo de fabricação e foi constatado que após a implantação do sistema Kanban, as melhorias presentes neste setor gerou uma redução de gastos de fabricação de $82,7 \%$ neste setor.

\section{CONCLUSÕES E CONSIDERAÇÕES FINAIS}

Depois de realizado toda a pesquisa bibliográfica e a pesquisa ação pode-se afirmar que o sistema Kanban é um controle de produção que não requer um investimento elevado para o seu funcionamento. 0 que é exigido para o seu bom funcionamento é a disciplina de cada funcionário para executar da maneira ideal o sistema.

O estudo reafirmou que o Kanban exige que se tenha na fabrica a filosofia JIT. 0 sistema Kanban traz resultados positivos qualitativamente em relação à organização e quantitativamente em relação a uma redução significativa de gastos e aumento da produtividade. A maior dificuldade do sistema Kanban é a disciplina do controle diário. O Sistema Kanban promove também uma descentralização das responsabilidades e da disponibilidade das informações sobre a produção, desta forma, as mesmas não ficam restritas e a cargo apenas do PCP, mas de todos os colaboradores envolvidos.

Diante dos resultados obtidos pode-se concluir que o objetivo proposto foi alcançado, pois a aplicação do Kanban trouxe diversos ganhos no setor, tais como: diminuição significativa de paradas de linha, melhor qualidade da informação através da visualização, organização no setor, maior confiabilidade nas informações e aumento da produtividade. 


\section{REFERÊNCIAS}

[1] BRASIL. Lei Complementar no 123, de 14 de Dezembro de 2006. Lei de estabelecimento das normas gerais relativas ao tratamento diferenciado e favorecido a ser dispensado às microempresas e empresas de pequeno porte no âmbito dos Poderes da União, dos Estados, do Distrito Federal e dos Municípios. Disponível em: <http://www.planalto.gov.br/ccivil_03/leis/lcp/lcp123.htm> Acesso em: 12/07/2019.

[2] CHASE, R. B.; JACOBS, F.R.;AQUILANO, N.J. Administração da produção para vantagem competitiva. Porto Alegre: Bookman, 2006.

[3] CORRÊA, H. L., GIANESI, I. G. N. Just in Time, MRP II e OPT: um enfoque estratégico. 2ª Ed. São Paulo: Atlas, 1993.

[4] GHINATO, P. Produção e Competitividade: aplicações eiInovações. Ed. Adiel, UFPE, Recife, 2000.

[5] MIGUEL, P. A. C. Estudo de caso na engenharia de produção: estruturação e recomendações para sua condução. Produção, v.17, n.1, p. 216 - 229. Janeiro/Abril 2007.

[6] MONDEN, Y. Adaptable kanban systems helps Toyota maintain Just-in-Time production. Industrial Engineering, may, 1981.

[7] MOURA, R. A. Kanban: A Simplicidade do Controle de Produção. 7ª ed. São Paulo: IMAM, 2007.

[8] PACE, J. H. O Kanban na Prática. Rio de Janeiro: Qualitymark, 2003.

[9] RAHMAN, N. A. A.; SHARIF, S.M.; ESA, M. M. Lean mnufacturing case study with kanban system implementation. International Conference on Economics and Business Research (ICEBR) 2013, p. 174-180.

[10] SCHONBERGER, R.J. Técnicas industriais japonesas: nove lições sobre a simplicidade. São Paulo: Pioneira, 1987.

[11] SLACK, N.;CHAMBERS, S.;JOHNSTON, R. Administração da Produção. 2ª ed. São Paulo: Atlas, 2007.

[12] TRIPP, D. Pesquisa-Ação: Uma Introdução Metodológica. Educação e Pesquisa, São Paulo, v.31, n.3, p. 443446, Setembro/Dezembro 2005.

[13] TUBINO, D. F. Planejamento e Controle da Produção: teoria e prática. $2^{a}$ ed. São Paulo: Atlas, 2009.

[14] VOLLMANN, T.E.; BERRY, W.L.; JACOBS, F. R.; WHYBARK, D.C. Sistemas de Planejamento \& Controle da Produção para o Gerenciamento da Cadeia de Suprimentos. 5a ed. Porto Alegre: Bookman, 2006. p. 25 - 40.

[15] WOMACK, J.P.; JONES, D.T. A Mentalidade Enxuta nas Empresas. Rio de Janeiro: Ed. Campus, 1998. 


\section{Capítulo 2}

\section{Aplicação da ferramenta FMEA em uma Indústria Têxtil de Pequeno Porte}

\section{Laine de Cássia Teixeira}

Shirley Lima Silva

Estefânia Paula da Silva

Resumo: A indústria têxtil movimenta grande parte da economia nacional devido ao seu amplo campo de atuação, destacando-se o setor de confecção, que faz parte da fase final da cadeia têxtil e fabrica diversos produtos, desde o vestuário até artigos confeccionados. Toda essa produção é direcionada para o comércio atacadista, varejista, lojas de departamentos, entre outros, estando tais clientes cada vez mais exigentes e o mercado gradativamente competitivo, o que exige que as confecções busquem meios de se manterem nesse mercado tão disputado. Tendo em vista que a manutenção possibilita aumentar a confiabilidade dos equipamentos, garantindo que o processo se mantenha produtivo e com qualidade, obtendo como resultado uma maior competitividade no mercado e assegurando sua sobrevivência no mesmo, o presente trabalho teve como objetivo aplicar a ferramenta FMEA - Análise de Modos e Efeitos das Falhas em uma indústria têxtil de pequeno porte, localizada na região centro-oeste de Minas Gerais. Para utilização de tal método realizou-se uma visita na confecção e uma entrevista nãoestruturada com a proprietária, a fim de coletar todos os dados necessários para a construção do quadro da ferramenta FMEA. Constatou-se que a máquina travete possui o maior NPR - Número de Prioridade de Risco, sendo tal fato justificado pelo fato da mesma possuir um alto índice de gravidade e ocorrência, enquanto tesouras e trocadores de agulha tem os menores NPRs, visto que ambas as ferramentas possuem os menores índices de detectabilidade da falha e baixos índices de gravidade. Como a máquina travete é a mais utilizada na empresa e sua quebra afeta diretamente toda a produção, recomenda-se criar um plano de manutenção para que a mesma não apresente número tão alto de risco e não coloque, assim, a produção em situação de perigo, sendo sugerida a utilização da ferramenta $5 \mathrm{~W} 1 \mathrm{H}$ como procedimento para manutenção preventiva da mesma.

Palavras-chave: Manutenção, Confiabilidade, Confecção 


\section{INTRODUÇÃO}

Existem, atualmente, inúmeros segmentos industriais que movimentam a economia brasileira, sendo o ramo da indústria têxtil, um dos maiores e mais importantes setores empresariais nacionais. Esse, por sua vez, é constituído pelos seguintes setores: produção de fibras, fiação, tecelagem e malharia, beneficiamento e confecção (PEREIRA, 2009).

O fato de movimentar diversos setores, necessitar de um número alto de força de trabalho alocada no setor e, também, força de trabalho relativa à outros setores da indústria manufatureira, além de empregos indiretos gerados nos demais elos da cadeia produtiva é que faz da produção têxtil um setor muito importante para a economia nacional (EMERY, 2007). Segundo a Associação Brasileira da Indústria Têxtil e Confecção - ABIT (2018), no ano de 2017 a cadeia têxtil e de confecção faturou US\$ 51,58 bilhões de dólares; com uma produção de aproximadamente 8,9 bilhões de peças. Os investimentos no setor foram de R\$ 3,1 milhões; sendo empregadas diretamente 1,5 milhão de pessoas, sendo $75 \%$ dessas, mão de obra feminina. Além disso, é o $2^{\text {o }}$ maior empregador da indústria de transformação, perdendo apenas para alimentos e bebidas (juntos); em que o número de empresas ultrapassa 27,5 mil em todo país. Diante desses números, é possível constatar a importância desse setor e perceber que, independentemente do segmento ou da região a ser instalada, a realidade é uma só para todos: a competitividade está cada vez mais intensa e os clientes cada vez mais exigentes.

Devido à essa grande movimentação econômica na indústria têxtil-confecção e os clientes cada vez mais meticulosos, o setor está paulatinamente mais competitivo e as empresas, por sua vez, expostas a este cenário, estão buscando estratégias para sobreviver nesse ambiente. Uma alternativa vista por muitas empresas, a fim de garantir alta produtividade, foi atentar-se para a questão da manutenção, pois, assim, conseguem obter uma maior disponibilidade dos equipamentos, maior flexibilidade de produção, velocidade de entrega dos produtos, entre outros pontos importantes, que as torna competitivas no mercado (SILVA, 2001).

As empresas brasileiras do setor têxtil, em sua maioria, são de pequeno e médio porte e, muitas vezes, desconhecem a importância da manutenção como aliada para a melhoria da produtividade e competitividade. Em consequência disso, não investem em recursos em tal atividade (SILVA, 2001). Poucos conseguem entender o quanto a manutenção está ligada ao processo, via disponibilidade e confiabilidade dos equipamentos, enxergando-a como meio de aumentar sua competitividade frente ao mercado (VIERRI, 1995).

Nesse contexto, o presente trabalho tem como objetivo aplicar a ferramenta FMEA - Análise de Modos e Efeitos das Falhas - em uma indústria têxtil de pequeno porte, localizada na região centro-oeste de Minas Gerais, abordando, também, a importância da manutenção.

\section{REFERENCIAL TEÓRICO}

\subsection{HISTÓRICO DA MANUTENÇÃO}

A manutenção está ligada à evolução do homem, a partir do momento que o mesmo passou a manusear instrumento para a caça e o plantio. Com o surgimento de equipamentos cada vez mais complexos e a necessidade de uma maior confiabilidade e disponibilidade dos mesmos, a manutenção passou a ter um papel cada vez mais importante (VIANA, 2014).

De acordo com Viana (2014), a palavra manutenção vem do latim manus tenere, que significa manter o que se tem. De acordo com a NBR 5462, a manutenção é a combinação de todas as ações técnicas e administrativas, incluindo as de supervisão, destinadas a manter ou recolocar um item em um estado no qual possa desempenhar uma função requerida, incluindo também a modificação do item (ABNT, 1994).

A missão principal, atualmente, da manutenção é garantir a disponibilidade da função dos equipamentos e instalações, de modo a atender a um processo de produção ou de serviço com confiabilidade, segurança, preservação do meio ambiente e custo adequado (KARDEC; NASCIF, 2017). 
Nesse aspecto, Kardec e Nascif (2017) classificam a manutenção em seis tipos básicos:

- Manutenção Corretiva Planejada: ação corretiva que ocorre devido ao acompanhamento preditivo, detectivo, ou de inspeção, visando corrigir uma situação diagnosticada, sendo feita de forma planejada.

- Manutenção Corretiva Não Planejada: realizada após a ocorrência, seja essa uma falha ou queda de desempenho, objetivando recolocar um item em condições de executar a função requerida.

- Manutenção Preventiva: é a ação executada com base em planos previamente elaborados, baseados em intervalos definidos (tempo, quilometragem, etc.).

- Manutenção Preditiva: é uma atuação realizada com base nas modificações identificadas dos parâmetros. Através das técnicas preditivas é feito o monitoramento da condição e a ação de correção, quando necessária, é realizada através de manutenção corretiva planejada.

- Manutenção Detectiva: é a atuação efetuada em sistemas de proteção, comando e controle, buscando detectar falhas ocultas ou não perceptíveis às pessoas da operação e manutenção.

\subsection{MANUTENÇÃO PRODUTIVA TOTAL (TPM)}

Um outro tipo de manutenção é a Manutenção Produtiva Total (TPM), que se constitui, atualmente, como um método de gestão da manutenção focado na identificação e eliminação das perdas nos setores produtivos e administrativos. A utilização plena dos equipamentos, a eficácia dos processos e o melhor desempenho do fator humano conduzem a empresa à um cenário de custos competitivos e produtos de qualidade total (KARDEC; NASCIF, 2017).

Segundo Wyrebski (1997), a TPM propõe a atividade da manutenção produtiva com a participação de todos os funcionários da empresa, desde o nível de presidente, até o de operário, mesmo que com envolvimentos diferenciados. 0 objetivo global da TPM é a melhoria da estrutura da empresa em termos materiais (máquinas, equipamentos, ferramentas, matéria- prima, produtos etc.) e em termos humanos (aprimoramento das capacitações pessoais envolvendo conhecimento, habilidades e atitudes).

A meta a ser alcançada é o rendimento operacional global (FREITAS, 2009). Os pilares da TPM envolvem todos os departamentos de uma empresa, habilitando-se a buscar metas, tais como Zero Defeito ou Falha Zero, estudos de disponibilidade, confiabilidade e lucratividade (PEREIRA, 2011).

\subsection{CONFIABILIDADE, DISPONIBILIDADE E MANUTENIBILIDADE}

Segundo Helman e Andery (1995), confiabilidade é a probabilidade de um determinado sistema desempenhar sem falhas uma função durante um determinado período. A disponibilidade, segundo Fogliato e Ribeiro (2011), pode ser definida como a capacidade de estar em condições de executar certa função requerida, em um determinado instante do tempo ou em um período de tempo predeterminado.

Outro indicador importante na gestão da manutenção é a manutenibilidade que, segundo Kardec e Nascif (2017), pode ser conceituada como sendo a característica de um equipamento ou instalação permitir um maior ou menor grau de facilidade na execução dos serviços de manutenção.

\section{4..FMEA - FAILURE MODE AND EFFECTS ANALYSIS}

Uma ferramenta muito útil na prevenção de falhas é o método FMEA (Failure Mode and Effects Analysis Análise do Modo e Efeito das Falhas), que de acordo com Pereira (2011), é uma técnica usada para conhecer e antecipar a causa e o efeito de cada modo de falha de um sistema ou produto. Para Helman e Andery (1995), é um método que permite a análise sistemática de um produto ou processo, buscando avaliar possíveis falhas, estabelecendo suas consequências e orientando a adoção de medidas corretivas e preventivas. Kardec e Nascif (2017) completam que a ferramenta FMEA é um sistema lógico que hierarquiza as falhas potenciais e fornece recomendações para ações corretivas. 
Eles ainda afirmam que os principais conceitos necessários para a análise, são:

- Causa: é o que gera ou pode gerar a falha;

- Efeito: resultado da falha para o processo ou produto;

- Modo: falha ocorrida ou que pode ocorrer.

Além desses, ainda há os índices que são classificados de 1 a 10, sendo 1 o menor e 10 o maior grau. Esses índices são a frequência, a gravidade e a detectabilidade da falha. A partir do valor dado a esses índices tem-se o Índice de Risco ou Número de Prioridades de Risco - NPR, que é o produto dos três (KARDEC; NASCIF, 2017).

A partir da ferramenta FMEA pode-se criar um Planejamento e Controle da Manutenção, que segundo Viana (2014), trata-se da estratégia de manutenção da organização. Um grande aliado nesse planejamento é a ferramenta 5W1H, que de acordo com Marshall Júnior et al. (2012), é utilizada, principalmente, no mapeamento e na padronização de processos, na elaboração de planos de ação e no estabelecimento de procedimentos associados aos indicadores. Eles completam, ainda, que essa ferramenta busca definir as responsabilidades, métodos, prazos e recursos associados. Sendo definidos por que (why), o que (what), onde (where), quando (when), quem (who) e como (how).

A ferramenta FMEA pode ser aplicada em qualquer indústria, inclusive, em confecções às quais a manutenção é fator importante em todos setores e, na área têxtil, não poderia ser diferente, devido à importância que essa tem para a economia brasileira. (PEREIRA, 2009).

A última etapa do processo industrial têxtil, como visto, é o setor de confecção, que oferece diversos produtos desde vestuário (roupa íntima, de dormir, esporte, classes especiais, etc.) até artigos confeccionados (roupa de cama, mesa, banho, entre outros). A produção desse setor é direcionada ao comércio atacadista, varejista, lojas de departamentos, especializadas e outras indústrias e atividades de serviços (SEBRAE, 2001).

As barreiras tecnológicas do segmento de confecção são ligadas, quase sempre, ao seu equipamento básico, a máquina de costura, e, para se manterem competitivas no mercado, as empresas precisam encontrar meios para driblar essa barreira. A manutenção é uma solução, já que está fortemente ligada com o processo, via disponibilidade e confiabilidade dos equipamentos (VIERRI, 1995). Logo, utiliza-se a manutenção como aliada para responder com eficiência, às necessidades impostas pelo mercado, garantindo alta produtividade (SILVA, 2001).

\section{MATERIAIS E MÉTODOS}

\subsection{CARACTERIZAÇÃO DA PESQUISA}

A priori, fez-se a caracterização da pesquisa. Uma pesquisa é caracterizada conforme a metodologia empregada no trabalho, levando-se em consideração a forma de abordagem, os métodos e as técnicas que estejam adequados ao estudo em questão (CERVO; BERVIAN, 2002). 0 trabalho desenvolvido tem a natureza de pesquisa aplicada. Segundo Appolinário (2011), pesquisas dessa natureza têm o objetivo de resolver problemas e necessidades concretas e imediatas.

No tocante à abordagem da pesquisa, é de cunho qualitativo. Godoy (1995) relata que na pesquisa qualitativa, o fenômeno pode ser melhor compreendido dentro do contexto em que acontece, e, portanto, deve ser avaliado dentro de uma perspectiva integrada. Nesse sentido, o presente trabalho tem o intuito de apreender o fenômeno em estudo pela perspectiva de todas as pessoas envolvidas, para que possa ponderar sobre os pontos de vista das mesmas.

Quanto ao objetivo geral, a pesquisa é de caráter exploratório, onde pode-se ter maior familiaridade com o tema abordado, aprimorando as ideias existentes e originando novos conhecimentos (GIL, 2010). Prodanov e Freitas (2013), por sua vez, relatam que a pesquisa exploratória visa obter uma quantidade maior de informações acerca do tema em estudo. 
Com relação ao método de pesquisa utilizado, caracteriza-se como estudo de caso e pesquisa bibliográfica. De acordo com Appolinário (2011), o estudo de caso é realizado com um único sujeito (uma pessoa, empresa, cidade etc.). Para Yin (2001), é uma estratégia de pesquisa que compreende um método, abrangendo tudo em abordagens específicas de coleta e análise de dados.

Para o constructo teórico, realizou-se uma pesquisa bibliográfica a respeito de Gestão da Manutenção. Para Marconi e Lakatos (2010), pesquisa bibliográfica é o levantamento de toda bibliografia já publicada, em forma de livros, revistas e publicações avulsas. Seu objetivo é colocar o pesquisador em contato direto com tudo aquilo que já foi escrito sobre o assunto, com a finalidade de oferecer meios para definir e resolver problemas conhecidos ou explorar novas áreas.

\subsection{CARACTERIZAÇÃO DO LOCAL DE ESTUDO}

0 presente trabalho foi desenvolvido em uma confecção de pequeno porte localizada na região centrooeste de Minas Gerais. A empresa, de acordo com a proprietária, está há 20 anos no mercado de confecção de lingeries, produzindo 50 conjuntos de calcinhas e sutiãs, diariamente, além de pijamas e robes, sendo vendidos para todo o país.

O processo produtivo consiste em corte, costura, montagem e acabamento. Conta com cinco funcionárias e a proprietária, sendo esta última, quem faz os acabamentos, cortes e controle de qualidade, além do gerenciamento. 0 expediente é de segunda a sexta, das sete da manhã às dezessete horas, parando uma hora e meia para almoço.

A organização possui onze máquinas de costura, sendo elas: duas overloques, uma prespontadeira, uma BT, uma calfadeira, uma travete, três galoneiras e uma corta viés.

\subsection{COLETA E ANÁLISE DE DADOS}

Foi realizada uma visita na empresa e fez-se uma entrevista não-estruturada com a proprietária. Marconi e Lakatos (2010) definem entrevista não-estruturada como quando o entrevistador tem a liberdade para desenvolver cada situação em qualquer direção considerada adequada. Geralmente, as perguntas são abertas e podem ser respondidas dentro de uma conversação informal.

Após a coleta dos dados, foi aplicado o método FMEA e, a partir dos resultados obtidos, foi realizado um Plano de Controle da Manutenção pautando-se da ferramenta 5W1H.

\section{RESULTADOS E DISCUSSÃO}

\subsection{MANUTENÇÃO NA EMPRESA}

As máquinas da empresa não falham com frequência, entretanto, a última que falhou (travete), parou a produção em uma semana (tempo de reparo). A máquina travete tem como função fazer acabamentos, fazer travas em pontos específicos, onde há maior tensão como bolsos, passantes, laterais, zíper, etc. Há três anos, a mesma também precisou de reparos e parou a produção em dois dias.

A confecção trabalha com o corte manual das peças, sendo a tesoura trocada uma vez ao ano. Com relação à lubrificação das máquinas, algumas mostram o nível de óleo, e só é feita a lubrificação quando está abaixo do nível ideal. Nas máquinas que não mostram o nível de óleo, a lubrificação é realizada diariamente, pelo próprio funcionário, uma vez que a empresa trabalha com o lema "cada um é responsável pela sua máquina", conforme a Manutenção Produtiva Total (TPM).

A desregulagem de ponto é um transtorno, relatado pela entrevistada, visto que uma corrente de ar que entra pela janela pode ocasionar o problema, e, às vezes, gastam-se horas para regular o ponto novamente. Há três máquinas, em que se nota a frequente quebra de agulhas, sendo gastas, em média, de 20 a 30 agulhas com cada uma. A ferramenta que é utilizada para trocar a agulha também desgasta bastante a ponta. 


\subsection{APLICAÇÃO DA FERRAMENTA FMEA}

O formulário de análise FMEA na empresa em questão é apresentado no Quadro 1, adiante.

Quadro 1: Análise FMEA

\begin{tabular}{|c|c|c|c|c|c|c|c|c|c|c|}
\hline \multirow{2}{*}{ Item } & \multirow{2}{*}{$\begin{array}{l}\text { Nome do } \\
\text { Componente }\end{array}$} & \multirow{2}{*}{ Função } & \multicolumn{3}{|c|}{ Falhas Possiveis } & \multirow{2}{*}{ Controles Atuais } & \multicolumn{4}{|c|}{ Índices } \\
\hline & & & Modo & Efeito & Causas & & G & 0 & D & $\mathbf{R}$ \\
\hline 1 & Agulha & $\begin{array}{l}\text { Introduzir a linha } \\
\text { no tecido. }\end{array}$ & Quebra & $\begin{array}{l}\text { Interrupção na } \\
\text { produção }\end{array}$ & $\begin{array}{l}\text { Uso incorreto, idade } \\
\text { da agulha, instalação } \\
\text { inadequada e tensão } \\
\text { incorreta. }\end{array}$ & $\begin{array}{l}\text { Usar uma agulha } \\
\text { de qualidade com } \\
\text { o diâmetro } \\
\text { adequado para o } \\
\text { trabalho, uso e }\end{array}$ & 7 & 10 & 1 & 70 \\
\hline 2 & Tesoura & Cortar & $\begin{array}{l}\text { Quebrar ou perder o } \\
\text { corte. }\end{array}$ & $\begin{array}{l}\text { Corte incorreto, } \\
\text { parada no }\end{array}$ & $\begin{array}{l}\text { Uso intensivo, sem } \\
\text { manutenção. }\end{array}$ & Afiar. & 6 & 4 & 1 & 24 \\
\hline 3 & $\begin{array}{c}\text { Trocador de } \\
\text { agulha (Allen) }\end{array}$ & $\begin{array}{l}\text { Auxiliar na troca da } \\
\text { agulha }\end{array}$ & $\begin{array}{l}\text { Desgaste na ponta e } \\
\text { quebra }\end{array}$ & $\begin{array}{l}\text { Parada no } \\
\text { processo. }\end{array}$ & $\begin{array}{l}\text { Uso inadequado e } \\
\text { depreciação. }\end{array}$ & Uso adequado. & 3 & 7 & 3 & 63 \\
\hline 4 & Travete & $\begin{array}{l}\text { Fazer travas em } \\
\text { pontos específicos, } \\
\text { onde há maior } \\
\text { tensão, como bolsos, }\end{array}$ & $\begin{array}{l}\text { Queima de fusivel, } \\
\text { desconfigurar e } \\
\text { queimar. }\end{array}$ & $\begin{array}{l}\text { Parada do } \\
\text { processo. }\end{array}$ & $\begin{array}{l}\text { Uso inadequado e } \\
\text { falta de manutenção. }\end{array}$ & $\begin{array}{l}\text { Uso adequado, } \\
\text { treinamento e } \\
\text { manutenção. }\end{array}$ & 10 & 8 & 2 & 160 \\
\hline 5 & Overlock & $\begin{array}{l}\text { Acabamento e } \\
\text { fechamento de } \\
\text { tecidos de malha. }\end{array}$ & $\begin{array}{l}\text { Queima, quebra de } \\
\text { peça ou falha. }\end{array}$ & \begin{tabular}{|l|} 
Parada do \\
processo. Perca \\
de qualidade
\end{tabular} & $\begin{array}{l}\text { Uso inadequado e } \\
\text { falta de manutenção. }\end{array}$ & $\begin{array}{l}\text { Uso adequado, } \\
\text { treinamento e } \\
\text { manutenção. }\end{array}$ & 10 & 3 & 4 & 120 \\
\hline 6 & BT & $\begin{array}{l}\text { Aplicação de } \\
\text { elástico. }\end{array}$ & $\begin{array}{l}\text { Queimar, quebra de } \\
\text { peça ou falha. }\end{array}$ & $\begin{array}{l}\text { Parada do } \\
\text { processo. Perca } \\
\text { de qualidade }\end{array}$ & $\begin{array}{l}\text { Uso inadequado e } \\
\text { falta de manutenção. }\end{array}$ & $\begin{array}{l}\text { Uso adequado, } \\
\text { treinamento e } \\
\text { manutenção. }\end{array}$ & 6 & 4 & 4 & 96 \\
\hline 7 & Galoneira & $\begin{array}{l}\text { Rebatimento de } \\
\text { elástico, confecção } \\
\text { de bainha, gola, etc. }\end{array}$ & $\begin{array}{l}\text { Queimar, quebra de } \\
\text { peça ou falha. }\end{array}$ & \begin{tabular}{|l|} 
Parada do \\
processo. Perca \\
de qualidade
\end{tabular} & $\begin{array}{l}\text { Uso inadequado e } \\
\text { falta de manutenção. }\end{array}$ & $\begin{array}{l}\text { Uso adequado, } \\
\text { treinamento e } \\
\text { manutenção. }\end{array}$ & 6 & 4 & 5 & 120 \\
\hline 8 & Corta viés & $\begin{array}{l}\text { Corta filete, tiras, } \\
\text { etc. }\end{array}$ & $\begin{array}{l}\text { Queimar, quebra de } \\
\text { peça ou falha. }\end{array}$ & $\begin{array}{l}\text { Parada do } \\
\text { processo. Perca } \\
\text { de qualidade }\end{array}$ & $\begin{array}{l}\text { Uso inadequado e } \\
\text { falta de manutenção. }\end{array}$ & $\begin{array}{l}\text { Uso adequado, } \\
\text { treinamento e } \\
\text { manutenção. }\end{array}$ & 5 & 4 & 5 & 100 \\
\hline 9 & Pespontadeira & Fazer pesponto. & $\begin{array}{l}\text { Queimar, quebra de } \\
\text { peça ou falha. }\end{array}$ & $\begin{array}{l}\text { Parada do } \\
\text { processo. Perca } \\
\text { de qualidade }\end{array}$ & $\begin{array}{l}\text { Uso inadequado e } \\
\text { falta de manutenção. }\end{array}$ & $\begin{array}{l}\text { Uso adequado, } \\
\text { treinamento e } \\
\text { manutenção. }\end{array}$ & 5 & 4 & 5 & 100 \\
\hline 10 & Ponto & $\begin{array}{l}\text { Fazer com que a } \\
\text { máquina trabalhe } \\
\text { corretamente. }\end{array}$ & Desregulagem. & $\begin{array}{l}\text { Trabalho } \\
\text { incorreto, e } \\
\text { costura } \\
\text { incorreta. }\end{array}$ & $\begin{array}{l}\text { Parafuso frouxo, } \\
\text { tamanho da agulha } \\
\text { incorreto, corrente } \\
\text { de ar em excesso no } \\
\text { ambiente laboral. }\end{array}$ & $\begin{array}{l}\text { Mudar o layout, } \\
\text { parafuso } \\
\text { apertado, agulha } \\
\text { compativel com o } \\
\text { trabalho. }\end{array}$ & 6 & 9 & 2 & 108 \\
\hline
\end{tabular}

Fonte: Adaptado de Helman e Andery (1995).

Como denota-se no Quadro 1, o maior NPR corresponde à máquina travete, sendo essa a máquina que mais trabalha na confecção, visto que todas as peças passam por ela. Percebe-se, assim, que essa máquina necessita de atenção especial, devendo ter um plano de manutenção que contemple as manutenções desta, de modo que a mesma não apresente número tão alto de risco e que possa colocar a produção em situação de perigo, como aconteceu na última vez em que a mesma falhou, parando o processo produtivo por uma semana. Entretanto, os equipamentos/processos que apresentaram menor NPR foram a tesoura e o trocador deagulha, sendo esses equipamentos de simples funcionamento, de baixo custo e fácil reposição.

\subsection{MÉTODO 5W1H}

Dado que a máquina travete apresentou maior NPR, recomenda-se a realização damanutenção preventiva. Para tanto, pode-se utilizar a ferramenta $5 \mathrm{~W} 1 \mathrm{H}$, em tal procedimento, como apresentado no Quadro 2. 
Quadro 2 - 5W1H para a máquina travete

\begin{tabular}{|c|c|c|c|c|c|}
\hline 0 que? & Quem? & Quando? & Onde? & Por quê? & Como? \\
\hline Manutenção & Profissional & Vistorias a & Na própria & Para identificar & Através \\
\hline Preventiva na & que trabalha & cada 15 & máquina & uso inadequado & monitoramento e \\
\hline Máquina & $\operatorname{com} \mathrm{a}$ & dias. & & do & avaliação da \\
\hline \multirow[t]{3}{*}{ Travete. } & máquina. & & & equipamento e & máquina. \\
\hline & & & & potenciais de & \\
\hline & & & & falhas. & \\
\hline
\end{tabular}

Fonte: Autoras (2018).

\section{CONCLUSÃO}

Com a utilização da ferramenta FMEA constatou-se que a máquina travete possui o maior NPR, sendo justificado pelo fato da mesma possuir um alto índice de gravidade e ocorrência, enquanto tesouras e trocadores de agulha tem os menores NPRs. Isso, por sua vez acontece porque ambas as ferramentas possuem os menores índices de detectabilidade (fácil detecção) da falha, além de baixos índices de gravidade.

Deste modo, constata-se que existe a necessidade de realizar correções em cada ferramenta/máquina analisada conforme ações de melhorias mencionadas no FMEA, mas atentando-se, principalmente, para a máquina travete, uma vez que é a máquina que mais trabalha na confecção, sendo que sua quebra acarreta em parada do processo e, consequentemente, atraso nas entregas.

Logo, a criação de um plano de manutenção, que contemple as manutenções de tal máquina é essencial para que a mesma não apresentenúmero tão alto de risco e influencie no processo produtivo. Recomendase, assim, a utilização da ferramenta $5 \mathrm{~W} 1 \mathrm{H}$ como procedimento para manutenção preventiva da máquina travete e, portanto, foi desenvolvido um plano de ação pautado em tal método.

Por conseguinte, o objetivo do estudo foi atingido, visto que a aplicação da ferramenta FMEA, proporcionou a identificação da máquina travete como a que mais necessita de atenção, dada a sua importância dentro do processo produtivo e as graves consequências que ocorrem caso a mesma seja danificada.

\section{REFERÊNCIAS}

[1] Appolinário, Fábio. Dicionário de metodologia científica: um guia para a produção do conhecimento científico. 2 ed. São Paulo. Atlas, 2011.

[2] Associação Brasileira da Indústria Têxtil e Confecção (ABIT). 2018. Disponível em: <http://www.abit.org.br>. Acesso em: 25 nov. 2018.

[3] Cervo, Amado; Bervian, Pedro. Metodologia Científica. 5 ed. São Paulo. Prentice Hall, 2002.

[4] Emery, Márcio de Morais. O Impacto da Abertura ao Comércio Exterior da Década de 1990 no Setor Têxtil Brasileiro. 2007. Tese. (Doutorado em Ciências Sociais - Relações Internacionais) - Pontifícia Universidade Católica de São Paulo, 2007. Disponívelem:

https://sapientia.pucsp.br/bitstream/handle/3822/1/Marcio\%20de\%20Morais\%20Emery.pdf>. Acesso em: 30 nov. 2018

[5] Fogliato, Flávio; Ribeiro, José Luís. Confiabilidade e Manutenção Industrial. Rio de Janeiro. Elsevier, 2011.

[6] Freitas, Eder Benevides. TPM - Manutenção Produtiva total. 2009. Disponível em: <http://engenhariadeproducaoindustrial.blogspot.com/2009/05/tpm-manutencao-produtiva-total.html>. Acesso em: 26 nov. 2018.

[7] Gil, Antônio Carlos. Como elaborar projeto de pesquisa. 5 ed. São Paulo. Atlas, 2010.

[8] Godoy, Arilda Schimit. Pesquisa qualitativa: tipos fundamentais. Revista de Administração de Empresas, v. 35, n. 3, p. 20-29, 1995.

[9] Helman, Horácio; Andery, Paulo Roberto. Análise de Falhas (Aplicação dos Métodos de FMEA e FTA). Belo Horizonte. Fundação Cristiano Ottoni, Escola de Engenharia da UFMG, 1995.

[10] Kardec, Alan; Nascif, Júlio. Manutenção: Função Estratégica. 4 ed. Rio de Janeiro. Qualitymark Editora, 2017.

[11] Lüdke, Menga; ANDRÉ, Marli. Pesquisa em educação: abordagens qualitativas. São Paulo. EPU, 1986 
[12] Marconi, Marina; Lakatos, Eva Maria. Fundamentos de Metodologia Científica. 7 ed. São Paulo. Atlas, 2010.

[13] Marconi, Marina; Lakatos, Eva Maria. Metodologia do trabalho científico: procedimentos básicos, pesquisa bibliográfica, projeto e relatório, publicações e trabalhos científicos. 7 ed. 5 reimp. São Paulo. Atlas, 2010.

[14] Marshall Júnior, Isnard; Rocha, Alexandre Varanda; MOTA, Edmarson Bacelar; Quintella, Odair Mesquita. Gestão da Qualidade e Processos. Rio de Janeiro. Editora FGV, 2012.

[15] NBR 5462-1994. Confiabilidade e manutenabilidade. Disponível em :< http://www.abnt.org.br>. Acesso em: 15 nov. 2018.

[16] Pereira, Gislaine de Souza. Materiais e Processos Têxteis, 2009. Disponível em: < https://wiki.ifsc.edu.br/mediawiki/images/temp/0/07/20090218180450!MPTEX6.pdf>. Acesso em: 30 nov. 2018.

[17] Pereira, Mário Jorge. Engenharia da Manutenção - Teoria e Prática. Rio de Janeiro: Editora Ciência Moderna Ltda, 2011.

[18] Prodanov, Cleber Cristiano; Freitas, Ernani Cesar de. Metodologia do Trabalho Científico: Método e Técnicas da Pesquisa e do Trabalho Acadêmico. 2 ed. Novo Hamburgo. Feevale, 2013.

[19] Serviço de Apoio ás Micro e Pequenas Empresas de São Paulo (SEBRAE - SP). O Desempenho das MPEs no Setor Têxtil-Confecção. São Paulo, 2001. Disponível em: https://m.sebrae.com.br/Sebrae/Portal\%20Sebrae/UFs/SP/Pesquisas/textil_confeccao.pdf>. Acesso em: 30 nov. 2018.

[20] Severino, Antonio Joaquim. Metodologia do Trabalho Científico. 23 ed. São Paulo. Cortez, 2007.

[21] Silva, Nivaldo Jose. da. Estudo da situação e proposta de uma política de manutenção otimizada para indústrias têxteis na região de Americana. 2001. Dissertação (Mestrado em Engenharia de Produção) - Universidade Metodista de $\quad$ Piracicaba, 2001. Disponível em: https://www.unimep.br/phpg/bibdig/pdfs/docs/23062015_164419_nivaldojosedasilva_ok.pdf>. Acesso em: 30 nov. 2018.

[22] Rampazzo, Lino. Metodologia Científica: para alunos de graduação e de pós-graduação. 3 ed. São Paulo. Edições Loyola, 2005.

[23] Viana, Herbert Ricardo Garcia. PCM, planejamento e controle da manutenção. Rio de Janeiro. Qualitymark Editora, 2014.

[24] Vierri, Luiz Alberto. Gerenciamento pela Qualidade Total na Manutenção Industrial: Aplicação Prática. 1995. Dissertação (Mestrado em Qualidade) - Instituto de Matemática, Estatística e Ciência da Computação, 1995. Disponível em: < http://repositorio.unicamp.br/bitstream/REPOSIP/305885/1/Verri_LuizAlberto_M.pdf>. Acesso em: 30 nov. 2018.

[25] Wyrebski, Jerzy. Manutenção produtiva total - Um modelo adaptado. Dissertação. Universidade Federal de $\begin{array}{lllll}\text { Santa } & \text { Catarina. } & \text { Florianópolis, } & \text { Disponível } & \text { em: }<\end{array}$ https://repositorio.ufsc.br/bitstream/handle/123456789/158161/108695.pdf?sequence=1\&isAllowed=y>. Acesso em: 26 nov. 2018.

[26] Yin, Robert. Estudo de Caso Planejamento e Métodos. Metodologia Científica Aplicada. Tradução: Daniel Grassi. Disponível em: <https://edisciplinas.usp.br/pluginfile.php/2326834/mod_resource/content/1/2013/estudo_de_caso_planejamento _e_metodos.pdf>. Acesso em: 5 nov. 2018. 


\section{Capítulo 3}

\section{Planejamento de manutenção para uma Empresa Siderúrgica na Produção de Cal}

\section{Vinícius Pimentel Martins \\ Bernardo Duarte Tofano \\ Manuel Antonio Molina Palma \\ Kelly Alonso Costa}

Resumo: No cenário econômico atual, possuir um diferencial competitivo é fator crítico para se alcançar o sucesso no mercado industrial. Com base em dados recentes da ABRAMAN (2013), os custos no setor de manutenção vêm crescendo de forma aceleradaa no passar dos anos, trazendo maior atenção para seus processos de gestão. A empresa em estudo atua tanto no cenário nacional quanto internacional da siderurgia e por atender demandas cada vez maiores, identificou como fator crítico de sucesso a fabricação de seus próprios insumos. A instalação de uma fábrica produtora de cal foi a estratégia empregada para avançar no mercado, porém a mesma não consegue performar de maneira plena devido seus constantes contratempos em seus eventos de manutenção, sejam eles em relação a atrasos em sua volta à produção, extrapolação de orçamentos, entre outros problemas situacionais. Desta forma, o presente estudo visou estruturar um projeto de planejamento robusto para o reparo de um dos fornos da fábrica, evidenciando todas suas etapas, analisando pontos de melhoria e reportando possíveis ganhos ao aumentar o nível de controle em eventos de grande porte. Como métrica, foram utilizados indicadores de desempenho do projeto relacionados à custos, prazos, acidentes pessoais, cumprimentos ambientais e legais, além de respeitar diferentes restrições impostas pela empresa. Como resultado, obteve-se a marca de 85\% de cumprimento dos objetivos, reportando uma economia de $2,78 \%$ do orçamento e controlando o atraso do forno à produção, que atingiu a marca de 8 horas.

Palavras-chave: Planejamento, gestão da manutenção, PCM, EAP, siderurgia. 


\section{INTRODUÇÃO}

A manutenção é fator imprescindível dentro das empresas e cada vez mais ela cresce em questão de importância. Dados da ABRAMAN (2013), a Associação Brasileira de Manutenção e Gestão de Ativos, mostram que em 1994 o custo da manutenção no Brasil foi de R \$14,87 milhões e em um horizonte de 18 anos, cresceu 1.390\% até chegar a marca de $\mathrm{R} \$ 206,50$ milhões em 2012.

Com foco na otimização da gestão produtiva, é essencial para as empresas que o planejamento da manutenção seja o mais organizado possível, para deste modo evitar gastos desnecessários e manter uma produção eficiente. 0 planejamento é primordial para garantir o correto funcionamento dos equipamentos e maquinários, pois visa maximizar a disponibilidade do equipamento, sem desviar do objetivo de aumento das receitas (SOUZA, J. 2008).

A tecnologia entra como aliada no ambiente da manutenção, criando métodos e ferramentas poderosas como relatórios, gráficos e softwares, que auxiliam e aceleram os processos de tomada de decisão. Por outro lado, como citado por Silva et al. (2017), seu uso ainda é limitado, havendo poucos softwares disponíveis para a gestão da manutenção e consequentemente, poucas empresas comsistemas totalmente informatizados.

A empresa analisada é uma siderúrgica de representatividade nacional e internacional, cujo foco, assim como tendência entre as empresas da atualidade, está na redução de gastos desnecessários e na plena utilização de seus recursos. 0 estudo foi conduzido em sua fábrica de cal, uma importante unidade fornecedora de insumos para os processos da cadeia produtiva do aço, que constantemente sofre com seus programas de manutenção. De acordo com registros, o reparo geral desta unidade frequentemente excede o orçamento, não cumpre os prazos estipulados e não registra fatos relevantes para manutenções futuras.

Desta forma, buscou-se implantar um projeto de planejamento de manutenção robusto, a partir da simulação de diversos cenários que atendessem todas as restrições e metas propostas. Posteriormente criou-se uma EAP que serviu de base na estruturação das atividades executadas, controlando todo o progresso do evento.

\section{A PERgunTa QUE ORIENTA ESTE TRABALHO É COMO O PLANEJAMENTO ROBUSTO VEM A MINIMIZAR AS PERDAS OCASIONADAS AO LONGO DOS REPAROS.}

Espera-se que o planejamento da manutenção se mostre eficiente no uso dos recursos tanto financeiros quanto físicos e sirva de base metodológica para otimização dos eventos futuros.

\section{REFERENCIAL TEÓRICO}

\subsection{MANUTENÇÃO}

A manutenção é a forma como as organizações tentam evitar a ocorrência das falhas em seus equipamentos, buscando preservar suas instalações físicas por longos períodos. Ela representa uma parte importante da maioria das atividades produtivas, e especialmente em empresas de grande porte, faz-se necessário a existência de um setor próprio de manutenção que execute uma constante vigilância e uma capacidade rápida de resposta ao longo das linhas produtivas (SLACK; CHAMBERS; JOHNSTON, 2009).

A princípio, as equipes responsáveis pela manutenção se restringiam a efetuar consertos apenas quando as máquinas apresentavam quebras ou falhas, porém, com o passar dos anos, o conceito de manutenção foi expandindo a ponto de tentar prever e evitar ao máximo que essas falhas ocorressem, se deslocando mais para o campo do planejamento do que do campo da ação(LUCATELLI, 2002).

\subsubsection{PLANEJAMENTO E CONTROLE DA MANUTENÇÃO (PCM)}

O Planejamento e Controle da Manutenção objetiva o aumento da produtividade e qualidade de trabalho por meio de um ativo envolvimento dos trabalhadores (SINGH et al., 2013), podendo ser esses, supervisores, engenheiros operadores, entre outros. De forma similar, o PCM também pode ser visto como uma metodologia de maximização do ciclo de vida dos equipamentos (PASCAL et al., 2019), pois monitora constantemente sua condição e consegue antever pontuais falhas.

Souza, J. (2008) cita que a gestão da manutenção deve estar estreitamente ligada a todo conjunto de ações, decisões e definições acerca do que deve realizar, possuir, utilizar, coordenar e controlar, visando entregar um serviço de manutenção confiável, necessitando desta forma, haver uma visão holística de todo o 
conjunto.

\subsection{GERENCIAMENTO DE PROJETOS}

Segundo o Project Management Institute (PMI) (2013), um projeto é "um esforço temporário empreendido para criar um produto, serviço ou resultado exclusivo". De acordo com Sena et al. (2011), um projeto é um conjunto de atividades, processos e informações, que têm como base análises de estudos ou fatos, tendo etapas bem definidas, visando auxiliar e orientar as tomadas de decisões, seja no planejamento ou na execução.

Mafra (2013) cita que a parte de maior importância de um projeto é definir de forma concisa os propósitos, sentidos, valores, o contexto, o tipo, a finalidade, do projeto que será executado ou planejado.

Ainda de acordo com o PMI (2013), no Guia PMBoK existem cinco categorias de processos principais, mostrados pela Figura 1, que compõem o gerenciamento de projetos, sendo eles essenciais para a condução e desenvolvimento do trabalho.

Figura 1 - Fases do gerenciamento de projetos

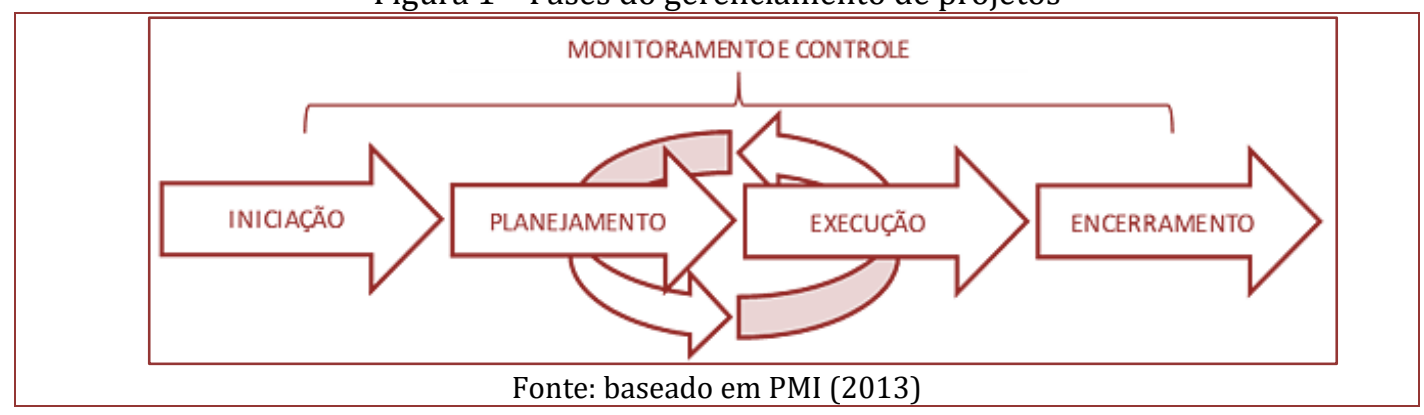

a) Iniciação - fase de definição de um novo projeto;

b) Planejamento - fase de definição do escopo do projeto, onde são apontados as diretrizes e os objetivos a serem alcançados;

c) Execução-conjunto dos processos e procedimentos essenciais para o desenvolvimento do projeto;

d) Monitoramento e Controle - procedimentos de gerenciamento, análise e controle do progresso do projeto;

e) Encerramento - processos necessários para a finalização do projeto, como avaliações de desempenho, lições aprendidas, revisões, registros e validações do produto/serviço.

De forma complementar Jr., Carvalho e Laurindo (2002) afirmam que a correta e eficaz ação (excelência) dentro dessas áreas de um projeto é fundamental para se atingir os objetivos anteriormente propostos.

\subsubsection{ESTRUTURA ANALÍTICA DO PROJETO (EAP)}

Conhecida também como Work Breakdown Structure (WBS) ou Estrutura Analítica do Projeto (EAP), é uma metodologia de desmembramento do projeto em ações, atividades e tarefas. É um recurso de suma importância para o gerenciamento do projeto, tanto no planejamento, na execução ou no controle, já que nela estão atribuídos praticamente todos os parâmetros do projeto como as estimativas de custo, prazo, pessoas, recursos, matérias, equipamentos e informações adicionais (MAFRA, 2013).A Figura 2 apresenta um exemplo de EAP. 
Figura 2 - Representação de uma EAP

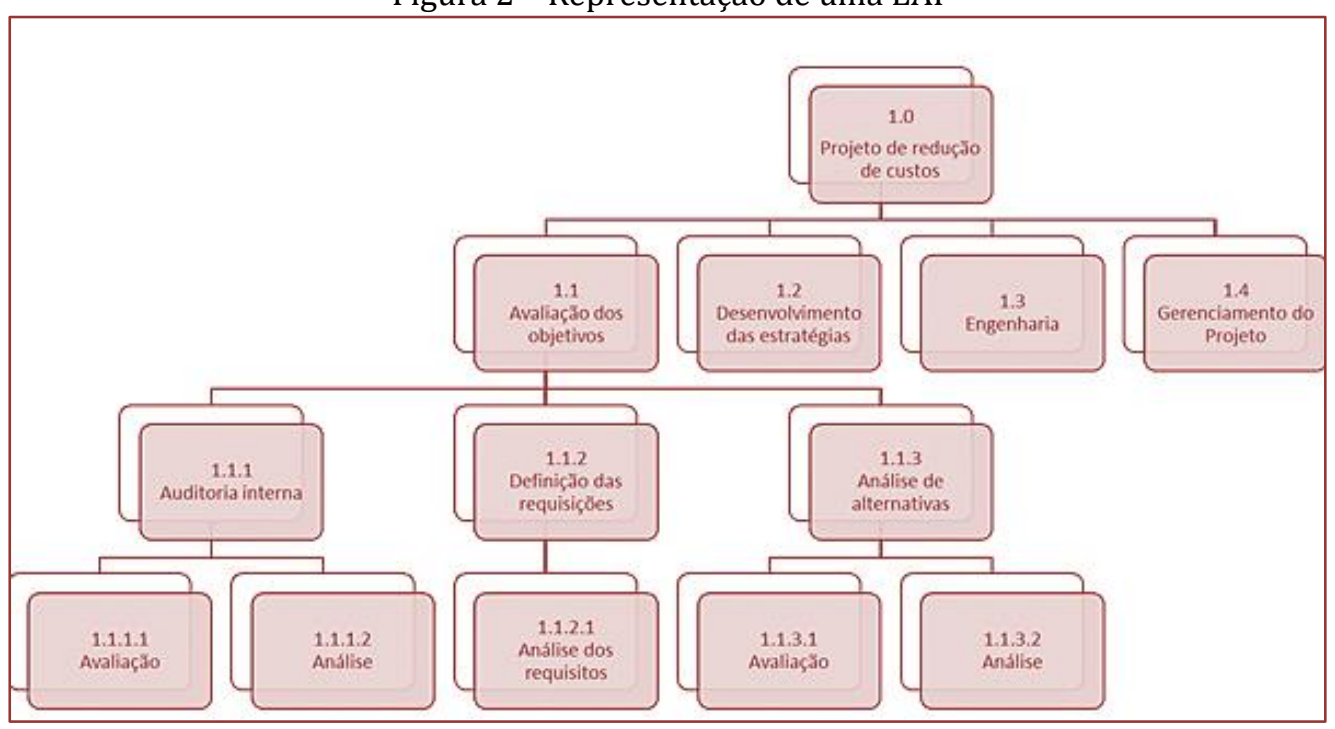

Fonte: baseado em PMI (2013)

A Figura 2 ainda destaca a complexidade estrutural de uma EAP ao levantar diversos grupos e subgrupos para análise e aomostrar a profundidade de detalhes que o projeto pode alcançar. A melhor forma de se criar uma EAP é possuindo o maior conjunto de informações acerca dos componentes, detalhes e características disponíveis (SIAMI-IRDEMOOSA; DINDARLOO; SHARIFZADEH, 2015).

De forma complementar, existem softwares e ferramentas que auxiliam na elaboração da EAP, como por exemplo o Microsoft Project ${ }^{\circledR}$ e o Oracle Primavera ${ }^{\circledR}$.

\section{METODOLOGIA}

0 estudo de caso, como estratégia trabalhada no presente documento, éutilizado quando o pesquisador usar das perguntas "como" e "porquê" em um conjunto de eventos contemporâneos, no qual ele exerce pouco ou nenhum controle sobre o evento.

Almeida (1996) aponta que um estudo de caso se baseia em efetuar a coleta e analisar as informações acerca de um determinado indivíduo, família, grupo ou comunidade, visando o estudo e compreensão dos aspectos variados de sua vida, de acordo com o assunto da pesquisa.

Yin (1994) ainda destaca que a essência do estudo de caso é demonstrar (iluminar) sobre como uma decisão ou um conjunto de decisões foi tomado.

A metodologia aplicada no desenvolvimento deste estudo de caso se dividiu em seis etapas, como representado na Figura 3.

Figura 3 - Fases da metodologia

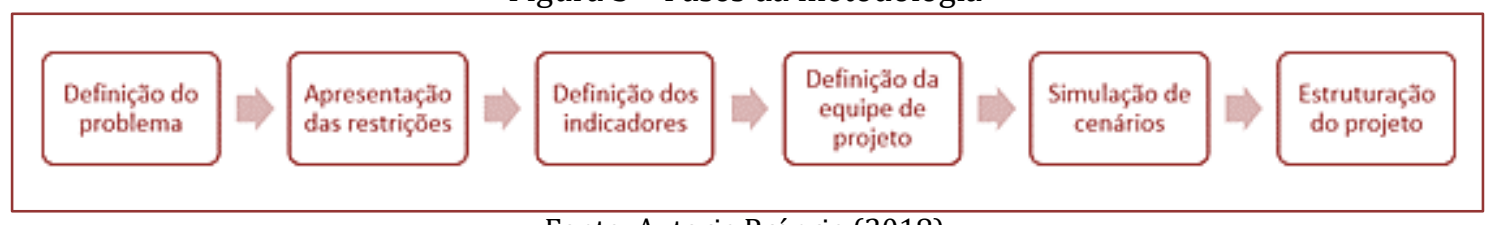

Fonte: Autoria Própria (2018)

As três primeiras fases do projeto foram definidas em reuniões com as partes interessadas no evento. Com objetivos em comum, ou seja, executar um evento de manutenção de forma planejada e estruturada, as equipes chegaram em um consenso entre os pontos levantados e se dispuseram a fornecer toda a base qualitativa e quantitativa posteriormente usada na formulação das equipes de projeto e na simulação dos cenários.

Com os dados levantados e cenários simulados, foi escolhido o quadro otimizado para criação do 
cronograma do projeto. A partir do software Oracle Primavera ${ }^{\circledR}$, a EAP foi desenvolvida juntamente com sua curva S, proporcionando uma visão do caminho crítico de execução do projeto ao longo de sua extensão. Por fim, buscou-se com um pontual acompanhamento controlar desvios que o projeto viesse a ter para não comprometer o prazo estipulado, além de manter os demais objetivos assegurados de seu cumprimento.

\subsection{BJETO DE ESTUDO}

\subsection{APRESENTAÇÃO DA EMPRESA}

O período em que a empresa em estudo foi fundada foi repleto de investimentos econômicos e avanços tecnológicos. Com o tempo, seus processos foram sendo otimizados e consequentemente, sua produção aumentada. Atendendo a uma demanda cada vez maior e visando aproveitar o positivo momento econômico vivenciado, o complexo industrial buscou formas de otimizar seus processos, enxergando uma oportunidade na fabricação de seus próprios insumos.

A cal, produto final do processo de calcinação do calcário, é utilizada como importante insumo em diversos setores da siderurgia. Devido sua larga utilização ao longo do fluxo de produção do aço, a empresa decidiu por instalar uma fábrica produtora da mesma e acreditou que este passo seria peça chave no processo de expansão de seus negócios. Esta importância é demonstrada na Figura 4, onde exemplifica sua participação como produto base de setores como Aciaria, Forno de Panela, Sinterizações e Estações de Tratamento de Efluentes Químicos (ETEQ).

Figura 4 - Fluxograma de processos

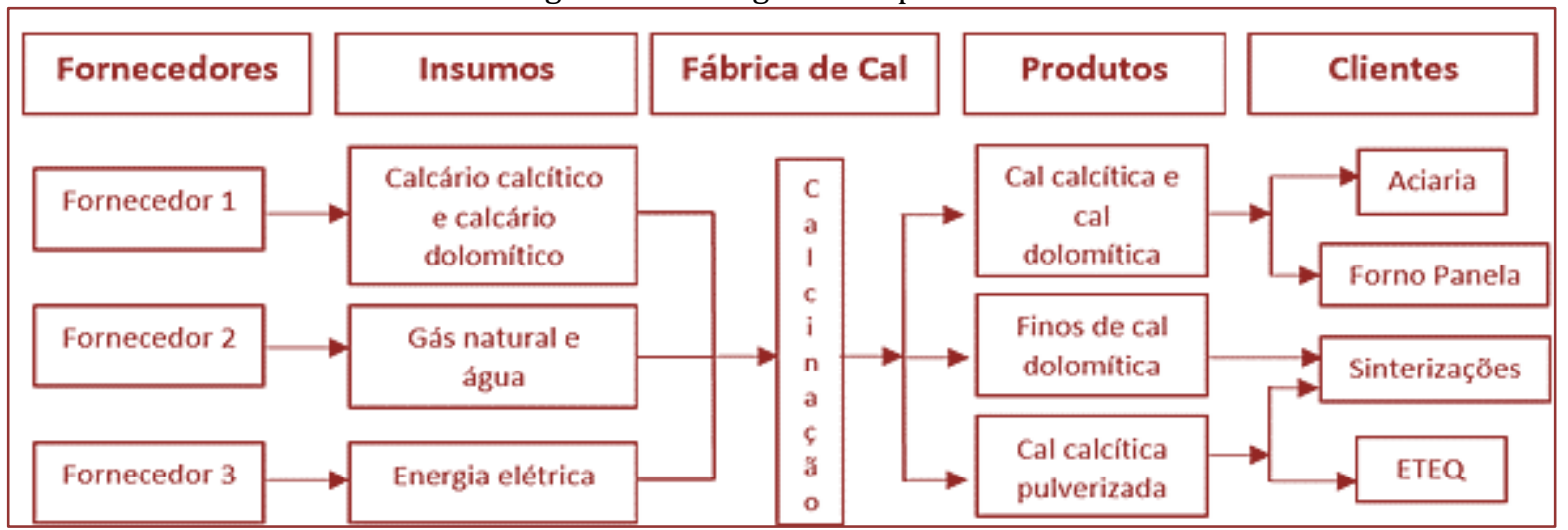

Fonte: Empresa em estudo, adaptado pelos Autores (2018)

A fábrica é composta por 4 fornos responsáveis pelo processo de calcinação, cujo escopo do trabalho foi delimitado a um deles, caracterizado aqui como forno exemplo, que devido ao seu elevado potencial produtivo, requer eficaz controle de manutenção de seus componentes para que possam operar ininterruptamente e sem impactar a produção geral do complexo industrial.

\section{DESENVOLVIMENTO}

\subsection{DEFINIÇÃO DO PROBLEMA}

Seguindo a filosofia de melhoria contínua, foi identificada a necessidade de realizar os eventos de manutenção com maior assertividade, visto que estes eram feitos sem um projeto de planejamento e frequentemente causavamgrandes atrasos na linha de produção, impactando negativamente todo o fluxo produtivo. A Tabela 1 mostra a falta de padronização de datas dos eventos de reparo. De acordo com a equipe de Engenharia de Manutenção, o reparo deveria ocorrer a cada 6 anos, o que não é observado ao analisar o histórico apresentado pela empresa durante os anos em destaque. 
Tabela 1 - Datas programadas de reparos

\begin{tabular}{|c|c|}
\hline Ano & Tempo decorrido \\
\hline 2002 & Sem informação \\
\hline 2005 & 3 anos \\
\hline 2009 & 4 anos \\
\hline 2016 & 7 anos \\
\hline
\end{tabular}

Fonte: Empresa em estudo, adaptado pelos Autores (2018)

O evento de manutenção foi programado para ser realizado no forno exemplo devido ao grande índice de desgaste da composição metálica e das peças eletromecânicas, além de estar com seu revestimento refratário no fim de sua vida útil, necessitando assim, de uma substituição completa das partes danificadas.

\subsection{APRESENTAÇÃO DAS RESTRIÇÕES}

De acordo com estudos da viabilidade do evento de manutenção do forno, algumas restrições foram impostas pelos diferentes setores presentes no projeto. Tais como:

- $\quad 0$ prazo máximo sem que impactasse a linha de produção fosse de 67 dias;

- $\quad$ O Departamento Financeiro restringiu à administração do evento que não superasse o valor inicialmente orçado em mais de 10\%;

Pública (ACPU);

- $\quad$ Utilização de apenas um guindaste.

\subsection{DEFINIÇÃO DOS INDICADORES}

Além de buscar cumprir o prazo, o orçamento previsto e as demais restrições impostas, foi definido como ponto fundamental a inserção de aspectos que fossem concernir os cuidados relacionados à segurança operacional e ao meio ambiente. A filosofia da empresa prega valores inegociáveis em relação às boas práticas de serviço e postura e por buscar ser referência entre as empresas do ramo siderúrgico, esses pontos não poderiam ser deixados de lado. Desta forma, foram adicionados ao objetivo inicial do projeto, o controle da segurança operacional, englobando ações práticas de prevenção de acidentes e o cumprimento de obrigações legaisambientais, para que não impactassem seus colaboradores e toda a população que reside ao entorno do conglomerado industrial. A Tabela 2 destaca a o painel consolidado de indicadores.

Tabela 2 - Painel de indicadores de desempenho

\begin{tabular}{|c|c|c|}
\hline Indicador & Resultado & Peso \\
\hline Duração & Abaixo de 67 dias & 1,5 \\
\hline Custo & Não ultrapassar em mais de 10\% & 1,5 \\
\hline Segurança & Evento com zero acidentes & 2,5 \\
\hline Cumprimentos ficais & Não realizar ACPU & 2 \\
\hline Meio ambiente & Cumprimento de obrigações ambientais & 2,5 \\
\hline
\end{tabular}

Fonte: Empresa em estudo, adaptado pelos Autores (2018)

O resultado do planejamento do evento ficou determinado a partir da combinação destes indicadores. Para uma avaliação justa dos parâmetros impostos, foi adotada a utilização de pesos para cada indicador, exemplificando seu nível de prioridade no evento.

\subsection{SIMULAÇÃO DE CENÁRIOS}

\subsubsection{ALOCAÇÃO DE RECURSOS}

Com os objetivos e restrições bem definidos, foram simulados diferentes cenários que considerassem o comportamento das variáveis globais e seus impactos no resultado final do projeto.Visando enxergar a 
forma como cada variável se apresenta, os cenários foram analisados e ajustados até encontrar o cenário ótimo.

Baseado no histórico de eventos anteriores, tirou-se como base uma média da quantidade de $\mathrm{Hh}$ dispendida em reparos no forno em estudo. Posteriormente, dividiu-se as equipes de trabalho em dois grandes grupos, os de manutenção da parte eletromecânica e os da parte do refratário. A partir do número meta de Hh necessários para execução do evento e da divisão de equipes, foram feitas simulações de diferentes escalas de trabalho para quepudesse ver seu impacto direto na duração final do evento.ATabela 3 abaixo evidencia que a jornada de trabalho e a duração do evento são inversamente proporcionas, pois quanto maior a jornada de trabalho, menor a quantidade de dias necessários para execução do reparo, e consequentemente maior o Hh médio.

Tabela 3 - Simulação de cenários

\begin{tabular}{|c|c|c|c|c|c|c|} 
Cenário & \multicolumn{2}{|c|}{$\begin{array}{c}\text { Eletromecânica } \\
\text { (jornada) }\end{array}$} & $\begin{array}{c}\text { Duração } \\
\text { (escala) }\end{array}$ & $\begin{array}{c}\text { Refratário } \\
\text { (jornada) }\end{array}$ & $\begin{array}{c}\text { Duração } \\
\text { (escala) }\end{array}$ & \multicolumn{2}{c|}{$\begin{array}{c}\text { Duração } \\
\text { total (dias) }\end{array}$} & $\begin{array}{c}\text { Hh } \\
\text { médio }\end{array}$ \\
\hline 1 & Administrativa & $\begin{array}{c}8 \mathrm{~h} / \text { dia }-5 \\
\text { dias/semana }\end{array}$ & Administrativa & $\begin{array}{c}8 \mathrm{~h} / \text { dia }-5 \\
\text { dias/semana }\end{array}$ & 156 & 10,51 \\
\hline 2 & 2 turnos & $\begin{array}{c}16 \mathrm{~h} / \text { dia }-5 \\
\text { dias/semana }\end{array}$ & Administrativa & $\begin{array}{c}8 \mathrm{~h} / \text { dia }-5 \\
\text { dias/semana }\end{array}$ & 142 & 11,64 \\
\hline 3 & Administrativa & $\begin{array}{c}8 \mathrm{~h} / \text { dia }-5 \\
\text { dias/semana }\end{array}$ & 2 turnos & $\begin{array}{c}20 \mathrm{~h} / \text { dia }-5 \\
\text { dias/semana }\end{array}$ & 86 & 19,20 \\
\hline 5 & 2 turnos & $\begin{array}{c}16 \mathrm{~h} / \text { dia }-5 \\
\text { dias/semana }\end{array}$ & 2 turnos & $\begin{array}{c}20 \mathrm{~h} / \text { dia }-5 \\
\text { dias/semana }\end{array}$ & 67 & 24,74 \\
\hline 5 & 2 turnos & $\begin{array}{c}16 \mathrm{~h} / \text { dia }-7 \\
\text { dias/semana }\end{array}$ & 2 turnos & $\begin{array}{c}20 \mathrm{~h} / \text { dia }-7 \\
\text { dias/semana }\end{array}$ & 39 & 42,59 \\
\hline
\end{tabular}

Fonte: Empresa em estudo, adaptado pelos Autores (2018)

NaFigura 5é demonstrado o comportamento de cada cenário ao gerar a dispersão da quantidade de mão de obra durante os dias de evento.

Figura 5 - Dispersão da quantidade de mão de obra (Hh) por cenário

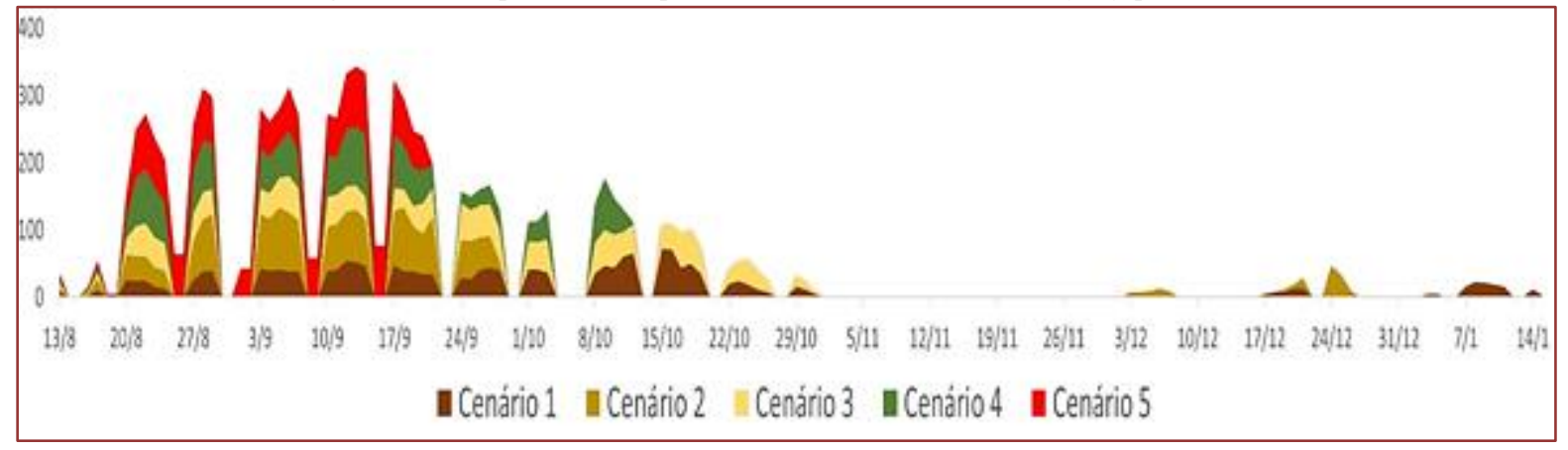

Fonte: Empresa em estudo, adaptado pelos Autores (2018)

Ao exceder o limite permitido de horas diário, o cenário 5 infringiu a ACPU por utilizar horas extras, não cumprindo desta forma, com uma das restrições previamente impostas no escopo do projeto.

\subsubsection{CUSTO DE MÃO DE OBRA}

Por questões de sigilo empresarial, os custos não foram apresentados com seu valor exato, apenas de forma percentual.

O custo de mão de obra contemplou os custos totais (CT) dos seguintes tipos:

- $\quad$ mão de obra direta;

- $\quad$ mão de obra usada no refratário;

- $\quad$ mão de obra da parte eletromecânica; 
- $\quad$ mão de obra utilizada no CCM;

- $\quad$ custo de preparação;

- $\quad$ custo de desmobilização.

Cada custo foi definido a partir da multiplicação da quantidade de Homem-hora utilizado pelo valor orçado do mesmo, como na equação (1):

$$
\text { CT = quantidadeHh } * \text { valorHh }
$$

Se utilizado hora extra, a equação para cálculo do custo total fica como apresentado na equação (2):

$$
\begin{gathered}
C T=\text { quantidadeHh } * \text { valorH }+ \text { quantidadehorasextra } * \text { valor } H h * 1,2+ \\
\text { multaACPU }(2)
\end{gathered}
$$

\subsubsection{CUSTO DE MATERIAL}

Contemplou o custo de material refratário e o custo de material eletromecânico previamente orçados juntamente às fornecedoras. Ambos são fixos, pois foram adquiridos por contratos junto ao departamento de Suprimentos da empresa.

\subsubsection{CUSTO DE RECURSOS}

0 recurso que mais impactou na configuração do orçamento total entre os demais recursos utilizados foi o da utilização do guindaste. Como este apresentou elevado valor por dia, quanto mais breve fosse a execução do projeto, menor seria o impacto no orçamento do evento. A Tabela 4 exemplifica a necessidade de utilização do guindaste em cada cenário.

Tabela 4 - Utilização do guindaste em cada cenário

\begin{tabular}{|c|c|}
\hline Cenário & Uso do guindaste (dias) \\
\hline 1 & 82 \\
\hline 2 & 75 \\
\hline 3 & 46 \\
\hline 4 & 44 \\
\hline 5 & 26 \\
\hline
\end{tabular}

Fonte: Empresa em estudo, adaptado pelos Autores (2018)

Com a soma de todos os custos apresentados, tem-se a representação financeira de cada cenário juntamente com a duração simulada de acordo com as diferentes jornadas de trabalho, como demonstrado na Figura 6. 
Figura 6 - Custo total de cada cenário e sua respectiva duração

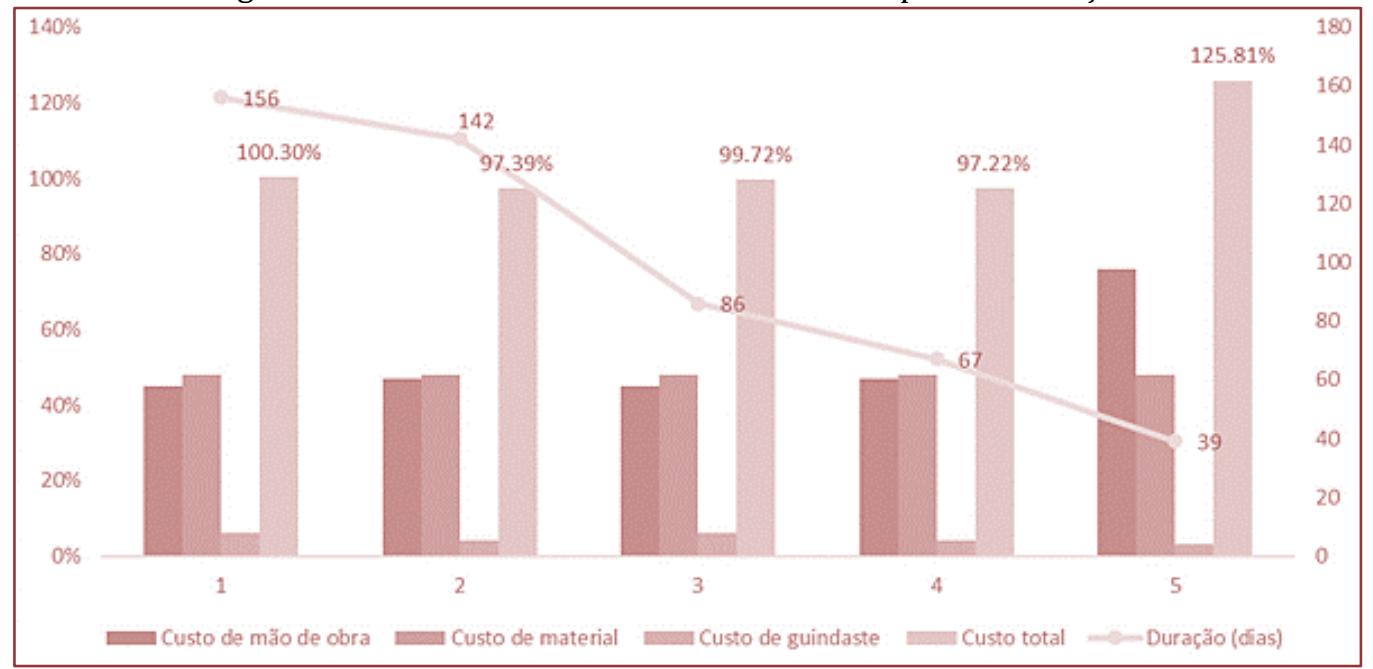

Fonte: Autoria Própria (2018)

Apesar de o cenário 5 apresentar o projeto com maior rapidez em sua execução, ele se tornou inviável ao infringir obrigações legais pertinentes ao uso de horas extras, além de superar os 10\% limites permitidos no total orçado.

O cenário 4 foi então escolhido como o cenário molde a ser seguido por apresentar duração de 67 dias, se enquadrando nos objetivos iniciais de duração e por permitir uma economia de $2,78 \%$ do montante disponibilizado para a execução do reparo.

\subsection{ESTRUTURAÇÃO DO PROJETO}

\subsubsection{PLANEJAMENTO DO PROJETO}

Com o cenário otimizado escolhido, teve-se a necessidade de preparar o cronograma do evento que cumprisse com a duração estipulada. A partir da criação da EAP com o auxílio do software Oracle Primavera ${ }^{\circledR}$, foram estruturadas todas as etapas de atuação das equipes de manutenção. Divididas por setores, foi feito o sequenciamento das atividades, a alocação de recursos, a atribuição da sequência lógica das atividades e dimensionamento da mão de obra disponível para cada frente de trabalho. Desta forma, ficou definido o cronograma linha de base, ou seja, o retrato do trabalho a ser executado durante toda a extensão do reparo do forno em estudo.A Figura 7 demonstra o cronograma consolidado com início planejado em 13/08 até 18/10, operando por67 dias.

Figura 7 - Cronograma linha de base

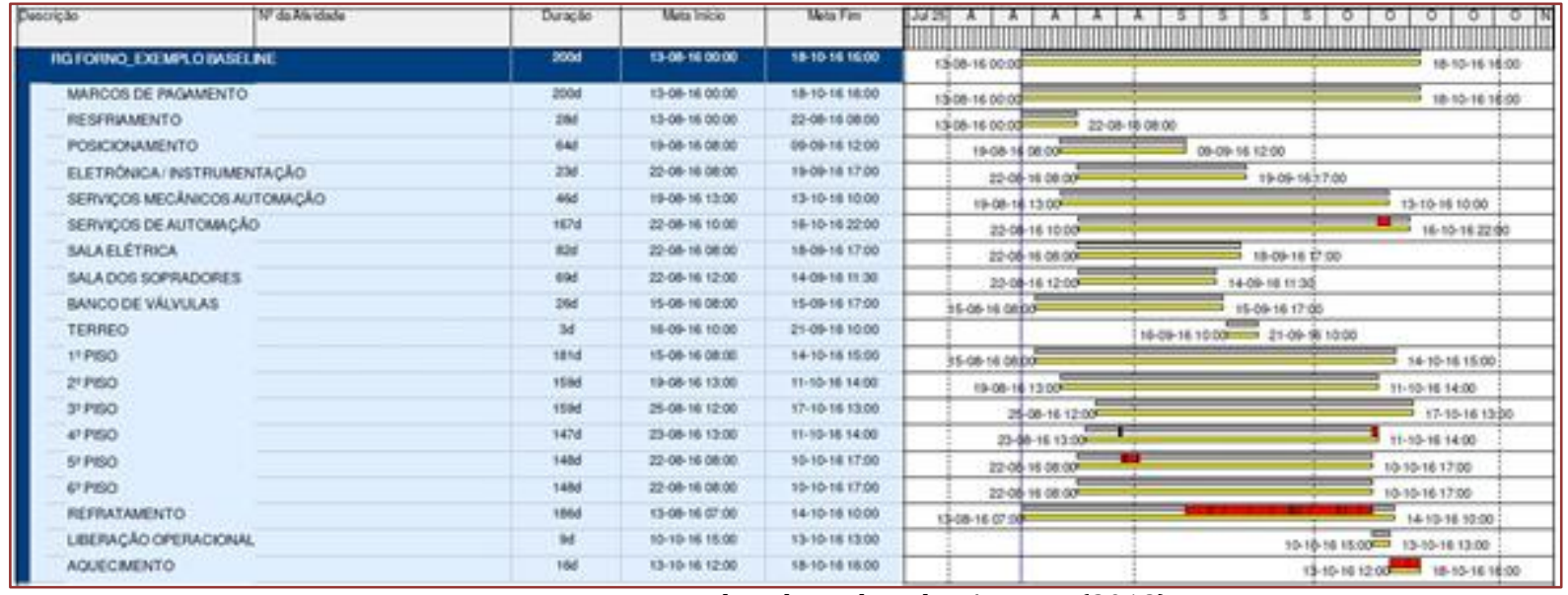

Fonte: Empresa em estudo, adaptado pelos Autores (2018) 
Os resultados eanálises de desempenho do projeto gerarama Curva S, curva representativa do caminho crítico de atividades, que contempla de forma gráfica as horas trabalhadas e os custos acumulados planejados em função do tempo (PMI, 2013).A Figura 8 reporta seu comportamento para o presente projeto e a mesma permitiu visualizar variações ao longos das atividades para que medidas fossem tomadas na busca do controle do prazo final.

Figura 8 - Curva S da linha de base

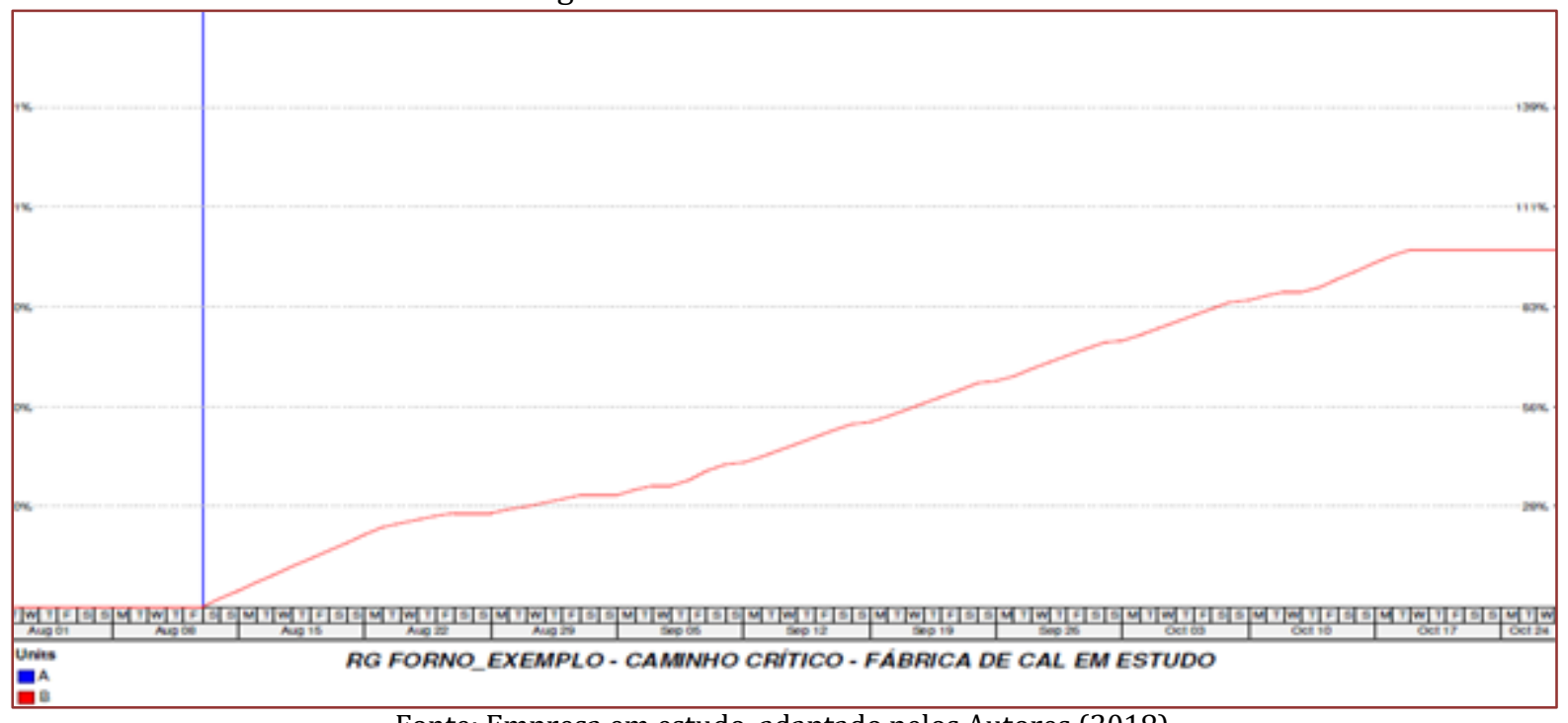

Fonte: Empresa em estudo, adaptado pelos Autores (2018)

\subsubsection{EXECUÇÃO E CONTROLE DO PROJETO}

O processo de execução do projeto buscou realizar as atividades de acordo com o programado na linha de base, para assim não comprometer a data final de evento e as métricas de desempenho do planejamento inicialmente definidas. A presença de equipes em monitoramento contínuo permitiu um alto grau de controle do real andamento do reparo, além de proporcionar rápida resposta à eventuais contratempos, como em diversos ajustes que permitiram ao projeto seguir seu curso natural em direção ao cumprimento do prazo.

\subsubsection{ENCERRAMENTO DO PROJETO}

O cronograma corrente mostra o comportamento do evento executado, reportando suas variações em comparação ao planejado inicialmente na linha de base, como demonstrado na Figura 9. 
Figura 9 - Cronograma corrente após o evento

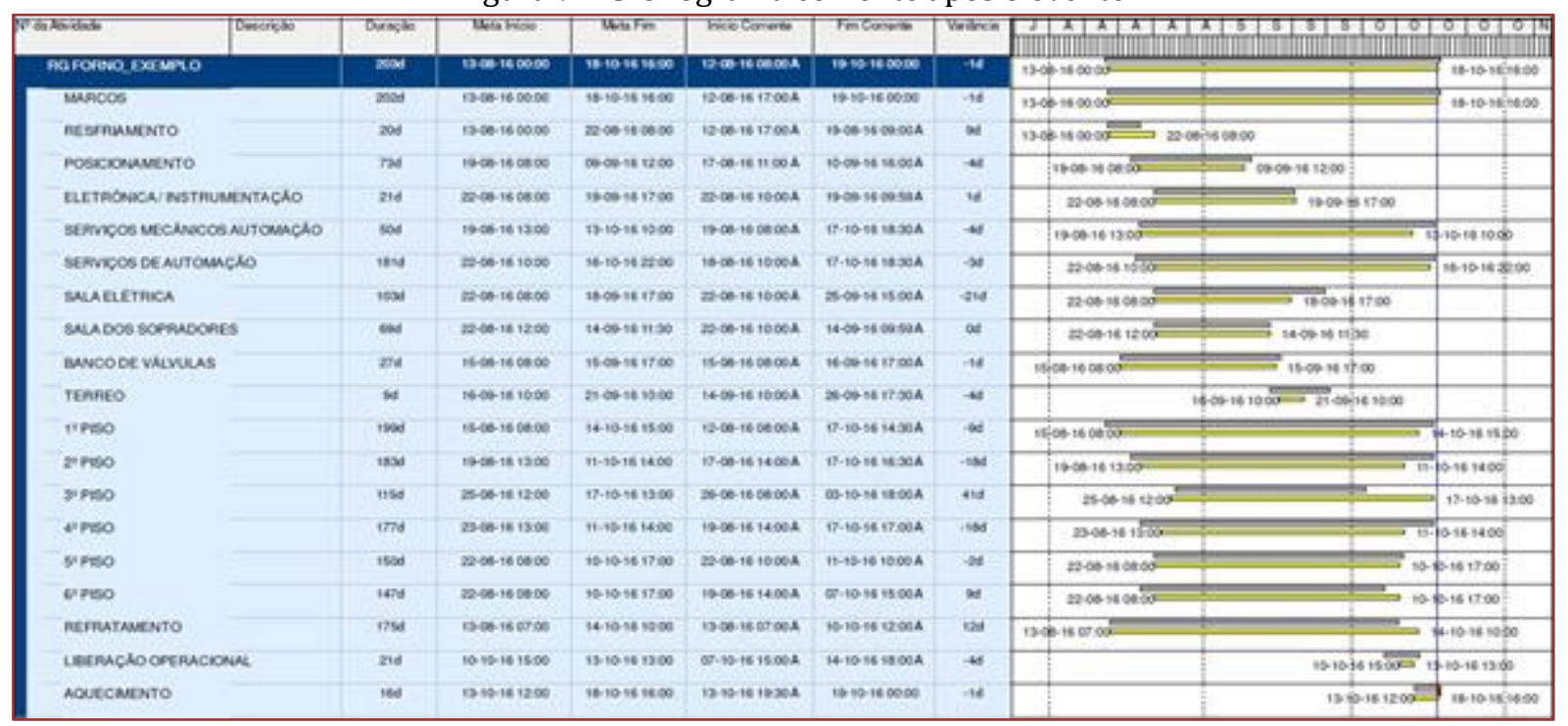

Fonte: Empresa em estudo, adaptado pelos Autores (2018)

Como visto acima, o acompanhamento assertivo do planejamento durante todas as atividades, seja com a presença da equipe na área ou com os constantes reajustes no sequenciamento das atividades, permitiu reduzir ao máximo o impacto de diversos impasses ao longo do projeto e finalizar o evento com um atraso de 8 horas para a volta do forno à produção. Um dos pontos de maior impacto foi no setor de Resfriamento, que estrategicamente foi iniciado com 7 horas de antecipação, gerando um ganho de 71 horas em relação ao planejado.Outro caso foi no Refratamento, onde foram aplicadas técnicas de montagem mais ágeis nas cubas e no teto do forno, gerando um ganho de 58 horas.

A curva S do evento final enfatiza o controle ao longo do projeto, mostrando pequenos desvios em relação à meta inicial, como pode ser destacado na Figura 10.

Figura 10 - Curva S após o evento

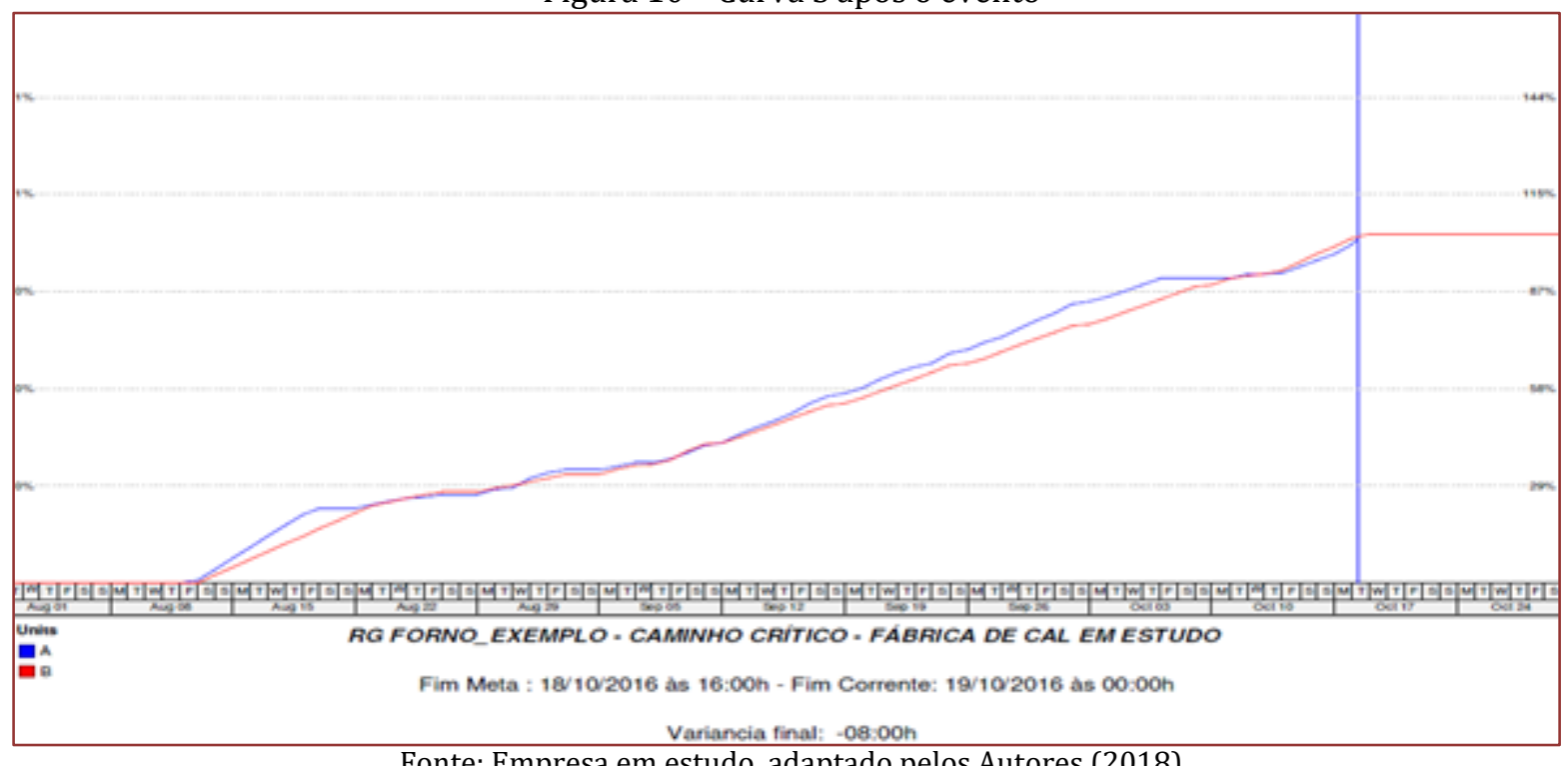

Fonte: Empresa em estudo, adaptado pelos Autores (2018)

A tabela 5 evidencia a marca de $85 \%$ de assertividade no desempenho do projeto. Cumprindo com todos objetivos, exceto o de duração, impossibilitados pelo atraso de 8 horas em relação ao planejado. 
Tabela 5 - Painel de indicadores de desempenho

\begin{tabular}{|c|c|c|c|}
\hline Indicador & Resultado & Peso & Atendido? \\
\hline Duração & Abaixo de 67 dias & 1,5 & Não \\
\hline Custo & Não ultrapassar em mais de $10 \%$ & 1,5 & Sim \\
\hline Segurança & Evento com zero acidentes & 2,5 & Sim \\
\hline Cumprimentos fiscais & Não realizar ACPU & 2 & Sim \\
\hline Meio ambiente & Cumprimento de obrigações ambientais & 2,5 & Sim \\
\hline
\end{tabular}

Fonte: Empresa em estudo, adaptado pelos Autores (2018)

\section{CONCLUSÕES}

No começo do trabalho a pergunta se voltou aos possíveis ganhos de se utilizar um projeto robusto e planejado ao longo de suas etapas. 0 mesmo, conseguiu responder à essa pergunta ao cumprir com a restrição orçamentária, porém falhou perante ao objetivo de cumprir o prazo de evento. Vale ressaltar que, durante a formulação do projeto, ainda foram adicionados outros objetivos como o cumprimento de obrigações fiscais, ambientais e a meta de realizar o reparo sem nenhum colaborador acidentado.

Considerando ser o primeiro evento em que houve um controle e acompanhamento do planejamento ao longo de todo o projeto, o resultado pode ser considerado satisfatório, atingindoo cumprimento de 4 dos 5 indicadores, proporcionandoainda uma economia de $2,78 \%$, e permitindo que o atraso do forno à produção fosse de apenas 8 horas.

0 evento foi posteriormente registrado para que servisse de base e lições aprendidas em eventos futuros, enfatizando a importância de se criar um histórico que monitore as evoluções dos eventos de manutenção.

Para trabalhos futuros sugere-se um levantamento mais profundo de dados históricos, de variáveis intrínsecas ao evento e de fatores externos que possam de certa forma impactar no planejamento, para que se possa atingiro maior nível de riqueza de detalhes possível.

\section{REFERÊNCIAS}

[1] Almeida, M. L. P. Como elaborar monografias. 4aㅡ Ed. Belém, 1996.

[2] Associação Brasileira de Manutenção e Gestão de Ativos - Abraman. Documento

[3] Nacional 2013: A Situação da Manutenção no Brasil. 5o Congresso Mundial de Manutenção e Gestão de Ativos. Salvador, 2013.

[4] JR., R. R.; Carvalho, M. M.; Laurindo, F. J. B. Fatores críticos para implementação de gerenciamento por projetos: o caso de uma organização de pesquisa. Revista Produção, v. 12, n. 2, 2002. Disponível em: http://www.scielo.br/pdf/prod/v12n2/v12n2a04. Acesso em: 20 fev. 2018.

[5] Lucatelli, M. V. Proposta de aplicação da manutenção centrada em confiabilidade em equipamentos médicohospitalares. 285 p. Tese (Pós-Gradução em Engenharia Elétrica) - Universidade Federal de Santa Catarina. Florianópolis, 2002.

[6] Mafra, N. Gerenciamento de Projetos: Como aplicar a metodologia a projetos ambientais. Belo Horizonte, 2013. Disponível em: http://www.academia.edu/download/31548415/Gerenciamento_de_Projetos_Ambientais.pdf.Acessoem: 20 fev. 2018.

[7] Pascal, V. et al. Control Engineering Practice Improvement indicators for Total Productive Maintenance policy. Control Engineering Practice, v. 82, n. July 2017, p. 86-96, 2019.

[8] PMI - (Project Management Institute). A guide to the Project Management Body of Knowledge (PMBoK®).5 Ed. 2013.

[9] Sena, C.; Miranda, I. O.; Cândido, P. P.; Laceda, R.; Andrade, S. M. de; PILAR, V.

[10] Gerenciamento de Projetos. Revista Expressão. 2011. Disponível em: http://www4.faculdadepromove.br/expressao/index.php/files/article/view/7. Acessoem: 01 mar. 2018.

[11] Siami-Irdemoosa, e.; Dindarloo, S. R.; Sharifzadeh, M. Automation in Construction Work breakdown structure ( WBS ) development for underground construction. Automation in Construction, v. 58, p. 85-94, 2015.

[12] Silva, E. P. da; Sacomano, J. B.; Correia, A. J.; Ribeiro, G. A.; Ciucco, R. L. Gestão da manutenção indústria em transição para a indústria 4.0: controle mobile, considerações sobre esta nova tecnologia. XXXVII Encontro Nacional $\begin{array}{llllllll}\text { de Engenharia } & \text { de } & \text { Produção, } & 21 & \text { p. } & 2017 . & \text { Disponível } & \text { em }\end{array}$ 
:http://www.abepro.org.br/biblioteca/TN_STO_238_381_33847.pdf. Acesso em: 10 fev. 2018.

[13] Singh, R. et al. Total Productive Maintenance ( TPM ) Implementation in a Machine Shop: A Case Study.Procedia Engineering, v. 51, n. Nuicone 2012, p. 592-599, 2013.

[14] Slack, N.; Chambers, S.; Johnston, R. Administração da Produção. 703p. São Paulo: Atlas, 2009.

[15] Souza, José Barrozo. Alinhamento das estratégias do Planejamento e Controle da Manutenção (PCM) com as finalidades e função do Planejamento e Controle da Produção (PCP): Uma abordagem Analítica. 169 p. Dissertação (Mestrado em Engenharia de Produção) - Universidade Tecnológica Federal do Paraná, Campus Ponta Grossa, 2008.

[16] Yin, R. K. Case Study Research: Design and Methods. 2ª Ed, v.5. Sage Publications, 1994. 


\section{Capítulo 4}

\section{Implementação do processo de PCP em uma Empresa de Pequeno Porte}

\section{Lenita Duarte \\ Macáliston Gonçalves da Silva \\ Rafael Maciel da Silva}

Resumo: 0 processo de PCP (Planejamento e Controle da Produção) reúne ações do sistema de gestão da empresa para suportar as tomadas de decisões nos níveis estratégicos, táticos e operacionais. São atividades que influenciam diretamente na competitividade do negócio. 0 objetivo geral deste trabalho é conhecer, intervir e explorar academicamente a realidade de uma pequena empresa produtora de máquinas de vendas automáticas, implementando em seu sistema de gestão rotinas de PCP. A metodologia adotada é a pesquisa-ação. Em linhas gerais, os resultados obtidos ao longo do ciclo de investigação foram a redução do lead time do produto em $11,16 \%$, redução do lead time de fornecimento das principais matérias-primas, incremento de $20 \%$ no índice de cumprimento de prazo de entrega, redução de $25 \%$ no período máximo de entrega em atraso, estabilidade nas margens de contribuição por venda, redução do tempo de ciclo da produção em 117 minutos e aumento do índice de eficiência da distribuição de carga por operador para 88\%. Além disso, os custos unitários de produção tornaram-se visíveis, a entrega ganhou confiabilidade e a qualidade do serviço prestado ao cliente melhorou.

Palavras-chave: PCP (Planejamento e Controle da Produção); Pequena empresa; Sistema de gestão. 


\section{INTRODUÇÃO}

O processo de PCP (Planejamento e Controle da Produção) é um conjunto de ações no sistema de gestão do meio empresarial que dá suporte às tomadas de decisões nos níveis estratégicos, táticos e operacionais. As atividades envolvidas influenciam diretamente na competitividade do negócio (MÖLLER et al., 2013). 0 processo de PCP consiste no planejamento, na programação e no controle de todo o fluxo de informação e de materiais do sistema produtivo, em horizontes de planejamento de longo, médio e curto prazo (CORRÊA; CORRÊA, 2017).

Além de sustentar as tomadas de decisões da empresa e trazer organização para o sistema produtivo (CRUZ; MESQUITA, 2018), a partir das definições de o que, quanto, quando e com quais recursos produzir, o processo de PCP impacta no desempenho das estratégias do negócio (CORRÊA; CORRÊA, 2017). 0 custo do produto, a velocidade de entrega, a confiabilidade na entrega, a flexibilidade das saídas e a qualidade do produto e serviço prestado ao cliente são dependentes das resoluções de PCP (EVANGELISTA et al., 2011). Ademais, a rotina de PCP visa equacionar a capacidade produtiva da empresa com o atendimento das demandas potenciais e as necessidades vigentes dos clientes, gerando satisfação aos mesmos e sustentabilidade para os negócios (DA SILVA et al., 2019).

Narcizo et al. (2015), Thurer e Godinho Filho (2012) argumentam que PCP na literatura é abordado preferencialmente no contexto de grandes organizações, apesar de estar presente em todo o tipo de empreendimento, inclusive em pequenas empresas. Conceitualmente os problemas enfrentados pela gerência são semelhantes, envolvendo o planejamento da produção, sequenciamento das atividades, suprimentos, gerenciamento da qualidade e manutenção, entre outros. A gestão de sistemas produtivos tente a ser crítica e complexa (DA SILVA et al., 2019; SIMÕES et al., 2015). Mesmo em pequenas empresas, o processo de PCP é importante para orientar a produção com informações fundamentais sobre operações e processos de fabricação, montagem, estoques, materiais e prioridades. Tal função é executada a partir da interação com diversas áreas de conhecimento, que fornecem particularidades como pedidos comerciais, roteiro de fabricação ou tempos operacionais (NARCIZO et al., 2015).

É possível apontar a garantia de abastecimento de informações relevantes oriundas de vários setores da empresa e a compatibilização de interesses entre áreas de trabalho como dificuldades ao se implementar processos de PCP. Estender et al. (2017) usam o exemplo da discordância da produção e da área comercial. Enquanto o setor comercial deseja flexibilidade e diversidade de produtos, a produção espera trabalhar em fluxo contínuo e em lotes. O PCP então atua para formação de um plano coeso, buscando atingir os objetivos da empresa em função da redução dos conflitos internos e do melhor atendimento dos clientes. Outro grande desafio é a adequação da estrutura organizacional da empresa (SILVA JR; DA SILVA, 2014) para receber as tarefas de PCP, bem como a revisão dos procedimentos e da logística interna, sendo necessário apurar fluxos de materiais e de informações. Para o funcionamento do processo de PCP é necessário um conjunto harmônico de atividades relacionadas com análise de demanda, análise das necessidades de recursos, análise das prioridades, análise da capacidade, análise do sequenciamento das tarefas, entre outras (MÖLLER et al., 2013; CORRÊA et al., 2019).

Neste sentido, acompanhando o crescimento rápido e representativo das vendas de uma pequena empresa brasileira do setor eletrônico em Curitiba, sem que a produção acompanhasse tal evolução, surge a oportunidade de pesquisa: como implementar o processo de PCP em uma empresa de pequeno porte? 0 presente estudo visa, através de uma pesquisa-ação, conhecer, intervir e explorar academicamente a realidade da empresa investigada, implementando em seu sistema de gestão rotinas de PCP. Para expor isso, primeiro é apresentada a seção com o referencial teórico da pesquisa. Depois, o detalhamento metodológico e os resultados alcançados. Por fim, as conclusões do trabalho.

\section{PROCESSO DE PCP}

O desempenho de uma empresa está diretamente ligado ao alinhamento entre a demanda (LI et al., 2013) e as decisões sobre planejamento, programação e controle da produção (SLACK et al., 2013). Equalizar a relação capacidade e demanda é um dos principais fundamentos no processo de PCP (OLHAGER; JOHANSSON, 2012). O comportamento do PCP induz a performance da produção no que se refere aos critérios de qualidade, velocidade, confiabilidade, flexibilidade e custo (GALVÃO et al., 2016).

0 processo de PCP adotado por uma empresa é responsável pela integração, tratamento e distribuição de informações necessárias para a execução da estratégia do negócio no âmbito do sistema produtivo. Pode ser entendido como um conjunto de procedimentos de coordenação, que suportam um fluxo de informações e decisões em direção as definições de ordens de produção e compras (CORRÊA et al., 2019; 
TUBINO, 2017). Para o sistema de PCP o principal recurso é a informação, para que o planejamento e controle ocorram as informações sobre posicionamento de estoques, situações de vendas, características dos produtos, modo e recursos de produção, além da capacidade instalada são indispensáveis (GALVÃo et al., 2016). Porém em uma perspectiva de desenvolvimento do processo de PCP, o ponto de partida geralmente tem procedimentos mais intuitivos e limitados, comum em pequenas empresas. Evangelista et al. (2011) manifestam que um PCP sistemático tende a reduzir incertezas nos processos decisórios. Sendo assim, os sistemas de gestão com processos de PCP mais sólidos e maduros já envolvem recursos humanos, de hardwares e de softwares. Além disso, fazem uso de modelos decisão estruturados com apoio em ferramentas de gestão, com destaque para ERP (Enterprise Resource Planning) (SILVA JR.; DA SILVA, 2014; OLIVEIRA; HATAKEYAMA, 2012), S\&OP (Sales \& Operations Planning), MRP (Material Requirement Planning), Plano Mestre de Produção (MPS - Master Production Schedule) (CORRÊA et al., 2019; TUBINO, 2017), MES (Manufacturing Execution System) (NEUHAUS et al., 2014; FRANCISCO; DA SILVA, 2014), APS (Advanced Planning and Scheduling) (GIACON; MESQUITA, 2011). O PCP tem o papel estratégico de apoio às tomadas de decisões (GALVÃO et al., 2016). Dependendo o tipo ou tamanho do empreendimento, o processo de PCP é exclusivo de uma área funcional, já em outros casos, acaba tendo suas tarefas diluídas por diversos setores da empresa.

Sistema produtivo é um conjunto interligado de entidades habilitadoras de processamento que visa transformar entradas (insumos) em saídas (produtos finais) (SLACK et al., 2013; CORRÊA; CORRÊA, 2017). Um processo de PCP existe para que o sistema produtivo funcione adequadamente, atendendo as decisões da direção da empresa. Möller et al. (2013) discutem PCP como uma área funcional ou um processo empresarial. Enfatizando os processos, o PCP é responsável por transformar matéria-prima em produto acabado, atuando nas escolhas da logística interna e de uso dos recursos, buscando maximizar lucros com o atendimento do cliente e minimizar custos da operação. Ou seja, trata-se de um arranjo de processos de apoio gerencial para agregação de valor ao negócio. Na essência, tal organização ocorre em função da declaração do mix e sequenciamento da produção, seguido do acompanhamento e controle da execução (CORRÊAA et al., 2019; TUBINO, 2017). Assim, no planejamento determina-se de forma antecipada quais são os objetivos e necessidades da produção, buscando otimizar os recursos de entrada. Evoluindo, procura-se responder o que fazer, quanto fazer, quando fazer e onde fazer. Já no controle devese medir os desempenhos da execução e efetuar correções apropriadas para atingir os objetivos traçados, ou ainda, sustentar reações. É a etapa de verificação da aderência entre planejado e executado (THURER; GODINHO FILHO, 2012).

Tubino (2017), Corrêa e Corrêa (2017) detalham de forma hierárquica as atividades desenvolvidas no processo de PCP (Figura 1):

- Planejamento Estratégico da Produção - momento de estabelecer um Plano de Produção a longo prazo, em geral por meses ou trimestres, utilizando como referência previsões de demandas, disponibilidades de recursos financeiros e de produção, oportunidades de novos produtos e mercados. 0 Plano de Produção reflete aspectos mais agregados, comumente aborda famílias de produtos, o que possibilita adaptar o direcionamento dos recursos produtivos à demanda visualizada. 0 resultado alcançado no Plano de Produção deve traduzir as escolhas estratégicas da Direção da empresa.

- Planejamento Tático da Produção - consiste na elaboração do Plano Mestre de Produção (MPS), detalhando no médio prazo as quantidades de cada produto final a serem produzidas no período planejado, geralmente em semanas. Com base nas estimativas de vendas no horizonte de planejamento, os pedidos já confirmados, capacidade produtiva, políticas e produtos em estoque, o MPS visa tornar compatível os níveis de estoque, a capacidade instalada e a variabilidade na demanda. Este processo é responsável pela integração entre o plano estratégico e os planos operacionais da empresa.

- Programação da Produção - fase das atividades de curto prazo que geram o programa de produção operacional para atendimento do MPS. A programação estipula o quanto e quando comprar, fabricar ou montar cada componente da estrutura de produto final, além de indicar com quais recursos produzir. Programar a produção é gerenciar os estoques, fazer o sequenciamento das atividades dos recursos produtivos, emitir ordens de compra e produção. 0 objetivo nesta etapa é sincronizar a produção e manter um fluxo produtivo eficaz e eficiente, o quanto possível.

- Acompanhamento e Controle da Produção - etapa responsável por garantir a execução da programação da produção de acordo com o planejado e retroalimentar os níveis de planejamento anteriores. Por meio de coleta e análise de dados, medidas de desempenho são utilizadas para sustentar a gestão da empresa, indicando o cumprimento do planejado ou sinalizando a necessidade de reação em 
função de desvios. Além disso, monitorar permite informar corretamente as condições do processo produtivo para as partes interessadas.

Figura 1 - Visão geral do processo de PCP.

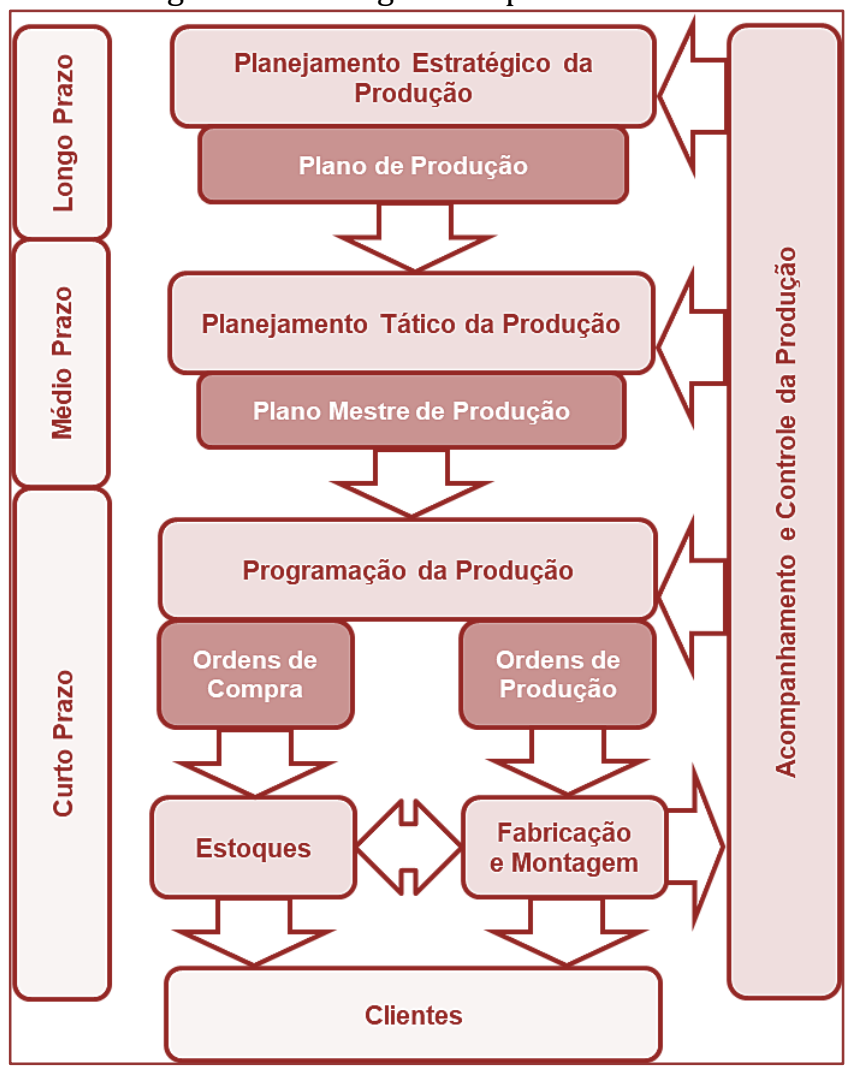

Fonte: Baseado em Tubino (2017), Corrêa e Corrêa (2017)

As práticas de PCP tem como finalidade alinhar os níveis estratégico, tático e operacional com as diretrizes da empresa, assim como, atuar como elemento integrador dos diferentes agentes do sistema produtivo (CORRÊA et al., 2019; DA SILVA et al., 2019). 0 êxito nesta postura potencializa a conciliação entre fornecimento e demanda, o que contribui para o avanço dos negócios em função de decisões que podem maximizar o atendimento ao cliente, maximizar lucros, minimizar custos, minimizar investimentos em estoques, minimizar flutuações na produção, maximizar a utilização dos recursos produtivos e minimizar variações na força de trabalho (SLACK et al., 2013; CORRÊA; CORRÊA, 2017).

Mas atingir a sistematização dos processos de planejamento e controle para garantir a objetividade na orientação de produção é um desafio para grandes e pequenas organizações. A forma hierárquica das atividades desenvolvidas em um processo de PCP genérico (TUBINO, 2017; CORRÊA; CORRÊA, 2017) aqui apresentado, reflete um conjunto de boas práticas exploradas pelos meios empresarial e acadêmico. As particularidades de cada caso de implementação exigirão as devidas análises e possíveis adaptações quanto aos procedimentos e mecanismos de execução. Diferentes contextos podem justificar diferentes caminhos de desenvolvimento do processo de PCP. Neste sentido, em especial sobre pequenas empresas, Narcizo et al. (2015) discutem incertezas e limitações a serem enfrentadas na implementação do PCP, tais como: documentações de engenharia incompletos, divergentes ou faltantes; modelo de gestão e estratégia indefinidos; variabilidade nos processos; arranjo físico e condições de trabalho inadequados; baixos índices de desempenho em diversas áreas; relacionamento frágil com fornecedores; capacitação limitada dos funcionários; restrição financeira para investimento; estrutura organizacional imprópria para o negócio. Estes aspectos tendem a implicar em um processo lento, gradual e árdua de implementação das rotinas de PCP, porém ainda importante e significativo para a performance e competitividade da empresa. 


\section{METODOLOGIA}

O objetivo geral deste trabalho é implementar o processo de PCP em uma pequena empresa. A metodologia adotada para o estudo é a pesquisa-ação (DE FREITAS; DA SILVA, 2017), onde segue um ciclo no qual se aprimora a prática através da interação entre agir e investigar. A abordagem envolve planejamento, tomada de ação e avaliação da mudança gerando reflexão e aprendizagem (MIGUEL et al., 2012). A pesquisa-ação pode ser dividida em macroetapas: identificação do problema; planejamento da solução; implementação; monitoramento e avaliação. 0 método de trabalho é distribuído como segue:

1. Identificação do problema - 0 problema é reconhecido visto que a empresa objeto de estudo deste trabalho teve um crescimento representativo de suas vendas em um curto espaço de tempo, vendia em torno de duas máquinas por mês e passou a vender quinze, sem que a produção tenha acompanhado tal evolução. Neste momento, a Direção da empresa considera prioritário para a operação do negócio: cumprir prazos de entrega aos clientes, uma vez que atua no regime sob encomenda; estimar os custos dos projetos, visando melhorar sua competitividade frente concorrentes globalizados.

2. Planejamento da solução - Com base em Barros Filho e Tubino (1999) e Fagundes e Pires (2013), é projetado o plano de intervenção para implementação do processo de PCP através dos seguintes passos: (a) definição da equipe responsável pelo projeto PCP; (b) sensibilização dos trabalhadores sobre a importância do PCP; (c) nivelamento do conhecimento dos trabalhadores sobre PCP; (d) caracterização do sistema de trabalho da empresa; (e) análise do sistema de trabalho original; (f) sistematização e simplificação deste sistema de trabalho; (h) execução da mudança.

3. Implementação - Após identificação do problema e objetivos, o primeiro passo na implementação do processo de PCP é a definição da equipe responsável pelo projeto, visando envolver lideranças de áreas relacionadas e beneficiadas. Na sequência, é realizada uma reunião inicial, com duração de uma hora e trinta minutos, onde todos os funcionários da empresa deverão estar presentes, a fim de conscientizá-los da importância desse projeto e da relevância do mesmo no desempenho do negócio. Além disso, a fim de manter o envolvimento dos colaboradores com as tarefas de PCP, são realizadas reuniões semanais de trinta minutos para tratar assuntos pertinentes ao projeto. Essas reuniões também são úteis para sanar eventuais dúvidas que surjam ao longo do desenvolvimento dos trabalhos, auxiliando no nivelamento de conhecimento dos funcionários no que diz respeito a PCP. O próximo passo é a caracterização dos trabalhos exercidos na empresa. É utilizado o mapeamento de processo para identificar os procedimentos e particularidades vigentes. 0 levantamento de dados é realizado através de questionários e entrevistas com os responsáveis pelas operações, além de observação durante as visitas na empresa e coleta direta de dados nos postos de trabalho. Depois a etapa de análise das características e dados apurados do sistema de trabalho, visando identificar potenciais oportunidades de melhoria. Neste caso, o intuito inicial é compreender a formação do preço de venda do produto e a velocidade da entrega. Após entender a situação original, são propostas ações para sistematizar e simplificar o sistema de trabalho. 0 último passo é efetivar a mudança na empresa a nível de processo de PCP.

4. Monitoramento e avaliação - Nesta etapa os dados coletados no mapeamento de processo original da empresa são comparados com os resultados obtidos após implementação do processo de PCP. Os indicadores que embasam essa comparação são: lead time do produto; prazo de entrega do produto; taxa de cumprimento do prazo de entrega; tempo de ciclo, lead time das matérias-primas e percentual de margem de contribuição obtida por produto.

\section{RESULTADOS}

\section{EMPRESA OBJETO DE ESTUDO}

A empresa nacional estudada pertence a indústria eletrônica, situada em Curitiba, Paraná. Foi fundada em 2009 onde sua principal atividade é a fabricação de máquinas de vendas automáticas. Ademais, está inserida em um mercado composto por maioria de players importadores, e não fabricantes. Inicialmente sua demanda de produção era em torno de duas máquinas por mês, gerando um faturamento de aproximadamente $\mathrm{R} \$ 50.000,00$. Em 2018, com a entrada de um novo sócio, sua demanda ascendeu para 15 máquinas mensais, o que aumentou seu faturamento para $\mathrm{R} \$ 375.000,00$. Com base nesse incremento considerável na demanda para a realidade da empresa, é exigido aumentar sua capacidade produtiva e buscar a formação de um sistema empresarial capaz de atender aos objetivos da Direção local, resultando em um sistema produtivo organizado, ágil e efetivo. Tendo em vista essa necessidade e dentro de um 
conjunto de esforços, a gestão do negócio optou então pela implementação do processo de PCP, visando tornar a empresa mais competitiva. As respostas iniciais definidas pela Direção com a iniciativa são: cumprir prazos de entrega e estimar os custos dos projetos da empresa.

\subsection{DEFINIÇÃO DA EQUIPE DE TRABALHO}

A definição da equipe de trabalho foi o primeiro passo para a implantação do processo de PCP na empresa estudada. Por se tratar de uma empresa pequena, optou-se por uma equipe com número reduzido de componentes e com pessoas de representatividade dentro dos processos de negócio. Foi definido como participantes da equipe: (i) o gestor comercial, buscando entender as necessidades comerciais da empresa, representando as visões dos clientes externos; (ii) o gestor industrial, responsável pela fábrica e todos os processos que a englobam, trazendo as dificuldades dos clientes internos; e (iii) os pesquisadores deste trabalho, prestando consultoria e suporte nesta jornada.

\subsection{SENSIBILIZAÇÃO E NIVELAMENTO DO CONHECIMENTO SOBRE PCP}

Conforme visto durante o desenvolvimento do trabalho, o PCP está diretamente ligado às características competitivas como custo, velocidade na entrega, confiabilidade na entrega, flexibilidade e qualidade. A efetiva colaboração do PCP no negócio vai ao encontro do interesse da empresa nessa fase de reestruturação.

A empresa tem uma equipe de sete colaboradores envolvidos no processo produtivo, todos inseridos na etapa de conscientização. Em um primeiro momento foi compartilhada a pesquisa que embasa este trabalho e, posteriormente, feita a reunião inicial com duração de uma hora e trinta minutos. Essa reunião teve o intuito de expor os motivos pelos quais a empresa buscou a implantação do processo de PCP, os benefícios esperados, as possíveis dificuldades na implementação e a importância do engajamento de todos na empresa.

Além disso, foram realizadas reuniões semanais com duração de trinta minutos, no início da jornada de trabalho, visando manter a equipe sensibilizada com o projeto e atuando em eventuais dúvidas sobre o mesmo. Os operadores receberam o projeto positivamente, uma vez que as tarefas operacionais não estavam bem definidas e o processo produtivo não seguia uma rotina. Cabe ressaltar que três dos operadores são estudantes de Engenharia, fato que facilitou a percepção do grupo sobre a intenção da mudança. Entretanto, todos os operadores estão na empresa há mais de quatro anos e possuem inúmeros vícios na rotina de trabalho.

\subsection{CARACTERIZAÇÃO DO SISTEMA DE TRABALHO}

Por se tratar de um produto específico, personalizado para cada cliente, o modelo de produção adotado pela empresa é sob encomenda, o que exige a organização da produção a cada novo pedido. Nesse tipo de produção o processo só é iniciado após recebimento de um pedido.

O orçamento para o cliente antecede o pedido. Nele deveriam constar matérias-primas necessárias, equipe alocada no projeto e um cronograma das atividades, pois tais informações impactam diretamente no custo e prazo de entrega do produto. Porém, a empresa objeto de estudo não trabalha dessa maneira. 0 processo de cotação é feito pelo setor comercial sem as considerações de custos reais do produto, mas com base em valor pré-estabelecido, que nem sempre condiz com a realidade do projeto. 0 prazo de entrega é algo informado ao cliente sem embasamento concreto e gera um índice de cumprimento de prazo de entrega na ordem de $50 \%$ dos pedidos. Após fechamento de um orçamento, a entrada do pedido para a fábrica é feita por telefone. 0 setor comercial passa para o responsável pela fábrica o pedido, contendo as características de cada projeto e de maneira informal. Muitas vezes o gestor da fábrica, durante a execução de um projeto, precisa consultar o setor comercial para discutir detalhes do produto que está em estágio de fabricação. 
Os dados de rotina da operação foram levantados, possibilitando melhor compreensão do cenário original no que diz respeito a jornada diária de trabalho. A Tabela 1 mostra os dados encontrados.

Tabela 1. Informações sobre a operação.

\begin{tabular}{|c|c|}
\hline \multicolumn{1}{|c|}{ ITEM } & DADOS COLETADOS \\
\hline Tempo total por dia de trabalho & 528 minutos \\
\hline Paradas planejadas & Almoço: 60 minutos \\
\hline Tempo diário disponível & 468 minutos \\
\hline Número total de pessoas envolvidas & 9 pessoas \\
\hline
\end{tabular}

Fonte: Autores.

Além disso, foi mapeado o processo produtivo original, apontando suas atividades, responsabilidades e tempos operacionais. 0 processo é expresso na Tabela 2.

Tabela 2. Mapeamento de processo original da produção.

\begin{tabular}{|c|c|c|c|}
\hline ETAPA & ATIVIDADE & RESPONSÁVEL & TEMPO (min) \\
\hline 1 & Receber gabinete & OPER1 & 20 \\
\hline 2 & Retirar gabinete da embalagem & OPER1 & 5 \\
\hline 3 & Fazer furações no gabinete & OPER1 & 60 \\
\hline 4 & Fixar estrutura & OPER2 & 90 \\
\hline 5 & Confeccionar molas & OPER1 & 90 \\
\hline 6 & Medir produtos a serem colocados na máquina & OPER2 & 30 \\
\hline 7 & Colocar as bandejas & OPER2 & 15 \\
\hline 8 & Montar 36 motores & OPER3 & 387 \\
\hline 9 & Colocar motores nas bandejas & OPER1/OPER2 & 78 \\
\hline 10 & Instalar chicotes elétricos & OPER2 & 70 \\
\hline 11 & Colocar elevador & OPER2 & 37 \\
\hline 12 & Instalar placa de controle & OPER4 & 48 \\
\hline 13 & Instalar módulo de comunicação & OPER4 & 23 \\
\hline 14 & Instalar tela touch & OPER4 & 42 \\
\hline 15 & Configurar software & OPER5 & 68 \\
\hline 16 & Instalar pinpad & OPER4 & 20 \\
\hline 17 & Configurar pinpad & OPER6 & 20 \\
\hline 18 & Adesivar & OPER7 & 240 \\
\hline & \multicolumn{2}{|l|}{ Tempo total } & 1343 \\
\hline
\end{tabular}

Ainda na coleta de dados, foi identificada a estrutura de produto genérica com os componentes necessários para a produção das máquinas e seus respectivos lead times, conforme Tabela 3. 
Tabela 3. Estrutura do produto.

\begin{tabular}{|c|c|c|c|}
\hline QUANTIDADE & UNIDADE & COMPONENTE & LEAD TIME (dias) \\
\hline 1 & Unidade & Gabinete & 60 \\
\hline 1 & Unidade & Porta & 15 \\
\hline 1 & Unidade & Elevador & 5 \\
\hline 6 & Unidade & Bandeja & 5 \\
\hline 36 & Unidade & Motor & 3 \\
\hline 6 & Barra & Barra de Alumínio & 1 \\
\hline 24 & Unidade & Roldana & 1 \\
\hline 1 & Unidade & Minicomputador & 7 \\
\hline 1 & Unidade & Placa de Controle & 30 \\
\hline 1 & Unidade & Roteador & 7 \\
\hline 36 & Unidade & Mola & 3 \\
\hline 1 & Unidade & Pinpad & 2 \\
\hline 1 & Unidade & Tela Touch & 7 \\
\hline 1 & Unidade & Cabo USB & 1 \\
\hline 1 & Unidade & Chicote elétrico & 25 \\
\hline 1 & Unidade & Teclado & 7 \\
\hline 1 & Unidade & $\begin{array}{c}\text { Visor de Cristal } \\
\text { Líquido }\end{array}$ & 7 \\
\hline 2 & Metro & Cabo de Rede & 1 \\
\hline 1 & Unidade & Fonte de Energia & 3 \\
\hline 1 & Unidade & Cabo de Energia & 1 \\
\hline 1 & Metro & Cabo HDMI & 1 \\
\hline 2 & Metro & Fita LED & 3 \\
\hline 5,25 & Metro & Adesivo Plotagem & 2 \\
\hline 1 & Unidade & Cola & 1 \\
\hline 164 & Unidade & Parafuso & 1 \\
\hline 5,3 & Metro & Borracha & 3 \\
\hline 4 & Unidade & Dobradiça & 1 \\
\hline 1 & Unidade & Fechadura Tetra & 1 \\
\hline
\end{tabular}

\subsection{ANÁLISE DO SISTEMA DE TRABALHO ORIGINAL}

É notório que há falhas no sistema original, uma vez que a empresa tem problemas generalizados com a definição de prazo de entrega e os custos do produto. 0 prazo de entrega informado ao cliente é 30 dias, mas o cumprimento desse prazo se dá em apenas metade dos pedidos que entram na fábrica. 0 período de atraso na entrega é na ordem de 40 a 60 dias. Referente ao custo do produto, trata-se de um produto com muita tecnologia embarcada, o que dá à empresa boas condições de margem de lucro. Porém, por se tratar de produto customizado em cada pedido, os custos variam entre $R \$ 8.000,00$ e $R \$ 15.000,00$, não avaliados plenamente na formação de preço. Os preços de venda são estipulados com base em mercado e valor pré-estabelecido de $\mathrm{R} \$ 25.000,00$.

0 mapeamento das atividades apresentado na Tabela 2 e a estrutura do produto apresentada na Tabela 3 foram elaborados visando clarear as informações para o setor comercial no momento da formalização de um orçamento para o cliente. Desta forma, o setor comercial pode fazer uso de um checklist dos itens necessários para produção da máquina, bem como analisar o lead time das matérias-primas e os tempos de cada processo, a fim de calcular com maior precisão o custo do produto e seu prazo de entrega.

De forma semelhante, esses instrumentos servem para comunicar e organizar o processo produtivo, uma vez que especificam o que, quanto e quando as atividades devem ser realizadas. Além disso, são ferramentas que melhoram o acompanhamento e monitoramento do processo produtivo, inclusive permitindo reação quando necessário, a fim de atingir os objetivos estipulados pela gestão da empresa. 


\subsection{SISTEMATIZAÇÃO E SIMPLIFICAÇÃO DO SISTEMA DE TRABALHO}

Os principais pontos observados durante a coleta de dados foram a falta de informação e padrão no que diz respeito a lead time de matéria-prima e a disparidade de carga dos funcionários. Enquanto alguns estão sobrecarregados, outros têm folga durante as atividades produtivas.

Buscou-se então reduzir o lead time de matéria-prima através de desenvolvimento de fornecedores parceiros. Essa tarefa ficou a cargo do administrador da empresa, que elencou os principais componentes da máquina (gabinete, chicotes elétricos e placa de controle) e procurou fornecedores mais próximos, com maior capacidade de atendimento e interesse em fortalecer relacionamento. No caso do gabinete, foi contratada uma metalúrgica local que recebeu toda a demanda da peça e, em troca, acordou o prazo de entrega de 60 para 30 dias. Já para os chicotes elétricos, há poucos fornecedores confiáveis, então a solução encontrada foi manter um estoque de segurança maior desses itens. Por fim, para as placas de controle, por ser o componente mais importante do produto, optou-se por um fornecedor de maior porte, com estoque, reduzindo o lead time de 30 para 10 dias.

Outro ponto analisado foi a disparidade de carga dos funcionários. O meio utilizado para sanar este problema foi a equalização dos tempos individuais de trabalho, definindo o número de postos de trabalho, agrupando as atividades por posto e somando os tempos gastos no processamento, o que pode ser visto na Tabela 4. Uma vez que o tempo de ciclo da produção é o maior tempo de processamento entre os postos, pode-se determinar que o tempo de ciclo do processo produtivo original é 387 minutos. Com esse dado é possível calcular o número de operadores $(N)$ necessários, conforme a Equação 1:

$$
N=\frac{\text { tempo total de produção }}{\text { tempo de ciclo }}
$$

Sendo o tempo total de produção igual a 1343 minutos (Tabela 3), o cálculo teórico aponta a necessidade de 3,47 operadores. Há, de fato, cinco operadores na produção, uma vez que os operadores (OPER) 5 e 6 têm pequenas participações dentro do processo produtivo e são alocados em outras atividades na área de inovação tecnológica e desenvolvimento de software. Com isso, o índice de eficiência da distribuição de carga atual é de $69,4 \%$.

Tabela 4. Distribuição original de atividades por operador.

\begin{tabular}{|c|c|c|c|}
\hline ATIVIDADE & RESPONSÁVEL & TEMPO (min) & TEMPO TOTAL (min) \\
\hline Receber gabinete & \multirow{5}{*}{ OPER1 } & 20 & \multirow{5}{*}{253} \\
\hline Retirar gabinete da embalagem & & 5 & \\
\hline Fazer furações no gabinete & & 60 & \\
\hline Confeccionar molas & & 90 & \\
\hline Colocar motores nas bandejas & & 78 & \\
\hline Fixar estrutura & \multirow{6}{*}{ OPER2 } & 90 & \multirow{6}{*}{320} \\
\hline Medir produtos a serem colocados na máquina & & 30 & \\
\hline Colocar as bandejas & & 15 & \\
\hline Instalar chicotes elétricos & & 70 & \\
\hline Colocar elevador & & 37 & \\
\hline Colocar motores nas bandejas & & 78 & \\
\hline Montar 36 motores & OPER3 & 387 & 387 \\
\hline Instalar placa de controle & \multirow{4}{*}{ OPER4 } & 48 & \multirow{4}{*}{133} \\
\hline Instalar módulo de comunicação & & 23 & \\
\hline Instalar tela touch & & 42 & \\
\hline Instalar pinpad & & 20 & \\
\hline Configurar software & OPER5 & 68 & 68 \\
\hline Configurar pinpad & OPER6 & 20 & 20 \\
\hline Adesivar & OPER7 & 240 & 240 \\
\hline
\end{tabular}


Para redistribuição das tarefas foi considerado a complexidade das atividades, visando equilibrar a jornada diária de cada operador e permitir maior fluidez no desempenho produtivo, agrupando as operações de tal forma que o somatório de suas respectivas durações se aproxime do tempo de ciclo da produção. 0 foco dessa redistribuição foi a redução do tempo de montagem dos motores, atividade identificada como gargalo da produção no mapeamento do estado original. Esse tempo foi reduzido alocando dois operadores para essa atividade ao invés de apenas um, como no estado inicial.

\subsection{EXECUÇÃO DA MUDANÇA NOS PROCEDIMENTOS DE PCP}

Após entender quais são as funções, benefícios e objetivos de um processo de PCP, conhecer o sistema de trabalho da empresa e suas necessidades, bem como, analisar propostas de mudanças de procedimentos em direção de uma nova realidade na empresa, foram implementadas as ações de desenvolvimento de um processo de PCP local. Essa implementação envolveu toda a empresa, onde todos estavam engajados e otimistas com as mudanças propostas.

Apesar de ser esperado do processo de PCP refletir de forma direta na produção, inicialmente, o setor que mais percebeu e fez uso das mudanças foi a área comercial. Esse setor passou a ter ferramentas para trabalhar e enxergar com mais clareza o funcionamento da produção. Os preços de venda passaram a ser calculados considerando as matérias-primas necessárias, os custos de cada etapa produtiva e lead times, evoluindo nas tratativas comerciais com os clientes finais.

No entanto, ainda sob a ótica do setor comercial foi identificado um ponto negativo nesta implementação, a perda de flexibilidade em relação a prazos de entrega especiais para alguns clientes. 0 que antes era praticado acabou sendo revisto, uma vez que comprometeria o fluxo da produção. Esse foi um ponto negativo levantado também pelo setor produtivo, porém sob outro ângulo: a perda de flexibilidade em relação a distribuição de tarefas. Como antes alguns operadores estavam com sobrecarga e outros com períodos ociosos durante a jornada de trabalho, eles acabavam dividindo as tarefas de acordo com a demanda do dia, o que hoje foi redesenhado. As tarefas operacionais foram redistribuídas e passaram a ser monitoradas, mudança esta que direcionou à padronização do processo produtivo. Em um primeiro estágio, permitiu maior controle sobre a operação e melhores condições de reações rápidas em casos de perturbações na produção, reduzindo o impacto de desvios sobre o volume produzido, custos operacionais e desatendimento do cliente final.

\subsection{MONITORAMENTO E AVALIAÇÃO DO PROCESSO DE PCP}

Após três meses de implementação das ações iniciais de mudanças em direção ao desenvolvimento de um processo pleno de PCP, nova coleta de dados foi realizada. Quanto às atividades de produção, o novo mapeamento de processo é mostrado na Tabela 5. Neste cenário pode-se ver que o tempo total de processamento foi reduzido em 150 minutos se comparado com o mapeamento de processo original, representando uma redução de 11,16\%. Como consequência, a capacidade de produção pode chegar a duas máquinas por dia. 
Tabela 5. Mapeamento de processo da produção após mudanças nos procedimentos de PCP.

\begin{tabular}{|c|c|c|c|}
\hline ETAPA & ATIVIDADE & RESPONSÁVEL & TEMPO (min) \\
\hline 1 & Receber gabinete & OPER1 & 20 \\
\hline 2 & Retirar gabinete da embalagem & OPER1 & 5 \\
\hline 3 & Fazer furações no gabinete & OPER1 & 60 \\
\hline 4 & Fixar estrutura & OPER1 & 60 \\
\hline 5 & Confeccionar molas & OPER1 & 90 \\
\hline 6 & Medir produtos a serem colocados na máquina & OPER2 & 30 \\
\hline 7 & Colocar as bandejas & OPER2 & 15 \\
\hline 8 & Montar 36 motores & OPER2/OPER3 & 270 \\
\hline 9 & Colocar motores nas bandejas & OPER1/OPER4 & 75 \\
\hline 10 & Instalar chicotes elétricos & OPER4 & 70 \\
\hline 11 & Colocar elevador & OPER3 & 37 \\
\hline 12 & Instalar placa de controle & OPER4 & 48 \\
\hline 13 & Instalar módulo de comunicação & OPER4 & 23 \\
\hline 14 & Instalar tela touch & OPER4 & 42 \\
\hline 15 & Configurar software & OPER5 & 68 \\
\hline 16 & Instalar pinpad & OPER4 & 20 \\
\hline 17 & Configurar pinpad & OPER6 & 20 \\
\hline 18 & Adesivar & OPER7 & 240 \\
\hline & \multicolumn{2}{|l|}{ Tempo total } & 1193 \\
\hline
\end{tabular}

Além disso, os tempos gastos por cada colaborador em operação foram analisados buscando a equalização dos mesmos, de forma a reduzir ociosidade e ganhar produtividade. Este movimento de equilíbrio de cargas por operador é representado na Figura 2.

Figura 2. Equilíbrio de cargas de trabalho por operador.

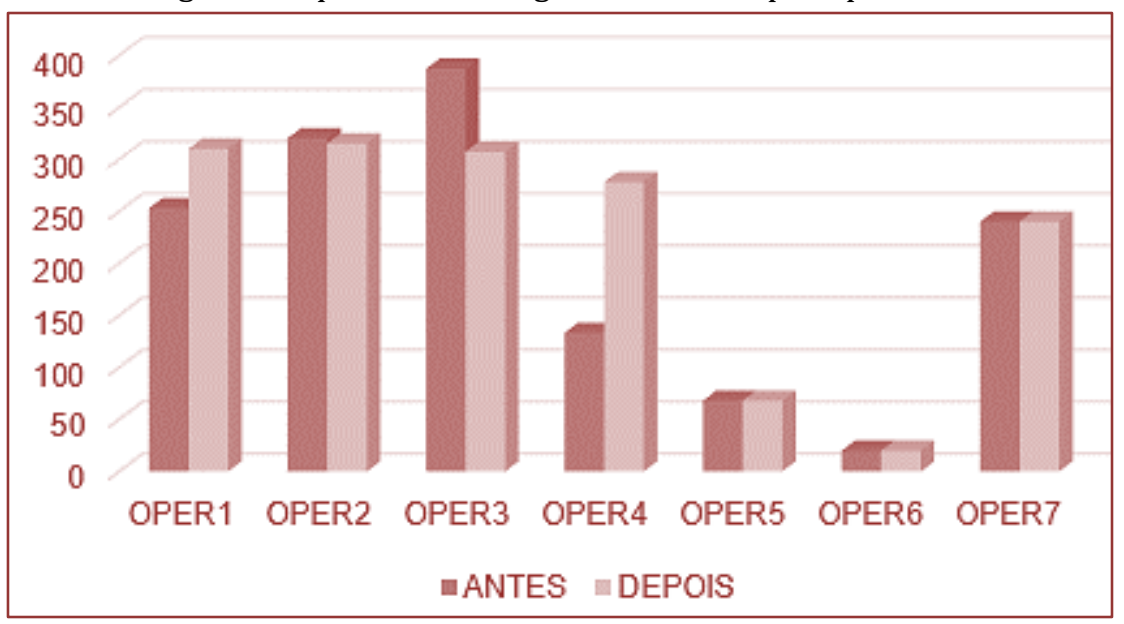

Fonte: Autores. 
É importante relembrar que, conforme já citato anteriormente, os operadores 5 e 6 se envolvem menos no processo produtivo, pois suas funções também estão vinculadas ao desenvolvimento e programação de software, bem como, prestar suporte aos clientes neste quesito, ou seja, carga de trabalho fora da produção. No entanto, é perceptível que o fluxo de trabalho estava distribuído de maneira tão desigual que comprometia a execução das atividades nos tempos estipulados.

A Tabela 6 sintetiza a comparação do estado original da empresa no que diz respeito aos indicadores do sistema de trabalho com os resultados obtidos após mudanças no âmbito de PCP.

Tabela 6. Síntese dos resultados do sistema de trabalho com as ações de mudança em PCP.

\begin{tabular}{|c|c|c|}
\hline INDICADOR & ANTES & DEPOIS \\
\hline Lead time do produto & 1343 minutos & 1193 minutos \\
\hline Lead time do gabinete & 60 dias & 30 dias \\
\hline Lead time da placa de controle & 30 dias & 10 dias \\
\hline Lead time dos chicotes elétricos & 25 dias & 25 dias \\
\hline Taxa de cumprimento de prazo de entrega & $50 \%$ & $70 \%$ \\
\hline Prazo de entrega prometido ao cliente & 30 dias & 45 dias \\
\hline Período máximo de entrega em atraso & 60 dias & 15 dias \\
\hline Percentual de margem de contribuição por venda & $40 \%$ a $68 \%$ & $50 \%$ a $60 \%$ \\
\hline Tempo de ciclo do processo & 387 minutos & 270 minutos \\
\hline Índice de eficiência da distribuição de carga & $69,40 \%$ & $88 \%$ \\
\hline \multicolumn{2}{|c}{} \\
\hline
\end{tabular}

Fonte: Autores.

Com base na Tabela 6, é possível afirmar que a empresa obteve ganhos após a implementação de ações no contexto de PCP. 0 lead time do produto foi reduzido em 150 minutos, o que representa uma melhoria de $11,16 \%$ no tempo de atravessamento e potencializa a capacidade instalada de 2 máquinas por dia. Quanto as matérias-primas principais (gabinete, placa de controle e chicotes elétricos), foi possível reduzir o lead time do gabinete e da placa de controle em $50 \%$ e $33 \%$, respectivamente. Já para os chicotes elétricos a melhoria buscada não foi alcançada. Porém, através deste estudo, foi possível identificar o problema e criar uma ação de contenção para o caso, o aumento do estoque de segurança do item. As propostas colaboram com a redução de desperdícios e de incidência de rupturas no fluxo de produção.

Com relação a prazo de entrega, foi identificado que o combinado com cliente era 30 dias, porém, apenas $50 \%$ dos pedidos eram cumpridos. Para os demais, o período de entrega em atraso chegava até 60 dias. Assim, além das mudanças no processo produtivo e no suprimento de matéria-prima, o setor comercial passou a adotar o período de entrega prometido ao cliente de 45 dias, atitude vinculada com o novo nível de conhecimento da operação e nova postura de relacionamento como o cliente, tentativa de recuperação quanto a confiança em entregas e de capacidade de parceria a longo prazo. 0 conjunto de ações elevou a taxa de cumprimento de prazo de entrega para $70 \%$. Cabe ressaltar que neste novo cenário o período de entrega em atraso reduziu para no máximo 15 dias por pedido.

Já na formação de preços, foi visto que os custos variavam entre $\mathrm{R} \$ 8.000,00$ e $\mathrm{R} \$ 15.000,00$ por máquina, entretanto o preço de venda definido era sempre $\mathrm{R} \$ 25.000,00$, fazendo com que os percentuais de margens de contribuição oscilassem entre $40 \%$ e $68 \%$. Visando coerência no quesito formação de preços, a gestão da empresa passou a adotar o percentual de margem de contribuição entre $50 \%$ e $60 \%$, dependendo da complexidade do projeto em questão.

Outro ponto analisado refere-se ao equilíbrio de cargas por operador. No mapeamento de processo original o tempo de ciclo da produção era de 387 minutos e o índice de eficiência da distribuição de carga era $69,4 \%$. Após redistribuição das tarefas por operador o tempo de ciclo produção passou a ser 270 minutos e o índice de eficiência da distribuição de carga ficou em $88 \%$.

Esses resultados ilustram o estágio obtido pela empresa após implementar novos procedimentos relacionados com PCP. Os gargalos da produção foram reduzidos, a mão de obra passa a ser mais eficiente, os custos unitários de produção tornaram-se visíveis, o que fez com que os preços de venda possam ser 
melhor definidos, na entrega ampliou-se o nível de confiabilidade e a qualidade do serviço prestado ao cliente aumentou. Reflexos de esforços para o equilíbrio da relação capacidade e demanda. Ainda, a satisfação interna dos funcionários melhorou em função da redução de desgaste com o cliente final e a clareza nas etapas de processamento da empresa, além da comunicação entre produção e demais setores com mais fluidez. Entretanto, cabe ressaltar que, apesar dos ganhos que a empresa já alcançou, esta rodada de mudanças foi um passo inicial do projeto de implementação plena do processo de PCP. Os resultados alcançados neste trabalho devem servir de entrada para futuras rodadas de melhorias.

\section{CONCLUSÕES}

O objetivo geral deste trabalho foi conhecer, intervir e explorar academicamente a realidade da empresa investigada, implementando em seu sistema de gestão rotinas de PCP. A pesquisa se desenvolveu em uma empresa de pequeno porte do setor eletrônico brasileiro. Julga-se que tal objetivo foi atingido, inclusive, com as mudanças o processo de trabalho da empresa ficou mais organizado, com mais informações objetivas e orientativas alimentando o sistema produtivo, implicações esperadas de um processo de PCP em funcionamento.

Como resultado obteve-se o detalhamento do processo produtivo e dos recursos necessários, ambos documentados, visando sistematizar o fluxo do produto e das informações para torná-los claros e acessíveis a todos os setores da empresa. Um caminho de construção de mecanismos de apoio à decisão, acompanhamento e controle na empresa. Além disso, o uso dos recursos humanos foi melhor aproveitado, uma vez que no início deste estudo parte da mão de obra estava ociosa e parte sobrecarregada. 0 lead time do produto foi reduzido em 150 minutos, ou seja, queda de 11,16\%. 0 lead time das matérias-primas principais diminuiu em $50 \%$ para o gabinete e $33 \%$ para a placa de controle. Em relação aos chicotes elétricos o lead time não alterou, então foi redimensionado o estoque de segurança para este item. A taxa de cumprimento do prazo de entrega passou de 50\% para 70\%. O custo do produto foi conhecido e estratégias de formação de preço foram potencializadas. As atividades operacionais foram redistribuídas para os operadores, resultando na diminuição do tempo de ciclo do processo de 387 minutos para 270 minutos. Logo, o índice de eficiência da distribuição de carga que era $69,4 \%$ ficou em $88 \%$.

Este trabalho deve servir como passo inicial do desenvolvimento do processo de PCP na empresa investigada. Tem-se como sugestões de avanço no caso: readequação do layout; desenvolvimento e aplicação de ferramentas de planejamento; desenvolvimento e aplicação de ferramentas de controle da produção.

\section{REFERÊNCIAS}

[1] Barros Filho, J. R.; Tubino, D. F. Implantação do Planejamento e Controle da Produção em pequenas e médias empresas. XIII Enegep - Encontro Nacional de Engenharia de Produção, 1999.

[2] Corrêa, H. L.; Corrêa, C. Administração da Produção e Operações - Manufatura e Serviços: uma Abordagem Estratégica. 4. ED. São Paulo: Atlas, 2017.

[3] Corrêa, H. L.; Gianesi, I. G. N.; Caon, M. Planejamento, programação e controle da produção. 6. ed. São Paulo: Atlas, 2019.

[4] Cruz, R. S.; Mesquita, M. A. um Modelo de Análise do Planejamento e Controle da Produção Para Pequenas e Médias Empresas. Revista Produção Online, V. 18, N. 4, P. 1495-1522, 2018.

[5] Da Silva, R. M.; Duarte, L.; da silva, M. G. Analysis of production planning and control (PPC) through the approach of systems thinking. Brazilian Journal of Development, 2019.

[6] De Freitas, E. S.; Da silva, M. G. Pesquisa-ação sobre a implementação do trabalho padronizado em uma célula de manufatura de uma fábrica de tratores. Revista Espacios, v. 38, n. 46, p. 21, 2017.

[7] Estender, A. C.; Sequeira, G. R.; Siqueira, N. A. S.; Candido, G. J. A Importância do Planejamento e Controle de Produção. VI Singep - Simpósio Internacional de Gestão de Projetos, Inovação e Sustentabilidade, 2017. 
[8] Evangelista, A. A., Alonso JR., N.; Braga JR., S.; Ramos, A. L. O impacto da eficiência do Planejamento e Controle de Produção (Pcp) como um fator de competitividade: um estudo de caso em uma empresa de médio porte. Ingepro Inovação, Gestão e Produção, v. 3, n. 7, p. 46-59, 2011.

[9] Fagundes, L. D.; Pires, J. Implantação do Planejamento e Controle da Produção em uma microempresa de usinagem e ferramentaria de molde. XXXIII Enegep - Encontro Nacional de Engenharia de Produção, 2013.

[10] Francisco, A. S.; da Silva, M. G. Análise do Mes (Manufacturing Execution System) na gestão do processo produtivo de rações. XXI Simpep - Simpósio de Engenharia de Produção, 2014.

[11] Galvão, H. M.; Junqueira, L. F.; Mota, J.; Avelar, T, P.; Silva, W. C. F. Fatores de influência no Planejamento e Controle da Produção para a competitividade empresarial. XXXVI Enegep - Encontro Nacional de Engenharia de Produção, 2016.

[12] Giacon, E.; Mesquita, M. A. Levantamento das práticas de programação detalhada da produção: um survey na indústria paulista. Gestão \& Produção, v. 18, n. 3, p. 487-498, 2011.

[13] LI, D.; Chang, C.; Liu, C.; Chen, W. A new approach for manufacturing forecast problems with insufficient data: the case of TFT-lcds. Journal of Intelligent Manufacturing, v. 24, n. 2, p. 225-233, 2013.

[14] Lustosa, L. J.; Mesquita, M. A.; Quelhas, O. L. G.; Oliveira, R. J. Planejamento e Controle da Produção. Rio de Janeiro: Elsevier, 2008.

[15] Miguel, P. A.; Fleury, A.; Mello, C. H. P.; nakano, D. N.; Lima, E. P.; Turrioni, J. B.; HO, L. L.; Morabito, R.; Martins, R.A.; Souza, R.; Costa, S. E. G.; Pureza, V. Metodologia de Pesquisa em Engenharia de Produção e Gestão de Operações. Rio de Janeiro: Elsevier, 2012.

[16] Möller, E. B.; Schattschneider, G. O.; Frank, A. G.; Ribeiro, J. L. D. Qualidade da informação no PCP: análise dos fatores de influência e proposta de um método de diagnóstico. Revista Produção Online, v. 13, n. 1, p. 37-60, 2013.

[17] Narcizo, R B; Cormack, A M; Camatta, D C. Um método de apoio ao diagnóstico de demandas por serviços tecnológicos no programa Sebraetec. XXII Simpep - Simpósio de Engenharia de Produção, 2015.

[18] Neuhaus, C. A.; da Silva, M. G.; Pacheco, D. A. J. Implicações de manufacturing execution systems na gestão da qualidade industrial. Revista Geintec, v. 4, n. 5, p. 1489-1500, 2014.

[19] Olhager, J.; Johansson, P. Linking long-term capacity management for manufacturing and service operations. Journal of Engineering and Technology Management, v. 29, n. 1, p. 22-33, 2012.

[20] Oliveira, L. S.; Hatakeyama, K. Um estudo sobre a implantação de sistemas ERP: pesquisa realizada em grandes empresas industriais. Produção, v. 22, n. 3, p. 596-611, 2012.

[21] Silva JR., R. F.; da Silva, M. G. Implicações a partir da implementação do ERP em uma empresa do setor EPC (Engineering, Procurement and Construction). Revista Espacios, v. 35, n. 11, p. 19, 2014.

[22] Simões, W. L.; Dalla Vecchia, R.; da Silva, M. G. Proposição de um modelo de otimização para programação da produção em Sistema Flexível de Manufatura (FMS) com tempos de setup dependentes da sequência: a combinação de esforços em sequenciamento e tempos de preparação na indústria eletrônica. Produto \& Produção, v. 16, n. 1, p. 81-99, 2015.

[23] Slack, N.; Brandon-Jones, A.; Johnston, R. Princípios de administração da produção. São Paulo: Atlas, 2013.

[24] Thurer, M; Godinho Filho, M. Redução do lead time e entregas no prazo em pequenas e médias empresas que fabricam sob encomenda: a abordagem Worload Control (WLC) para o Planejamento e Controle da Produção (PCP). Gestão \& Produção, v. 19, n. 1, p. 43-58, 2012.

[25] Tubino, D F. Planejamento e Controle da Produção: Teoria e Prática. 3 ed. São Paulo: Atlas, 2017. 


\section{Capítulo 5}

Um estudo sobre planejamento e controle da qualidade e desenvolvimento de software através do enfoque meta-analítico

\section{David de Almeida Moysés \\ Alexandre Bonfim Martins \\ Leonardo Daniel Straub \\ Patrícia Mota Milhomem \\ Edgard Costa Oliveira}

Resumo: Diante das transformações tecnológicas ao longo dos anos de revoluções industriais, ressalta-se a importância dos processos de desenvolvimento de softwares, uma vez que o seu produto final impacta diretamente na eficiência de seu propósito, ou seja, do processo que ele é aplicado. Sendo assim, revela-se a necessidade da gestão no desenvolvimento desses sistemas, bem como a garantia de sua qualidade a fim de cumprir o propósito para o qual é elaborado e gerar um efeito positivo em sua aplicação. Dentro o universo de gestão da qualidade de softwares tem-se diversas práticas consolidadas no mercado, sendo o caso da CMM, CMMi e da ISO 9126, entretanto, é comum encontrar na literatura modelos particulares de gestão desenvolvidos pelos autores. Dessa forma, o presente trabalho tem como objetivo apresentar uma análise do estado da arte do planejamento e controle da qualidade aplicado aos processos de desenvolvimento de softwares. Para esta finalidade, foi utilizada a Teoria do Enfoque Meta-Analítico Consolidado (TEMAC), cuja plataforma de dados explorada foi o Web of Science, na qual foram encontrados e analisados 292 artigos científicos. Deste modo, foi possível identificar que um dos assuntos mais abordados é a necessidade de gerir a qualidade por meio de números, criando métricas para tal objetivo. Observou-se também uma evolução do tema no que concerne à aplicabilidade da gestão da qualidade nos processos de desenvolvimento de software. Antigamente a discussão girava em torno da criação de um modelo de qualidade, enquanto, atualmente o foco é na automação de modelos consolidados de gestão.

Palavras-chave: planejamento e controle da qualidade, desenvolvimento de software, revisão sistemática da literatura, TEMAC. 


\section{INTRODUÇÃO}

À medida que os sistemas se expandem e sua complexidade aumenta, os dados gerados e usados durante o ciclo de vida do software estão se tornando cada vez mais importantes (GUZMAN et al., 2017), o que reflete diretamente no controle de qualidade durante o processo de desenvolvimento de software (PDS). De acordo com Li et al. (2000), a qualidade do produto de software é assegurada pela aplicação de técnicas e métodos de garantia de qualidade de software (SQA) ao PDS.

Osmundson et al. (2003) apontaram que o gerenciamento de requisitos, pessoas e riscos são essenciais para desenvolver um software que atenda às necessidades dos usuários, no qual podem ser estimados por meio de métricas de qualidade para controle do produto durante todo o processo. Entretanto, recentes estudos sugerem que as deficiências de software podem ser o resultado da omissão de práticas de qualidade de desenvolvimento de software, no qual Ghanbari, Vartiainen \& Siponen (2018) mostraram por meio de uma revisão sistemática, que a literatura atual não considera a omissão de práticas de qualidade de forma adequada em relação à por que e como os desenvolvedores de software tomam a decisão de omitir uma prática de qualidade. Isso demonstra se tornar essencial o aprofundamento do estado da arte sobre a relação de práticas de planejamento de controle de qualidade durante o desenvolvimento de software.

A vista disso, o objetivo deste estudo é analisar à evolução das principais práticas de gestão da qualidade durante o desenvolvimento de software. Dessa maneira, a pesquisa tem o escopo voltado para responder a seguinte questão: Como tem sido aplicada a gestão da qualidade no PDS? Para alcançar esse resultado, utilizou-se a metodologia do Teoria do Enfoque Meta Analítico Consolidado, que se trata de uma abordagem derivada da meta análise, porém com um objetivo distinto de mapear a literatura, propondo marcos conceituais (MARIANO et al., 2011).

\section{METODOLOGIA}

A pesquisa se refere a uma revisão sistemática do tipo exploratória, com abordagem quali-quantitativa baseada na Teoria do Enfoque Meta Analítico Consolidado (TEMAC) de Mariano \& Rocha (2017). Essa abordagem fundamenta-se em três passos, conforme apresenta a Figura $1 .$.

Figura 1 - Etapas da metodologia de revisão sistemática

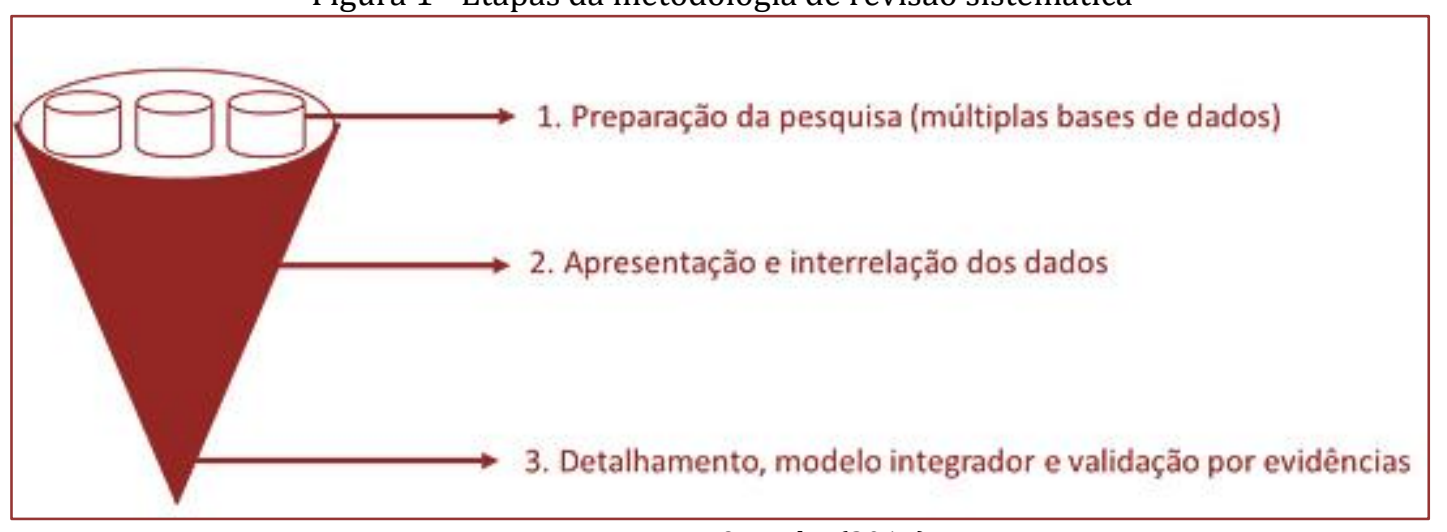

Fonte: Mariano \& Rocha (2017).

A primeira etapa consiste na preparação da pesquisa, na qual definem-se os critérios para coleta dos dados, tais como os descritores de busca, ou seja, as palavras-chave, período de busca dos artigos, as áreas de conhecimento e as bases de dados.

A segunda etapa consiste na apresentação e inter-relação dos dados. Com a finalidade de gerar um panorama das principais linhas de pesquisa, foram utilizadas as palavras-chave contidas nos documentos coletados que mais remetem ao tema pesquisado, revelando os conteúdos mais abordados dentro do tema. Após realizada a pesquisa por meio das palavras-chave definidas, utilizou-se a ferramenta online TagCrowd para elaborar uma nuvem de palavras com os 30 principais termos. 
A terceira etapa consiste no detalhamento, modelo integrador e validação por evidências, em que são realizadas análises bibliográficas com mapas de calor por meio do software VosViewer. Esses mapas se utilizam de cores mais quentes e fontes em negrito para enfatizar autores/conceitos que são usados com frequência, enquanto as palavras que são usadas apenas esporadicamente são mostradas em cores mais frias e fontes menores (ZUPIC; ČATER, 2015).

Realizou-se também uma análise baseada no co-citation que informa as aparições em conjunto dos autores e conceitos que constam na base de dados da pesquisa, ou seja, que são citados simultaneamente em outros trabalhos. Já o bibliographic coupling apresenta os nomes que são citados recorrentemente por diversos trabalhos, gerando uma perspectiva interessante de fronts de pesquisa que mais são explorados pela área.

Por fim, foi realizada uma discussão sobre o panorama geral do planejamento e controle da produção aplicado ao desenvolvimento de softwares, por meio de alguns critérios definidos nas escolhas dos artigos, como os 4 artigos mais citados, o mais antigo, o mais recente, aquele que possui a maior relevância de acordo com o WoS e o artigo que apresenta uma perspectiva específica sobre o tema abordado, aplicando TQM ao PDS.

\section{RESULTADOS}

\subsection{ANÁLISE GERAL E APRESENTAÇÃO DAS REVISTAS DA DISCIPLINA}

Na etapa 1, foi realizada uma busca na base de dados Web of Science utilizando os termos quality manag*, quality control* ou TQM vinculados aos termos software develop* ou software develop* process, gerando um total de 419 artigos. 0 asterisco foi usado para isolar o radical da palavra e buscar todas as variações da mesma, tornando a pesquisa mais abrangente sem perder a qualidade do refinamento. Para refinar os resultados obtidos, foram selecionadas as áreas de pesquisa relacionadas a área de TI obtendo no final 292 artigos, deste conjunto o artigo mais antigo foi publicado no ano de 1988. A partir da coleta realizada, prosseguiu-se para a apresentação da inter-relação dos dados (Etapa 2) e do detalhamento das análises bibliográficas (Etapa 3).

0 universo de artigos encontrados relacionados ao tema em questão registrou 1.638 citações até o dia 25 de abril de 2019. A distribuição não segue uma tendência gradativa de crescimento ao longo dos anos, porém, percebe-se um aumento na quantidade de publicações a partir do ano de 2007, quando houve uma quantidade mínima de 10 publicações por ano.

Figura 2- Citações por ano.

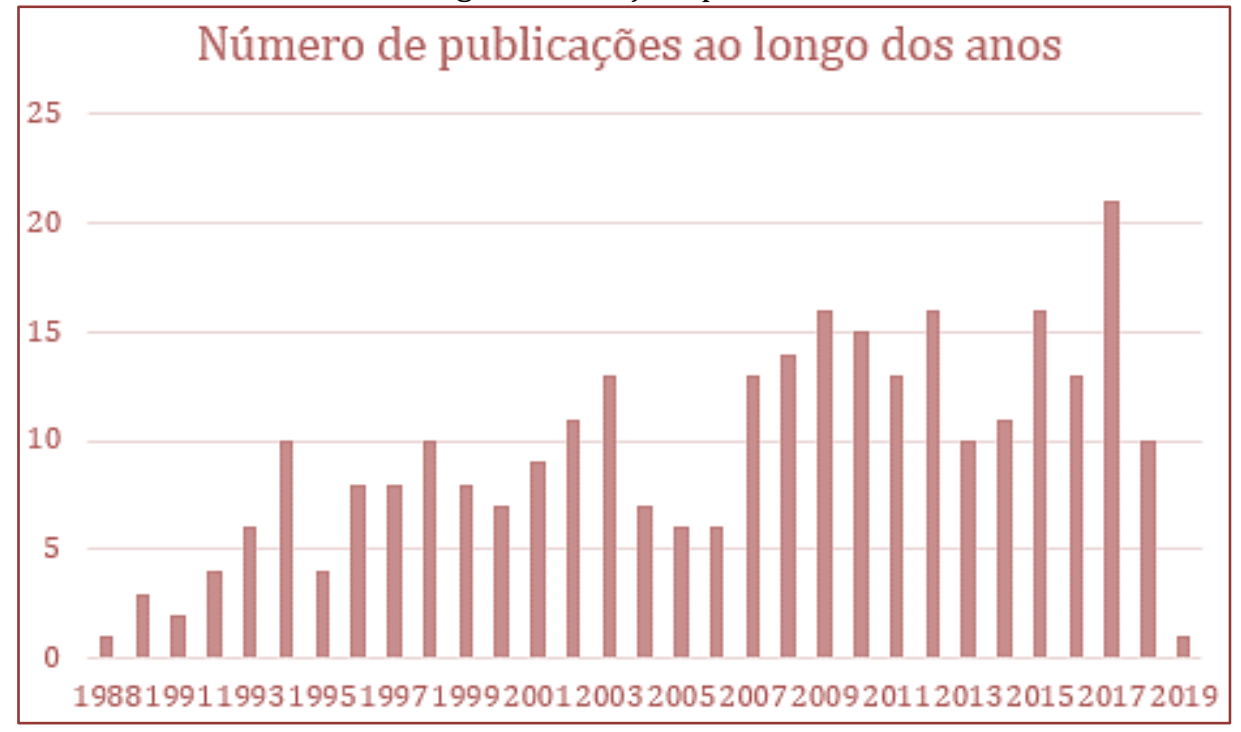

Fonte: Base Web of Science. 
A média durante o período de 2007 até 2018 é de 14 publicações por ano, enquanto que ao longo de todo o período observado foi de 9,7. Isso demonstra que houve um aumento na quantidade de publicações durante esse período.

Quanto aos países que mais publicaram, os Estados Unidos lideram o ranking com 69 registros obtidos, seguido pela Alemanha com 34 registros. Juntos, esses dois países representam aproximadamente 1/3 de todas as publicações observadas na base de dados. 0 Brasil figura-se na 16a colocação, com 5 registros, representando $1,7 \%$ das publicações do tema.

Dentre as revistas que mais publicaram, destacam-se a Lecture Notes in Computer Science com 22 artigos e Fator de Impacto (FI): 0.6 e Software Quality Journal com 20 artigos e FI: 1.6. Os autores que mais publicaram foram Wilson DN (5), O'Connor RV (4), Piattini M (4), Poth A (4) e Yamada S (4). Dos 802 autores que publicaram sobre o tema, apenas 54 publicaram duas ou mais vezes. Quanto aos autores com maior número de citações, encontramos Ravichandran, T. \& Rai, A. com 150 citações em seu trabalho denominado Quality management in systems development: An organizational system perspective (2000), o qual sugere que as metas de qualidade de software são melhores alcançadas quando a alta gerência cria uma infra-estrutura de gerenciamento que promove melhorias nos processos e incentiva as partes interessadas a aprimorar os processos de desenvolvimento.

A segunda publicação com maior número de citações foi de Clarke, Paul; O'Connor, Rory V., com 110 citações, em seu trabalho intitulado The situational factors that affect the software development process: Towards a comprehensive reference framework (2012) forneceu uma estrutura de referência de suporte para profissionais que são desafiados a definir e manter processos de desenvolvimento de software.

Quanto ao número de citações, existe uma tendência de crescimento ao longo dos anos. Um ponto que chamou a atenção, foi a existência de um padrão que se repetiu a cada dois anos a partir do ano de 2004. Após o crescimento da quantidade de citações em um ano, o ano seguinte manteve esse valor, voltando a crescer no ano posterior. 0 único ano que fugiu desse padrão foi o ano de 2018. A Figura 3 a seguir mostra essas informações.

Figura 3- Citações por ano.

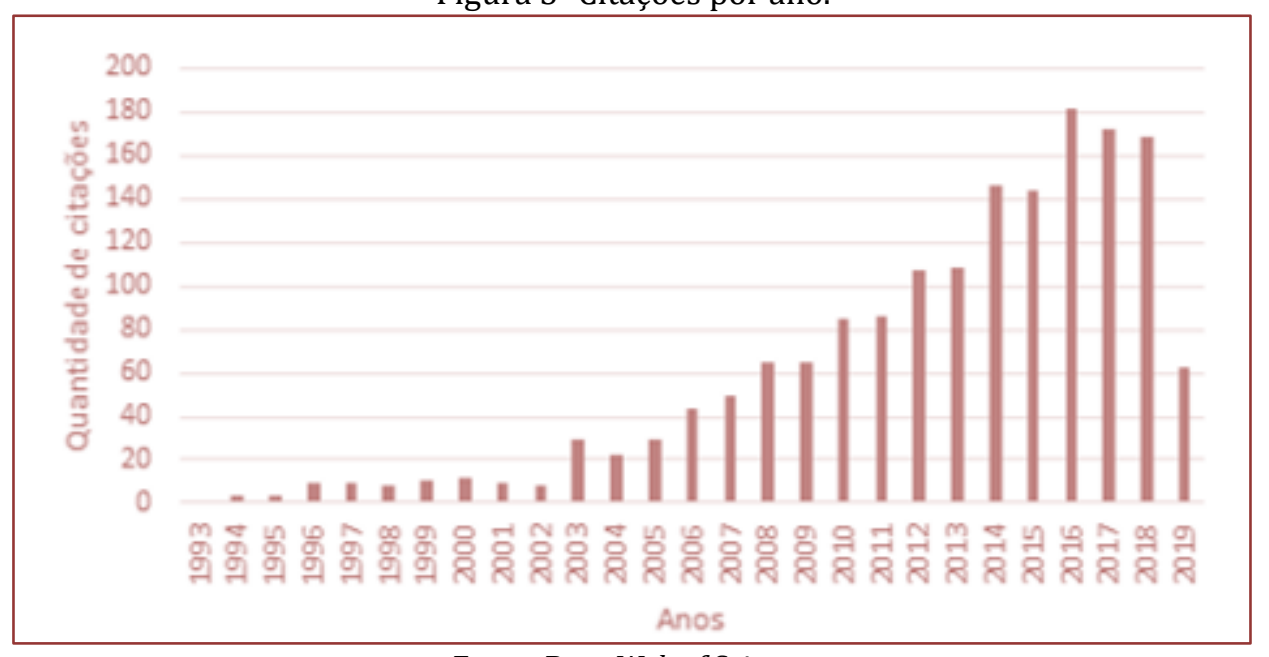

Fonte: Base Web of Science.

Observa-se também que o ano de 2019 apresenta um quantitativo de citações superior aos anos de 2007 até 1994 e, no atual momento, semelhante ao ano de 2008 e 2009, o que permite influir que a comunidade científica tem se preocupado em pesquisar e estudar mais o tema, devido aos avanços tecnológicos e a busca pela automação de modelos consolidados de gestão. Com a finalidade de analisar as palavras-chave que mais apareceram nos 292 artigos levantados pela pesquisa, foi elaborada uma nuvem de palavras por meio da ferramenta online TagCrowd. Ressalta-se que as palavras utilizadas para a pesquisa no Web of Science foram retiradas da nuvem de palavras para não interferir na análise dos dados, uma vez que elas foram as direcionadoras da pesquisa e são inerentes aos documentos. A Figura 4 apresenta os principais termos e a quantidade de vezes em que cada um apareceu. 


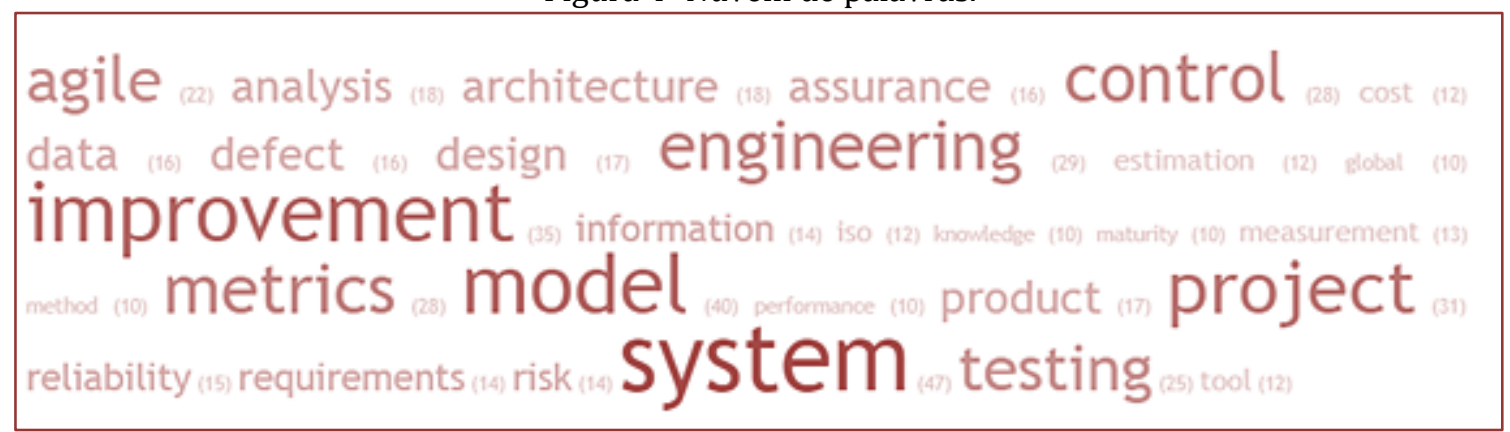

Fonte: TagCrowd.

Após a pesquisa, constatou-se que as palavras mais recorrentes encontradas foram system (47), model (40), improvement (35) e project (31) e estão de acordo com o tema pesquisado, uma vez que o planejamento e controle da qualidade aplicado ao desenvolvimento de software remete diretamente a melhoria de processos por meio de modelos de desenvolvimento de sistemas. Integrando os termos, percebe-se que há uma tendência sobre modelos de projetos de sistemas voltados para a garantia e melhoria da qualidade. SIEVI-KORTE, Outi; BEECHAM, Sarah; RICHARDSON, Ita. Challenges and recommended practices for software architecting in global software development. Information and Software Technology, v. 106, p. 234-253, 2019.

\subsection{ANÁLISE DOS ARTIGOS}

0 artigo mais recente que aborda o tema da pesquisa é dos autores Sievi-Korte, Beecham e Richardson, cujo título "Challenges and recommended practices for software architecting in global software development" (SIEVI-KORTE et al., 2019), em que aborda os desafios do desenvolvimento de software global no que concerne a coordenação e comunicação da equipe e apresenta as práticas existentes na literatura para amenizar esses desafios. Além disso, elabora uma classificação que apresenta as seguintes áreas de divisão dos desafios elencados: organização (estrutura e recursos), métodos de trabalho (gestão do conhecimento em arquitetura, gestão da mudança e gestão da qualidade), práticas de design, modularidade e alocação de tarefas.

Em relação ao registro mais antigo da pesquisa, tem-se o artigo de Shabalin (1988) "Growth of complexity of a developing program", publicado em novembro de 1988 que estudou o crescimento da complexidade de um programa dependendo do seu nível de representação abstrata, aplicada no método de programação descendente, podendo utilizar os dados para realizar o controle da qualidade no processo de desenvolvimento.

É interessante ressaltar que antigamente a preocupação dos trabalhos científicos em torno do tema girava em estudar o processo de desenvolvimento de softwares e a evolução de sua complexidade. Enquanto atualmente é possível perceber uma tendência no estudo de diferentes técnicas de desenvolvimento e como elas se relacionam na busca pela qualidade do produto final, ressaltando a integração e o trabalho em conjunto como a principal ferramenta.

Para melhor explorar os artigos encontrados foram definidos alguns critérios para a seleção destes, como representado na Tabela 1, onde a primeira coluna apresenta o autor do artigo, a segunda o seu título e a terceira a justificativa de sua escolha. 
Tabela 1- Principais artigos de acordo com o critério adotado.

\begin{tabular}{|c|c|c|c|}
\hline Autores & Título do artigo & Colaborações/Amostra & Justificativa \\
\hline $\begin{array}{l}\text { Sievi-Korte, } \\
\text { Outi; } \\
\text { Beecham, } \\
\text { Sarah; } \\
\text { Richardson, } \\
\text { Ita (2019). }\end{array}$ & $\begin{array}{l}\text { Challenges and } \\
\text { recommended } \\
\text { practices for software } \\
\text { architecting in global } \\
\text { software } \\
\text { development }\end{array}$ & $\begin{array}{l}\text { Aborda os desafios do desenvolvimento de software global no } \\
\text { que concerne a coordenação e comunicação da equipe e } \\
\text { apresenta as práticas existentes na literatura para mitigar } \\
\text { esses desafios. Além disso, elabora uma classificação que } \\
\text { apresenta as seguintes áreas de divisão dos desafios } \\
\text { elencados: organização (estrutura e recursos), métodos de } \\
\text { trabalho (gestão do conhecimento em arquitetura, gestão da } \\
\text { mudança e gestão da qualidade), práticas de design, } \\
\text { modularidade e alocação de tarefas. }\end{array}$ & $\begin{array}{l}\text { Registro mais } \\
\text { recente. }\end{array}$ \\
\hline $\begin{array}{l}\text { Ravichandra } \\
\text { n, T; Rai, A } \\
\text { (2000). }\end{array}$ & $\begin{array}{l}\text { Quality management } \\
\quad \text { in systems } \\
\text { development: An } \\
\text { organizational } \\
\text { system perspective }\end{array}$ & $\begin{array}{l}\text { Foi proposto e testado um modelo que inter-relaciona a } \\
\text { liderança da alta direção, uma infraestrutura de } \\
\text { gerenciamento sofisticada, a eficácia do gerenciamento de } \\
\text { processos e a participação dos stakeholders como elementos } \\
\text { importantes de um sistema organizacional orientado à } \\
\text { qualidade para o desenvolvimento de software. }\end{array}$ & $\begin{array}{l}\text { Artigo mais } \\
\text { citado. }\end{array}$ \\
\hline $\begin{array}{l}\text { Clarke, P; } \\
\text { O'Connor, RV } \\
\text { (2012). }\end{array}$ & $\begin{array}{l}\text { The situational } \\
\text { factors that affect the } \\
\text { software } \\
\text { development process: } \\
\text { Towards a } \\
\text { comprehensive } \\
\text { reference framework }\end{array}$ & $\begin{array}{l}\text { Fornece uma lista de referência útil para a comunidade de } \\
\text { pesquisa e para os comitês envolvidos no desenvolvimento de } \\
\text { padrões, além de um suporte para profissionais que são } \\
\text { desafiados a definir e manter processos de desenvolvimento } \\
\text { de software. Pode ser usada também para desenvolver um } \\
\text { perfil das características situacionais de uma configuração de } \\
\text { desenvolvimento de software. }\end{array}$ & $\begin{array}{l}2^{\mathrm{o}} \quad \text { artigo } \\
\text { mais citado. }\end{array}$ \\
\hline $\begin{array}{c}\text { Shabalin, NA } \\
\text { (1988). }\end{array}$ & $\begin{array}{l}\text { Growth of complexity } \\
\text { of a developing } \\
\text { programm }\end{array}$ & $\begin{array}{l}\text { Estuda o crescimento da complexidade de um programa } \\
\text { dependendo do seu nível de representação abstrata aplicada } \\
\text { no método de programação descendente, podendo utilizar os } \\
\text { dados para realizar o controle da qualidade no processo de } \\
\text { desenvolvimento. }\end{array}$ & $\begin{array}{l}\text { Registro mais } \\
\text { antigo. }\end{array}$ \\
\hline $\begin{array}{l}\text { Huang, FT; } \\
\text { Sun, TT } \\
\text { (2013). }\end{array}$ & $\begin{array}{l}\text { Software Project } \\
\text { Metrics and Quality } \\
\text { Management }\end{array}$ & $\begin{array}{l}\text { Descreve uma métrica de projeto de software e conhecimento } \\
\text { de gerenciamento de qualidade, combinado com a } \\
\text { experiência prática do gerenciamento de qualidade de projeto } \\
\text { de software. }\end{array}$ & $\begin{array}{l}\text { Artigo mais } \\
\text { relevante de } \\
\text { acordo com o } \\
\text { WoS. }\end{array}$ \\
\hline $\begin{array}{l}\text { Wang, WL; } \\
\text { Pan, D; Chen, } \\
\text { MH (2006). }\end{array}$ & $\begin{array}{l}\text { Architecture-based } \\
\text { software reliability } \\
\quad \text { modeling }\end{array}$ & $\begin{array}{l}\text { O artigo demonstra o processo de extensão do whitebox para } \\
\text { uma abordagem baseada em arquitetura, utilizando as } \\
\text { características dos estilos arquiteturais para capturar } \\
\text { informações de design e para realizar comportamentos de } \\
\text { software heterogêneos não uniformes. Sua abordagem } \\
\text { permite que a confiabilidade seja modelada no estágio de } \\
\text { projeto arquitetônico para decidir componentes para } \\
\text { reutilização, bem como fases posteriores de teste e } \\
\text { manutenção para evolução contínua do software. }\end{array}$ & $\begin{array}{l}3^{0} \text { artigo } \\
\text { mais citado. }\end{array}$ \\
\hline $\begin{array}{l}\text { McCarthy, DJ; } \\
\text { Campbell, } \\
\text { KR; Lun, ATL; } \\
\text { Wills, QF } \\
\text { (2017). }\end{array}$ & $\begin{array}{l}\text { Scater: pre- } \\
\text { processing, quality } \\
\quad \text { control, } \\
\text { normalization and } \\
\text { visualization of } \\
\text { single-cell } R N A \text {-seq } \\
\quad \text { data in } R\end{array}$ & $\begin{array}{l}\text { Foi desenvolvida uma biblioteca em R para facilitar o pré- } \\
\text { processamento rigoroso, controle de qualidade, normalização } \\
\text { e visualização de dados de scRNA-seq. }\end{array}$ & $\begin{array}{l}\text { Maior média } \\
\text { de citações } \\
\text { por ano e } 4 \text { o } \\
\text { artigo mais } \\
\text { citado. }\end{array}$ \\
\hline $\begin{array}{l}\text { Kan, SH; } \\
\text { Basili, VR; } \\
\text { Shapiro, LN } \\
\text { (1994). }\end{array}$ & $\begin{array}{l}\text { Software quality - an } \\
\text { overview from the } \\
\text { perspective of total } \\
\text { quality management }\end{array}$ & $\begin{array}{l}\text { Aborda a qualidade de software no contexto da gestão da } \\
\text { qualidade total (TQM). É feito um resumo das principais } \\
\text { orientações para melhorias de qualidade de software. }\end{array}$ & $\begin{array}{l}\text { Interessante } \\
\text { link entre } \\
\text { desenvolvime } \\
\text { nto de } \\
\text { software e o } \\
\text { TQM. }\end{array}$ \\
\hline
\end{tabular}

Fonte: Própria. 


\subsection{ANÁLISE DO MAPA DE CALOR}

Com o objetivo de analisar os autores e artigos adquiridos na pesquisa, foram elaboradas figuras utilizando o software VosViewer, no formato de mapas de calor. Esses gráficos utilizam cores quentes e palavras em negrito para destacar os autores que são citados com maior frequência, por outro lado, os autores que são citados em uma frequência menor aparecem em zonas de cores frias e as palavras não apresentam o negrito. 0 primeiro mapa diz respeito à técnica de análise bibliométrica co-citation (Figura 5), enquanto o segundo mapa diz respeito à técnica bibliographic coupling (Figura 6).

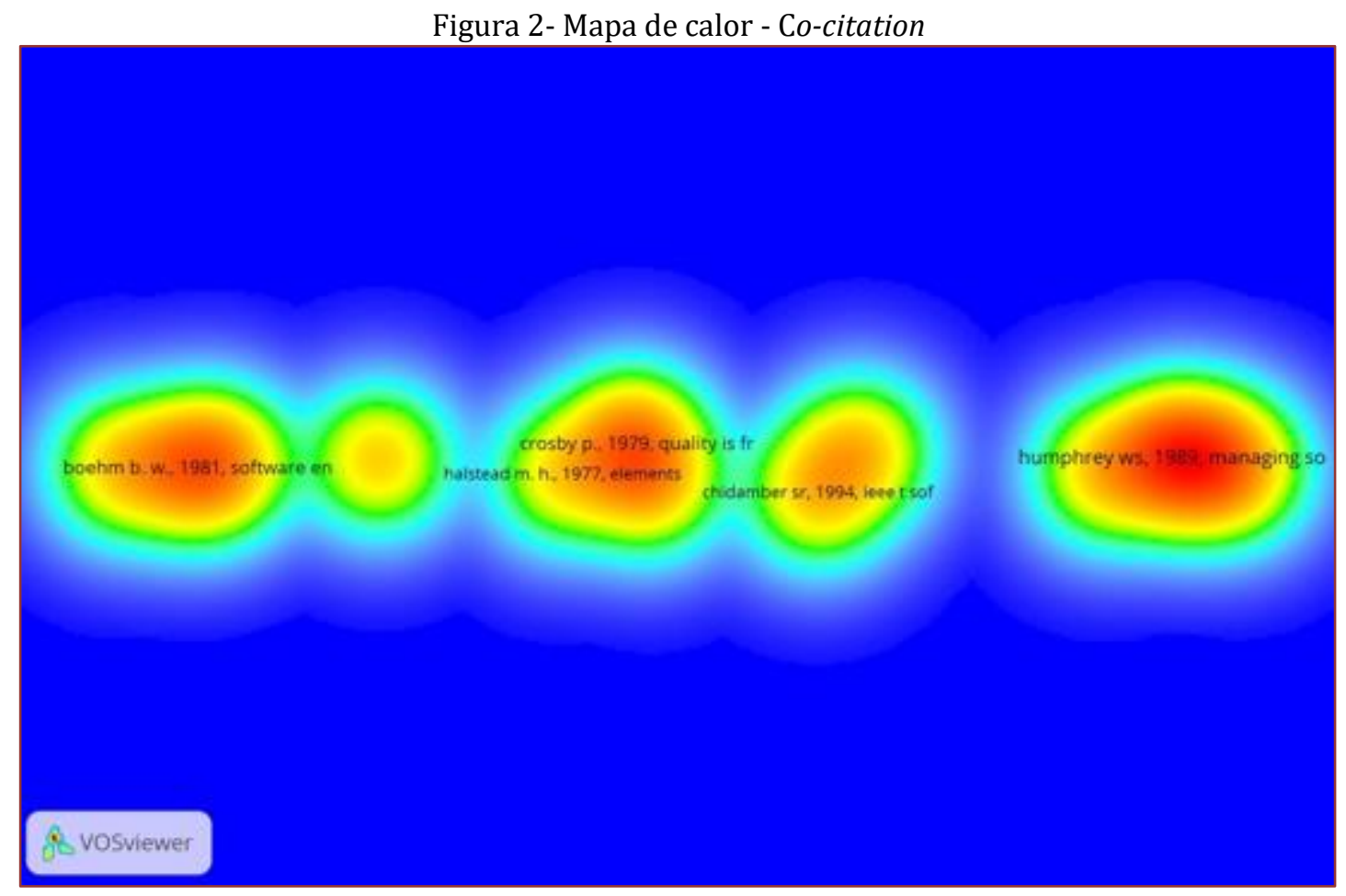

Fonte: própria. Extraído do software VOSViewer.

Na Figura 5 é apresentado o mapa de calor co-citation, elaborado com um recorte temporal de 1988 a 2019. Dessa forma, pode-se perceber a presença de 4 clusters (ilhas de calor), onde as manchas avermelhadas representam os seus centros, cada um deles possui um campo de estudo diferente, que compõe o tema da pesquisa. A proximidade entre os autores indica que seus trabalhos estão em campos de pesquisa relacionados.

O primeiro cluster, representado por Barry W. Boehm (1981) como o autor mais citado nesse agrupamento, apresenta uma perspectiva de projetos de desenvolvimento de software, abordando diferentes metodologias para sua gestão e suas comparações, com o objetivo de garantir a confiabilidade e qualidade do sistema. Dessa forma, Boehm (1981) segue uma linha de trabalho relacionada à modelos de custos aplicados a avaliação de softwares e seus projetos, provendo uma visão sobre a aplicabilidade de técnicas de análise econômica na engenharia e gestão de softwares.

Já o segundo cluster, que possui Watts S Humphray (1989) como principal expoente, segue uma temática relacionada à aplicação de modelos e controle da qualidade no desenvolvimento de softwares, abordando também, guias de boas práticas durante a gestão dos projetos, manutenção dos produtos e desenvolvimento de softwares por meio do Global Software Development (GSD). Sendo assim, Humphray (1989) explicita em seu trabalho orientações práticas para melhorar o processo de desenvolvimento e manutenção de softwares, se concentrando na compreensão e no gerenciamento do processo de software, onde o autor percebeu uma grande necessidade de melhoria.

Em relação ao terceiro cluster, onde Shyam R. Chidamber (1994) aparece como o autor mais citado, tem-se uma visão sobre a necessidade da utilização de métricas para auxiliar na gestão do desenvolvimento de softwares, apresentando diferentes formas de implementação e utilização de modelos de métricas para tal finalidade. Seguindo a mesma temática Chidamber (1994) demonstra em seu trabalho a necessidade da 
criação de métricas para a abordagem de orientação à objetos (Object Orientation - 00) no desenvolvimento de softwares por meio da criação e implementação de novos modelos.

No quarto cluster, o guru da qualidade Philip Crosby aparece como autor central. A perspectiva que permeia a esse cluster aborda uma visão voltada a qualidade com enfoque comportamental, elucidando os fatores que devem ser trabalhados para melhorar o desempenho dos projetos, possibilitando formular práticas e tecnologias de desenvolvimento de software mais eficazes. Crosby (1979) se destina a abordagem da qualidade na perspectiva da busca por antecipar e evitar os defeitos antes que eles aconteçam. Além disso, o autor trata da necessidade da conformidade das exigências do cliente.

A Figura 6 apresenta o mapa de calor bibliographic coupling, que possui um universo temporal dos últimos quatro anos de produção científica presentes no WoS sobre o tema, ou seja, de 2016 a 2019.

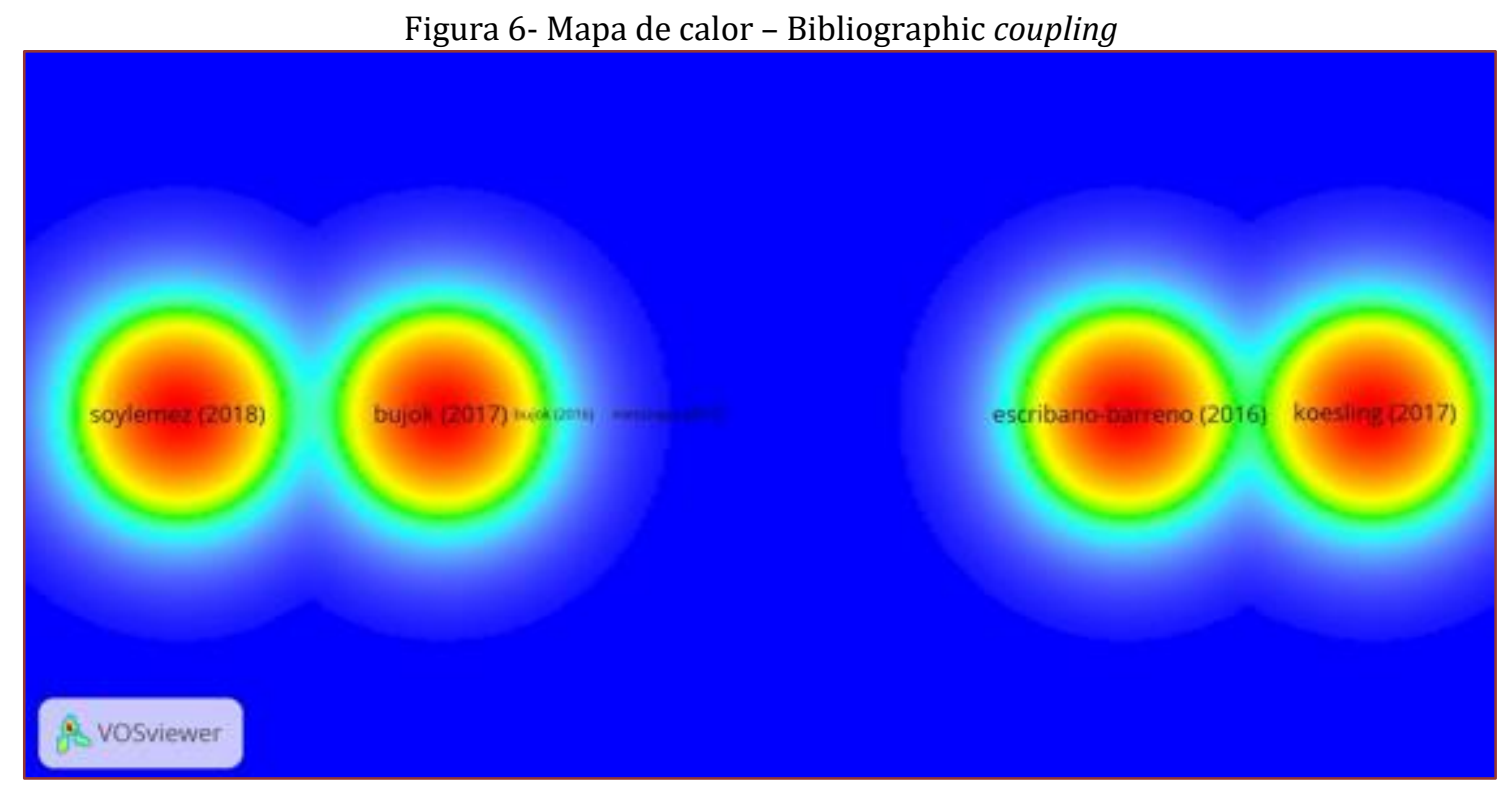

Fonte: própria. Extraído do software VOSViewer.

Neste mapa, podemos observar a existência de 4 manchas avermelhadas, indicando a presença de 3 clusters, já que os trabalhos de Escribano-Barreno (2016) \& Koesling (2017) apresentam abordagens similares de acordo com a análise realizada no programa VosViewer. Dessa forma, pode-se perceber três diferentes tendências de pesquisa na atualidade, cada uma liderada pelo principal expoente do cluster.

No primeiro cluster, onde o nome em destaque é o de Mehmet Söylemez, tem-se uma abordagem em relação a análise de causas de defeitos existentes nos softwares e quais as suas conexões com o processo de desenvolvimento e implementação. Söylemez (2018) apresenta um método e resultados da aplicação de análise de causa raiz, para defeitos de software registrados em um projeto intensivo de sistemas com instituto certificado pelo CMMI ML3. O método sugerido combina a coleta e análise de dados de enactment do processo com Orthogonal Defect Classification, uma técnica conhecida na análise de causa raiz de defeitos.

No segundo cluster, Bujok (2017) aparece como tendência de pesquisa. Seu trabalho detalha uma investigação das normas relevantes que as empresas precisam implementar para satisfazer os requisitos regulatórios, examinando os padrões relevantes de desenvolvimento do sistema de gestão da qualidade, gerenciamento de risco e padrões de desenvolvimento de software nos domínios críticos de segurança. Essa perspectiva surge com o aumento do uso de softwares para fornecer funcionalidade em domínios críticos, que devido a sua complexidade na etapa de desenvolvimento pode trazer desafios relacionados à proteção e segurança.

O terceiro cluster é formado por Julio Escribano-Barreno \& Marc Kösling. Escribano-Barreno (2016) os autores elucidam em seu trabalho a importância da garantia da qualidade durante todo o processo de desenvolvimento de software e que, para isso, existem ferramentas eficientes e baratas, como é o caso da SonarQube, uma plataforma de código livre para a gestão da qualidade. A concepção e desenvolvimento específicos desses plugins é um esforço significativo de projeto que garante o manuseio correto das 
diferentes fases envolvidas no processo de qualidade de software. Além disso, apresenta o desenvolvimento de um componente para a extensão da funcionalidade da estrutura de código aberto para o gerenciamento da qualidade do software. Já Marc Kösling (2017), trabalha com uma vertente de desenvolvimento ágil que permite que sejam estabelecidos procedimentos automatizados de qualidade para o desenvolvimento de produtos. A partir disso, destaca-se a criação e teste de um aplicativo em nuvem que possua a funcionalidade de gestão da qualidade do produto.

Outra frente de pesquisa que é vista como tendência é a implementação de aplicativos de software de Gerenciamento de Conteúdo Corporativo (ECM). Esse assunto é abordado por Katuu (2016), o qual destaca que embora alguns acadêmicos do ECM tenham fornecido orientações sobre a implementação do ECM, existe uma lacuna na forma de avaliar os benefícios advindos da implementação. Seu estudo tem como objetivo analisar a utilidade de outro modelo de maturidade ECM, o ECM3, como uma ferramenta de avaliação.

Enquanto, Tyler (2017) realizou um estudo de caso sobre a gestão de ativos, classificação e valor da documentação de qualidade em um ambiente real, mostrando que o valor e importância da documentação são perdidos quando ninguém assume a propriedade. Por fim, outro front identificado através do mapa de calor foi o estudado pelo Marcelo Cavaglieri. Cavaglieri (2017) buscou aplicar o Lean office na gestão de arquivos tendo como objetivo verificar a aplicabilidade do pensamento Lean na arquivística.

\section{CONSIDERAÇÕES FINAIS}

A aplicação da metodologia de revisão sistemática TEMAC permitiu realizar um levantamento histórico sobre a utilização do planejamento e gestão da qualidade no desenvolvimento de softwares. Ressalta-se a constante presença da necessidade de automação do processo de gestão da qualidade nesse âmbito, quanto mais recente ou mais citado o artigo é, foi abordo essa perspectiva.

Outros dois assuntos que se mostram muito presentes durante toda o recorte temporal, foram a necessidade de utilização de métricas para medir a qualidade do processo de desenvolvimento de softwares e a gestão da qualidade durante todo o processo, deixando de se restringir ao final do projeto ou a remediação de erros.

De modo geral, destaca-se a crescente presença da aplicação da gestão e controle da qualidade aplicada ao desenvolvimento global de softwares. A principal discussão sobre o tema em seus registros mais antigos gira em torno da criação e aplicação de modelos de qualidade aplicados ao desenvolvimento de software, enquanto hoje o foco gira em torno de sua automação.

\section{AGRADECIMENTOS}

Agradecemos a Universidade de Brasília - UnB e ao Projeto de Pesquisa MAP.

\section{REFERÊNCIAS}

[1] Boehm, BW. An experiment in small-scale application software engineering, Ieee Transactions on Software Engineering, volume 7, n. 5, p. 482-493, 1981.

[2] Bujok, Andrzej Beniamin; Macmahon, Silvana Togneri; Grant, Peadar; Whelan, Dick; Rickard, William J; MCCAFFERY, Fergal, Approach to the development of a Unified Framework for Safety Critical Software Development, 16th International Conference on Software Process Improvement and Capability Determination (SPICE), volume 54, n. 3, p. 152-161, nov 2017.

[3] Chidamber, SR; Kemerer, CF, A Metrics suite for object-oriented design, Ieee Transactions On Software Engineering, volume 20, n. 6, p.476-493, jun 1994.

[4] Clarke, Paul; Connor, Rory. The situational factors that affect the software development process: Towards a comprehensive reference framework. Information and Software Technology Volume 54, Issue 5, May 2012, Pages 433-447

[5] Crosby, F. Quality is Free: The Art of Making Quality Certain, McGraw-Hill; 1st edition (December 28, 1979), 309 páginas.

[6] Escribano-Barreno, Julio; Garcia-Munoz, Javier; Garcia-Valls, Marisol; Improved Metrics Handling in SonarQube for Software Quality Monitoring, 13th International Conference on Distributed Computing and Artificial Intelligence (DCAI 2016), volume 474, p. 463-470. 2016. 
[7] Ghanbari, Hadi; Vartiainen, Tero; Siponen, Mikko. Omission of Quality Software Development Practices: A Systematic Literature Review. ACM Computing Surveys (CSUR), v. 51, n. 2, p. 38, 2018.

[8] Guzmán, Liliana et al. How can quality awareness support rapid software development?-a research preview. In: International Working Conference on Requirements Engineering: Foundation for Software Quality. Springer, Cham, 2017. p. 167-173.

[9] Huang, FT; Sun, TT. Software Project Metrics and Quality Management, 2013 Ninth International Conference on Intelligent Information Hiding and Multimedia Signal Processing (IIH-MSP 2013), p. 615-618, 2013.

[10] Kan, SH; Basili, VR; Shapiro, In. Software quality - an overview from the perspective of total quality management, IBM Systems Journal, volume 33, n. 1, p. 4-19, 1994.

[11] Korte, OutiSievi; Richardson, Ita. Challenges and recommended practices for software architecting in global software development. Information and Software Technology Volume 106, February 2019, Pages 234-253.

[12] Koesling, M; Poth, A. Agile Development Offers the Chance to Establish Automated Quality Procedures, 24th European Conference on Systems, Software and Services Process Improvement (EuroSPI), volume 748, p. 495-503, 2017.

[13] Li, Eldon Y.; Chen, Houn-Gee; Cheung, Waiman. Total quality management in software development process. The Journal of Quality Assurance Institute, v. 14, n. 1, p. 4-6, 2000.

[14] Mariano, Ari Melo; Rocha, Maíra Santos. Revisão da Literatura: Apresentação de uma Abordagem Integradora. In: XXVI Congreso Internacional de la Academia Europea de Dirección y Economía de la Empresa (Aedem), Reggio Calabria. 2017.

[15] Mccarthy, DJ; Campbell, KR; Lun, Atl; Wills, QF. Scater: pre-processing, quality control, normalization and visualization of single-cell RNA-seq data in R, volume 33, n. 8, p. 1179-1186, abril 2017.

[16] Osmundson, John S. et al. Quality management metrics for software development. Information \& Management, v. 40, n. 8, p. 799-812, 2003.

[17] Ravichandran, T; RAI, Arun. Quality Management in Systems Development: An Organizational System Perspective. MIS Quarterly. Vol. 24, No. 3 (Sep., 2000), pp. 381-415. 2000.

[18] Shabalin, An. Growth of complexity of a developing program, programming and computer software, volume 14, n. 6, p. 269-273, Nov-Dec 1988.

[19] Sievi-Korte, Outi; Beecham, Sarah; Richardson, Ita. Challenges and recommended practices for software architecting in global software development. Information and Software Technology, v. 106, p. 234-253, 2019.

[20] Soylemez, Mehmet; Tarhan, A. Challenges of software process and product quality improvement: catalyzing defect root-cause investigation by process enactment data analysis, Software Quality Journal, volume 26, n. 2, p. 779807, jun 2018.

[21] Wang, WL; Pan, D; Chen, MH. Architecture-based software reliability modeling, Journal of Systems and Software, volume 79, n.1, p. 132-146, jan 2006.

[22] Zupic, I; Čater, T. Bibliometric Methods in Management and Organization, Organizational Research Methods, 10.1177/1094428114562629, 18, 3, (429-472), 2014. 


\section{Capítulo 6}

\section{Corrosão em próteses implantadas cirurgicamente}

\section{Leonardo Rodrigues}

Resumo: A corrosão em próteses implantadas cirurgicamente é um fenômeno que degrada a prótese de metal através de uma reação química, comprometendo a integridade da peça e na maioria dos casos acarretando outras consequências mais graves ao corpo humano. Existem diversas formas de corrosão que afetam os metais, mas em relação às próteses a corrosão por "pites" é uma das principais vilãs, podendo ser controlada por meio de uma boa camada de passivação, formada na superfície da peça pela reação entre os elementos de passivação contidos na composição da peça e o meio em que ela está inserida. Assim, existem ligas de aço inoxidável e ligas metálicas com certa especificidade na composição química, para atender aos requisitos exigidos nas normativas ASTM, ISO NBR, AISI, que em muitos casos são utilizadas em implantes cirúrgicos. Ainda há uma série de prerrogativas estabelecidas que permeiam desde a composição química dos elementos das ligas, processos de produção, resistências mecânicas, resistências químicas, biocompatibilidade, bioadesão, entre outros até o tamanho e o crescimento do grão microestrutural. Este trabalho, com a aplicação de uma pesquisa bibliográfica buscou sanar alguns questionamentos levantados, que por resultado trouxeram esclarecimentos sobre como e porque ocorre a corrosão da prótese dentro do corpo humano, quais os principais métodos de controlar ou retardar a corrosão e as novidades na área de processos de desenvolvimento e produção de próteses implantáveis.

Palavras Chave: Próteses, Corrosão, Implantes. 


\section{INTRODUÇÃO}

Após instrução acadêmica na área de biomateriais, foi constatada uma deficiência que vem ocorrendo nas próteses implantadas, relacionada à corrosão das próteses in vivo, com base nessa curiosidade o autor buscou referências sobre o acontecimento, sua comprovação, as causas e consequências que este defeito desencadeia e o resultado sofrido pelo corpo humano.

0 presente estudo trata de assuntos diretamente relacionados às próteses implantáveis cirurgicamente in vivo, abordando o princípio da corrosão, sua classificação em respeito aos metais, formas de controlar esse fenômeno, a influência da composição química e dos elementos de liga sobre vários aspectos de relevância às próteses. Ainda são abordados alguns dos principais processos de fabricação, os biomateriais mais utilizados como próteses de implante, suas características e aplicabilidades.

\section{CORROSÃO}

\subsection{CONCEITO}

A corrosão ocorre de forma espontânea através de um processo de deterioração. Nos metais e aços em geral o processo se dá em razão de ações químicas e eletroquímicas dos mesmos com o ambiente em que se encontram. (TOLENTINO, 2015)

Os materiais afetados pela deterioração têm suas características funcionais, como: resistências, resiliência, durabilidade, confiabilidade, entre outras, altamente comprometidas, prejudicando diretamente sua utilização e seu desempenho. A corrosão dos metais e suas ligas pode ser encontrada em diversas situações, como: na rede elétrica e cabos de comunicação, tanques de detenção de fluídos, meios de transporte, todos os tipos de aparelhos eletrônicos e eletrodomésticos, construções, píeres, tubulações, gasodutos, oleodutos, próteses mecânicas, etc. (TOLENTINO, 2015)

A corrosão é um fenômeno superficial, quando ataca os metais a substância gerada pela deterioração do material se deposita sobre a superfície formando uma espécie de barreira entre o objeto e o meio corrosivo, a corrosão está ligada diretamente ao meio em que o objeto está inserido. Devido a reações de oxirredução entre o metal e o oxigênio, pode-se dizer que todos os metais estão sujeitos a corrosão, a menos que o ambiente ao qual estão expostos não possua oxigênio. Próteses ortopédicas, por exemplo, tendem a sofrer corrosão por "pites" - um desgaste localizado que ocorre a partir do rompimento da película de óxido protetora na superfície da peça. (TOLENTINO, 2015)

\subsection{CLASSIFICAÇÕES DA CORROSÃO}

Considerando as diversas formas de corrosão, pode-se classifica-las de acordo com sua forma de ataque, aparência, ou mecanismo de corrosão, onde se destacam as seguintes formas ocorrentes em metais: (GENTIL, 2011).

1. Corrosão uniforme;

2. Corrosão em forma de placas;

3. Corrosão alveolar;

4. Corrosão puntiforme ou por pites;

5. Corrosão intergranular;

6. Corrosão intragranular ou transcristalina;

7. Corrosão filiforme;

8. Corrosão por esfoliação;

9. Corrosão em torno do cordão de solda;

10. Corrosão por empolamento;

11. Corrosão grafítica;

12. Corrosão por dezinficação. 
Considera-se que as principais formas de corrosão encontradas em próteses implantadas cirurgicamente são a corrosão puntiforme ou por "pites" e a corrosão intergranular, que terão ênfase maior a seguir.

\subsubsection{CORROSÃO PUNTIFORME OU POR PITES}

Considerada por alguns estudiosos uma das mais destrutivas formas de corrosão, a corrosão puntiforme ou por "pites" se espalha em pontos e pequenas áreas da superfície metálica exposta, resultando assim nos chamados "pites", que por sua vez são cavidades com sua profundidade superior ao seu diâmetro e uma certa angulosidade de perfuração (GENTIL, 2011)

\subsubsection{CORROSÃO INTERGRANULAR}

Esta forma de corrosão se processa diretamente na rede cristalina dos metais, mais precisamente entre os grãos da estrutura cristalina, afetando seu contorno e modificando a estrutura do grão, gerando tensões internas que prejudicam as propriedades mecânicas do metal, levando a uma possível fratura quando exigido um maior esforço mecânico, também conhecida como a corrosão sob tensão fraturante (CTF) ou (Stress Corrosion Cracking, SCC). (GENTIL, 2011)

\subsection{CONTROLE DA CORROSÃO EM METAIS}

Desde que conhecidos os seguintes fatores, mecanismo de corrosão, composição do material e meio corrosivo é possível propor alguma medida para diminuir a velocidade de degradação. Os revestimentos superficiais são muito utilizados quando se trata de controle de corrosão, eles geram uma película protetora que impede o contato do material com a solução ou meio degradante, como neste estudo abordam-se principalmente os metais, apesar de existirem revestimentos metálicos, não metálicos inorgânicos e não metálicos orgânicos, sendo os revestimentos metálicos os de maior relevância. (TOLENTINO, 2015)

Dentre os revestimentos metálicos, o revestimento por cladização forma através do processo de laminação a quente uma placa metálica unindo metal base com o metal de revestimento. 0 revestimento por aspersão térmica ocorre quando o metal de revestimento em forma de pó ou de fio é aquecido por chama de oxiacetileno, arco elétrico ou em casos específicos plasma, após a fusão, o material de revestimento é depositado sobre a superfície por meio de jatos de ar comprimido, onde solidifica formando a camada protetora. Já com metal de revestimento em pó, o processo de revestimento por cementação se dá, quando o metal que será revestido é posto em um vaso rotativo junto com o pó do metal de revestimento e aquecidos a altas temperaturas para gerar a película de proteção. A eletrodeposição é um processo de revestimento vantajoso, capaz de formar uma fina película protetora, possibilitando o uso de pouco material para revestimento, o processo ocorre por eletrólise, onde metal base é usado como catodo e imerso em uma solução preparada com o sal do metal de revestimento, que se depositará em forma metálica na superfície do catodo. Por fim, com o sal do metal de revestimento é possível realizar um revestimento por redução química, usando o conceito da oxirredução, o sal contendo o metal de revestimento através da troca de elétrons se precipita na superfície do metal a ser revestido, formando uma camada que protege a peça. (TOLENTINO, 2015)

\section{COMPOSIÇÃO QUÍMICA}

Agora que se entende melhor o que é corrosão, como ela age nos metais e quais fatores influenciam nesse processo, este capítulo irá aprofundar o conhecimento em relação a composição do aço inoxidável austenítico AISI 316L, das ligas de Cromo-Cobalto ASTM F90 e ASTM F75, e da Liga de Titânio Ti-6Al-4V, por serem os materiais mais utilizados na produção de próteses implantáveis segundo. (BRUKE, 1996

\subsection{AÇO INOXIDÁVEL AISI 316L}

Os aços AISI 316L (American Iron and Steel Institute) são aços inoxidáveis austeníticos, com baixo teor de carbono, utilizados em uma grande quantidade de aplicações das quais são mais relevantes os implantes de dispositivos temporários como: placas de fraturas, parafusos e pregos de quadril. Quanto à composição química, apresentam uma ampla gama de concentrações dos elementos químicos, como pode ser visto de 
maneira simplificada na Tabela 1, assim um aço que atende ao requisito AISI 316L, também pode se enquadrar em diferentes normas e suas especificações como: ASTM A240, ASTM A276, ASTM A 269, ASTM F138, ASTM F139 e ISO 5832-1 (GAM, KS, \& MG, 2011. On-line).

Tabela 1- Composição química do aço AISI 316L

\begin{tabular}{|c|c|c|c|c|c|c|}
\hline Composição & $\mathrm{C}$ & $\mathrm{Mn}$ & $\mathrm{Si}$ & $\mathrm{Cr}$ & $\mathrm{Ni}$ & Mo \\
\hline Percentual & 0,03 & 2,00 & 1,00 & $16,0-18,0$ & $10,0-14,0$ & $2,0-3,0$ \\
\hline
\end{tabular}

Fonte: (GAM, KS, \& MG, 2011)

\subsection{LIGAS DE CROMO-COBALTO}

As ligas de Cr-Co são ligas especiais também conhecidas como superligas, são classificadas em quatro principais categorias, sendo:

a) Ligas resistentes ao calor;

b) Ligas resistentes ao desgaste;

c) Ligas resistentes à corrosão;

d) Ligas magnéticas.

Nesse caso as ligas Cr-Co com aplicações em implantes, possuem boa resistência ao desgaste e à corrosão, por tanto não se enquadram em uma única classificação, porém ainda há uma subclassificação estipulada às que estão representadas dentro das normativas ASTM F75 e ASTM F90.

De acordo com a norma ASTM as ligas de cobalto possuem duas principais aplicações direcionadas aos implantes, sendo ligas de recobrimento e ligas trabalhadas, a seguinte pesquisa contempla uma opção para cada aplicação disponibilizada pela norma, tendo a liga ASTM F75 como liga de recobrimento e a liga ASTM F90 como liga trabalhada, respectivamente nas Tabela 2 e Tabela 3. (SANTOS, 2012)

Tabela 2- Composição química da liga ASTM F75.

\begin{tabular}{|c|c|c|c|c|c|c|c|c|c|} 
Composição & $\mathrm{C}$ & $\mathrm{Mn}$ & $\mathrm{Fe}$ & $\mathrm{Si}$ & $\mathrm{Cr}$ & $\mathrm{Co}$ & $\mathrm{Mo}$ & $\mathrm{Ni}$ \\
\hline Percentual & 0,35 & 1,00 & 0,75 & 1,00 & $27,0-30,0$ & Balanceado & $5,0-7,0$ & 0,5 \\
\hline \multicolumn{8}{c|}{ Fonte: (ANTUNES, 2017. Pag. 37) }
\end{tabular}

Tabela 3- Composição química da liga ASTM F90

\begin{tabular}{|c|c|c|c|c|c|c|c|c|} 
Composição & $\mathrm{C}$ & $\mathrm{Mn}$ & $\mathrm{Fe}$ & $\mathrm{Si}$ & $\mathrm{Cr}$ & $\mathrm{Co}$ & $\mathrm{W}$ & $\mathrm{Ni}$ \\
\hline Percentual & $0,05-0,15$ & $1,0-2,0$ & 3,0 & 0,40 & $19,0-21,0$ & Bal. & $14,0-16,0$ & $0,9-11,0$ \\
\hline \multicolumn{8}{|c|}{ Fonte: (ANTUNES, 2017. Pag. 37) }
\end{tabular}

\subsection{LIGA DE TITÂNIO TI-6AL-4V}

Segundo os preceitos básicos para aplicações biomédicas sendo: resistência à corrosão, biocompatibilidade, bioadesão, módulo de elasticidade (quanto mais aproximado da ordem de 10 - 30 GPa, como o osso humano, melhor), resistência a fadiga e boa processabilidade, o titânio e suas ligas comportam todos os requisitos de maneira superior aos outros materiais, por isso vêm sendo aplicados na reconstrução de articulações e fixação de fraturas a décadas, como destaque destas ligas esta pesquisa explora a ASTM F136, também conhecida comercialmente como (Ti-6Al-4V Extra Low Interticial) detalhada na Tabela 4. (SANTOS, 2012) 
Tabela 4- Composição química da liga. Ti-6Al-4V ASTM F136

\begin{tabular}{|c|c|c|c|c|c|c|c|}
\hline Composição & $C$ & $\mathrm{Fe}$ & 0 & $\mathrm{Al}$ & V & $\mathrm{Ti}$ & $\mathrm{N}$ \\
\hline Percentual & 0,08 & 0,25 & 0,13 & $5,5-6,5$ & $3,5-4,5$ & Bal. & 0,05 \\
\hline
\end{tabular}

\section{PROCESSOS DE FABRICAÇÃO}

Aços inoxidáveis austeníticos e ligas especiais quando utilizados para produção de implantes, devem seguir critérios de fabricação específicos segundo as normas ABNT NBR ISO 21534, ABNT NBR ISO 5832 ou ASTM 1537, além de também atender aos requisitos de composição química na fabricação, das mesmas.

Através destas normas citadas, temos algumas opções de processos utilizados na fabricação de implantes, dos quais quatro se destacam positivamente.

\section{VIM (Fusão por Indução a Vácuo)}

Sua principal vantagem é a fusão e o vazamento de ligas metálicas sob atmosferas com baixa quantidade de oxigênio e outros gases. Esta condição é obtida graças à alta potência do conjunto de bombas de vácuo, capazes de elevar a atmosfera da câmara a pressões da ordem de 2 - 10 Mbar. Assim, lingotes com baixíssimo nível de inclusões são obtidos e ligas com faixas muito estreitas de composição química podem ser produzidas, incluindo ligas com baixos teores de gases. (METALS, 2019, on-line)

\section{ESR (Refusão por escória eletro condutora)}

Voltado aos produtos de alta solicitação - em termos de propriedades mecânicas e isotropia -, garantindo baixo nível de inclusões não metálicas. Pode ser aplicado em lingotes produzidos no VIM. Como resultado, gera produtos com níveis reduzidos de segregação, assim como excelente microestrutura bruta de solidificação. (METALS, 2019. on-line)

\section{VAR (Refusão por arco-elétrico a vácuo)}

Similar ao ESR, mas, ao invés da escória, utiliza um arco elétrico como fonte de calor e trabalha em uma câmara sob vácuo. Após a refusão, a solidificação é similar à do ESR. Os produtos refinados por VAR possuem baixo nível de segregação, excelente microestrutura bruta de solidificação, alta isotropia e teores muito baixos de gases dissolvidos. (METALS, 2019. on-line)

\section{DMLS (Direct Metal Laser Sintering)}

A matéria prima, em forma de pó, se encontra sobre uma plataforma dentro de uma câmara de atmosfera inerte de nitrogênio. A plataforma é mantida aquecida em uma temperatura pouco abaixo de seu ponto de fusão. Dois espelhos controlados por galvanômetros formam um sistema de varredura que permitem um feixe de laser desenhar, sobre o pó espalhado, a geometria da camada da peça em duas dimensões. A incidência do laser nas partículas de pó fundem as mesmas à camada anteriormente obtida. A plataforma se desloca verticalmente para baixo de uma distância igual à espessura da camada fatiada virtualmente e uma nova camada de pó é espalhado por um rolo sobre a camada já fundida. Um novo ciclo se repete até a peça ser totalmente construída. (BUSATO JUNIOR, 2018. p. 46)

\section{BIOMATERIAIS}

Biomateriais são materiais sintéticos ou naturais, utilizados na substituição de sistemas vivos ou em parte deles com contato direto em tecidos vivos. Os biomateriais possuem capacidade de auxiliar, no tratamento, na substituição ou mesmo no aumento de qualquer tecido, órgão ou osso produzido pelo sistema biológico. (KENDALL, 2007)

Biomaterias são subdivididos em duas classificações gerais, os implantáveis e os não implantáveis, destas apenas a classificação dos implantáveis será foco do estudo, estes materiais devem atender a um complexo conjunto do caracteristicas exigidas para serem utilisados, dentre estes materiais basicamente pode-se dizer que há mais uma subdivisão, enquadrando-os de acordo com a sua composição química e matéria base em: poliméricos, cerâmicos, metálicos e compósitos. (BUSATO JUNIOR, 2018)

Nesta pesquisa será abordada principalmente a categoria dos biomateriais metálicos implantáveis, que melhor se adaptem aos rigorósos requisitos estipulados nas normativas que regem suas caracterizações necessárias para fins de implantes cirurgicos. 


\subsection{AÇO INOXIDÁVEL AISI 316L.}

Com ênfaxe principalmente no processo de corrosão desta liga de aço austenítico 316, tem-se a variação "L" (Low carbon). 0 baixo teor de carbono da liga melhora o desempenho em meio biológico, minimizando a segregação dos átomos de carbono dos cristais, para impedir a reação com os átomos de cromo, precipitando-se junto ao contorno de grão em forma de cromo-carbonetos, esta reação resulta em menor concentração de cromo na região, predispondo à corrosão intergranular causadora de falhas dramáticas em meios corrosivos. (GOMES, 2015)

Ainda sobre o aço 316 há outras adequações, como o aço 316 LVM (Low carbon, Vacuum Melting) visando a redução das inclusões, que levam a falência mecânica por fadiga. 0 processo de fusão a vácuo deu origem a esta liga que apresenta menores teor e tamanho de inclusões produzindo uma maior resistência à fadiga, entretanto, buscando uma composição com maior resistência à corrosão alterações na constituição dos componentes desta liga em relação aos teores de Cromo e Molibdênio, resultaram em normatizações específicas (ISO 5832-1 ou ASTM F138-92), quanto ao teor de Nitrogênio e Nióbio (ISO 5832-9 ou ASTM 1586-95) e redução dos teores de Níquel (F2229). (GOMES, 2015)

\subsection{LIGAS DE CROMO-COBALTO}

Na área biomédica, as ligas a base de cobalto desenvolvidas em 1932 pelo pesquisador Albert W. Merrick, denominadas Vitallium,deram início a um novo material capaz de suprir os rigorosos requisitos para implantes cirúrgicos, com a composição $(60,6 \%$ Co, 31,5\% Cr, $6 \%$ Mo e $1 \% \mathrm{Si}, \mathrm{Mn}, \mathrm{C})$. Esta liga foi considerada inerte e compatível ao tecido humano, apresentando elevada resistência à corrosão e boa biocompatibilidade tornou-se uma boa alternativa nas áreas de ortopedia, odontologia, neurologia e cardiologia, com aplicações em diversos componentes cirúrgicos, substituição parcial do crânio, parafusos de fixação e juntas de quadril. As principais adequações feitas nesta liga com o passar do tempo foram em relação a sua microestrutura, formação de carbonetos e métodos de produção (fundição, forjamento ou metalurgia do pó), a ASTM (American Society for Testing and Materials) lista quatro ligas de cobalto que são utilizadas para implantes cirúrgicos (F75, F90, F562, F1537), a norma brasileira também indica ligas de cobalto para o mesmo fim (NBR ISO 5832-4, 12) (SANTOS, 2012)

\subsection{LIGA DE TITÂNIO TI-6AL-4V}

As ligas de titânio têm como grandes atrativos aos implantes protéticos, sua alta resistência mecânica, excelente biocompatibilidade, boa bioadesão facilitando a osteointegração, auto passivação pela grande afinidade ao oxigênio o que eleva sua resistência à corrosão, seu baixo módulo de elasticidade $(E=110$ $\mathrm{GPa}$ ), que resulta em flexibilidade 2 vezes maior e resistência à fadiga no mínimo $30 \%$ maior que as ligas de aço Inox. Estas características habilitam as ligas de titânio (Ti-6Al-4V, ou Ti-6Al-7Nb) para utilização em implantes destinados à fixação biológica não cimentada, titânio comercialmente puro (ASTM F67), eventualmente é utilizado em determinadas regiões de implantes em forma de superfícies micro porosas com o objetivo de osteointegração, novas ligas e novos processamentos estão sendo recentemente introduzidos, como o caso das Ligas de Titânio $\beta$ que apresentam módulo de elasticidade ainda mais baixo (cerca de $80 \mathrm{GPa}$ ) como a liga (Ti-13Nb-13Zr). (GOMES, 2015)

A seguir na Figura 1 é possível entender através de um comparativo, as proporções e disparidades nos módulos de elasticidade das ligas metálicas, principal causa do fenômeno conhecido como stress shielding (estresse por blindagem), quando o módulo de elasticidade do metal é muito maior que dos tecidos ósseos, os esforços aos quais os ossos estarão submetidos serão muito menores que os normalmente suportados, causando a deterioração do osso. (BUSATO JUNIOR, 2018) 
Figura 1: Módulos de elasticidade das principais ligas metálicas implantáveis comparadas ao osso humano

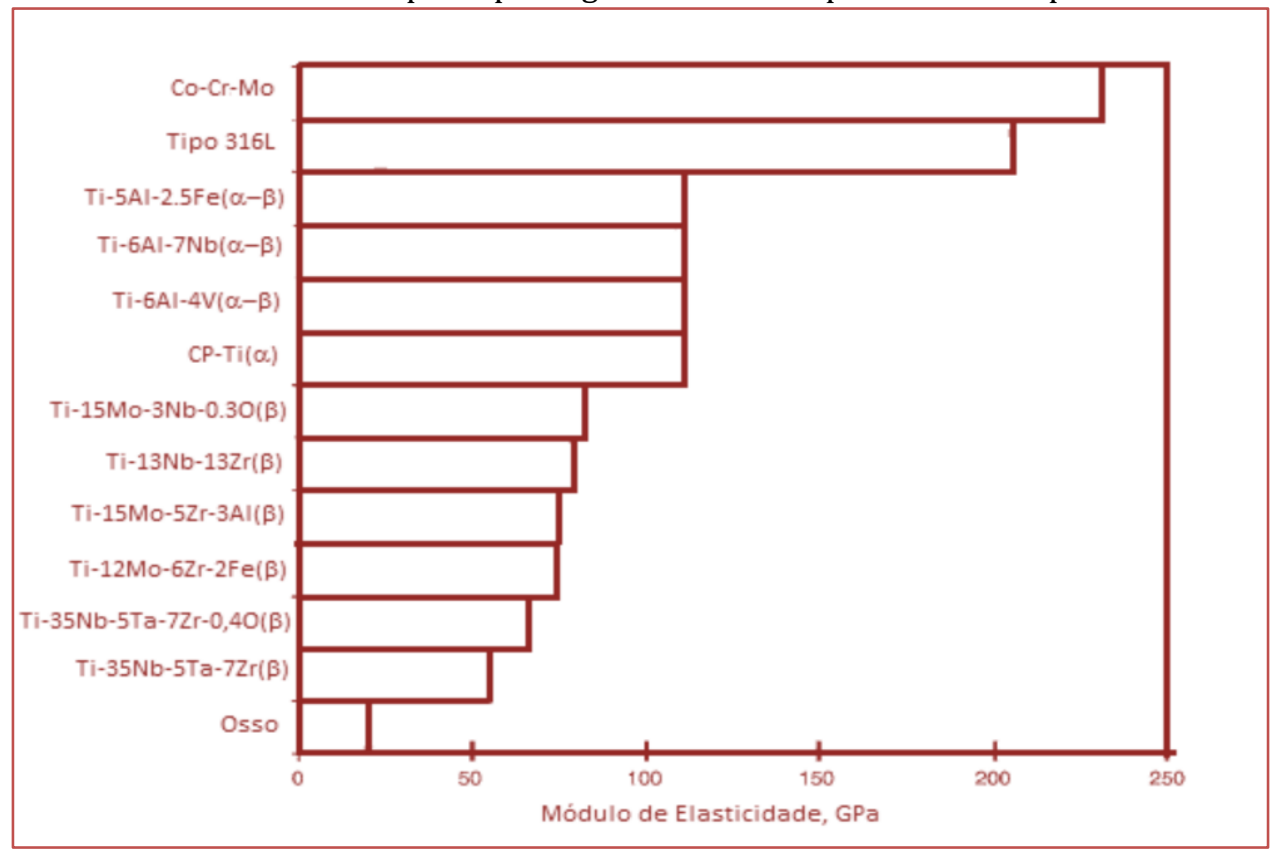

Fonte: (BUSATO JUNIOR, 2018. Pag. 22)

\section{METODOLOGIA}

A metodologia utilizada para desenvolver este estudo foi a pesquisa exploratória/explicativa de abordagem qualitativa, que tem estruturação em levantamento de dados teóricos e arguição segundo análise textual discursiva em fundamentação teórica e bibliográfica, para que se possa identificar e compreender os fatores que envolvem o estudo como um todo relacionado, assim citando (Lakatos, 2017, p. 295) que define a ciência em relação ao levantamento de dados e a importancia de sua sustentação, "A ciência é uma modalidade de conhecimento que não se constitui simplesmente como mero levantamento de dados. Levantados os dados, eles precisam ser articulados de forma lógica com o real e segundo uma teoria que lhes dê sustentação", também é possível entender a metodologia através das classificações metodológicas de pesquisa explicativa, que diz respeito aos objetivos, e compreende a coleta de dados como: levantamento bibliográfico, entrevistas com pessoas experientes em relação ao assunto, análise de exemplos e referências, e da pesquisa exploratória que se compreende como: pesquisa bibliográfica, estudo de caso, levantamento de campo, entre outros. (LAKATOS, 2017)

\subsection{DESCRIÇÃO DO OBJETO DE ESTUDO}

Nesta pesquisa os objetos de estudo são os materiais metálicos utilizados nas próteses implantadas cirurgicamente, como: aço inoxidável 316L, ligas de cromo-cobalto, ASTM F75 e ASTM F95, titânio e suas ligas, Ti-6Al-4V. (BRUKE et al., 1996)

Sem excluir as possibilidades de acrescentar qualquer material, método, processo ou produto relacionado aos objetos e à melhoria de suas características e/ou aplicações, principalmente aqueles que possuam a capacidade de prolongamento da vida útil ou alguma possibilidade substancial de aumento da qualidade, seja no incremento dos objetos ou até mesmo na possível substituição por outro mais adequado.

Levando em consideração o principal processo de degradação dos metais, o qual instigou o autor a esta pesquisa, a corrosão também será abordada de maneira mais aprofundada como sendo um objeto de pesquisa, tendo ênfase na compreensão de sua origem, formação, formas de manifestação, soluções de controle e qualquer outra característica que for julgada relevante para o enriquecimento deste assunto.

O fluxograma do procedimento metodológico está representado na Figura 2. 
Figura 2 - Macro fluxograma do procedimento metodológico

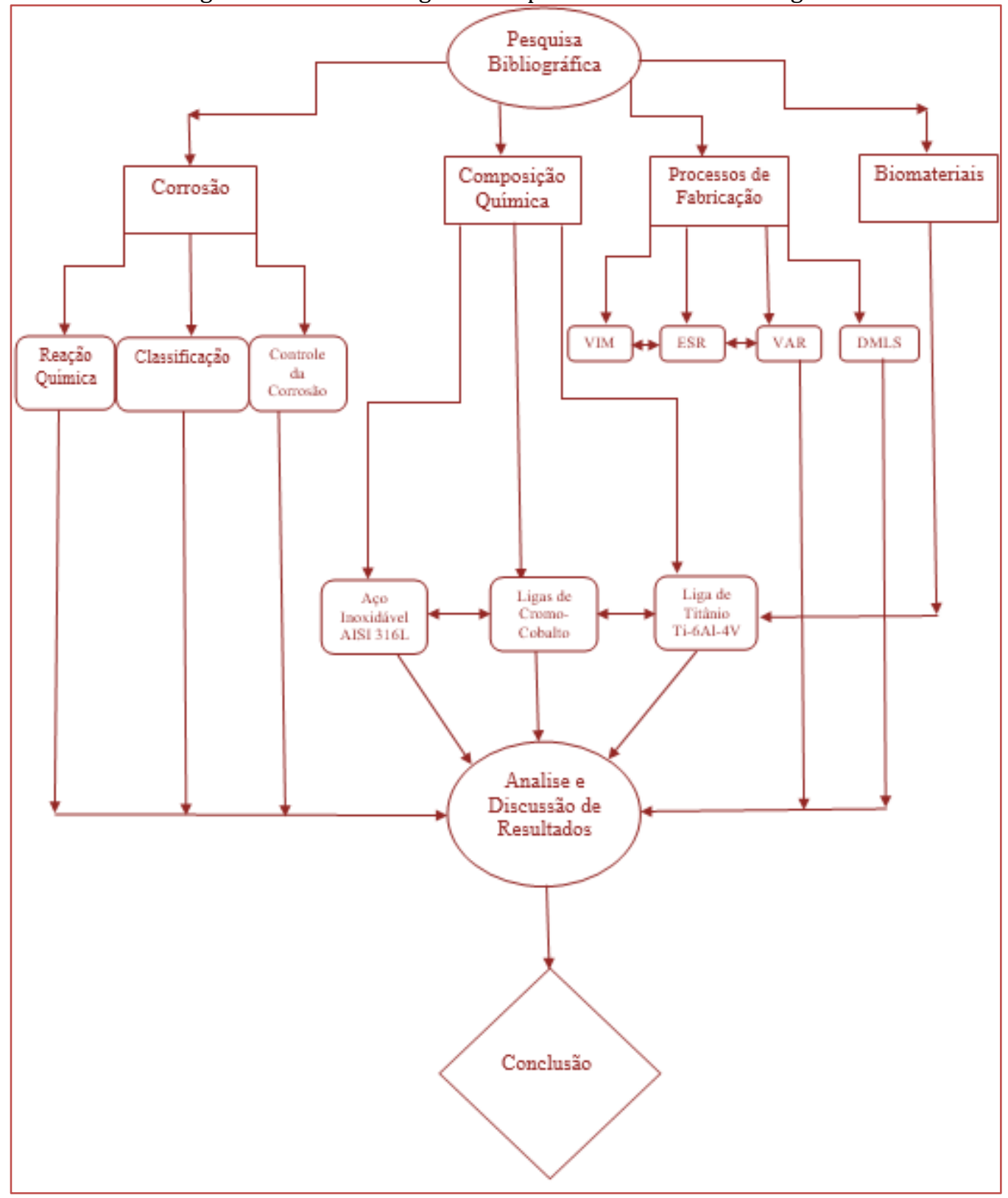

Fonte: elaborado pelo autor (2019)

\section{APRESENTAÇÃO E ANÁLISE DOS RESULTADOS}

\subsection{MOTIVO DA OXIDAÇÃO IN VIVO.}

"É importante ressaltar que, como biomaterial implantável, há exposição ao pH dos líquidos corpóreos, que gira em torno de 7,3, em regiões machucadas e hematomas, o $\mathrm{pH}$ pode se tornar ácido e atingir valores próximos a 4,0. A presença de íons $\mathrm{Cl}$-, $\mathrm{Na}+$ e HCO3- nos fluidos em contato com o implante metálico pode promover a ação corrosiva no metal." (AZEVEDO \& Jr, 2002, p. 1349)

"A resistência à corrosão é um parâmetro fundamental para a escolha de uma liga metálica utilizada na fabricação de um produto implantável, uma vez que os fluídos biológicos presentes no corpo humano possuem alto poder corrosivo." (GAM, KS, \& MG, 2011. Pag.2).

"Em próteses implantadas a camada de passivação protege o metal contra o ataque corrosivo de íons cloreto, presentes no sangue e nos demais fluídos biológicos." (GAM, KS, \& MG, 2011, p. 2)

"Meios contendo halogenetos como cloretos ou fluoretos promovem a corrosão por pites. 0 fenômeno acontece inicialmente devido a uma descontinuidade local do filme de proteção, por defeitos microscópicos como uma inclusão ou imperfeição mecânica." (BUSATO JUNIOR, 2018, p. 33) 


\subsection{FORMAS DE RETARDAR A CORROSÃO DAS PRÓTESES IMPLANTÁVEIS}

"A elevada resistência à corrosão dos aços inoxidáveis se deve, principalmente, ao seu elevado teor de cromo (acima de 11\%): o cromo presente na superfície do aço reage quimicamente com oxigênio, formando uma fina camada de óxido de cromo (Cr203) sobre o metal, denominada camada de passivação, a qual confere proteção contra agentes corrosivos." (GAM, KS, \& MG, 2011. p.2)

"Durante o processo de fabricação de um aço, a adição de molibdênio, em teores acima de $2 \%$, permite a formação de uma camada de passivação mais resistente a meios salinos agressivos. Um baixo teor de carbono também inibe a corrosão" (GAM, KS, \& MG, 2011, p. 3)

"Portanto, são fatores que podem favorecer à corrosão localizada em aços inoxidáveis: variações na composição de um aço, na medida em que tais variações, mesmo que pequenas, resultem em teores inadequados dos elementos que formam a camada de passivação; e a presença de impurezas no aço, as quais podem formar "brechas" na camada de passivação ou contribuir para a formação de estruturas heterogêneas no metal." (GAM, KS, \& MG, 2011, p. 3)

Este trabalho estudou a superfície do Ti cp e a liga metálica de Ti-6Al-4V usados como biomateriais para implantes, antes e após a modificação superficial (revestimento) empregando-se a aspersão térmica de dióxido de titânio por meio da técnica de plasma spray. A finalidade deste tratamento foi produzir um suporte funcional e quimicamente adequado possuindo grande área específica favorável para uma posterior osseointegração, o que garante uma melhor adesão do osso regenerado à superfície do implante usado para a prótese. (ALENCAR, 2002, p. 10)

\subsection{NOVIDADES NA FABRICAÇÃO DE PRÓTESES IMPLANTÁVEIS.}

Segundo (VOLPATO et al., 2006). Na evolução da manufatura aditiva (Sinterização), muitas tecnologias e distintos equipamentos foram criados em um curto período de tempo. Atualmente existem processos que usam matérias primas líquidas, sólidas e em pó. A esse estudo, interessam somente os processos baseados em pó, pois são os que permitem a fabricação de produtos em ligas metálicas implantáveis. Existem atualmente cinco processos disponíveis com diferentes tecnologias baseadas em pó. (apud BUSATO JUNIOR, 2018, p. 45)

São eles:

1. Sinterização a laser (SLS)

2. Sinterização a laser (DMLS)

3. Fabricação da forma final a laser (LENS)

4. Impressão tridimensional (3DP)

5. Impressão tridimensional (3DP) - Prometal.

Todas estas tecnologias em processos de fabricação surgiram entre 1987 (SLS) e 1997 (3DP - Prometal).

Dentre elas (BUSATO JUNIOR, 2018, Pag 120) utilizou o método de sinterização a laser (DMLS), para a fabricação de uma prótese apta para implante cirúrgico produzida em aço inoxidável austenítico EOS 316L, a conclusão dele em relação a liga é: "O uso do pó metálico EOS 316L e a flexibilidade de construção do processo DMLS permitirá a obtenção de implantes cirúrgicos de geometria complexa, em aço inoxidável F138 como normalizado pela ASTM."

Para melhor compreensão da possível complexidade citada por Busato Jr, a seguir na Figura 3, temos um caso real ocorrido no Brasil, "O Hospital de Clínicas (HC) da Unicamp em Campinas (SP), realizou a primeira cirurgia com placa de titânio produzida em impressão 3D do Brasil". (ANTGARCIA, 2015, online) 


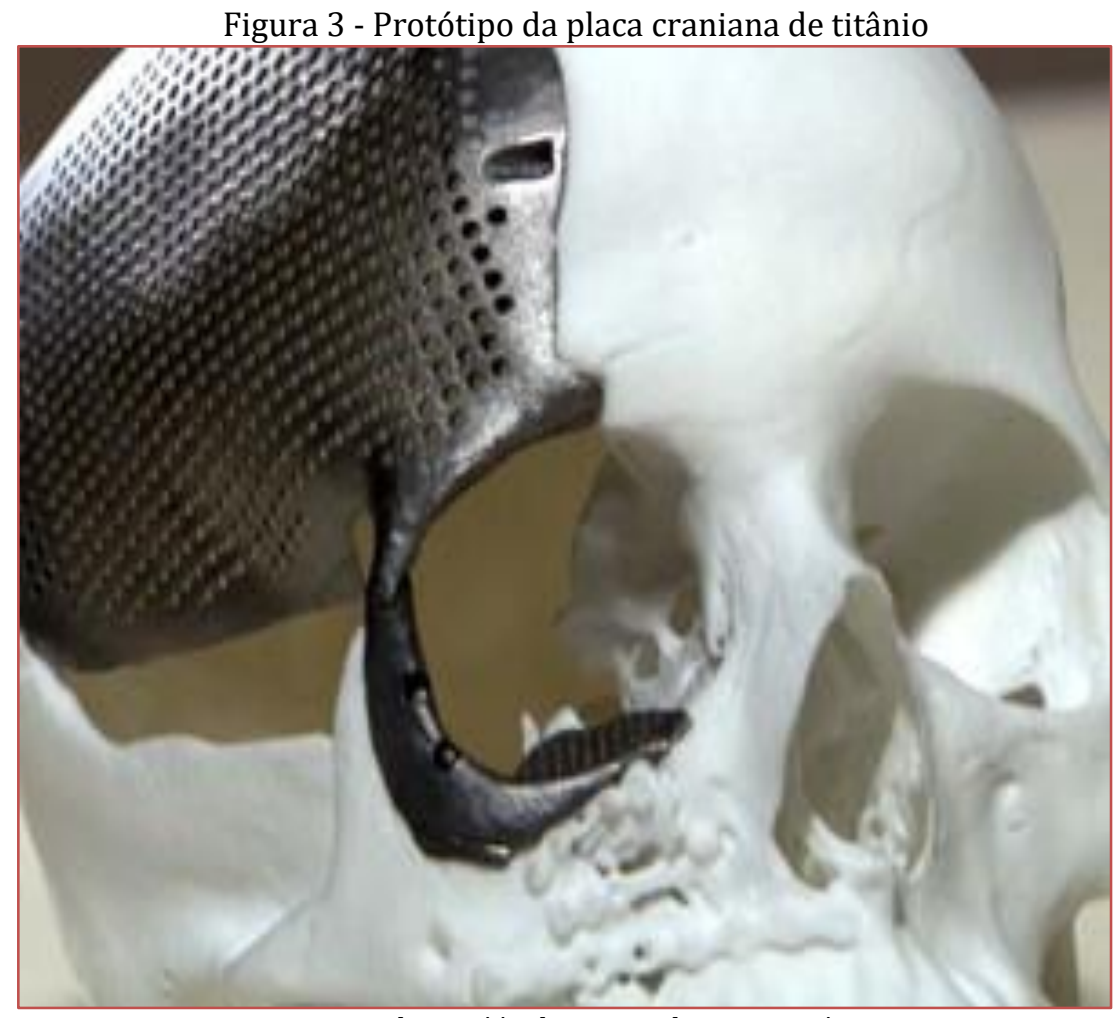

Fonte: https://polisgn.wordpress.com/a

\section{CONCLUSÃO}

Considera-se que existem alguns fatores que influenciam diretamente na origem da oxidação protética dentro do corpo humano, exposição ao pH dos líquidos corpóreos é uma delas, normalmente alcalinos com aproximadamente $7,3 \mathrm{pH}$, mas quando há um ferimento ou hematoma o sistema imunológico identifica a região e demanda fluídos com $\mathrm{pH}$ ácido, na ordem de até $4 \mathrm{pH}$, com o intuito de exterminar qualquer contaminação na região afetada.

A presença de íons $\mathrm{Cl}-$, $\mathrm{Na}+$ e HCO3- nos fluidos em contato com o implante metálico, é um dos principais motivos da degradação das próteses, o ataque corrosivo de íons cloreto, presentes no sangue e nos demais fluídos biológicos infringe a camada de passivação da prótese, resultando na corrosão por "pites". Outros determinantes na questão da oxidação de implantes são os defeitos microscópicos, como inclusões ou imperfeições mecânicas que causam a descontinuidade da camada de passivação, em meios agressivos promovem a corrosão por "pites".

As melhores formas de retardar a corrosão nas próteses implantáveis são através de suas composições químicas e quantidades exatas de elementos de liga, garantindo uma boa formação da camada de passivação. Um processo de fabricação adequado, que permita controlar essa composição química e auxilie na prevenção de inclusões micro estruturais, também é uma boa forma de influenciar neste quesito, buscando um produto mais homogêneo.

0 método mais recentemente utilizado com êxito na produção de uma prótese implantada cirurgicamente seria produção por impressão 3D, ou impressão tridimensional, que permite ao processo entregar uma alta complexidade, com um bom acabamento e ótimo controle dimensional.

\section{REFERÊNCIAS}

[1] ALENCAR, A. C. Tese de Doutorado: Estudo das modificações na superfície do Ti cp (titânio comercialmente puro) e da liga Ti-6AI-4V usados como biomateriais utilizando-se deposição por plasma spray. Fonte: Repositorio.unesp.br, 2002. Disponível em: <https://repositorio.unesp.br/handle/11449/10259>. Acesso em: 01 de junho de 2019.

[2] ANTGARCIA. Flash News. Fonte: polisgn.wordpress.com, 2015. Disponível em: <https://polisgn.wordpress.com/author/polisgar/page/171/>. Acesso em: 05 de junho de 2019. 
[3] ANTUNES, L. H. Dissertação de Mestrado: Caracterização da liga Co-28Cr-6Mo obtida por manufatura aditiva e micro fundição. Campinas, 2017.

[4] AZEVEDO, C. R., \& Jr, E. H. Análise de falhas de implantes Cirúrgicos. Cadernos de Saúde Pública, 2002. Pag. 1347-1358.

[5] BRUKE, J., DIDISHEIM, P., GOUPIL, D., HELLER, J., KANE, J., KATZ, J., ... YARMUSH, M. Orthopedic Applications. Application of Materials in Medicine and Dentistry. In: B.D. RATNER; A.S. HOFFMAN; F.J. SCHOEN; J.E. LEMONS (eds.), Biomaterials Science: An Introduction to Materials in Medicine. New York: Academic Press, 1996.

[6] BUSATO JUNIOR, E. Caracterização comparativa entre os aços inoxidáveis austeníticos para implantes cirúrgicos ASTM F138 comercial e obtido por manufatura aditiva DMLS. Dissertação de Mestrado. Campinas, São Paulo, Brasil: Universidade Estadual de Campinas, 2018.

[7] CORP, F. W. Sobre a empresa: Fort Wayne Metal, 2019. Disponível em: <https://fwmetals.com.br/services/resource-library/ti-6al-4v-eli/>. Acesso em: 27 de junho de 2019.

[8] GAM, B., KS, D., \& MG, V. Utilização de aços inoxidáveis em implantes. Brasília, Brasil, 2011. Disponível em: <http://www.anvisa.gov.br/boletim_tecno/boletim_tecno_dezembro_ed_especial/boletim_tecno.html >. Acesso em: 09 de junho de 2019.

[9] GENTIL, V. Corrosão. Rio de Janeiro: LTC, 2011.

[10] GOMES, L. S. Cirurgia Preservadora do Quadril Adulto. Rio de Janeiro: Atheneu, 2015.

[11] KENDALL, J. B. Biomaterials Research Advances. New York: Nova Science Publishers, 2007.

[12] LAKATOS, E. M. Metodologia científica. Rio de Janeiro: Atlas, 2017.

[13] METALS, V. Sobre a Empresa: Villares Metals S.A. Fonte: Site da Villares Metals a voestalpine company, 2019. Disponível em: <http://www.villaresmetals.com.br/pt/Empresa/Producao/Aciaria-Especial>. Acesso em: 17 de abril de 2019.

[14] SANTOS, L. A. Processamento e Caracterização da liga 66Co-28Cr-6Mo para implantes. Dissertação de Mestrado. Lorena, São Paulo, Brasil: USP/EEL, 2012.

[15] TOLENTINO, N. M. Processos Químicos Industriais: Matérias-primas, técnicas de produção e métodos de controle de corrosão. São Paulo: Érica, 2015.

[16] VOLPATO, N. e. Prototipagem Rápida: tecnologia e aplicações. São Paulo: Blücher, 2006. 


\section{Capítulo 7}

Modelo de Matriz de Diagnóstico e Avaliação de Desempenho de Sistemas de Gestão Integrados (SGI) da Qualidade, Meio Ambiente, Segurança e Saúde no Trabalho

Raymundo Jorge de Sousa Mançú

Luís Manuel Borges Gouveia

Silvério dos Santos Brunhoso Cordeiro

Resumo: Este trabalho tem como objetivo analisar e realizar a correspondência e integração entre as 4 (quatro) fases do ciclo PDCA, com as Seções 4, 5, 6, 7, 8, 9 e 10 dos sistemas de gestão das normas ISO 9001:2015; ISO 14001:2015 e ISO 45001:2018, requisitos comuns e específicos, práticas de gestão e práticas operacionais, para diagnóstico e/ou avaliação de desempenho dos Sistemas de Gestão Integrados (SGI), em organizações não certificadas e/ou certificadas no SGI. A metodologia utilizada como estratégia de pesquisa foi uma revisão bibliográfica e pesquisa documental sobre sistemas de gestão, conforme as normas ABNT NBR ISO 9001:2015, ISO 14001 e ISO 45001:2018 (QMS\&ST) e sistemas de gestão integrados (SGI). Como resultado foi estruturado um modelo de matriz de correspondência dividido nas 4 (quatro) fases do ciclo PDCA, com a integração das Seções 4, 5, 6, 7, 8, 9 e 10 e seus requisitos comuns e específicos certificáveis dos sistemas de gestão de QMS\&ST, que caracterizaram o SGI. Desta forma, conclui-se que o modelo da matriz de correspondência estruturada no ciclo PDCA, está composta por 75 requisitos e 172 práticas de gestão e operacionais, para elaboração de instrumentos de coleta de dados do tipo: roteiro de entrevista, questionário e listas de verificação (LV), para realizar diagnóstico e/ou avaliação de desempenho da SGI, assim como possibilitara integração com outros tipos de sistemas de gerenciamento exigidos por órgãos reguladores na gestão global de uma organização, como de segurança operacional e de integridade estrutural das instalações, dutos terrestres, sistemas submarinos e poços produtores de petróleo e gás natural e injetores de fluidos, definidos pela Agência Nacional de Petróleo (ANP) no Brasil.

Palavras-chave: Sistemas de Gestão Integrados; Ciclo PDCA; Qualidade. Meio Ambiente. Segurança e Saúde no Trabalho 


\section{INTRODUÇÃO}

As organizações estão vivenciando na economia global um grande processo de mudança, que envolvem inovação e avanços tecnológicos nas áreas de informação e comunicação, através da internet, redes sociais, inteligência artificial e automação de processos, lançamento de novos produtos e serviços, com aumento da concorrência e das exigências legais, assim como das demais partes interessadas, quanto à qualidade, preservação ambiental, responsabilidade social, segurança e saúde no trabalho.

Nesse contexto, torna-se relevante a incorporação no sistema de gestão global da organização de normas de sistemas de gestão para certificação como Qualidade, Meio Ambiente, Segurança e Saúde no Trabalho: ISO 9001:2015 (SGQ); ISO 14001:2015 (SGA) e ISO 45001:2018 (SGS\&ST), que caracterizam os Sistemas de Gestão Integrados (SGI), como forma alternativa para atingir as novas exigências de mercado, visando a competitividade e sustentabilidade do negócio.

Segundo Poltronieri, Gerolamo e Carpinetti (2015) em 2003 foram observados que havia no mundo 497.919 empresas certificadas na norma da qualidade ISO 9001, e na norma ambiental ISO 14001 tinha apenas 64.996, sendo que ao longo dos últimos anos foi evidenciado um crescimento nessas certificações, totalizado 1.129.446 empresas certificadas na norma ISO 9001, enquanto que na norma ISO 14001 totalizaram 301.647 em 2013.

Portanto, a Associação Brasileira de Normas Técnicas (ABNT) publicou as normas NBR ISO 9001:2015, NBR ISO 14001:2015 e ISO 45001:2018, com estruturas similares em 10 (dez) Seções que podem ser integradas, conforme o ciclo PDCA, de aplicação voluntária, através das Seções 4, 5, 6, 7, 8, 9 e 10 e seus requisitos para certificação no SGI.

Entretanto, este artigo tem como objetivo analisar e realizar a correspondência e integração entre as 4 (quatro) fases do ciclo PDCA, com as Seções 4, 5, 6, 7, 8, 9 e 10 dos Sistemas de Gestão das normas ISO 9001:2015; ISO 14001:2015 e ISO 45001:2018, requisitos comuns e específicos, práticas de gestão e práticas operacionais, para diagnóstico e/ou avaliação de desempenho dos Sistemas de Gestão Integrados (SGI), em organizações não certificadas e/ou certificadas no SGI.

\section{REVISÃO DA LITERATURA}

\subsection{SISTEMA DE GESTÃO DA QUALIDADE (SGQ) - NORMA ISO 9001:2015}

Para a ABNT NBR ISO 9000:2015 (p. 2) o "SGQ compreende atividades pelas quais a organização identifica seus objetivos e determina os processos e recursos necessários para alcançar os resultados desejados". Com o SGQ estabelece a sequência e interação dos processos, com disponibilidade e utilização otimizada de recursos para atender as necessidades das partes interessadas, através da provisão de produtos e serviços com valor agregado.

A norma ISO 9001:2015 define os critérios para o SGQ, enfatizando o atendimento das necessidades do cliente e apresenta uma estrutura de requisitos para certificação de uma organização, definidas em 7 (sete) Seções 4, 5, 6, 7, 8, 9 e 10, para certificação de uma organização, que caracteriza o processo de melhoria contínua, o aumento competitividade e sustentabilidade do negócio, conforme Figura 1. 
Figura 1 - Seções 4, 5, 6, 7, 8, 9 e 10 do SGQ agrupadas em relação ao ciclo PDCA

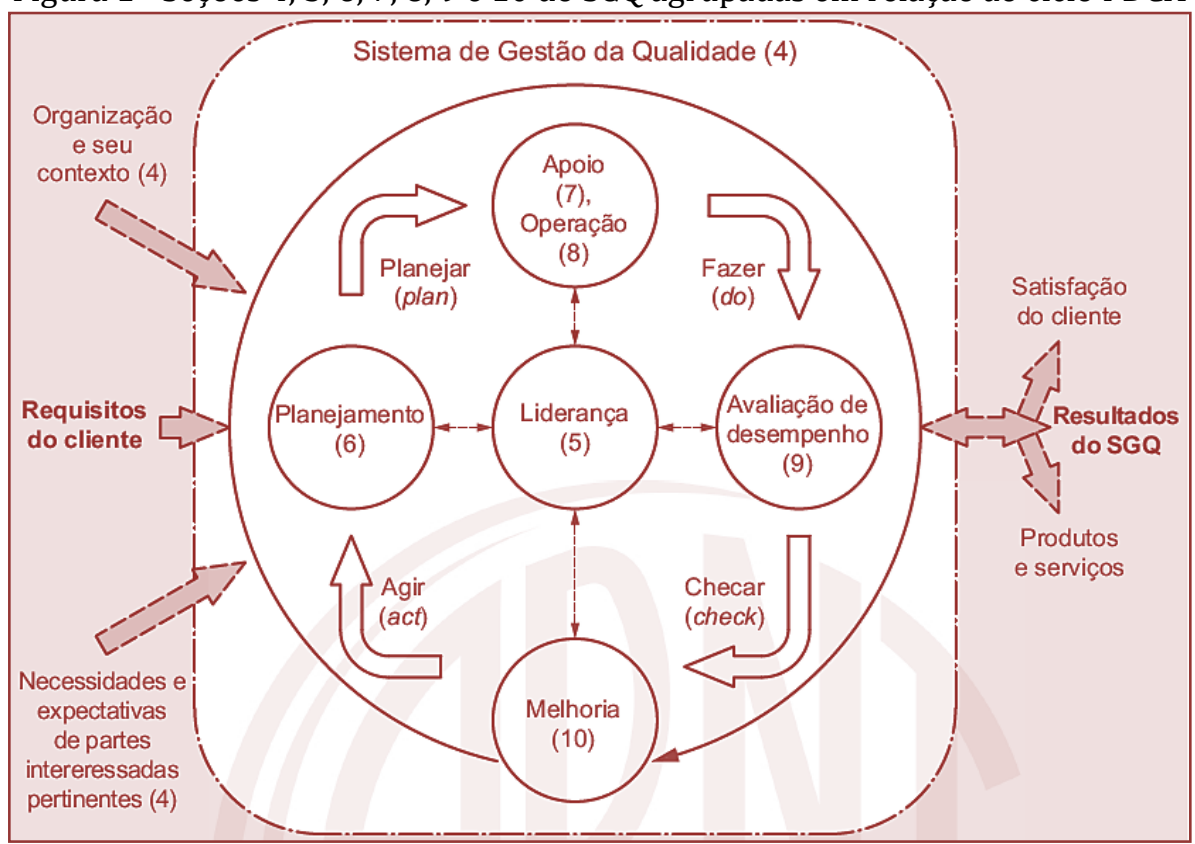

Fonte: ABNT NBR ISO 9001:2015

Segundo Bertolino e Couto (2018) atualmente o número de certificação na norma ISO 9001 no mundo supera mais de um milhão de empresas. Corroborando, Ribeiro Neto, Tavares e Hoffmann (2017), afirma que em um estudo concluído pela ISO no final de 2015 foi observada a existência de mais de um milhão de certificados de conformidade com a norma ISO 9001 (SGQ) emitidos para organizações de 201 países, sendo esta norma caracterizada como a mais conhecida no mundo, quando comparado com a norma ISO 14001 (SGA) e a norma OHSAS 18001 (SGS\&SO), atualmente a ISO 45001 (SGS\&ST).

\subsection{SISTEMA DE GESTÃO AMBIENTAL (SGA) - NORMA ISO 14001:2015}

O SGA é parte de um sistema de gestão global que tem como objetivo gerenciar os aspectos ambientais dos processos industriais, atividades e tarefas na produção dos bens e serviços, identificar riscos e oportunidades, atender aos requisitos legais e outros requisitos em uma organização (ABNT, 2015).

Para Ribeiro Neto, Tavares e Hoffmann (2017) a norma ISO 14001:2015 disponibiliza uma estrutura para as organizações, que possibilita uma gestão para a proteção do meio ambiente e a resposta às mudanças ambientais, alinhadas às suas necessidades socioeconômicas, por meio de ações para a implementação da política ambiental, identificação e controle dos aspectos e impactos ambientais, estabelecer processos sistematizados, aumentar a conscientização em relação ao meio ambiente, estabelecer controles operacionais e avaliar o desempenho ambiental.

Na estrutura da norma ISO 14001:2015 constam os requisitos do SGA com seus itens e subitens, numa sequência e interação lógica, para a implementação na gestão global da organização, composto por 7 (sete) Seções do SGA, sendo estes 4, 5, 6, 7, 8, 9 e 10, conforme Figura 2, para a certificação e melhorias nos resultados de desempenho ambiental. 
Figura 2- Seções 4, 5, 6, 7, 8, 9 e 10 do SGA agrupadas em relação ao ciclo PDCA

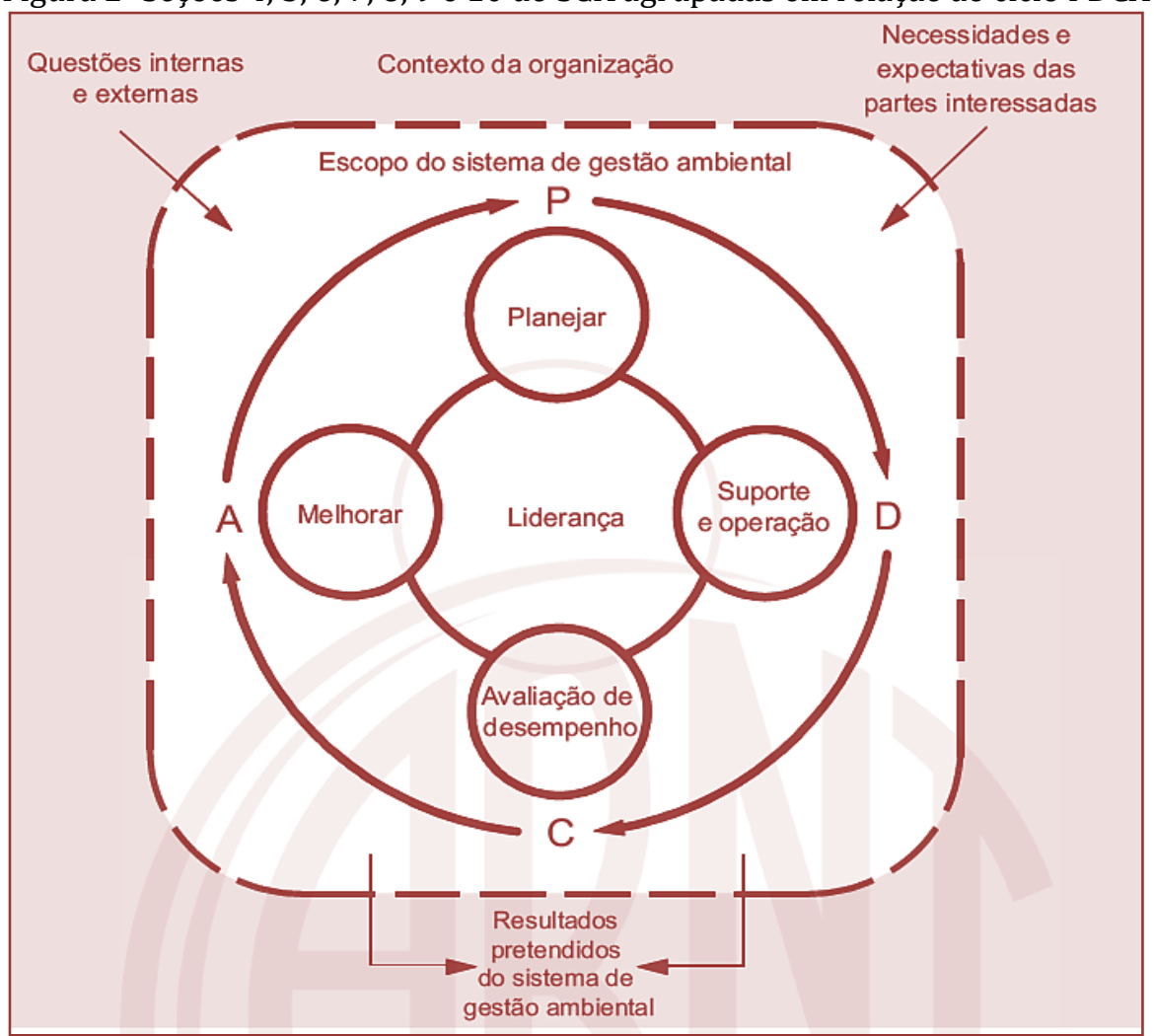

Fonte: ABNT NBR ISO 14001:2015

A Norma ISO 14001:2015 tem como objetivo: "prover às organizações uma estrutura para a proteção do meio ambiente e possibilitar uma resposta às mudanças das condições ambientais em equilíbrio com as necessidades socioeconômicas" (ABNT, 2015, p. 8), e com possibilidade de integração com as normas ISO 9001:2015 e ISO 45001:2018.

\subsection{SISTEMA DE GESTÃo DA SEgURANÇA E SAÚDE NO TRABALHO (SGS\&ST) - NORMA ISO 45001:2018}

O Sistema de Gestão de Segurança e Saúde no Trabalho é parte de um conjunto de elementos interrelacionados ou interativos de uma organização usados para gerenciar os perigos e riscos dos processos, atividades e tarefas para elaborar os produtos ou serviços de uma organização, cumprir requisitos legais e outros requisitos, e abordar riscos e oportunidades (ABNT, 2018).

A ISO criou o comitê ISO/PC 283, Occupational Health and Safety Management Systems - Requeriments, para iniciar em 2013 a elaboração de uma norma internacional para Sistemas de Gestão de Segurança e Saúde no Trabalho, que foi concluída e publicada em 2018 e conhecida como norma ISO 45001:2018, com estrutura similar composto por 7 (sete) Seções do SGS\&ST 4, 5, 6, 7, 8, 9 e 10,conforme Figura 3,com requisitos comuns, para facilitar a integração com a norma ISO 9001:2015 e com a norma ISO 14001:2015 (De Cicco, 2018). 
Figura 3 - Seções 4, 5, 6, 7, 8, 9 e 10 do SGS\&ST agrupadas em relação ao ciclo PDCA

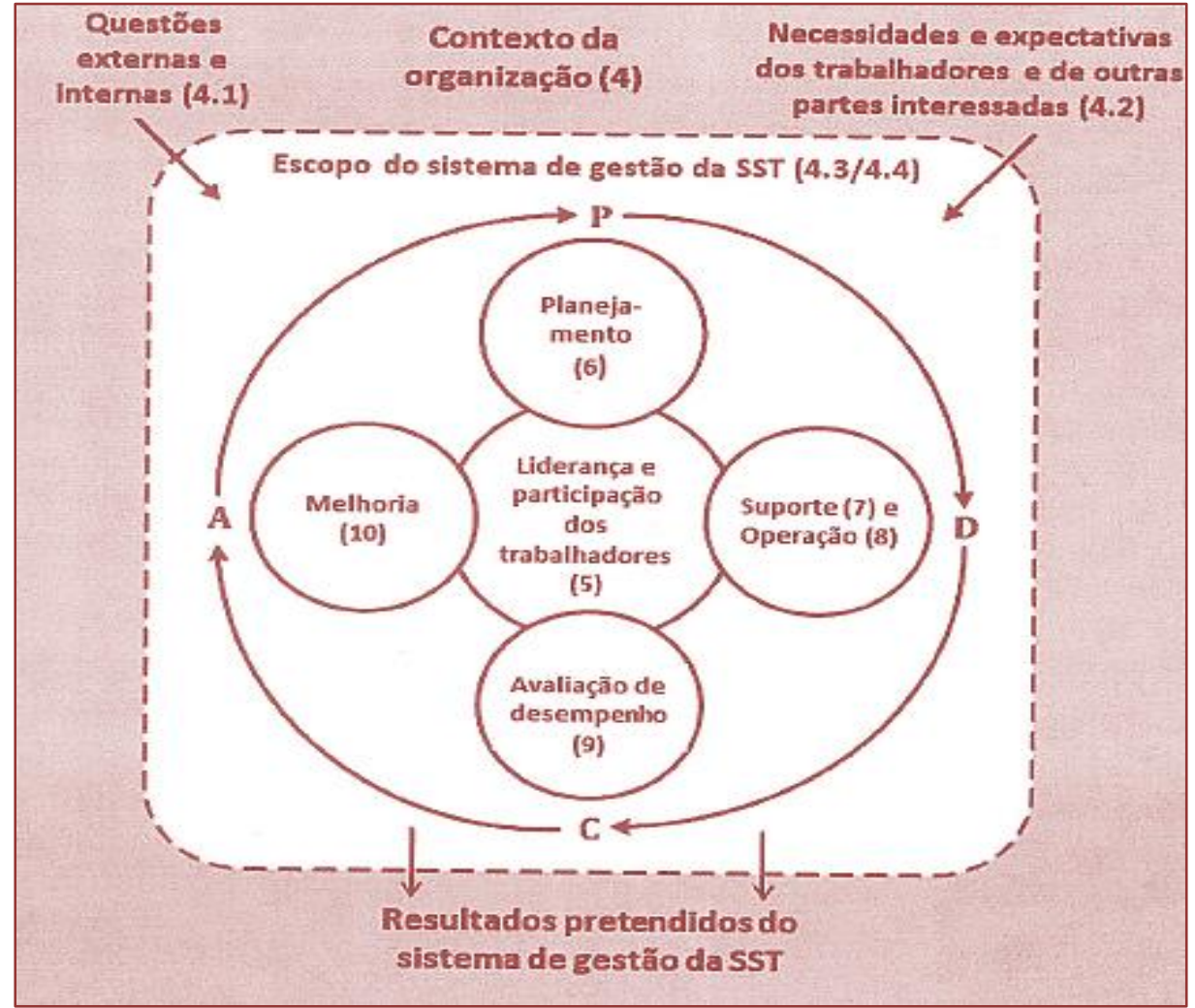

Fonte: De Cicco, 2018

Segundo Ribeiro Neto, Tavares e Hoffmann (2017) e De Cicco (2018), o SGS\&ST preocupa-se com o controle dos perigos e riscos na área de segurança e saúde no trabalho, para eliminar ou minimizar os riscos para as pessoas e assegurar a conformidade com a política de S\&ST e como consequência a redução dos acidentes de trabalho. No entanto, observa-se que cada norma tem os seus objetivos específicos e requisitos comuns tornando-se estratégico adotar os sistemas de gestão integrados (SGI), para garantir a qualidade, a preservação ambiental, a segurança e saúde no trabalho na organização.

\subsection{SISTEMAS DE GESTÃO INTEGRADOS (SGI): ISO 9001:2015, ISO 14001:2015 E IS0 45001:2018}

Os Sistemas de Gestão Integrados (SGI) concretizam-se quando duas ou mais normas de certificação são unificadas, devido às compatibilidades dos requisitos dos sistemas de gestão, porém sem perder as suas características individuais (BERTOLINO e COUTO, 2018). Corroborando Santos et al., (2018, p.287) afirma que "a integração dos sistemas de gestão da qualidade (SGQ), ambiental (SGA) e da segurança e saúde no trabalho (SGS\&ST) podem ser por fases e de forma parcial (SGQ e SGA ou SGQ e SGS\&ST ou SGA e SGS\&ST) ou total (SGQ e SGA e SGS\&ST), identificando todos os campos de aplicação comuns dos sistemas de gestão", para caracterizar o SGI.

Para Poltronieri (2014) a implantação de sistemas de gestão de forma isolada apresenta problema na utilização de normas e procedimentos de forma separada, na duplicação de documentos e de controle de registros. Corroborando, Coelho (2010) afirma que o SGI contribui para a otimização de recursos, ampliação de conhecimento, redução da burocracia, melhoria no relacionamento e na integração com subsistemas de características semelhantes, para uma gestão global integrada, mais eficiente e eficaz.

Uma das estratégias de uma organização em adotar um Sistema de Gestão Integrada (SGI) é a possibilidade de integração dos requisitos da norma ISO 9001:2015, com os das normas ISO 14001:2015 e ISO 45001:2018, isto porque esses sistemas de gestão apresentam requisitos comuns, estruturas definidas em 10 (dez) Seções nas ultimas revisões em 2015 e 2018 respectivamente, sendo as Seções de 4, 5, 6, 7, 8, 9 e 10 (Figura 4), de aplicação voluntária, para a certificação de uma organização no SGI (BERTOLINO e COUTO, 2018 e SANTOS et al., 2018). 
Figura 4 - Matriz de correspondência entre os requisitos das normas do SGI (ABNT NBR ISO 9001:2015, ABNT NBR ISO 14001:2015 e ISO 45001:2018)

\begin{tabular}{|c|c|c|}
\hline \multicolumn{3}{|c|}{ MATRIZ DE CORRESPONDÊNCIA ENTRE OS REQUISITOS DAS NORMAS ABNT NBR ISO DO SGI } \\
\hline NBR ISO 9001:2015 & NBR ISO 14001:2015 & ISO 45001:2018 \\
\hline Seção 4 - Contexto da organização & Seção 4 - Contexto da organização & $\begin{array}{l}\text { Seção } 4 \text { - Contexto da } \\
\text { organização }\end{array}$ \\
\hline $\begin{array}{l}4.1 \text { Entendendo a organização e seu } \\
\text { contexto }\end{array}$ & $\begin{array}{l}4.1 \text { Entendendo a organização e seu } \\
\text { contexto }\end{array}$ & $\begin{array}{l}\text { 4.1 Entendendo a organização e } \\
\text { seu contexto }\end{array}$ \\
\hline $\begin{array}{l}\text { 4.2 Entendendo as necessidades e } \\
\text { expectativas de partes interessadas }\end{array}$ & $\begin{array}{l}\text { 4.2 Entendendo as necessidades e } \\
\text { expectativas de partes interessadas }\end{array}$ & $\begin{array}{l}\text { 4.2 Entendendo as necessidades } \\
\text { e expectativas de partes } \\
\text { interessadas }\end{array}$ \\
\hline $\begin{array}{l}\text { 4.3 Determinando o escopo do sistema } \\
\text { de gestão da qualidade }\end{array}$ & $\begin{array}{l}4.3 \text { Determinando o escopo do } \\
\text { sistema de gestão ambiental }\end{array}$ & $\begin{array}{l}\text { 4.3 Determinando o escopo do } \\
\text { sistema de gestão da segurança } \\
\text { e da saúde }\end{array}$ \\
\hline $\begin{array}{l}\text { 4.4 Sistema de gestão da qualidade e } \\
\text { seus processos }\end{array}$ & 4.4 Sistema de gestão ambiental & $\begin{array}{l}\text { 4.4 Sistema de gestão da } \\
\text { segurança e da saúde }\end{array}$ \\
\hline Seção 5 - Liderança & Seção 5 - Liderança & Seção 5 - Liderança \\
\hline 5.1 Liderança e comprometimento & \multirow{3}{*}{ 5.1 Liderança e comprometimento } & \multirow{3}{*}{$\begin{array}{l}\text { 5.1 Liderança e } \\
\text { comprometimento }\end{array}$} \\
\hline 5.1.1 Generalidades & & \\
\hline 5.1.2 Foco no cliente & & \\
\hline 5.2 Política & \multirow{3}{*}{ 5.2 Política ambiental } & \multirow{3}{*}{$\begin{array}{l}5.2 \text { Política da segurança e da } \\
\text { saúde }\end{array}$} \\
\hline $\begin{array}{l}5.2 .1 \text { desenvolvendo a política da } \\
\text { qualidade }\end{array}$ & & \\
\hline $\begin{array}{l}\text { 5.2.2 Comunicando a política da } \\
\text { qualidade }\end{array}$ & & \\
\hline $\begin{array}{l}5.3 \text { Papéis, responsabilidades e } \\
\text { autoridades organizacionais }\end{array}$ & $\begin{array}{l}\text { 5.3 Papéis, responsabilidades e } \\
\text { autoridades organizacionais }\end{array}$ & $\begin{array}{l}\text { 5.3 Papéis, responsabilidades e } \\
\text { autoridades organizacionais }\end{array}$ \\
\hline Seção 6 - Planejamento & Seção 6 - Planejamento & Seção 6 - Planejamento \\
\hline \multirow{5}{*}{$\begin{array}{l}\text { 6.1 Ações para abordar riscos e } \\
\text { oportunidades }\end{array}$} & $\begin{array}{l}\text { 6.1 Ações para abordar riscos e } \\
\text { oportunidades }\end{array}$ & $\begin{array}{l}\text { 6.1 Ações para abordar riscos e } \\
\text { oportunidades }\end{array}$ \\
\hline & 6.1.1 Generalidades & 6.1.1 Generalidades \\
\hline & 6.1.2 Aspectos ambientais & 6.1.2 Perigos e riscos \\
\hline & $\begin{array}{l}6.1 .3 \text { Requisitos legais e outros } \\
\text { requisitos }\end{array}$ & $\begin{array}{l}6.1 .3 \text { Requisitos legais e outros } \\
\text { requisitos }\end{array}$ \\
\hline & 6.1.4 Planejamento de ações & 6.1.4 Planejamento de ações \\
\hline \multirow{3}{*}{$\begin{array}{l}6.2 \text { Objetivos da qualidade e } \\
\text { planejamento para alcançá-los }\end{array}$} & $\begin{array}{l}6.2 \text { Objetivos ambientais e } \\
\text { planejamento para alcançá-los }\end{array}$ & $\begin{array}{l}6.2 \text { Objetivos da segurança e da } \\
\text { saúde e planejamento para } \\
\text { alcançá-los }\end{array}$ \\
\hline & 6.2.1 Objetivos ambientais & $\begin{array}{l}\text { 6.2.1 Objetivos da segurança e } \\
\text { da saúde }\end{array}$ \\
\hline & $\begin{array}{l}\text { 6.2.2 Planejamento de ações para } \\
\text { atingir os objetivos ambientais }\end{array}$ & $\begin{array}{l}\text { 6.2.2 Planejamento de ações } \\
\text { para atingir os objetivos da } \\
\text { segurança e da saúde }\end{array}$ \\
\hline 6.3 Planejamento de mudanças & 6.3 Planejamento de mudanças & 6.3 Planejamento de mudanças \\
\hline Seção 7 - Apoio & Seção 7 - Apoio & Seção 7 - Apoio \\
\hline 7.1 Recursos & \multirow{7}{*}{ 7.1 Recursos } & \multirow{7}{*}{ 7.1 Recursos } \\
\hline 7.1.1 Generalidades & & \\
\hline 7.1.2 Pessoas & & \\
\hline 7.1.3 Infraestrutura & & \\
\hline $\begin{array}{l}\text { 7.1.4 Ambiente para a operação dos } \\
\text { processos }\end{array}$ & & \\
\hline $\begin{array}{l}\text { 7.1.5 Recursos de monitoramento e } \\
\text { medição }\end{array}$ & & \\
\hline 7.1.6 Conhecimento organizacional & & \\
\hline 7.2 Competência & 7.2 Competência & 7.2 Competência \\
\hline 7.3 Conscientização & 7.3 Conscientização & 7.3 Conscientização \\
\hline \multirow{4}{*}{ 7.4 Comunicação } & 7.4 Comunicação & 7.4 Comunicação \\
\hline & 7.4.1 Generalidades & 7.4.1 Generalidades \\
\hline & 7.4.2 Comunicação interna & 7.4.2 Comunicação interna \\
\hline & 7.4.3 Comunicação externa & 7.4.3 Comunicação externa \\
\hline 7.5 Informação documentada & 7.5 Informação documentada & 7.5 Informação documentada \\
\hline
\end{tabular}


(continuação ...)

Figura 4 - Matriz de correspondência entre os requisitos das normas do SGI (ABNT NBR ISO 9001:2015, ABNT NBR ISO 14001:2015 e ISO 45001:2018)

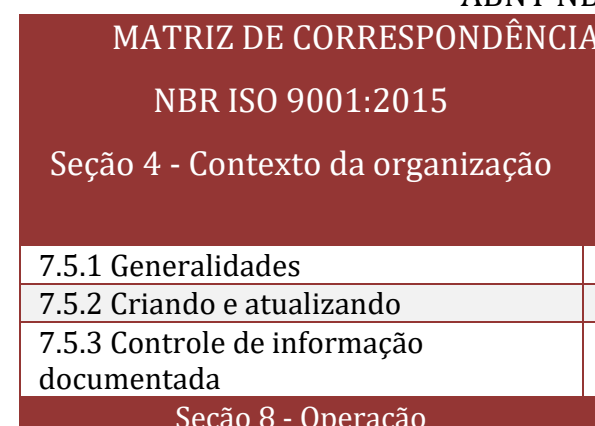

8.1 Planejament operacional

8.2 Requisitos para produtos e serviços

8.2.1 Comunicação com o cliente

8.2.2 Determinação de requisitos relativos a produtos e serviços

8.2.3 Análise crítica de requisitos relativos a produtos e serviços

8.2.4 Mudanças nos requisitos para produtos e serviços

8.3 Projeto e desenvolvimento de produtos e serviços

8.3.1 Generalidades

8.3.2 Planejamento de projeto e desenvolvimento

8.3.3 Entradas de projeto e desenvolvimento

8.3.4 Controle de projeto e desenvolvimento 8.3.5 Saídas de projeto e desenvolvimento 8.3.6 Mudanças de projeto e desenvolvimento

8.4 Controle de processos, produtos e serviços externamente

8.4.1 Generalidades

8.4.2 Tipo e extensão de controle

8.4.3 Informação para provedores externos

8.5 Produção e provisão de serviço 8.5.1 Controle de produção e de provisão de serviço

8.5.2 Identificação e rastreabilidade

8.5.3 Propriedade pertencente a clientes e provedores externos

8.5.4 Preservação

8.5.5 Atividades pós-entrega

8.5.6 Controle de mudanças

8.6 Liberação de produtos e serviços

8.7 Controle de saídas não conformes

\section{Seção 9 - Avaliação de desempenho}

9.1 Monitoramento, medição, análise e avaliação

9.1.1 Generalidades

9.1.2 Satisfação do cliente

9.1.3 Análise e avaliação
NBR ISO 14001:2015

Seção 4 - Contexto da organização

7.5.1 Generalidades

7.5.2 Criando e atualizando

7.5.3 Controle de informação

documentada

Seção 8 - Operação

8.1 Planejamento e controle

operacional

8.2 Preparação e resposta a

emergências
ISO 45001:2018

Seção 4 - Contexto da organização

7.5.1 Generalidades 7.5.2 Criando e atualizando 7.5.3 Controle de informação documentada Seção 8 - Operacão

8.1 Planejamento e controle operacional

8.2 Preparação e resposta a emergências

\section{Seção 9 - Avaliação de desempenho}

9.1 Monitoramento, medição, análise e avaliação

9.1.1 Generalidades

9.1.2 Avaliação dos requisitos legais e outros requisitos
Seção 9 - Avaliação de desempenho

9.1 Monitoramento, medição, análise e avaliação

9.1.1 Generalidades

9.1.2 Avaliação dos requisitos legais e outros requisitos 
continuação ...)

Figura 4 - Matriz de correspondência entre os requisitos das normas do SGI (ABNT NBR ISO 9001:2015, ABNT NBR ISO 14001:2015 e ISO 45001:2018)

\begin{tabular}{|c|c|c|}
\hline \multicolumn{3}{|c|}{ MATRIZ DE CORRESPONDÊNCIA ENTRE OS REQUISITOS DAS NORMAS ABNT NBR ISO DO SGI } \\
\hline $\begin{array}{c}\text { NBR ISO 9001:2015 } \\
\text { Seção } 4 \text { - Contexto da organização }\end{array}$ & $\begin{array}{c}\text { NBR ISO 14001:2015 } \\
\text { Seção } 4 \text { - Contexto da organização }\end{array}$ & $\begin{array}{c}\text { ISO } 45001: 2018 \\
\text { Seção } 4 \text { - Contexto da } \\
\text { organização }\end{array}$ \\
\hline \multirow{3}{*}{ 9.2 Auditoria interna } & 9.2 Auditoria interna & 9.2 Auditoria interna \\
\hline & 9.2.1 Generalidades & 9.2.1 Generalidades \\
\hline & 9.2.2 Programa de auditoria interna & $\begin{array}{l}\text { 9.2.2 Programa de auditoria } \\
\text { interna }\end{array}$ \\
\hline 9.3 Análise crítica pela direção & 9.3 Análise crítica pela direção & 9.3 Análise crítica pela direção \\
\hline Seção 10 - Melhoria & Seção 10 - Melhoria & Seção 10 - Melhoria \\
\hline 10.1 Generalidades & 10.1 Generalidades & 10.1 Generalidades \\
\hline $\begin{array}{l}10.2 \text { Não conformidade e ação } \\
\text { corretiva }\end{array}$ & $\begin{array}{l}10.2 \text { Não conformidade e ação } \\
\text { corretiva }\end{array}$ & $\begin{array}{l}10.2 \text { Não conformidade e ação } \\
\text { corretiva }\end{array}$ \\
\hline 10.3 Melhoria contínua & 10.3 Melhoria contínua & 10.3 Melhoria contínua \\
\hline
\end{tabular}

Fonte: Adaptado das normas NBR ISO 9001:2015; NBR ISO 14001:2015 e ISO 45001:2018.

Nesta matriz de correspondência das Seções e requisitos das normas de sistemas de gestão constam na estrutura da ISO 9001:2015 10 Seções e 62 requisitos; na ISO 14001:2015 10 Seções e 39 requisitos e na ISO 45001:2018 10 Seções e 39 Requisitos, para integração dos requisitos comuns e específicos no SGI.

\section{METODOLOGIA}

A metodologia utilizada quanto à estratégia de pesquisa foi uma revisão bibliográfica e pesquisa documental. A pesquisa bibliográfica se caracteriza por um levantamento de todas as informações atreladas ao assunto a ser pesquisado em artigos acadêmicos e livros reconhecidos, sendo esta prática comum a quase todos os trabalhos científicos, onde permite ao investigador uma cobertura abrangente de informações necessárias (MORETTI, 2017; GIL, 2017; MARTINS, 2016).

Já a pesquisa documental busca pesquisar material não editado, como cartas, memorandos, relatórios escritos, estudos formais, documentos administrativos, procedimentos, regulamentos, políticas e diretrizes organizacionais, cada vez mais disponíveis na internet (MARTINS, 2016; GIL (2016); YIN, 2015; VERGARA, 2015).

\section{RESULTADOS E DISCUSSÃO}

Foi realizado estudo das normas ABNT NBR ISO do SGI, livros, dissertações e artigos, com o objetivo de utilizar a estrutura das fases do ciclo PDCA e da norma NBR ISO 9001:2015 como referência, para a integração dos requisitos das Seções 4, 5, 6, 7, 8, 9 e 10 dos sistemas de gestão integrados (SGI), com os requisitos, práticas de gestão e operacionais (Figura 5), para a implementação no sistema de gestão global da organização, para fins ou não de certificação. 
Figura 5 - Correspondência entre o ciclo PDCA e as Seções das normas do SGI MATRIZ DE CORRESPONDÊNCIA ENTRE O CICLO PDCA E AS SEÇÕES DAS NORMAS DA ABNT NBR ISO DO SGI CICLO PDCA ISO $9001: 2015$

\section{ISO 14001:2015}

\begin{tabular}{|l|l|l|l|} 
& $\begin{array}{l}\text { Seção 4 - Contexto da } \\
\text { organização }\end{array}$ & $\begin{array}{l}\text { Seção 4 - Contexto da } \\
\text { organização }\end{array}$ & $\begin{array}{l}\text { Seção 4 - Contexto da } \\
\text { organização }\end{array}$ \\
\cline { 2 - 4 } $\begin{array}{l}\text { PLAN } \\
\text { (PLANEJAR) }\end{array}$ & Seção 5 - Liderança & Seção 5 - Liderança & $\begin{array}{l}\text { Seção 5 - Liderança e } \\
\text { Participação dos } \\
\text { Trabalhadores }\end{array}$ \\
\cline { 2 - 4 } & Seção 6 - Planejamento & Seção 6 - Planejamento & Seção 6 - Planejamento \\
\cline { 2 - 4 } & Seção 7 - Suporte & Seção 7 - Suporte & Seção 7 - Suporte \\
\hline DO (EXECUTAR) & Seção 8 - Operação & Seção 8 - Operação & Seção - Operação \\
\hline $\begin{array}{l}\text { CHECK } \\
\text { (VERIFICAR) }\end{array}$ & $\begin{array}{l}\text { Seção 9 - Avaliação de } \\
\text { desempenho }\end{array}$ & $\begin{array}{l}\text { Seção 9 - Avaliação de } \\
\text { desempenho }\end{array}$ & $\begin{array}{l}\text { Seçaliaça de } \\
\text { desempenho }\end{array}$ \\
\hline ACTION (AGIR) & Seção 10 - Melhoria & Seção 10 - Melhoria & Seção 10 - Melhoria \\
\hline
\end{tabular}

Fonte: Adaptado de Santos et al., 2018

\section{ISO 45001:2018}

Seção 4 - Contexto da

Seção 6 - Planejamento

Seção 10 - Melhoria

A correspondência entre o ciclo PDCA, seções e requisitos das normas dos sistemas de gestão integrados (SGI), em uma matriz de correspondência, torna-se relevante para a definição de uma estrutura padrão, para elaborar instrumento de coleta de dados de diagnóstico e/ou avaliação de desempenho de SGI, lista de verificação ou Boletim Diário de Operação (BDO), para monitoramento e medição na organização.

A Seção 4 e requisitos 4.1 a 4.4 do SGI (Figura 6) aborda o planejamento de um sistema de gestão e de autoconhecimento de uma organização, quanto ao contexto, identificar necessidades de partes interessadas, aos processos com as sequências e interações, métodos, medição, indicadores de desempenho e definição do escopo, para atendimento do SGI.

Figura 6 - Matriz de integração do ciclo PDCA, comas seções e requisitos das normas NBR ISO no SGI , com práticas de gestão e operacional

\begin{tabular}{|c|c|c|c|c|}
\hline \multicolumn{5}{|c|}{$\begin{array}{c}\text { MATRIZ DE INTEGRAÇÃO DO CICLO PDCA, SEÇÕES E REQUISITOS DAS NORMAS ABNT NBR ISO DO SGI E } \\
\text { PRÁTICAS DE GESTÃO E OPERACIONAL }\end{array}$} \\
\hline $\begin{array}{l}\text { CICLO } \\
\text { PDCA }\end{array}$ & $\begin{array}{l}\text { NORMA } \\
\text { ABNT NBR } \\
\text { ISO }\end{array}$ & $\begin{array}{l}\text { № DO } \\
\text { REQ. }\end{array}$ & \multirow{2}{*}{$\begin{array}{l}\text { REQUISITOS DO SGI } \\
\text { SEÇÃO } 4 \text { - CONTEXTO DA } \\
\text { ORGANIZAÇÃO }\end{array}$} & PRÁTICAS DE GESTÃO E OPERACIONAL \\
\hline PLAN & QMS\&ST & 4 & & \\
\hline \multirow{3}{*}{ PLAN } & \multirow{3}{*}{ QMS\&ST } & \multirow{3}{*}{4.1} & \multirow{3}{*}{$\begin{array}{l}\text { Entendendo a organização } \\
\text { e seu contexto }\end{array}$} & $\begin{array}{l}\text { A organização realiza análise com matriz SWOT } \\
\text { / FOFA e PESTAL, para entender o seu contexto } \\
\text { interno e externo. }\end{array}$ \\
\hline & & & & $\begin{array}{l}\text { - A organização determina as questões internas e } \\
\text { externas, para definicão de objetivos do SGI. }\end{array}$ \\
\hline & & & & $\begin{array}{l}\text { - A organização monitora as questões internas e } \\
\text { externas definidas nos objetivos do SGI. }\end{array}$ \\
\hline \multirow{2}{*}{ PLAN } & \multirow{2}{*}{ QMS\&ST } & \multirow{2}{*}{4.2} & \multirow{2}{*}{$\begin{array}{l}\text { Entendendo as } \\
\text { necessidades e } \\
\text { expectativas de partes } \\
\text { interessadas }\end{array}$} & $\begin{array}{l}\text { A organização determina as necessidades } \\
\text { e expectativas da força de trabalho. }\end{array}$ \\
\hline & & & & $\begin{array}{l}\text { A organização determina as necessidades } \\
\text { e expectativas das demais partes interessadas. }\end{array}$ \\
\hline \multirow[t]{2}{*}{ PLAN } & \multirow[t]{2}{*}{ QMS\&ST } & \multirow[t]{2}{*}{4.3} & \multirow{2}{*}{$\begin{array}{l}\text { Determinando o escopo } \\
\text { do sistema de gestão da } \\
\text { qualidade, ambiental e } \\
\text { segurança e saúde no } \\
\text { trabalho (SGI) }\end{array}$} & $\begin{array}{l}\text { Na definição do escopo do SGI a } \\
\text { organização considera as questões internas e } \\
\text { externas, as partes interessadas, os seus produtos } \\
\text { e serviços. }\end{array}$ \\
\hline & & & & $\begin{array}{l}\text { O escopo do SGI está disponível e } \\
\text { mantido como informação documentado }\end{array}$ \\
\hline \multirow{3}{*}{ PLAN } & \multirow{3}{*}{ QMS\&ST } & \multirow{3}{*}{4.4} & \multirow{3}{*}{$\begin{array}{l}\text { Sistemas de gestão da } \\
\text { qualidade, ambiental, } \\
\text { segurança e saúde no } \\
\text { trabalho (SGI) e seus } \\
\text { processos }\end{array}$} & $\begin{array}{l}\text { Os processos necessários, a sua sequência } \\
\text { e interações são estabelecidas no SGI. }\end{array}$ \\
\hline & & & & $\begin{array}{l}\text { A organização define os critérios para a } \\
\text { gestão, as atribuições e responsabilidades, os } \\
\text { recursos, métodos, as medições e os indicadores } \\
\text { de desempenho, para garantir o funcionamento e } \\
\text { controle eficaz do SGI. }\end{array}$ \\
\hline & & & & $\begin{array}{l}\text { A organização avalia os riscos, as } \\
\text { oportunidades e avaliados os processos para } \\
\text { assegurar o alcance dos resultados pretendidos. }\end{array}$ \\
\hline
\end{tabular}


Para análise interna e externa no requisito 4.1 a organização necessita definir um grupo de trabalho (GT) multidisciplinar de especialistas, para realizar análise externa (SWOT/PESTAL): política, econômica, social, tecnológica, ambiental e legal no mercado onde atua ou pretende atuar. E na análise interna a organização deve adotar métodos formais qualitativos ou quantitativos, como: matriz SWOT/FOFA/PESTAL, GUT, APR, HAZOP, FMEA e outros (CARPINETTI e GEROLAMO, 2016; SANTOS, et al, 2018; BERTOLINO e COUTO, 2018).

Na Seção 5 e requisitos 5.1 a 5.4 a liderança estabelece compromissos, disponibiliza os recursos, consulta e participação dos trabalhadores, com definição da visão, missão, valores, comportamentos esperados, princípios de negócio, responsabilidades pela eficácia do SGI, estabelecendo uma política integrada e objetivos compatíveis com as questões externas e internas, propósitos da organização e com abordagem por processo.

\begin{tabular}{|c|c|c|c|c|}
\hline $\begin{array}{l}\text { CICLO } \\
\text { PDCA } \\
\text { PLAN }\end{array}$ & $\begin{array}{l}\text { NORMA } \\
\text { ABNT NBR } \\
\text { ISSO } \\
\text { QMS\&ST }\end{array}$ & $\begin{array}{l}\text { № DO } \\
\text { REQ. }\end{array}$ & $\begin{array}{l}\text { REQUISITOS DO } \\
\text { SGI } \\
\text { SEÇÃO } 5 \text { - } \\
\text { LIDERANÇA }\end{array}$ & PRÁTICAS DE GESTÃO E OPERACIONAL \\
\hline \multirow[b]{2}{*}{ PLAN } & QMS\&ST & \multirow[b]{2}{*}{5.1} & \multirow[b]{2}{*}{$\begin{array}{l}\text { Liderança e } \\
\text { comprometimento }\end{array}$} & $\begin{array}{l}\text { - A alta direção demonstra liderança e } \\
\text { comprometimento com relação ao SGI. }\end{array}$ \\
\hline & S\&ST & & & $\begin{array}{l}\text { A alta direção protege os trabalhadores de } \\
\text { represálias ao relatar incidentes, perigos, riscos e } \\
\text { oportunidades. }\end{array}$ \\
\hline \multirow{5}{*}{ PLAN } & \multirow{5}{*}{ QMS\&ST } & \multirow{5}{*}{5.1 .1} & \multirow{5}{*}{ Generalidades } & $\begin{array}{l}\text { A alta direção responsabiliza-se pela eficácia } \\
\text { do SGI. }\end{array}$ \\
\hline & & & & $\begin{array}{l}\text { A alta direção promove o uso da abordagem } \\
\text { de processo e da mentalidade de risco. }\end{array}$ \\
\hline & & & & $\begin{array}{l}\text { A alta direção assegura e disponibiliza os } \\
\text { recursos necessários para o SGI. }\end{array}$ \\
\hline & & & & $\begin{array}{l}\text { A alta direção comunica a importância de } \\
\text { uma gestão eficaz e de estar conforme com aos } \\
\text { requisitos do SGI. }\end{array}$ \\
\hline & & & & $\begin{array}{l}\text { A alta direção assegura que o SGI alcance } \\
\text { seus resultados pretendidos e a melhoria contínua. }\end{array}$ \\
\hline \multirow{10}{*}{ PLAN } & Q & \multirow{10}{*}{5.1 .2} & \multirow{10}{*}{$\begin{array}{l}\text { Foco no cliente, } \\
\text { ambiental, } \\
\text { segurança e saúde } \\
\text { no trabalho }\end{array}$} & $\begin{array}{l}\text { Os requisitos do cliente, e os requisitos } \\
\text { estatutários e regulamentares pertinentes são } \\
\text { determinados na organização. }\end{array}$ \\
\hline & Q & & & $\begin{array}{l}\text { Os requisitos do cliente e os requisitos } \\
\text { estatutários e regulamentares pertinentes são } \\
\text { comunicados em toda organização. }\end{array}$ \\
\hline & Q & & & $\begin{array}{l}\text { Os requisitos do cliente e os requisitos } \\
\text { estatutários e regulamentares pertinentes são } \\
\text { atendidos na organização. }\end{array}$ \\
\hline & M & & & $\begin{array}{l}\text { Os requisitos ambientais são determinados } \\
\text { na organização. }\end{array}$ \\
\hline & M & & & $\begin{array}{l}\text { Os requisitos ambientais são comunicados } \\
\text { em toda organização. }\end{array}$ \\
\hline & M & & & $\begin{array}{l}\text { Os requisitos ambientais são atendidos na } \\
\text { organização. }\end{array}$ \\
\hline & S\&ST & & & $\begin{array}{l}\text { Os requisitos de segurança e saúde no } \\
\text { trabalho são determinados na organização. }\end{array}$ \\
\hline & S\&ST & & & $\begin{array}{l}\text { Os requisitos de segurança e saúde no } \\
\text { trabalho são comunicados em toda organização. }\end{array}$ \\
\hline & S\&ST & & & $\begin{array}{l}\text { Os requisitos de segurança e saúde no } \\
\text { trabalho são atendidos na organização. }\end{array}$ \\
\hline & QMS\&ST & & & $\begin{array}{l}\text { A organização determina e aborda os riscos e } \\
\text { oportunidades que possam afetar a conformidade de } \\
\text { produtos e serviços e a capacidade de aumentar a } \\
\text { satisfação das partes interessadas. }\end{array}$ \\
\hline
\end{tabular}




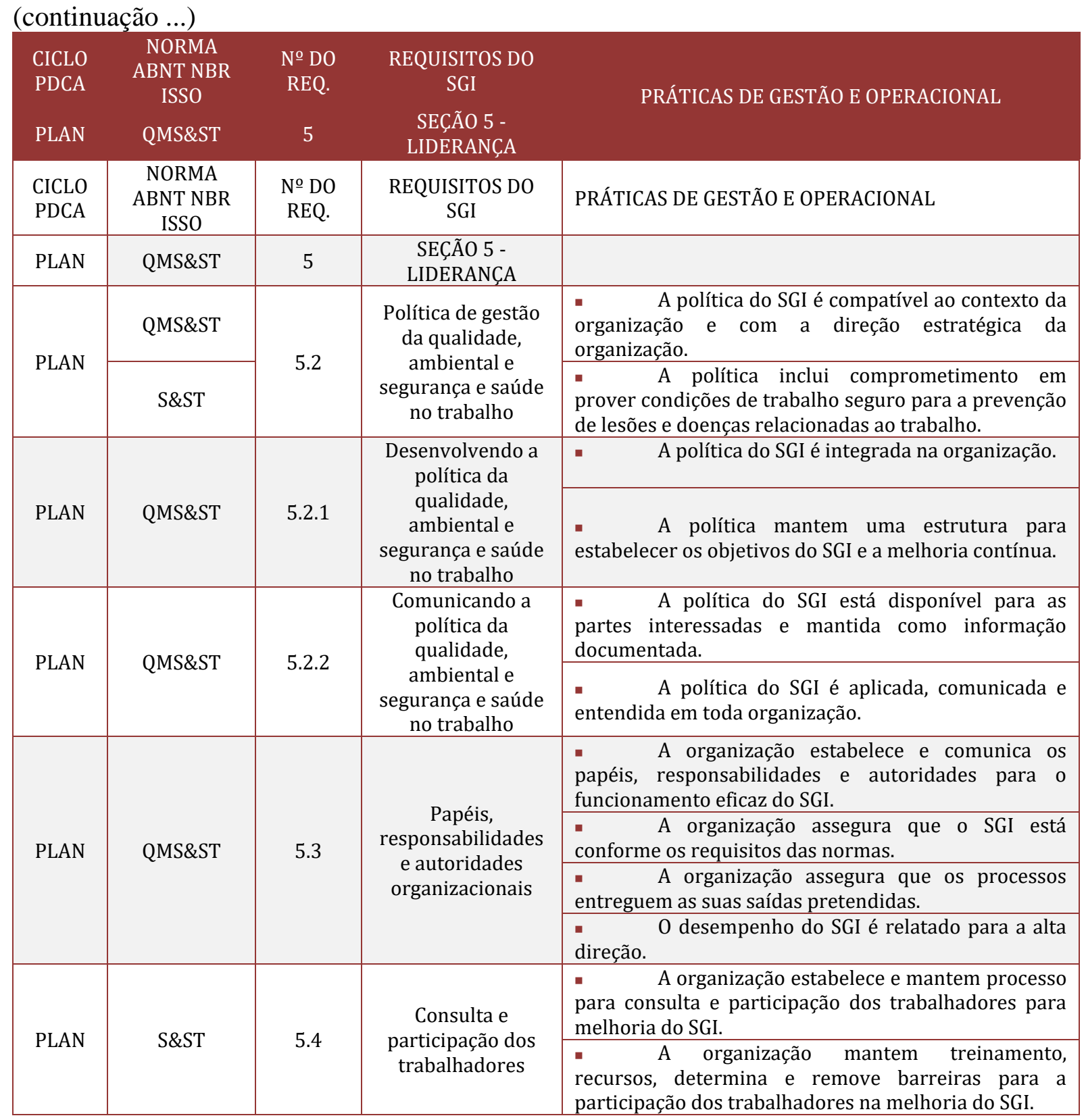

No requisito 5.1.2, a liderança deve assegurar o atendimento dos requisitosdo cliente e as demais partes interessadas, estatutários e regulamentares, abordar os riscos e oportunidades que possam afetar a conformidade dos produtos e serviços, definir e comunicar responsabilidades e autoridades organizacionais, para assegurar a conformidade com os requisitos do SGI (SANTOS, et al, 2018; BERTOLINO e COUTO, 2018).

Na Seção 6 e requisitos 6.1 a 6.3 aborda-se no planejamento a necessidade de identificar e avaliar os requisitos legais, riscos (efeito da incerteza) e as oportunidades, os aspectos, impactos, perigos, riscos e ações de controle, onde o efeito pode ser positivo ou negativo, de origem das questões externas e internas da organização e das necessidades das partes interessadas, com definição e comunicação dos objetivos do SGI, planejamento de ações para o SGI e para as mudanças. 


\begin{tabular}{|c|c|c|c|c|}
\hline $\begin{array}{l}\text { CICLO } \\
\text { PDCA }\end{array}$ & $\begin{array}{l}\text { NORMA } \\
\text { ABNT NBR } \\
\quad \text { ISO }\end{array}$ & $\begin{array}{l}\text { № } \\
\text { DO } \\
\text { REQ. }\end{array}$ & \multirow{2}{*}{$\begin{array}{l}\text { REQUISITOS DO SGI } \\
\text { SEÇÃO } 6 \text { - } \\
\text { PLANEJAMENTO }\end{array}$} & PRÁTICAS DE GESTÃO E OPERACIONAL \\
\hline PLAN & QMS\&ST & 6 & & \\
\hline \multirow{3}{*}{ PLAN } & \multirow{3}{*}{ QMS\&ST } & \multirow{3}{*}{6.1} & \multirow{3}{*}{$\begin{array}{l}\text { Ações para abordar } \\
\text { riscos e } \\
\text { oportunidades }\end{array}$} & $\begin{array}{l}\text { - A organização define as ações para abordar os riscos e } \\
\text { oportunidades e aumentou os efeitos desejáveis, para } \\
\text { garantir os resultados esperados no SGI. }\end{array}$ \\
\hline & & & & $\begin{array}{l}\text { - A organização previne os efeitos indesejáveis e } \\
\text { aumentou os efeitos desejáveis, para garantir os resultados } \\
\text { esperados e a melhoria contínua no SGI. }\end{array}$ \\
\hline & & & & $\begin{array}{l}\text { - A organização avalia a eficácia das ações para abordar os } \\
\text { riscos e oportunidades. }\end{array}$ \\
\hline \multirow{3}{*}{ PLAN } & \multirow{3}{*}{ MS\&ST } & \multirow{3}{*}{6.1 .1} & \multirow{3}{*}{ Generalidades } & $\begin{array}{l}\text { - A organização considera as questões externas e internas, } \\
\text { os requisitos das partes interessadas, determina e avalia os } \\
\text { riscos e oportunidades que precisam ser abordados no SGI. }\end{array}$ \\
\hline & & & & $\begin{array}{l}\text { - A organização mantem informação documentada sobre } \\
\text { riscos e oportunidade, processos e ações necessárias para } \\
\text { abordá-las. }\end{array}$ \\
\hline & & & & $\begin{array}{l}\text { - A organização fez a integração das ações para tratar os } \\
\text { riscos e oportunidades para os processos do SGI. }\end{array}$ \\
\hline \multirow{4}{*}{ PLAN } & \multirow{3}{*}{ MS\&ST } & \multirow{4}{*}{6.1 .2} & \multirow{3}{*}{$\begin{array}{l}\text { Aspectos } \\
\text { ambientais e } \\
\text { Perigos e riscos }\end{array}$} & $\begin{array}{l}\text { Os aspectos, impactos, perigos e riscos foram } \\
\text { identificados. }\end{array}$ \\
\hline & & & & $\begin{array}{l}\text { - Na identificação dos perigos são consideradas atividades } \\
\text { rotineiras e não rotineiras, incidentes, emergências, fatores } \\
\text { humanos, sociais e mudanças. }\end{array}$ \\
\hline & & & & $\begin{array}{l}\text { - A organização mantem informações documentadas dos } \\
\text { aspectos e impactos ambientais significativos e de perigos } \\
\text { e riscos de S\&ST. }\end{array}$ \\
\hline & S\&ST & & $\begin{array}{l}\text { Avaliação de riscos } \\
\text { e oportunidades de } \\
\text { S\&ST }\end{array}$ & $\begin{array}{l}\text { - A organização determina e avalia os riscos e } \\
\text { oportunidades de S\&ST. }\end{array}$ \\
\hline \multirow{2}{*}{ PLAN } & QMS\&ST & \multirow{2}{*}{6.1 .3} & \multirow{2}{*}{$\begin{array}{l}\text { Requisitos legais e } \\
\text { outros requisitos }\end{array}$} & $\begin{array}{l}\text { Os requisitos legais e outros requisitos são atendidos no } \\
\text { SGI. }\end{array}$ \\
\hline & MS\&ST & & & $\begin{array}{l}\text { - A organização mantem informação documentada sobre } \\
\text { seus requisitos legais e outros requisitos }\end{array}$ \\
\hline \multirow{2}{*}{ PLAN } & \multirow{2}{*}{ QMS\&ST } & \multirow{2}{*}{6.1 .4} & \multirow{2}{*}{$\begin{array}{l}\text { Planejamento de } \\
\text { ações }\end{array}$} & $\begin{array}{l}\text { - A organização planeja as ações de controle para os } \\
\text { aspectos, impactos, perigos e riscos das atividades. }\end{array}$ \\
\hline & & & & $\begin{array}{l}\text { - A organização planeja as ações para atender aos } \\
\text { requisitos legais e outros requisitos do SGI }\end{array}$ \\
\hline \multirow{4}{*}{ PLAN } & \multirow{4}{*}{ QMS\&ST } & \multirow{4}{*}{$\begin{array}{l}6.2 \\
/ \\
6.2 .1\end{array}$} & \multirow{4}{*}{$\begin{array}{c}\text { Objetivos da } \\
\text { qualidade, } \\
\text { ambientais, } \\
\text { segurança e da } \\
\text { saúde no trabalho } \\
\text { (SGI), e } \\
\text { planejamento para } \\
\text { alcançá-los }\end{array}$} & $\begin{array}{l}\text { - Os objetivos do SGI foram planejados conforme a direção } \\
\text { estratégica da organização. }\end{array}$ \\
\hline & & & & $\begin{array}{l}\text { - Os objetivos do SGI foram planejados em níveis } \\
\text { relevantes de departamento e individual para a } \\
\text { organização. }\end{array}$ \\
\hline & & & & $\begin{array}{l}\text { - Os objetivos do SGI foram comunicados em toda } \\
\text { organização. }\end{array}$ \\
\hline & & & & $\begin{array}{l}\text { - Os objetivos do SGI estão mantidos como informação } \\
\text { documentada. }\end{array}$ \\
\hline PLAN & QMS\&ST & 6.2 .2 & $\begin{array}{l}\text { Planejamento de } \\
\text { ações para atingir } \\
\text { os objetivos do SGI }\end{array}$ & $\begin{array}{l}\text { - A organização planeja recursos, ações, responsáveis e } \\
\text { prazos para atingir os objetivos do SGI e os resultados são } \\
\text { avaliados e atendidos. }\end{array}$ \\
\hline PLAN & Q & 6.3 & $\begin{array}{l}\text { Planejamento de } \\
\text { mudanças }\end{array}$ & $\begin{array}{l}\text { - A organização define processo de implementação e } \\
\text { gestão de mudança, disponibilidade de recursos e definição } \\
\text { de responsabilidades e autoridades, para garantir a } \\
\text { integridade do SGQ. }\end{array}$ \\
\hline
\end{tabular}

Ainda nesta fase nos requisitos 6.1 à 6.3 a organização necessita analisar os processos, as atividades, tarefas, funções, produtos, serviços, para identificar os aspectos e impactos ambientais, perigos, riscos e oportunidades de segurança e saúde no trabalho, requisitos legais e outros requisitos, com definição dos objetivos e metas do SGI compatíveis com a política integrada e manter informação documentada (SANTOS, et al, 2018; BERTOLINO e COUTO, 2018). 
Na Seção 7 e requisitos 7.1 a 7.4 à liderança deve garantir os recursos para a implementação, manutenção e melhoria do sistema de gestão integrado, com orientação e direção para atingir resultados, com necessidade de treinamento e qualificação de pessoal, com competências e habilidades, infraestrutura e ambiente para executar tarefas, sistema de monitoramento, e medição, comunicação, entre outros.

\begin{tabular}{|c|c|c|c|c|}
\hline $\begin{array}{l}\text { CICLO } \\
\text { PDCA }\end{array}$ & $\begin{array}{l}\text { NORMA } \\
\text { ABNT NBR } \\
\quad \text { ISO }\end{array}$ & $\begin{array}{l}\text { № DO } \\
\text { REQ. }\end{array}$ & \multirow{2}{*}{$\begin{array}{l}\text { REQUISITOS } \\
\text { DO SGI } \\
\text { SEÇÃO } 7 \text { - } \\
\text { APOIO }\end{array}$} & \multirow{2}{*}{ PRÁTICAS DE GESTÃO E OPERACIONAL } \\
\hline PLAN & QMS\&ST & 7 & & \\
\hline PLAN & QMS\&ST & 7.1 & Recursos & $\begin{array}{l}\text { A organização mantem recursos necessários para } \\
\text { a implementação, manutenção e melhoria contínua do SGI. }\end{array}$ \\
\hline \multirow{2}{*}{ PLAN } & \multirow[t]{2}{*}{ QMS\&ST } & \multirow{2}{*}{7.1 .1} & \multirow{2}{*}{ Generalidades } & $\begin{array}{l}\text { A organização considera as capacidades e } \\
\text { restrições de recursos internos existentes para atender o } \\
\text { SGI. }\end{array}$ \\
\hline & & & & $\begin{array}{l}\text { A organização considera recursos de provedores } \\
\text { externos para atender ao SGI. }\end{array}$ \\
\hline PLAN & QMS\&ST & 7.1 .2 & Pessoas & $\begin{array}{l}\text { A organização mantem pessoas necessários, para } \\
\text { implementar, manter e melhorar o SGI. }\end{array}$ \\
\hline PLAN & QMS\&ST & 7.1 .3 & Infraestrutura & $\begin{array}{l}\text { A organização fornece os recursos de } \\
\text { infraestrutura necessários, para implementar, manter e } \\
\text { melhorar o SGI. }\end{array}$ \\
\hline PLAN & QMS\&ST & 7.1 .4 & $\begin{array}{l}\text { Ambiente para } \\
\text { a operação dos } \\
\text { processos }\end{array}$ & $\begin{array}{l}\text { A organização mantem um ambiente necessário, } \\
\text { para a operação dos seus processos. }\end{array}$ \\
\hline \multirow{3}{*}{ PLAN } & QMS\&ST & \multirow{3}{*}{7.1 .5} & \multirow{3}{*}{$\begin{array}{l}\text { Recursos de } \\
\text { monitorament } \\
\text { o e medição }\end{array}$} & $\begin{array}{l}\text { A organização fornece os recursos de } \\
\text { monitoramento e medição necessários, para comprovar a } \\
\text { conformidade dos produtos e serviços. }\end{array}$ \\
\hline & \multirow{2}{*}{ Q } & & & $\begin{array}{l}\text { Os equipamentos de medição estão identificados, } \\
\text { calibrados e rastreáveis. }\end{array}$ \\
\hline & & & & $\begin{array}{l}\text { Os recursos de medição e a base de calibração do } \\
\text { equipamento estão retidos como informação documentada. }\end{array}$ \\
\hline \multirow{4}{*}{ PLAN } & \multirow{4}{*}{ QMS\&ST } & \multirow{4}{*}{7.1 .6} & \multirow{4}{*}{$\begin{array}{l}\text { Conhecimento } \\
\text { organizacional }\end{array}$} & $\begin{array}{l}\text { A organização determina o conhecimento } \\
\text { necessário, para a operação dos seus processos. }\end{array}$ \\
\hline & & & & $\begin{array}{l}\text { A organização determina } 0 \text { conhecimento } \\
\text { necessário, para a conformidade de seus produtos e } \\
\text { serviços. }\end{array}$ \\
\hline & & & & $\begin{array}{l}\text { A organização mantem e disponibiliza } \quad \text { o } \\
\text { conhecimento organizacional. }\end{array}$ \\
\hline & & & & $\begin{array}{l}\text { A organização mantem processo de lições } \\
\text { aprendidas. }\end{array}$ \\
\hline \multirow{5}{*}{ PLAN } & \multirow{5}{*}{ QMS\&ST } & \multirow{5}{*}{7.2} & \multirow{5}{*}{ Competência } & $\begin{array}{l}\text { A organização determina a competência dos } \\
\text { colaboradores que podem afetar o SGI. }\end{array}$ \\
\hline & & & & $\begin{array}{l}\text { A organização assegura que os colaboradores são } \\
\text { competentes com base na formação, treinamento ou } \\
\text { experiência. }\end{array}$ \\
\hline & & & & $\begin{array}{l}\text { A organização toma medidas para assegurar que } \\
\text { os colaboradores possam adquirir as competências } \\
\text { necessárias. }\end{array}$ \\
\hline & & & & $\begin{array}{l}\text { A organização avalia a eficácia das ações tomadas } \\
\text { para a competência dos colaboradores. }\end{array}$ \\
\hline & & & & $\begin{array}{l}\text { A organização retém informação documentada, } \\
\text { apropriada como evidência de competência dos } \\
\text { colaboradores. }\end{array}$ \\
\hline \multirow{3}{*}{ PLAN } & \multirow{3}{*}{ QMS\&ST } & \multirow{3}{*}{7.3} & \multirow{3}{*}{$\begin{array}{l}\text { Conscientizaçã } \\
\text { o }\end{array}$} & $\begin{array}{l}\text { A organização assegura que os colaboradores } \\
\text { estejam conscientes da política do SGI. }\end{array}$ \\
\hline & & & & $\begin{array}{l}\text { A organização assegura que os colaboradores } \\
\text { estejam conscientes dos objetivos do SGI. }\end{array}$ \\
\hline & & & & $\begin{array}{l}\text { A organização assegura que os colaboradores } \\
\text { estejam conscientes da sua contribuição para a eficácia do } \\
\text { SGI. }\end{array}$ \\
\hline PLAN & QMS\&ST & 7.4 & Comunicação & $\begin{array}{l}\text { A organização determina as comunicações } \\
\text { internas e externas pertinentes para o SGI. }\end{array}$ \\
\hline
\end{tabular}


Na Seção 7, os requisitos 7.1 à 7.4 definem a necessidade de recursos para garantir o atendimento dos requisitos do SGI, como materiais, insumos, força de trabalho, procedimentos, conhecimento organizacional, competências, programas de conscientização, infraestrutura, sistema de monitoramento e medição e de avaliação da eficácia e outros (CARPINETTI e GEROLAMO, 2016; SANTOS, et al, 2018; BERTOLINO e COUTO, 2018).

Os requisitos 7.4.1 a 7.5.3 caracteriza o processo de comunicação interna para a conscientização da força de trabalho, e externa para as demais partes interessadas, sendo estratégico na organização, para a divulgação da política, objetivos e escopo do SGI, as responsabilidades e autoridades, processos internos, procedimentos de gestão e operacional, instrução de trabalho e registros.

\begin{tabular}{|c|c|c|c|c|}
\hline \multicolumn{5}{|c|}{ CONTINUAÇÃO DA SEÇÃO 7 - APOIO } \\
\hline \multirow{4}{*}{ PLAN } & \multirow{4}{*}{ QMS\&ST } & \multirow{4}{*}{ 7.4.1 } & \multirow{4}{*}{ Generalidades } & $\begin{array}{l}\text { A organização estabelece o(s) seu(s) processo(s) } \\
\text { de comunicação do SGI, levando em consideração seus } \\
\text { requisitos legais e outros requisitos. }\end{array}$ \\
\hline & & & & $\begin{array}{l}\text { A organização estabelece o(s) seu(s) processo(s) } \\
\text { de comunicação do SGI, assegurando que a informação } \\
\text { comunicada seja confiável. }\end{array}$ \\
\hline & & & & $\begin{array}{l}\text { A organização responde as comunicações } \\
\text { pertinentes, referentes ao seu SGI. }\end{array}$ \\
\hline & & & & $\begin{array}{l}\text { A organização retém informação documentada } \\
\text { como evidência de suas comunicações. }\end{array}$ \\
\hline \multirow[t]{2}{*}{ PLAN } & \multirow[t]{2}{*}{ MS\&ST } & \multirow[t]{2}{*}{7.4 .2} & \multirow{2}{*}{$\begin{array}{l}\text { Comunicação } \\
\text { interna }\end{array}$} & $\begin{array}{l}\text { A organização comunica internamente as } \\
\text { informações pertinentes para o SGI entre os diversos } \\
\text { níveis e funções da organização. }\end{array}$ \\
\hline & & & & $\begin{array}{l}\text { A organização comunica internamente as } \\
\text { mudanças no SGI, como apropriado. }\end{array}$ \\
\hline PLAN & MS\&ST & 7.4.3 & $\begin{array}{l}\text { Comunicação } \\
\text { externa }\end{array}$ & $\begin{array}{l}\text { A organização comunica externamente as } \\
\text { informações pertinentes para o SGI, como estabelecido } \\
\text { pelo (s) processo (s) de comunicação da organização e } \\
\text { como requerido por seus requisitos legais e outros } \\
\text { requisitos. }\end{array}$ \\
\hline PLAN & QMS\&ST & 7.5 & $\begin{array}{l}\text { Informação } \\
\text { documentada }\end{array}$ & $\begin{array}{l}\text { A organização determina as informações } \\
\text { necessárias para a implementação eficaz e funcionamento } \\
\text { do SGI. }\end{array}$ \\
\hline \multirow[b]{2}{*}{ PLAN } & \multirow[b]{2}{*}{ QMS\&ST } & \multirow[b]{2}{*}{ 7.5.1 } & \multirow[b]{2}{*}{ Generalidades } & $\begin{array}{l}\text { O SGI inclui informação documentada, conforme } \\
\text { requeridas pelas normas. }\end{array}$ \\
\hline & & & & $\begin{array}{l}\text { A organização determina a informação } \\
\text { documentada, como sendo necessária para a eficácia do } \\
\text { SGI. }\end{array}$ \\
\hline PLAN & QMS\&ST & 7.5 .2 & $\begin{array}{ll}\text { Criando } & \mathrm{e} \\
\text { atualizando } & \end{array}$ & $\begin{array}{l}\text { A organização cria e atualiza a informação } \\
\text { documentada, assegura a identificação, descrição, o } \\
\text { formato, a análise crítica e a aprovação. }\end{array}$ \\
\hline \multirow[b]{2}{*}{ PLAN } & \multirow[b]{2}{*}{ QMS\&ST } & \multirow[b]{2}{*}{ 7.5.3 } & \multirow[b]{2}{*}{$\begin{array}{l}\text { Controle de } \\
\text { informação } \\
\text { documentada }\end{array}$} & 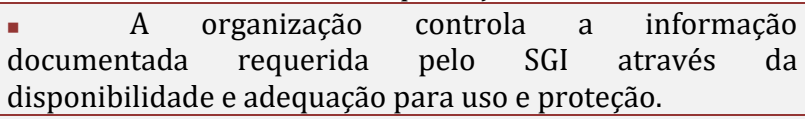 \\
\hline & & & & $\begin{array}{l}\text { A organização controla a informação } \\
\text { documentada requerida pelo SGI através da abordagem } \\
\text { das atividades de distribuição, acesso, recuperação, uso, } \\
\text { armazenamento, preservação, controle de alterações, } \\
\text { retenção e disposição. }\end{array}$ \\
\hline
\end{tabular}

Nos requisitos 7.4.1 a 7.5.3 a organização deve desenvolver e implementar um processo de comunicação do SGI, disponibilizar, divulgar e fazer cumprir a política do SGI junto a força de trabalho, além de realizar a comunicação interna e externa para as demais partes interessadas, com a manutenção, retenção, disponibilidade e controle de informação documentada (SANTOS, et al., 2018; BERTOLINO e COUTO, 2018).

Na Seção 8 Operação consta nos requisitos 8.1 a 8.2 .1 a necessidade de planejamento e controle operacional, através de como executar as atividades, com os limites de controle, a partir de padrões de desempenho em SGI e comunicação com clientes, estabelecidos pela organização e negociados com as 
partes interessadas, com processo de preparação e respostas a emergências, manutenção e retenção de informação documentada.

\begin{tabular}{|c|c|c|c|c|}
\hline $\begin{array}{l}\text { CICLO } \\
\text { PDCA }\end{array}$ & $\begin{array}{l}\text { NORMA } \\
\text { ABNT } \\
\text { NBR ISO }\end{array}$ & $\begin{array}{c}\text { № } \\
\text { DO } \\
\text { REQ. }\end{array}$ & \multirow{2}{*}{$\begin{array}{l}\text { REQUISITOS } \\
\text { DO SGI } \\
\text { SEÇÃO } 8 \text { - } \\
\text { OPERAÇÃO }\end{array}$} & \multirow[t]{2}{*}{ PRÁTICAS DE GESTÃO E OPERACIONAL } \\
\hline DO & QMS\&ST & 8 & & \\
\hline DO & Q & \multirow{6}{*}{8.1} & \multirow{6}{*}{$\begin{array}{l}\text { Planejamento } \\
\text { e controle } \\
\text { operacionais }\end{array}$} & $\begin{array}{l}\text { A organização define processo de planejamento e } \\
\text { controle operacional para o fornecimento de produtos e serviços, } \\
\text { que atendam aos requisitos do cliente. }\end{array}$ \\
\hline \multirow{5}{*}{ DO } & \multirow{5}{*}{ QMS\&ST } & & & $\begin{array}{l}\text { A organização estabelece critérios operacionais para } \\
\mathrm{o}(\mathrm{s}) \text { processo(s). }\end{array}$ \\
\hline & & & & $\begin{array}{l}\text { A organização implementa controle de processo(s), de } \\
\text { acordo com os critérios operacionais. }\end{array}$ \\
\hline & & & & $\begin{array}{l}\text { A organização controla as mudanças planejadas e } \\
\text { analisa criticamente as consequências de mudanças não } \\
\text { intencionais, tomando ações para mitigar quaisquer efeitos } \\
\text { adversos. }\end{array}$ \\
\hline & & & & $\begin{array}{l}\text { A organização assegura que a saída do planejamento } \\
\text { deve ser adequada as operações. }\end{array}$ \\
\hline & & & & $\begin{array}{l}\text { A organização assegura que os processos terceirizados } \\
\text { sejam controlados. }\end{array}$ \\
\hline \multirow{7}{*}{ DO } & \multirow{7}{*}{ MS\&ST } & \multirow{7}{*}{8.2} & \multirow{7}{*}{$\begin{array}{l}\text { Preparação e } \\
\text { resposta a } \\
\text { emergências }\end{array}$} & $\begin{array}{l}\text { A organização implementa e mantém o(s) processo(s) } \\
\text { necessário(s) para preparar-se e responder a potenciais } \\
\text { situações de emergências identificadas. }\end{array}$ \\
\hline & & & & $\begin{array}{l}\text { A organização prepara-se para responder pelo } \\
\text { planejamento de ações para prevenir ou mitigar impactos } \\
\text { ambientais adversos de situações de emergências e responder a } \\
\text { situações de emergências reais. }\end{array}$ \\
\hline & & & & $\begin{array}{l}\text { A organização toma ações para prevenir ou mitigar as } \\
\text { consequências decorrentes de situações de emergência. }\end{array}$ \\
\hline & & & & $\begin{array}{l}\text { A organização testa periodicamente as ações de } \\
\text { resposta planejadas, onde viável. }\end{array}$ \\
\hline & & & & $\begin{array}{l}\text { A organização periodicamente, analisa criticamente e } \\
\text { revisa o(s) processo(s) e as ações de resposta planejadas, em } \\
\text { particular, após a ocorrência de situações de emergência ou } \\
\text { testes. }\end{array}$ \\
\hline & & & & $\begin{array}{l}\text { A organização provem informações pertinentes e } \\
\text { treinamento relacionado à preparação e resposta a emergências, } \\
\text { incluindo pessoas que realizam trabalhos sob o seu controle. }\end{array}$ \\
\hline & & & & $\begin{array}{l}\text { A organização mantém informação documentada na } \\
\text { extensão necessária, para ter confiança de que o(s) processo(s) } \\
\text { seja(m) realizado(s) conforme planejado(s). }\end{array}$ \\
\hline DO & Q & 8.2 & $\begin{array}{l}\text { Requisitos } \\
\text { para produtos } \\
\text { e serviços }\end{array}$ & $\begin{array}{l}\text { A organização define processo que estabelece o } \\
\text { fornecimento de produtos e serviços, que atendam aos requisitos } \\
\text { do cliente. }\end{array}$ \\
\hline \multirow{2}{*}{ DO } & \multirow{2}{*}{ Q } & \multirow{2}{*}{ 8.2.1 } & \multirow{2}{*}{$\begin{array}{l}\text { Comunicação } \\
\text { com o cliente }\end{array}$} & $\begin{array}{l}\text { A organização tem um processo definido de revisar e } \\
\text { comunicar-se com os clientes em relação às informações } \\
\text { relativas dos produtos e serviços. }\end{array}$ \\
\hline & & & & $\begin{array}{l}\text { A organização revisa as informações relativas aos } \\
\text { produtos e serviços antes dos compromissos de fornecer os } \\
\text { produtos e serviços aos clientes. }\end{array}$ \\
\hline
\end{tabular}

Para os requisitos 8.1 à 8.2.1 a organização deve planejar as atividades e tarefas operacionais, comunicarse com os clientes sobre informações de produtos e serviços e revisar quando necessário antes do fornecimento, assim como está preparado e em prontidão para a resposta a emergências (CARPINETTI e GEROLAMO, 2016; SANTOS, et al, 2018; BERTOLINO e COUTO, 2018).

Nos requisitos 8.2.2 a 8.3.2 observa-se a necessidade da definição e análise crítica dos requisitos do cliente para os produtos e serviços, assim como de gestão de mudança para alteração desses requisitos, no projeto e desenvolvimento para provisão de produtos e serviços, com análise crítica, controle de interface 
entre pessoas e atividades de verificação e validação, recursos disponíveis e níveis de controle do processo.

\begin{tabular}{|c|c|c|c|c|}
\hline \multicolumn{5}{|c|}{ CONTINUAÇÃO DA SEÇÃO 8 - OPERAÇÃO } \\
\hline DO & $Q$ & 8.2 .2 & $\begin{array}{l}\text { Determinação de } \\
\text { requisitos relativos a } \\
\text { produtos e serviços }\end{array}$ & $\begin{array}{l}\text { A organização determina os requisitos relativos a } \\
\text { produtos e serviços. }\end{array}$ \\
\hline DO & $Q$ & 8.2 .3 & $\begin{array}{l}\text { Análise crítica de } \\
\text { requisitos relativos a } \\
\text { produtos e serviços }\end{array}$ & $\begin{array}{l}\text { A organização realiza a análise crítica dos requisitos } \\
\text { relativos a produtos e serviços. }\end{array}$ \\
\hline DO & $\mathrm{Q}$ & 8.2.4 & $\begin{array}{l}\text { Mudanças nos } \\
\text { requisitos para } \\
\text { produtos e serviços }\end{array}$ & $\begin{array}{l}\text { - As modificações são planejadas, realizadas de forma } \\
\text { controlada e são tomadas medidas para mitigar efeitos contrários. }\end{array}$ \\
\hline DO & Q & 8.3 & $\begin{array}{l}\text { Projeto e } \\
\text { desenvolvimento de } \\
\text { produtos e serviços }\end{array}$ & $\begin{array}{l}\text { A organização estabelece e implementa projeto e } \\
\text { desenvolvimento de produtos e serviços de acordo com os } \\
\text { requisitos da norma. }\end{array}$ \\
\hline DO & Q & 8.3 .1 & Generalidades & $\begin{array}{l}\text { A organização estabelece, implementa e mantém um } \\
\text { processo de projeto e desenvolvimento que seja apropriado para } \\
\text { assegurar a subsequente provisão de produtos e serviços. }\end{array}$ \\
\hline \multirow{10}{*}{ DO } & \multirow{10}{*}{ Q } & \multirow{10}{*}{8.3 .2} & \multirow{10}{*}{$\begin{array}{l}\text { Planejamento de } \\
\text { projeto e } \\
\text { desenvolvimento }\end{array}$} & $\begin{array}{l}\text { A organização considera a natureza, duração e } \\
\text { complexidade das atividades de projeto e desenvolvimento. }\end{array}$ \\
\hline & & & & $\begin{array}{l}\text { A organização considera } \begin{array}{l}\text { os estágios de processo } \\
\text { requeridos, incluindo análises } \\
\text { críticas de }\end{array} \text { projeto e } \\
\text { desenvolvimento aplicáveis. }\end{array}$ \\
\hline & & & & $\begin{array}{l}\text { A organização considera as atividades de verificação e } \\
\text { validação de projeto e desenvolvimento requeridas. }\end{array}$ \\
\hline & & & & $\begin{array}{l}\text { A organização considera as responsabilidades e } \\
\text { autoridades envolvidas no processo de projeto e desenvolvimento. }\end{array}$ \\
\hline & & & & $\begin{array}{l}\text { A organização considera os recursos internos e externos } \\
\text { necessários para o projeto e desenvolvimento de produtos e } \\
\text { serviços. }\end{array}$ \\
\hline & & & & $\begin{array}{l}\text { A organização considera a necessidade de controlar } \\
\text { interfaces entre pessoas envolvidas no processo de projeto e } \\
\text { desenvolvimento. }\end{array}$ \\
\hline & & & & $\begin{array}{l}\text { A organização considera a necessidade de envolvimento } \\
\text { de clientes e usuários no processo de projeto e desenvolvimento. }\end{array}$ \\
\hline & & & & $\begin{array}{l}\text { A organização considera os requisitos para a provisão } \\
\text { subsequente de produtos e serviços. }\end{array}$ \\
\hline & & & & $\begin{array}{l}\text { A organização considera o nível de controle esperado } \\
\text { para o processo de projeto e desenvolvimento por clientes e outras } \\
\text { partes interessadas pertinentes. }\end{array}$ \\
\hline & & & & $\begin{array}{l}\text { A organização considera a informação documentada } \\
\text { necessária para demonstrar que os requisitos de projeto e } \\
\text { desenvolvimento foram atendidos. }\end{array}$ \\
\hline
\end{tabular}

No projeto e desenvolvimento de novos produtos e serviços nos requisitos 8.2.2 à 8.3.2 a organização deve assegurar a provisão dos produtos e serviços, considerar os riscos ocupacionais e ambientais, com atividades de verificação e validação requerida, definição das responsabilidades, controle das interfaces entre pessoas, envolvimento de clientes e usuários, considerando os requisitos funcionais e de desempenho, controles, saídas e mudanças do projeto e desenvolvimento e análise crítica (SANTOS, et al., 2018; BERTOLINO e COUTO, 2018).

Para os requisitos 8.3.3 a 8.3.5 nas entradas e saídas do processo de projeto e desenvolvimento a organização deve considerar os requisitos do SGI, normas e melhores práticas do mercado, e analise dos riscos na aquisição quanto na entrega de bens e serviços, retendo a informação documentada, controle do projeto e do desenvolvimento. 


\begin{tabular}{|c|c|c|c|c|}
\hline \multicolumn{5}{|c|}{ CONTINUAÇÃO DA SEÇÃO 8 - OPERAÇÃO } \\
\hline \multirow{6}{*}{ DO } & \multirow{6}{*}{ Q } & \multirow{6}{*}{ 8.3.3 } & \multirow{6}{*}{$\begin{array}{l}\text { Entradas de projeto e } \\
\text { desenvolvimento }\end{array}$} & $\begin{array}{l}\text { A organização considera os requisitos funcionais e de } \\
\text { desempenho. }\end{array}$ \\
\hline & & & & $\begin{array}{c}\text { A organização considera a informação derivada de } \\
\text { atividades similares de projeto e desenvolvimento anteriores. }\end{array}$ \\
\hline & & & & $\begin{array}{l}\text { A organização considera os requisitos estatutários e } \\
\text { regulamentares. }\end{array}$ \\
\hline & & & & $\begin{array}{l}\text { A organização considera as normas ou códigos de prática } \\
\text { que a organização tenha se comprometido a implementar. }\end{array}$ \\
\hline & & & & $\begin{array}{l}\text { A organização considera as consequências potenciais de } \\
\text { falhas devidas à natureza de produtos e serviços. }\end{array}$ \\
\hline & & & & $\begin{array}{l}\text { A organização retém informação documentada de entradas } \\
\text { de projeto e desenvolvimento. }\end{array}$ \\
\hline \multirow{6}{*}{ DO } & \multirow{6}{*}{$Q$} & \multirow{6}{*}{ 8.3.4 } & \multirow{6}{*}{$\begin{array}{l}\text { Controle de projeto e } \\
\text { desenvolvimento }\end{array}$} & $\begin{array}{l}\text { A organização aplica controles para o processo de projeto e } \\
\text { desenvolvimento para assegurar que os resultados a serem } \\
\text { alcançados estejam definidos. }\end{array}$ \\
\hline & & & & $\begin{array}{l}\text { A organização assegura que análises críticas sejam } \\
\text { conduzidas para avaliar a capacidade de os resultados de projeto e } \\
\text { desenvolvimento atenderem a requisitos. }\end{array}$ \\
\hline & & & & $\begin{array}{l}\text { A organização assegura que atividades de verificação sejam } \\
\text { conduzidas para assegurar que as saídas de projeto e } \\
\text { desenvolvimento atendam aos requisitos de entrada }\end{array}$ \\
\hline & & & & $\begin{array}{l}\text { A organização assegura que atividades de validação sejam } \\
\text { conduzidas para assegurar que os produtos e serviços resultantes } \\
\text { atendam aos requisitos para a aplicação especificada ou uso } \\
\text { pretendido; }\end{array}$ \\
\hline & & & & $\begin{array}{l}\text { A organização assegura que quaisquer ações necessárias } \\
\text { sejam tomadas sobre os problemas determinados durante as análises } \\
\text { críticas ou atividades de verificação e validação }\end{array}$ \\
\hline & & & & $\begin{array}{l}\text { A organização assegura que informação documentada sobre } \\
\text { essas atividades seja retida. }\end{array}$ \\
\hline \multirow{5}{*}{ DO } & \multirow{5}{*}{ Q } & \multirow{5}{*}{ 8.3.5 } & \multirow{5}{*}{$\begin{array}{l}\text { Saídas de projeto e } \\
\text { desenvolvimento }\end{array}$} & $\begin{array}{l}\text { A organização assegura que saídas de projeto e } \\
\text { desenvolvimento atendam aos requisitos de entrada. }\end{array}$ \\
\hline & & & & $\begin{array}{l}\text { A organização assegura que saídas de projeto e } \\
\text { desenvolvimento sejam adequadas para os processos subsequentes } \\
\text { para a provisão de produtos e serviços. }\end{array}$ \\
\hline & & & & $\begin{array}{l}\text { A organização assegura que saídas de projeto e } \\
\text { desenvolvimento incluam ou referenciem requisitos de } \\
\text { monitoramento e medição, como apropriado, e critérios de aceitação. }\end{array}$ \\
\hline & & & & $\begin{array}{l}\text { A organização assegura que saídas de projeto e } \\
\text { desenvolvimento especifiquem as características dos produtos e } \\
\text { serviços que sejam essenciais para o propósito } \\
\text { pretendido e sua provisão segura e apropriada. }\end{array}$ \\
\hline & & & & $\begin{array}{l}\text { A organização retém informação documentada sobre as } \\
\text { saídas de projeto e desenvolvimento. }\end{array}$ \\
\hline
\end{tabular}

Para aquisição e controle de fornecedores de matérias primas, insumos, embalagens e de prestadores de serviços em projeto e desenvolvimento nos requisitos 8.3.3 à 8.3.5 a organização deve especificar os produtos e serviços com foco nos requisitos de SGI, verificar a conformidade das aquisições, avaliar e selecionar os fornecedores, documentar as rotinas de compra e procedimentos, manter e reter informações documentadas (CARPINETTI e GEROLAMO, 2016; SANTOS, et al, 2018; BERTOLINO e COUTO, 2018).

No requisito 8.3.6 a 8.5.3 na produção e provisão de serviço deve gerenciar as mudanças de projeto e desenvolvimento, controlar, disponibilizar informação documentada, características dos produtos e serviços, critérios de avaliação e reavaliação, seleção, monitoramento de desempenho e medição. 


\begin{tabular}{|c|c|c|c|c|}
\hline \multicolumn{5}{|c|}{ CONTINUAÇÃO DA SEÇÃO 8 - OPERAÇÃO } \\
\hline \multirow[b]{2}{*}{ DO } & \multirow[b]{2}{*}{ Q } & \multirow[b]{2}{*}{ 8.3.6 } & \multirow[b]{2}{*}{$\begin{array}{l}\text { Mudanças de projeto } \\
\text { e desenvolvimento }\end{array}$} & $\begin{array}{l}\text { A organização identifica, analisa criticamente e controla } \\
\text { mudanças feitas durante, ou subsequentemente ao projeto e } \\
\text { desenvolvimento de produtos e serviços. }\end{array}$ \\
\hline & & & & $\begin{array}{l}\text { A organização retém informação documentada sobre as } \\
\text { mudanças de projeto e desenvolvimento, os resultados de análises } \\
\text { críticas, a autorização das mudanças, e as ações tomadas para } \\
\text { prevenir impactos adversos. }\end{array}$ \\
\hline DO & Q & 8.4 & $\begin{array}{l}\text { Controle de } \\
\text { processos, produtos e } \\
\text { serviços providos } \\
\text { externamente }\end{array}$ & $\begin{array}{l}\text { A organização assegura que processos, produtos e serviços } \\
\text { providos externamente estejam conformes com requisitos }\end{array}$ \\
\hline \multirow{5}{*}{ DO } & \multirow{5}{*}{$\mathrm{Q}$} & \multirow{5}{*}{8.4 .1} & \multirow{5}{*}{ Generalidades } & $\begin{array}{l}\text { A organização determina os controles quando produtos e } \\
\text { serviços de provedores externos são destinados a incorporação nos } \\
\text { produtos e serviços da própria organização. }\end{array}$ \\
\hline & & & & $\begin{array}{l}\text { A organização determina os controles quando produtos e } \\
\text { serviços são providos diretamente para o(s) cliente(s) por } \\
\text { provedores externos em nome da organização. }\end{array}$ \\
\hline & & & & $\begin{array}{l}\text { A organização determina os controles quando um processo, } \\
\text { ou parte de um processo, é provido por um provedor externo como } \\
\text { um resultado de uma decisão da organização }\end{array}$ \\
\hline & & & & $\begin{array}{l}\text { A organização determina e aplica critérios para a avaliação, } \\
\text { seleção, monitoramento de desempenho e reavaliação de provedores } \\
\text { externos. }\end{array}$ \\
\hline & & & & $\begin{array}{l}\text { A organização retém informação documentada dessas } \\
\text { atividades e de quaisquer ações necessárias decorrentes das } \\
\text { avaliações. }\end{array}$ \\
\hline DO & $\mathrm{Q}$ & 8.4 .2 & $\begin{array}{l}\text { Tipo e extensão de } \\
\text { controle }\end{array}$ & $\begin{array}{l}\text { A organização assegura que processos, produtos e serviços } \\
\text { providos externamente não afetem adversamente a capacidade da } \\
\text { organização de entregar consistentemente produtos e serviços } \\
\text { conformes para seus clientes. }\end{array}$ \\
\hline DO & Q & 8.4 .3 & $\begin{array}{l}\text { Informação para } \\
\text { provedores externos }\end{array}$ & $\begin{array}{l}\text { A organização comunica para provedores externos seus } \\
\text { requisitos para os processos, produtos e serviços a serem providos; }\end{array}$ \\
\hline DO & $\mathrm{Q}$ & 8.5 & $\begin{array}{l}\text { Produção e provisão } \\
\text { de serviço }\end{array}$ & $\begin{array}{l}\text { A organização disponibiliza informações documentadas que } \\
\text { definem as características dos produtos e provisão de serviços. }\end{array}$ \\
\hline DO & $\mathrm{Q}$ & 8.5.1 & $\begin{array}{l}\text { Controle de produção } \\
\text { e de provisão de } \\
\text { serviço }\end{array}$ & $\begin{array}{l}\text { A organização controla o fornecimento dos seus produtos e } \\
\text { provisão de serviços, quanto a disponibilidade de informações } \\
\text { documentadas que definem as atividades e resultados esperados. }\end{array}$ \\
\hline DO & $\mathrm{Q}$ & 8.5 .2 & $\begin{array}{l}\text { Identificação } \\
\text { rastreabilidade }\end{array}$ & $\begin{array}{l}\text { A organização define métodos eficazes para garantir a } \\
\text { identificação e rastreabilidade dos produtos e serviços durante o } \\
\text { processo de funcionamento. }\end{array}$ \\
\hline DO & $\mathrm{Q}$ & 8.5.3 & $\begin{array}{l}\text { Propriedade } \\
\text { pertencente a } \\
\text { clientes e provedores } \\
\text { externos }\end{array}$ & $\begin{array}{l}\text { A organização garante um controle efetivo de uso de } \\
\text { propriedade de clientes ou fornecedores externos, utilizados no } \\
\text { fornecimento de produtos e Serviços. }\end{array}$ \\
\hline
\end{tabular}

A organização nos requisitos 8.3.6 à 8.5.3 deve disponibilizar a infraestrutura e ambiente de trabalho adequado, com pessoas competentes, validação e revalidação da capacidade e ações para prevenir erros em atender os requisitos do SGI, estabelecer atividades de liberação, procedimentos para garantir a identificação e rastreabilidade dos produtos e serviços, controlar a propriedade de clientes e/ou fornecedores com os mesmos cuidados como se fosse próprio (SANTOS, et al., 2018; BERTOLINO e COUTO, 2018).

A organização nos requisitos 8.5.4 a 8,7 deve assegurar a produção e provisão de serviços, define critérios de aceitação, realiza o monitoramento e medição, preserva as saídas, atende a requisitos, define e faz gestão das atividades pós-entrega, analisa criticamente e controla as mudanças, assim como realiza a gestão das não conformidades para evitar o uso intencional e retém informação documentada. 


\begin{tabular}{|c|c|c|c|c|}
\hline \multicolumn{5}{|c|}{ CONTINUAÇÃO DA SEÇÃO 8 - OPERAÇÃO } \\
\hline DO & $Q$ & 8.5.4 & Preservação & $\begin{array}{l}\text { A organização preserva as saídas durante produção e } \\
\text { provisão de serviço na extensão necessária, para assegurar } \\
\text { conformidade com requisitos. }\end{array}$ \\
\hline \multirow[b]{3}{*}{ DO } & \multirow[b]{3}{*}{ Q } & \multirow[b]{3}{*}{8.5 .5} & \multirow[b]{3}{*}{$\begin{array}{l}\text { Atividades pós- } \\
\text { entrega }\end{array}$} & $\begin{array}{l}\text { A organização atende aos requisitos para atividades pós- } \\
\text { entrega associadas com os produtos e serviços. }\end{array}$ \\
\hline & & & & - $\quad$ A organização define e administra as atividades pós-entrega. \\
\hline & & & & $\begin{array}{l}\text { A organização considera os requisitos estatutários e } \\
\text { regulamentares, as consequências indesejáveis potenciais, a natureza, } \\
\text { uso e o tempo de vida pretendido, requisitos do cliente e } \\
\text { retroalimentação de cliente nas atividades pós-entrega. }\end{array}$ \\
\hline \multirow[t]{2}{*}{ DO } & \multirow[t]{2}{*}{ Q } & \multirow[t]{2}{*}{ 8.5.6 } & \multirow{2}{*}{$\begin{array}{l}\text { Controle de } \\
\text { mudanças }\end{array}$} & $\begin{array}{l}\text { A organização analisa criticamente e controla mudanças } \\
\text { para produção ou provisão de serviços na extensão necessária para } \\
\text { assegurar continuamente conformidade com requisitos. }\end{array}$ \\
\hline & & & & $\begin{array}{l}\text { A organização retém informação documentada, que } \\
\text { descreva os resultados das análises críticas de mudanças. }\end{array}$ \\
\hline \multirow[b]{2}{*}{ DO } & \multirow[b]{2}{*}{ Q } & \multirow[b]{2}{*}{8.6} & \multirow[b]{2}{*}{$\begin{array}{l}\text { Liberação de } \\
\text { produtos e serviços }\end{array}$} & $\begin{array}{l}\text { A organização define os critérios de aceitação dos produtos } \\
\text { e serviços. }\end{array}$ \\
\hline & & & & $\begin{array}{l}\text { A organização define as atividades de monitoramentos e } \\
\text { medição para verificar os critérios de aceitação para controle e } \\
\text { resultados de processo. }\end{array}$ \\
\hline DO & Q & 8.7 & $\begin{array}{l}\text { Controle de saídas } \\
\text { não conformes }\end{array}$ & $\begin{array}{l}\text { A organização administra os resultados do processo de não } \\
\text { conformidades de modo a impedir seu uso intencional. }\end{array}$ \\
\hline
\end{tabular}

No final desse processo nos requisitos 8.5 .4 à 8.7 a organização deve garantir a preservação das saídas durante a produção e provisão dos serviços em todas as suas fases, atender os requisitos de pós entrega e a retroalimentação dos clientes, controlar mudanças e alterações de processos, rotinas de liberação de produtos e serviços e controlar os não conformes, estabelecer e treinar pessoal na preparação e resposta a emergência, com simulados e gestão de crise (SANTOS, et al., 2018; BERTOLINO e COUTO, 2018).

Na Seção 9 e requisitos 9.1 a 9.1 .3 preocupam-se com a análise e avaliação de dados e informações de produzir resultados desejados, com foco na avaliação da eficácia do SGI, atendimento dos objetivos e metas e a eficácia dos controles operacionais, definição de métodos, com mecanismos de retroalimentação, monitoramentos, medição, análise e avaliação do desempenho do SGI e reter informação documentada (registros).

\begin{tabular}{|c|c|c|c|c|}
\hline $\begin{array}{l}\text { CICLO } \\
\text { PDCA }\end{array}$ & $\begin{array}{c}\text { NORMA } \\
\text { ABNT NBR } \\
\text { ISO } \\
\text { QMS\&ST }\end{array}$ & $\begin{array}{c}\text { № } \\
\text { DO } \\
\text { REQ. } \\
9\end{array}$ & $\begin{array}{l}\text { REQUISITOS DO } \\
\text { SGI } \\
\text { SEÇÃO } 9 \text { - } \\
\text { AVALIAÇÃO DE } \\
\text { DESEMPENHO }\end{array}$ & PRÁTICAS DE GESTÃO E OPERACIONAL \\
\hline CHECK & QMS\&ST & 9.1 & $\begin{array}{l}\text { Monitoramento, } \\
\text { medição, análise e } \\
\text { avaliação }\end{array}$ & $\begin{array}{l}\text { A organização determina o monitoramento, } \\
\text { medição, análise e avaliação da eficácia do SGI. }\end{array}$ \\
\hline \multirow{6}{*}{ CHECK } & \multirow{6}{*}{ QMS\&ST } & \multirow{6}{*}{9.1 .1} & \multirow{6}{*}{ Generalidades } & $\begin{array}{l}\text { A organização determina o que precisa ser } \\
\text { monitorado e medido. }\end{array}$ \\
\hline & & & & $\begin{array}{l}\text { A organização determina os métodos para } \\
\text { monitoramento, medição, análise e avaliação necessários } \\
\text { para assegurar resultados válidos. }\end{array}$ \\
\hline & & & & $\begin{array}{cccc}\text { A organização determina quando } & \text { o } \\
\text { monitoramento e a medição devem ser realizados. } & \end{array}$ \\
\hline & & & & $\begin{array}{l}\text { A organização determina quando os resultados de } \\
\text { monitoramento e medição devem ser analisados e } \\
\text { avaliados }\end{array}$ \\
\hline & & & & $\begin{array}{l}\text { A organização avalia o desempenho e a eficácia do } \\
\text { sistema de gestão da qualidade. }\end{array}$ \\
\hline & & & & $\begin{array}{l}\text { A organização retém informação documentada } \\
\text { apropriada como evidência dos resultados. }\end{array}$ \\
\hline
\end{tabular}




\begin{tabular}{|c|c|c|c|c|}
\hline $\begin{array}{l}\text { CICLO } \\
\text { PDCA }\end{array}$ & $\begin{array}{l}\text { NORMA } \\
\text { ABNT NBR } \\
\quad \text { ISO }\end{array}$ & $\begin{array}{l}\text { № } \\
\text { DO } \\
\text { REQ. }\end{array}$ & \multirow{2}{*}{$\begin{array}{l}\text { REQUISITOS DO } \\
\text { SGI } \\
\text { SEÇÃO } 9 \text { - } \\
\text { AVALIAÇÃO DE } \\
\text { DESEMPENHO }\end{array}$} & \multirow[b]{2}{*}{ PRÁTICAS DE GESTÃO E OPERACIONAL } \\
\hline CHECK & QMS\&ST & $\mathrm{NLQ}$ & & \\
\hline \multirow[t]{2}{*}{ CHECK } & \multirow[t]{2}{*}{ Q } & \multirow[t]{2}{*}{9.1 .2} & \multirow{2}{*}{$\begin{array}{l}\text { Satisfação do } \\
\text { cliente }\end{array}$} & $\begin{array}{l}\text { A organização monitora a percepção de clientes } \\
\text { do grau em que suas necessidades e expectativas foram } \\
\text { atendidas. }\end{array}$ \\
\hline & & & & $\begin{array}{l}\text { A organização determina os métodos para obter, } \\
\text { monitorar e analisar criticamente essa informação. }\end{array}$ \\
\hline CHECK & MS\&ST & 9.1 .2 & $\begin{array}{l}\text { Avaliação dos } \\
\text { requisitos legais e } \\
\text { outros requisitos }\end{array}$ & $\begin{array}{l}\text { A organização implementa e mantem o(s) } \\
\text { processo(s) necessário(s) para avaliar o atendimento aos } \\
\text { seus requisitos legais e outros requisitos. }\end{array}$ \\
\hline \multirow{5}{*}{ CHECK } & \multirow{5}{*}{ QMS\&ST } & \multirow{5}{*}{9.1 .3} & \multirow{5}{*}{ Análise e avaliação } & $\begin{array}{l}\text { A organização analisa e avaliam dados e } \\
\text { informacções apropriados provenientes de monitoramento } \\
\text { e medição. }\end{array}$ \\
\hline & & & & $\begin{array}{l}\text { A organização avalia a conformidade de produtos } \\
\text { e serviço, o grau de satisfação das partes interessadas, o } \\
\text { desempenho e a eficácia do SGI. }\end{array}$ \\
\hline & & & & $\begin{array}{l}\text { A organização avalia se o planejamento foi } \\
\text { implementado eficazmente. }\end{array}$ \\
\hline & & & & $\begin{array}{l}\text { A organização avalia a eficácia das ações tomadas } \\
\text { para abordar riscos e oportunidades. }\end{array}$ \\
\hline & & & & $\begin{array}{l}\text { A organização avalia o desempenho de } \\
\text { provedores externos e a necessidade de melhorias no SGI. }\end{array}$ \\
\hline
\end{tabular}

A análise e avaliação dos processos, produtos e serviços, requisitos legais e outros requisitos nos requisitos 9.1 à 9.1 .3 deve ser realizada periodicamente, devido às modificações e publicação de novas leis, regulamentos e outros requisitos e reter informação documentada dessas avaliações, como processo de melhoria continua do SGI (SANTOS, et al., 2018; BERTOLINO e COUTO, 2018).

No requisito 9.2 a 9.3 define a necessidade da programação e condução de auditorias internas periódicas, com análise crítica pela alta direção, para avaliar o desempenho e conformidades com os requisitos do SGI, tratar as não conformidades e desenvolver o processo de melhoria contínua.

\begin{tabular}{|c|c|c|c|c|}
\hline \multicolumn{5}{|c|}{ CONTINUACC̃O DA SECC̃̃O 9 - AVALIACC̃̃O DE DESEMPENHO } \\
\hline \multirow{6}{*}{ CHECK } & \multirow{6}{*}{ QMS\&ST } & \multirow{6}{*}{$\begin{array}{c}9.2 \\
9.2 .1\end{array}$} & \multirow{6}{*}{$\begin{array}{l}\text { Auditoria } \\
\text { interna } \\
\text { Generalidades }\end{array}$} & $\begin{array}{l}\text { A organização conduz auditorias internas a intervalos } \\
\text { planejados para prover informação sobre se o SGI. }\end{array}$ \\
\hline & & & & $\begin{array}{l}\text { A organização define os critérios de auditoria e o } \\
\text { escopo para cada auditoria; }\end{array}$ \\
\hline & & & & $\begin{array}{l}\text { A organização seleciona auditores e conduz auditorias } \\
\text { para assegurar a objetividade e a imparcialidade do processo de } \\
\text { auditoria; }\end{array}$ \\
\hline & & & & $\begin{array}{l}\text { A organização assegura que os resultados das } \\
\text { auditorias sejam relatados para a gerência pertinente; }\end{array}$ \\
\hline & & & & $\begin{array}{l}\text { A organização executa correção e ações corretivas } \\
\text { apropriadas sem demora indevida; }\end{array}$ \\
\hline & & & & $\begin{array}{l}\text { A organização retém informação documentada como } \\
\text { evidência da implementação do programa de auditoria e dos } \\
\text { resultados de auditoria. }\end{array}$ \\
\hline CUГCИ & ד & $0 ? ?$ & Programa de & $\begin{array}{l}\text { A organização implementa e mantém um programa de } \\
\text { auditoria, incluindo a frequência, métodos, responsabilidades e } \\
\text { requisitos. }\end{array}$ \\
\hline СHECK & QIMS\&SI & 9.2 .2 & $\begin{array}{c}\text { auditorla } \\
\text { interna }\end{array}$ & $\begin{array}{l}\text { A organização considera no programa de auditoria a } \\
\text { importância dos processos concernentes, as mudanças que } \\
\text { afetam a organização e os resultados de auditorias anteriores. }\end{array}$ \\
\hline CHECK & QMS\&ST & 9.3 & $\begin{array}{l}\text { Análise crítica } \\
\text { pela direção }\end{array}$ & $\begin{array}{l}\text { A Alta Direção analisa criticamente } \\
\text { - o SGI da } \\
\text { organização, a intervalos planejados. }\end{array}$ \\
\hline
\end{tabular}


A avaliação do desempenho, a análise crítica dos resultados dos processos de gestão e operacional, incluindo osde auditorias internas, definidos nos requisitos 9.2 a 9.3 identificam as necessidades e oportunidades de melhorias na organização (De Cicco, 2018).

E na última Seção 10 das normas ISO do SGI, nos requisitos 10.1 a 10.3 a organização deve garantir a melhoria contínua, para alcançar patamares mais elevados em desempenho de SGI, estruturados a partir do ciclo PDCA, para melhorar os produtos e serviços, tornar os processos mais seguros e alcançar a eficácia do SGI.

\begin{tabular}{|c|c|c|c|c|}
\hline $\begin{array}{l}\text { CICLO } \\
\text { PDCA }\end{array}$ & $\begin{array}{l}\text { NORMA } \\
\text { ABNT } \\
\text { NBR ISO }\end{array}$ & $\begin{array}{l}\text { № DO } \\
\text { REQ. }\end{array}$ & \multirow{2}{*}{$\begin{array}{l}\text { REQUISITOS } \\
\text { DO SGI } \\
\text { SECCÃO } 10- \\
\text { MELHORIA }\end{array}$} & \multirow{2}{*}{ PRÁTICAS DE GESTÃO E OPERACIONAL } \\
\hline ACT & QMS\&ST & 10 & & \\
\hline \multirow{3}{*}{ ACT } & \multirow{2}{*}{ QMS\&ST } & \multirow{2}{*}{10.1} & \multirow{2}{*}{ Generalidades } & $\begin{array}{l}\text { A organização determina e seleciona oportunidades } \\
\text { para melhoria, e implementa ações necessárias para atender a } \\
\text { requisitos do cliente e aumentar a sua satisfação. }\end{array}$ \\
\hline & & & & $\begin{array}{l}\text { A organização inclui melhoria em produtos e serviços } \\
\text { para atender a requisitos, assim como para abordar futuras } \\
\text { necessidades e expectativas de clientes. }\end{array}$ \\
\hline & & & & $\begin{array}{l}\text { A organização corrige, preveni ou reduz efeitos } \\
\text { indesejados, melhora o desempenho e a eficácia do sistema de } \\
\text { gestão da qualidade. }\end{array}$ \\
\hline \multirow{7}{*}{ ACT } & \multirow{7}{*}{ QMS\&ST } & \multirow{7}{*}{10.2} & \multirow{7}{*}{$\begin{array}{l}\text { Não } \\
\text { conformidade e } \\
\text { ação corretiva }\end{array}$} & $\begin{array}{l}\text { A organização reage a não conformidade e, como } \\
\text { aplicável, toma ação para controlá-la e corrigi-la e lida com as } \\
\text { consequências. }\end{array}$ \\
\hline & & & & $\begin{array}{l}\text { A organização avalia a necessidade de ação para } \\
\text { eliminar a(s) causa(s) da não conformidade, a fim de que ela } \\
\text { não se repita ou ocorra em outro lugar. }\end{array}$ \\
\hline & & & & $\begin{array}{l}\text { A organização analisa criticamente a não } \\
\text { conformidade e determina as causas da não conformidade. }\end{array}$ \\
\hline & & & & $\begin{array}{l}\text { A organização implementa ação necessária e analisa } \\
\text { criticamente a eficácia de ação corretiva tomada. }\end{array}$ \\
\hline & & & & $\begin{array}{l}\text { A organização atualiza riscos e oportunidades } \\
\text { determinados durante o planejamento. }\end{array}$ \\
\hline & & & & $\begin{array}{lrrrrrr}\text { A } & \text { organização } & \text { realiza } & \text { mudanças no } & \text { SGI, se } \\
\text { necessário. } & & & & & & \\
\end{array}$ \\
\hline & & & & $\begin{array}{l}\text { A organização retém informação documentada como } \\
\text { evidência. }\end{array}$ \\
\hline \multirow[b]{2}{*}{ ACT } & \multirow[b]{2}{*}{ QMS\&ST } & \multirow[b]{2}{*}{10.3} & \multirow[b]{2}{*}{$\begin{array}{l}\text { Melhoria } \\
\text { contínua }\end{array}$} & $\begin{array}{l}\text { A organização melhora continuamente a adequação, } \\
\text { suficiência e eficácia do SGI. }\end{array}$ \\
\hline & & & & $\begin{array}{l}\text { A organização considera os resultados de análise e } \\
\text { avaliação e as saídas de análise crítica pela direção para } \\
\text { determinar se existem necessidades ou oportunidades que } \\
\text { devem ser abordadas como parte de melhoria contínua. }\end{array}$ \\
\hline
\end{tabular}

Fonte: Adaptado das normas NBR ISO 9001:2015; NBR ISO 14001:2015 e ISO 45001:2018 e Santos, et al., 2018.

A organização deve identificar as oportunidades de melhoria, com ações para tender as necessidades das partes interessadas, assim como análise crítica dos resultados do SGI, com implementação e manutenção de processo de comunicação, investigação e tomada de ações, para gerenciar não conformidades e incidentes, e reter informação documentada (registros) (CARPINETTI e GEROLAMO, 2016; SANTOS, et al., 2018; BERTOLINO e COUTO, 2018).

\section{CONSIDERAÇÕES FINAIS}

\subsection{CONCLUSÃO}

o modelo da matriz de correspondência estruturada no ciclo PDCA, está composta por 75 requisitos e 172 práticas de gestão e operacionais por Seção das normas ABNT NBR ISO de QMS\&ST, para elaboração de instrumentos de coleta de dados do tipo: roteiro de entrevista, questionário e listas de verificação (LV), para realizar diagnóstico e/ou avaliação de desempenho da SGI, assim como possibilitar a integração com 
outros tipos de sistemas de gerenciamento exigidos por órgãos reguladores na gestão global de uma organização, como de segurança operacional e de integridade estrutural das instalações, dutos terrestres, sistemas submarinos e poços produtores de petróleo e gás natural e injetores de fluidos, definidos pela Agência Nacional de Petróleo (ANP) no Brasil.

Na matriz do SGI a Seção 4, tem 4 (quatro) requisitos e 9 (nove) práticas de gestão e operacionais; na Seção 5, com 7 (sete) requisitos e 20 (vinte); na Seção 6, com 8 (oito) requisitos e 13 práticas de gestão e operacionais; na Seção 7, com 18 requisitos e 31 práticas de gestão e operacionais; na Seção 8, com 27 seções e 71 práticas de gestão e operacionais; na Seção 9, com 9 (nove) requisitos e 20 (vinte) práticas de gestão e operacionais.

\subsection{RECOMENDAÇÕES DE PESQUISAS FUTURAS}

Utilizar a matriz de correlação do SGI como referência para a integração de requisitos de sistemas de gerenciamento de órgãos reguladores, como de segurança operacional (segurança de processo e ocupacional) e de integridade das instalações, definidos em regulamentos técnicos da Agência Nacional do Petróleo (ANP), para diagnóstico e avaliação de desempenho de empresas brasileiras de exploração e produção de petróleo e gás natural.

\section{REFERÊNCIAS}

[1] Associação Brasileira de Normas Técnicas - ABNT NBR ISO 9001:2015. Sistema de gestão da qualidade. Requisitos.

[2] Associação Brasileira de Normas Técnicas - ABNT NBR ISO 14001:2015. Sistema de gestão ambiental. Requisitos com orientações para uso.

[3] Associação Brasileira de Normas Técnicas - ABNT NBR ISO 45001:2018. Sistema de gestão da segurança e saúde ocupacional. Requisitos com orientações para uso.

[4] Bertolino, Marco Túlio; Couto, Marcello. Sistemas de gestão integrados ISO 9001, ISO 14001 e ISO 45001 : gestão da qualidade, ambiental e da segurança e saúde ocupacional com foco em resultados. - 1. Ed. - Rio de Janeiro: Qualitymark Editora, 2018.256 p.

[5] Carpinetti, Luiz. Cezar Ribeiro; Gerolamo, Matheus Cecílio. Gestão da qualidade ISO 9001: requisitos e integração com ISO 14001: 2015 - 1.ed. - São Paulo: Atlas, 2016. 204 p.

[6] Coelho, Guilherme Jorge. Identificação de fatores críticos em sistemas de gestão integrados (SGI) na indústria de construção e montagem (C\&M) para o refino de petróleo: um estudo de caso. Universidade Federal Fluminense Centro Tecnológico Mestrado Profissional Em Sistemas de Gestão. Niterói - RJ, 2010.

[7] De cicco, francesco. Iso 45001:2018 sistemas de gestão da segurança e saúde no trabalho : requisitos com orientações para uso. - são paulo : risk tecnologia, 2018.

[8] Gil, Antonio Carlos. Métodos e técnicas de pesquisa social. - 6a ed. - 7. Reimp. - São Paulo: Atlas, 2016.

[9] Gil, Antonio Carlos. Como elaborar projetos de pesquisa. - 6aㅡ ed. São Paulo: Atlas, 2017.

[10] Martins, Gilberto de Andrade de; THEÓFILO, Carlos Renato. Metodologia da investigação científica para ciências sociais aplicadas. - 3. ed. - São Paulo: Atlas, 2016.

[11] Moretti, Eduardo de Araujo. Estudo das dificuldades observadas na implantação de sistemas RFID. Universidade Estadual de Campinas. Faculdade de Engenharia Mecânica. Campinas, SP: [s.n.], 2017.

[12] Poltronieri, Camila Fabrício. Avaliação do grau de maturidade de sistemas de gestão integrados. $118 f$. Dissertação (Mestrado) - Engenharia de Produção. Escola de Engenharia de São Carlos (USP), São Carlos, Brasil, 2014.

[13] Poltronieri, Camila Fabrício; Gerolano, M.; Carpinetti, Luiz. Cezar Ribeiro. Um instrumento para a avaliação de sistemas de gestão integrados. Gestão \& Produção, São Carlos. Disponível em: http://dx.doi.org/

[14] 10.1590/0104-530X1697-14,2015.

[15] Ribeiro Neto, João Batista M.; TAVARES, José Cunha; Hoffmann Silvana Carvalho. Sistemas de gestão integrados: qualidade, meio ambiente, responsabilidade social, segurança e saúde no trabalho. 5a edição rev. - São Paulo: Editora Senac, 2017.

[16] Santos, Gilberto, et al. Sistemas integrados de gestão:qualidade, ambiente e segurança. 3.- Edição. Revista e Aumentada. Editora Engebook, 2018.

[17] Vergara, Sylvia Constant. Métodos de pesquisa em administração. - São Paulo: Atlas, 2005

[18] Yin, Robert K. Estudo de caso: planejamento e métodos / Robert K. Yin; tradução: Cristhian Matheus Herrera. - 5. ed. Porto Alegre: Bookman, 2015 


\section{Capítulo 8}

Gestão de processos aplicado no planejamento de Call Center enfatizando a previsão de demanda - Estudo de caso em Empresa de Seguros

\section{Nelson Antonio de Mello Silva Junior}

Nicolas André Alves da Silva

Yuri Faro

Resumo: É imprescindível que as empresas estudem a possibilidade de implementação de uma área de planejamento, que vá mostrar a ela quais e quantos recursos terá que haver no período futuro para atender a demanda com qualidade e conseqüentemente satisfação do cliente externo. Outros pontos são a redução de custos por redução de funcionários para atender a demanda e tempo hábil para todas as áreas da empresa se programarem para os eventos dos períodos futuros, tomando ações para atingirem as estratégias acordadas pela organização. Este artigo mostrará o quanto a gestão de processos pode agregar valores na parte de planejamento e controle da produção na prestação deste serviço de Call Center (Empresa de atendimento). A previsão de demanda (Forecasting) tem papel fundamental no funcionamento destes tipos de empresa para a alocação de recursos tecnológicos e humanos de acordo com a necessidade de cada produto. Será analisado como foi implantado estes conceitos, em uma das maiores empresas do ramo de seguros, em sua central de atendimento e a redução de custo que foi proporcionada.

Palavras-Chave: Gestão de Processos, Forecasting, Planejamento e Controle da Produção, Custos. 


\section{INTRODUÇÃO}

0 trabalho tem por objetivo principal integrar dois métodos importantes de gerenciamento de produção, gestão por processos e previsão de demanda, e aplicá-los no planejamento de forma conjunta. Tendo em vista a maximização neste processo tão importante para o controle da produção.

Com isso poderemos ter as informações prontas com bastante antecedência, ou até mesmo mudar a estratégia e fazer uma nova previsão caso haja alguma mudança de sazonalidade no produto. Tendo à disposição tais ferramentas o produto final da empresa estará sempre prezando pela qualidade e satisfação do cliente pela preparação de toda a organização para atender ao mesmo.

Para isso, foram realizadas pesquisas bibliográficas que proporcionaram o método desenvolvido, que será apresentado, e o estudo de caso da sua aplicação. Ao final do presente artigo, estarão apresentados os resultados obtidos, as análises e tabelas com informações sobre os ganhos proporcionados a empresa de Call Center, em que foi utilizado o método.

\section{MATERIAIS E MÉTODOS}

Para entendermos melhor o que são os tipos de processos, podemos tomar um exemplo citado por Araujo (2011) que ilustra esta situação como quando pensamos em descrever uma saída nossa ao shopping ou a loja favorita. Esqueçamos de algumas atividades, como escolha da roupa, o meio de transporte e sua disponibilidade, se houve greve ou não, enfim, aspectos que influenciam indiretamente o alcance do nosso objetivo, colocando-os sem importância caso algum falhe, o êxito será comprometido.

Por isso vários escritores nos exortam: que é importante saber quais são os processos que justificam a existência da empresa e quais dão suporte à atividade fim da mesma.

De acordo com Araujo (2011) processos que justificam a existência da empresa são os processos de negócios ou essenciais, responsáveis por atender o cliente externo com os produtos finais ou serviços.

E os processos de gestão ou suporte, atividades de apoio, suportam os processos de negócios ou essenciais, focam na organização e não no cliente externo. São responsáveis por viabilizar a realização dos processos essenciais, estes processos influenciam indiretamente nos resultados da empresa.

Figura 1: Tipos de processos.

\begin{tabular}{|c|c|}
\hline \multicolumn{2}{|c|}{ PROCESSOS } \\
\hline DE NEGÓCIOS OU ESSENCIAIS & DE GESTÃO OU SUPORTE \\
\hline Justificam a existência da empresa & Dão suporte \\
\hline
\end{tabular}

Fonte: Araujo (2011)

Um assunto muito importante, dentro deste tema, é a modelagem de processos que de acordo com Oliveira (2008), modelos são representações dos processos, dos quais existe uma grande variedade.

O autor Oliveira (2008), nos afirma que em geral são utilizados uma ou mais ferramentas de analise e modelagem de processos para a criação dos modelos desejados, Alguns exemplos são:

a) Script de processos Organogramas;

b) Organogramas;

c) UML;

d) Mapa de processos: diagramas (SIPOC, diagrama de bloco, fluxograma vertical, fluxograma funcional ou horizontal, planilhas e formulários);

e) Outros (rede PERT, diagrama de classe etc.).

Segundo Oliveira (2008), as etapas para ser iniciada a modelagem dos processos são:

- Reunir todos os elementos relativos a cada processo, exemplo: relatórios, documentos, faturas, registros.

- Selecionar e analisar um processo de cada vez. 
Se já houver a descrição do processo, re-avalie (agregação de valor, redundância, racionalizando).

$$
\begin{aligned}
& \text { - } \quad \text { Se não houver descreva o mesmo em detalhes (script). } \\
& \text { - } \quad \text { Escolha a ferramenta de modelagem que melhor se adapta a empresa. }
\end{aligned}
$$

Como já foi citado podemos realizar a analise ou modelagem de processos usando uma ou mais ferramentas, que, citado por Oliveira (2008), são desde o Microsoft Word, até os softwares mais sofisticados. Existem mais de 300 softwares disponíveis no mercado, entre eles livres (free wares) ate muito caros, exemplos: MS visio, Smart Draw, Process Marker, Bonaport (BPMG 2005). Cada software apresenta vários modelos prontos e mais de uma técnica de Modelagem de Processos. Alguns também possuem recursos de análise e simulação dos processos.

Portanto podemos seguir as etapas sugeridas e escolher as ferramentas de análise e modelagem conforme a disponibilização da empresa que trabalhamos.

De acordo com os conceitos citados acima, vejamos as vantagens da utilização de uma destas ferramentas o fluxograma. Para Oliveira (2008), também conhecidos como flowcharts, são técnicas de modelagem originadas da lógica de programação, introduzidas entre 1940 e 1950 à modelagem de negocio e se tornaram populares nos anos 70 .

De acordo com Oliveira (2008), eles representam graficamente e de forma detalhada, a seqüência lógica dos processos, permitindo a representação de ações e desvios.

Algumas de suas vantagens são: facilita a organização (do raciocínio, das atividades e tarefas), identificar pendências, relacionamentos, gargalos, atividades que não agregam valor, localizar elos e elementos desconexos ou perdidos, controlar o processo, pontos de verificação, decisão, revisão, registro, arquivamento, entre outros.

Segundo Oliveira (2008) o Fluxograma Vertical é um modelo desenvolvido pelo Instituto Nacional Americano de Padronização, por este motivo também é chamado de Fluxograma Padrão ANSI.

Mesmo sendo um dos mais antigos, ainda é muito utilizado principalmente nas representações de fluxos de processos computacionais.

Figura 2: Exemplo Fluxograma Vertical

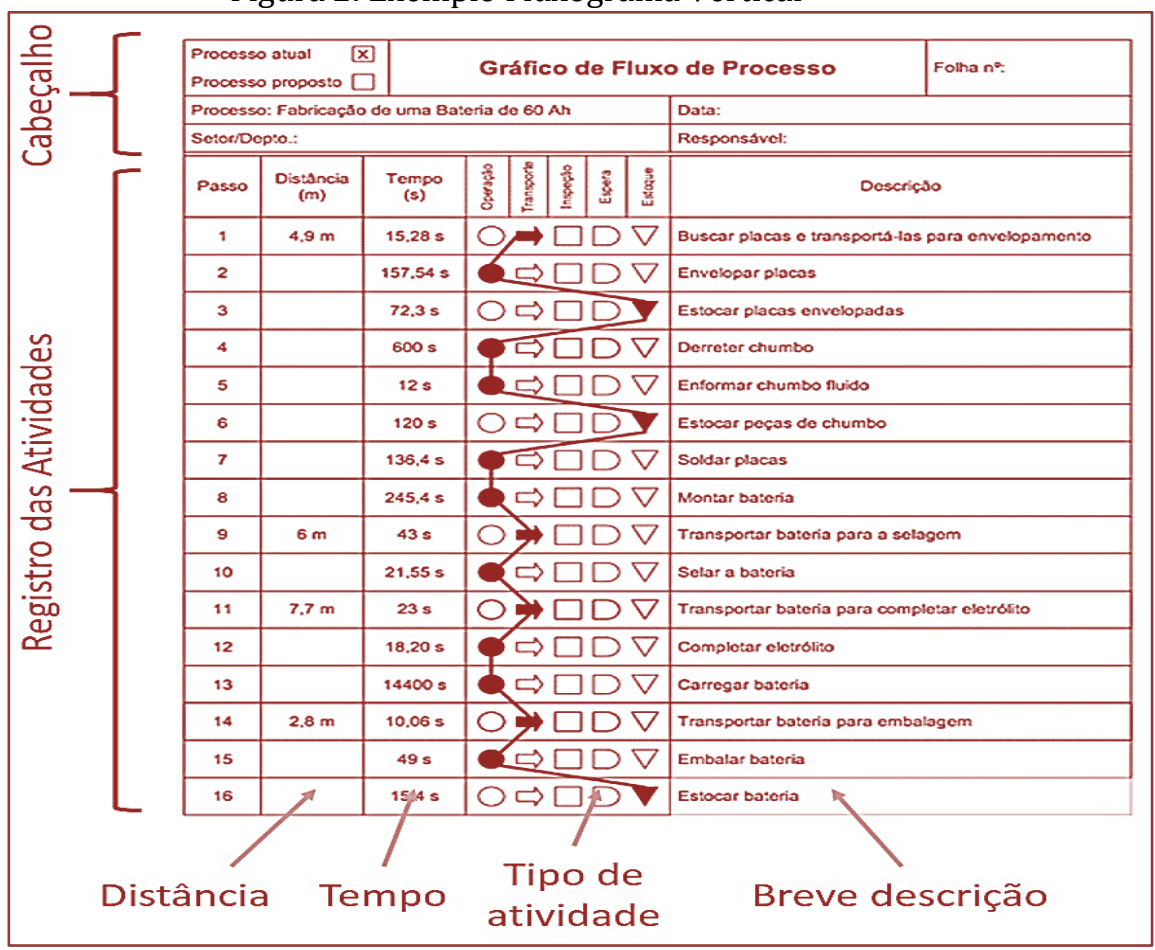

Fonte: Lima (2016) 
Sobre o modelo de Fluxograma Horizontal, de acordo com Oliveira (2008), é usado para representar os papéis de todos os agentes envolvidos nos processos representados. Por isso também é conhecido como Fluxograma Funcional ou Modelo Swinlane.

Segue um exemplo mostrando como o fluxograma ilustra as etapas e quem as executa até seu término.

Figura 3: Exemplo Fluxograma Horizontal

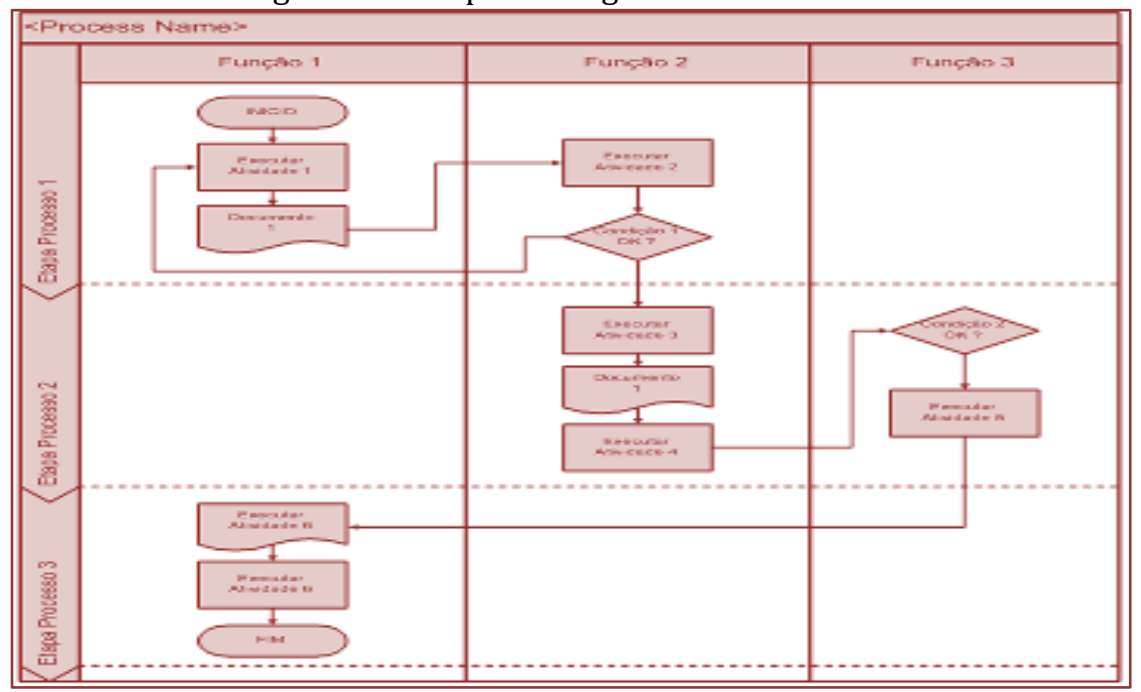

Fonte: Aghata Maxi Consulting (2011)

Partindo para a outra etapa da pesquisa, observemos a importância da previsão de demanda para as instituições.

Muitos autores, dentre eles Gonçalves (2007), nos mostra que a previsão é necessária para o planejamento da capacidade instalada, gestão de estoques, fluxo de caixa, otimização de custos, entre outros. Independentemente da atividade da empresa, produto ou serviço, podem ocorrer grandes volumes de estoque, ociosidade de funcionários, incertezas de demandas (que geram demora no tempo de resposta e insatisfação do cliente).

Por isso, segundo Gonçalves (2007), dentro das cadeias de suprimento mais adequadas aos dias atuais encontramos relacionamentos de parceria, pequenos volumes de estoque ao longo da cadeia, e tempos de resposta rápidos.

0 processo de previsão deve ser contínuo, integrando uma visão sistêmica do passado, presente e futuro, tendo em vista alcançar os objetivos da empresa.

Segue fluxograma representando os benefícios para a produção da previsão de demanda. 
Figura 4: Desdobramento de decisões

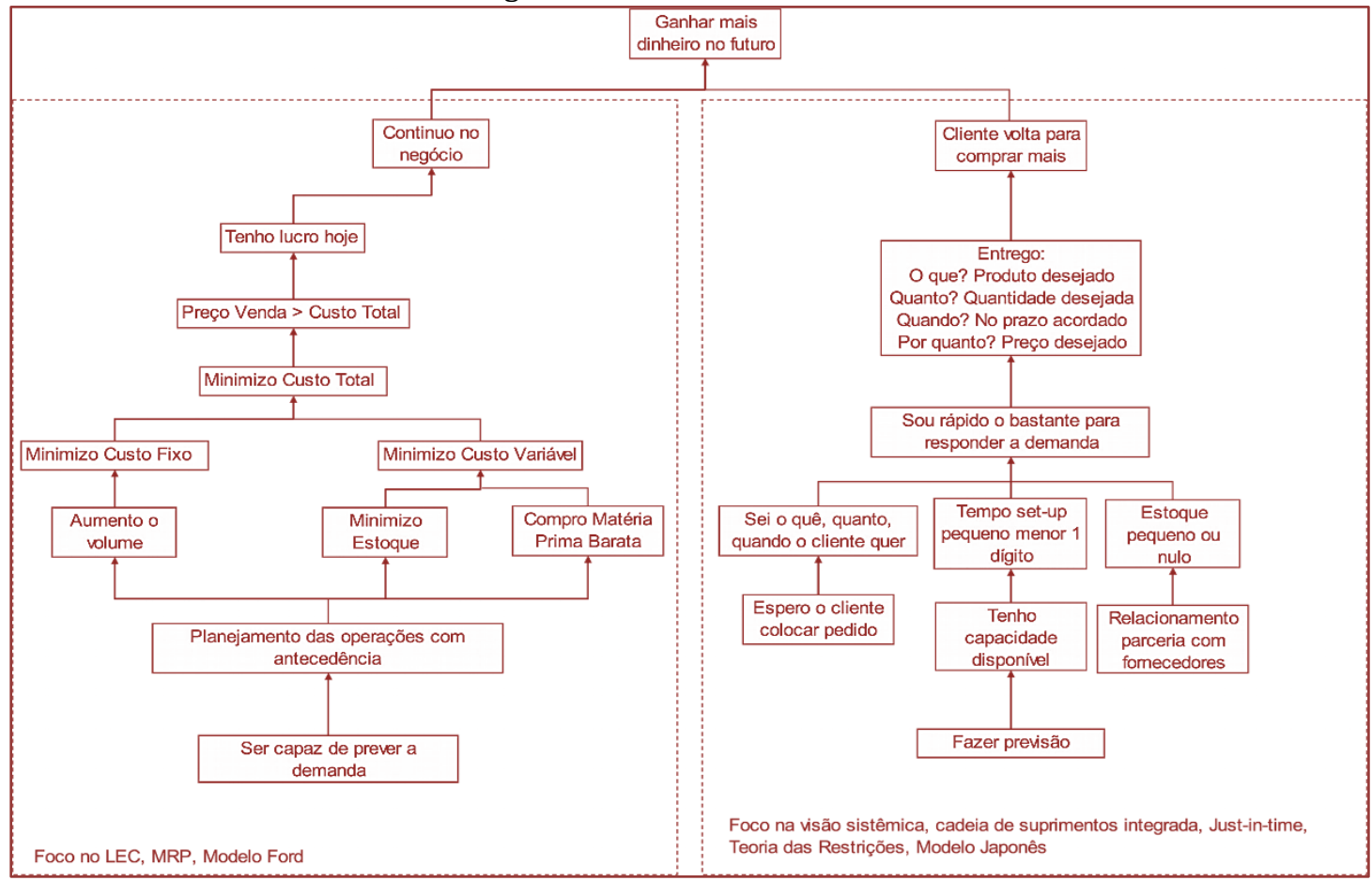

Fonte: Gonçalves, 2007 p. 5

\section{RESULTADOS E DISCUSSÕES}

Baseando-se neste estudo, foi observado um modelo seguindo os padrões de gestão de processos, aplicando-o conforme as ações a seguir.

Figura 5: Etapas da Previsão de Demanda.

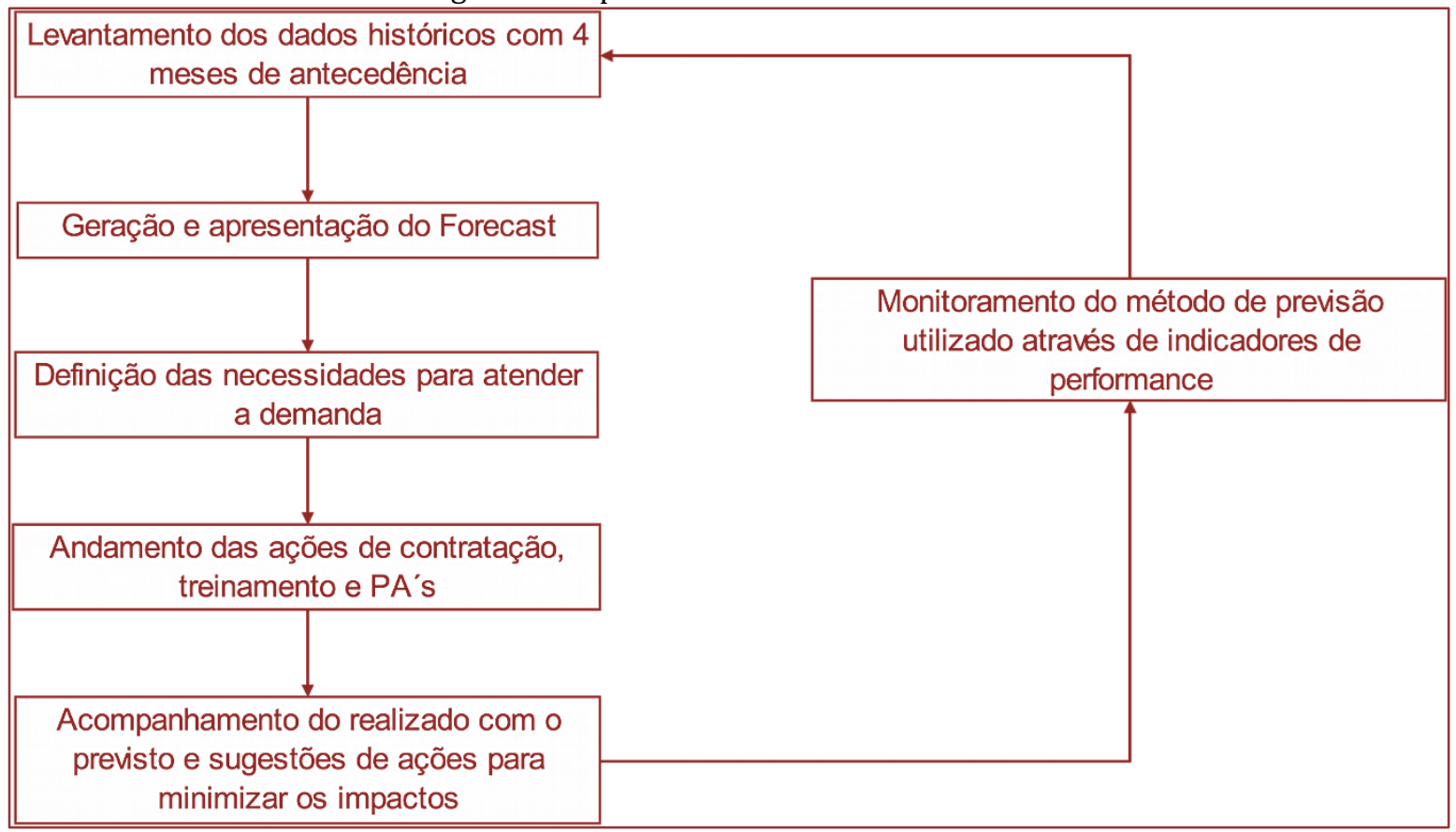

Fonte: Autor. 
A partir destes fatos podemos concluir o quanto é importante conhecer a demanda com antecedência para que sejam traçadas as estratégias de contratação para a entrega dos funcionários necessários para atender a demanda. Por isso foi criado um fluxograma mostrando as responsabilidades dos setores, dentro da área de planejamento, de longo prazo, curto prazo e gestores da operação.

Figura 6: Fluxograma Horizontal Previsão de Demanda Call Center.

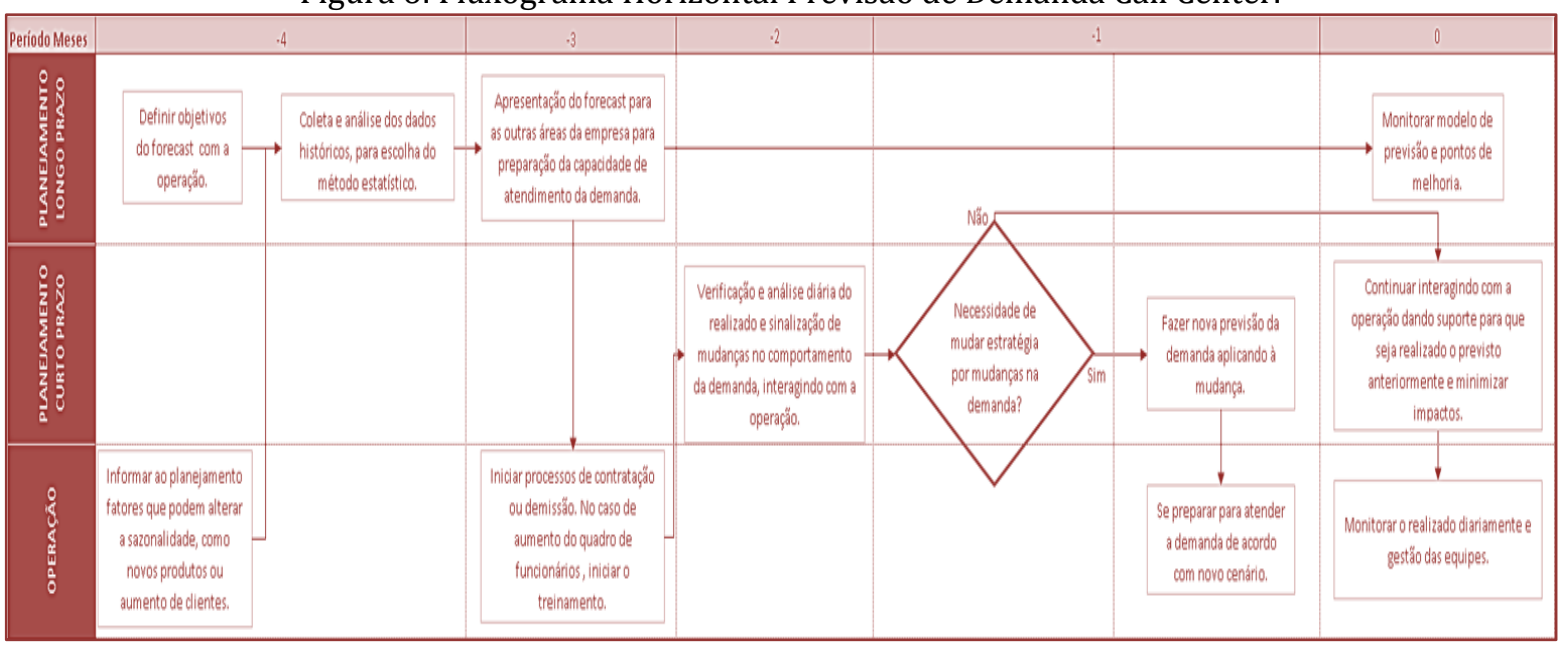

Fonte: Autor.

Seguindo as etapas necessárias para o forecasting, foi criada uma tabela, onde podemos analisar os resultados de vários métodos de previsão de demanda, fazer o acompanhamento do histórico da demanda e verificar se o setor está sendo eficiente para suprir as necessidades de informações da operação. Que precisa se antecipar a demanda, para adquirir o número necessário de atendentes e treiná-los para a quantidade de chamadas.

O estudo em questão é sobre a geração de forecasting realizada em uma empresa de Call Center que utiliza vários métodos estatísticos em um programa bastante acessível do Microsoft Office, o Excel.

Após a coleta dos dados históricos da demanda, através de uma planilha os dados do histórico da demanda são observados, assim como os números previstos e seus erros ou fatores de sazonalidade. Os dados são reais de uma célula de atendimento em uma empresa de grande porte, do ramo de seguros.

Tabela 1: Métodos de Forecast

\begin{tabular}{|c|c|c|c|c|c|c|c|c|c|c|c|c|c|c|c|c|c|}
\hline Volume & $\begin{array}{l}\text { Cresdim. } \\
\text { Volume }\end{array}$ & $\begin{array}{l}\text { Fator Afast. } \\
\text { Tendência }\end{array}$ & $\begin{array}{l}\text { Fator Sazon. } \\
\text { Tendênda }\end{array}$ & $\begin{array}{l}\text { Fator Afast. } \\
\text { Crescim. }\end{array}$ & $\begin{array}{l}\text { Fator Sazon. } \\
\text { Cresdim. }\end{array}$ & $\begin{array}{l}\text { Tendênda } \\
\text { Tróf́ego }\end{array}$ & $\begin{array}{l}\text { Ressultado } \\
\text { (Tendência) }\end{array}$ & $\begin{array}{l}\text { Resultado } \\
\text { (Crescim) }\end{array}$ & $\begin{array}{c}\text { Resultado } \\
\text { (Rate) }\end{array}$ & $\begin{array}{c}\text { Resultado } \\
\text { (Média Movel }\end{array}$ & $\begin{array}{c}\text { Resultado } \\
\text { (Média Móvel }\end{array}$ & $\begin{array}{l}\text { Resultado } \\
\text { (Médla Móvel }\end{array}$ & Agente FCT & PAFCT & $\begin{array}{l}\text { Minutos por } \\
\text { Agente FCT }\end{array}$ & $\begin{array}{c}\text { TX de } \\
\text { Oappaçäo }\end{array}$ & NSFCT \\
\hline 6.839 & 6.998 & 1,09 & 1,06 & 1,06 & 1,08 & 25.517 & 7.267 & 7.558 & 6.505 & 6.302 & 6.659 & 6.277 & & & & & \\
\hline 6.799 & 6.976 & 0,91 & 0,81 & 0,89 & 0,82 & 15.260 & 5.500 & 5.749 & 6.138 & 6.083 & 6.247 & 6.523 & 11 & 11 & 2.388 & 1,00 & $86,3 \%$ \\
\hline 6.766 & 6.958 & 1,18 & 0,83 & 1,14 & 0,85 & 36.587 & 5.634 & 5.920 & 6.222 & 5.984 & 5.998 & 6.123 & 11 & 11 & 2.754 & 1,00 & $88,2 \%$ \\
\hline 6.707 & 6.905 & 1,24 & 0,79 & 1,20 & 0,81 & 26.414 & 5.273 & 5.560 & 6.145 & 5.871 & 5.881 & 5.907 & 11 & 11 & 2.404 & 1,00 & $82,5 \%$ \\
\hline 6.766 & 6.983 & 1,69 & 0,79 & 1,64 & 0,81 & 29.965 & 5.352 & 5.665 & 6.620 & 6.085 & 5.979 & 5.962 & 11 & 11 & 2.218 & 1,00 & $80,9 \%$ \\
\hline 7.036 & 7.279 & 0,80 & 0,95 & 0,78 & 0,98 & 30.308 & 6.683 & 7.117 & 7.560 & 6.758 & 6.570 & 6.363 & 13 & 13 & 2.450 & 1,00 & $80,7 \%$ \\
\hline 7.033 & 7.286 & 1,16 & 1,21 & 1,12 & 1,25 & 32.414 & 8.528 & 9.113 & 6.195 & 6.485 & 6.738 & 6.576 & 12 & 12 & 3.387 & 1,00 & $80,1 \%$ \\
\hline 7.340 & 7.618 & 1,15 & 1,03 & 1,11 & 1,07 & 33.194 & 7.575 & 8.115 & 6.271 & 7.219 & 6.968 & 7.043 & 13 & 13 & 2.992 & 1,00 & $87,4 \%$ \\
\hline 7.662 & 7.970 & 1,13 & 1,33 & 1,08 & 1,38 & 31.118 & 10.215 & 10.975 & 8.282 & 7.759 & 7.740 & 7.377 & 11 & 11 & 3.733 & 1,00 & $84,1 \%$ \\
\hline 8.460 & 8.737 & 0,89 & 1,08 & 0,86 & 1,11 & 29.604 & 9.101 & 9.716 & 11.338 & 9.610 & 9.167 & 8.772 & 12 & 12 & 3.153 & 1,00 & $82,4 \%$ \\
\hline 8.228 & 8.453 & 0,82 & 0,92 & 0,80 & 0,96 & 29.567 & 7.607 & 8.078 & 5.693 & 7.630 & 8.759 & 8.545 & 14 & 14 & 2.524 & 1,00 & $80,7 \%$ \\
\hline 8.410 & 8.687 & 0,67 & 0,99 & 0,64 & 1,02 & 33.236 & 8.325 & 8.885 & 8.189 & 7.910 & 7.533 & 8.462 & 18 & 18 & 2.579 & 1,00 & $81,8 \%$ \\
\hline 8.609 & 8.939 & 0,99 & 1,07 & 0,95 & 1,07 & 30.615 & 9.217 & 9.601 & 8.218 & 8.193 & 8.067 & 7.694 & 21 & 21 & 2.247 & 1,00 & $80,6 \%$ \\
\hline 8.805 & 9.187 & 1,03 & 0,84 & 0,98 & 0,85 & 27.989 & 7.430 & 7.774 & 8.238 & 8.415 & 8.393 & 8.249 & 20 & 20 & 2.309 & 1,00 & $81,9 \%$ \\
\hline 8.821 & 9.230 & 0,84 & 0,95 & 0,81 & 0,95 & 36.328 & 8.353 & 8.751 & 7.222 & 7.967 & 8.183 & 8.220 & 15 & 15 & 2.877 & 1,00 & $85,6 \%$ \\
\hline 8.729 & 9.130 & 0,86 & 0,94 & 0,82 & 0,94 & 28.920 & 8.176 & 8.559 & 6.459 & 7.353 & 7.481 & 7.779 & 14 & 14 & 3.004 & 1,00 & $81,5 \%$ \\
\hline 8.497 & 8.824 & 0,93 & 1,09 & 0,89 & 1,09 & 36.375 & 9.278 & 9.599 & 5.443 & 6.478 & 6.608 & 6.910 & 14 & 14 & 3.141 & 1,00 & $81,5 \%$ \\
\hline 8.649 & 9.012 & 0,89 & 0,90 & 0,86 & 0,91 & 34.333 & 7.791 & 8.205 & 8.366 & 7.485 & 6.901 & 6.936 & 14 & 14 & 3.043 & 1,00 & \\
\hline 8.851 & 9.253 & 0,91 & 1,20 & 0,87 & 1,21 & 34.867 & 10.591 & 11,183 & 8.889 & 8.267 & 8.148 & 7.520 & 14 & 14 & 3.182 & 1,00 & \\
\hline 8.841 & 9.256 & 0,93 & 1,07 & 0,89 & 1,08 & 38.938 & 9.485 & 10.007 & 7.302 & 7.855 & 8.213 & 8.126 & 15 & 15 & 3.182 & 1,00 & \\
\hline
\end{tabular}


A pesquisa bibliográfica proposta nos permite realizar simulações da efetividade de um modelo de gerenciamento de processos aplicado a previsão de demanda.

Utilizando como base dados médios dos custos praticados pela empresa de Call Center, em que foi feito este estudo de caso, podemos fazer uma projeção dos custos anuais. No caso observado, após ser colocada em prática a metodologia exposta neste trabalho, foi analisado uma média de 10 operadores a mais em cada mês do ano. 0 que se comparado a uma operação de quase 4.000 atendentes, alocados em várias células de atendimento, pode representar um percentual baixo, porém de custo muito elevado conforme mostrado na tabela abaixo.

Esta análise nos ilustra o quanto a capacitação dos gestores e utilização das ferramentas de qualidade são essenciais neste setor. Com isso entendemos a importância da previsão de demanda para evitar gastos que possam comprometer a receita da empresa, seja ela prestadora de serviços, tendo que assumir custos fora do combinado no contrato, ou contratante, podendo mitigar os custos desnecessários.

Figura 7: Custo de PA e Operador em Média

\begin{tabular}{|c|r|r|}
\hline Computador & $\mathrm{R} \$$ & $1.300,00$ \\
\hline Licença de software de telemarketing & $\mathrm{R} \$$ & 500,00 \\
\hline Linha telefônica & $\mathrm{R} \$$ & $\mathbf{9 0 0 , 0 0}$ \\
\hline Mesa com divisória & $\mathrm{R} \$$ & 40,00 \\
\hline Cadeira & $\mathrm{R} \$$ & $2.250,00$ \\
\hline $\begin{array}{c}\text { Custo por operador: Salário + benefícios (vale } \\
\text { transporte, vale refeição e assistência médica) } \\
\text { conta telefônica }\end{array}$ & $\mathrm{R} \$$ & $4.780,00$ \\
\hline $\begin{array}{c}\text { Custo por PA } \\
\text { Custo para 10 operadores }\end{array}$ & $\mathbf{R} \$$ & $\mathbf{4 7 . 8 0 0 , 0 0}$ \\
\hline Custo anual & $\mathbf{R} \$$ & $573.600,00$ \\
\hline
\end{tabular}

Fonte: Dados da Empresa adaptado pelo autor.

Como resultados destes procedimentos a empresa poderá prestar o serviço de atendimento com qualidade. Mantendo a capacidade de atendimento, preparada para a quantidade de chamadas previstas, e reduzindo os custos mencionados na tabela de custos por operador, evitando o pagamento de muitos operadores a mais do que o necessário. Que podem gerar gastos acima de $\mathrm{R} \$ 500.000,00$ por ano utilizando como base apenas 10 operadores desnecessários a mais por mês, o que pode variar de acordo com o número de contratados e quantidade de células de atendimento.

\section{CONCLUSÃO}

Através das análises apresentadas e pesquisas sobre os temas abordados, gestão de processos e previsão de demanda, pôde ser visualizada com clareza todas as etapas fundamentais do processo de planejamento, forecasting e o quanto é importante para a empresa que sejam utilizados estes métodos da forma correta, para que se atendam seus interesses de lucro e redução de custos.

Obtivemos demonstrações da efetividade em redução de custos, em uma empresa de Call Center, que a previsão de demanda utilizada de maneira analítica, seguindo os processos de melhoria contínua e controles de assertividade podem gerar. Utilizando como base, dados reais, média praticada neste segmento, de preços cobrados por operador e PA (Posto de Atendimento) em empresas prestadoras de serviço de atendimento, calculamos o quanto poderia gerar de custos desnecessários, certa quantidade de atendentes a mais que o necessário para atender à demanda. 0 resultado, foram gastos de mais de $\mathrm{R} \$ 500.000,00$ por ano, podendo chegar até a mais de $\mathrm{R} \$ 1.000 .000,00$ dependendo da quantidade de operadores e do tamanho da empresa. 


\section{REFERÊNCIAS}

[1] Lima, Rafael. Fluxograma Vertical mais Modelo de Fluxograma. Disponível em: < http://aprendendogestao.com.br/fluxograma-vertical-modelo-de-fluxograma/>. Acesso em: 31 jul. 2017.

[2] Aghata Maxi Consulting. Como Desenhar Fluxogramas de Processos de Negócios. Disponível em: < https://aghatha.wordpress.com/2011/07/03/como-desenhar-fluxogramas-de-processos-de- negocio-1-parteintroducao-conceitos-e-modelos/>. Acesso em: 31 jul. 2017.

[3] Gonçalves, F. - Excel Avançado 2003/2007 Forecast: Analise e Previsão de Demanda - 1āa edição, Ciência Moderna - 2007, p. 5-100.

[4] De Oliveira, S. B. - Gestão por Processos: fundamentos, técnicas e modelo de implementação - 2ª edição, Qualitymark, 2006.

[5] Fernandes, F. Cesar Faria. - Planejamento e Controle da Produção: dos fundamentos ao essencial - 1aㅡ edição, São Paulo: Atlas - 2010 .

[6] Araujo, Luis Cezar G. de - Gestão de Processos: melhores resultados e excelência organizacional, - 1aa edição, São Paulo: Atlas - 2011, p.10-120.

[7] Tubino, D. F. - Planejamento e Controle da Produção: Teoria e prática, 2ª edição, São Paulo: Atlas, 2009 , p. 88.

[8] Muller, Cláudio J. - Modelo de Gestão Integrando Planejamento Estratégico, Sistemas de Avaliação de Desempenho e Gerenciamento de Processos (MEIO - Modelo de Estratégia, Indicadores e Operações). 2003. 252f. Tese (Doutorado em Engenharia) - Universidade Federal do Rio Grande do Sul, Rio Grande do Sul. 2003.

[9] Corrêa, Henrique L., 1960 - Planejamento, programação e controle da produção: MRP II/ ERP: conceitos, uso e implatação: base para SAP, Oracle Applications e outros softwares integrados de gestão - 5a edição - 3므 reimpressão, São Paulo: Atlas - 2009. 


\section{Capítulo 9}

Proposta de melhoria no gerenciamento de projetos inovadores em startup de base tecnológica utilizando modelo híbrido de gestão de projeto

\section{Gustavo de Souza}

Isotilia Costa Melo

Karoline Arguelho da Silva

Diogo Ferraz.

Daisy Aparecida do Nascimento Rebelatto

Resumo: 0 desenvolvimento de projetos inovadores, que chegam ao mercado rapidamente e causam mudanças disruptivas no contexto de atuação, tornam startups de base tecnológica muito competitivas. Uma importante fonte recursos para o fomento de áreas de P\&D em pequenas empresas é o PIPE (Pesquisa Inovativa em Pequena Empresa) da FAPESP. Contudo, o baixo tempo de trabalho e a falta de experiência da startup no gerenciamento de projetos desse tipo, pode levar à condução de projetos de forma menos eficiente. Foi aplicado um questionário a uma startup a fim de caracterizar o nível de gerenciamento utilizado em seus projetos PIPE. A partir da análise crítica das respostas, foram propostas ferramentas híbridas (ágeis e tradicionais), que se encaixassem na cultura organizacional da empresa e pudessem levar ao desenvolvimento mais dinâmico dos projetos. A análise feita mostrou uma gestão atual com foco na figura central do GP (Gerente de Projetos). As ferramentas ágeis propostas aumentam o nível de participação da equipe na tomada de decisões e as tradicionais melhoram a organização das etapas de planejamento e desenvolvimento. No final, um guia passo-a-passo, com um roteiro de gestão nas etapas do projeto foi elaborado afim de ajudar a dinamizar a gestão de projetos inovadores, levando ao desenvolvimento de equipes autogeridas e o envolvimento maior do cliente no ciclo do projeto.

Palavras-chaves: Gerenciamento Híbrido; gerenciamento Ágil; startup; PIPE-Fapesp; ferramentas de gestão. 


\section{INTRODUÇÃO}

Para uma startup de base tecnológica, desenvolver e colocar um produto no mercado é um desafio que requer investimento econômico elevado para a realidade da empresa. Além disso, para ela se manter viva no mercado, o timing de desenvolvimento desse produto deve ser pequeno e, em contrapartida, o grau de inovação deve ser primordialmente elevado. Nesse cenário, os fundos de captação de recursos existentes são fundamentais para a manutenção da competitividade da empresa de pequeno porte. Dentre eles, o PIPE (Pesquisa Inovativa em Pequenas Empresas) da FAPESP (Fundação de Amparo à Pesquisa do Estado de São Paulo) é uma alternativa aos empreendedores do estado de São Paulo (SP). 0 PIPE tem por objetivo apoiar a pesquisa em ciência e tecnologia como instrumento para promover a inovação tecnológica, promover o desenvolvimento empresarial e aumentar a competitividade das pequenas empresas. Ele possibilita que as empresas se associem a pesquisadores do ambiente acadêmico em projetos de pesquisa visando à inovação tecnológica (PADRÃO; ANDREASSI, 2013; BRITO, 2018; FAPESP, 2019).

As propostas de pesquisa das startups para o PIPE devem demonstrar claramente: (1) que a empresa possui uma equipe com competência para executar esse projeto específico, (2) que há um potencial de inovação que demanda pesquisa científica ou tecnológica e (3) que essa inovação levará ao desenvolvimento de um produto, processo ou serviço economicamente sustentável e que trará ganhos comerciais para a empresa. As submissões para o PIPE são organizadas em três Fases, como mostra a com o QUADRO 1 (FAPESP, 2019).

QUADRO 1. Fases e requisitos do programa PIPE da FAPESP. Adaptado de FAPESP (2019).

\begin{tabular}{|c|c|c|c|}
\hline & FASE 1 & FASE 2 & FASE 3 \\
\hline Objetivo & $\begin{array}{l}\text { Análise de viabilidade } \\
\text { Técnico-Científica }\end{array}$ & $\begin{array}{c}\text { Desenvolvimento da } \\
\text { proposta }\end{array}$ & $\begin{array}{l}\text { Desenvolvimento } \\
\text { comercial e industrial do } \\
\text { produto/ processo }\end{array}$ \\
\hline Duração máxima (meses) & 9 & 24 & - \\
\hline $\begin{array}{l}\text { Valor do financiamento } \\
\text { (R\$) }\end{array}$ & 200.000 & 1.000 .000 & Editais junto ao FINEP \\
\hline Requisitos & - & $\begin{array}{l}\text { Apresentar plano de } \\
\text { negócios }\end{array}$ & Ter 250 empregados \\
\hline Chamadas & A cada 3 meses & - & - \\
\hline
\end{tabular}

Para desenvolver projetos excelentes, de alto grau de inovação e a curtos intervalos de tempo (3 meses, para a primeira chamada do PIPE), a empresa precisa ter o setor de estruturação e ideação de projetos organizado, além de, é claro, mão de obra qualificada e especializada para conduzir o projeto durante sua execução. Devido ao baixo tempo de execução e ao dinamismo envolvido no desenvolvimento das atividades, ferramentas precisas e abordagens inovadoras de gestão de projetos podem auxiliar as empresas a serem mais eficientes, sendo um diferencial competitivo no mercado. A abordagem ágil pode se encaixar nesse contexto dependendo, entre outros fatores, da cultura organizacional.

No cenário dos projetos de produtos inovadores, incerteza é uma palavra chave. Pode haver incerteza nos resultados, recursos, prazo, risco e todas as demais dimensões do gerenciamento. Amaral et al. (2011) fazem uma reflexão crítica sobre se ágil seria realmente uma abordagem alternativa ao gerenciamento de projetos dito tradicional. Os autores mostram que gerenciamento ágil é um conjunto de práticas complementares às já existentes, que endossam o corpo de conhecimento como um todo e não rivalizam com a teoria tradicional.

A empresa, junto a qual o projeto foi desenvolvido, foi fundada em 2014 na incubadora de startups Parque tecnológico (ParqTec), localizada no município de São Carlos - SP. Hoje, em uma sede própria, a empresa, que atua na área de soluções em polímeros, conta com 16 funcionários. As atividades da empresa se subdividem principalmente nos setores de análise de materiais poliméricos, pesquisa \& desenvolvimento (P\&D) e consultoria.

No setor de P\&D, os projetos PIPE são uma importante fonte de financiamento para a empresa, principalmente, os de Fase 1, que ocorrem em ciclos a cada três meses e são destinadas ao financiamento de uma pesquisa de viabilidade técnica, ramo de especialidade da empresa, que utiliza o apoio para o 
desenvolvimento de novos materiais. A empresa, que já teve dois projetos concluídos nessa modalidade, visa a aumentar o número de propostas enviadas, sendo a meta enviar pelo menos uma proposta por chamada da FAPESP.

Devido aos outros dois setores de atividades da empresa, que são sua principal fonte de recurso, os funcionários e a alta gerência têm tempo limitado para o gerenciamento das propostas para projetos PIPEFAPESP.

O objetivo do presente trabalho foi levantar o desenvolvimento dos um dos projetos PIPE-FAPESP, que a empresa já teve e, por meio de questionário, mapear a situação atual da empresa quanto ao nível de gerenciamento desses projetos. Em seguida, com base nos conceitos e ferramentas de gestão tradicional e da gestão ágil, foi proposto o uso de ferramentas híbridas de gestão de projetos, a fim de dinamizar o processo de gestão na empresa. Ao final, um modelo conceitual do passo-a-passo de gestão envolvendo desde a etapa da ideação até a conclusão do projeto foi criado.

\section{MÉTODO}

O levantamento do histórico de gerenciamento de projetos se deu por meio de uma entrevista semiestruturada com um membro de alta gerência da empresa, envolvido diretamente na gestão. Dessa forma, foi feita a caracterização da empresa e de seus processos de ideação de propostas para projeto.

A partir da leitura das respostas obtidas, foi feita uma análise crítica a fim de identificar os principais gaps no modelo atual de gestão. Então, foi feita uma busca na literatura sobre a abordagem de gestão ágil e, juntamente com os elementos da abordagem tradicional, foi proposto um guia de melhores práticas para a empresa conduzir seus projetos com maior dinamismo, por meio da autogestão e integração da equipe. Um modelo conceitual híbrido foi proposto.

\section{RESULTADOS E DISCUSSÕES}

\subsection{CARACTERIZAÇÃO DA STARTUP E SEUS PROCESSOS}

Primeiramente, nota-se que apesar da empresa ser relativamente nova (6 anos) e com poucos funcionários, ela já possui um escritório de P\&D graças, majoritariamente, à implementação de projetos PIPE-FAPESP, que dispõe recursos para o fomento à inovação na empresa. Essa realidade é diferencial, uma vez que a grande maioria de empresas nacionais (já consolidadas) não possuem um escritório de P\&D. Além disso, o Gerente de Projetos (GP) atribui o fator de sucesso e vantagem competitiva da empresa, à elevada qualidade técnica de sua equipe.

Quanto ao desenvolvimento dos projetos PIPE-FAPESP, a ideação surge em reuniões entre dois sócios (doutores em engenharia de materiais) e um professor doutor aposentado, que atua como assessor e mentor acadêmico. 0 foco dos projetos é voltado para compostos de matrizes poliméricas recicladas reforçados com carga vegetal, área de formação e de grande domínio dos envolvidos. 0 grau inovador dos projetos se encontra no forte apelo ambiental pelo desenvolvimento de polímeros commodities a partir de resíduos sólidos das indústrias produtoras, tanto do polímero matriz quanto das cargas (resíduo vegetal). 0 potencial do projeto na criação de rotas de economia circular é de interesse das grandes indústrias.

Após a fase de ideação, ambos os sócios escrevem o projeto e um deles se torna oficialmente o GP. 0 projeto é, então, revisado em termos técnicos pelo professor assessor e, posteriormente, submetido à FAPESP. No projeto, além da concepção e da forma de condução, são fatores importantes o detalhamento do escopo, do orçamento e dos prazos para a realização das atividades. Dada a aprovação, as atividades devem ser realizadas conforme proposto e assinado em termo de outorga.

Depois da aprovação do projeto que, englobando todas as etapas pode levar de 9 a 15 meses, a equipe de trabalho é formada e o GP distribui as tarefas, gerenciando o projeto por meio do controle do cronograma estipulado no plano de trabalho. As tarefas envolvem a montagem e a realização de ensaios técnicos, que é dividida entre funcionários e colaboradores terceiros, cabendo ao GP a análise e a escrita do relatório final.

São feitas reuniões de acompanhamento diárias com os membros da equipe para discutir o andamento das tarefas e o GP faz uma reunião mensal com o professor assessor para mostrar o avanço do projeto. Contudo, não há um monitoramento ou controle dos assuntos discutidos nas reuniões por meio de atas. As tarefas realizadas e as etapas de desenvolvimento pré-estabelecidas no plano de trabalho são os marcos e medidores de avanço do projeto, existindo, portanto, uma necessidade de indicadores mais precisos. 0 
espaço de reuniões é interno na empresa, porém, não é exclusivo da área de projetos, sendo compartilhado com as outras áreas de atuação da empresa.

O esquema apresentado na FIGURA 1 ilustra o modelo atual, centrado no GP, onde M1, M2, M3...Mn, seriam os membros da equipe de projetos.

FIGURA 1 Modelo atual de gestão dos projetos PIPE-FAPESP, centrado na figura do GP.

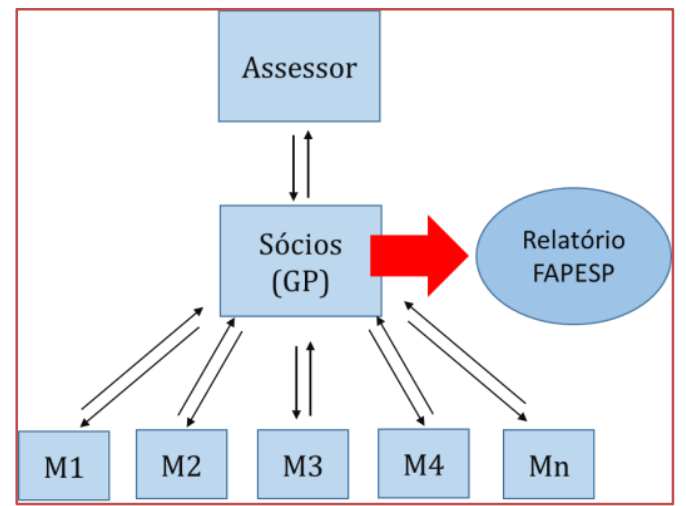

Ao término do projeto, os principais resultados são agrupados pelo GP, que monta o relatório final. 0 relatório é revisado pelo professor assessor e submetido à FAPESP. A aprovação do relatório marca o final do projeto. Não há uma reunião de fechamento com a equipe e não existe um registro de lições aprendidas durante o processo.

O QUADRO 2 mostra as notas de 1-5 atribuídas pelo GP aos principais pontos chave do desenvolvimento do projeto PIPE-FAPESP realizado pela empresa. Os critérios foram considerados de igual importância (5) pelo GP.

QUADRO 2. Notas atribuídas pelo gestor aos principais pontos durante o desenvolvimento do projeto PIPE-FAPESP.

\begin{tabular}{|c|c|c|}
\hline Ruim(1-2) & Regular/Bom (3-4) & Excelente (5) \\
\hline \multirow[t]{3}{*}{ Nada consta. } & Ideação & Integração entre a equipe \\
\hline & Desenvolvimento & Comunicação entre os participantes \\
\hline & $\begin{array}{l}\text { Medida de desempenho dos } \\
\text { participantes }\end{array}$ & \\
\hline
\end{tabular}

\subsection{MODELO ATUAL DE GESTÃO E SEUS GAPS}

A partir da análise do modelo de condução atual dos projetos PIPE, desenvolvidos pela empresa, identificam-se alguns elementos que favorecem o modelo de gestão tradicional tais como: escopo, prazo e tempo fixos e o desenvolvimento do projeto centralizado no GP, que monitora o andamento do projeto por meio do controle do cronograma de atividades. No modelo atual, o cronograma de atividades é a única ferramenta de monitoramento e controle usada.

Outro ponto que remonta ao modelo tradicional de gestão é o baixo grau de incerteza e riscos na concepção e desenvolvimento do projeto. 0 projeto é proposto na área de expertise tanto do GP quando do assessor e, durante a execução, o melhor caminho é escolhido, baseado na experiência dos pesquisadores. Desse modo, o plano de trabalho tem grande probabilidade de dar certo sem que ocorram mudanças bruscas de escopo.

O modelo baseado na figura central e controladora do GP tem suas limitações, principalmente, quando se trabalha com uma equipe de alta qualidade técnica, como é o caso da empresa entrevistada. 0 papel de executor de tarefas, destinado aos colaboradores, pode, a médio e longo prazos, desmotivar o grupo em 
virtude da falta de inovação e da rotina gerada pelas atividades técnicas. Uma vez que eles não participam ativamente das decisões, pode ser desenvolvido um senso de não pertencimento, ao não acompanharem o desenvolvimento do projeto como um todo.

Além disso, ter o relatório final como único marco de fechamento do projeto pode empobrecer a relação dos colaboradores com o projeto, fazendo com que os integrantes não possuam (ou possuam em menor grau) o sentimento de realização e conquista alcançados no final de um projeto. Com isso, o nível de motivação a novos desafios nos projetos posteriores pode ser menor.

Por fim, a ausência de um espaço físico destinado exclusivamente ao projeto pode inibir a integração entre os membros da equipe que dividem a atenção entre as atividades do projeto em execução e as outras funções da empresa (prestação de serviço e consultoria). Outro ponto é que, sem o registro de lições aprendidas pelo GP e demais membros, pode-se, em projetos futuros, perder tempo e recurso com desafios que já foram superados em projetos passados.

\subsection{MODELO DE GESTÃO SUGERIDO}

Como visto, a forma de desenvolvimento conduzida pela empresa no projeto PIPE-FAPESP tem raízes no modelo tradicional de gerenciamento. Com isso, algumas ferramentas tradicionais se tornam pertinentes nas etapas a serem desenvolvidas. Por exemplo, a partir do momento em que a ideia do projeto foi concebida e o escopo definido, pode-se utilizar a estrutura analítica de projetos (EAP) para detalhar as atividades até chegar aos pacotes de trabalho. Contudo, como há uma limitação com relação ao andamento do projeto centrado na figura do GP, é possível implementar os conceitos e abordagem da metodologia ágil, a fim de motivar e integrar a equipe visando a um processo de autogestão e autorganização.

A abordagem de gerenciamento Ágil proposta por Amaral et al. (2011), ao contrário de outras literaturas sobre o tema, não contrapõe o gerenciamento ágil ao gerenciamento tradicional e, sim, trata a filosofia de gestão ágil como uma abordagem adicional à tradicional, na qual sua funcionalidade depende do contexto e da cultura organizacional, podendo fazer o uso de ferramentas específicas. Portanto, no cenário de análise atual, há a possibilidade de aplicação de um modelo híbrido, onde fundamentos tanto do tradicional quanto do ágil possam ser implementados.

Tendo em mente que a abordagem ágil, onde a equipe deve ser integrada e participativa rumo ao desenvolvimento da autogestão, sugere-se que, logo após a fase de ideação, justificativa e delineamento do que é pretendido para o andamento do projeto, realizada entre os sócios e o professor assessor, seja feita uma reunião com os possíveis membros da equipe explicando o objetivo geral e o escopo do projeto. Nessa reunião, com auxílio da equipe, o GP teria a missão de construir a visão do produto do projeto, conceito que vai além do escopo. A partir do momento que a visão fica clara para todos os colaboradores, o senso de pertencimento e a motivação da equipe em trabalhar no projeto aumentam. Eles irão contribuir com o máximo de suas capacidades, se sentirem motivados.

Como o projeto demora um período de tempo considerável para ser aprovado, é permitido despender certo tempo na fase de planejamento inicial para o detalhamento das atividades, conforme manda o rito tradicional. Com isso, os pacotes de trabalho podem ser desdobrados em atividades detalhadas. A partir desse detalhamento, as fases e marcos do projeto (milestones) podem ser delimitadas.

Para a realização da lista de tarefas, atribuição de tempo, custo e responsável, bem como elencar a interdependência das tarefas realizadas, as ferramentas computacionais MS Project $\circledast$, WBS schedule Pro® e Trello® podem ser empregadas. É sugerido a alocação de um membro da equipe responsável por estruturar os pacotes de trabalho nos programas adequados e, com ajuda dos demais membros, quantificar e apresentar as tarefas a serem executadas durante o projeto.

Ainda na etapa de planejamento, podem ser feitos os cronogramas das reuniões mensais que serão realizadas entre o GP e o professor assessor juntamente com os tópicos esperados para discussão nesses encontros. Essas reuniões devem ocorrer em pontos estratégicos do andamento do projeto, por exemplo, a cada milestone finalizado. Como o PIPE-FAPESP Fase I tem duração de 9 meses, serão realizadas 9 reuniões mensais e, portanto, 9 milestones podem ser atribuídos ao projeto.

Durante a realização das reuniões mensais, é importante que um certo rigor seja empregado do ponto de vista de controle do projeto. Nesses encontros, é sugerido que sejam feitas atas dos assuntos tratados e que, nesse documento, contenham, principalmente, respostas para às seguintes perguntas:

- Houve necessidade de replanejamento ou alteração do escopo? 
- $\quad$ Foram acrescentadas novas tarefas ao projeto? Se sim, por quê?

Ao final de cada reunião, os arquivos de monitoramento e controle do MS Project, Trello e WBS schedule pro serão atualizados. Além disso, é de extrema importância que haja a participação ativa dos membros da equipe nas reuniões mensais, de forma a manter o engajamento e o senso de participação dos colaboradores.

Durante a etapa de monitoramento e controle, além do gráfico de Gantt, já utilizado pela empresa, sugerese algumas ferramentas adicionais, de simples visualização. Nessa etapa, portanto, voltamos sugere-se à abordagem ágil de gestão, para a criação de um painel de controle visual e iterativo de gestão.

Amaral et al. (2011) propõem o enfoque no monitoramento visual como forma de controle ágil do projeto. Para isso, é sugerida a criação de um quadro físico iterativo, contendo as principais fases do projeto e suas respectivas entregas. No presente estudo, propõe-se para a empresa, a criação do quadro PVPCP (Painel Visual de Planejamento e Controle de Projetos). No quadro físico, estarão as principais etapas do projeto (pré-, desenvolvimento e pós- projeto), onde suas fases e entregas estão distribuídas de maneira genérica. 0 preenchimento das entregas deve ser feito de forma manual por meio de cartões autoadesivos, onde as entradas são as entregas elaboradas durante a criação da EAP. Uma versão eletrônica também deve ser mantida para controle do GP. Sugere-se que a equipe preencha o quadro em conjunto, de modo a aumentar a integração dos participantes. No presente quadro, é omitida a parte da iterativade proposta por Amaral et al. (2011) uma vez que, o escopo e o total de tarefas são bem definidos no início do projeto. O replanejamento (se necessário) ocorreria apenas ao final de cada reunião mensal.

É sugerido que as tarefas a serem executadas durante a semana sejam discutidas em uma reunião informal no início da semana. 0 preenchimento do quadro também deve ser feito de maneira conjunta. Além da entrega, o cartão também deve apresentar o responsável pela entrega. Se uma entrega durar mais do que uma semana, essa deve ser dividida em mais cartões e suas atribuições devem ser destacadas como uma tarefa longa.

Ao final da semana, as tarefas realizadas são agrupadas e a ferramenta computacional utilizada no monitoramento e controle é alimentada com o número de tarefas realizadas e tarefas pendentes. A partir desses dados, juntamente com os dados da criação da lista detalhadas de tarefa e da distribuição dessas tarefas ao longo do tempo, no período do projeto (feito no início do planejamento), é possível criar um gráfico do tipo burn down. 0 gráfico mostra, juntamente com as tarefas planejadas, o andamento das realizações das mesmas ao longo do tempo.

Do gráfico, é possível retirar indicadores de desempenho da equipe, uma vez que quando o valor da curva de tarefas realizas menos as tarefas planejadas é positivo, significa que a equipe realizou menos tarefas do que o planejado e, portanto, encontra-se em atraso. Quando, por outro lado, o valor é negativo, a equipe está avançada em relação ao planejamento. Quando o valor é 0 (zero), a equipe está no prazo estipulado. Vale ressaltar a limitação dessa análise, ao considerar o peso de todas as tarefas de maneira igualitária e, portanto, sua aplicação deve ser realizada com cautela.

Para manter o controle visual do projeto, propõe- se a criação de dois quadros, o primeiro que deve ser maior, conterá a visão do produto do projeto em destaque, juntamente com o PVPCP, o gráfico burn down e o indicativo de andamento do projeto, que nada mais é do que a razão entre tarefas realizadas e as tarefas planejadas. Esse quadro deve permanecer no espaço físico destinado às reuniões de acompanhamento do projeto. 0 segundo quadro, de dimensões menores, apresentará a visão do produto e o QPFS (Quadro de Planejamento Fino Semanal) e deve permanecer no local de trabalho dos membros da equipe, sendo de fácil acesso para consulta e modificação pelos colaboradores durante a semana.

Ainda na visão de gerenciamento ágil, existe o papel fundamental que a integração do cliente representa para o sucesso do projeto. Como o projeto é financiado por uma fundação pública em conjunto com a empresa, esse inicia-se sem um cliente específico. Propõem-se que, mediante o desenvolvimento do projeto, na medida em que as propriedades dos novos materiais desenvolvidos forem sendo caracterizadas, deve-se buscar potenciais clientes para o produto e trazer esses clientes para reuniões de acompanhamento do projeto. Conforme o interesse e necessidade desses potenciais clientes, pequenas alterações ou novos projetos podem ser desenvolvidos em conjunto, para a chegada mais rápida da inovação ao mercado.

Quando o período de desenvolvimento do projeto chegar ao fim e todas as atividades forem cumpridas, o encerramento do projeto deve ser feito em uma reunião formal. Nessa reunião, devem ser discutidos os principais avanços que o projeto proporcionou, suas principais entregas, as lições aprendidas e as dificuldades superadas. Um membro da equipe deve ser responsável por anotar e formalizar o documento 
final. O discurso do GP, nessa reunião, deve ser motivador de forma a manter o espírito de superar desafios promovido na equipe para os próximos projetos.

Por fim, é sugerida a construção de uma "estante de repositório de projetos" (AMARAL et al., 2011). Nesse móvel, deve-se agrupar os projetos por pastas, onde, dentro delas, seja colocada a folha de identificação do projeto, as atas das reuniões e a folha de lições aprendidas. A estante deve ser de fácil acesso a todos os membros e ficar no espaço físico destinado às reuniões do projeto. Além da organização, a presença do móvel no ambiente com o catálogo de projetos já realizados pelo grupo serve de motivação na realização do projeto atual. 0 repositório também pode ser montado de forma digital, permanecendo na intranet da empresa e de fácil acesso a todos.

A FIGURA 2 sintetiza a forma de gestão proposta para a empresa no desenvolvimento de futuros Projetos PIPE-FAPESP.

FIGURA 2 Forma de gestão proposta para a empresa, visando à integração e autogestão.

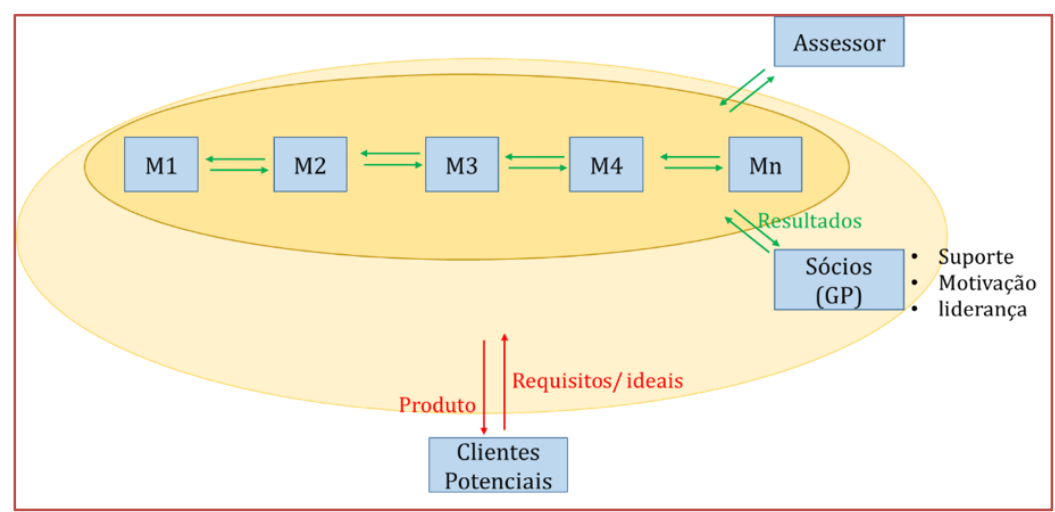

No QUADRO 3, é relacionado o aspecto do projeto com a abordagem (tradicional ou ágil) do qual ele foi adaptado para o contexto desta empresa, onde é possível observar, mais uma vez, o delineamento de uma solução hibrida para a gestão de projetos PIPE-FAPESP da empresa.

QUADRO 3. Aspectos do projeto estudado e o modelo utilizado para a proposição das ferramentas (tradicional ou Ágil).

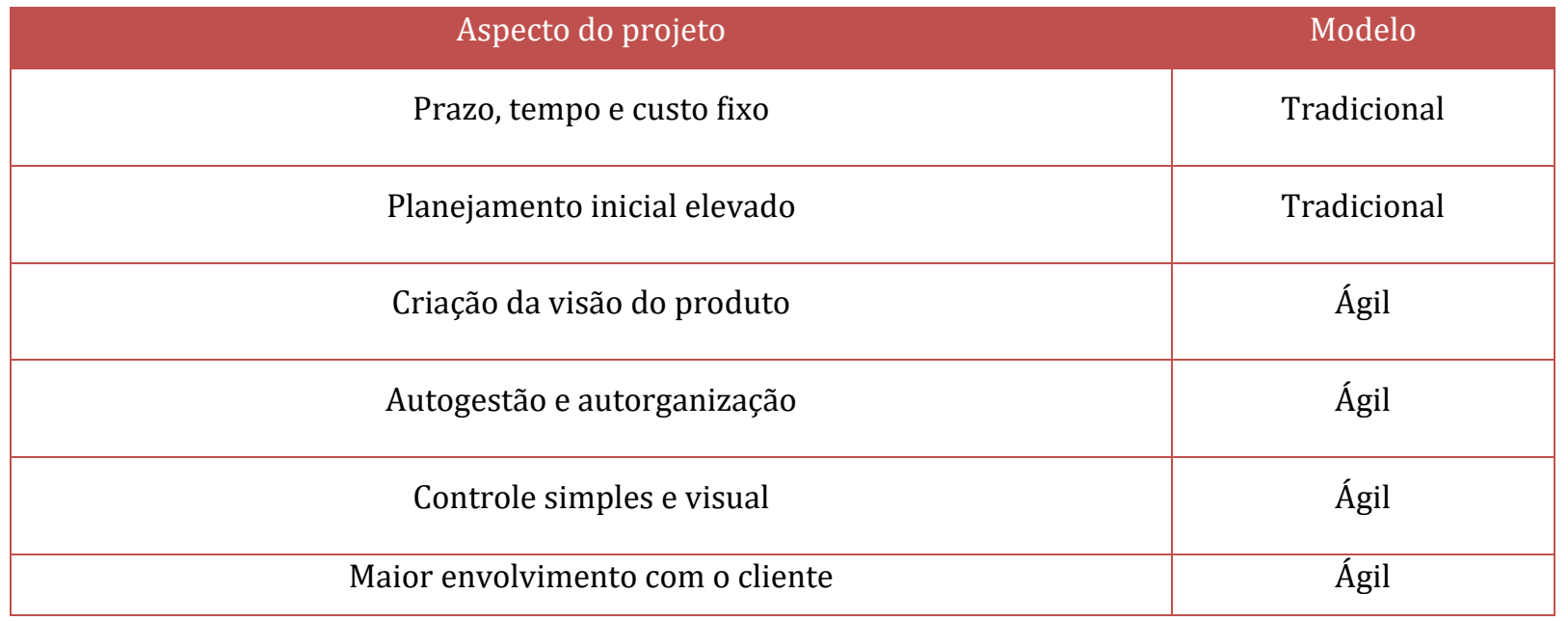

O organograma da FIGURA 2 ilustra o modelo, passo a passo, proposto pelo presente trabalho. 
FIGURA 3 Modelo proposto para o desenvolvimento do ciclo de projeto.

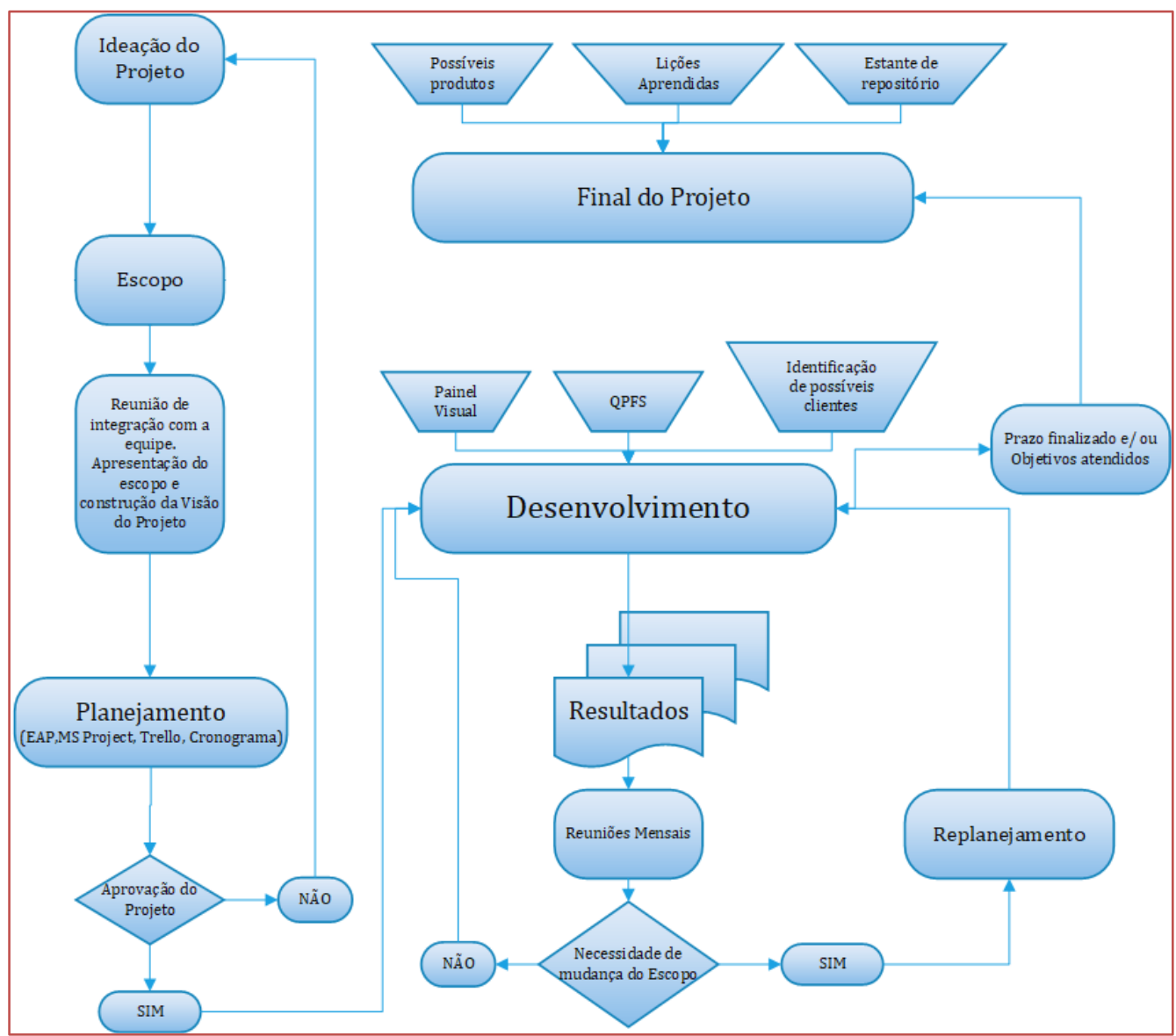

\section{CONSIDERAÇÕES FINAIS}

O presente trabalho buscou propor um modelo de gestão híbrido aliando práticas tradicionais juntamente com a abordagem ágil proposta por Amaral et al. (2011) para a implementação de melhoria no modelo de gestão de projetos de inovação fomentado pela FAPESP, por meio dos projetos PIPE, realizados por uma empresa de base tecnológica na área de engenharia de materiais.

A partir da entrevista inicial, foi identificada a importância dessa linha de fomento para a existência e manutenção da área de P\&D na empresa. Uma análise crítica das respostas recebidas mostrou que o modelo de gestão dos projetos conduzidos pela empresa é centrado na figura do GP, o qual, por meio do controle do cronograma do projeto, designa as tarefas pertinentes para os membros da equipe. A médio e longo prazo, vislumbrou-se que esse modelo de gestão, puramente tradicional, pode apresentar certas ressalvas em relação à motivação e ao desempenho da equipe que, por não ter uma visão do projeto como um todo e ser somente composta por executores das tarefas técnicas, pode perder o interesse e não desenvolver sua plena capacidade de trabalho.

O modelo proposto visou a aliar as práticas de gestão tradicional (complementando o modelo atual) com a sugestão de algumas ferramentas voltadas para a gestão ágil, inserindo fundamentos de visão do produto do projeto, autogestão e autorganização da equipe com ferramentas de gestão simples e visuais. Ressaltase que, nesse contexto, uma abordagem totalmente ágil não poderia ser proposta, uma vez que, necessariamente, a partir da aprovação do projeto junto a FAPESP, deve-se controlar prazo, escopo, e custo de execução.

O passo a passo proposto para a gestão de um projeto desse tipo visou a aumentar o dinamismo e a integração entre os membros da equipe, propor um acompanhamento mais detalhado dos passos da execução e, como resultado, melhorar a qualidade das entregas. Cabe agora ao GP e demais stakeholders do projeto, a aplicação do modelo proposto, fazendo as correções e adaptações práticas das possíveis limitações, em virtude da cultura organizacional e do contexto dos projetos realizados. A partir das 
devidas adequações, durante a implementação, espera-se que o modelo auxilie a empresa no melhor desenvolvimento de seus projetos e que possa motivar outras empresas, com modelo semelhante de negócio, a buscarem se aperfeiçoar na gestão dos projetos por elas realizados.

\section{REFERÊNCIAS}

[1] AMARAL, Daniel Capaldo et al. Gerenciamento ágil de projetos: aplicação em produtos inovadores. São Paulo: Saraiva, 2011.

[2] BRITO, Débora. Startups crescem no Brasil e consolidam nova geração de empreendedores. 2018. Disponível em: <http://agenciabrasil.ebc.com.br/economia/noticia/2018-07/startups-crescem-no-brasil-e-consolidam-novageracao-de-empreendedores>. Acesso em: 10 jun. 2019.

[3] FAPESP. Pesquisa Inovativa em Pequenas Empresas (PIPE). 2019. Disponível em: <http://www.fapesp.br/pipe/>. Acesso em: 10 jun. 2019.

[4] PADRÃO, Luis Carlos; ANDREASSI, Tales. O desempenho de startups de base tecnológica em regiões geográficas brasileiras. Revista da Micro e Pequena Empresa. Campinas, p. 66-79. ago. 2013. 


\section{Capítulo 10}

\section{Inovações na manufatura aditiva}

\section{Júlia Estefane Gonçalves}

\section{Lisley Panfilo Santos}

Marcelo Franca Alves Júnior

Roberto Guzman Sanchez.

Resumo: Este artigo apresenta uma análise e aplicação da manufatura aditiva na elaboração de um protótipo simplificado. 0 mesmo foi produzido em uma impressora 3D, a partir de um modelo virtual desenvolvido em CAD (Computer Aided Design). Introduzido pelas definições de desenho técnico e seu avanço, o objetivo consiste em conceituar a manufatura aditiva e a prototipagem rápida, paralela à impressora 3D. Com base nos resultados obtidos por meio da metodologia realizada, conclui-se que há uma aplicação prática na qual a manufatura aditiva possui ampla chance de crescimento e desenvolvimento nacional. Existe um potêncial para inovações e avanços no setor, oriundos de investimentos que ainda são escassos nesta área.

Palavras-chave: Manufatura Aditiva, Impressão 3D, Desenho técnico, Protótipo, Inovação. 


\section{INTRODUÇÃO}

Desde tempos remotos, a arte de gravura está inserida na sociedade como forma de transmitir informações às gerações. Com o avanço social e intelectual humano, o desenvolvimento da representação gráfica foi intensificado pelas descobertas e concepções da geometria, baseada na matemática. Os gregos, em particular Pitágoras e Platão, também perceberam as vantagens do estudo da Geometria espacial, associando-a ao estudo da metafísica e da religião, devido às formas abstratas que os sólidos apresentam (ARAÚJO, 2007).

Em conceito geral, o desenho é uma maneira de representar visões, formas e ideias. Essa imagem, obtida por meio da impressão de uma matriz artesanal, pode ser executada à mão livre ou auxiliada por instrumentos e aparelhos sofisticados. Dada a necessidade de reproduzir com precisão os objetos tridimensionais em um plano, o desenho técnico é uma derivação da geometria descritiva.

Amplamente utilizado como linguagem universal na Engenharia e Arquitetura, o desenho técnico engloba um conjunto de metodologias e padrões, com linhas, números e indicações escritas de acordo com normas ABNT específicas.

De acordo com Ulbricht (1992) e Silva (2001), o desenho técnico é uma linguagem de expressão gráfica que permite a transmissão de informações técnicas entre indivíduos. Assim sendo, trata-se de uma forma eficiente para propagação de ideias e soluções para os projetos de qualquer ramo das engenharias, imprescindível nos currículos dos cursos da área.

Com o avanço e propagação da tecnologia, os desenhos auxiliados por ferramentas computacionais se tornaram mais acessíveis e viáveis. Concomitante a esse desenvolvimento, houve um crescimento na variação de softwares utilizados para sua criação. Alguns dos grandes concorrentes do mercado são o Fusion360 da Autodesk e o Solidworks da Dassault Systems, este segundo será melhor explanado no decorrer do artigo. Dada essa grande popularização dos softwares de CAD (Computer Aided Design), o desenvolvimento da engenharia e da indústria vem progredindo, influenciando instituições de ensino.

A partir deste pressuposto, o trabalho visa aplicar o conceito de desenho técnico, com auxílio da manufatura aditiva, para elaboração de um protótipo em uma impressora 3D.

\section{OBJETIVOS}

Desenvolver, aplicar e avaliar um modelo de manufatura aditiva e prototipagem rápida em pequena escala.

Identificar e explorar os fatores diferenciais da manufatura aditiva e seus componentes, diretamente ou indiretamente relacionados.

Aplicar os conhecimentos de sala de aula de uma maneira eficiente e bem- sucedida.

\section{DESENVOLVIMENTO}

Na manufatura subtrativa, retira-se material indesejado de um corpo maior de matéria prima, de acordo com o necessário. Por sua vez, na manufatura manipulativa, opera-se a forma de um material a fim de obter um produto específico. Essa técnica é muito utilizada na fabricação de correntes metálicas. Diferentemente das anteriores, a manufatura aditiva envolve a adição de componentes, criando um produto físico a partir de um espaço vazio, uma bobina de material e um modelo virtual desenvolvido em CAD (Computer Aided design), sigla em português para "Desenho assistido por computador".

A manufatura aditiva pode ser utilizada para inúmeras aplicações, desde a prototipagem de um produto, com o intuito de levá-lo a produção em massa, até pequenos utensílios de cozinha feitos sob demanda para aplicação específica. Este método possibilita a produção de peças muito complexas e com diferentes materiais em sua composição. De acordo com a necessidade do produto, complexidade, material utilizado, custo benefício, são agregados materiais à sua composição. 
Para ser executada, a impressão 3D necessita de alguns elementos essenciais: (1) 0 modelo desejado, que pode ser adquirido por meio da internet, idealizado pelo próprio usuário, ou ter sua construção executada por alguma fonte terceirizada; (2) A impressora, equipamento sofisticado, utilizado para traduzir o objeto modelado em movimentos mecânicos e acurados; e (3) 0 material para impressão, dos quais polímeros ABS ou PLA são os mais tradicionais.

Nas impressoras de tecnologia de ponta, os materiais metálicos também podem ser utilizados. Vidro e isopor são materiais em desenvolvimento, de diferentes formas, volumes e aplicações, de acordo com a especificidade do cliente. Cada um destes elementos é modificado para melhor suprir a necessidade do produto final, o que leva à alta gama de possibilidades para personalização.

A partir daqui, por razões didáticas, a manufatura aditiva será abordada com o nome de “impressão 3D”.

\section{MATERIAIS E MÉTODOS}

O Modelo impresso foi formado a partir do logo preexistente do Centro Universitário Adventista de São Paulo (UNASP). 0 material aplicado foi o PLA (Ácido Polilático) da cor branca e a impressora utilizada neste processo foi a MakerBot Replicator.

A atividade se iniciou com a idealização do desenho, no modelo desejado. A partir de então, a imagem foi vetorizada por meio do software Inkscape e transformada em um modelo 3D via software Solidworks.

Após a modelagem, o próximo passo foi a transferência do arquivo para o software da impressora 3D, MakerBot Print, que realizou todo o trabalho de simulação e cálculo de tempo necessário para a impressão, bem como a estimativa de material utilizado no processo. Também executado pelo software, foram feitos os cálculos de valores, indicando o movimento e funcionamento da impressora de acordo com o protótipo esperado.

O processo de impressão é simples, preciso e relativamente rápido (quando comparado a tempos de impressão de objetos mais complexos e volumosos). Camadas são sobrepostas por novas camadas e juntas formam o corpo final. Estas se formam devido ao derretimento e extrusão do PLA, através do bico extrusor. Seu posicionamento ocorre em uma bandeja móvel, responsável pela altura, largura e comprimento do objeto em formação.

\section{RESULTADOS}

A impressão realizada foi bem-sucedida. Não houve nenhum erro ou defeito na geração do produto final e teve duração aproximada de $4 \mathrm{~h}$ para imprimir o modelo completo.

Após a conclusão da impressão, o material de apoio (utilizado para suporte da estrutura em seu processo de impressão) deve ser removido e o produto final pode ser retocado, com lixa, tinta ou outros tratamentos cosméticos. Nenhuma dessas finalizações foi utilizada no produto final deste artigo.

Com o produto final em mãos, o próximo passo é levá-lo a um local apropriado para que se faça o molde do produto, objetificando a a produção em massa. Tal produção pode ser executada com a injeção de metais ou polímeros em molde gerado a partir do produto inicial.

\section{CONSIDERAÇõES FINAIS}

Conforme a metodologia simplificada, fica claro que a manufatura aditiva tem grande potêncial na engenharia de produção, seja por meio da concepção do produto, desenvolvimento no mercado ou planejamento estratégico. As oportunidades na área se fazem crescer à medida que a indústria e tecnologia se desenvolvem.

Há um vasto campo para personalização de processo produtivo quando se fala de manufatura aditiva. Dentro da infinidade de variáveis, sejam elas matéria prima, infraestrutura, impressora ou aplicação, existem inúmeras possibilidades para modificar e aprimorar o sistema de impressões 3D, afim de que se obtenha a máxima performance para determinado propósito.

Atualmente, os investimentos na inovação da manufatura aditiva são insuficientes, retardando seu desenvolvimento. Considerando a importância desse método, é válido ressaltar a necessidade de aplicação no setor. A área acadêmica, desde o nível básico até o superior, pode se beneficiar em grande escala dos 
recursos oferecidos pela impressão 3D. 0 conhecimento em parceria com a manufatura aditiva se torna mais didático e compreensível.

Como um bom exemplo, a geometria espacial, assunto que é abordado em todos os graus de educação e em suas diferentes complexidades, ao possuir modelos visuais de todo o funcionamento e composição, oriundos da impressão em 3D, facilita o aprendizado. Crianças e adolescentes podem ter suas dificuldades diminuídas em relação ao assunto, aumentando sua efetividade para os indivíduos que não tem a habilidade de visualização espacial.

Em suma, há alto potencial inerente em todo o modelo seguido neste artigo. Tudo o que se desenvolve na atualidade tem sua velocidade aumentada em função dos avanços tecnológicos, e a manufatura aditiva faz com que todo o processo siga este fluxo. 0 mercado de trabalho que se relaciona ao objeto de estudo deste artigo, tem uma tendência grande para crescimento e inovação, que poderão futuramente auxiliar o desenvolvimento científico e tecnológico no brasil.

Ademais, pôde-se aplicar conhecimentos teóricos obtidos em sala de aula para aplicação prática em uma simulação de um caso real. 0 conhecimento prático e raciocínio lógico que se relacionam com o tema são efetivos na solução de problemas e produção de ferramentas que possibilitem a realização de determinada tarefa.

\section{REFERÊNCIAS}

[1] BMW GROUP. BMW Group Additive Manufacturing Campus Disponível em: <https://www.youtube.com/watch?v=wsVe-IAwQe8> Acesso em: 31 de outubro de 2018

[2] DESIMONE, Joseph. What if 3D printing was 100x faster? | Joseph DeSimone Disponível em: <https://www.youtube.com/watch?v=ihR9SX7dgRo> Acesso em: 31 de outubro de 2018

[3] KEATING, Steven. From Bacteria to Buildings: Additive Manufacturing Outside of the Box - S. Keating - MIT PhD Defense Disponível em: <https://www.youtube.com/watch?v=IRBQv2TJFX4\&t=611s> Acesso em: 31 de outubro de 2018

[4] LWT SISTEMAS. Qual a diferença entre as manufaturas aditiva e subtrativa?Disponível em: < http://www.lwtsistemas.com.br/manufaturas-aditiva-e-subtrativa/> Acesso em: 31 de outubro de 2018

[5] SERRA, S. M. B. Breve Histórico do Desenho Técnico. Disponível em: <http://livresaber.sead.ufscar.br:8080/jspui/bitstream/123456789/1391/1/AT1breve\%20historico.pdf > Acesso em: 23 de outubro de 2018

[6] WIKIPEDIA. Desenho técnico Disponível em: <https://pt.wikipedia.org/wiki/Desenho_t\%C3\%A9cnico> Acesso em: 31 de outubro de 2018 


\section{Capítulo 11}

\section{Industry 4.0: Is there any impact on worker's health and safety? - A literature review}

\section{Jessica Alves Justo Mendes}

Carlos Alberto Chaves

Abstract: With its origins in Germany, the Fourth Industrial Revolution or Industry 4.0, has been the subject of much research for it encompasses the main technological innovations of many fields, such as automation and information technology whose application on manufacturing processes leads to an increase on efficiency, flexibility, speed and autonomy. However, the ways in which these innovations can affect the health and safety of worker's has not yet been widely studied. Therefore, this paper goal was to systematically analyze the literature regarding Industry 4.0 and its relationship to Occupational Health and Safety, in order to identify the ways in which the fourth industrial revolution changed human health and safety. Results showed that while many of the physical risks of human labor were diminished, new ones surged, especially those related to the psychological health. It was also shown that the literature on the subject is incipient and needs to be better developed.

Keywords. Industry 4.0., Fourth Industrial Revolution, Occupational Health and Safety. 


\section{INTRODUCTION}

Elements of Information Technology (IT) become a normal occurrence in all aspects of our lives. The increase use of technology therefore brought forth big changes, both qualitative and quantitative, on industrial processes, which has come to be known as the Fourth Industrial Revolution (MARESOVA et. al., 2018).

The fourth industrial revolution, also known as Industry 4.0, began in Germany and has attracted much interest in recent years, being closely related to the Internet of Things (IoT), information and communications technology (ICT), Cyber Physical System (CPS), Enterprise Integration (EI) and Enterprise Architecture (EA) (LU, 2017).

With the fast spread of the Industry 4.0 a change is happening in various operations that depend on manual labor, with people being required to manage and exploit technologies by interacting with automation devices, which are replacing people in manual, repetitive tasks such as shop-floor and office operations (Chiabert et. al., 2018).

The rise of the Industry 4.0 has brought forth several types of new workplace hazards, especially those relating to the psychosocial category, which are often ignored by engineers and designers of advanced production systems, which may lead to a great range of problems to be dealt with, since psychosocial risks already are a huge challenge in terms of Occupational Health and Safety management systems and its legislation (Leka, Jain, 2010).

Therefore, this paper aims to systematically analyze the literature regarding Industry 4.0 and its relationship to Occupational Health and Safety, in order to identify the ways in which the fourth industrial revolution changed human health and safety.

\section{LITERATURE REVIEW}

This session presents an overview of the state of art of the literature on Industry 4.0 and how it relates to Occupational Health and Safety.

\subsection{INDUSTRY 4.0}

In modern times it is clear there are rapid advances in a multitude of areas. Regarding industrialization, those advances have given light to a new industry revolution, known as the Fourth Industrial Revolution, or Industry 4.0, which has spurred a tremendous progress in developing the manufacturing technology. (XU, XU, LI, 2018).

The history of the Industrial Revolution began at the end of the 18th century, with the introduction of mechanical production on the basis of steam and water replacing the use of animals to generate force. At the beginning of the 20th century, the second Industrial Revolution took form with the concept of mass production (with important names such as Henry Ford and Frederick Taylor) and the use of conveyor belts. This was followed by the third Industrial Revolution, with the integration of digital automation to the production process by means of electronics and Information Technology (IT) system. Now, the fourth Industrial Revolution is being marked by the rise of the Internet of Things, autonomous robots, cyber physical systems and so on (BAHRIN et. al., 2016).

It is worth noting, regarding the characteristics of the Industry 4.0, some principles that are key to its existence, such as: data integration, real-time capability, secure communication, inclusion of cloud/intranet, flexible adaptation, intelligent self-organizing, virtualization, decentralization, interoperability, modularity, optimization of the manufacturing process, and service orientation (JI et. al., 2016; Vogel-Heuser et. al., 2016). Expanding on some of these principles, Kagermann et. al. (2013) brought the following conclusions: 
1. Real-time Capability: the ability to collect and process data instantly, enabling real-time qualified decision making.

2. Virtualization: it is the proposal of a virtual copy of the intelligent factories, thanks to sensors scattered throughout the plant. In this way, one can remotely track and monitor all processes.

3. Decentralization: it is the idea of the machine itself to be responsible for decision making, because of its ability to self-adjust, evaluate the needs of the plant in real time and provide information about its work cycles.

4. Service orientation: it is a concept in which softwares are oriented to offer solutions as services, connected with the whole industry.

5. Modularity: allows modules to be coupled and decoupled according to factory demand, offering great flexibility in changing tasks.

6. Interoperability: borrows the internet concept of things, in which machines and systems can communicate with each other.

As for the aim of Industry 4.0, it is pointed out the ability to provide automatic and flexible adaptation of the production chain, IT-enabled mass customization of manufactured products; to track parts and products; to achieve IoT-enabled production optimization in smart factories; to facilitate communication among parts, products, and machines; to apply human-machine interaction (HMI) paradigms; and to provide new types of services and business models of interaction in the value chain (Shafiq et. al., 2016). Some of the goals of the Industry 4.0 were first explained by Kagermann (2013), as described below:

1. Cyber-physical system: it is the combination of the physical and the virtual world, a connection that is made possible by the creation of the so-called cyber-physical system (CPS). The development of a CPS is characterized by three stages, being the first the identification technologies such as RFID tags, which are used for unique identification and tracking, while the second stage of the CPS consists of sensors equipped with a limited range of functions, and the third stage permits the storage and analysis of data, equipped with sensors and connected to the network (Kagermann, 2013).

2. Internet of Things (IoT) can be defined as a network in which CPS collaborate through unique links. The IoT allows "things" and "object" as RFID, mobile phones integrate into unique links and sensors which can work together with other objects to achieve a common goal. Some examples of the use of the IoT include the Smart factories, homes or networks (Kagermann, 2013).

3. Internet of Service (IoS) allows the provision of services via Internet, consisting of business models, participants, infrastructure services, and services themselves. The services are offered and merged into value-added services from different vendors, while communications are offered via various channels. This approach permits different variants of distribution in the value chain (Kagermann, 2013).

4. Smart Factory is defined as a factory and machinery that assist people to fulfill their tasks, with the objective of feeding the basis of information obtained online, so at every moment it is possible to ascertain the status of the device, the position and the like. These systems accomplish their tasks by analyzing the information from the virtual and the physical world. While the information from the physical world is given as location or condition of the machine, the information from the virtual world is given as electronic documents, drawings or simulation models (Kagermann, 2013).

The advantages of the Industry 4.0 can be seen on the reduction of lead times, the increase of flexibility, customization of small batch sizes and reduction of costs (Shafiq et. al., 2016). As for the disadvantages, it can be difficult to exploit the full potential of Industry 4.0 in countries that lack the powerful tools necessary to implement this type of industry (XU, XU, LI, 2018).

Despite the growing importance of the Industry 4.0 for the global economy, there are not many publications that study the new occupational health and safety (OHS) risks that are specific to this type of industry (Fernández, Pérez, 2015). In order to analyze the way in which the OHS is being addressed by the Industry 4.0, firstly, it is important to understand what configures OHS in a broader sense. Therefore, this paper presents a literary review on the subject of OHS. 


\subsection{OCCUPATIONAL HEALTH AND SAFETY}

In order to understand the overall importance of OHS, some essential concepts need to be known. Firstly, the concept of safety, which can be defined as the use of the right tool or technology in order to identify hazards situation and prevent accidents (Lees, 2012). Situations where the worker's action may result in injury (or organization loss) can be considered a hazard situation. The same can be said for environmental conditions that can result in harm to the workers' health and safety. Another concept of vital importance to OHS is the concept of Risk, which can be classified as the probability of occurrence of an accident or hazard situation. Seeing as no situation is completely risk free, the job of those who work as safety professionals is to identify the greatest inherent risk of the activities, in order to reduce or eliminate said risk (Friend, Kohn, 2007; Li, Guldenmund 2018).

In lieu of those concepts, OHS can be defined as the protection of human and facility resources, which involves aiding workers by preventing them from being injured or becoming. ill due to hazards situations in their workplaces, while, at the same time, increasing the quality and efficiency of production (Friend, Kohn, 2007), with the safety of an industry being judged by its acceptable risk (Li, Guldenmund, 2018). Regarding the increase in production performance, there is empirical evidence which suggests that the improvement of health and safety standards and practices leads to an improvement in the efficiency of production (Fernández-Muñiz et al., 2009).

With the globalization and the advances of technology it became imperative for the survival of companies to not only be profitable, but to present a good image, which has motivated the implementation of OHS practices, for they can decrease losses (both human and economic) with the use of techniques such as loss prevention. This can be defined as a process of identification and correction of potential accidents before they result in an injury or financial loss, or loss control, which works to minimize how a work injury or financial loss can affect the company.

It is evident that a health and safe workplace environment leads to fewer hazard situations. The relationship between OHS and the work performance within companies was first identified by Walton (1973), a researcher that sought ways to associate quality of life at work with performance in companies by a proposed model that analyzed eight (8) factors, as follows:

1) Fair and Adequate Compensation: this criterion sought to measure the quality of life at work by given proper remuneration appropriate to the work performed.

2) Working Conditions: the assessment of health conditions and physical environment where the worker performs its activities.

3) Use of Capacity Development: this examines the opportunities offered to workers to apply their knowledge in their work routine, development of autonomy and obtaining information about work and the production process.

4) Opportunity for Growth and Security: analysis of the opportunities offered to workers in relation to their personal development and growth and the stability of their jobs.

5) Social Integration in the Organization: it was done by measuring the social integration among workers, by analyzing prejudices, absence of differences and the culture of good relationship.

6) Constitutionalism: the goal was to measure the application of labor laws in the company.

7) Work and Total Living Space: observes the balance between the work and the life of the worker.

8) Social Importance of Life at Work: analysis of the perception that each employee has of the company and its social responsibility.

The literature regarding OHS is vast, as proven by the thousands of studies any reliable database will possess, however, little is known regarding the challenges and changes the fourth industrial revolution has brought to the field (Drossler, 2018). The use of the various technologies adopted by Industry 4.0, such as collaborative robots, has brought various advantages, such as reducing the physical tool in many activities that used to be performed by humans. 
However, the risks of a not well thought process, as well as the psychological burdens of increasingly monitoring and demanding more of the worker need to be better evaluated and decision-making requirements human-robot interaction might also have some risks if human factors considerations are not well thought throughout the process. (Bragança et. al., 2019; Drossler, 2018).

\section{METHODOLOGY}

The systematic review of the existing literature was related to Industry 4.0 and Occupational Health and Safety (OHS). The search intended to find papers related to Industry 4.0 and it has affected OHS by searching in the IS Web of Science Database. Therefore, the articles searched needed to have the words "Industry 4.0" OR "Industrie 4.0" OR "Fourth Industrial Revolution" AND "Occupational Health and Safety" OR "OHS" OR "Health and Safety". A workflow (Figure1) was used to demonstrate the steps followed by this research.

Figure 1 - Workflow of the Literature Review

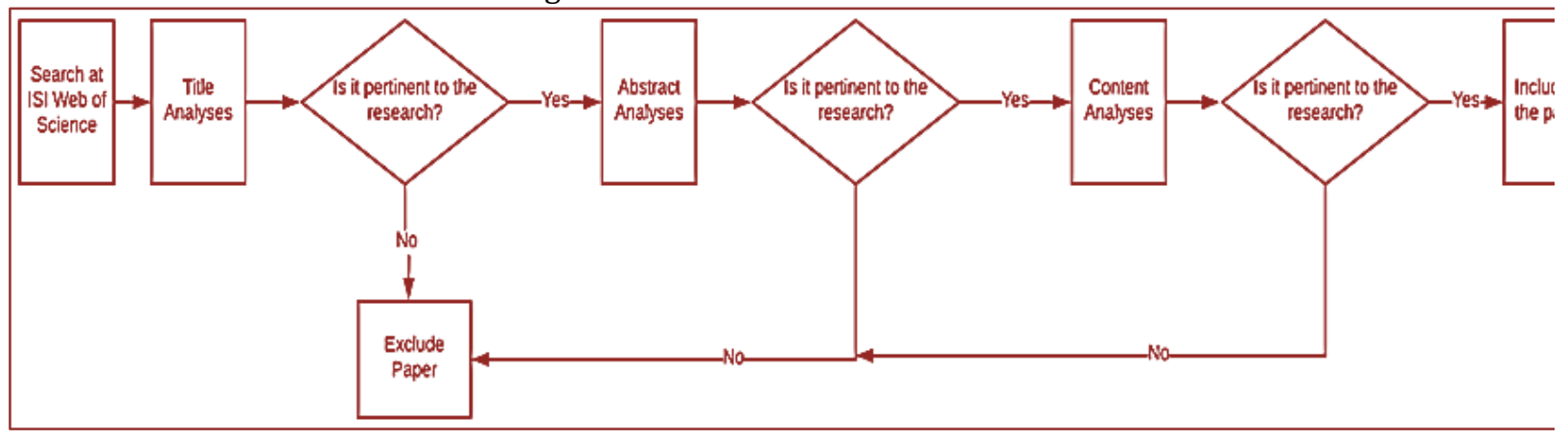

Source: Design by the authors, 2019

The search resulted in fitty one (51) studies, of which, by analyzing each title, fourteen (14) were considered to be useful to this research. After the abstract of those fourteen (14) papers were carefully read, ten (10) were selected as part of the content analyses. Table 1 summarizes the results that were found.

Table 1 - Research on the Literature Review

\begin{tabular}{|c|c|c|c|c|}
\hline Database & Search Results & Title Analyses & Abstract Analyses & Content Analyses \\
\hline ISI Web of Science & 51 & 14 & 14 & 10 \\
\hline
\end{tabular}

Source: Design by the authors, 2019

\section{RESULTS AND DISCUSSION}

The papers considered in this research were summarized in Table 2. 
Table 2 - Papers Analyzed by This Research

\begin{tabular}{|c|c|c|c|}
\hline Title & Authors & Jonrnal/Conference & Year \\
\hline $\begin{array}{l}\text { Occupational health and safety in the industry } 4.0 \text { era: A cause for } \\
\text { major concern? }\end{array}$ & $\begin{array}{l}\text { Badri, Adel; Boudreau-Tnudel, Bryan; } \\
\text { Souissi, Ahmed Saadeddine. }\end{array}$ & Safety Science & 2018 \\
\hline $\begin{array}{l}\text { The Dark Side of the Moon: The Internet of Things, Industry } 4.0 \text {, and } \\
\text { The Quantified Planet. }\end{array}$ & Ozdemir, Vural. & $\begin{array}{c}\text { Omics-A Journal Of Integrative } \\
\text { Biology }\end{array}$ & 2018 \\
\hline The occupational health and safety dimension of Industry 4.0 . & $\begin{array}{l}\text { Leso, Veruscka; Fontana, Luca; Iavicoli, } \\
\text { Ivo. }\end{array}$ & Medicina Del Lavoro & 2018 \\
\hline Industry 4.0: technologies and OS\&H implications. & $\begin{array}{l}\text { Chiabert, Paolo; D'Antonio, Gianluca; } \\
\text { Maida, Luisa. }\end{array}$ & $\begin{array}{l}\text { Geam-Geoengineering } \\
\text { Environment And Mining }\end{array}$ & 2018 \\
\hline $\begin{array}{l}\text { The role of basic and applied research activities for the improvement of } \\
\text { OS\&H conditions and the dissemination of the Culnure of Safety. }\end{array}$ & $\begin{array}{l}\text { Baldissone, Gabriele; Comberti, Lorenzo; } \\
\text { Fargione, Paolo; }\end{array}$ & $\begin{array}{l}\text { Geam-Geoengineering } \\
\text { Environment And Mining }\end{array}$ & 2018 \\
\hline Evolution experiences in industry 4.0 . & Mosca, Francesco; Lose, Maurizio Teppati. & $\begin{array}{l}\text { Geam-Geoengineering } \\
\text { Environment And Mining }\end{array}$ & 2018 \\
\hline $\begin{array}{l}\text { How Data Will Transform Industrial Processes: Crowdsensing, } \\
\text { Crowdsourcing and Big Data as Pillars of Industry 4.0. }\end{array}$ & Pilloni, Virginia. & Future Internet & 2018 \\
\hline $\begin{array}{l}\text { Challenges for Psychosocial Risk Assessment During the Digital } \\
\text { Transformation of Industry: A Qualitative Interview Study. }\end{array}$ & $\begin{array}{l}\text { Diebig, Mathias; Jungmann, Franziska; } \\
\text { Mueller, Andreas; }\end{array}$ & $\begin{array}{l}\text { Zeitschrift Fur Arbeits-Und } \\
\text { Organisationspsychologie }\end{array}$ & 2018 \\
\hline $\begin{array}{l}\text { Healtlyy work in pioneer branclues (GAP). } \\
\text { The fourth industrial revolution in the semiconductor industry - } 2 \text { case } \\
\text { studies }\end{array}$ & $\begin{array}{l}\text { Drossler, S; Steputat, A; Baranyi, } \\
\text { G; Kampf, D; Seidler, A }\end{array}$ & $\begin{array}{l}\text { Zentralblatt Fur Arbeitsmedizin } \\
\text { Arbeitsschutz Und Ergonomie }\end{array}$ & 2018 \\
\hline $\begin{array}{l}\text { Need for a new workplace safety and health (WSH) strategy for } \\
\text { the fourth Industrial Revolution }\end{array}$ & $\begin{array}{l}\text { Chia, G: Lim, SM: Sng, GKJ: Hwang, } \\
\text { YFJ; Chia, KS }\end{array}$ & $\begin{array}{c}\text { American Journal of Industrial } \\
\text { Medicine }\end{array}$ & 2019 \\
\hline
\end{tabular}

Source: Design by the authors, 2019

Analyzing the ten (10) papers that compose this literary review, it was possible to classify them into four (4) categories that considered the focus of each research, as explained in Table 3.

Table 3 - Classification of Papers Analyzed by This Research

\begin{tabular}{|c|c|c|}
\hline Main Focus & Authors & Year \\
\hline \multirow{2}{*}{$\begin{array}{l}\text { Large Digital Data and its } \\
\text { Effects on Workers and } \\
\text { Workplace Environment }\end{array}$} & $\begin{array}{l}\text { Badri, Adel; Boudreau-Trudel, Bryan; Souissi, } \\
\text { Ahmed Saadeddine. }\end{array}$ & \multirow[t]{2}{*}{2018} \\
\hline & Ozdemir, Vural. & \\
\hline \multirow{4}{*}{$\begin{array}{c}\text { Relationship Between } \\
\text { Psychosocial Risks and } \\
\text { Industry } 4.0\end{array}$} & Leso, Veruscka; Fontana, Luca; Iavicoli, Ivo. & \multirow{4}{*}{2018} \\
\hline & $\begin{array}{l}\text { Chiabert, Paolo; D'Antonio, Gianluca; Maida, } \\
\text { Luisa. }\end{array}$ & \\
\hline & $\begin{array}{c}\text { Diebig, Mathias; Jungmann, Franziska; Mueller, } \\
\text { Andreas; }\end{array}$ & \\
\hline & $\begin{array}{c}\text { Drossler, S; Steputat, A; Baranyi, G; Kampf, } \\
\text { D; Seidler, A }\end{array}$ & \\
\hline \multirow{2}{*}{$\begin{array}{l}\text { Literary Review on Industry } \\
4.0 \text { and how it relates to OHS }\end{array}$} & \begin{tabular}{|c|} 
Baldissone, Gabriele; Comberti, Lorenzo; Fargione, \\
Paolo;
\end{tabular} & \multirow{2}{*}{2018} \\
\hline & Mosca, Francesco; Lose, Maurizio Teppati. & \\
\hline \multirow[t]{2}{*}{ Other } & $\begin{array}{c}\text { Chia, G; Lim, SM; Sng, GKJ; Hwang, YFJ; Chia, } \\
\text { KS }\end{array}$ & 2019 \\
\hline & Pilloni, Virginia. & 2018 \\
\hline
\end{tabular}

Source: Design by the authors, 2019

In order to better understand how the classification of each paper was made, a summary of their main points is presented below.

Badri et al. (2018) article demonstrated that even though there are large data regarding Industry 4.0, it remains scarce the literature that analyzes the incorporation of OHS into the Industry 4.0, which can lead to the multiplication of workplace hazards during a transition period. Akin to Badri's et. al. (2018) findings, Ozdemir (2018) analyzes the way digital connectivity can be toxic to various groups, affecting, negatively, the workplace environment, and it suggests that Industry 4.0 needs to diminish digital network toxicity in order to be effective. 
The research done by Leso et al. (2018) elucidates a comprehensive overview of the opportunities and problematical aspects of Industry 4.0 in relation to OHS, reaching the conclusion that, although Industry 4.0 can make worker's activities safer, more flexible and more socially inclusive, it can also lead to higher levels of psychosocial stress, as well as expose the workers to health and safety risks intrinsically related to automated tools. Therefore, it concludes that those responsible for safeguarding health in the workplace should promote and protect the health and safety of workers through careful risk management based on continuous occupational training and information while at the same time, make an adequate assessment of the risks attributable to 4.0 tools. In regards to psychosocial stress, Diebig et al. (2018) conducts a study that analyzes the advancements in the process of psychosocial risk assessment in the Industry 4.0 context, since the ongoing industrial digitization has brought a fundamental transformation of working conditions, deeming it necessary to re-evaluate how we measure psychosocial risk. Conversely, similar results have been found by Chiabert et al. (2018), whose paper brought more details on how the rapid spread of Industry 4.0 has shifted the role of human operators from manual work to knowledge work. Another research to analyze the psychological burdens Industry 4.0 has on its workers can be found in Drossler et al. (2018), where the impacts of increasing monitoring and decision-making requirements were analyzed, reaching the conclusion that, more than looking only at the classical OHS hazards the issues regarding occupational health and safety must take into account the new demands that Industry 4.0 brought, otherwise the OHS practices will not be very effective.

Baldissone et al. (2018) paper gives an overview on the history of OHS in the European context, showing that the accident indices of the last few years do not greatly differ from those registered in 1970s, leading to the conclusion that the dissemination of a Culture of Safety can encourage a bilateral synergy "IndustryUniversity" from an OHS point of view, which can be facilitated by the rise of Industry 4.0 and the available technology. In line with Baldissone et al. (2018) work, Mosca et al. (2018) also shows the evolution of OHS in the fourth industrial revolution scenario, giving more evidence to the advantages it brought, such as: a higher safety level reached through a better man-machine interaction and interfacing, which allowed a meaningful reduction in errors and accidents as well as an improvement of safety and ergonomics in the working place, while at the same time, supports and assists workers in their tasks, reduces work related stress and helps to overcome some of the limits related to trained human resources availability, work force ageing, integration of workers with disability and such.

Pilloni (2018) brings a deeper discussion on the effects that the introduction of Internet of Things (IoT), Cyber-Physical Systems (CPS), crowdsensing, crowdsourcing, cloud computing and big data will have on industrial processes, relating them with an increase on various fields, being important to discuss, due to the scope of this research, the ones that depict workplace health and safety. Pilloni's (2018) work does not enter on details on the way the Industry 4.0 has affected OHS, however, it shows how many key aspects of the fourth industrial revolution have positively affected workplace safety, as well as the health and safety of workers.

Finally, the work of Chia et al. (2019) suggests a new strategy to deal with workplace safety and health in the Industry 4.0, as this type of industry requires highly adaptive and highly responsive approach to promote Total Worker Health in view of the rapid technological advancements and changes in employment relationships that Industry 4.0 has brought.

\section{CONCLUSIONS}

By analyzing the literature regarding Industry 4.0 and its effects on OHS it was possible to infer that, despite the many advantages brought on by the rise of Industry 4.0, the OHS risks they present are scarcely investigated. The majority of research that do investigate these risks, have elucidated the rise of psychosocial burden in worker's life. It is also worth to mention that the literature on the subject in question is new, as proven by the fact that the articles range from 2018 to 2019. Another point to take notice is the fact that all literature regarding the role of OHS in Industry 4.0 belongs to developed countries, which opens a possibility of researching the subject in developing countries, such as Brazil and other countries in Mercosul. 


\section{ACKNOWLEDGMENT}

Our acknowledgments go to National Council for Scientific and Technological Development (CNPq) and the Coordination for the Improvement of Higher Education Personnel (Capes).

\section{REFERENCES}

[1] Badri, A. Boudreau-Trudel, B. Souissi, A. S. (2018). Occupational Health and Safety in the Industry 4.0 Era: A Cause for Major Concern? Safety Science. Volume: 109. Pg.: 403-411

[2] Bahrin, M. A. K., Othman, M. F., Azli, N. H. N., Talib, M.F. (2016). Industry 4.0: A Review on Industrial Automation and Robotic. Jurnal Teknologi. Vol 78, No 6-13

[3] Baldissone, G. Comberti, L. Fargione, P. (2018). The Role of Basic and Applied Research Activities for the Improvement of OS\&H Conditions and the Dissemination of the Culture of Safety. Geam-Geoingegneria Ambientale e Mineraria-Geam-Geoengineering Environment And Mining. Issue: 154. Pg.: 32-41

[4] Bragança, s. Costa, e. Castellucci, I. Arezes, Pedro M. (2019). A Brief Overview of the Use of Collaborative Robots in Industry 4.0: Human Role and Safety. Occupational And Environmental Safety And Health. Pg: 641-650

[5] Chia, G. Lim, M. Gek Khim, J. Yi-Fu, J. H. Chia, K. S. (2019). Need for a New Workplace Safety and Health (WSH) Strategy for The Fourth Industrial Revolution. American Journal of Industrial Medicine. Volume: 62. Issue: 4.

[6] Chiabert, P. D'antonio, G. Maida, L. Industry 4.0: Technologies and OS\&H Implications. (2018). GeamGeoingegneria Ambientale e Mineraria-Geam-Geoengineering Environment And Mining. Issue: 154. Pg.: 21-26

[7] Diebig, M. Jungmann, F. Mueller, A. (2018). Challenges for Psychosocial Risk Assessment During the Digital Transformation of Industry: A Qualitative Interview Study. Zeitschrift Fur Arbeits-Und Organisationspsychologie. Volume: 62. Issue: 2. Pg: 53-67

[8] Drossler, S. Steputat, A. Baranyi, G. Kampf, D. Seidler, A. (2018). Healthy Work in Pioneer Branches (GAP). The Fourth Industrial Revolution in the Semiconductor Industry - 2 Case Studies. Zentralblatt Fur Arbeitsmedizin Arbeitsschutz Und Ergonomie. Volume: 68. Issue: 3. Pg: 146-150

[9] Fernández-Muñiz, B., Montes-Peón, J.M. \& Vázquez-Ordás, C.J. (2009). Relation Between Occupational Safety Management and Firm Performance. Safety Science 47(7), 980-991.

[10] Friend, M. A. Kohn, J. P. (2007). Fundamentals of Occupational Safety and Health. Government Institutes AN Imprint Of The Scarecrow Press, INC. Fourth Edition

[11] Ji, C. Shao, Q. Sun, J. Liu, S. Pan, L. Wu, L. Yang, C. (2016). Device Data Ingestion for Industrial Big Data Platforms with a Case Study. Sensors 16 (3) 279.

[12] Kagermann, H., W. et al. (2013). Recommendations for Implementing the Strategic Initiative Industrie 4.0: Final Report of the Industrie 4.0 Working Group.

[13] Kharchenko, V. Illiashenko, O. Boyarchuk, A. (2017). Emerging Curriculum for Industry and Human Applications in Internet of Things. 9th Ieee International Conference On Intelligent Data Acquisition And Advanced Computing Systems - Technology And Applications (Idaacs). Local: Bucharest, ROMANIA Data: Sep 21-23.

[14] Lees, F. (2012) Lees' Loss Prevention in the Process Industries: Hazard Identification, Assessment and Control. Butterworth-Heinemann (Fourth ed.)

[15] Leka, S., Jain, A. (2010). Health Impact of Psychosocial Hazards at Work: An Overview. World Health Organization, Geneva, pp. 136.

[16] Leso, V. Fontana, L. Iavicoli, I. (2018). The Occupational Health and Safety Dimension of Industry 4.0. Medicina Del Lavoro. Volume: 109. Issue: 5. Pg: 327-338

[17] Li, Y. Guldenmund, F. W. (2018). Safety Management Systems: A Broad Overview of The Literature. Safety Science. 103 94-123

[18] Lu, Y. (2017). Industry 4.0: A Survey on Technologies, Applications and Open Research Issues. Journal OF Industrial Information Integration. Volume 6, June 2017, Pages 1-10

[19] Maresova, P. Soukal, I. Svobodova, L. Hedvicakova, M. Javanmardi, E. Selamat, A. Krejcar, O. (2018). Consequences of Industry 4.0 in Business and Economics. Economies, 6(3), 46; https://doi.org/10.3390/economies6030046 Mosca, F. LOSE, M. T. (2018). Evolution experiences in industry 4.0. Geam-Geoingegneria Ambientale E Mineraria-Geam-Geoengineering Environment And Mining. Issue: 154 Pg: 64-69 
[20] Ozdemir, V. (2018). The Dark Side of the Moon: The Internet of Things, Industry 4.0, and The Quantified Planet. Omics-A Journal OF Integrative Biology. Volume: 22. Issue: 10. Pg: 637-641

[21] Pilloni, V. (2018). How Data Will Transform Industrial Processes: Crowdsensing, Crowdsourcing and Big Data as Pillars of Industry 4.0. Future Internet. Volume: 10. Issue: 3

[22] Shafiq, S.I. Sanin, C. Szczerbicki, E. Toro, C. (2016). Virtual Engineering Factory: Creating Experience Base for Industry 4.0. Cybern. SYST. 47 (1-2) 32-47.

[23] Vogel-Heuser, B. Hess, D. Industry 4.0-Prerequisites and Visions. (2016). Ieee Trans. Autom. Sci. Eng. 13 (2) 411-413.

[24] Walton, R. E. (1973). Quality of Work Life: What Is It? Sloan Management Review. 15(1), 11-21.

[25] Xu L.D., Xu, E.L. LI, L. (2018). Industry 4.0: State of The Art and Future Trends. International Journal Of Production Research. Volume: 56. Issue: 8. Pages 2941-2962 


\section{Capítulo 12}

Gestão de estoque: A previsão de demanda aplicada em uma Distribuidora de Frangos

\section{Kelly Vanessa Barbosa Conceição \\ Marco André Matos Cutrim \\ Antonilton Serra Sousa Junior \\ Luidson Coelho Fernandes \\ Cássio Ricelly Souza Costa}

Resumo: Diante de uma nova conjuntura mundial, os avanços da tecnologia, e a economia cada vez mais globalizada, o mercado tem se tornado um ambiente de alta competitividade. Nesse cenário, para se destacar, as empresas buscam a melhoria constante dos processos produtivos. Dessa forma, a implantação de novos métodos e técnicas de gestão permite o melhor desempenho dos processos, um planejamento eficaz, e a redução dos custos operacionais. Os modelos de previsão de demanda surgem como métodos capazes de gerenciar os estoques e auxiliar gerentes no processo decisório. Nesse sentido, o objetivo deste trabalho é identificar qual o método de previsão de demanda, que se adequa a uma distribuidora de frangos. A metodologia aplicada neste estudo, caracteriza-se inicialmente, por uma revisão bibliográfica, seguida de uma pesquisa quantitativa, envolvendo coleta de dados numéricos para tratamento. Dessa maneira, calculou-se cada método de previsão: média móvel simples, amortecimento exponencial e regressão linear. Após a obtenção dos resultados, comparou-se cada estimativa dos métodos com a demanda real em relação ao mês de abril, concluindo-se que nenhum método conseguiu se aproximar do que ocorreu no referente mês.

Palavras-chave: Gestão de estoque. Previsão de demanda. Métodos de previsão. 


\section{INTRODUÇÃO}

Apesar das crises econômicas, políticas e sociais, que o País vem sofrendo, o setor de alimentos demonstra sinais significativos de crescimento, no que se refere ao consumo per capita de frangos ( $\mathrm{kg} / \mathrm{habitante)}$. Dados da Associação Brasileira de Proteína Animal (ABPA), revelam que a produção brasileira de carne de frango no ano de 2017 foi de 13,05 milhões de toneladas, fazendo do Brasil o segundo maior produtor mundial, atrás apenas dos Estados Unidos com 18,59 milhões de toneladas por ano.

Segundo a Secretaria de Estado Indústria e Comércio do Maranhão (SEINC-MA), no ano de 2016, o Maranhão demonstrava um forte potencial no setor avícola, contando com 5 unidades produtoras, nas quais, são gerados cerca de 15 mil empregos diretos e indiretos. 0 mercado consumidor demanda em torno de 300 mil toneladas ao ano. Porém, o Estado só consegue produzir 25\% do que consome, comprovando a disponibilidade para o aumento na produção de aves.

Empresas atuantes nesse mercado, como as distribuidoras de frangos, precisam planejar de forma eficaz a demanda necessária para o atendimento dos clientes. Em virtude disso, a aplicação dos métodos de previsão de demandas, como uma forma de gerenciar os estoques, permite às organizações o controle dos produtos acabados e prevê a necessidade futura do seu público.

Nesse contexto, este estudo foi realizado em uma empresa distribuidora de frangos, localizada no munícipio de São José de Ribamar, Maranhão. 0 objetivo desta pesquisa consistiu na identificação do método adequado para prever a demanda para uma distribuidora de frangos.

A metodologia adotada, iniciou-se através de material bibliográfico. Em seguida, realizaram-se entrevistas não-estruturadas com os funcionários e a gerência da empresa, a fim de obter informações a respeito das vendas e estoque da empresa. Além disso, através dos dados fornecidos pela empresa entre os meses de abril de 2017 e março de 2018, calculou-se a previsão de demanda através de três métodos: média móvel simples, amortecimento exponencial e regressão linear.

\section{REVISÃO TEÓRICA: GESTÃO DE ESTOQUES}

Para iniciar as considerações acerca deste tópico, faz-se necessária a abordagem conceitual sobre a gestão de estoque. Etimologicamente, a palavra gestão deriva do verbo gerir, que traz a ideia de administrar, gerenciar algo, ou seja, trabalhar em uma escala de organização linear com determinado material, seja ele físico ou digital, trazendo esses apontamentos para a atividade de estocagem. A gestão de estoques, em um conceito simplificado, seria a gerência de material físico ou digital armazenado como fonte de reserva para demandas futuras, podendo estas ser a curto ou a longo prazo. Nas lições de Szabo (2015), a gestão de estoque tem se mostrado uma das áreas mais importantes e mais difíceis da logística.

Com o intuito de evitar prejuízos e desperdícios, a gestão de estoques ganha protagonismo nas atividades comerciais e torna-se uma das ferramentas principais para a indústria. Talvez seja mais interessante, a estimativa de demanda e o controle dos produtos ofertados, sendo, então, apresentados como os maiores desafios da gestão de estoque e seus principais objetivos.

De acordo com Paoleschi (2013), para um planejamento correto do estoque, é necessário realizar uma classificação dos materiais de acordo com sua importância e valor para a empresa. Sabe-se, que, a boa gestão de estoques resulta em maiores lucros, algo que é o objetivo principal de toda atividade econômica. Em contrapartida, os altos níveis de estoques podem ter por consequência maiores despesas de manutenção e de produção.

A gestão de estoque se mostra a peça fundamental nos processos industriais de fabricação de produto, pois, esta quando é feita com excelência, gera reflexos positivos em todas as escalas produtivas, bem como: redução nos custos da produção, melhora do preço de mercado para os clientes, e por consequência, aumento da demanda pelo produto fornecido

\subsection{PREVISÃO DE DEMANDA}

Um dos fatores cruciais na gestão de estoque é a previsão da demanda, uma vez que, é a partir deste ponto, que será traçada toda dinâmica de planejamento da gestão, determinando quais as matérias necessárias para a produção de determinados bens, isto dentro de um processo industrial, ou mesmo no caso do fornecimento de um produto já fabricado, que é armazenado em estoque. 
Para que seja realizado o levantamento prévio de forma eficaz, torna-se necessário, levar em consideração alguns aspectos influenciadores, que são os aspectos estatísticos relacionados ao produto, buscando a melhor forma de compreensão dos padrões de demanda do passado, visando, assim, atender as demandas futuras. Esta pesquisa fundamenta-se no estudo de dados anteriores de um mesmo produto, traçando uma estimativa futura de venda. Na visão de Albertin e Pontes (2016), as empresas devem ficar atentas aos desejos dos consumidores, e para ajudar nesse objetivo devem utilizar a previsão de demanda, que tem como função colaborar com informações para um bom planejamento e controle de produção, visando obter informações da quantidade de produtos e serviços que a empresa necessita vender no futuro.

Mediante a diversidade de produtos e serviços oferecidos pelas empresas, nem sempre se dispõe dos valores de demandas para todos os períodos considerados. Nesses casos, a fim de se estimar aquela demanda, utiliza-se o método da interpolação. Segundo Pires (2015), o método de interpolação é definido como uma aproximação de uma determinada função $f(x)$ em relação a outra função $g(x)$, em que essas funções são previamente definidas satisfazendo, assim, algumas propriedades, visto que, a função $g(x)$ é substituída pela função $\mathrm{f}(\mathrm{x})$. Ainda para Pires (2015), existem dois principais motivos que levam a essa substituição, a saber: quando os dados numéricos da função são conhecidos em um certo conjunto, de maneira a calcular o valor da função de um ou mais pontos não tabulados; e, quando uma função em análise apresenta uma expressão, com operações como a diferenciação e integração, têm dificuldades de serem realizadas.

Com a concorrência acirrada do mercado atual, prever a demanda adequada torna-se uma tarefa crucial e faz diferença para o empresário: quanto mais eficaz o estudo da demanda, melhor será o resultado.

\subsection{ERROS DE PREVISÃO}

Segundo Martins e Laugeni (2016), quando se trabalha com estimativa, se faz necessário levar em consideração a possibilidade de ocorrência de erros. Haja vista, a previsão da demanda, além de estimar as quantidades equivalentes, deve traçar possibilidades de eventuais erros. 0 erro de previsão ocorre quando se estima determinado valor quantitativo e na realidade ocorre valor diverso, deixando uma diferença. Como exemplo, pode-se citar uma indústria de calçado que estimou a venda de 200 pares de calçados, que na realidade vendeu 180, havendo o erro de 20 pares.

o grande desafio da previsão da demanda, tem sido diminuir o erro de previsão, fato este que proporcionará a redução de desperdícios como compras e produção desnecessárias, gastos com transportes demandados desnecessários e, consequentemente, um bom lucro ao empreendedor.

Conforme entendimento de Correia e Correia (2007, p.251), existem alguns erros corriqueiros na previsão de demanda:

- Erro 1 - Confundir previsões com metas e, consequentemente, considerar as metas como se fossem previsões;

- $\quad$ Erro 2 - Gastar tempo discutindo se acerta ou erra nas previsões, quando o mais importante é discutir o quanto está errado, de forma a reduzir os erros;

- $\quad$ Erro 3 - Levar em conta somente o valor da previsão para se apoiar nas decisões. Previsão deve ser avaliada com dois números: a previsão e o erro da previsão;

- Erro 4 - Desistir, ou não se esforçar o suficiente, para melhorar os processos de previsão e o erro da previsão.

Assim sendo, "Prever o erro" faz parte do processo de estimativa da demanda, quanto maior o número de possibilidades de erro for estudado, maior será a possibilidade de a previsão de demanda ser assertiva.

\subsection{MÉTODOS DE PREVISÃO}

Devido à grande dificuldade de as empresas preverem as reais necessidades do mercado, foram desenvolvidos métodos, que pudessem prever a demanda da empresa a partir de informações delineadas por uma compilação de recursos. Nesse sentido, as empresas objetivam encontrar o método mais assertivo possível, dentro de uma compreensão, que não existe nenhum método absoluto, mas, sim, diferentes tipos que possam adequar as características do negócio. 
De acordo com Seleme e Seleme (2013), os métodos de previsão são baseados em horizontes de longo, médio e curto prazo. E, os gerentes de produção devem possuir entendimento para com todos eles, logo, assim, aplicando-os de acordo com suas necessidades, conforme mostrado no Quadro 1.

Quadro 1 - Horizonte de previsão versus intervalo de tempo
\begin{tabular}{c|c|} 
Horizonte de previsão & Intervalo de tempo \\
\hline Longo prazo & Mais de 1 ano \\
\hline Médio prazo & De 3 meses a 1 ano \\
\hline Curto prazo & De 0 a 3 meses \\
\hline
\end{tabular}

Fonte: Seleme e Seleme (2013)

Para a aplicação de previsões de curto prazo, utilizam-se intervalos semanais. Geralmente esse método é mais aplicado quando se pretende estimar estoques de curto prazo de produtos específicos, capacidade de maquinário, entre outros. Ao passo que, para previsões de médio prazo, que, normalmente, são usadas para prever estoques de matérias-primas, plano de vendas, capacidade de setores, realizam-se com períodos mensais. E, ainda, nas previsões de longo prazo, consideram-se intervalos de tempo anuais, logo esse método é mais utilizado para prever planejamentos a longo prazo como por exemplo: instalações de novas linhas de montagem/produção, novas linhas de produtos, e outros.

Os métodos de previsão estão subdivididos em dois grupos, a saber: métodos objetivos ou quantitativos e métodos subjetivos ou qualitativos. Chiavenato (2014) aborda que as técnicas qualitativas são vantajosas por fornecerem informações descritivas e explicativas, e não têm como objetivo levantar dados, o que torna sua aplicação mais simples do que as técnicas quantitativas. Porém, as técnicas quantitativas são mais usadas nas empresas por utilizarem modelos estatísticos e fornecerem resultados numéricos, o que faz essa técnica mais precisa.

0 presente estudo vai se restringir apenas à abordagem dos métodos quantitativos, nomeadamente: Média móvel simples, Amortecimento Exponencial e Regressão Linear.

\subsubsection{MÉDIA MÓVEL SIMPLES}

O método da Média Móvel simples é utilizado quando a demanda é relativamente, estável, não apresentando componentes de tendências significativas. Nesse método, a previsão fundamenta-se em fazer uma média aritmética simples em relação a um determinado número de períodos. Conforme o entendimento de Seleme e Seleme (2013), a média móvel calcula a média dos dados de períodos sequenciais para a previsão do período seguinte.

Desse modo, a aplicação do modelo de média móvel simples se resume em calcular a demanda média para n períodos de tempo mais recentes, e utilizar esta média como referência para o próximo período. Tal método pode ser descrito pela seguinte fórmula:

$$
\text { Média Móvel }=\frac{\sum \text { demanda dos n períodos }}{n}
$$

\subsubsection{AMORTECIMENTO EXPONENCIAL}

Assim como a média móvel simples, este método também é utilizado para demandas, relativamente estáveis, sendo este um pouco mais sofisticado.

Como explica Szabo (2015), para que seja realizada esta ponderação é necessário utilizar um fator de amortecimento $\alpha$ (alpha), que tem valor entre zero e um. Levam-se em conta vários períodos, mas, necessariamente, somente o anterior ao do resultado real e do fator de amortecimento $\alpha$ (alpha). 
Os elementos do método são os seguintes: $\left(\mathrm{P}_{\mathrm{t}+1}\right)$ é previsão para o período seguinte; $(\alpha)$ fator de amortecimento; $\left(\mathrm{D}_{\mathrm{t}}\right)$ demanda real observado no período t e $\left(\mathrm{P}_{\mathrm{t}}\right)$ previsão referente ao período t. Logo o presente método pode ser expresso pela seguinte fórmula:

$$
P_{t+1}=\alpha\left(D_{t}\right)+(1-\alpha) *\left(P_{t}\right)
$$

O método exige que se tenha uma previsão anterior e a demanda, quando não se dispõe dessa estimativa para a primeira previsão, leva-se em consideração a previsão igual à demanda do período anterior.

\subsubsection{REGRESSÃO LINEAR}

Trata-se de um método mais clássico dentre os que consideram a existência de componentes de tendência, sazonais ou cíclicos, trabalhando com a comparação de dados dispostos em uma curva com o objetivo de encontrar a equação da curva que mais se aproxima desses dados. De acordo com Castanheira (2016), o método de regressão linear é utilizado para obter uma análise da relação existente entre duas variáveis, uma dependente e outra independente, e serve para realizar previsões do comportamento futuro de algum fenômeno de interesse de todos, baseando-se em dados históricos sobre ele.

O objetivo principal desse método visa encontrar um valor que, inicialmente, não é estimado, e sua aplicação estima sempre o relacionamento entre as observações reais e outra variável que culmina em uma equação com coeficientes que ganham utilidade na feitura das previsões.

Larson e Farber (2015) explicam que a equação de uma reta de regressão permite que você use a variável independente (explanatória) x para fazer previsões para a variável dependente (resposta) y. A equação de uma reta de regressão para uma variável independente $\mathrm{x}$ e uma variável dependente y é: $\hat{y}=\mathrm{mx}+\mathrm{b}$ em que $\hat{y}$ é o valor previsto de y para um dado valor de $\mathrm{x}$. A inclinação m e o intercepto em y, b, são dados por:

$$
\mathrm{m}=\frac{\mathrm{n} \sum \mathrm{xy}-\left(\sum \mathrm{x}\right)^{*}\left(\sum \mathrm{y}\right)}{\mathrm{n} \sum \mathrm{x}^{2}-\left(\sum \mathrm{x}\right)^{2}} \text { e } \mathrm{b}=\overline{\mathrm{y}}-\mathrm{m} \overline{\mathrm{x}}=\frac{\sum \mathrm{y}}{\mathrm{n}}-\mathrm{m} \frac{\sum \mathrm{x}}{\mathrm{n}}
$$

O erro amostral é estimado pelos resíduos que é a diferença dos valores observados Y e o estimado pela reta $\hat{y}$.

$$
\sum_{i=1}^{n} \widehat{\varepsilon}^{2}=\sum_{i=1}^{n}\left(Y_{i}-\widehat{Y}_{i}\right)^{2}
$$

Aplicando o método com a reta temos:

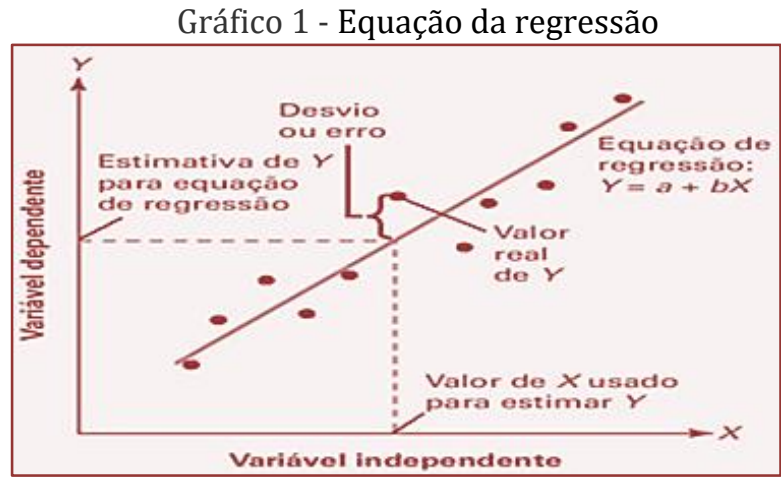

Fonte: Krajewski, Ritzman e Malhotra (2004) 


\section{ESTUDO DE CASO}

O presente estudo foi realizado em uma empresa localizada no Município de São José de Ribamar no Estado do Maranhão, atuando no ramo alimentício e na área de distribuição de frangos há, aproximadamente, 11 anos. A empresa é composta por 18 empregados, e recebe $50 \%$ do seu fornecimento vindo de fora do Estado e 50\% dentro de sua região. Além disso, realiza venda de frangos vivos e abatidos, efetuando sua distribuição nos Municípios do Estado e uma pequena parcela destinada para o interior, apresentando uma distribuição média de 3.000 frangos, diariamente. A empresa dispõe de dois polos de distribuição, sendo um central, onde o produto fica estocado, e outro utilizado somente para vendas.

A metodologia aplicada a este estudo, caracteriza-se inicialmente por uma revisão bibliográfica. De acordo a Gil (2002), são desenvolvidas com base em material existente como livros e artigos científicos, de forma a subsidiar maior entendimento técnico sobre o estudo referente à previsão de demanda e os seus métodos de aplicação, tornando-se um instrumento chave para o pesquisador.

Além disso, foram realizadas entrevistas com os empregados da empresa, com o objetivo de identificar se a empresa utiliza algum método de previsão de demanda para seus processos, como também avaliar a forma de gerenciamento de estoque em estudo.

Por fim, utilizou-se uma pesquisa quantitativa, que de acordo com Pereira (2016, p.87), "trata de mensurar dados numéricos por meio de recursos e de técnicas estatísticas como média, percentagem, coeficiente de correlação, análise de regressão, entre outros.".

Os dados coletados são referentes às quantidades vendidas de frangos em 12 meses, avaliando o período de abril de 2017 a março de 2018, de maneira a prever a demanda para o mês de abril/2018 na distribuidora.

Para determinação dessa demanda foram utilizados três métodos, a saber: média móvel simples, em que aplicou-se uma análise de verificação (somando a demanda dos $\mathrm{n}$ períodos anteriores e dividindo por $\mathrm{n}$, sendo utilizados 2, 3 e 4 períodos para aplicação); análise de amortecimento exponencial (onde o coeficiente de ponderação $\alpha$ (alpha) deve estar entre 0 e 1), e, finalmente, o método de regressão linear (em que foram consideradas as demandas e os períodos para a elaboração do gráfico de dispersão).

Os resultados obtidos através das análises serão comparados com a venda real do mês de abril de 2018, com o objetivo de determinar, dentre os métodos, aquele que melhor se ajusta à empresa em questão.

\section{ANÁLISE DOS RESULTADOS}

Com base nos dados coletados na empresa, obtiveram-se informações acerca das quantidades vendidas por mês no período de 12 meses, de abril de 2017 a março de 2018, como pode ser observado pelo Gráfico 2 .

Gráfico 2 - Quantidade vendida de frangos

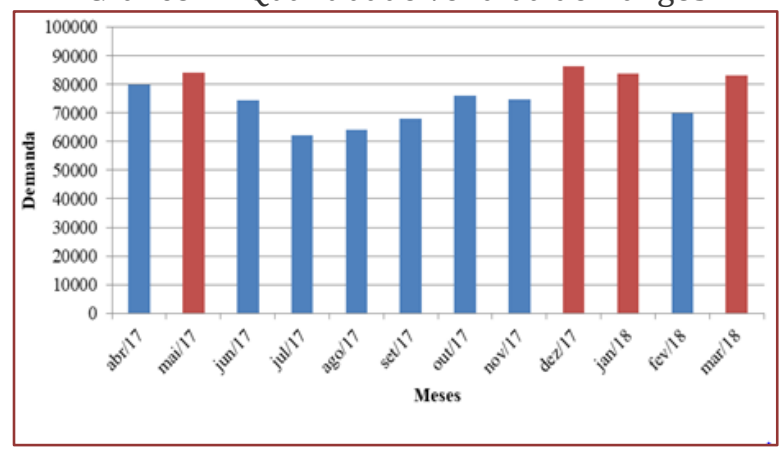

Fonte: Elaboração dos autores

Observa-se no gráfico 2, que ocorre uma demanda maior do produto, nos meses de maio, dezembro, janeiro e março. De acordo com o gestor da empresa, esses picos ocorrem em virtude das datas comemorativas referentes ao período de fim de ano e Semana Santa. 
Com base nas informações coletadas, pode-se obter, através da aplicação dos métodos de previsão: média móvel simples, amortecimento exponencial e regressão linear, a demanda para o mês de abril de 2018.

\subsection{MÉDIA MÓVEL SIMPLES}

Para o cálculo da média móvel foi utilizada a fórmula (1), com base de cálculo de 2 períodos, 3 períodos e 4 períodos, a fim de se obter a melhor estimativa de previsão para o mês de abril.

Tabela 1 - Média móvel simples: 2 períodos, 3 períodos, 4 períodos

\begin{tabular}{|c|c|c|c|c|c|c|c|}
\hline \multicolumn{8}{|c|}{ Média Móvel Simples } \\
\hline \multicolumn{2}{|c|}{ Demanda Real } & $2 p$ & Erro (et) & $3 p$ & Erro (et) & $4 p$ & Erro (et) \\
\hline $\mathrm{abr} / 17$ & 79819 & $\mathrm{x}$ & $\mathrm{x}$ & $\mathrm{x}$ & $\mathrm{x}$ & $\mathrm{x}$ & $\mathrm{x}$ \\
\hline mai/17 & 84000 & $\mathrm{x}$ & $\mathrm{x}$ & $\mathrm{x}$ & $\mathrm{x}$ & $\mathrm{x}$ & $\mathrm{x}$ \\
\hline jun/17 & 74483 & 81910 & -7427 & $\mathrm{x}$ & $\mathrm{x}$ & $\mathrm{x}$ & $\mathrm{x}$ \\
\hline jul/17 & 62223 & 79242 & -17019 & 79434 & -17211 & $\mathrm{x}$ & $\mathrm{x}$ \\
\hline ago/17 & 64111 & 68353 & -4242 & 73569 & -9458 & 75131 & -11020 \\
\hline set/17 & 67964 & 63167 & 4797 & 66939 & 1025 & 71204 & -3240 \\
\hline out/17 & 76022 & 66038 & 9985 & 64766 & 11256 & 67195 & 8827 \\
\hline nov/17 & 74680 & 71993 & 2687 & 69366 & 5314 & 67580 & 7100 \\
\hline $\mathrm{dez} / 17$ & 86266 & 75351 & 10915 & 72889 & 13377 & 70694 & 15572 \\
\hline jan/18 & 83730 & 80473 & 3257 & 79989 & 4741 & 76233 & 7497 \\
\hline $\mathrm{fev} / 18$ & 69820 & 84998 & -15178 & 81559 & -11739 & 80175 & -10355 \\
\hline mar/18 & 83122 & 76775 & 6347 & 79939 & 3183 & 78624 & 4498 \\
\hline $\mathrm{abr} / 18$ & & 76471 & & 78891 & & 80735 & \\
\hline
\end{tabular}

Fonte: Elaboração dos autores

No resultado do método, a previsão para o mês de abril de 2018 com 2 períodos foi de 76471 unidades de frangos, para 3 períodos a previsão estimada é de 78891 unidades e para 4 períodos a previsão é de 80735 unidades. Havendo, portanto, uma diferença em torno de dois e três por cento ao considerar-se os distintos períodos.

\subsection{AMORTECIMENTO EXPONENCIAL}

Para o cálculo do método de amortecimento exponencial utilizou-se a fórmula (2), atribuindo ao fator de amortecimento $\alpha$ (alpha) o valor igual a 1. Pois após tentativas com outros valores de $\alpha$ (alpha), o resultado que mais se aproximou com a demanda real ocorrida foi aquele obtido quando $\alpha$ (alpha) testado era o valor 1 .

Tabela 2 - Amortecimento Exponencial

\begin{tabular}{|c|c|c|c|}
\hline Demanda Real & $\begin{array}{c}\text { Previsão } \\
\text { Amortecimento Exponencial }\end{array}$ & Erro & $\begin{array}{l}\alpha \\
1\end{array}$ \\
\hline 79819 & 79819 & 0 & \\
\hline 84000 & 79819 & 4181 & \\
\hline 74483 & 84000 & -9517 & \\
\hline 62223 & 74483 & -12260 & \\
\hline 64111 & 62223 & 1888 & \\
\hline 67964 & 64111 & 3853 & \\
\hline 76022 & 67964 & 8058 & \\
\hline 74680 & 76022 & -1342 & \\
\hline 86266 & 74680 & 11586 & \\
\hline 83730 & 86266 & -2536 & \\
\hline 69820 & 83730 & -13910 & \\
\hline 83122 & 69820 & 13302 & \\
\hline Demanda Real & 83122 & & \\
\hline
\end{tabular}


Após a aplicação do método obteve-se uma estimativa para o mês de abril de 83122 unidades, conforme visto na Tabela 2 .

\subsection{REGRESSÃO LINEAR}

Na aplicação do método de regressão foi utilizado um gráfico de dispersão, a fim de se obter a equação da regressão e o valor de $\mathrm{R}^{2}$.

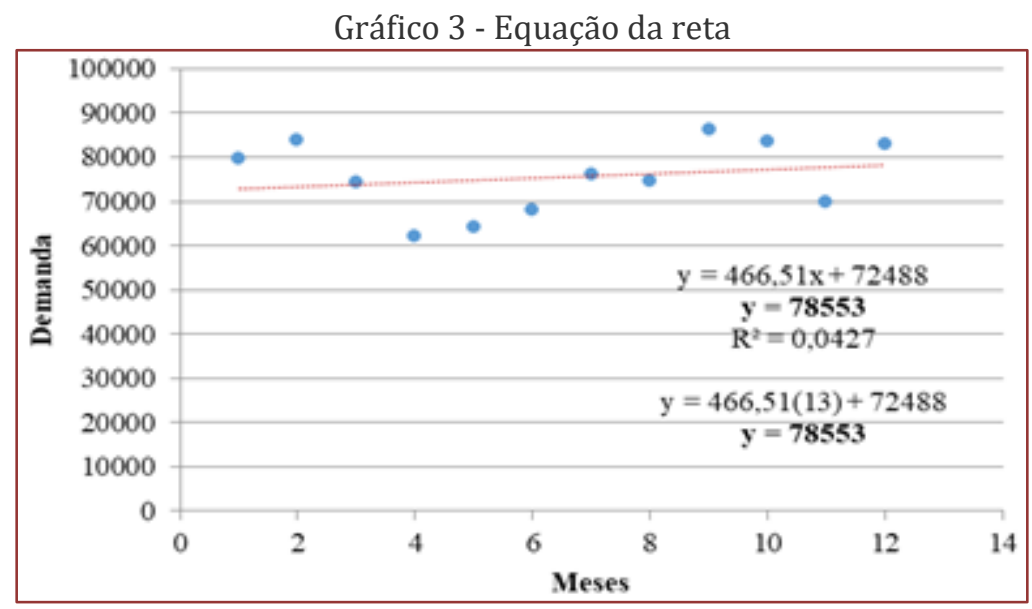

Fonte: Elaboração dos autores

Em conformidade com o Gráfico 3, foi possível encontrar a equação da reta, a qual utilizou-se para encontrar a previsão. 0 coeficiente de determinação $R^{2}$ é de apenas 0,0427 (4,27\%), mostrando que a demanda depende muito pouco do tempo e muito mais de outros fatores. A previsão da demanda por essa técnica é de apenas 78553 unidades, com erro de 8654 (9,2\%), a menor.

A Tabela 3, mostra a demanda determinada por todas as técnicas, juntamente com os erros encontrados, descritos a seguir.

Tabela 3 - Distribuição da previsão da demanda para abril de 2018, segundo o método utilizado e erro

\begin{tabular}{|c|c|c|c|c|c|}
\hline \multicolumn{2}{|c|}{ Demanda Real } & $\begin{array}{c}\text { RESULTADOS } \\
\text { MÉTODOS DE PREVISÃO }\end{array}$ & Previsão Abril & Erro (Et) & Erro \% \\
\hline $\mathrm{abr} / 17$ & 79819 & & & & \\
\hline mai/17 & 84000 & MÉDIA MOVEL SIMOLES & & & \\
\hline jun/17 & 74483 & 2 PERÍODOS & 76471 & -10736 & $-12,3$ \\
\hline jul/17 & 62223 & 3 PERÍODOS & 78891 & -8316 & $-9,5$ \\
\hline ago/17 & 64111 & 4 PERÍODOS & 80735 & -6472 & $-7,4$ \\
\hline set/17 & 67964 & & & & \\
\hline out/17 & 76022 & AMORTECIMENTO EXPONENCIAL & 83122 & -4085 & $-4,7$ \\
\hline nov/17 & 74680 & & & & \\
\hline $\operatorname{dez} / 17$ & 86266 & REGRESSÃO LINEAR & 78553 & -8654 & $-9,2$ \\
\hline jan/18 & 83730 & & & & \\
\hline fev/18 & 69820 & & & & \\
\hline $\operatorname{mar} / 18$ & 83122 & & & & \\
\hline & & Demandas Real de Abril-87207 & & & \\
\hline
\end{tabular}

Fonte: Elaboração dos autores

Observa-se que, mesmo fazendo uso de métodos diferentes para previsão da demanda de abril, o erro em todas as técnicas apresenta-se alto, o que nos leva a uma análise mais detalhada da série real utilizada. 
Gráfico 4 - Comparação da demanda real e dos preços por quilograma, no período abril 2017 a abril de

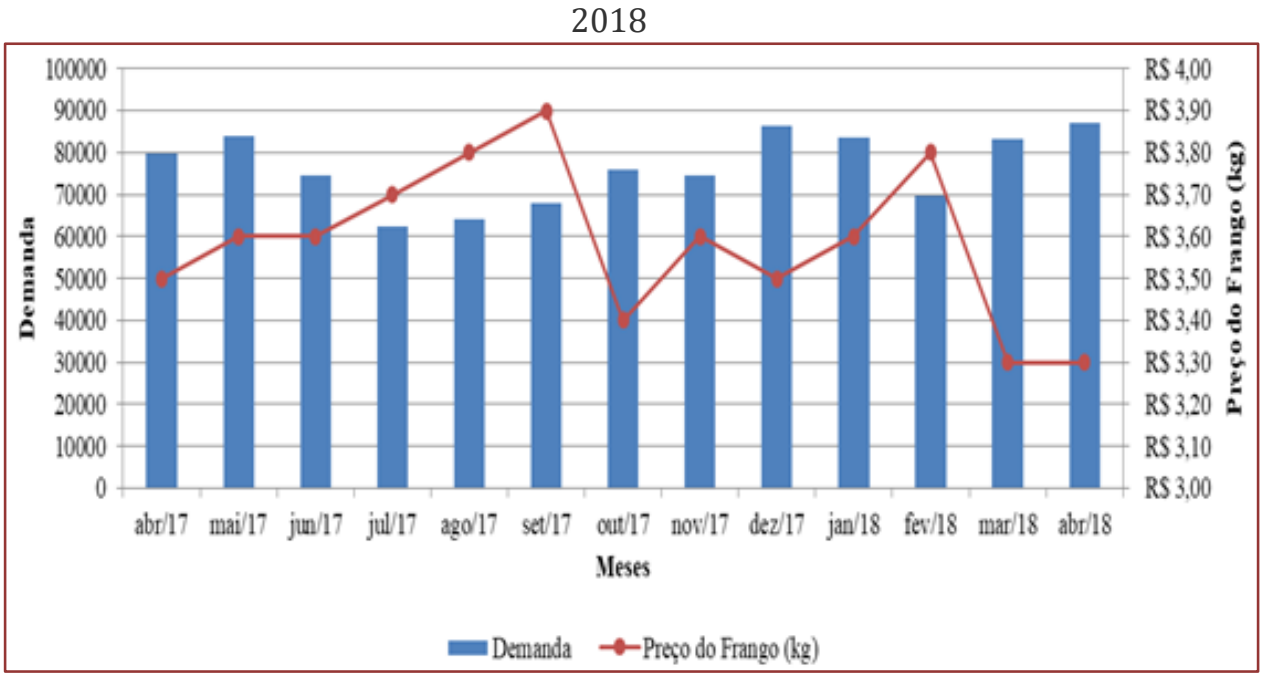

Fonte: Elaboração dos autores

Observando-se o Gráfico 4, verifica-se que no período de abril a setembro de 2017, houve uma política deliberada, por alguma razão, de aumento de preços. Havendo, naturalmente também, queda na demanda. No período seguinte, de outubro a dezembro de 2017, há recuperação devido à baixa dos preços. Com a tentativa de aumento de preços novamente, em janeiro e fevereiro de 2018, a demanda diminuiu bruscamente, e volta a se recuperar nos dois meses subsequentes em função da decisão de forte redução de preços. Com fortes variações de queda e recuperação, em períodos variados, há dificuldade de adaptação de qualquer método de previsão, como visto nos resultados apresentados na Tabela 3.

Continuando a análise do gráfico, foi possível identificar que houve uma queda significativa na demanda do mês de fevereiro de 2018, o que inviabiliza qualquer tentativa de previsão para meses subsequentes. Para melhor prever a demanda de abril, houve necessidade de ajuste na demanda de fevereiro para um valor mais próximo da realidade dos dados. Esse ajuste foi realizado com uma interpolação para esse mês, usando uma média dos dois meses anteriores e do último, encontrando-se o valor de 81.840 unidades para o mês de fevereiro. Com o ajuste foram realizadas novas previsões conforme a Tabela 4.

Tabela 4 - Resultados da demanda ajustada

\begin{tabular}{|c|c|c|c|c|c|c|c|}
\hline \multicolumn{8}{|c|}{ Comparação dos Resultados } \\
\hline $\begin{array}{l}\text { MÉTODOS DE } \\
\text { PREVISÃO }\end{array}$ & $\begin{array}{l}\text { Previsão } \\
\text { (dados não } \\
\text { ajustados) }\end{array}$ & Erro (et) & Erro \% & $\begin{array}{l}\text { Previsão abril } \\
\text { (dados } \\
\text { ajustados) }\end{array}$ & Erro (et) & Erro \% & $\begin{array}{l}\text { Diferença } \\
\text { entre as } \\
\text { Previsões }\end{array}$ \\
\hline \multicolumn{8}{|l|}{$\begin{array}{l}\text { MÉDIA MOVEL } \\
\text { SIMPLES }\end{array}$} \\
\hline 2 PERÍODOS & 76471 & 10736 & 12,3 & 82841 & 4366 & 5 & 6370 \\
\hline 3 PERÍODOS & 78891 & 8316 & 9,5 & 82897 & 4310 & 4,9 & 4006 \\
\hline 4 PERÍODOS & 80735 & 6472 & 7,4 & 83740 & 3467 & 3,9 & 3005 \\
\hline $\begin{array}{l}\text { AMORTECIMENTO } \\
\text { EXPONENCIAL }\end{array}$ & 83122 & 4085 & 4,7 & 83122 & 4085 & 4,7 & 0 \\
\hline $\begin{array}{l}\text { REGRESSÃO } \\
\text { LINEAR }\end{array}$ & 78553 & 8654 & 9,9 & 82013 & 5104 & 6 & 3460 \\
\hline \multicolumn{8}{|c|}{ Demanda Real de Abril: 87207} \\
\hline
\end{tabular}


Comparando os dados apresentados nas duas previsões (Tabela 4), verifica-se o seguinte:

- $\quad$ A melhor previsão da demanda para abril de 2018, quando não ajustados os dados, é de 83122, quando utilizado o método do amortecimento exponencial com $\alpha$ (alpha) igual a 1. Esse procedimento gera um erro de 4,7\% em relação à demanda real de 87207.

- $\quad$ Entretanto, quando os dados são ajustados a melhor previsão é aquela que estima a quantidade de 83740 unidades, do método da média móvel com quatro períodos. Esse procedimento gera um erro de 3,9\%. Tem-se, portanto, neste caso, a melhor previsão.

\section{CONSIDERAÇÕES FINAIS}

Teoricamente, os métodos de previsão de demanda são ajustáveis a qualquer empresa, entretanto, para se ter previsões mais precisas, necessita-se de um acompanhamento a longo prazo das informações reais.

Por restrições, a empresa forneceu dados relativos a apenas 12 meses, dificultando sobremaneira, uma análise mais aprofundada do comportamento das informações. A limitação da quantidade de dados tratados dificultou uma aproximação maior da demanda real. Tendo em vista, que a demanda que ocorreu em abril 2018, de 87207 unidades, foi atípica, nenhum dos métodos conseguiu se aproximar bem, dessa demanda real.

A variação na demanda, que ocorreu no mês de fevereiro, prejudicou ainda mais as estimativas. Ao avaliar com o gestor o porquê dessa variação, ele informou que se tratava de um aumento no preço do kg de frango naquele mês, o que acarretou uma queda significativa na sua demanda de fevereiro. A fim de recuperar essa baixa, foi feita uma correção no preço do kg de frango, baixando em 13,1\%, o que gerou um aumento expressivo da demanda para os meses de março e abril.

No estudo de caso, após a primeira aplicação dos métodos, e a verificação de que nenhum se aproximava da demanda real, foi realizada uma nova aplicação com uma demanda ajustada em fevereiro de 2018. Uma interpolação foi feita na demanda do mês de fevereiro, na qual ocorreu a baixa, e assim refeitas as aplicações dos métodos, a fim de estimar uma demanda mais próxima da real. Embora não sendo possível ficar tão próximo, pode-se, entretanto, após ajuste, chegar a uma demanda de 83740 unidades com erro de 3,9\%. É importante lembrar que os métodos de previsão servem de apoio à tomada de decisões do gestor, de modo que, a análise dos resultados da previsão deve ser feita pelo gestor e pelos colaboradores experientes no mercado em que a empresa está inserida. Desse modo, um método de previsão quantitativo, ao ser combinado com um método qualitativo - em que se tem a opinião dos especialistas e gestores pode trazer mais eficácia na sua implantação.

Para melhorar qualquer previsão, sugere-se, para pesquisas futuras, a análise de pelo menos vinte e quatro meses de informações, para que se possa eliminar tendências e outros efeitos indesejáveis, podendo, dessa maneira, adaptar melhor um método de previsão à empresa foco deste estudo.

\section{REFERÊNCIAS}

[1] Albertin, M. R; Pontes, H. L. J. Administração da produção e operações. Curitiba: Intersaberes, 2016.

[2] Associação Brasileira de Proteína Animal, Relatório Anual de 2018. 18.ed. São Paulo: ABPA, 2018. Disponível em: <http://abpabr.com.br/setores/avicultura/publicacoes/relatorios-anuais> Acesso em: 22 de março de 2019.

[3] Castanheira, N. P. Cálculo aplicado à gestão e aos negócios. Curitiba: Intersaberes, 2016.

[4] Chiavenato, I. Gestão de vendas: uma abordagem introdutória. 3. ed. - Barueri, SP: Manole, 2014.

[5] Gil, A. C. Como elaborar projeto de pesquisa. 4.ed. São Paulo: Atlas, 2017.

[6] Krajewski, L. J.; Ritzman, L.; Malhotra, M. J. Administração de produção e operações: 8. ed. São Paulo: Pearson Prentice hall, 2004.

[7] Larson, R.; Farber, B. Estatística aplicada. 6.ed. São Paulo: Pearson Education do Brasil, 2015.

[8] Martins, P. G.; Laugeni, F. P. Administração da produção: 3. ed. rev. e atual. São Paulo: Saraiva, 2016.

[9] Paoleschi, B. Almoxarifado e gestão de estoques. 2. Ed. São Paulo: Érica, 2013.

[10] Pires, A. B. Cálculo Numérico: prática com algoritmos e planilhas. São Paulo: Atlas, 2015. 
[11] Secretaria de Estado de Indústria, Comércio e Energia do Estado do Maranhão. Governo e Embrapa discutem avanços da cadeia produtiva da avicultura: Avicultura Industrial do Maranhão. Disponível em: <www.ma.gov.br/governo-e-embrapa-discutem-avancos-da-cadeia-produtiva-da-avicultura/>. Acesso em: 22 de março de 2019.

[12] Seleme, R.; Seleme, R. B. Automação da produção: uma abordagem gerencial. Curitiba: InterSaberes, 2013.

[13] Szabo, V. Gestão de estoques. São Paulo: Pearson Education Do Brasil, 2015. Disponível em: <http://ceuma.bv3.digitalpages.com.br/users/publications/9788543013855/pages/-12>. Acesso em: 01 de maio de 2018. 


\title{
Capitulo 13
}

\section{Uma revisão sistemática da literatura sobre tecnologias da gestão de documentos}

\author{
David de Almeida Moysés \\ Brenda Baumann Gewehr \\ Isabella Helena Tavares de Morais \\ Ari Melo Mariano \\ Edgard Costa Oliveira
}

Resumo: Uma vez que as organizações devem aperfeiçoar os processos de negócio por meio do gerenciamento de documentos e arquivos, realizou-se um estudo cujo objetivo é identificar as principais abordagens da literatura com relação à gestão de informação em organizações por meio de uma revisão sistemática das principais contribuições da literatura no que tange à temática de gerenciamento de informações. Além disso, buscou-se analisar os principais artigos do assunto aplicado às organizações militares. Assim, foi realizada uma pesquisa exploratória por meio da Teoria do Enfoque Meta Analítico Consolidado - TEMAC, de Mariano e Rocha (2017). A base de dados utilizada para coleta foi Web of Science. Nesse contexto, a análise dos dados coletados mostrou que as organizações buscam diferentes maneiras de resolver a questão da gestão documental ao adaptar tecnologias para o próprio contexto. As principais referências de ferramentas, técnicas e práticas para organização de documentos organizacionais identificadas foram: Enterprise Content Management (ECM), Business Process Management (BPM), CMIS Java 2 Platform, Enterprise Edition (J2EE), Collaborative Document Management System (CDMS), Electronic Document Management Systems (EDMS).

Palavras-chave: Revisão sistemática da literatura, gerenciamento de informações, gerenciamento de documentos, organização militar, TEMAC. 


\section{INTRODUÇÃO}

Em um mundo em que constantemente cresce a quantidade de dados e informações, as organizações devem buscar gerenciar seus documentos e arquivos de maneira a otimizar seus processos de negócio. Segundo Ottonicar, Santos e Moraes (2017), tanto a gestão da informação quanto a competência informacional e a organização do conhecimento disseminam as informações a fim de que sejam utilizadas pela comunidade ou pela organização, sendo que a representação do conhecimento propicia ao profissional a utilização da informação para alcançar um objetivo com efetividade.

A partir deste princípio, Costa, Soares e De Sousa (2016) realizaram uma revisão sistemática da literatura com relação à gestão conhecimento, informação e inovação. Os autores concluíram que o desenvolvimento de modelos e abordagens de tomada de decisão colaborativos têm uma importante relevância para pequenas e médias empresas, enquanto o governo e as agências de apoio institucionais desempenhem um papel interessante ao apoiar estratégias internacionais, principalmente através da aprendizagem experiencial e do desenvolvimento de redes de trabalho. Entretanto, pôde-se verificar uma carência na literatura com relação às tecnologias de gestão documental a partir do levantamento do estado da arte, em que pouco é explorado o tema no contexto de organizações militares.

Assim, este estudo pretende responder duas questões de pesquisa: Quais são as principais práticas e ferramentas adotadas nas organizações para a gestão da informação e de documentos? Como as organizações militares lidam com a gestão da informação? 0 objetivo deste estudo é identificar as principais abordagens da literatura com relação à gestão de informação em organizações público e privadas. Para então alcançar este objetivo, foi realizada uma revisão sistemática da literatura com artigos de alto impacto a partir da Web of Science. Dessa maneira, pretende-se contribuir no âmbito militar ao consolidar as contribuições técnicas sobre o controle de documentos realizado por organizações militares, ao mesmo tempo que no âmbito acadêmico ao apresentar um modelo de revisão de sistemática da literatura aplicável em diversas áreas do conhecimento, tais como os estudos de Pedra et al. (2018), Silva, Shimoihi e Mariano (2018) e Romano et al. (2018).

\section{METODOLOGIA}

Esse estudo é caracterizado como exploratório, em que se realizou uma revisão sistemática da literatura a partir da Teoria do Enfoque Meta Analítico (TEMAC) de Mariano e Rocha (2017). Esta técnica baseia-se na utilização de três etapas para identificar literaturas relevantes sobre o tema abordado.

Na etapa 1, de preparação da pesquisa, definiu-se como termos para a pesquisa as expressões "Information management" e "Document management", e a base de dados utilizada foi Web Of Science, no de período de 1945-2019, uma vez que segundo Lopes et al. (2012), esta possui excelente cobertura temporal e grande número de registros enriquecido com as referências citadas, além de ter sido a primeira base de dados a incorporar o h-índex, que é utilizado para quantificar a produtividade e o impacto de pesquisador baseando-se nos seus artigos mais citados. A partir da busca foram encontrados 116 resultados relevantes.

Além disso, a fim de analisar o desenvolvimento do gerenciamento de documentos dentro de uma organização governamental, foi realizada também na base de dados Web of Science, uma pesquisa utilizando as palavras-chave "military" e "Document management", no período de 1945-2019. A busca de publicações abordando gerenciamento de documentos no contexto de organizações militares, resultou em 6 artigos, dentre os quais o Brasil não possui participação nos estudos realizados.

Na etapa 2, após estabelecidos os critérios de preparação da pesquisa e assegurado a pertinência dos resultados encontrados, faz-se necessário iniciar a apresentação e inter-relação dos dados (MARIANO; ROCHA, 2017). Essa etapa trata-se da apresentação geral sobre o tema a partir de alguns indicadores, tais como autores com mais publicações na área, revistas e artigos mais relevantes, principais conferências e periódicos, dentre outros.

For fim, na etapa 3, após construídas as impressões básicas sobre o tema é necessário analisá-lo de modo mais acentuado. Assim, esta etapa consiste no detalhamento, modelo integrador e validação por evidências. 0 software utilizado para a elaboração dos mapas de calor foi o VOSViewer. Este faz uma leitura dos dados da base Web Of Science e, por meio de algoritmos de clusterização, separa os autores em grupos de acordo com suas vertentes de estudo (MARIANO; ROCHA, 2017). As informações bibliométricas 
são consideradas a fim de definir os atributos dos autores e, a partir da hipótese de que pesquisadores com os mesmos atributos possuem maior frequência de citação entre si, a rede é separada por clusters.

\section{REVISÃO DA LITERATURA}

\subsection{GESTÃO DA INFORMAÇÃO E GESTÃO DE DOCUMENTOS NA LITERATURA}

Foram encontradas 116 pesquisas sobre os assuntos, das quais, 33.62\% das publicações estão inseridos em estudos na área de Information Science Library Science, seguido por estudos em Computer Science Information Systems com 30.17\%.

Como já esperado, $88.79 \%$ das publicações são em inglês, em decorrência da base de dados ser nesse idioma, porém, encontram-se também cinco artigos em português. Por outro lado, 16.38\% da publicação são provenientes da República Popular da China, tornando-se a maior responsável por pesquisas nesse assunto, seguida pela Inglaterra e os Estados Unidos, ambas responsáveis por 13.79\% das publicações. Já o Brasil encontra-se na 6⿳亠丷厂 posição com uma participação de 4.31\% do total de publicações ocorridas.

A primeira publicação sobre o tema é o artigo "Optical Disk Technology for Information" (BRUMM, 1991), que trata sobre o processamento de imagens de documentos a partir de 1988-90 concentra-se na tecnologia WORM (write once read many) e em discos ópticos regraváveis e exclui o CD-ROM.

Entre os autores que mais publicaram sobre o tema estão Al Qady M., Bergmam O. e Kandil A. Os autores Al Qady e Kandil A., possuem três publicações sobre o tema, nos quais abordam em seus estudos técnicas e sistemas de gerenciamentos de documentos eletrônicos com relação ao conhecimento semântico de documentos, a fim de melhorar as funções do gerenciamento (AL QADY; KANDIL, 2010, 2013a, 2013b). 0 artigo com mais citações é o Concept Relation Extraction from Construction Documents Using Natural Language Processing (AL QADY; KANDIL, 2010), que apresenta uma técnica de gerenciar o conhecimento contido em documentos contratuais cuja finalidade é acessar de maneira rápida e eficiente este conhecimento para utilizá-lo no gerenciamento de projetos e administração de contratos.

O autor Bergmam também possui três publicações na base de dados Web Of Science, entretanto, sua abordagem difere dos autores anteriores no fato que seus estudos estão voltados para os usuários. No seu artigo mais citado, Shared Files: The Retrieval Perspective, de 2014, o autor apresenta uma comparação entre Gerenciamento de Informações do Grupo (GIM) e o Gerenciamento de Informações Pessoais (PIM) em um estudo de recuperação de informações pessoais em grande escala de modo a justificar a razão pela qual os participantes preferiram o PIM ao GIM.

Entre os artigos mais citados estão Electronic Document Management - Challenges and Opportunities for Information-Systems Managers (SPRAGUE JR, 1995), com 56 citações e Automated classification of construction project documents (CALDAS; SOIBELMAN, HAN, 2002) com 55 citações.

Sprague (1995) analisa o valor da nova tecnologia de gerenciamento de documentos a fim de ilustrar os diversos modos pelos quais esse valor pode ser realizado, desenvolver estruturas que visa compreender esse campo em evolução e sugerir ações que os gerentes de sistemas de informações podem adotar para se prepararem para essa revolução no gerenciamento de informações.

Caldas, Soibelman e Han (2002) apresentam uma maneira de melhorar a organização e o acesso à informação em sistemas interorganizacionais conforme uma classificação automatizada de documentos de projeto de construção segundo os componentes de projeto relacionados haja vista que a quantidade de documentos produzidos em um projeto de construção e armazenados em sistemas de informações interorganizacionais é considerável.

Com o objetivo de representar os dados de modo visual, utilizou-se a ferramenta online de análise de conteúdo TagCrowd, que oferece a possibilidade de visualizar as palavras coletadas a partir da frequência e idioma escolhido. Conforme Mariano e Rocha (2017), cria-se então a word cloud. Foram inseridas na ferramenta todas as palavras-chave dos 116 documentos e obtidos após a pesquisa na base Web of Science. Assim, o software gerou um diagrama representativo das 50 palavras-chave com maior número de frequências. Nessa conjuntura, faz-se necessário destacar que a escala de tamanho da fonte das palavras exibidas no diagrama é proporcional ao número de citações de cada palavra, e consequentemente permite a identificação das principais linhas de pesquisa relacionadas ao tema escolhido. 
Figura 1- Mapa de frequência de palavras-chave.

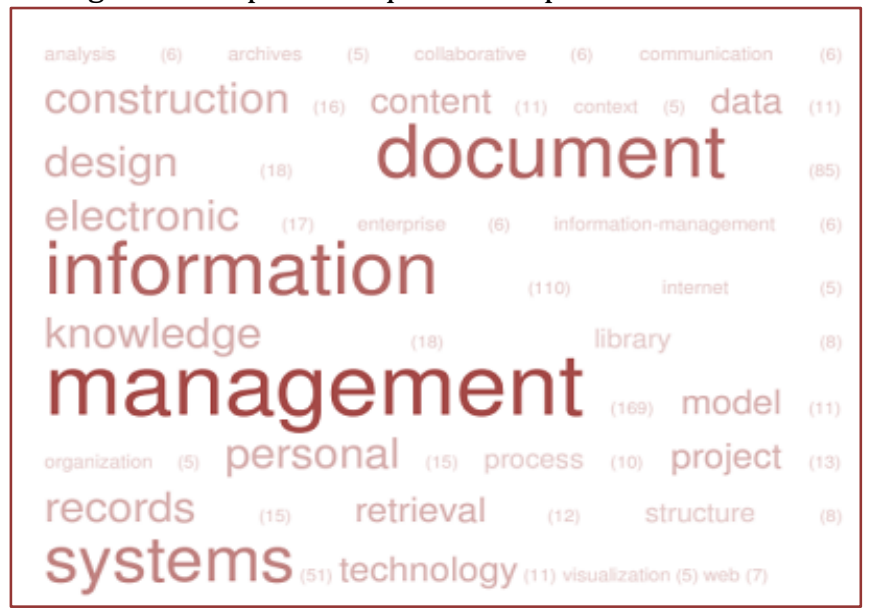

Fonte: própria.

As palavras-chave revelam características específicas de cada trabalho, permitindo agrupar os estudos e classificá-los. Assim, ao analisar a figura, pode-se verificar que a principal temática de pesquisa se refere ao gerenciamento de documentos e de informações utilizando sistemas de informações e tecnologias de suporte de gerenciamento. Nota-se também que palavras como construção, conhecimento, projeto, comunicação também foram recorrentes nos artigos, indicando diferentes perspectivas sobre a gestão da informação.

\subsection{DETALHAMENTO: ANÁLISES BIBLIOMÉTRICAS POR MEIO DE MAPAS DE CALOR}

Para o aprofundamento da análise dos autores e dos artigos, analisou-se os gráficos chamados mapas de calor gerados por meio do software VOSViewer. As análises bibliométricas de co-citation e o coupling foram realizadas.

A análise de co-citation verifica os artigos mais citados à medida que aparecem juntos a outros, sugerindo então uma semelhança entre estes estudos. De acordo com o mapa de calor (Figura 2), é possível notar a relevância de estudos de quatro autores para o tema, os quais, entretanto, seguem uma mesma linha de conhecimento. Assim, esses autores tendem a serem citados em mesmos artigos ou publicações.

Figura 2- Mapa de calor de co-citation

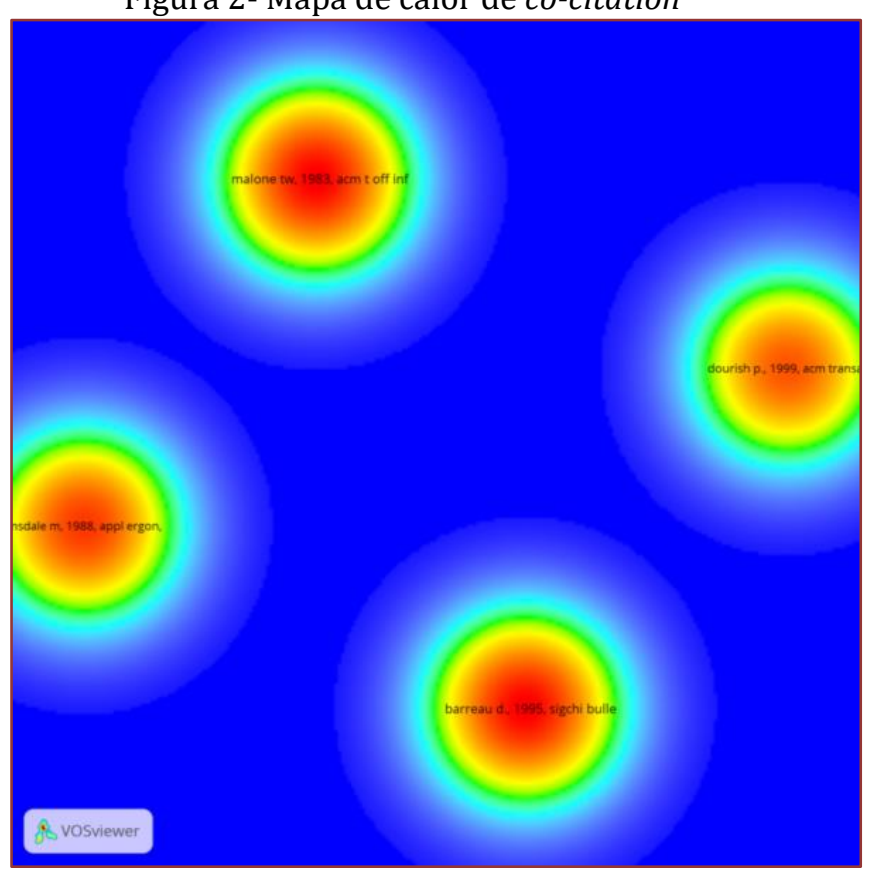

Fonte: própria. Extraído do software VOSViewer 1.6.10 
A partir do mapa de calor, analisa-se a maior influência de Malone, seguido por Barreau, Lansdale e Dourish. Esses autores abordam a utilização de sistemas de informação baseados em computador no âmbito organizacional e implicação dos mesmos no gerenciamento da informação e de documentos.

Analisando essas publicações mais detalhadamente, percebe-se que Malone (1983) realizou um estudo voltado para como os trabalhadores de escritório organizam as informações em suas mesas e escritórios. Em seu artigo é discutida uma série de implicações para o projeto de sistemas de informação baseados em computador "naturais" e convenientes. A partir das reivindicações dos trabalhadores e de como as mesas são organizadas, o autor propõe como os sistemas baseados em computador podem ser úteis dentro das organizações com os problemas levantados na pesquisa.

Já Lansdale (1988) aborda a dificuldade do "escritório sem papel", ilustrando quantas das questões envolvidas na automação do gerenciamento de informações são essencialmente de natureza psicológica. 0 artigo apresenta exemplos de técnicas de gerenciamento de informações existentes que mostram como há uma tendência a automatizar com vista a simular práticas de escritório ou a se desenvolver de acordo com a disponibilidade de soluções tecnológicas. De forma geral o artigo discute e apresenta uma estrutura para o desenvolvimento de sistemas de gerenciamento de informações orientados ao usuário.

Barreau (1995) estuda os sistemas de Gerenciamento de Informações Pessoais (PIM), que são sistemas de informação desenvolvidos por indivíduos para uso em um ambiente de trabalho. A publicação resume e sintetiza os estudos sobre como os usuários organizam e localizam arquivos em seus computadores.

Por fim, Dourish (1999) propõem e estuda um protótipo de sistema de gerenciamento de documentos, o Presto, que oferece interação rica com documentos por meio de atributos significativos de documentos no nível do usuário. "Os atributos do documento capturam as várias funções diferentes que um único documento pode desempenhar e permitem que os usuários reorganizem rapidamente o espaço do documento para a tarefa em questão" (DOURISH et al., 1999). A relevância desse estudo está relacionada ao fato dele pode ser utilizado como uma base para o design de novos sistemas de documentos e novas abordagens para gerenciamento de documentos e interação.

Além disso, outra análise foi realizada através do mapa de calor de coupling (Figura 3). 0 coupling apresenta os artigos que possuem referências em comum e as principais frentes de pesquisa, e com isso, ele revela quais são as abordagens que estão se fortalecendo a partir da situação atual.

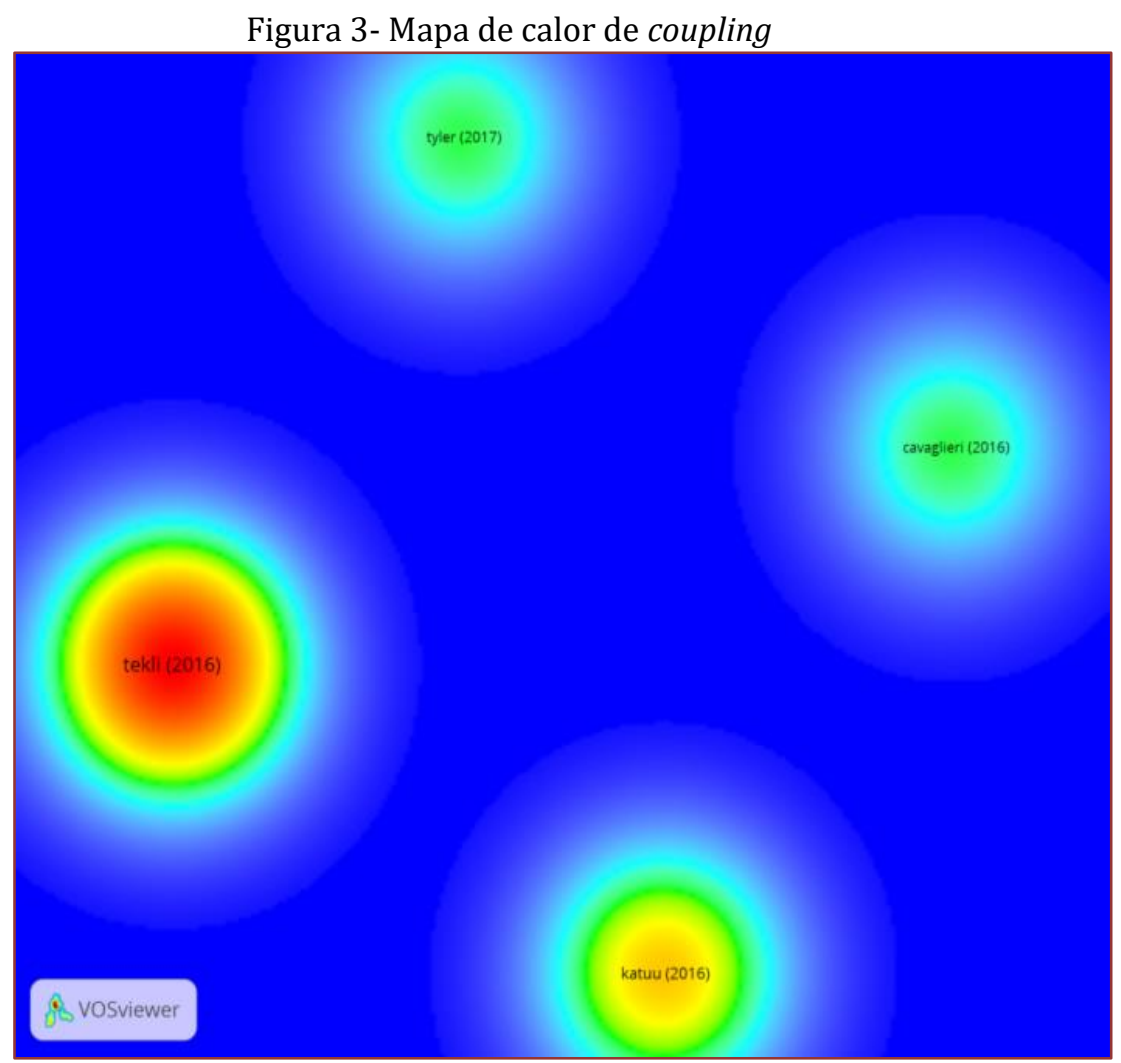

Fonte: própria. Extraído do software VOSViewer 1.6.10 
Nota-se que há quatro abordagens que se destacam. 0 estudo representado pelo pólo vermelho no mapa é de Tekli (2016), indicando que há uma tendência de pesquisas voltadas para seu trabalho. Tal pesquisa aborda a temática XML, que ganhou força como o padrão para gerenciamento de informações da Web e representação complexa de dados. Tekli (2016) fornece uma análise concisa e abrangente dos métodos relacionados à análise semântica estruturada e desambiguação baseada em XML.

Outra frente de pesquisa que é vista como tendência é a implementação de aplicativos de software de Gerenciamento de Conteúdo Corporativo (ECM). Esse assunto é abordado por Katuu (2016), o qual destaca que embora alguns acadêmicos do ECM tenham fornecido orientações sobre a implementação do ECM, existe uma lacuna na forma de avaliar os benefícios advindos da implementação. Seu estudo tem como objetivo analisar a utilidade de outro modelo de maturidade ECM, o ECM3, como uma ferramenta de avaliação.

Enquanto, Tyler (2017) realizou um estudo de caso sobre a gestão de ativos, classificação e valor da documentação de qualidade em um ambiente real, mostrando que o valor e importância da documentação são perdidos quando ninguém assume a propriedade. Por fim, outro front identificado através do mapa de calor foi o estudado pelo Marcelo Cavaglieri. Cavaglieri (2017) buscou aplicar o Lean office na gestão de arquivos tendo como objetivo verificar a aplicabilidade do pensamento Lean na arquivística.

\subsection{GERENCIAMENTO DE DOCUMENTOS SIGILOSOS EM INSTITUIÇÕES GOVERNAMENTAIS}

A partir do estudo é possível perceber que a implementação de tecnologias para gerenciamento de documentos é capaz de contribuir de diversas formas para as organizações, como automatizar o fluxo de documentos, possibilitar acesso mais fácil a informações atualizadas e a busca e recuperação aprimoradas (HJELT; BJORK, 2007; JAAKONMAEKI et al., 2018). Entretanto, existem também desafios relacionados a essa implementação, destacando-se principalmente a preocupação com documentos sigilosos e crimes virtuais, como espionagem e hacktivismo.

Nesse contexto, analisa-se nesse estudo as principais ferramentas utilizadas por instituições governamentais para lidar com esses desafios. No caso, a pesquisa foi realizada analisando o contexto militar, o qual é influenciado por essa problemática constantemente. Foram desenvolvidas técnicas para gerenciamento de documentos nas quais são utilizadas codificações a fim de assegurar a autenticidade dos documentos.

Assim, no artigo de Geisselhardt e Iqbal (2008), propõem-se uma abordagem para codificação de fundo invisível de alta capacidade para autenticação digital de documentos impressos. Esta técnica permite que o conteúdo completo do texto em primeiro plano seja codificado na imagem de fundo sobreposta em formato legível por máquina. Os dados são codificados de maneira uniforme ao longo da imagem de fundo e os erros causados pela sobreposição de conteúdos de primeiro plano são corrigidos por criptografia de dados e codificação de correção de erros. Caso haja uma inspeção visual da imagem de fundo sobreposta não é possível indicar a existência de dados codificados. Dessa maneira, a técnica de leitura de dados pega a imagem digitalizada como entrada e recupera o conteúdo codificado da imagem do documento digitalizado. (GEISSELHARDT; IQBAL, 2008).

Uma vez que a divulgação não intencional ou acesso malicioso a informações confidenciais podem consequentemente acarretar efeitos indesejáveis significativos a fim de realizar o gerenciamento de documentos, Lu e Sagduyu (2016) propõe um mecanismo de controle de acesso que não garante acesso imediato a um documento após a criação de uma conta de usuário, mas usa análise de texto e análise comportamental de forma a complementar o risco de divulgação de informações e conceder o acesso somente se o risco é avaliado baixo. Esse mecanismo consiste em uma análise quantitativa do controle de acesso baseado na análise de riscos que pode ser útil ao tratar de documentos cujo conteúdo é confidencial como aqueles com informações sobre operações militares sigilosas (LU; SAGDUYU, 2016).

A partir dos resultados obtidos na pesquisa na base Web of Science, analisou-se as publicações em busca de sistemas e ferramentas que estão sendo utilizadas para auxiliar o gerenciamento de documentos dentro das organizações. De acordo com a Tabela 1, pode-se notar a existência de seis sistemas e ferramentas capazes de auxiliarem as organizações, além de oferecer contribuições valiosas, como, maior controle dos processos e documentos, diminuição de custos, entre outros. 
Tabela 1- Tecnologias para gerenciamento de documentos

\begin{tabular}{|c|c|c|c|}
\hline Tecnologias & Definição/Contribuição & Artigos & Fonte \\
\hline $\begin{array}{l}\text { Enterprise } \\
\text { Content } \\
\text { Management } \\
\text { (ECM) }\end{array}$ & $\begin{array}{l}\text { É uma combinação dinâmica de } \\
\text { estratégias, métodos e ferramentas, } \\
\text { usada para capturar, gerenciar, } \\
\text { armazenar, preservar e fornecer } \\
\text { informações que suportam os } \\
\text { principais processos organizacionais. O } \\
\text { termo ECM tem sido usado em para } \\
\text { designar uma plataforma para } \\
\text { gerenciar documentos eletrônicos }\end{array}$ & $\begin{array}{l}\text { "ECM implementations in practice: } \\
\text { objectives, processes, and } \\
\text { technologies" } \\
\text { "BPM and ECM: Similarities, } \\
\text { differences, conceptual, and } \\
\text { technological limits" } \\
\text { "Assessing the functionality of the } \\
\text { enterprise content management } \\
\text { maturity model } \\
\text { ECM" }\end{array}$ & $\begin{array}{l}\text { (DE SOUZA } \\
\text { MENDES; } \\
\text { BAX, 2018; } \\
\text { JAAKONMAE } \\
\text { KI et al., } \\
\text { 2018; } \\
\text { KATUU, } \\
\text { 2016a) }\end{array}$ \\
\hline $\begin{array}{l}\text { Business Process } \\
\text { Management } \\
\text { (BPM) }\end{array}$ & $\begin{array}{l}\text { É uma abordagem de gestão que } \\
\text { procura entender e melhorar o } \\
\text { desempenho das empresas, adquirindo } \\
\text { conhecimento, modelando e } \\
\text { melhorando seus processos. Utilizada } \\
\text { para identificar, projetar, executar, } \\
\text { documentar, medir, monitorar, } \\
\text { controlar e melhorar os processos de } \\
\text { negócios a fim atingir resultados } \\
\text { consistentes e alinhados com os } \\
\text { objetivos estratégicos de uma } \\
\text { organização. }\end{array}$ & $\begin{array}{l}\text { "BPM and ECM: Similarities, } \\
\text { differences, conceptual, and } \\
\text { technological limits" }\end{array}$ & $\begin{array}{l}\text { (DE SOUZA } \\
\text { MENDES; } \\
\text { BAX, 2018) }\end{array}$ \\
\hline CMIS & $\begin{array}{l}\text { É utilizada para manter a } \\
\text { interoperabilidade entre BPM e ECM, } \\
\text { no que diz respeito aos serviços de } \\
\text { acesso para manipular diferentes } \\
\text { repositórios de tipos de documentos. O } \\
\text { CMIS é uma tecnologia essencial para } \\
\text { reduzir a impedância de comunicação } \\
\text { entre as plataformas de BPM e os } \\
\text { repositórios de ECM. O CMIS também } \\
\text { permite que diferentes ferramentas } \\
\text { ECM interoperem. }\end{array}$ & $\begin{array}{l}\text { "BPM and ECM: Similarities, } \\
\text { differences, conceptual, and } \\
\text { technological limits" }\end{array}$ & $\begin{array}{l}\text { (DE SOUZA } \\
\text { MENDES; } \\
\text { BAX, 2018) }\end{array}$ \\
\hline $\begin{array}{l}\text { Java } 2 \text { Platform, } \\
\text { Enterprise } \\
\text { Edition (J2EE) }\end{array}$ & $\begin{array}{l}\text { É baseado na plataforma principal do } \\
\text { Java e é usado principalmente para } \\
\text { design, desenvolvimento, } \\
\text { implementação e gerenciamento de } \\
\text { software rápido. O framework J2EE } \\
\text { fornece aos desenvolvedores um bom } \\
\text { ambiente de desenvolvimento de } \\
\text { aplicativos de escalabilidade. Através } \\
\text { do método baseado no componente, } \\
\text { podem-se projetar aplicativos } \\
\text { corporativos. }\end{array}$ & $\begin{array}{l}\text { "Government Management } \\
\text { Information System based on J2EE" }\end{array}$ & $\begin{array}{c}\text { (QIYUAN, } \\
\text { 2016) }\end{array}$ \\
\hline
\end{tabular}


Tabela 1- Tecnologias para gerenciamento de documentos

\begin{tabular}{|c|c|c|c|}
\hline Tecnologias & Definição/ Contribuição & Artigos & Fonte \\
\hline $\begin{array}{l}\text { Collaborative } \\
\text { Document } \\
\text { Management } \\
\text { System (CDMS) }\end{array}$ & $\begin{array}{l}\text { Um aplicativo da Web baseado em Java, } \\
\text { desenvolvido para aplicar os conceitos } \\
\text { de controle de concorrência em } \\
\text { documentos de texto. Esta plataforma } \\
\text { colaborativa é apresentada com } \\
\text { listagem de documentos, upload de } \\
\text { documentos, compartilhamento de } \\
\text { documentos com recurso de edição } \\
\text { simultânea e um fórum de discussão } \\
\text { para usuários. }\end{array}$ & $\begin{array}{l}\text { "A novel collaborative platform for } \\
\text { document management" }\end{array}$ & $\begin{array}{l}\text { (SINGHAL et } \\
\text { al., 2014) }\end{array}$ \\
\hline $\begin{array}{c}\text { Electronic } \\
\text { Document } \\
\text { Management } \\
\text { Systems (EDMS) }\end{array}$ & $\begin{array}{l}\text { Os sistemas EDM apoiam os processos } \\
\text { de informação, fornecendo aos usuários } \\
\text { maneiras simples, lógicas e rápidas de } \\
\text { armazenar, encontrar e recuperar } \\
\text { documentos em formato eletrônico. } \\
\text { Esses sistemas podem incorporar o } \\
\text { GroupWare, o fluxo de trabalho e a } \\
\text { funcionalidade de recuperação de texto, } \\
\text { com alguma sobreposição entre eles. }\end{array}$ & $\begin{array}{l}\text { "eGovernment Document } \\
\text { Management System: A case analysis } \\
\text { of risk and reward" } \\
\text { "Electronic Document Management - } \\
\text { challenges and opportunities for } \\
\text { information-systems managers" } \\
\text { "Document management systems } \\
\text { from current capabilities towards } \\
\text { intelligent information retrieval: an } \\
\text { overview" } \\
\text { "End-user attitudes toward EDM use } \\
\text { in construction project work: Case } \\
\text { study" }\end{array}$ & $\begin{array}{l}\text { (HJELT; } \\
\text { BJORK, 2007; } \\
\text { JONES, 2012; } \\
\text { SPRAGUE, } \\
\text { 1995; } \\
\text { ZANTOUT; } \\
\text { MARIR, } \\
\text { 1999) }\end{array}$ \\
\hline
\end{tabular}

Fonte: própria.

Dentre as tecnologias apresentadas na tabela 1, torna-se relevante abordar sobre o Java 2 Platform, Enterprise Edition (J2EE), pois este software está sendo utilizado para o desenvolvimento do sistema de informações do governo. A utilização do J2EE pode reduzir o custo de desenvolvimento e manutenção de software para a organização. Entretanto, a principal vantagem de utilizar o J2EE está relacionada a forte função de prevenção de segurança, o que é muito adequado para o desenvolvimento do sistema de alta confidencialidade (QIYUAN, 2016).

\section{CONSIDERAÇÕES FINAIS}

Analisando os estudos sobre essa temática em relação aos seus respectivos anos de publicação é possível perceber a evolução não apenas do tema, mas da abordagem de sistema de informação e desenvolvimento da área com o passar dos anos. Sendo possível notar que com esse desenvolvimento passa-se a estudar soluções tecnológicas para questões relacionadas ao gerenciamento de documentos.

Este estudo teve como objetivo identificar as principais abordagens da literatura com relação à gestão de informação em organizações público e privadas, em que através de uma revisão sistemática da literatura, buscou responder a duas questões: Quais são as principais práticas e ferramentas adotadas nas organizações para a gestão da informação e de documentos? Como as organizações militares lidam com a gestão da informação?

Pôde-se perceber que as organizações buscam diferentes maneiras de resolver a questão da gestão documental, adaptando tecnologias para seus devidos contextos. As principais referências de ferramentas, técnicas e práticas para organização de documentos organizacionais identificadas foram: Enterprise Content Management (ECM), Business Process Management (BPM), CMIS Java 2 Platform, Enterprise Edition 
(J2EE), Collaborative Document Management System (CDMS), Electronic Document Management Systems (EDMS). As contribuições de cada tecnologia foram explicadas por meio de um quadro consolidado.

\section{REFERÊNCIAS}

[1] AL Qady, M.; Kandil, A. Concept Relation Extraction from Construction Documents Using Natural Language Processing. Journal of Construction Engineering and Management, v. 136, n. 3, p. 294-302, 2009.

[2] Barreau, Deborah; Nardi, Bonnie A. Finding and Reminding: File Organization from the Desktop, 1995.

[3] Bergman, O. Shared Files: The Retrieval Perspective Ofer. v. 1, n. 6, p. 2581-2583, 2010.

[4] Brumm, Eugenia K. Optical disc technology for information management. Annual review of information science and technology, v. 26, p. 197-240, 1991.

[5] Caldas, C. H.; Soibelman, L.; Han, J. Automated Classification of Construction Project Documents. Journal of Computing in Civil Engineering, v. 16, n. 4, p. 234-243, 2002.

[6] Cavaglieri, Marcelo; Juliani, Jordan Paulesky. Lean Archives: 0 emprego do Lean Office na gestão de arquivos. Perspectivas em Ciência da Informação, [s. l.], v. 21, n. 4, p. 180-201, 2017.

[7] Da Silva, Roberto Bernardo; Shimoishi, José Matsuo; Mariano, Ari Melo. Usabilidade No Transporte Público (Tp): Uma Revisão Bibliométrica Dos Últimos 27 Anos (1990-2017). 32 Congresso de Pesquisa e Ensino em Transporte da ANPET, Gramado. Volume: 32. 2018.

[8] De Souza Mendes, Marco Aurelio; Bax, Marcello Peixoto. BPM and ECM: Similarities, differences, conceptual, and technological limits. Transinformacao, Nucleo Editoracao Sbi-Ccv, Campus Ii Av John Boyd Dunlop S-N Predio Ontologia Jd Ipaussurama, Campinas, SP 13060-904, BRAZIL, v. 30, n. 1, p. 95-105, 2018.

[9] Dourish, Paul et al. Presto: an experimental architecture for fluid interactive document spaces. ACM Transactions on Computer-Human Interaction, [s. l.], v. 6, n. 2, p. 133-161, 1999.

[10] Hjelt, Mathias; Bjork, Bo-Christer. End-user attitudes toward EDM use in construction project work: Case study. Journal Of Computing In Civil Engineering, 1801 Alexander Bell Dr, Reston, VA 20191-4400 USA, v. 21, n. 4, p. 289-300, 2007.

[11] Geisselhardt, W.; Iqbal, T. High-capacity invisible background encoding for digital authentication of hardcopy documents. Lecture Notes in Computer Science (including subseries Lecture Notes in Artificial Intelligence and Lecture Notes in Bioinformatics), v. 5041 LNCS, p. 203-221, 2008.

[12] Jaakonmaeki, Roope et al. ECM implementations in practice: objectives, processes, and technologies. Journal Of Enterprise Information Management, Howard House, Wagon Lane, Bingley BD16 1WA, W Yorkshire, England, v. 31, n. 5, p. 704-723, 2018.

[13] Jones, Steve. eGovernment Document Management System: A case analysis of risk and reward. International Journal Of Information Management, The Boulevard, Langford Lane, Kidlington, Oxford Ox5 1gb, Oxon, England, v. 32, n. 4, p. 396-400, 2012.

[14] Katuu, Shadrack. Assessing the functionality of the enterprise content management maturity model. Records Management Journal, Howard House, Wagon Lane, Bingley BD16 1WA, W Yorkshire, England, v. 26, n. 2, p. 218-238, 2016. a.

[15] Lansdale, M. The psychology of personal information management. Applied Ergonomics, [s. l.], n. March, p. 55-66, 1988.

[16] Lopes, S., Costa, M. T., Fernández-Llimós, F., Amante, M. J., \& Lopes, P. F. (2012, October). A Bibliometria e a Avaliação da Produção Científica: indicadores e ferramentas. In Actas do congresso Nacional de bibliotecários, arquivistas e documentalistas (No. 11).

[17] Lu, Z:; Sagduyu, Y. Risk assessment based access control with text and behavior analysis for document management. Proceedings - IEEE Military Communications Conference MILCOM, p. 37-42, 2016.

[18] Malone, Thomas W. How do people organize their desks?: Implications for the design of office information systems. ACM Transactions on Information Systems, [s. l.], v. 1, n. 1, p. 99-112, 1983.

[19] Mariano, A.M; Rocha, M.S. Revisão da Literatura: Apresentação de uma Abordagem Integradora. AEDM International Conference - Economy, Business and Uncertainty: Ideas for a European and Mediterranean industrial policy. Reggio Calabria (Italia). 2017.

[20] Qiyuan, Hou. Government Management Information System based on J2EE. In: 2015 International Conference On Intelligent Transportation, Big Data And Smart City (ICITBS) 2016, 345 E 47TH ST, New York, NY 10017 USA. Anais... 345 E 47TH ST, New York, NY 10017 USA: IEEE, 2016. 
[21] Ottonicar, Selma Leticia Capinzaiki; SANTOS, Beatriz Rosa Pinheiro dos; MORAES, Isabela Santana de. Aplicabilidade da Competência em Informação e da Organização do Conhecimento no processo de Gestão da Informação. RDBCI: Revista Digital de Biblioteconomia e Ciência da Informação, v. 15, n. 3, p. 629, 2017.

[22] Pedra, Alexandre Corrêa et al. Panorama das Pesquisas Sobre Competências Individuais e Organizacionais: Um Estudo Bibliométrico Utilizando o Método Temac. XXXVIII Encontro Nacional De Engenharia De Producao, Maceió. 2018.

[23] Romano, Amanda Basilio et al. Revisão Bibliométrica dos Fatores que Influenciam o Uso de Bicicleta Fazendo Uso Da Teoria do Enfoque Meta Analítico Consolidado (Temac). 32 Congresso de Pesquisa e Ensino em Transporte da ANPET, Gramado. 2018.

[24] Singhal, Surabhi et al. A novel collaborative platform for document management. Proceedings Of The 7th India Software Engineering Conference 2014, ISEC `14 2014, 1515 Broadway, New York, NY 10036-9998 Usa. Anais... 1515 Broadway, New York, NY 10036-9998 USA: Assoc Computing Machinery, 2014.

[25] Sprague JR, R. H. Electronic Document Management - Challenges And Opportunities For Information-Systems Managers. Mis Quarterly, Univ Minnesota-Sch Management 269 19th AVE South, Minneapolis, MN 55455, v. 19, n. 1, p. 29-49, 1995.

[26] Tyler, Jacqueline Edana. Asset management the track towards quality documentation. Records Management Journal, Howard House, Wagon Lane, Bingley BD16 1WA, W Yorkshire, England, v. 27, n. 3, p. 302-317, 2017.

[27] Zantout, H.; Marir, F. Document management systems from current capabilities towards intelligent information retrieval: an overview. International Journal Of Information Management, The Boulevard, Langford Lane, Kidlington, Oxford OX5 1GB, Oxon, England, v. 19, n. 6, p. 471-484, 1999. 


\title{
Capítulo 14
}

Gestão das Relações Interorganizacionais na Cadeia de Suprimentos Convencional da Construção Civil: Uma revisão sistemática

\author{
Christiane Wagner Mainardes Krainer \\ Jefferson Augusto Krainer \\ Daniel Getúlio Fernandes Ribeiro \\ Alfredo Iarozinski Neto \\ Cezar Augusto Romano
}

Resumo: A literatura destaca a importância de se desenvolver o relacionamento entre construtoras e fornecedores no intuito de melhorar o desempenho organizacional. Este artigo tem como objetivo mapear, de forma estruturada, trabalhos científicos que exploram o tema "gestão das relações interorganizacionais na cadeia de suprimentos convencional da construção civil". Para alcançar esse objetivo foi realizada uma revisão sistemática da literatura com o auxílio dos softwares Start e CiteSpace II. Os dados brutos (publicações limitadas ao período de 2000 a 2019) foram extraídos da Web of Science e, após processados, resultaram 76 artigos relevantes sobre o tema em questão. Esses artigos, em síntese, têm como foco os fornecedores, as construtoras e os canteiros de obras e estão relacionados à confiança, à colaboração, ao compartilhamento de informações, à integração, aos relacionamentos e à tecnologia da informação (em especial, RFID, BIM e GIS) na cadeia de suprimentos da construção civil. Os resultados obtidos não só fornecem referências para estudiosos sobre o tema, mas também apresenta critérios objetivos para a construção de um sólido referencial teórico.

Palavras chave: Construção Civil, Gestão da Cadeia de Suprimento, Fornecedores, Relacionamento interorganizacional. 


\section{INTRODUÇÃO}

São características da cadeia de suprimentos da construção civil: predomínio de relações adversas e de curto prazo; coexistência de múltiplos projetos fragmentados; e composição por participantes multidisciplinares e heterogêneos que tendem a tomar decisões, de forma independente, com base em seus próprios objetivos e sistemas de valores, desconsiderando o desempenho holístico do projeto (CHAN et al. 2004; LOVE et al., 2004; BRISCOE; DAINTY, 2005; BANKVALL et al., 2010; LAHDENPERÄ, 2012; ERIKSSON, 2015; KANG; HONG, 2015; WANG et al., 2017). Os autores destacam, também, o fraco desempenho organizacional das empresas integrantes da cadeia (DE TREVILLE et al., 2004; BANKVALL et al., 2010; MENG, 2012; ERIKSSON, 2015; WANG et al., 2017), especialmente em termos de tempo, custo e de qualidade (ERIKSSON; WESTERBERG, 2011; LU et al., 2011; MENG, 2012). Eriksson (2015) ressalta que as empresas de construção enfrentam desafios de competitividade em relação, principalmente, à cadeia de suprimentos, à disponibilidade de recursos humanos capacitados e à falta de familiaridade com os parceiros comerciais.

O fato da indústria da construção civil ser fragmentada e as construtoras, em geral, separarem o projeto da construção do empreendimento, gera problemas de eficiência, como a falta de coordenação e integração entre as variadas faces funcionais da cadeia de suprimentos (XUE et al., 2007). Logo, o funcionamento em conjunto dos agentes envolvidos na cadeia de suprimentos pode garantir a plena e correta execução das atividades dentro do canteiro de obras (VRIJHOEF; KOSKELA, 2000). A cooperação entre empresas impacta no desempenho da cadeia, pois possibilita a realização de ações conjuntas, além de viabilizar a transação de recursos (ISATT0, 2013).

Segundo Bandeira et al. (2009), as deficiências apresentadas pelo setor têm origem na gestão da cadeia de suprimentos. Diante deste cenário, que reflete a pouca exploração e utilização de processos gerenciais no segmento da construção, o presente trabalho tem como objetivo mapear, de forma estruturada, trabalhos científicos que exploram o tema "gestão das relações interorganizacionais na cadeia de suprimentos convencional da construção civil”.

\section{REVISÃO BIBLIOGRÁFICA}

A indústria da construção civil apresenta peculiaridades e especificidades que a diferem significativamente de outras indústrias de manufatura em série. 0 processo produtivo na indústria da construção civil leva em conta o produto final imóvel, em geral único, com longo ciclo de existência e inconstância de utilização de recursos (ISATTO, 2013).

Vrijhoef e Koskela (2000) acrescentam que a cadeia de suprimentos da construção civil é: a) convergente: os suprimentos convergem para o canteiro de obras; b) temporária: as organizações que se formam para a realização de um empreendimento único não costumam perdurar para o empreendimento seguinte e podem assumir uma configuração diferente da anterior; e c) make-to-order: cada projeto cria um produto único e com pouca repetição.

As empresas do setor têm implementado a gestão da cadeia de suprimentos (ou, do inglês, Supply Chain Management - SCM) como medida estratégica para um gerenciamento efetivo tendente a melhorar o desempenho organizacional (BANKVALL et al., 2010). Briscoe e Dainty (2005) conceituem o SCM como uma rede de diferentes organizações, unidas a montante e a jusante em uma cadeia, com a finalidade de produzir, por meio de processos integrados, qualidade e valor nos serviços e produtos para os consumidores finais. Segundo Bandeira et al. (2009), o objetivo da SCM é a eficiência em termos de produção e de custos para todo o sistema (desde a produção das matérias primas até a distribuição dos produtos acabados). 0 foco da gestão da cadeia de suprimentos está na gestão de relações, na confiança, no reconhecimento e na cooperação, para alcançar um resultado satisfatório e com lucros para a cadeia (ISATTO, 2013).

A indústria da construção civil opera em uma cadeia produtiva com muitos fornecedores, serviços de comercialização e manutenção, logo as relações interorganizacionais são uma realidade no setor e com grande impacto no desempenho das empresas da cadeia (BANDEIRA et al., 2009).

As organizações voltadas para o mercado devem adotar a gestão da cadeia de suprimento como forma de integrar tarefas e processos de todas as organizações envolvidas, apoiando-se em um sistema de informações que permita, do início ao fim, a visualização de toda cadeia de fornecimento e a identificação de atividades que não agregam valor (BANKVALL et al., 2010). 
A indústria da construção civil não acompanhou a evolução que sofreu os outros setores industriais e assim sempre conviveu com desperdício e improvisos dentro dos seus processos. É necessária uma melhoria contínua do processo construtivo e atividades gerenciais das empresas construtoras, afim de que haja uma agilização das atividades construtivas, aumento da produtividade e diminuição de perdas e desperdícios. As perdas e desperdícios estão relacionados com uma questão logística pouco desenvolvida (XUE et al., 2007).

\section{METODOLOGIA DA PESQUISA}

A revisão sistemática de literatura (RSL) pode ser definida como um processo de coletar, conhecer, compreender, analisar, sintetizar e avaliar um conjunto de artigos científicos, com o propósito de estabelecer um embasamento teórico-científico (estado da arte) sobre um determinado tópico ou assunto pesquisado (LEVY; ELLIS, 2006). São aspectos relacionados à RSL: processo formal e replicável de realização da revisão da literatura; unificação de um elevado volume de informações; e análise e apresentação de forma compreensível quando associada a métodos como a meta-análise e a metassíntese (LOUREIRO et al., 2016).

Levy e Ellis (2006) propõe três fases de uma RSL: a entrada, o processamento e a saída, como representado na Figura 2.

Figura 2 - Etapas de uma revisão bibliográfica efetiva.

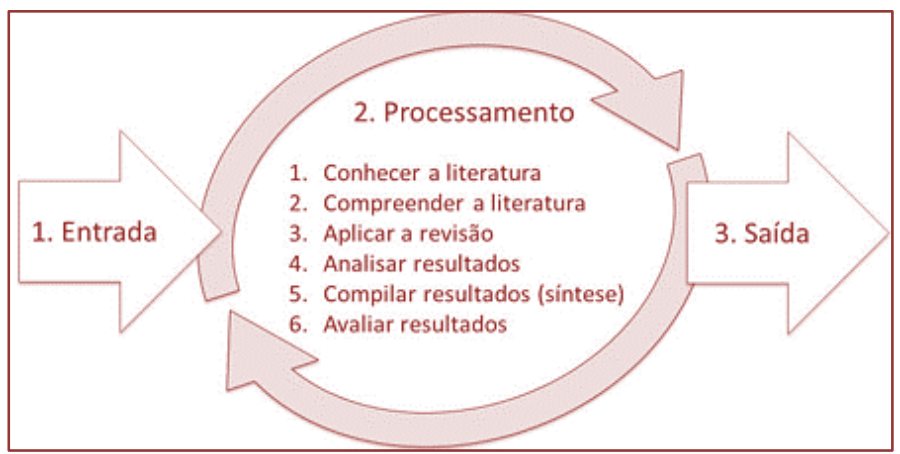

Fonte: Adaptado de Levy e Ellis (2006)

Na presente pesquisa a RSL foi dividida em 3 etapas:

1. Entrada (seleção de dados brutos): definição das palavras-chave; escolha da base de dados de textos científicos; e fixação de critérios de busca.

2. Processamento (análise bibliométrica): formação, com auxílio do software CiteSpace II, de redes e clusters (agrupamentos) a partir das referências dos dados de entrada; seleção dos clusters alinhado ao tema de pesquisa e composição dos dados iniciais; e filtragem dos dados iniciais (exclusão de obras não publicadas em periódicos; escolha das pesquisas relacionadas ao setor da construção civil; e obtenção do PB).

3. Saída (resultados): apresentação do PB.

Utilizou-se do Start (software gratuito de gerenciamento de revisão sistemática de bibliografia desenvolvido pelo Laboratório de Pesquisa em Engenharia de Software da UFSCar) para realização dos procedimentos de filtragem dos dados iniciais.

A apresentação do PB contempla, não só a compilação e detalhamento dos resultados obtidos, mas também a análise de aderência ao tema pesquisado e de relevância (qualidade) das obras integrantes do PB.

\section{RESULTADOS}

Para seleção dos dados brutos (primeira etapa da pesquisa), partiu-se do eixo de pesquisa previamente definido (escopo deste trabalho), qual seja: "gestão da cadeia de suprimentos na construção civil", realizando-se as seguintes sub-etapas: 
a) Definição de palavras-chave: "supply chain management" e "construction industry". Para a realização do filtro de busca, foram utilizadas as combinações das palavras-chave: "supply chain management" e "construction industry";

b) Escolha da base de dados: Web of Science (WoS) - Coleção Principal (Clarivate Analytics). Optouse pela WoS por ser a principal fonte de dados para o CiteSpace II e, de acordo com Chadegani et al. (2013), contemplar periódicos com maior fator de impacto se comparado àqueles abrangidos pela Scopus (Elsevier). Além disso, a análise das referências dos artigos possibilita ampliar o acesso à periódicos de outras bases.

c) Fixação de critérios de busca na base de dados:

- $\quad$ Temporal: publicações de 2000 a 2019;

- $\quad$ Tipos de publicações: artigos de periódicos;

- Idioma: textos em inglês;

- $\quad$ Período de busca: de 01 a 31 de março de 2019.

A combinação das palavras-chave com atendimento aos critérios de busca definidos pelos autores retornou um total de 806 artigos (Quadro 1).

Quadro 1 - Palavras-chave e resultados obtidos nas bases de dados

\begin{tabular}{c|c|c|c|c|c|}
\multicolumn{4}{c}{ BASE DE } \\
DADOS
\end{tabular}

Fonte: Autores, 2019

Finalizada a primeira etapa, iniciou-se o processamento. O CiteSpace II desenhou as redes de inter-relação entre as obras e formou clusters de pesquisa (Figura 4).

Figura 4 - Redes e clusters - software CiteSpace II

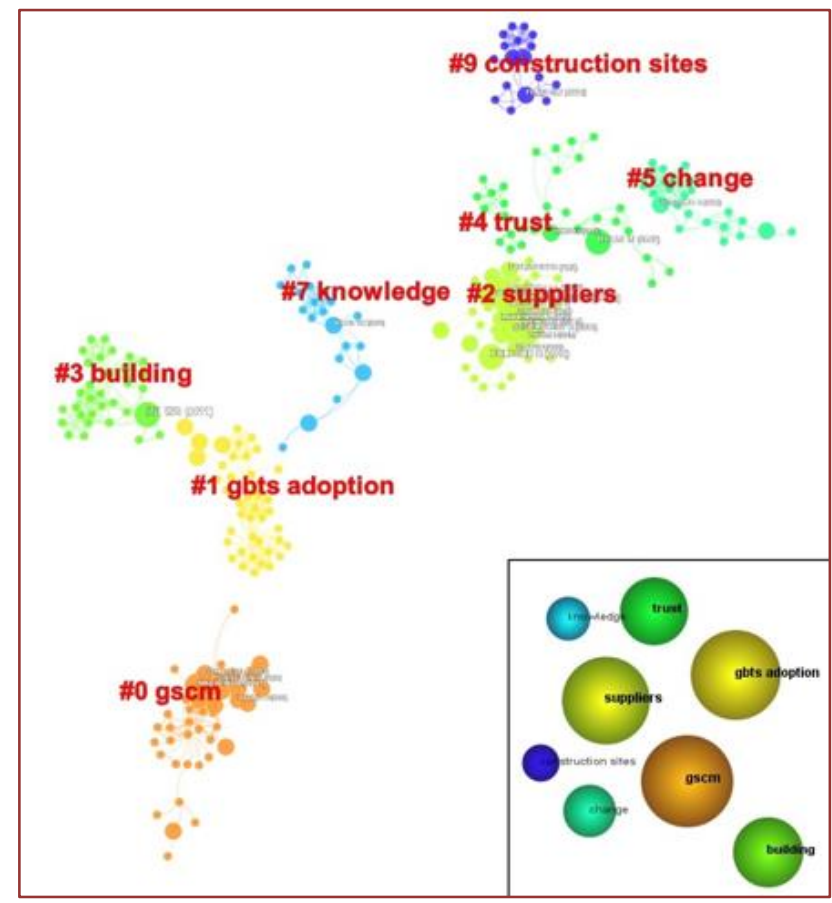

Fonte: Autores, 2019 
Foram agrupadas 38.819 referências extraídas dos 806 artigos de entrada, rotulando (atribuindo nome) a 8 clusters principais. 0 Quadro 2 apresenta os 8 principais clusters rotulados e seus respectivos números de membros integrantes (obras científicas).

Quadro 2 - 8 principais clusters e número de obras (membros)

\begin{tabular}{|c|c|c|}
\hline CLUSTERS & RÓTULOS & № DE OBRAS \\
\hline 0 & gscm (green supply chain management) & 42 \\
\hline 1 & gbts (green building technologies) adoption & 41 \\
\hline 2 & suppliers & 40 \\
\hline 3 & building & 32 \\
\hline 4 & trust & 31 \\
\hline 5 & change & 24 \\
\hline 7 & knowledge & 20 \\
\hline 9 & construction sites & 17 \\
\hline
\end{tabular}

Fonte: Autores, 2019

O escopo deste trabalho é o estudo da cadeia de suprimentos "convencional" da construção civil, ou seja, foge do objeto desta pesquisa a incorporação de questões ambientais, sustentáveis e/ou verdes. Assim, os clusters selecionados foram os de número 2, 3, 4, 5, 7 e 9. Foram excluídos os clusters referentes à cadeia de suprimentos verde e/ou sustentável ( 0 e 1 ).

No Quadro 3 constam as principais palavras-chave dos artigos que compõem os clusters selecionados.

\begin{tabular}{|c|c|c|}
\hline CLUSTERS & PRINCIPAIS PALAVRAS CHAVE & № DE OBRAS \\
\hline 2 & $\begin{array}{l}\text { supplier, provide, buyer-supplier relationship, procurement, supplier } \\
\text { selection, strategy integration, supply chain integration }\end{array}$ & 40 \\
\hline 3 & $\begin{array}{c}\text { information tecnologic, knowledge of construction informatics, information } \\
\text { database, construction engineering projects }\end{array}$ & 32 \\
\hline 4 & $\begin{array}{l}\text { trust, partnering, relationship management, collaboration, supply chain } \\
\text { management }\end{array}$ & 31 \\
\hline 5 & $\begin{array}{c}\text { relationship, supply chain management, strategy, supplier, knowledge, supplu } \\
\text { chain integration, }\end{array}$ & 24 \\
\hline 7 & $\begin{array}{c}\text { knowledge, BIM, collaboration, information system, BIM and GIS, project } \\
\text { information }\end{array}$ & 20 \\
\hline 9 & construction and supply, construction management, knowledge, supply & 17 \\
\hline \multicolumn{2}{|r|}{ № DE OBRAS } & 164 \\
\hline
\end{tabular}

Fonte: Autores, 2019

Com apoio da ferramenta Start selecionou-se apenas os artigos publicados em periódicos, os quais são, necessariamente, revisados por pares. Foram rejeitados 13 artigos de conferências e editoriais, resultando em 151 obras. Na sequência, o Start permitiu identificar 121 estudos realizados no segmento da construção civil, os demais foram excluídos, pois não eram específicos, diziam respeito a outros setores.

Por fim, analisou-se a aderência ao tema de pesquisa dos 121 textos relacionados à construção civil. Foram retirados 45 trabalhos que abordam pesquisas referentes à gestão de operações, mais especificamente associados à entrega de concreto, a materiais pré-fabricados, à produtividade mão de obra, ao design modular de produtos, dentre outros. Concluída a filtragem dos dados iniciais, obteve-se um PB de 76 artigos.

A Figura 4 demostra, sinteticamente, os números (resultados) obtidos nas etapas 1 e 2. 
Figura 4 - Etapas 1 e 2 - resultados

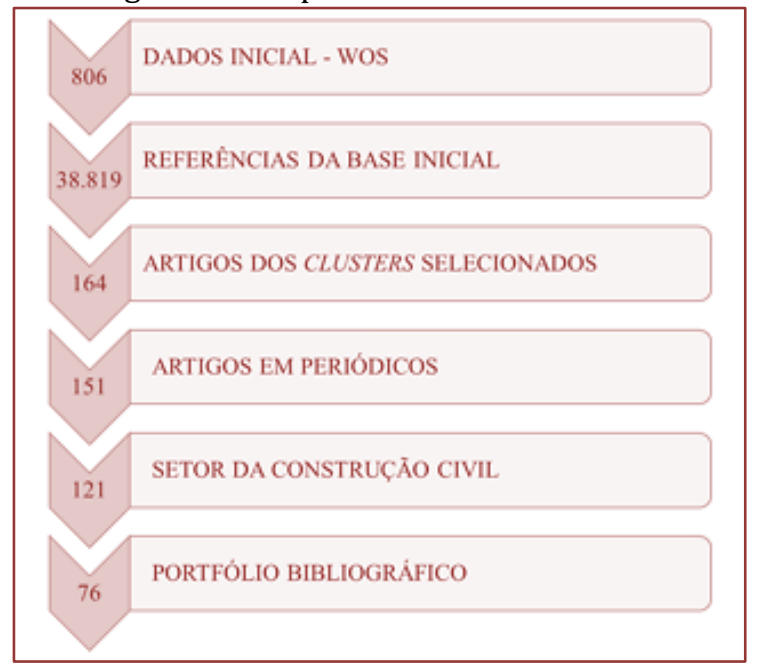

Fonte: Autores, 2019

O Anexo contempla a relação dos 76 artigos componentes do PB, ordenados decrescentemente de acordo com o número de citações recebidas no Google Acadêmico. Considerou-se como mais influente e, portanto, mais relevante os artigos que receberam mais citações.

A relevância foi determinada, também, com base nos indicadores dos periódicos, quais sejam: fator de impacto (FI), publicado pelo Institute for Science Information (ISI) no Journal Citation Reports (JCR); índice H dos periódicos da SCImago Journal \& Country Rank (SJR); e classificação Qualis/CAPES dentro das Áreas de Administração, Interdisciplinar e das Engenharia I e III. O Quadro 4 traz a frequência de publicação (número de artigos publicados) e os respectivos indicadores das revistas (JCR, SJR e Qualis), nas quais os artigos do PB foram publicados.

Quadro 4 - Periódicos dos artigos do PB e seus respectivos indicadores

\begin{tabular}{|l|c|c|c|c|}
\hline \multicolumn{1}{|c|}{ JOURNAL } & ARTIGOS PB & JCR & SJR & \multicolumn{2}{c|}{ QUALIS } \\
\hline Automation in Construction & 21 & 4.032 & 1.61 & ENG I/III - A1 \\
\hline International Journal of Project Management & 12 & 4.328 & 1.46 & ENG III - A1 \\
\hline Supply Chain Management-an International Journal & 8 & 3.833 & 0.21 & ENG III - A2 \\
\hline Advanced Engineering Informatics & 6 & 3.358 & 1.17 & ENG I - A2 \\
\hline Construction Management and Economics & 5 & NC & 0.82 & ENG I - B1/ENG III - B2 \\
\hline Journal of Purchasing and Supply Management & 5 & 3.667 & 2.00 & NC \\
\hline Journal of Computing in Civil Engineering & 4 & 2.310 & 0.70 & INTERDISCIPLINAR \\
\hline $\begin{array}{l}\text { International Journal of Management Science and } \\
\text { Engineering Management }\end{array}$ & 2 & NC & 0.46 & NC \\
\hline Journal of Management in Engineering & 2 & 2.282 & 1.23 & ENG I - A2 \\
\hline Journal of Operations Management & 1 & 4.899 & 5.74 & NC \\
\hline Benchmarking-an International Journal & 1 & NC & 0.56 & ENG III - B3 \\
\hline Computers in Industry & 1 & 2.850 & 1053 & ENG III - B1 \\
\hline $\begin{array}{l}\text { Engineering, Construction and Architectural } \\
\text { Management }\end{array}$ & 1 & NC & 0.65 & ENG I - B1 \\
\hline Industrial Marketing Management & 1 & 3.678 & 1.66 & ENG III - A2 \\
\hline Journal of Business Logistics & 1 & 2.891 & 2.09 & NC \\
\hline $\begin{array}{l}\text { Journal of Construction Engineering and Management- } \\
\text { ASCE }\end{array}$ & 1 & 2.201 & 1.02 & ENG I - A1/ENG III - A2 \\
\hline Journal of Management & 1 & 8.080 & 6.46 & NC \\
\hline Journal of Service Research & 1 & 6.842 & 5.25 & ADM I \\
\hline Sustainability & 1 & 2.075 & 0.54 & ENG I - A2 \\
\hline $\begin{array}{l}\text { Transportation Research Part E: Logistics and } \\
\text { Transportation Review }\end{array}$ & 1 & 3.289 & 1.90 & ENG I - A1 \\
\hline
\end{tabular}


Para visualizar a localização das publicações do PB, confeccionou-se o Gráfico (Figura 5), que elenca os países de origem das pesquisas, ou seja, que apresenta a frequência de pesquisas que se dedicam ao estudo do tema pesquisado por localidade de origem. Do que se percebe na Figura 5, há um maior número de estudos no Reino Unido, nos Estados Unidos, em Hong Kong, na Coréia do Sul e na Suécia.

Figura 5 - Frequência de localidade das pesquisas realizadas

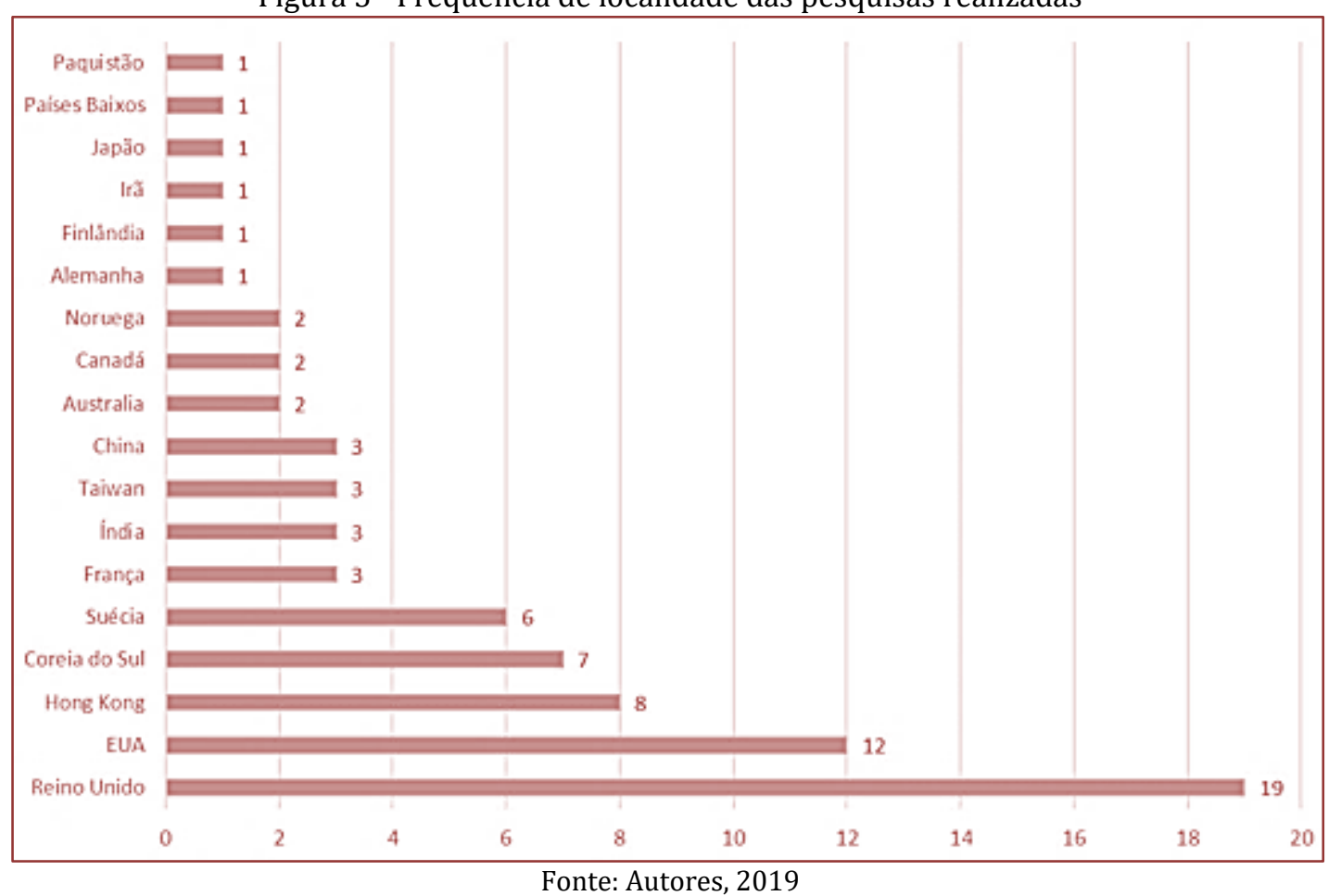

Extrai-se da leitura das publicações contidas no PB que, em geral, as pesquisas realizadas estão concentradas em três principais subtemas: integração, relacionamentos e tecnologia na cadeia de suprimentos da construção civil.

Segundo Eriksson (2015), a gestão da cadeia de suprimentos das empresas do setor da construção contribui para o alcance da integração do processo produtivo que tem diversas interfaces complexas entre seus membros e muitos problemas oriundos da falta de coordenação. A integração dos processos, adoção de objetivos compartilhados e a realização de trabalhos colaborativos na cadeia de fornecimento promovem melhoria no desempenho do projeto, que consequentemente aumentam o valor global do ciclo do projeto para todas as partes envolvidas (AKINTOYE; MAIN, 2007; BYGBALLE et al., 2010; YEUNG et al., 2012). Coordenar e integrar a cadeia de fornecimento pode desencadear os seguintes benefícios: redução de custos, melhores margens e produtividade, vantagem competitiva, entrega no prazo, criação de valor, maior confiança no planejamento de longo prazo e melhores relações entre as partes (LOVE et al. 2004; BYGBALLE et al., 2010; ERIKSSON; WESTERBERG, 2011; MENG, 2012).

Os pesquisadores destacam a importância de se desenvolver o relacionamento entre construtorafornecedor na indústria da construção (LOVE et al. 2004; BRISCOE; DAINTY, 2005; PINTO et al., 2009; ERIKSSON, 2015). Aprimorar o relacionamento reduz custos e aumenta as oportunidades de trabalho colaborativo, propiciando ganhos de produtividade e de desempenho (COX, 2004; BEACH et al., 2005; MENG et al., 2011; MENG, 2012). Para uma efetiva gestão de relacionamentos, faz-se necessária a coordenação dos processos das construtoras e os dos seus principais fornecedores (BEACH et al 2005; AKINTOYE; MAIN, 2007; PINTO et al., 2009). Wang et al. (2017) identificaram como críticas na relação construtora e fornecedores as seguintes questões: tempo de entrega variáveis, nível de estoque de segurança inconsistente, e processo de seleção e de avaliação de fornecedores inexistentes ou pouco desenvolvidos.

Os indicadores-chave para a construção de um efetivo relacionamento da cadeia de suprimentos são: objetivos mútuos, ganhos e compartilhamento de dificuldades, confiança, cultura, trabalho conjunto, comunicação, resolução de problemas, alocação de risco, medição de desempenho e melhoria contínua 
(PINTO et al., 2009; BYGBALLE et al., 2010; MENG, 2012; YEUNG et al., 2012). Construtoras e fornecedores devem se concentrar no desenvolvimento de confiança com a finalidade de obter relacionamentos de longo prazo baseados em progressivas melhorais de performance do projeto de engenharia (LUI; NGO, 2004; LÖNNGREN et al., 2010; YEUNG et al., 2012). A natureza de longo prazo é essencial para obter melhores resultados na gestão das partes no processo produtivo (DE TREVILLE et al., 2004; BYGBALLE et al., 2010; MENG, 2012). No entanto, as organizações do setor têm um histórico de relações adversas, pouco colaborativo e de curso prazo com implementação lenta da construção de relacionamentos com fornecedores (YEUNG et al., 2012).

Estruturar as relações na cadeia de abastecimento exige que as organizações partícipes desenvolvam um ambiente colaborativo, confiável e baseado em compartilhamento de informações (CHAN et al., 2004; MENG, 2012; YEUNG et al., 2012). Compartilhar colaborativamente as informações envolve a implantação de tecnologias eletrônicas de informação e comunicação (TIC) (SANDERS; PREMUS, 2005; IRIZARRY et al., 2013, MIGNARD; NICOLLE, 2014). Dentre as TICs mais estudadas destacam-se: sistema de radiofrequência (RFID) (REN et al., 2011; LEE et al., 2012; COSTIN et al. 2012); modelagem de informação da construção (BIM) (SUCCAR, 2009) e os sistemas de informações geográficas (GIS) (IRIZARRY et al., 2013; MIGNARD; NICOLLE, 2014; KANG; HONG, 2015; DENG et al., 2016; WANG et al., 2017).

As TICs são utilizadas para especificar, transferir e integrar dados e também para melhorar os relacionamentos na cadeia de abastecimento da construção (IRIZARRY et al., 2013). Problemas de heterogeneidade de dados e de compartilhamento de informação na indústria da construção podem ser resolvidos com a padronização (SANDERS; PREMUS, 2005). Deng et al. (2016) ressaltam que a utilização de tecnologias de localização e de monitoramento de materiais apresenta benefícios tangíveis como o aumento da visibilidade da rede de fornecimento durante o processo construtivo, reduzindo a quantidade de materiais. Kang e Hong (2015) apontam o uso da tecnologia BIM como ferramenta para integração da cadeia de suprimentos da construção, propiciando apoio, principalmente, na tomada de decisões gerenciais, no desenvolvimento de parcerias e na redução de atrasos na entrega de materiais.

\section{CONCLUSÕES}

Os pesquisadores são uníssonos ao apontarem a gestão da cadeia de suprimentos - e mais especificamente a gestão das relações interorganizacionais - como uma ferramenta fundamental para melhorar o desempenho organizacional na indústria da construção civil (obtenção de vantagem competitiva, redução de custos, produtividade, criação de valor, dentre outros). A última década, inclusive, testemunhou um rápido desenvolvimento na literatura sobre o tema. No entanto, poucas foram as tentativas de mapear, de forma estruturada e com abordagem bibliométrica, a pesquisa global existente. Assim, conhecer o corpo de conhecimento existente e compreender a evolução da pesquisa torna-se uma meta essencial para pesquisadores, países e instituições que queiram se aprofundar sobre o tema. Com base em 38.819 referências extraídas de 806 artigos sobre SCM na construção civil coletados na WoS, os autores chegaram a um portfólio bibliográfico de 76 artigos relevantes sobre gestão de relações interorganizacionais na cadeia de suprimentos da construção civil no período de 2000 a 2019.

Os resultados demonstram a importância dos trabalhos de autores como Succar, Sanders, Cox, De Treville, Chan, Lui, Meng, Pinto, Eriksson, Briscoe, Beach, e outros relacionados no Anexo. A maioria (68\%) das publicações originaram-se do Reino Unido (25\%), Estados Unidos (16\%), Hong Kong (11\%), Coréia do Sul (9\%) e na Suécia (8\%). Automation in Construction, International Journal of Project Management, Supply Chain Management - an International Journal, Advanced Engineering Informatics, Journal of Purchasing and Supply Management, e Journal of Computing in Civil Engineering foram os periódicos que mais publicaram sobre o tema.

Os agrupamentos dominantes da pesquisa (clusters - Quadro 2) foram "fornecedores", "construção", "confiança", "mudança", "conhecimento" e "canteiro de obras". Em apertada síntese, os trabalhos analisados têm como foco os fornecedores, as construtoras e os canteiros de obras e estão relacionados à confiança, à colaboração, ao compartilhamento de informações, à integração, aos relacionamentos e à tecnologia da informação (em especial, RFID, BIM e GIS) na cadeia de suprimentos da construção civil.

Por fim, a adoção, na presente pesquisa, de um método estruturado de RSL associado à análise bibliométrica, inclusive com o apoio de software específicos (CiteSpace II e Start), não só fornece referências para estudiosos sobre o tema, mas também apresenta critérios objetivos para a construção de um sólido referencial teórico. 
Sugere-se como trabalhos futuros: (1) utilizar outras ferramentas bibliométricas (VantagePoint, VOSviewer, Netdraw, Bibexcel, HistCite e outros) para comparar os resultados obtidos; (2) repetir a pesquisa com dados de entrada extraídos de outras bases (Scopus, Proquest, Access Engineering, Engineering Village, etc.).

\section{REFERÊNCIAS}

[1] Akintoye, Akintola; Main, Jamie. Collaborative relationships in construction: the UK contractors' perception. Engineering, Construction and Architectural Management, v. 14, n. 6, p. 597-617, 2007.

[2] Bandeira, Renata Albergaria de Mello; Mello, Luiz Carlos Brasil de Brito; Macada, Antonio Carlos Gastaud. Relacionamento interorganizacional na cadeia de suprimentos: um estudo de caso na indústria da construção civil. Produção. vol. 19, n. 2, p. 376-387, 2009.

[3] Bankvall, Lars; Bygballe, Lena E.; Dubois, Anna; Jahre, Marianne. Interdependence in supply chains and projects in construction. Supply chain management: an international journal, v. 15, n. 5, p. 385-393, 2010.

[4] Beach, Roger; Webster, Margaret; Campbell, Kerrie M. An evaluation of partnership development in the construction industry. International journal of project management, v. 23, n. 8, p. 611-621, 2005.

[5] Briscoe, Geoffrey; Dainty, Andrew. Construction supply chain integration: an elusive goal? Supply chain management: an international journal, v. 10, n. 4, p. 319-326, 2005.

[6] Bygballe, Lena E.; Ingemansson, Malena. The logic of innovation in construction. Industrial Marketing Management, v. 43, n. 3, p. 512-524, 2014.

[7] Chadegani, Arezoo A.; Salehi, Hadi; Yunus, Melor, Farhadi, Hadi, Fooladi, Masood, Farhadi, Maryam; Ebrahim, Nader A. A comparison between two main academic literature collections: Web of Science and Scopus databases. Asian Social Science, v. 9, n. 5, p. 18-26, Apr. 2013.

[8] Chan, Albert P. C.; Chan, Daniel W. M.; Chiang, Y. H.; TANG, B. S.; Chan Edwin H. W.; HO Kathy S. K. Exploring critical success factors for partnering in construction projects. Journal of construction engineering and management, v. 130, n. 2, p. 188-198, 2004.

[9] Costin, Aaron; Pradhananga, Nipesh; TEIZER, Jochen. Leveraging passive Rfid technology for construction resource field mobility and status monitoring in a high-rise renovation project. Automation in Construction, v. 24, p. 1$15,2012$.

[10] Cox, Andrew. The art of the possible: relationship management in power regimes and supply chains. Supply chain management: an international journal, v. 9, n. 5, p. 346-356, 2004.

[11] De Treville, Suzanne; Shapiro, Roy D.; Hameri, Ari-Pekka. From supply chain to demand chain: the role of lead time reduction in improving demand chain performance. Journal of Operations Management, v. 21, n. 6, p. 613$627,2004$.

[12] Deng, Yichuan; Cheng, Jack CP; Anumba, Chimay. Mapping between BIM and 3D GIS in different levels of detail using schema mediation and instance comparison. Automation in Construction, v. 67, p. 1-21, 2016.

[13] Eriksson, Per Erik. Partnering in engineering projects: Four dimensions of supply chain integration. Journal of Purchasing and Supply Management, v. 21, n. 1, p. 38-50, 2015.

[14] Eriksson, Per Erik; Westerberg, Mats. Effects of cooperative procurement procedures on construction project performance: A conceptual framework. International journal of project management, v. 29, n. 2, p. 197-208, 2011.

[15] Irizarry, Javier; Karan, Ebrahim P.; Jalaei, Farzad. Integrating BIM and GIS to improve the visual monitoring of construction supply chain management. Automation in construction, v. 31, p. 241-254, 2013.

[16] Isatto, Eduardo L.; Azambuja, Marcelo; Formoso, Carlos T. The Role of Commitments in the Management of Construction Make-to-Order Supply Chains. Journal of Management in Engineering, v. 31, n. 4, p. 04014053, 2013.

[17] Kang, Tae Wook; HONG, Chang Hee. A study on software architecture for effective BIM/GIS-based facility management data integration. Automation in Construction, v. 54, p. 25-38, 2015.

[18] Lahdenperä, Pertti. Making sense of the multi-party contractual arrangements of project partnering, project alliancing and integrated project delivery. Construction management and economics, v. 30, n. 1, p. 57-79, 2012.

[19] Lee, Hyun-Soo et al. Rfid-based real-time locating system for construction safety management. Journal of Computing in Civil Engineering, v. 26, n. 3, p. 366-377, 2011.

[20] Levy, Yair; Ellis, Timothy J. A systems approach to conduct an effective literature review in support of information systems research. Informing Science, v. 9, 2006. 
[21] Lönngren, Hans-Martin; Rosenkranz, Christoph; Kolbe, Harald. Aggregated construction supply chains: success factors in implementation of strategic partnerships. Supply Chain Management: An International Journal, v. 15, n. 5, p. 404-411, 2010.

[22] Loureiro, Sergio A.; Noletto, Ana Paula R.; Santos, Lilian S.; Santos Júnior, José B. S.; Lima Júnior, Orlando F. 0 uso do método de revisão sistemática da literatura na pesquisa em logística, transportes e cadeia de suprimentos. Transportes, v. 24, n. 1, p. 95-106, 2016.

[23] Love, Peter ED; Irani, Zahir; Edwards, David J. A seamless supply chain management model for construction. Supply chain management: an international journal, v. 9, n. 1, p. 43-56, 2004.

[24] Lu, Weisheng; Huang, George Q.; LI, Heng. Scenarios for applying RFID technology in construction project management. Automation in construction, v. 20, n. 2, p. 101-106, 2011.

[25] Lui, Steven S.; Ngo, Hang-yue. The role of trust and contractual safeguards on cooperation in non-equity alliances. Journal of management, v. 30, n. 4, p. 471-485, 2004.

[26] Meng, Xianhai; Sun, Ming; Jones, Martyn. Maturity model for supply chain relationships in construction. Journal of Management in Engineering, v. 27, n. 2, p. 97-105, 2011.

[27] Meng, Xianhai. The effect of relationship management on project performance in construction. International journal of project management, v. 30, n. 2, p. 188-198, 2012.

[28] Mignard, Clement; Nicolle, Christophe. Merging BIM and GIS using ontologies application to urban facility management in Active3d. Computers in Industry, v. 65, n. 9, p. 1276-1290, 2014.

[29] Pinto, Jeffrey K.; Slevin, Dennis P.; English, Brent. Trust in projects: An empirical assessment of owner/contractor relationships. International Journal of Project Management, v. 27, n. 6, p. 638-648, 2009.

[30] Ren, Zhaomin; Anumba, Chimay J.; Tah, J. Rfid-facilitated construction materials management (Rfid-Cmm)-A case study of water-supply project. Advanced Engineering Informatics, v. 25, n. 2, p. 198-207, 2011.

[31] Sanders, Nada R.; Premus, Robert. Modeling the relationship between firm IT capability, collaboration, and performance. Journal of business logistics, v. 26, n. 1, p. 1-23, 2005.

[32] Succar, Bilal. Building information modelling framework: A research and delivery foundation for industry stakeholders. Automation in construction, v. 18, n. 3, p. 357-375, 2009.

[33] Vrijhoef Ruben, Koskela Lauri. The four holes of supply chain management in construction. European Journal of Purchasing \&Supply Management, vol. 6, pp 169-178, 2000.

[34] Wang, Ting-Kwei; Zhang, Qian; Chong, Heap-Yih; Wang, Xiangyu. Integrated supplier selection framework in a resilient construction supply chain: An approach via analytic hierarchy process (Ahp) and grey relational analysis (Gra). Sustainability, v. 9, n. 2, p. 289, 2017.

[35] Xue, Xiaolong; Wang, Yaowu; Shen, Qiping; Yu, Xiaoguo. Coordination mechanisms for construction supply chain management in the Internet environment. International Journal of project management, v. 25, n. 2, p. 150-157, 2007.

[36] Yeung, John F. Y.; Chan, Albert P. C.; Chan, Daniel W. M. Defining relational contracting from the Wittgenstein family-resemblance philosophy. International journal of project management, v. 30, n. 2, p. 225-239, 2012. 


\begin{tabular}{|c|c|c|c|c|c|}
\hline \multicolumn{6}{|c|}{ Anexo } \\
\hline № & PUBLICAÇÕES & AUTORES & ANO & PAÍS & CITAÇÕES \\
\hline 1 & $\begin{array}{l}\text { Building information modelling } \\
\text { framework: A research and } \\
\text { deliveryfoundation for industry } \\
\text { stakeholders }\end{array}$ & SUCCAR, B. & 2009 & Australia & 1057 \\
\hline 2 & $\begin{array}{l}\text { Modeling the relationship between firm IT } \\
\text { capability, collaboration, and performance }\end{array}$ & $\begin{array}{l}\text { SANDERS, N. R.; } \\
\text { PREMUS, R. }\end{array}$ & 2005 & EUA & 477 \\
\hline 3 & $\begin{array}{l}\text { The art of the possible: relationship } \\
\text { management in power regimes and supply } \\
\text { chains }\end{array}$ & COX, A. & 2004 & Reino Unido & 467 \\
\hline 4 & $\begin{array}{l}\text { From supply chain to demand chain: the } \\
\text { role of lead time reduction inimproving } \\
\text { demand chain performance }\end{array}$ & $\begin{array}{l}\text { DE TREVILLE, S.; } \\
\text { SHAPIRO, R.D.; } \\
\text { HAMERI, A. }\end{array}$ & 2004 & EUA & 464 \\
\hline 5 & $\begin{array}{l}\text { Exploring critical success factors for } \\
\text { partnering in construction projects }\end{array}$ & CHAN et al. & 2004 & Hong Kong & 459 \\
\hline 6 & $\begin{array}{l}\text { The role of trust and contractual } \\
\text { safeguards on cooperation innon-equity } \\
\text { alliances }\end{array}$ & LUI, S. S.; NGO, H. & 2004 & Hong Kong & 448 \\
\hline 7 & $\begin{array}{l}\text { Radio-frequency identification (RFID) } \\
\text { applications: A brief introduction }\end{array}$ & $\begin{array}{l}\text { DOMDOUZIS, K.; } \\
\text { KUMAR, B.; ANUMBA, } \\
\text { C. }\end{array}$ & 2007 & Reino Unido & 382 \\
\hline 8 & $\begin{array}{l}\text { The effect of relationship management on } \\
\text { project performance in construction }\end{array}$ & MENG, X. & 2012 & Reino Unido & 323 \\
\hline 9 & $\begin{array}{l}\text { The application of active radio frequency } \\
\text { identification technology fortool tracking } \\
\text { on construction job sites }\end{array}$ & $\begin{array}{l}\text { GOODRUM, P. M.; } \\
\text { MCLAREN, M. A.; } \\
\text { DURFEE, A. }\end{array}$ & 2006 & EUA & 322 \\
\hline 10 & $\begin{array}{l}\text { Trust in projects: An empirical assessment } \\
\text { of owner/contractor relationships }\end{array}$ & $\begin{array}{l}\text { PINTO, J. K.; SLEVIN, } \\
\text { D. P.; ENGLISH, B. }\end{array}$ & 2009 & EUA & 316 \\
\hline 11 & $\begin{array}{l}\text { Effects of cooperative procurement } \\
\text { procedures on construction project } \\
\text { performance: A conceptual framework }\end{array}$ & $\begin{array}{l}\text { ERIKSSON,P.E.; } \\
\text { WESTERBERG, M. }\end{array}$ & 2011 & Suécia & 290 \\
\hline 12 & $\begin{array}{l}\text { Making sense of the multi-party } \\
\text { contractual arrangements of project } \\
\text { partnering, project alliancing and } \\
\text { integrated project delivery }\end{array}$ & LAHDENPERÄ, P. & 2012 & Finlândia & 288 \\
\hline 13 & $\begin{array}{l}\text { Construction supply chain integration: an } \\
\text { elusive goal? }\end{array}$ & $\begin{array}{l}\text { BRISCOE, G.; DAINTY, } \\
\text { A. }\end{array}$ & 2005 & Reino Unido & 265 \\
\hline 14 & $\begin{array}{l}\text { An evaluation of partnership development } \\
\text { in the construction industry }\end{array}$ & $\begin{array}{c}\text { BEACH, R.; } \\
\text { WEBSTER, M. ; } \\
\text { CAMPBELL, K.M. }\end{array}$ & 2005 & Reino Unido & 258 \\
\hline 15 & $\begin{array}{l}\text { Requirements for building information } \\
\text { modeling based lean production } \\
\text { management systems for construction }\end{array}$ & $\begin{array}{l}\text { SACKS, R.; } \\
\text { RADOSAVLJEVIC, M.; } \\
\text { BARAK, R. }\end{array}$ & 2010 & Reino Unido & 250 \\
\hline 16 & $\begin{array}{l}\text { Partnering relationships in construction: A } \\
\text { literature review }\end{array}$ & $\begin{array}{c}\text { BYGBALLE, L.E.; } \\
\text { JAHRE, M.; SWÄRD, A. }\end{array}$ & 2010 & Noruega & 232 \\
\hline 17 & $\begin{array}{l}\text { A seamless supply chain management } \\
\text { model for construction }\end{array}$ & $\begin{array}{l}\text { LOVE, P. ED; IRANI, } \\
\text { Z.; EDWARDS, D. J. }\end{array}$ & 2004 & Australia & 222 \\
\hline 18 & $\begin{array}{l}\text { Dynamic mobile RFID-based supply chain } \\
\text { control and management system in } \\
\text { construction }\end{array}$ & $\begin{array}{l}\text { WANG, L.C.; LIN, Y.C.; } \\
\text { LIN, P.H. }\end{array}$ & 2007 & Taiwan & 209 \\
\hline 19 & $\begin{array}{l}\text { Enhancing construction quality inspection } \\
\text { and management using RFID technology }\end{array}$ & WANG, L.C. & 2008 & Taiwan & 205 \\
\hline 20 & $\begin{array}{l}\text { Integrating BIM and GIS to improve the } \\
\text { visual monitoring of constructionsupply } \\
\text { chain management }\end{array}$ & $\begin{array}{l}\text { IRIZARRY, J.; KARAN, } \\
\text { E. P.; JALAEI, F. }\end{array}$ & 2013 & EUA & 205 \\
\hline 21 & $\begin{array}{l}\text { Evaluation of image-based modeling and } \\
\text { laser scanning accuracy for emerging } \\
\text { automated performance monitoring } \\
\text { techniques }\end{array}$ & $\begin{array}{l}\text { GOLPARVAR-FARD, } \\
\text { M.; BOHN, J.; TEIZER, } \\
\text { J.; SAVARESE, S.; } \\
\text { PEÑA-MORA, F. }\end{array}$ & 2011 & EUA & 204 \\
\hline
\end{tabular}


(continuação ...)

\begin{tabular}{|c|c|c|c|c|c|}
\hline \multicolumn{6}{|c|}{ Anexo } \\
\hline № & PUBLICAÇÕES & AUTORES & ANO & PAÍS & CITAÇÕES \\
\hline 22 & $\begin{array}{l}\text { Coordination mechanisms for construction } \\
\text { supply chain management in the Internet } \\
\text { environment }\end{array}$ & $\begin{array}{l}\text { XUE,X.; WANG,Y.; } \\
\text { SHEN,Q.; YU,X. }\end{array}$ & 2007 & China & 190 \\
\hline 23 & $\begin{array}{l}\text { Stakeholder management studies in mega } \\
\text { construction projects: A reviewand future } \\
\text { directions }\end{array}$ & $\begin{array}{l}\text { MOK, K.Y.; SHEN, G.Q.; } \\
\text { YANG, J. }\end{array}$ & 2015 & Hong Kong & 183 \\
\hline 24 & $\begin{array}{l}\text { Collaborative relationships in } \\
\text { construction: The UK contractors' } \\
\text { perception }\end{array}$ & $\begin{array}{l}\text { AKINTOYE, A.; MAIN, } \\
\text { J. }\end{array}$ & 2007 & Reino Unido & 173 \\
\hline 25 & Building trust in construction projects & $\begin{array}{l}\text { KHALFAN, M. MA; } \\
\text { MCDERMOTT, P.; } \\
\text { SWAN, W. }\end{array}$ & 2007 & Reino Unido & 171 \\
\hline 26 & $\begin{array}{l}\text { Improving construction supply chain } \\
\text { collaboration and performance: A lean } \\
\text { construction pilot project }\end{array}$ & ERIKSSON, P. E. & 2010 & Suécia & 169 \\
\hline 27 & $\begin{array}{l}\text { Performance-based evaluation of RFID- } \\
\text { based indoor location sensingsolutions for } \\
\text { the built environment }\end{array}$ & $\begin{array}{l}\text { LI, N.; BECERIK- } \\
\text { GERBER, B. }\end{array}$ & 2011 & EUA & 169 \\
\hline 28 & $\begin{array}{l}\text { Interdependence in supply chains and } \\
\text { projects in construction }\end{array}$ & $\begin{array}{c}\text { BANKVALL, L.; } \\
\text { BYGBALLE, L. E.; } \\
\text { DUBOIS, A.; JAHRE, M. }\end{array}$ & 2010 & Suécia & 161 \\
\hline 29 & $\begin{array}{l}\text { Deconstructing partnering in project- } \\
\text { based organisation: Seven pillars, seven } \\
\text { paradoxes and seven deadly sins }\end{array}$ & BRESNEN, M. & 2007 & Reino Unido & 156 \\
\hline 30 & $\begin{array}{l}\text { Scenarios for applying RFID technology in } \\
\text { construction project management }\end{array}$ & $\begin{array}{l}\text { LU, W.; HUANG, G. Q.; } \\
\text { LI, H. }\end{array}$ & 2011 & Hong Kong & 156 \\
\hline 31 & $\begin{array}{l}\text { Partnering in the construction industry- } \\
\text { Problems and opportunities }\end{array}$ & $\begin{array}{l}\text { GADDE, L.-E.; } \\
\text { DUBOIS, A. }\end{array}$ & 2010 & Suécia & 151 \\
\hline 32 & $\begin{array}{l}\text { Towards an autonomous real-time } \\
\text { tracking system of near-miss accidentson } \\
\text { construction sites }\end{array}$ & $\begin{array}{l}\text { WU, W.; YANG, H.; } \\
\text { CHEW, D. A.; YANG, S. } \\
\text { H.; GIBB, A. G.; LI, Q. }\end{array}$ & 2010 & China & 148 \\
\hline 33 & $\begin{array}{l}\text { RFID+4D CAD for progress management of } \\
\text { structural steel works inhigh-rise buildings }\end{array}$ & $\begin{array}{l}\text { CHIN, S.; YOON, S.; } \\
\text { CHOI, C.; CHO, C. }\end{array}$ & 2008 & Coréia do Sul & 135 \\
\hline 34 & $\begin{array}{l}\text { Application of RFID technology to } \\
\text { prevention of collision accident with heavy } \\
\text { equipment }\end{array}$ & CHAE, S.; YOSHIDA, T. & 2010 & Japan & 130 \\
\hline 35 & $\begin{array}{l}\text { Automated vision tracking of project } \\
\text { related entities }\end{array}$ & $\begin{array}{l}\text { BRILAKIS, I.; PARK, } \\
\text { M.-W.; JOG, G. }\end{array}$ & 2011 & EUA & 127 \\
\hline 36 & $\begin{array}{l}\text { A framework for using mobile computing } \\
\text { for information management } \\
\text { onconstruction sites }\end{array}$ & $\begin{array}{c}\text { CHEN, Y.; KAMARA, J. } \\
\text { M. }\end{array}$ & 2011 & China & 125 \\
\hline 37 & $\begin{array}{l}\text { Partnering in major contracts: Paradox and } \\
\text { metaphor }\end{array}$ & $\begin{array}{l}\text { ALDERMAN, N.; } \\
\text { IVORY, C. }\end{array}$ & 2007 & Reino Unido & 123 \\
\hline 38 & The logic of innovation in construction & $\begin{array}{l}\text { BYGBALLE,L.E.;INGE } \\
\text { MANSSON,M. }\end{array}$ & 2014 & Noruega & 120 \\
\hline 39 & $\begin{array}{l}\text { Making sense of supply chain } \\
\text { management: A comparative study of } \\
\text { aerospace and construction }\end{array}$ & $\begin{array}{l}\text { GREEN,S.D.;FERNIE,S. } \\
\text {;WELLER,S. }\end{array}$ & 2005 & Reino Unido & 115 \\
\hline 40 & $\begin{array}{l}\text { Resilient supplier selection and order } \\
\text { allocation under operational and } \\
\text { disruption risks }\end{array}$ & $\begin{array}{l}\text { TORABI, S. A.; } \\
\text { BAGHERSAD, M.; } \\
\text { MANSOURI, S. A. }\end{array}$ & 2015 & Iran & 110 \\
\hline 41 & $\begin{array}{l}\text { Maturity Model for Supply Chain } \\
\text { Relationships in Construction }\end{array}$ & $\begin{array}{l}\text { MENG, X.; SUN, M.; } \\
\text { JONES, M. }\end{array}$ & 2011 & Reino Unido & 109 \\
\hline 42 & $\begin{array}{l}\text { Building trust in construction partnering } \\
\text { projects: An exploratorycase-study }\end{array}$ & $\begin{array}{l}\text { LAAN, A.; } \\
\text { NOORDERHAVEN, N.; } \\
\text { VOORDIJK, H.; } \\
\text { DEWULF, G. }\end{array}$ & 2011 & Países Baixos & 106 \\
\hline
\end{tabular}


(continuação ...)

\begin{tabular}{|c|c|c|c|c|c|}
\hline \multicolumn{6}{|c|}{ Anexo } \\
\hline № & PUBLICAÇÕES & AUTORES & ANO & PAÍS & CITAÇÕES \\
\hline 43 & $\begin{array}{l}\text { Interpersonal trust and inter-firm trust in } \\
\text { construction projects }\end{array}$ & $\begin{array}{l}\text { LAU, E.; ROWLINSON, } \\
\text { S. }\end{array}$ & 2009 & Hong Kong & 105 \\
\hline 44 & $\begin{array}{l}\text { Managing key business-to-business } \\
\text { relationships - What marketing canlearn } \\
\text { from supply chain management }\end{array}$ & $\begin{array}{c}\text { RYALS, L. J.; } \\
\text { HUMPHRIES, A. S. }\end{array}$ & 2007 & Reino Unido & 104 \\
\hline 45 & $\begin{array}{l}\text { RFID-based real-time locating system for } \\
\text { construction safety management }\end{array}$ & $\begin{array}{l}\text { LEE, H.-S. ; LEE, K.-P. ; } \\
\text { PARK, M. ; BAEK, Y. ; } \\
\text { LEE, S. }\end{array}$ & 2012 & Coréia do Sul & 100 \\
\hline 46 & $\begin{array}{l}\text { Using a real-time integrated } \\
\text { communication system to monitor } \\
\text { theprogress and quality of construction } \\
\text { works }\end{array}$ & $\begin{array}{l}\text { LEUNG, S.; MAK, S.; } \\
\text { LEE, Bill L. P. }\end{array}$ & 2008 & Hong Kong & 96 \\
\hline 47 & $\begin{array}{l}\text { A study on software architecture for } \\
\text { effective BIM/GIS-based } \\
\text { facilitymanagement data integration }\end{array}$ & $\begin{array}{l}\text { KANG, T. W.; HONG, C. } \\
\text { H. }\end{array}$ & 2015 & Coréia do Sul & 94 \\
\hline 48 & $\begin{array}{l}\text { Multisensor data fusion for on-site } \\
\text { materials tracking in construction }\end{array}$ & $\begin{array}{l}\text { RAZAVI, S. N.; HAAS, } \\
\text { C. T. } \\
\end{array}$ & 2010 & Canadá & 91 \\
\hline 49 & $\begin{array}{l}\text { Leveraging passive RFID technology for } \\
\text { construction resource fieldmobility and } \\
\text { status monitoring in a high-rise renovation } \\
\text { project }\end{array}$ & $\begin{array}{l}\text { COSTIN, A.; } \\
\text { PRADHANANGA, N.; } \\
\text { TEIZER, J. }\end{array}$ & 2012 & EUA & 88 \\
\hline 50 & $\begin{array}{l}\text { Comparative study of vision tracking } \\
\text { methods for tracking ofconstruction site } \\
\text { resources }\end{array}$ & $\begin{array}{l}\text { PARK, M.-W.; } \\
\text { MAKHMALBAF, A.; } \\
\text { BRILAKIS, I. }\end{array}$ & 2011 & EUA & 82 \\
\hline 51 & $\begin{array}{l}\text { Partnering in engineering projects: Four } \\
\text { dimensions of supply chain integration }\end{array}$ & ERIKSSON, P. E. & 2015 & Suécia & 77 \\
\hline 52 & $\begin{array}{l}\text { Relational competence in complex } \\
\text { temporary organizations: The case of } \\
\text { aFrench hospital construction project } \\
\text { network }\end{array}$ & PAUGET, B.; WALD, A. & 2013 & França & 75 \\
\hline 53 & $\begin{array}{l}\text { Assessment framework for construction } \\
\text { supply chain relationships:Development } \\
\text { and evaluation }\end{array}$ & MENG, X. & 2010 & Reino Unido & 74 \\
\hline 54 & $\begin{array}{l}\text { Aggregated construction supply chains: } \\
\text { success factors in implementationof } \\
\text { strategic partnerships }\end{array}$ & $\begin{array}{l}\text { LÖNNGREN, H.M.; } \\
\text { ROSENKRANZ, C.; } \\
\text { KOLBE, H. }\end{array}$ & 2010 & Alemanha & 72 \\
\hline 55 & $\begin{array}{l}\text { Managing appropriately in construction } \\
\text { power regimes: understanding theimpact } \\
\text { of regularity in the project environment }\end{array}$ & IRELAND, P. & 2004 & Reino Unido & 70 \\
\hline 56 & $\begin{array}{l}\text { RFID-facilitated construction materials } \\
\text { management (RFID-CMM) - A casestudy of } \\
\text { water-supply project }\end{array}$ & $\begin{array}{l}\text { REN, Z.; ANUMBA, C. } \\
\text { J.; TAH, J. }\end{array}$ & 2011 & Reino Unido & 66 \\
\hline 57 & $\begin{array}{l}\text { Mapping between BIM and 3D GIS in } \\
\text { different levels of detail using schema } \\
\text { mediation and instance comparison }\end{array}$ & $\begin{array}{l}\text { DENG, Y.; CHENG, J. } \\
\text { CP; ANUMBA, C. }\end{array}$ & 2016 & Hong Kong & 64 \\
\hline 58 & $\begin{array}{l}\text { Merging BIM and GIS using ontologies } \\
\text { application to urban facilitymanagement in } \\
\text { ACTIV e 3D }\end{array}$ & $\begin{array}{l}\text { MIGNARD, C.; } \\
\text { NICOLLE, C. }\end{array}$ & 2014 & França & 63 \\
\hline 59 & $\begin{array}{l}\text { Industrial renewal with in the construction } \\
\text { network }\end{array}$ & $\begin{array}{l}\text { HÅKANSSON, H.; } \\
\text { INGEMANSSON, M. }\end{array}$ & 2013 & Suécia & 57 \\
\hline 60 & $\begin{array}{l}\text { Static and dynamic performance } \\
\text { evaluation of a commercially- } \\
\text { availableultra wideband tracking system }\end{array}$ & $\begin{array}{l}\text { SAIDI, K. S.; TEIZER, } \\
\text { J.; FRANASZEK, M.; } \\
\text { LYTLE, A. M. }\end{array}$ & 2011 & EUA & 57 \\
\hline 61 & $\begin{array}{l}\text { Trust influencing factors in main } \\
\text { contractor and subcontractor relationships } \\
\text { during projects }\end{array}$ & $\begin{array}{l}\text { MANU, E.; ANKRAH, } \\
\text { N.; CHINYIO, E.; } \\
\text { PROVERBS, D. } \\
\end{array}$ & 2015 & Reino Unido & 55 \\
\hline 62 & $\begin{array}{l}\text { Estimate at Completion for construction } \\
\text { projects using EvolutionarySupport Vector } \\
\text { Machine Inference Model }\end{array}$ & $\begin{array}{l}\text { CHENG, M. Y.; PENG, } \\
\text { H. S.; WU, Y. W.; } \\
\text { CHEN, T. L. }\end{array}$ & 2010 & Taiwan & 54 \\
\hline
\end{tabular}


(continuação ...)

\begin{tabular}{|c|c|c|c|c|c|}
\hline \multicolumn{6}{|c|}{ Anexo } \\
\hline № & PUBLICAÇÕES & AUTORES & ANO & PAÍS & CITAÇÕES \\
\hline 63 & $\begin{array}{l}\text { Using reference RFID tags for calibrating } \\
\text { the estimated locations ofconstruction } \\
\text { materials }\end{array}$ & $\begin{array}{l}\text { RAZAVI, S. N.; HAAS, } \\
\text { C. T. }\end{array}$ & 2011 & Canadá & 52 \\
\hline 64 & $\begin{array}{l}\text { Defining relational contracting from the } \\
\text { Wittgenstein family-resemblance } \\
\text { philosophy }\end{array}$ & $\begin{array}{l}\text { YEUNG, J. FY; CHAN, } \\
\text { A. PC; CHAN, D. WM. }\end{array}$ & 2012 & Hong Kong & 48 \\
\hline 65 & $\begin{array}{l}\text { Information lifecycle management with } \\
\text { RFID for material control onconstruction } \\
\text { sites }\end{array}$ & $\begin{array}{l}\text { LEE, J. H.; SONG, J. H.; } \\
\text { OH, K. S.; GU, N. }\end{array}$ & 2013 & Coréia do Sul & 48 \\
\hline 66 & $\begin{array}{l}\text { The reluctance of construction purchasers } \\
\text { towards project partnering }\end{array}$ & $\begin{array}{l}\text { CRESPIN-MAZET, F.; } \\
\text { PORTIER, P }\end{array}$ & 2010 & França & 45 \\
\hline 67 & $\begin{array}{l}\text { Agent-based construction supply chain } \\
\text { simulator (CS2) for measuring the value of } \\
\text { real-time information sharing in } \\
\text { construction }\end{array}$ & $\begin{array}{c}\text { MIN, J. U.; } \\
\text { BJORNSSON, H. C. }\end{array}$ & 2008 & Coréia do Sul & 36 \\
\hline 68 & $\begin{array}{l}\text { Resilient supplier selection under a fuzzy } \\
\text { environment }\end{array}$ & $\begin{array}{l}\text { HALDAR, A. ; RAY, A. ; } \\
\text { BANERJEE, D. ; } \\
\text { GHOSH, S. }\end{array}$ & 2014 & Índia & 35 \\
\hline 69 & $\begin{array}{l}\text { Embedded system for construction asset } \\
\text { tracking combining radio and ultrasound } \\
\text { signals }\end{array}$ & $\begin{array}{l}\text { JANG, W.-S.; } \\
\text { SKIBNIEWSKI, M. J. }\end{array}$ & 2009 & Coréia do Sul & 35 \\
\hline 70 & $\begin{array}{l}\text { A hybrid MCDM model for resilient } \\
\text { supplier selection }\end{array}$ & $\begin{array}{l}\text { HALDAR, A. ; RAY, A. ; } \\
\text { BANERJEE, D. ; } \\
\text { GHOSH, S. } \\
\end{array}$ & 2012 & Índia & 34 \\
\hline 71 & $\begin{array}{l}\text { Emergent discourses of construction } \\
\text { competitiveness: Localized learning and } \\
\text { embeddedness }\end{array}$ & $\begin{array}{l}\text { KAO, C.-C.; GREEN, S. } \\
\text { D.; LARSEN, G. D. }\end{array}$ & 2009 & Reino Unido & 33 \\
\hline 72 & $\begin{array}{l}\text { Integrated Supplier Selection Framework } \\
\text { in a Resilient ConstructionSupply Chain: } \\
\text { An Approach via Analytic Hierarchy } \\
\text { Process (AHP) and GreyRelational Analysis } \\
\text { (GRA) }\end{array}$ & $\begin{array}{l}\text { WANG, T.-K.; ZHANG, } \\
\text { Q.; CHONG, H.-Y.; } \\
\text { WANG, X. }\end{array}$ & 2017 & Reino Unido & 32 \\
\hline 73 & $\begin{array}{l}\text { Managing construction information using } \\
\text { RFID-based semantic contexts }\end{array}$ & $\begin{array}{l}\text { ELGHAMRAWY, T.; } \\
\text { BOUKAMP, F. }\end{array}$ & 2010 & EUA & 32 \\
\hline 74 & $\begin{array}{l}\text { Evaluation and selection of resilient } \\
\text { suppliers in fuzzy environmentExploration } \\
\text { of fuzzy-VIKOR }\end{array}$ & $\begin{array}{l}\text { SAHU, A. K.; DATTA, } \\
\text { S.; MAHAPATRA, S. S. }\end{array}$ & 2016 & Índia & 28 \\
\hline 75 & $\begin{array}{l}\text { Delivery of pedestrian real-time location } \\
\text { and routing information tomobile } \\
\text { architectural guide }\end{array}$ & $\begin{array}{l}\text { SAEED, G.; BROWN, } \\
\text { A.; KNIGHT, M.; } \\
\text { WINCHESTER, M. } \\
\end{array}$ & 2010 & Paquistão & 21 \\
\hline 76 & $\begin{array}{l}\text { RFID and CCTV-Based Material Delivery } \\
\text { Monitoring for Cable-Stayed } \\
\text { BridgeConstruction }\end{array}$ & JU, Y.; KIM, C.; KIM, H. & 2012 & Coréia do Sul & 18 \\
\hline
\end{tabular}




\section{Capítulo 15}

Estudo da pegada hídrica para gestão dos recursos hídricos em Região Semiárida Brasileira

\section{Rodolfo José Sabiá}

Thais Aparecida Ribeiro Clementino

Luis Gabriel de Alencar Alves

Caio Vinicius de Araujo Ferreira Gomes

Pedro Eugênio Sabiá

Resumo: 0 estudo da pegada hídrica possui sua relevância no atual cenário global para melhor gerenciamento dos recursos hídricos e em especial, das bacias hidrográficas. A quantidade de produtos exportados pela Região Nordeste do Brasil para outros países, possui uma quantidade indireta de água contida nessas mercadorias exportadas, produtos estes divididos em básicos, manufaturados e semimanufaturados. Analisar e calcular a quantidade de água exportada indiretamente desses estados para outras nações possui sua contribuição para avaliação de indicadores de sustentabilidade e melhor viabilização da gestão de recursos hídricos da região em análise. 0 trabalho tem por objetivo avaliar a pegada hídrica de exportação dos nove estados da região nordeste do país, no ano de 2017. Após os cálculos das nove pegadas hídricas de exportação correspondente por estado, estas foram comparadas com as capacidades total e atual das doze Bacias Hidrográficas do Ceará, revelando que no ano de 2017, o estado do Ceará possui capacidade para suprir com seu volume atual, toda a quantidade de água exportada indiretamente pelos seus produtos para outras nações, pois o estado não irá esgotar o volume de seus reservatórios para suprimento dessa água indireta exportada, lembrando que o foco de estudo trata apenas da gestão dos recursos hídricos, não vinculando a pesquisa em análise econômica ou política.

Palavras-chave: Pegada Hídrica, Bacia hidrográfica, Exportação, Região Nordeste, Indicadores de Sustentabilidade 


\section{INTRODUÇÃO}

A bacia hidrográfica é uma unidade fundamental para se analisar a gestão de recursos hídricos. No entanto, extrapolando essa visão surge um conceito de fluxo de água virtual visualizando-se a exportação de commodities de água, através da exportação de produtos que contém água indireta em sua produção. Dessa forma, a sociedade começa a compreender o papel da água para o desenvolvimento dos países, regiões e estados.

Nessa perspectiva, a pesquisa analisa a Região Nordeste do Brasil, composta por nove estados. Foi-se calculado toda a água indireta exportada por cada estado da região para outros países, obtendo-se assim, a pegada hídrica exportada, ou seja, o rastro da água que foi usado indiretamente na produção de cada produto exportado no ano de 2017. Esses valores calculados possuem sua contribuição para análise da gestão dos recursos hídricos, pois representam um valor expressivo de volume de água exportado.

Assim, o trabalho tem por objetivo quantificar todo o volume de água exportado indiretamente pelos produtos de origem agropecuária dos nove estados da região nordeste. Dessa forma, analisa-se qual o impacto que esses valores representam para a avaliação da gestão dos recursos hídricos, contribuindo assim como um indicador de sustentabilidade e melhor distribuição de água dessa região do país.

\section{REFERENCIAL TEÓRICO}

\subsection{IMPORTÂNCIA DA GESTÃO DOS RECURSOS HÍDRICOS}

A manutenção do equilíbrio entre as sustentabilidades socioeconômicas e ambientais requer não apenas uma compreensão dos fluxos econômicos, mas também o conhecimento de quanto da capacidade biológica é necessário para absorver os impactos ambientais produzidos pela humanidade. 0 conceito dominante de desenvolvimento sustentável consiste em descobrir como o planeta pode proporcionar recursos suficientes para assegurar o bem-estar das pessoas, em toda parte. Neste particular, as pegadas ecológica, hídrica e de carbono demonstram que a humanidade está vivendo, atualmente, além da capacidade da Terra (Galli et al., 2012).

As atividades humanas consomem e poluem uma grande quantidade de água. Em uma escala global, a maior parte do uso da água ocorre na produção agrícola, mas há também volumes substanciais de água consumida e poluída pelos setores industriais e domésticos (WWAP, 2009). 0 consumo e a poluição da água podem estar associados a atividades específicas como irrigação, higiene pessoal, limpeza, refrigeração e processamento. 0 total de consumo e poluição da água é geralmente considerado como a soma de uma multiplicidade de demandas de água e de atividades poluentes independentes. Tem-se prestado pouca atenção ao fato de que, no final, o total de consumo de água e geração de poluição está relacionado com o que e quanto certas comunidades consomem e à estrutura da economia global que fornece os diversos bens de consumo e serviços (HOEKSTRA et al., 2011).

Até o passado recente, havia poucas abordagens na ciência e na prática de gestão de recursos hídricos sobre consumo e poluição da água ao longo de toda a cadeia de produção e abastecimento. Hoekstra e Chapagain (2008) mostraram que visualizar o uso oculto da água em produtos pode ajudar no entendimento do caráter global da água doce e na quantificação dos efeitos do consumo e do comércio na utilização dos recursos hídricos. 0 aperfeiçoamento desta compreensão pode constituir a base para um melhor gerenciamento dos recursos hídricos do planeta (HOEKSTRA et al., 2011).

\subsection{PEGADA HÍDRICA: CONCEITOS E DEFINIÇÕES}

A pegada hídrica é um indicador do uso da água que considera não apenas o seu uso direto por um consumidor ou produtor, mas, também, seu uso indireto. A pegada hídrica pode ser considerada como um indicador abrangente da apropriação de recursos hídricos, vis a vis ao conceito tradicional e restrito de captação de água. A pegada hídrica de um produto é o volume de água utilizado para produzi-lo, medida ao longo de toda cadeia produtiva. É um indicador multidimensional, que mostra os volumes de consumo de água por fonte e os volumes de poluição pelo tipo de poluição; todas as componentes de uma pegada hídrica total são especificadas geográfica e temporalmente. 
A pegada hídrica, portanto, oferece uma perspectiva mais adequada e mais ampla sobre a forma como um consumidor ou produtor se relaciona com o uso dos sistemas de água doce (HOEKSTRA et al., 2011).

\subsection{PEGADA HÍDRICA AZUL, VERDE E CINZA}

A pegada hídrica azul de um produto refere-se ao consumo de água azul (superficial e subterrânea) ao longo de sua cadeia produtiva. "Consumo" refere-se à perda de água (superficial ou subterrânea) disponível em uma bacia hidrográfica. A perda ocorre quando a água evapora, retorna a outra bacia ou ao mar ou é incorporada em um produto. A pegada hídrica verde refere-se ao consumo de água verde (água de chuva, desde que não escoe). A pegada hídrica cinza refere-se à poluição e é definida como o volume de água doce necessário para assimilar a carga de poluentes, a partir de concentrações naturais e de padrões de qualidade da água existentes (HOEKSTRA et al., 2011).

\section{MATERIAIS E MÉTODOS}

\subsection{BACIAS HIDROGRÁFICAS DO ESTADO DO CEARÁ}

É de responsabilidade do Conselho Nacional dos Recursos Hídricos planejar sobre o planejamento e gestão das águas que de sua respectiva bacia hidrográfica. Bacia hidrográfica é uma área onde toda chuva que cai drena, por riachos e rios secundários, para um mesmo rio principal, localizada num ponto mais baixo de paisagem sendo separada das outras Bacias por uma linha divisória denominada divisor de água. O estado do Ceará, segundo o Plano Estadual dos Recursos Hídricos, está dividido em 12 Bacias Hidrográficas (COGERH, 2018).

As bacias hidrográficas que compõem o estado do Ceará são compostas pela Bacia do Acaraú, Alto Jaguaribe, Baixo Jaguaribe, Médio Jaguaribe, Banabuiú, Coreaú, Curu, Litoral, Metropolitana, Serra da Ipiapaba, Sertões de Crateús e o Salgado, contabilizando uma capacidade total de $18.630,25 \mathrm{hm}^{3}$, porém no ano de 2017, o volume atual das bacias do Ceará é de apenas $3.150,18 \mathrm{hm}^{3}$, correspondendo apenas a 16,9\% da capacidade total dos açudes das 12 bacias do Ceará (FUNCEME, 2018). Os dados dos volumes de cada bacia hidrográfica foram necessários para a comparação com a pegada hídrica exportada no presente trabalho, mostrados na tabela abaixo.

Tabela 1 - Reservatórios por bacia hidrográfica do estado do Ceará

\begin{tabular}{|c|c|c|}
\hline Bacia Hidrográfica & Capacidade total $\left(\mathrm{hm}^{3}\right)$ & Capacidade atual $\left(\mathrm{hm}^{3}\right)$ \\
\hline Acaraú & $1.718,27$ & 633,27 \\
\hline Alto Jaguaribe & $2.778,52$ & 293,04 \\
\hline Baixo Jaguaribe & 24,00 & 14,47 \\
\hline Banabuiú & $2.755,32$ & 273,32 \\
\hline Coreaú & 303,74 & 277,64 \\
\hline Curu & $1.028,80$ & 163,74 \\
\hline Litoral & 214,90 & 169,45 \\
\hline Metropolitana & $1.378,61$ & 441,41 \\
\hline Médio Jaguaribe & $7.386,69$ & 633,14 \\
\hline Serra da Ibiapaba & 141,00 & 50,88 \\
\hline Sertões de Crateús & 448,09 & 68,06 \\
\hline Salgado & 452,31 & 131,76 \\
\hline TOTAL & 18.630 & $3.150,18$ \\
\hline
\end{tabular}

Fonte: Adaptado de FUNCEME - Fundação Cearense de Meteorologia e Recursos hídricos (2018)

Para análise e cálculo da pegada hídrica é necessário definir o tempo e local que está sendo estudado. Dessa maneira utilizou-se tanto os volumes atuais e totais dos doze reservatórios do estado do Ceará, para a compreensão de que a pegada hídrica gera um impacto maior ou menor dependendo dos tempos de seca e chuva, por exemplo. 


\subsection{CÁLCULO DA PEGADA HÍDRICA DE EXPORTAÇÃO}

A pegada hídrica de exportação calculada corresponde ao volume de água exportada indiretamente dos estados do Nordeste brasileiro para outros países, e se trata da pegada hídrica de exportação da Região Nordeste, que é a pegada hídrica de uma área delimitada geograficamente.

Os produtos exportados pelo Brasil são divididos em três (3) categorias: produtos básicos, semimanufaturados e manufaturados. O Ministério da Indústria, Comércio Exterior e Serviços - MDIC é um órgão integrante da estrutura da administração pública federal direta do país, é responsável por quantificar todos os produtos que são importados e exportados pelo Brasil, mensalmente e anualmente, detalhando os produtos por fator agregado, estado, quantidade (em toneladas), colocação, origens das importações, destino das exportações, dentre outros dados.

Foram selecionados os produtos exportados pelo Brasil das três categorias citadas acima, e separado a quantidade (em tonelada) pelos nove estados do Nordeste brasileiro, de cada produto correspondente. Após isso, foi calculada a pegada hídrica por produto exportado e posteriormente, a pegada hídrica total de todos os produtos exportados, divididos por estado, como mostrado na fórmula abaixo:

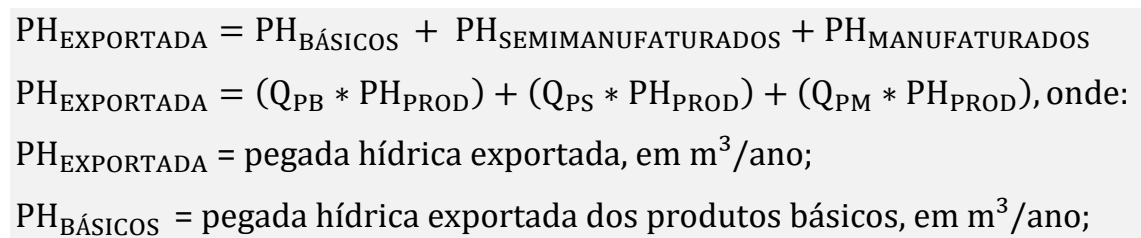

$\mathrm{PH}_{\text {SEMIMANUFATURADOS }}$ = pegada hídrica exportada dos produtos semimanufaturados, $\mathrm{em}^{3}$ /ano;

$\mathrm{PH}_{\text {MANUFATURADOs }}=$ pegada hídrica exportada dos produtos manufaturados, $\mathrm{em}^{3} / \mathrm{ano}$;

$\mathrm{Q}_{\mathrm{PB}}=$ quantidade do respectivo produto básico, em Kg;

$\mathrm{Q}_{\mathrm{PS}}=$ quantidade do respectivo produto semimanufaturado, em Kg;

$\mathrm{Q}_{\mathrm{PM}}=$ quantidade do respectivo produto manufaturado, $\mathrm{em} \mathrm{Kg}$;

$\mathrm{PH}_{\mathrm{PROD}}=$ pegada hídrica de um produto, em L/Kg. (HOEKSTRA et al., 2011).

\section{RESULTADOS}

As pegadas hídricas de exportação dos estados da Região Nordeste do Brasil foram computadas através do cálculo de trinta e dois (32) produtos básicos, trinta e um (31) produtos manufaturados e oito (8) produtos semimanufaturados, observando que todos os produtos utilizados para o cálculo da pegada hídrica de exportação são de origem agropecuária.

Tabela 2 - Pegada hídrica importação anual da Região Nordeste (2017)

\begin{tabular}{|c|c|c|c|c|}
\hline Estado & $\begin{array}{c}\text { Pegada Hídrica } \\
\text { produtos básicos } \\
\left(\mathrm{m}^{3} / \mathrm{ano}\right)\end{array}$ & $\begin{array}{l}\text { Pegada Hídrica } \\
\text { produtos } \\
\text { manufaturados } \\
\left(\mathrm{m}^{3} / \mathrm{ano}\right)\end{array}$ & $\begin{array}{c}\text { Pegada Hídrica } \\
\text { produtos } \\
\text { semimanufaturados } \\
\left(\mathrm{m}^{3} / \mathrm{ano}\right)\end{array}$ & $\begin{array}{c}\text { Pegada Hídrica } \\
\text { exportada }\left(\mathrm{m}^{3} / \mathrm{ano}\right)\end{array}$ \\
\hline Bahia & $8.904 .187 .277,65$ & 54.357.362,98 & $1.807 .032 .285,75$ & $10.765 .576 .926,38$ \\
\hline Pernambuco & $226.205 .139,45$ & $321.546 .759,35$ & $321.191 .233,31$ & $868.943 .132,11$ \\
\hline Maranhão & $4.752 .643 .933,65$ & $359.055,04$ & $7.190 .643,94$ & $4.760 .193 .632,63$ \\
\hline Ceará & $170.690 .787,74$ & $373.572 .191,65$ & $273.539 .345,56$ & $817.802 .324,96$ \\
\hline Alagoas & 0,0 & $57.790 .796,50$ & $1.850 .209 .340,78$ & $1.908 .000 .137,27$ \\
\hline Piauí & $1.797 .110 .288,50$ & 0,0 & $5.152 .774,48$ & $1.802 .263 .062,98$ \\
\hline Paraíba & $5.085 .154,89$ & $92.008 .808,95$ & $101.062 .887,56$ & $198.156 .851,40$ \\
\hline Rio Grande do Norte & $99.194 .213,87$ & $37.614 .807,48$ & $13.326 .546,57$ & $150.135 .567,91$ \\
\hline Sergipe & $883.824,39$ & $76.054 .256,64$ & $2.522 .111,62$ & $79.460 .192,66$ \\
\hline TOTAL & $15.956 .000 .620,14$ & $1.013 .304 .038,59$ & $4.381 .227 .169,58$ & $21.350 .531 .828,30$ \\
\hline
\end{tabular}


A tabela 2 acima quantifica a pegada hídrica total exportada pelos nove estados da região nordeste do brasil, contabilizando um total de $21.350 .531 .828,30 \mathrm{~m}^{3}$ /ano. 0 estado a possuir a maior pegada hídrica de exportação no ano de 2017 foi o estado da bahia, seguidos pelos estados maranhão e alagoas. 0 estado do ceará ficou em $6^{\circ}$ lugar, e sergipe o estado com a menor pegada hídrica de exportação.

Destacando o estado do Ceará, este foi o maior exportador de castanha de caju do país (correspondendo a 80,4\% das exportações) e de calçados da região nordeste (correspondendo a 26,5\% do total das exportações de calçados do país), e o segundo maior exportador de algodão no ano de 2017. Já a Bahia é o maior exportador de óleo de cacau e manteiga, correspondendo a 98\% do total exportado no país em 2017.

Segundo Bowersox e Closs (2007), quando a estratégia de uma cadeia de suprimentos se torna global, novas complexidades são encontradas. Destacam-se entre elas o aumento da distância, diferenciais de demanda, a diversidade cultural, leis governamentais e complexidade na documentação. Independente do foco estratégico de cada empresa, o sucesso no comércio internacional dependerá de sua capacidade logística.

No entanto, destaca-se como grande desafio do Brasil, em foco a região nordeste, a constituição de diferenciais estratégicos de logística entre seus estados para integrar politicas públicas, relações sociais e econômicas. Ressaltam os dados em estudo, que tais medidas já vêm tomando corpo, exemplificado acima os resultados de commodities como a castanha de caju no Ceará e os derivados do Cacau na Bahia, onde os estados citados lideram no Brasil o volume de exportações desses produtos através da integração das relações de logística entre organizações e estados produtores, somando esses excelentes resultados.

A clareza desses fatos, impõem urgentes questionamentos de políticas e ofertas de soluções de engenharia das diversas ciências e setores, para assumirem esse grande potencial de forma sustentável. Mostra-se a seguir os produtos e setores desse universo, focando o estado do Ceará e Bahia para entendimento desses potenciais e em sequência as representações da pegada hídrica, objeto do estudo.

Figura 1 - Visão Geral dos Produtos Exportados - Estado: Ceará (2017)

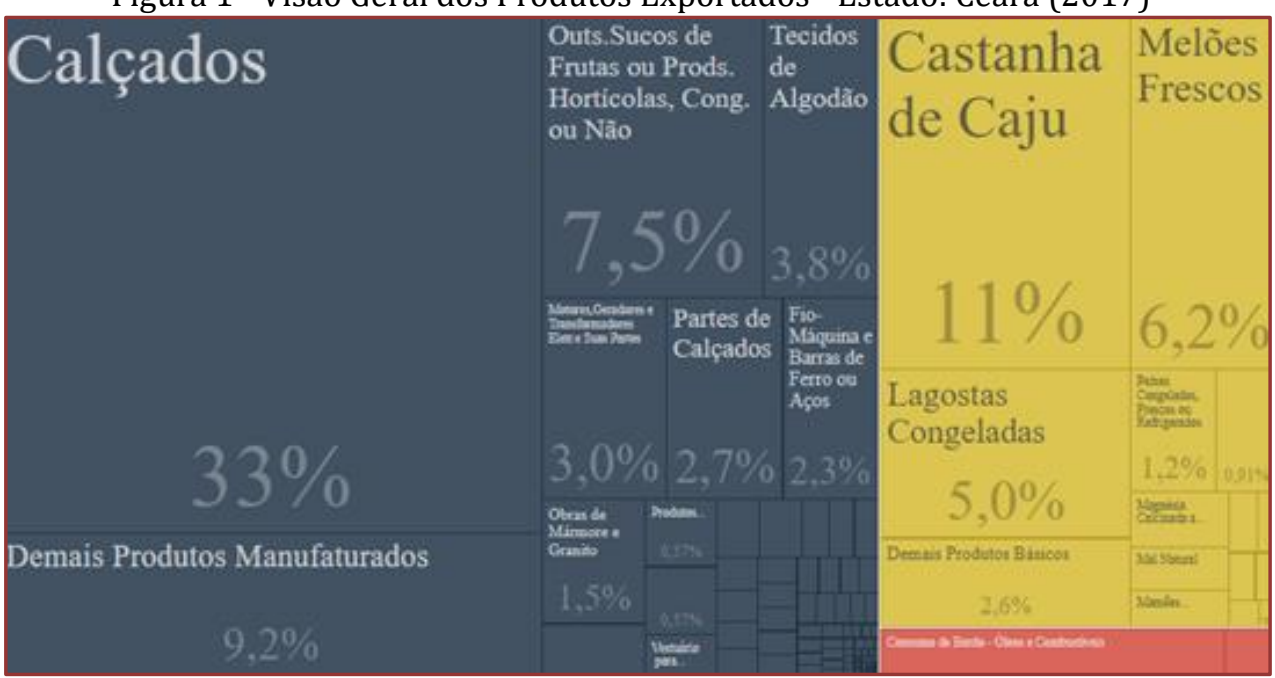

Fonte: Ministério da Indústria, Comércio Exterior e Serviços - MDIC, 2017. 
Figura 2: Visão Geral dos Produtos Exportados - Estado: Bahia (2017)

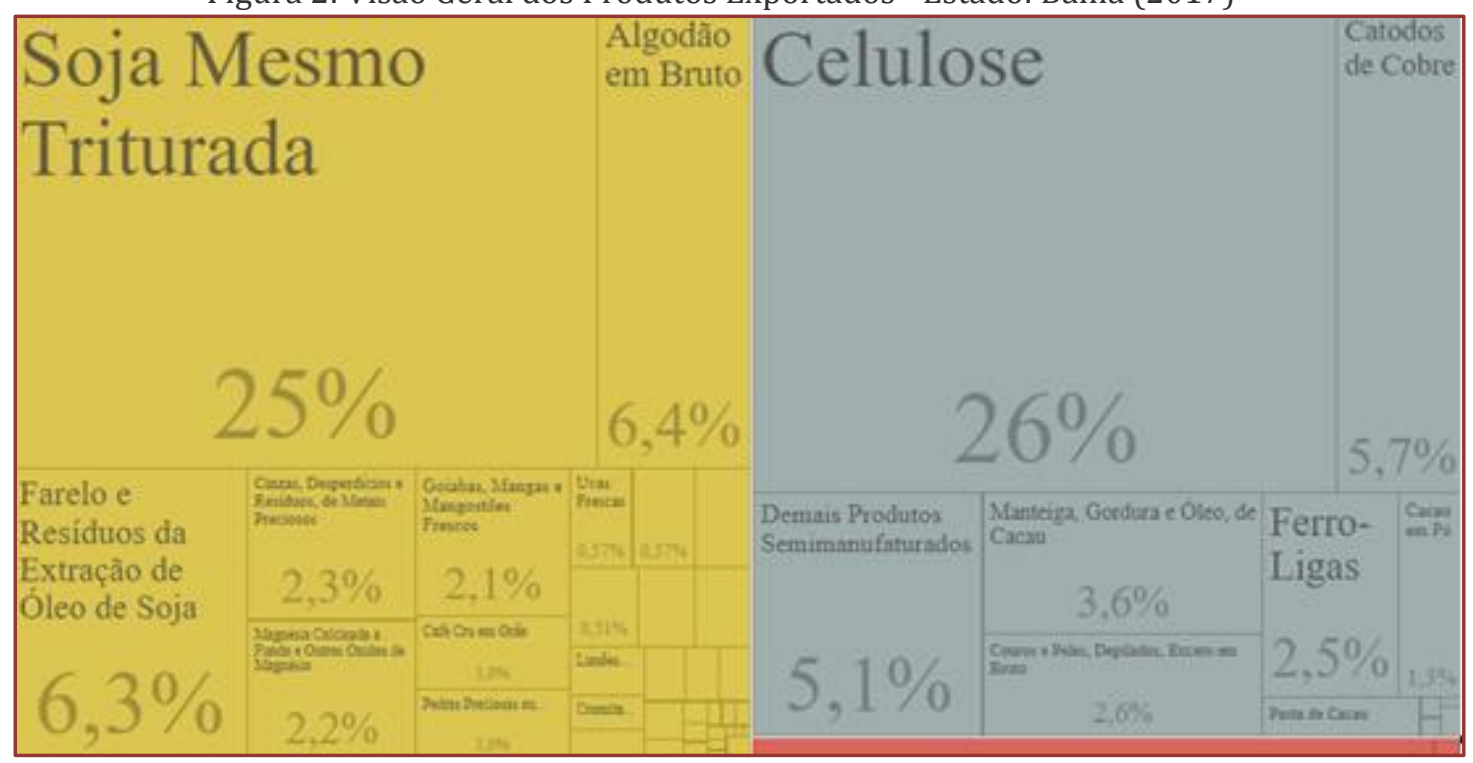

Fonte: Ministério da Indústria, Comércio Exterior e Serviços - MDIC, 2017.

Figura 3 - Pegada Hídrica de exportação dos estados do Nordeste - Brasil (2017)

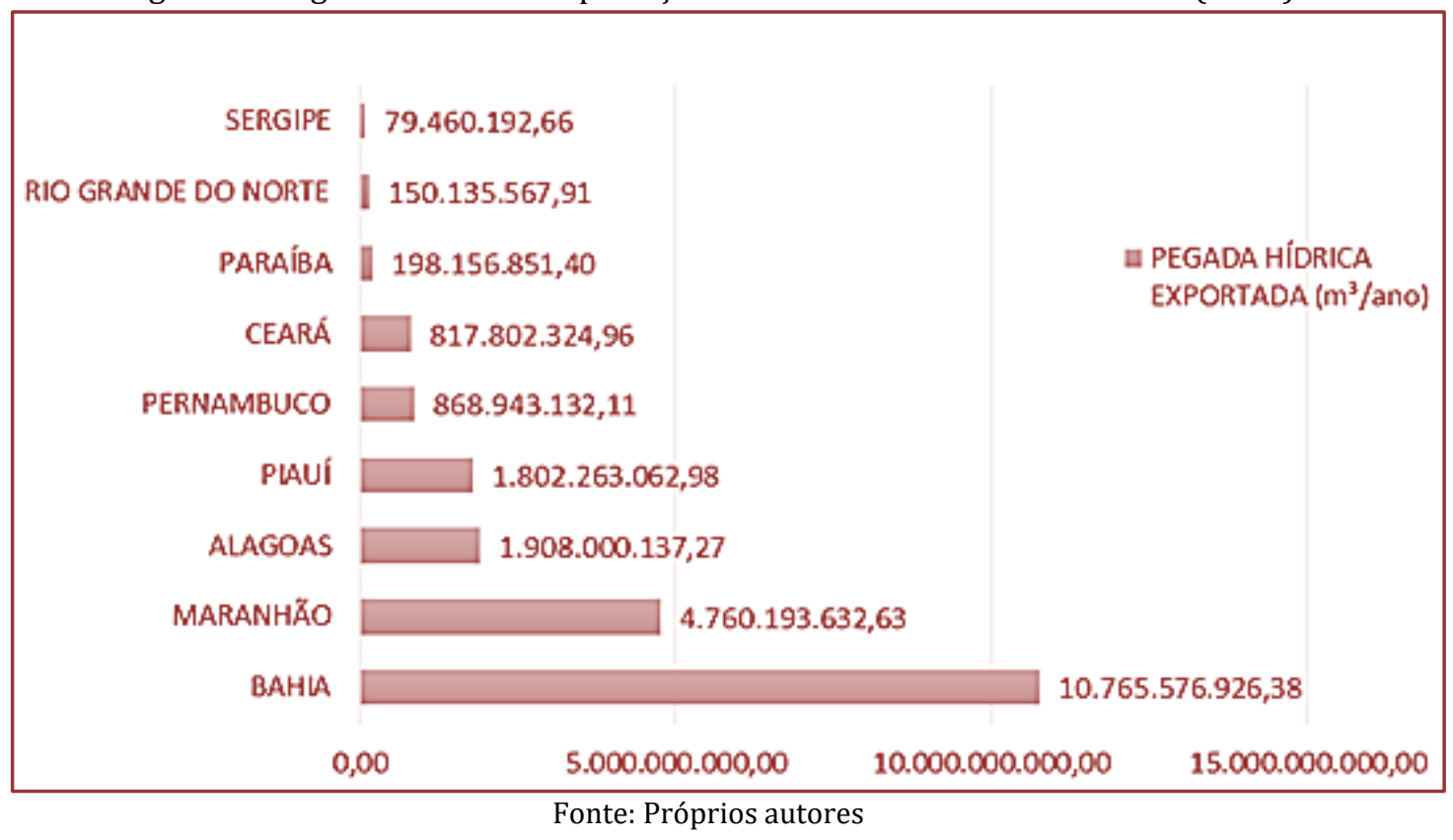

Logo após calculado a pegada hídrica exportada por estado da região nordeste, foram-se comparadas as nove pegadas hídricas de exportação com a capacidade total e atual das doze bacias hidrográficas do estado do Ceará, como mostrado na figura 4.

Os valores representam que a pegada hídrica exportada da Bahia corresponde a 57,79\% da capacidade total das 12 bacias hidrográficas do Ceará e de quase 3 vezes mais a capacidade atual dessas bacias. 0 estado do Ceará necessita apenas de 4,39\% da capacidade total desse volume para suprir a água exportada indiretamente e $25,93 \%$ da água atual desses açudes. 0 Sergipe por possuir a menor pegada hídrica de exportação corresponde apenas a 0,43\% da capacidade total e 2,52\% do volume atual das 12 bacias hidrográficas do Ceará. A escolha para comparação das pegadas hídricas de exportação com a capacidade dos 12 reservatórios do Ceará se deu devido o estado possuir a maior capacidade de água da região nordeste e ser referência na gestão dos recursos hídricos. 
Figura 4 - Comparação da Pegada Hídrica de exportação da Região Nordeste brasileira com a capacidade de reservatórios por Bacia Hidrográfica do estado do Ceará (2017)

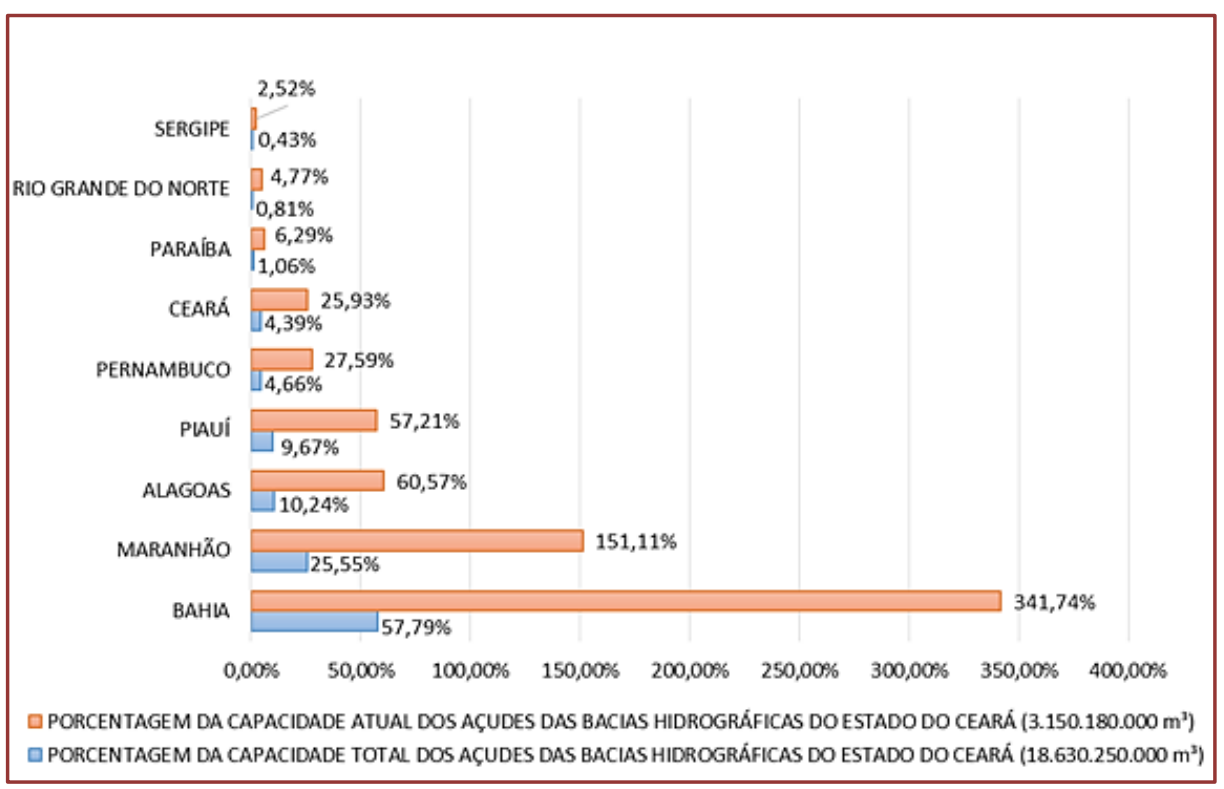

Fonte: Próprios autores

\section{CONCLUSÃO}

O estudo da pegada hídrica possui sua importância para estudo quantitativo da gestão de recursos hídricos, pois representa uma quantidade de água indireta usada na cadeia produtiva que as vezes possui um valor maior se comparado com o abastecimento humano do local em estudo. A pegada hídrica total exportada da região nordeste para outros países corresponde um valor de $21.350 .531 .828,30 \mathrm{~m}^{3} / \mathrm{ano}$, revelando a quantidade abundante de água que é exportada indiretamente desses nove estados para outros países. Quando se analisa que o estado do Ceará gasta 25,93\% da capacidade atual de água de suas bacias, pode-se concluir que o estado exporta uma quantidade expressiva de água indireta contida em seus produtos.

Deve-se, entretanto, primeiramente analisar o fator de abastecimento humano para suprir a melhor distribuição de água para atender a demanda de toda a população de forma satisfatória e correta. Se no estado do Ceará 7.948.707 habitantes ao consumir 150L/habitante dia, em um ano, consumirão 435.191.708,25 m³ /ano, isso corresponde a 13,81\% da capacidade atual dos açudes do estado do Ceará, sendo esses $13,81 \%$ exclusivamente destinado ao abastecimento humano das residências, juntamente com os 25,93\% necessários para a água indireta contida nos produtos exportados, seriam necessários 39,74\% da capacidade atual dos reservatórios para suprir o abastecimento humano e água indireta exportada, concluindo assim que o Ceará possui capacidade para suprir toda a água exportada para outros países, restando 60,26\% para o uso da água nas demais atividades e distribuição para o estado.

Isso significa que do ponto de vista da gestão dos recursos hídricos, fica nítido que o estado pode exportar esses produtos mesmo com a quantidade de água gasta na sua produção de produtos de origem agropecuária, pois não irá esgotar o volume de água que está contido nas doze bacias hidrográficas do estado.

É importante destacar que a análise parte apenas do ponto de vista da gestão dos recursos hídricos, não evidenciando a relação econômica nessa pesquisa.

\section{AGRADECIMENTOS}

Os autores agradecem ao Conselho Nacional de Desenvolvimento Científico e Tecnológico (CNPq) e a Universidade Regional do Cariri (URCA) pelo fomento e incentivo as pesquisas e produções científicas. 


\section{REFERÊNCIAS}

[1] Bowersox, Donald J. Closs, David J. Logística Empresarial. 0 processo de integração da cadeia de suprimentos. 1 a ed. São Paulo; Atlas, 2007, 594p.

[2] Companhia de Gestão dos Recursos Hídricos - Cogerh. Bacias hidrográficas, 2018. Disponível em: <https://www.cogerh.com.br/bacias-hidrografica.html>. Acesso em: 08 maio 2018.

[3] Fundação Cearense de Meteorologia e Recursos Hídricos - FUNCEME. Portal Hidrológico do Ceará Reservatórios, 2018. Disponível em: <http://www.hidro.ce.gov.br/>. Acesso em: 08 maio 2018.

[4] Galli, A.; Wiedmann, T.; Ercin, E.; Knoblauch, D.; Ewing, B.; Giljum, S. Integrating Ecological, Carbon and Water footprint into a "Footprint Family" of indicators: Definition and role in tracking human pressure on the planet. Ecological Indicators, v.16, p.100-112, 2012.

[5] Hoekstra, Arjen Y.; Chapagain, Ashok; Aldaya, Maite M.; Mekonnen, Mesfin Mergia. Manual de Avaliação da Pegada Hídrica: Estabelecendo o Padrão Global. Earthscan, p. 216, 2011.

[6] Hoekstra, A. Y. e Chapagain, A. K. Globalização da Água: Compartilhando os Recursos de Água Doce do Planeta, Blackwell Publishing, Oxford, 2008.

[7] Mekonnen, Mesfin Mergia; Hoekstra, Arjen Y. The green, blue and grey water footprint of crops and derived crop products. Hydrology and Earth System Sciences, v. 15, n. 5, p. 1577-1600, 2011.

[8] Ministério da Indústria, Comércio Exterior e Serviç os - MDIC. Comex Vis: Visualizações de Comércio Exterior, 2017. Disponível em: <http://www.mdic.gov.br/comercio-exterior/estatisticas-de-comercio-exterior/comex-vis>. Acesso em: 08 maio 2018.

[9] WWAP (World Water Assessment Programme) (2009) The United Nations World Water Development Report 3: Water in a Changing World, WWAP, UNESCO Publishing, Paris, and Earthscan, London WWF (2008) Living Planet Report 2008, WWF International, Gland, Switzerland. 


\section{Capítulo 16}

\section{Análise da influência da roteirização de veículos na performance térmica da distribuição de produtos da cadeia do frio}

\section{Gabriel Alexandre Müller}

Vanina Macowski Durski Silva

\section{Diogo Lôndero da Silva}

Resumo: Para manter a qualidade de produtos perecíveis como frutas, carnes e verduras, há necessidade de mantê-los sob condições específicas de temperatura e umidade, não somente durante a armazenagem, como também durante seu transporte desde os poontos de produção até o seu consumo final. Essas condições devem ser implementadas e monitoradas para que não haja deterioração e perda de qualidade do produto adquirido pelo consumidor. Este conjunto de produtos, que requerem controle térmico, são componentes de estudo da Cadeia do Frio, a qual preocupa-se também em analisar os principais fatores envolvidos na distribuiçãofísica dos mesmos, desde equipamentos e veículos utilizados até o modo de roteirização empregado na distribuição dos produtos. Assim, neste artigo maior no manuseio das mercadorias em estoque e transporte. Sendo assim, neste artigo será proposto um modelomatemático que considere o comportamento térmico de produtos refrigerados durante a distribuição física dos mesmos. Implementado computacionalmente o modelo, espera-se estudar rotas eficientes, evitando o ganho acumulado de calor, consequentemente diminuindo a temperatura adquirida pelo produto no decorrer da realização da rota de distribuição dos produtos.

Palavras Chave: Cadeia do frio, logística, distribuição física, simulação, performance térmica 


\section{INTRODUÇÃO}

O termo cadeia do frio tem sido utilizado para denominar os processos e elos de produção e logística de produtos refrigerados, com o objetivo de conservar e evitar o seu desperdício. 0 objetivo da cadeia do frio, conforme definida por Heap (2006), IIR (2004) e, Likar e Jevsnik (2006), compreende o controle da temperatura do produto em todas as fases de transporte e estocagem, até a entrega ao cliente final. Quando o produto alcança uma determinada temperatura acima de seu limite superior pode sofrer diminuição de sua qualidade final, ocasionando sua rejeição. Porém, temperaturas abaixo do limite inferior suportado pelo produto também podem prejudicar suas características iniciais, cobrando uma complexidade logística maior no manuseio das mercadorias em estoque e transporte.

Sendo assim, neste artigo será proposto um modelo matemático que considere o comportamento térmico de produtos refrigerados durante a distribuição física dos mesmos. Implementado computacionalmente o modelo, espera-se estudar rotas eficientes, evitando o ganho acumulado de calor, consequentemente diminuindo a temperatura adquirida pelo produto no decorrer da realização da rota de distribuição dos produtos.

\section{REFERENCIAL TEÓRICO}

No processo de entrega de produtos da cadeia do frio (resfriados, refrigerados e congelados), existem comportamentos operacionais praticados pelas indústrias e varejos que devem ser seguidos para melhor monitoramento das etapas críticas da cadeia do frio, tais como: a entrega e o recebimento da mercadoria com pontualidade, e o respeito do colaborador com as normas de manuseio da carga e sistema de refrigeração, evitar da porta de isolamento do veículo se manter aberta excessivamente sem devidos cuidados do operador, para tornar todo o processo mais eficiente. Na etapa de carregamento da mercadoria no veículo refrigerado tem-se que o produto já deve estar com sua temperatura definida anteriormente, pois o modal de transporte não é projetado para resfriá-la, mas sim, para manter a mercadoria dentro dos limites térmicos (Estrada-Flores e Eddy, 2006; Pereira et al., 2010).

Carvalho (2013) adapta o modelo de Hoang et al. (2012), para ser aplicado a um sistema de roteirização dinâmico com possíveis alterações de rota no decorrer das entregas. A capacidade de isolamento do baú do caminhão diminui com o tempo percorrido e a temperatura interna do veículo de cargas não é apenas influenciada pela troca de calor por suas paredes, mas também pela abertura de portas na operação de carga e descarga. Tem-se também que a variabilidade da temperatura da carga se correlaciona com o tempo requerido para a unidade de transporte recuperar o controle de temperatura após a abertura de portas, e a diferença entre o valor térmico máximo e mínimo atingido durante a etapa de carga e descarga (Estrada-Flores e Eddy, 2006; Hoang et al., 2012). Portanto, a abordagem de Carvalho (2013) para controle constante da temperatura da rota durante a entrega, tem como objetivo evitar o aumento térmico acumulado na carga, planejando e atualizando a rota ideal em cada processo de carga e descarga. Tal modelo será analisado posteriormente.

\subsection{PROBLEMA DE ROTEIRIZAÇÃO DE VEÍCULOS}

A distribuição física de produtos é definida por ballou (2006) como sendo uma atividade que tem por objetivo encontrar uma ou mais rotas ótimas designadas a veículos que farão a entrega dos produtos na literatura pode-se encontrar diversos modelos existentes de roteirização, destacando-se o problema do caixeiro viajante (pcv), cujo objetivo é encontrar a menor rota possível dado um conjunto de nós (clientes) a ser atendidos. (cunha, 2000). Apesar de ignorar uma- gama de variáveis e restrições encontradas em problemas reais, é considerado um problema do tipo np-hard, quanto à complexidade computacional, e não havendo ainda um método exato para resolução de problemas de grande porte em tempo razoável, é comum a prática de métodos heurísticos em sua resolução.

Um método heurístico que é utilizado para resolver o tsp é o "método do vizinho mais próximo", que segundo cunha et al. (2002) considera o seguinte: um veículo inicia sua trajetória de viagem em um ponto qualquer do grafo e então segue para um ponto que esteja mais próximo; a partir deste, busca-se outro ponto mais próximo ainda não visitado e assim sucessivamente até que todos os pontos sejam visitados, retornando então para o ponto de origem. Tal método será utilizado no modelo aqui proposto. 


\section{MATERIAIS E MÉTODOS}

\subsection{ROTEIRIZAÇÃO DE VEÍCULO REFRIGERADO JUNTO À OTIMIZAÇÃO LOGÍSTICA}

Ao realizar a modelagem matemática do problema de roteirização de produtos refrigerados, objetiva-se impedir que os limites máximos e mínimos de temperatura do produto transportado sejam violados, e assim, verifica-se se a rota estipulada para realizar a distribuição dos produtos pode gerar prejuízos aos produtos quanto ao aumento térmico não esperado e, então analisam-se novas rotas. A Figura 1 ilustra dados de tempo e temperatura em uma rota de um caminhão de entrega, onde pode-se verificar a relação do acúmulo de temperatura do produto e a relação das temperaturas iniciais e finais do processo de entrega.

Figura 1 - Comportamento técnico do veículo em relação ao roteiro de entrega

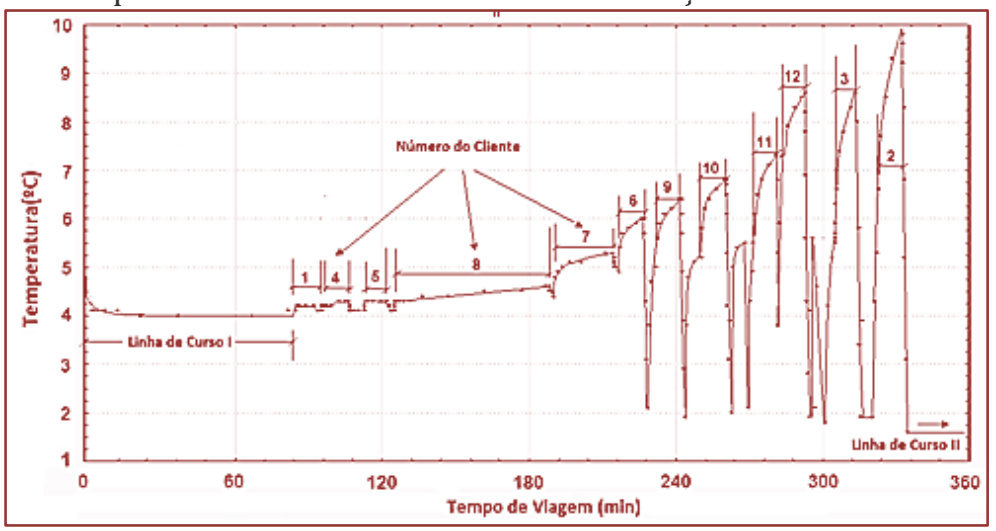

Fonte: Carvalho (2013)

\subsection{MODELAGEM MATEMÁTICA DE COMPORTAMENTO TÉRMICO DE PRODUTOS}

Carvalho (2013) propôs três modelos matemáticos termodinâmicos, cada um responsável por uma etapa da rota durante a execução da distribuição de produtos da cadeia do frio. Considere um ponto de origem (P0), de onde parte o veículo que fará entregas de produtos refrigerados e, 5 pontos adicionais (P1 até $\mathrm{P} 5)$, considerados como pontos de entregas. 0 veículo parte da origem (PO), desloca-se até o primeiro cliente (P1), realiza a descarga planejada, segue viagem até o ponto subsequente definido pela rota planejada, realiza nova entrega, e assim sucessivamente, até que por fim, entrega toda a carga existente em seu interior, retornando vazio ao ponto de origem (PO) da rota. Verifique a Figura 2, onde LDC1 e LDC2 são, respectivamente, Linhas de Curso 1 e 2.

Figura 2 - Estrutura da Modelagem de Entrega

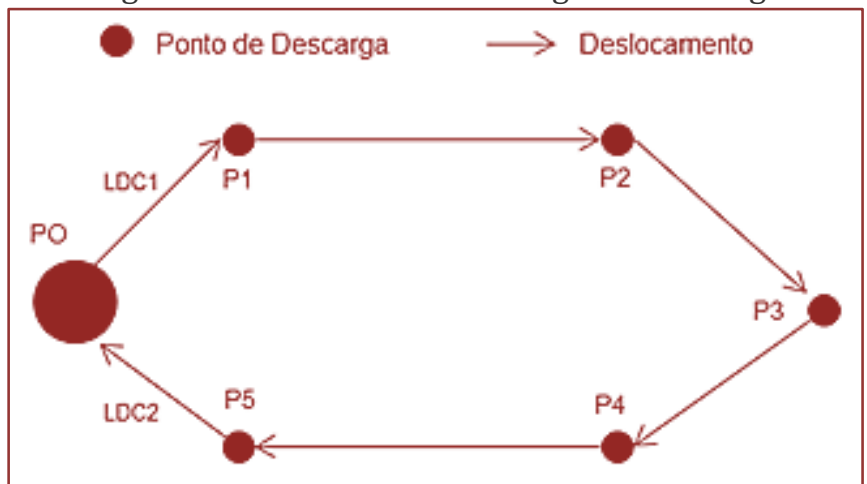

Fonte: Autores, baseado em Carvalho (2013) 
A primeira etapa do percurso de distribuição de produtos trata da "etapa das linhas de curso", Linhas de Curso I e II, que são responsáveis por calcular a temperatura interna do veículo desde o ponto de origem (PO) até o primeiro ponto de entrega (P1), LDC1, e do último cliente visitado retornando ao ponto de origem (PO), LDC2. Assim, tem-se a equação:

$$
\theta(j)=\theta_{j-1} \exp \left(\frac{\beta \cdot d t_{j-1, j}}{m}\right)
$$

Sendo $\theta(j)$ a temperatura do ar $\left({ }^{\circ} \mathrm{C}\right)$ no ponto j, $\theta_{j-1}$ é a temperatura inicial do produto no momento de saída (uniforme), m é a razão de massa total contida no veículo ( $\mathrm{kg}$ ), $d t$ é o intervalo de tempo (min), $\beta$ é o coeficiente de calibração dos dados.

Assim que a unidade de transporte chega em um ponto de entrega, a "etapa de descarga" se inicia. Ocorre a abertura das portas do veículo para acesso à carga. Enquanto o operador realiza a função desta etapa há uma troca de calor do ar externo com o interno durante todo o processo, comportamento este expresso pela equação de descarga:

$$
\theta(\tau)=\alpha_{1} \cdot \theta_{0} \cdot \theta_{\text {ext }}^{\alpha_{2}} \cdot \exp \left(\beta_{\text {unl }} \cdot \frac{\tau}{Q_{i}}\right)
$$

Sendo $\tau$ o tempo em minutos, $\theta_{\text {ext }}$ a temperatura externa ao ambiente, tem-se que esta temperatura não muda significativamente no decorrer do processo de entrega, faz-se uma média do valor medido no início com o final da etapa. Os coeficientes $\alpha_{1}, \alpha$ e $\beta_{\text {unl }}$ foram ajustados através da regressão dos dados adquiridos por Carvalho (2013) com o simulador CoolVan (verificar Tabela 1). 0 valor de $Q_{i}$ é constante, sendo uma fração da carga total obtida através da média aritmética das frações de carga inicial e final do processo de descarga.

Tabela 1 --_Coeficientes do Modelo de Entrega

\begin{tabular}{|cl|}
\hline Coeficientes & Valor \\
\hline$\alpha_{1}$ & 0,3234 \\
$\alpha_{2}$ & 0,4517 \\
$\beta_{u n l}$ & 0,00081 \\
\hline
\end{tabular}

Fonte: Autores

A terceira e última etapa do processo trata da "etapa do deslocamento" entre os pontos de entrega da rota. Quanto mais tempo a unidade de transporte percorrer entre os pontos de entrega, mais próxima do limite de temperatura inferior a carga estará. A equação (3) representa o modelo matemático que simula esta etapa do processo.

$$
\theta_{t v l}=\alpha_{1} \cdot \theta_{0} \cdot \tau^{\alpha_{2}} \cdot Q_{i B}^{\alpha_{3}}
$$

Sendo $\theta_{t v l}$ a temperatura do veículo quando ele chega ao próximo cliente, $\tau$ é o tempo do trecho entre o cliente $i$ e $i+1, Q_{i}$ é a razão de massa total dentro do veículo; $\alpha_{1}, \alpha_{2}$ e $\alpha_{3}$ são os coeficientes que foram ajustados para estarem próximos dos resultados térmicos obtidos pelo simulador, os quais se encontram na Tabela 2. 
Tabela 2 - Coeficientes do Modelo de Deslocamento

\begin{tabular}{|cc|}
\hline Coeficientes & Valor \\
\hline$\alpha_{1}$ & 1,094 \\
$\alpha_{2}$ & $-0,0745$ \\
$\alpha_{3}$ & 0,1016 \\
\hline
\end{tabular}

Fonte: Autores

\subsection{MODELAGEM MATEMÁTICA DA DISTRIBUIÇÃO DE PRODUTOS DA CADEIA DO FRIO}

Após o estudo dos modelos de Carvalho (2013), os mesmos foram implementados em Matlab® (R2013a) no intuito de utilizá-los para possíveis aplicações reais. Para realização desta etapa foram estabelecidos cinco pontos de entrega (aqui considerados como clientes, numerados de 2 a 6) contendo dados de tempo de carga e de descarga, uma matriz de tempo de viagem entre um ponto $i$ (cliente) para todos os outros pontos (considerando o ponto de origem como sendo o ponto 1) e a razão de massa entregue nestes pontos. Os dados podem ser verificados na Tabela 3, juntamente com a matriz de tempo, na Tabela 4.

Tabela 3 - Dados Utilizados

\begin{tabular}{|c|c|c|}
\hline Pontos & $\begin{array}{c}\text { Tempo de Descarga } \\
\text { (min) }\end{array}$ & Massa (\%) \\
\hline 2 & 20 & 15 \\
\hline 3 & 35 & 30 \\
\hline 4 & 20 & 15 \\
\hline 5 & 10 & 10 \\
\hline 6 & 25 & 30 \\
\hline
\end{tabular}

Fonte: Autores

Tabela 4 - Matriz de Tempos

\begin{tabular}{|c|c|c|c|c|c|c|}
\hline O/D & 1 & 2 & 3 & 4 & 5 & 6 \\
\hline 1 & 0 & 8,4 & 10,2 & 15 & 18 & 16 \\
\hline 2 & 8,4 & 0 & $4,, 8$ & 10 & 15 & 29 \\
\hline 3 & 10,2 & 4,8 & 0 & 6,1 & 3,9 & 32 \\
\hline 4 & 15 & 10 & 6,1 & 0 & 4,3 & 27 \\
\hline 5 & 18 & 15 & 3,9 & 4,3 & 0 & 24 \\
\hline 6 & 16 & 29 & 32 & 27 & 24 & 0 \\
\hline
\end{tabular}

Na matriz de tempos, tem-se que o valor de $a_{i j}$ representa o tempo (em minutos) que o veículo leva para percorrer entre o ponto $i$ até o ponto $j$.

\subsection{MODELAGEM MATEMÁTICA DOS CUSTOS DE REFRIGERAÇÃO X ROTAS}

Para poder realizar o estudo das rotas de distribuição considerando a performance térmica dos produtos foram estabelecidos valores de consumo de combustível conforme distância e tempo percorridos entre os pontos de entrega e, algumas premissas adotadas: o sistema de refrigeração é responsável por cerca de $20 \%$ do consumo total e, durante o processo de descarga o veículo juntamente com seus equipamentos estarão desligados. Para estudo inicial, considerou-se a velocidade do veículo como constante de (50 $\mathrm{km} / \mathrm{h}$ ) em todo o processo de entrega. Para o cálculo do custo total do trajeto, considerou-se a seguinte equação:

$$
\text { P.C.V. } \tau=\$
$$


Onde P representa o preço do combustível ( 3 \$/litro), C representa o consumo do veículo $(0,2$ litro/ $\mathrm{km}), \mathrm{V}$ trata da velocidade média do veículo $(0,83 \mathrm{~km} / \mathrm{min})$, $\tau$ é o tempo do deslocamento total em minutos e \$ representa o custo total em unidades monetárias. Os valores dessas constantes foram definidos pelos autores para fins de análise. Para fins de análise da geração de rotas, foi considerado e implementado o algoritmo da heurística do vizinho mais próximo desenvolvido por Moresco e Silva (2017).

\section{RESULTADOS E DISCUSSÃO}

Após o estudo dos modelos de Carvalho (2013) e Moresco e Silva (2017), os mesmos foram implementados em um modelo de simulação. Os valores contidos na Gráfico 1 foram gerados pela simulação através de dados pré-definidos, tendo como rota os pontos $\mathrm{PO} \rightarrow 1 \rightarrow 2 \rightarrow 3 \rightarrow 4 \rightarrow 5 \rightarrow \mathrm{PO}$, podendo perceber uma quebra de continuidade do resultado das temperaturas (obtidas pela implementação das equações) na transição da etapa de descarga com o processo de deslocamento e vice-versa, conforme destacado.

Gráfico 1 - Comportamento da variação de temperatura x tempo (modelo de Carvalho, 2013)

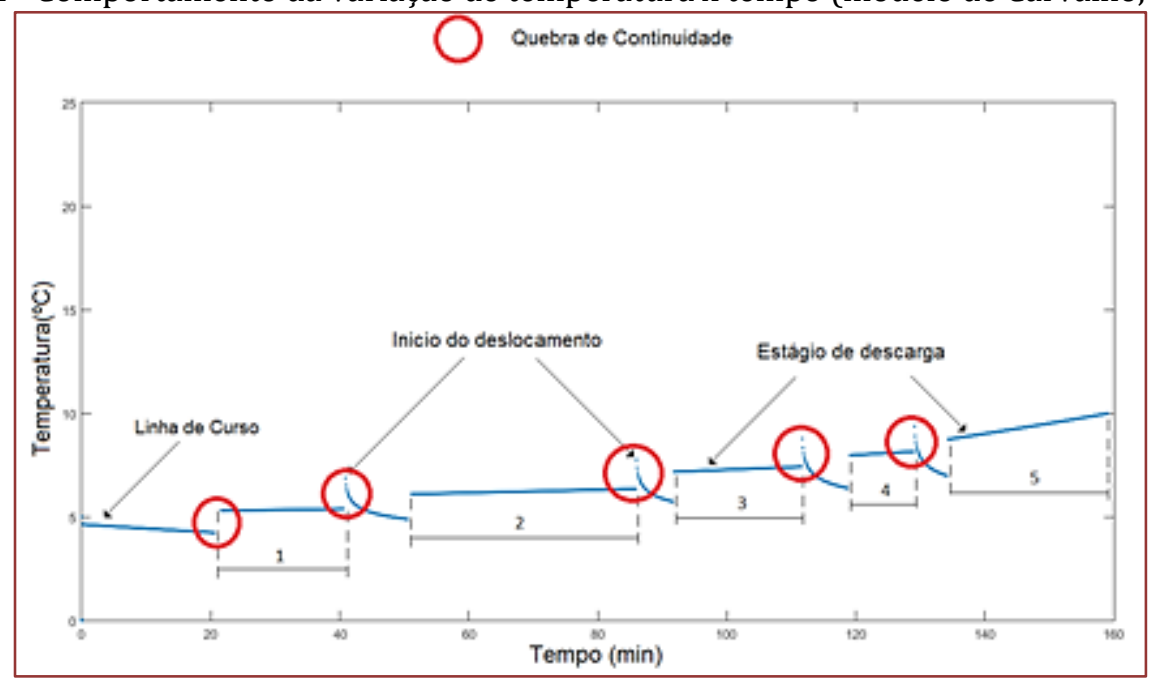

Fonte: Autores

Esse fenômeno de quebra de continuidade ocorre quando as equações de deslocamento e descarga não respeitam as condições necessárias de continuidade, neste caso, quando o tempo da equação for $\tau=0$, a temperatura do modelo deve igualar-se a temperatura inicial fornecida, $\theta(0)=\theta_{0}$.

\subsection{ANÁLISE DA EQUAÇÃO DE DESCARGA}

Considerando a equação (3) e aplicando $\tau=0$ para verificar a condição de continuidade onde $\theta(0)=\theta_{0}$ tem-se:

$$
\theta(\tau)=\alpha_{1} \cdot \theta_{0} \cdot \theta_{\text {ext }}^{\alpha_{2}}
$$

Se espera que a temperatura do modelo $\theta(j)$ seja igual à temperatura inicial $\left(\theta_{0}\right)$. Percebe-se que para tal condição ser verdadeira os valores que multiplicam $\theta_{0}$ devem ser igual a 1 , ou seja, $\alpha_{1} \cdot \theta_{\text {ext }}^{\alpha_{2-}}=1$, situação que não condiz com a realidade do modelo, pois os valores de $\alpha_{1}$ e $\theta_{\text {ext }}$ são constantes no estudo e diferentes de 1. Portanto, pode-se afirmar que o modelo de descarga, apresentado por Carvalho (2013) não respeita a condição de continuidade, responsável por manter as temperaturas contínuas no decorrer da simulação. Se esta condição for violada tem-se valores de temperatura que resultam em saltos, um comportamento não real em situações normais de distribuição de produtos. 


\subsection{ANÁLISE DA EQUAÇÃO DE DESLOCAMENTO}

Da mesma forma que no estudo anterior, aplicando $\tau=0$ na equação (4) encontra-se:

$$
\theta_{t v l}=0
$$

Portanto, pode-se perceber que há uma quebra na continuidade da equação de deslocamento por conta do resultado obtido na equação (8), pois em toda e qualquer temperatura inicial $\theta_{0_{-}}$dada, quando o tempo for $\tau=0$, ter-se-á obtido o resultado $\theta_{t v l}=0$, valor não condizente com a realidade, pois no tempo nulo a temperatura deve estar inalterada. Assim, o valor esperado para o modelo nestas condições está apresentado na equação (7), representando a temperatura inicial do sistema, pois se o tempo é nulo, significa que ainda não houve alterações na temperatura do produto.

$$
\theta_{t v l}=\theta_{0}
$$

\subsection{Proposta de um Modelo Matemático Para Análise da Performance Térmica da Carga}

Por conta do problema de quebra de continuidade analisado anteriormente, e como forma de contribuição para o estado da arte sobre este tema de estudo, propôs-se para este trabalho um novo modelo para substituir as equações (3) e (4); buscando manter a continuidade do comportamento térmico da carga durante todo o processo de descarga e deslocamento, onde:

$$
\begin{gathered}
\tau \equiv \text { Tempo (min) } \\
\theta_{0} \equiv \text { Temperatura inicial }\left({ }^{\circ} \mathrm{C}\right) \\
m \equiv \text { Massa no caminhão }(\%) \\
\beta \equiv \text { Coeficiente térmico do produto } \\
\theta(\tau) \equiv \text { Temperatura no tempo } \tau\left({ }^{\circ} \mathrm{C}\right) \\
\theta_{\text {fonte }} \equiv \text { Temperatura do ambiente externo }\left({ }^{\circ} \mathrm{C}\right) \\
\theta(\tau)=\theta_{\text {fonte }}+\left(\theta_{0}-\theta_{\text {fonte }}\right) \cdot \exp \left(\beta \cdot \frac{\tau}{m}\right)
\end{gathered}
$$

Onde $\theta(\tau)$ representa a temperatura $\left({ }^{\circ} \mathrm{C}\right)$ do produto no tempo $\tau(\mathrm{min}), \theta_{0}$ é a temperatura inicial do produto, $\mathrm{m}$ é a razão de massa de produto contida no caminhão, $\beta$ é o coeficiente de variação de temperatura, o qual será discutido adiante, e $\theta_{\text {fonte }}$ representa a temperatura que o sistema exerce sobre o produto, assumindo os valores $4^{\circ} \mathrm{C}$ quando no estado de deslocamento entre pontos e $20^{\circ} \mathrm{C}$ quando está sendo realizada uma entrega. Tais valores foram definidos pelos autores para estudo do comportamento do modelo. Assim, obteve-se um novo comportamento para a variação de temperatura no produto (Gráfico 2).

Nestas condições, tem-se um comportamento contínuo em todo o percurso de entrega, onde os trechos com aumento de temperatura representam os momentos em que ocorre a descarga do produto em determinado ponto/cliente; já onde há declínio da temperatura ocorre o deslocamento do veículo entre pontos de entrega de produtos. A taxa de crescimento ou decrescimento térmico da carga é dada pelo coeficiente $\beta$ do modelo, que representa o comportamento da temperatura do produto com o ambiente, e assim, quanto menor o seu valor mais lentamente será o ganho ou perda de temperatura e vice-versa. 


\section{Gráfico 2 - Comportamento da variação de temperatura x tempo (modelo proposto)}

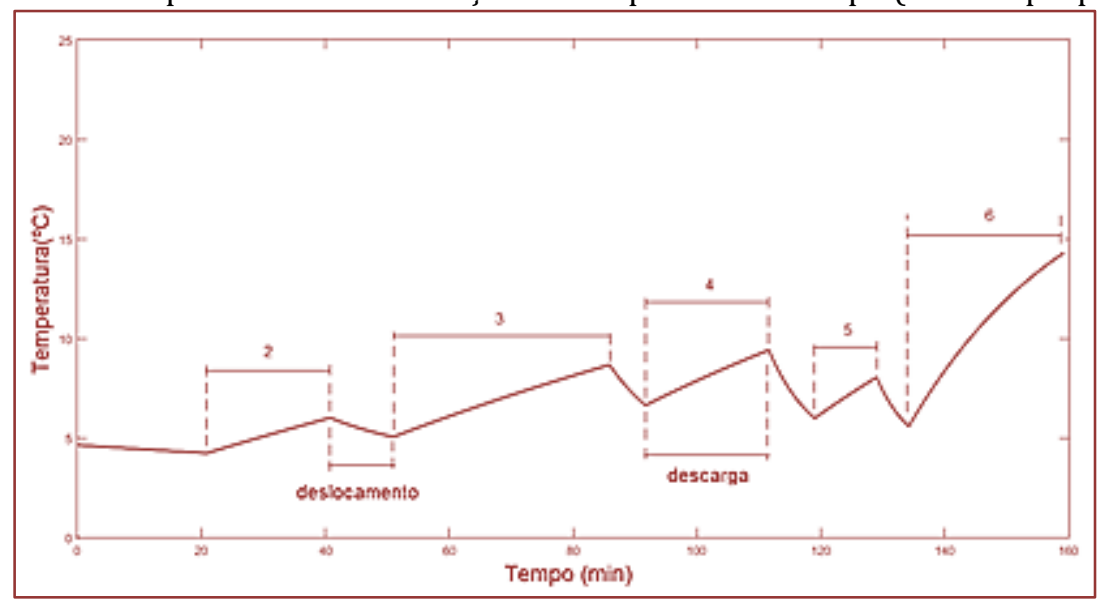

Fonte: Autores (2018)

\subsection{ANÁLISE DA ROTEIRIZAÇÃO DO VEÍCULO}

Ajustada a questão e continuidade do comportamento térmico, pôde-se realizar a análise térmica da carga refrigerada no decorrer de uma rota de distribuição física. Após a obtenção de uma rota, inicia-se um processo de simulação, através do qual se realiza a análise da temperatura do produto no decorrer do tempo. Após a implementação do modelo matemático proposto e análise do Gráfico 2, desenvolveu-se o algoritmo "Controle", capaz de buscar uma possível rota que mantenha a temperatura do produto abaixo do limite térmico estabelecido. Ver Figura 3 onde pode-se perceber que o processo da heurística de roteirização (para o PCV) e a Simulação são parte de sua estrutura (Linhas 4, 5, 18, 20).

Figura 3 - Algoritmo de Controle

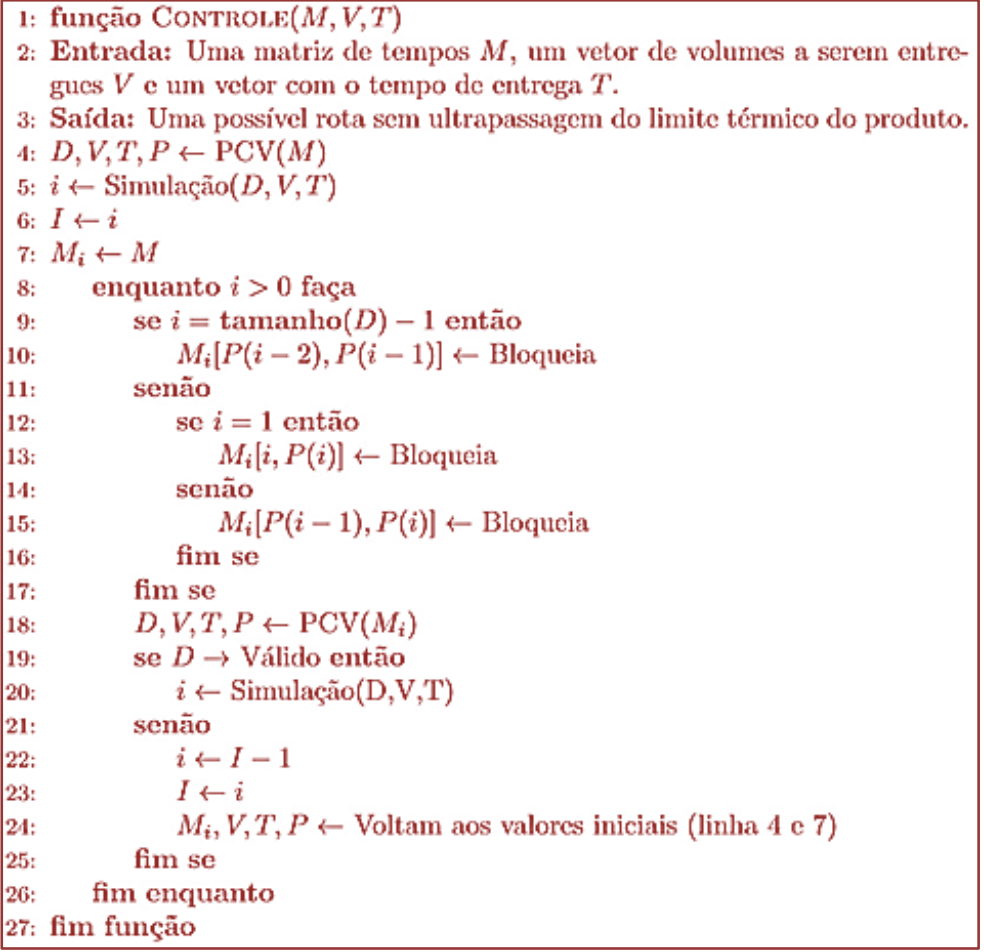

Fonte: Autores

\subsection{ANÁLISE DOS RESULTADOS DA ROTEIRIZAÇÃO X ALGORITMO}

Para fins de simulação e análise dos resultados do modelo proposto, utilizou-se os dados das Tabelas 3 e 4 , e o limite de temperatura máxima foi estabelecido como $10^{\circ} \mathrm{C}$ para fins de análise. 
Tabela 5 - Resultados

\begin{tabular}{|c|c|c|c|}
\hline Rota & Custo $(\mathrm{R} \$)$ & Temp. Final $\left({ }^{\circ} \mathrm{C}\right)$ & Caminho \\
\hline 1 & 21 & 10,4 & 23546 \\
\hline 2 & 30,7 & 11,8 & 23564 \\
\hline 3 & 22,1 & 10,2 & 23456 \\
\hline 4 & 33,4 & 10,3 & 23465 \\
\hline 5 & 26,1 & 9,8 & 24536 \\
\hline \multicolumn{4}{|c|}{ Fonte: Autores } \\
\hline \multicolumn{3}{|c|}{}
\end{tabular}

A primeira rota resultante, rota 1 da Figura 4 1(2-3-5-4-6)1, com custo total calculado pela equação (6) de $\$ 21$ (sendo $\$ 4,2$ o custo representado pelo sistema de refrigeração, que é responsável por $20 \%$ do consumo de combustível do veículo) e o abuso de temperatura ocorre na entrega no ponto 6, alcançando $10,42^{\circ} \mathrm{C}$. A justificativa para este abuso consiste na forma que a temperatura é acumulada durante 0 processo de entrega, e assim, o produto é entregue de maneira ineficiente, tendo em vista a temperatura como variável de maior importância. Portanto, na descarga do último ponto o abuso é uma consequência das etapas anteriores.

Figura 4 - Rota 1

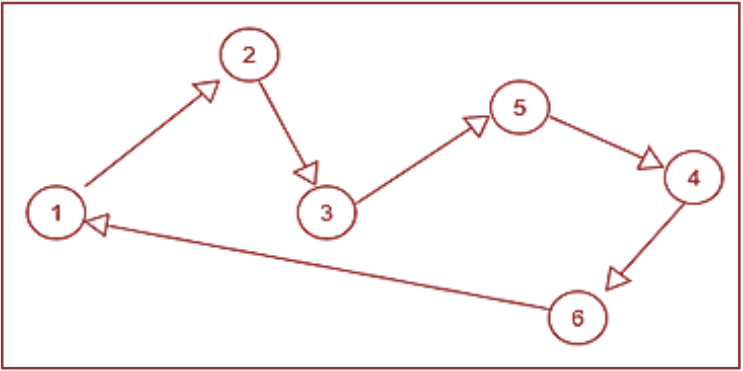

Fonte: Autores (2018)

A Figura 5 apresenta os resultados obtidos através da análise térmica da rota 1, sendo que o gráfico superior apresenta o comportamento da temperatura ao decorrer do tempo e o inferior apresenta as curvas de custos, sendo a superior referente ao custo total de transporte e a inferior, referente ao custo da refrigeração.

Figura 5 - Resultados da Rota 1
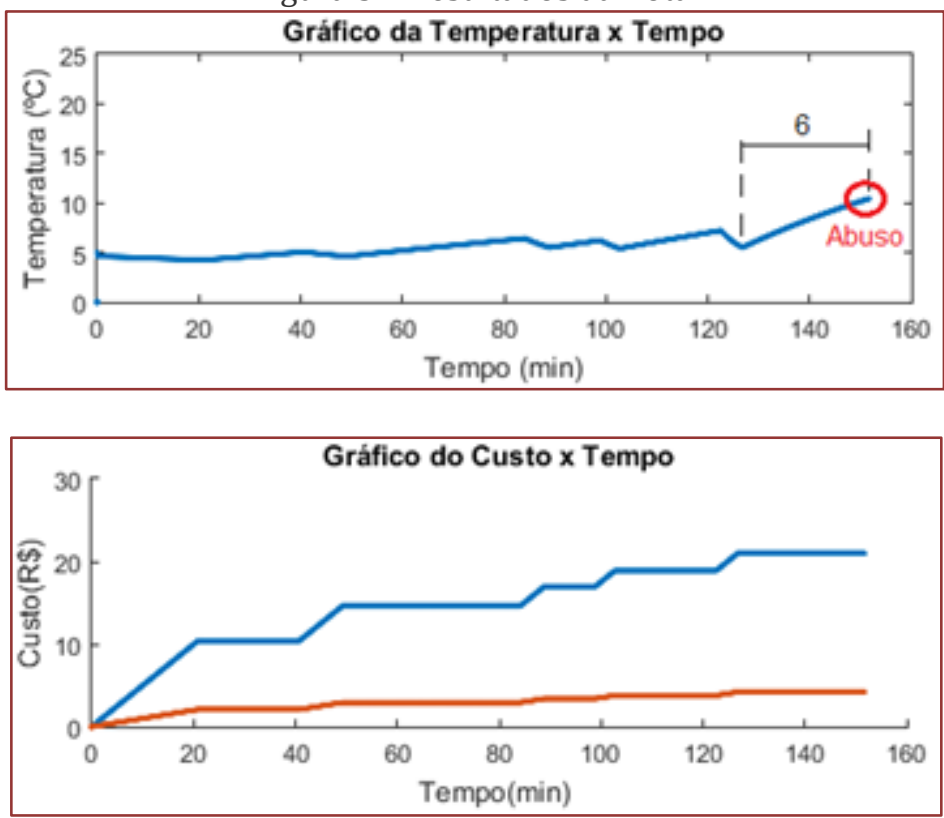

Fonte: Autores 
0 resultado final do algoritmo (rota 6) teve um custo total de $\$ 26$ (com $\$ 5,23$ através do sistema de refrigeração) alcançando uma temperatura final de $9,89^{\circ} \mathrm{C}$, que está abaixo do limite estabelecido $\left(10^{\circ}{ }_{-} \mathrm{C}\right)$, logo, demonstra que um resultado satisfatório foi atingido. A rota obtida é 1(2-4-5-3-6), apresentada na Figura 6 e, seus dados de custo e temperatura são apresentados na Figura 7. Da mesma forma como foi analisado o resultado da rota 1, pode-se estender a explicação para o resultado desta rota 6 . Em caso de | ineficiência operacional, -pode acontecer o acúmulo de temperatura em algum ponto da rota. A referida rota permitiu encontrar uma sequência de pontos de entrega que diminuiu o acúmulo ganho de temperatura, fazendo com que a distância de deslocamento entre alguns pontos fosse aumentada, e desta forma, o sistema de refrigeração pôde trabalhar por mais tempo mantendo o controle da temperatura.

Figura 6 - Rota 6, sem abuso de temperatura

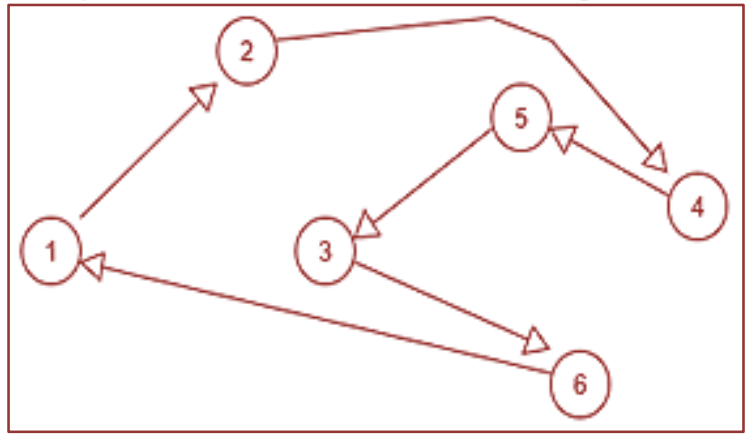

Fonte: Autores (2018)

Figura 7 - Resultados da Rota 6
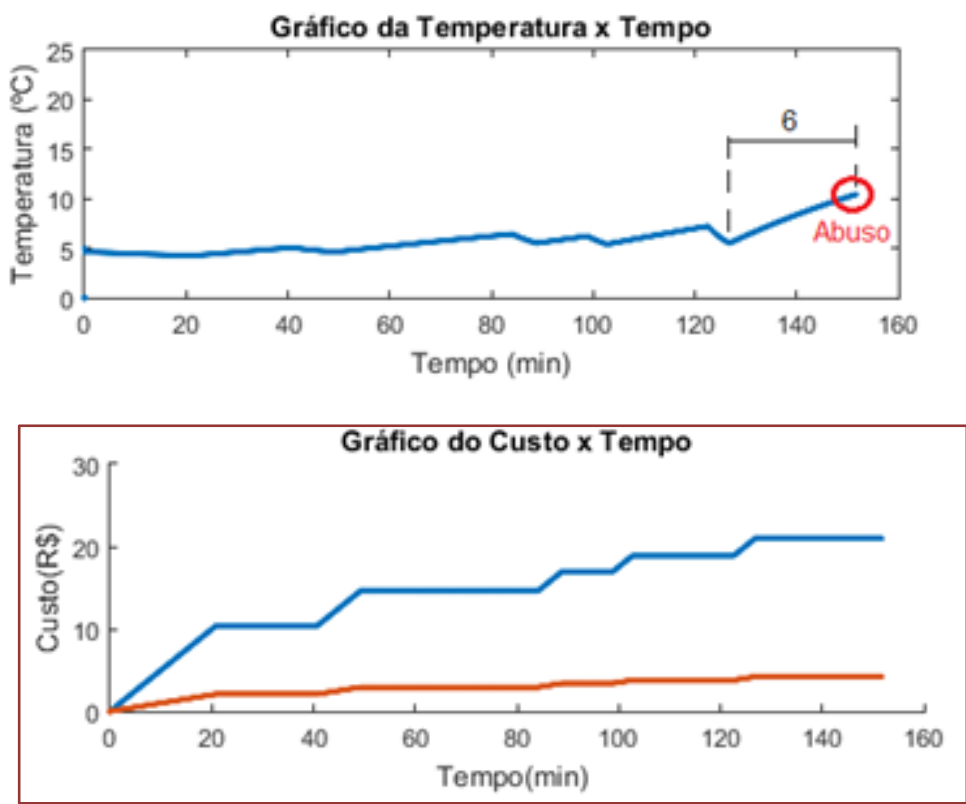

Fonte: Autores (2018)

Pode-se dizer que o algoritmo cumpre com sua finalidade de simular diferentes rotas para a distribuição de produtos considerando a variação de temperatura e assim, um caminho sem abuso de temperatura foi encontrado, porém gerando um acréscimo de aproximadamente $24 \%$ (de $\$ 21$ para \$26) no custo total do transporte, quando comparado à rota 6.0 aumento no custo ocorre por conta de se escolher trajetos mais longos (de 42,89 $\mathrm{km}$ da primeira rota para 49,68 $\mathrm{km}$ da rota 6, portanto, 6,79 $\mathrm{km}$ mais extenso) entre pontos, gerando, consequentemente, um maior consumo de combustível do veículo. 


\section{CONSIDERAÇÕES FINAIS}

0 presente estudo consistiu em analisar artigos e periódicos com ênfase no problema de roteirização e à cadeia do frio, e através disso buscar integrar as duas temáticas de forma que o problema de roteirização pudesse ser considerado dinâmico, ou seja, tendo a temperatura do produto a ser transportado controlada.

Neste artigo apresentou-se uma visão geral sobre distribuição física de produtos da cadeia do frio e performance térmica dos mesmos, propondo-se um modelo matemático no intuito de encontrar rotas de distribuição para os produtos sem a extrapolação da temperatura dos mesmos durante este processo. Para tal objetivo, estabeleceram-se modelos matemáticos capazes de simular a variação de temperatura dos produtos em função do tempo e, também, uma heurística para resolução do problema de roteirização e, a implementação do algoritmo pôde encontrar resultados satisfatórios para este estudo incipiente.

Nem todos os problemas de roteirização de cargas refrigeradas terão solução satisfatórias, pois dependendo do limite térmico e dos dados do sistema estabelecido, pode ser impossível encontrar uma rota onde o produto consiga ser mantido nas temperaturas ideais. A solução para o problema do abuso de temperatura na prática, consiste em prolongar as distâncias entre pontos de entrega, e desta forma, o sistema de refrigeração pode operar na temperatura do produto durante um intervalo maior de tempo. Portanto, não há nenhuma alteração nos processos de entrega em si, já que o tempo de entrega continuará o mesmo após a aplicação do algoritmo.

Ao produto que requer controle térmico se mantido constantemente abaixo de sua temperatura limite durante o transporte resulta-se na redução de perdas e também no ganho de qualidade. Com o estudo realizado é perceptível que a temperatura do interior do veículo e do produto são fortemente dependentes da capacitação dos colaboradores no quesito de distribuição física dos produtos, pois quando há uma baixa qualidade nesse quesito pode-se gerar más práticas de operação, isto é, tempo indevido de portas abertas do veículo, descarregamentos não eficientes, etc. De maneira geral, o resultado obtido neste estudo incipiente não leva em consideração fatores humanos, como atrasos e más operações, porém isto não torna a pesquisa inválida, uma vez que os imprevistos citados acima podem ser incrementados futuramente para aprimoramento do processo, aproximando o estudo da realidade.

Para futuros ajustes e estudos pode ser viável uma análise mais detalhada dos coeficientes do modelo matemático proposto pelos autores, com validações práticas e acréscimos de variáveis no sistema de deslocamento e entrega, como trânsito lento, atrasos humanos e instalações de cortinas de ar, por exemplo.

\section{REFERÊNCIAS}

[1] Ballou, Ronald H. Gerenciamento na Cadeia de Suprimentos: planejamento, organização e logística empresarial. 4. Ed. Porto Alegre: Bookmam, 2006

[2] Carvalho, Carolina Correa de. Otimização Dinâmica da Logística de Distribuição de Produtos Alimentícios Refrigerados e Congelados. 2013. 254 f. Tese (Doutorado) - Curso de Faculdade de Engenharia Civil, Arquitetura e Urbanismo, Universidade Estadual de Campinas, Campinas, 2013.

[3] Christofides, N. (1985) "Vehicle routing", in: E.L. Lawler, J.K. Lenstra, A.H.G. Rinnooy Kan and D.B. Shmoys, (eds.). The Traveling Salesman Problem. A Guided Tour of Combinatorial Optimization, Wiley, Chichester, 431-448.

[4] Cunha, C. B. (2000) Aspectos práticos da aplicação de modelos de roteirização de veículos a problemas reais. Transportes, v. 8, n. 2, p. 51.

[5] Cunha, Claudio \& Bonasser, Ulisses \& Abrahão, Fernando. (2002). Experimentos computacionais com heurísticas de melhorias para o problema do caixeiro viajante.

[6] Desrochers, M., Lenstra, J.K., and Savelsbergh, M.W.P. (1990), "A classification scheme for vehicle routing and scheduling problems", European Journal of Operational Research 46, 322-332.

[7] Estrada-Flores, S., Eddy, A. (2006) Thermal Performance Indicators for Refrigerated Road Vehicles, International Journal of Refrigeration, v. 29, pp. 889-898.

[8] Food and Agriculture Organization (Roma) (Org.). Desperdício de alimentos tem consequências no clima, na água, na terra e na biodiversidade. 2013. Disponível em: <http://www.fao.org.br/daccatb.asp>. Acesso em: 15 maio 2018.

[9] Ghiani, G., Quaranta, A., Triki C. (2007) New policies for the dynamic traveling salesman problem. Optimization Methods and Software, vol. 22, No. 6, December, 971-983. 
[10] Heap, R. D. (2006) Cold chain performance issues now and in the future. IIR Bulletin, n. 4, p. 1-11.

[11] Heap, R.; Kierstan, M.; Ford, G. (1998), Food transportation. Londres: Blackie Academic \& Professional.

[12] Hoffman, W. (2006). Hot Market, Cool Freight. Journal of Commerce.http://dx.doi.org/10.1016/j.jfoodeng.2012.06.020.International Institute of Refrigeration - IIR (2004). Temperature indicators and time-temperature integrators: 3rd informatory note on refrigeration and food. Paris.

[13] Isabela Neto Piccirillo; Daiane Maria de Genaro Chiroli; Luciana Torres Correia de Mello. Roteirização com o método da varredura: uma proposta para melhorar a formatação de cargas, reduzir custos e satisfazer cliente. Caracas: Espacios, 2016.

[14] Laporte, G, Louveaux, F. Mercure, H. (1992) The vehicle routing problem with stochastic travel times, Transportation Science 26 (3) 161-170.

[15] Laporte, G., and Nobert, Y. (1987), "Exact algorithms for the vehicle routing problem", in: S. Martello, G. Laporte, M. Minoux and C. Ribeiro (eds.), Surveys in Combinatorial Optimization, North-Holland, Amsterdam, 147-184.

[16] Likar, K.; Jevsnik, M. (2006) “Cold Chain Maintaining in Food Trade”. Food Control, v. 17, pp. 108 -113.

[17] M.h, Hoang, M.h. O Laguerre, J Moureh, D Flicket al. Heat transfer modelling in a ventilated cavity loaded with food product: Application to a refrigerated vehicle. Journal of Food Engineering, [s.l.], v. 113, n. 3, p.389-398, dez. 2012. Elsevier BV.

[18] Moresco, Gustavo Henrique; Silva, Vanina Macowski Durski. Cadeia do Frio: estudo de Roteirização e Performance Térmica Durante a Distribuição de Alimentos Congelados. Encontro Nacional de Engenharia de Produção. Joinville, p. 1-13. out. 2017.

[19] Novaes, A.G.; Frazzon, E.M., and Burin, P.J. (2010). Dynamic Routing in Over Congested Urban Areas, Proceedings LDIC 2009, Second International Conference on Dynamics in Logistics, Bremen, August, pp. 103-112

[20] Novaes, Antônio Galvão. Logística e gerenciamento da cadeia de distribuição. Rio de Janeiro: Elsevier, 2007.

[21] Pereira, V. F.; Doria, E. C. B.; Carvalho Júnior, B. C.; Neves Filho, L. C.; Silveira Júnior, V. (2010) Avaliação de temperaturas em câmaras frigoríficas de transporte urbano de alimentos resfriados e congelados. Ciência e Tecnologia de Alimentos, Campinas-SP, v. 30, n. 1, p 158-165. 


\section{Capítulo 17}

\section{A concepção do biodigestor para produção de biogás}

na agroindústria, utilizando o Sistema de Automação Industrial para controle das variáveis de processo ${ }^{1}$

\section{Adão Robson Vieira da Cruz \\ Alexandre Gaspary Haupt}

Resumo: A indústria de laticínios é uma das indústrias de alimentos mais poluentes, devido a quantidade de resíduos sólidos, líquidos e gasosos que geram durante o processo produtivo, principalmente na fabricação de queijos, que possui uma carga orgânica expressiva, porém a destinação destes resíduos tem alto custo associado. 0 presente estudo foi motivado a partir deste contexto, com a implantação de um Biodigestor Anaeróbio, para produção de biogás, a partir dos resíduos de uma Indústria de Laticínios. 0 objetivo principal foi buscar alternativas sustentáveis para geração de energia, através do reaproveitamento dos rejeitos da agroindústria e automatizando o controle interno do Biodigestor, monitorando e controlando as variáveis do processo, pressão e temperatura, durante a produção de biogás, minimizando os riscos de explosão e de produção de Biogás insuficiente, permitindo assim, que a produção se mantenha de forma contínua, no interior do Biodigestor. Este trabalho emprega a metodologia experimental. Para o experimento, foi montado um protótipo de um biodigestor de decomposição anaeróbia, caseiro. Adicionalmente, o sistema automatizado foi acoplado ao Biodigestor, o qual fornece informações ao operador através de uma interface com indicadores do processo, atingindo portanto, o objetivo proposto de controlar a temperatura e a pressão interna do Biodigestor, assim como a produção de biogás, que será utilizado para geração e consumo de energia na agroindústria e, a produção de biofertilizantes, que poderão ser usados nas pastagens e na produção agrícola de propriedades rurais, fornecedoras da matéria-prima da indústria de laticínios, do Rio Grande do Sul.

Palavras Chave: Automação Industrial, Biodigestor, Biogás. 


\section{INTRODUÇÃO}

Após a Revolução Industrial, a produção de alimentos passou a ser mecanizada, possibilitando a criação de novos produtos a partir de uma matéria-prima. 0 processo que antes era artesanal, passou a contar com novas tecnologias, consequentemente, o volume de resíduos deste processo produtivo aumentou, assim como, o consumo energético de fontes não-renováveis.

Visando a busca de soluções ecologicamente corretas e o crescimento econômico aliado à sustentabilidade, o presente estudo, foi direcionado a Indústria de Laticínios, que é uma das mais poluentes entre as demais indústrias de alimentos, pois a quantidade de resíduos que são lançados, diariamente, ao meio ambiente sem um prévio tratamento, traz consequências graves ao solo, a água e ao ar. Portanto, para que a produção seja eficaz e a indústria de laticínios atenda a todas exigências imposta por leis sanitárias e ambientais, faz-se necessário, a destinação adequada destes resíduos, para que os recursos naturais ao entorno da área industrial sofram pouco e/ou nenhum impacto ambiental.

Desta forma, o objetivo geral deste estudo foi buscar alternativas sustentáveis para geração de energia, através do reaproveitamento dos rejeitos da agroindústria em um Biodigestor Anaeróbio, do tipo lagoa coberta, para produção de biogás, automatizando o controle interno de pressão e temperatura do Biodigestor, melhorando a eficiência na fermentação da matéria orgânica e controlando as variáveis do processo durante a produção de biogás, minimizando os riscos de explosão.

Objetivos específicos deste experimento:

Desenvolver um reator para produção de Biogás;

- Verificar quais variáveis devem ser monitoradas e quais devem ser controladas para produção eficiente do biogás;

- Desenvolver um sistema de automação baseado em micro controlador para monitorar e controlar as variáveis do processo;

- $\quad$ Desenvolver o software em linguagem C;

- Testar o sistema.

\section{PERGUNTA DA PESQUISA}

É Possível reutilizar os resíduos da Agroindústria para geração de energia de forma sustentável, reduzindo e/ou eliminando os impactos ambientais?

\section{REVISÃO BIBLIOGRÁFICA}

O Brasil é o terceiro maior produtor mundial de leite, acumulando em 2017, a captação de 24,12 bilhões de litros de leite, 4,1\% a mais que em 2016 (NOTÍCIAS AGRÍCOLAS, 2018).

o setor da indústria brasileira de laticínios é marcado pela concentração de um grande número de empresas de micro e pequeno porte, com algumas empresas de grande porte (FERREIRA et al., 2008; BRUNOZI, JÚNIOR et al., 2012). Este perfil pode ser reforçado pelo registro de mais de 6.000 indústrias de laticínios no País (MTE, 2015), em 2014, os 13 maiores concentraram 38,1\% de toda a captação formal de leite cru (MILKPOINT, 2015).

Apesar da vasta contribuição econômica e social, a atividade láctea se destaca pela geração de resíduos líquidos, pelo lançamento de efluentes nas águas receptoras e pelo elevado consumo de água no processo de produção e higienização dos laticínios (CARVALHO; PRAZERES; RIVAS, 2013). Os resíduos da indústria de laticínios, oriundos de seu processo produtivo, podem ser de origem líquida, sólida ou gasosa. A maior parte destes resíduos acabam lançados ao meio ambiente sem nenhum tratamento prévio. Estima-se que aproximadamente $50 \%$ do soro produzido no Brasil ainda são descartados na natureza sem nenhum tipo de tratamento (SILVEIRA, 2004), em média, cada tonelada de soro não tratado despejado por dia equivale à poluição diária de cerca de 470 pessoas (ATRA, 2005), consequentemente, os aspectos ambientais geram impactos ao meio ambiente. A relação entre os aspectos ambientais e seus impactos é de causa e efeito. Os aspectos são fatores de desequilíbrio ambiental e o impacto é o próprio desequilíbrio. Quando os aspectos interagem com o meio ambiente, causam impactos. (MOREIRA, 2006).

O soro do leite é o resíduo mais poluente da indústria de laticínios, devido a sua alta concentração de 
matéria orgânica. Segundo Rodrigues e Marinho (2012) o soro do queijo, por exemplo, quando descartado junto com os efluentes líquidos, se torna um forte agravante devido ao seu elevado potencial poluidor (DBO entre 30.000 a $50.000 \mathrm{mg} \mathrm{02/L).} \mathrm{Uma} \mathrm{indústria} \mathrm{com} \mathrm{produção} \mathrm{média} \mathrm{de} 300.000$ litros de soro por dia, polui o equivalente, a uma cidade com 150.000 habitantes (MACHADO, 2002).

A ABNT NBR ISO 14001:2015, especifica os requisitos para um sistema de gestão ambiental que uma organização pode usar para aumentar seu desempenho ambiental. Esta Norma é destinada ao uso por uma organização que busca gerenciar suas responsabilidades ambientais de uma forma sistemática, que contribua para o pilar ambiental da sustentabilidade.

\subsection{PROCESSO DE TRATAMENTO DE EFLUENTES DA INDÚSTRIA DE LATICÍNIOS}

O processo inicia-se pela identificação das características dos resíduos para que haja a definição correta na forma de armazená-los e, posteriormente, a melhor solução para o tratamento. Por vezes, até mesmo uma ETE local não consegue suprir a demanda para o descarte adequado em redes ou corpos d'água devido à alta complexidade na remoção da carga orgânica, daí a necessidade de parcerias (TERA AMBIENTAL, 2016).

Nos países desenvolvidos, o reuso de efluentes nas indústrias já é uma realidade, entretanto o Brasil ainda enfrenta dificuldades nessa área. Enquanto nos Estados Unidos cerca de $60 \%$ das indústrias possuem sistemas para reuso de efluentes, no Brasil este montante equivale apenas 1\% (FURTAD0, 2005). Este cenário se deve principalmente à falta de alternativas de tratamento que gerem efluentes com a qualidade requerida para reuso. No Brasil, as principais técnicas convencionais de tratamento de efluentes são caracterizadas por alta demanda de área, alto custo e baixa eficiência quando aplicadas como sistema único de tratamento, muitas vezes não se enquadrando nos padrões de lançamento exigidos pelos órgãos ambientais e gerando efluentes longe de atender aos padrões de reuso. Assim, as indústrias têm buscado novos sistemas de tratamento que superem os problemas dos sistemas convencionais e gerem efluentes tratados com a qualidade requerida (ANDRADE, 2011).

\subsection{PROCESSO DE BIODIGESTÃO ANAERÓBIA}

A biodigestão anaeróbia é o processo de decomposição de matéria orgânica que ocorre na ausência de oxigênio gerando o biogás e um resíduo líquido rico em minerais que pode ser utilizado como biofertilizante. 0 biogás é composto principalmente de metano e gás carbônico, ambos com ampla utilização na indústria. A combustão do metano libera energia térmica que pode ser convertida em outras formas de energia, o que dá ao biogás a conotação de Fonte de Energia Renovável. 0 uso do biogás como fonte de energia tem aumentado muito o seu valor de mercado e criando setores específicos como o de biodigestores (PORTALDOBIOGAS, 2013).

O sucesso da biodigestão depende do balanceamento entre as bactérias que produzem gás metano (CH4) a partir dos ácidos orgânicos e este, é dado pela carga diária (sólidos voláteis), alcalinidade, pH, temperatura e qualidade do material orgânico, ou seja, qualquer variação entre eles pode comprometer o processo. A entrada de antibióticos, inseticidas e desinfetantes no biodigestor também pode inibir a atividade biológica diminuindo sensivelmente a capacidade do sistema em produzir biogás (KUNZ et al., 2004).

\subsection{AUTOMAÇÃO INDUSTRIAL}

Automação é a substituição do trabalho humano ou animal por máquina. Automação é a operação de máquina ou de sistema automaticamente ou por controle remoto, com a mínima interferência do operador humano. Automação é o controle de processos automáticos. Automático significa ter um mecanismo de atuação própria, que faça uma ação requerida em tempo determinado ou em resposta a certas condições (RIBEIR0, 2001). Este processo ocorre por microcontroladores.

De acordo com (HAUPT e DACHI), 2016, microcontroladores são Circuitos Integrados que contem no mesmo invólucro funções da Unidade central de processamento, memórias e entradas e saída de dados. A figura 1 ilustra o diagrama geral do micro controlador. 
Figura 1 - Diagrama Geral Do Microcontrolador

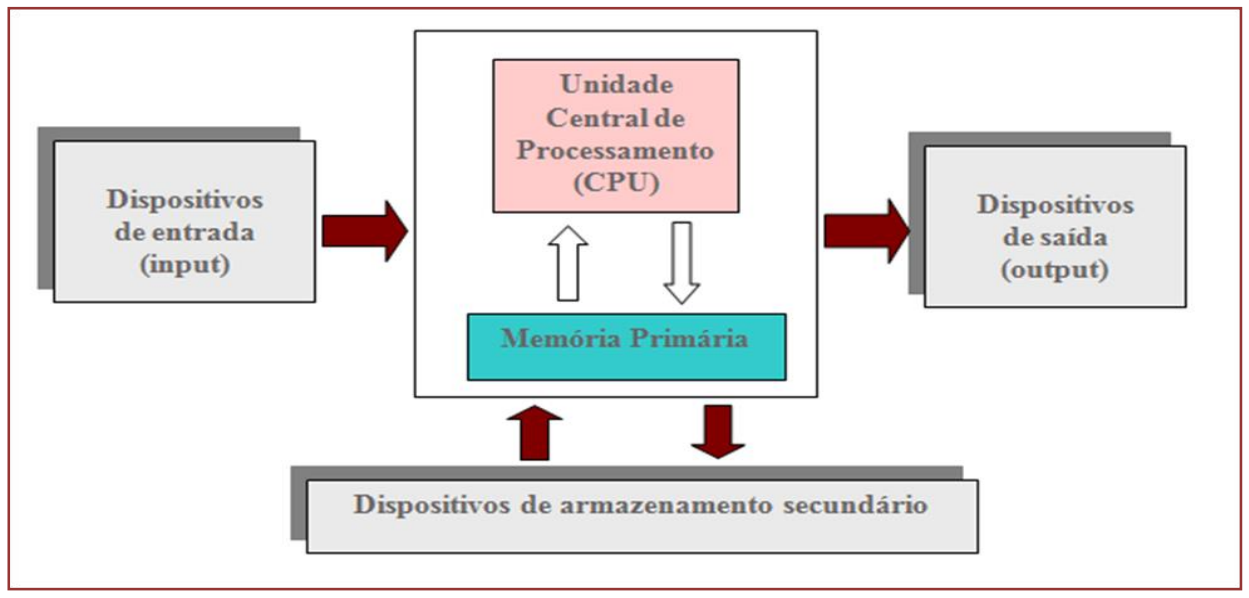

Fonte: HAUPT e DACHI, 2016

Um microcontrolador consegue realizar toda a parte de gerência de outros dispositivos que estejam ligados a ele. Através de sensores e atuadores, podem-se captar informações do ambiente externo transformando-as em dados ou traduzindo comandos enviados de um ponto externo indicando ações ou movimentos mecânicos, respectivamente (MONK, 2013).

Esse tipo de sistema tecnológico pode ser encontrado em kits de desenvolvimento, como o Arduino, permitindo a automação de pequenos dispositivos a preços acessíveis e com uma interface de programação amigável.

\section{METODOLOGIA APLICADA}

Este trabalho emprega a metodologia experimental com a concepção de um Biodigestor de Decomposição Anaeróbia (capacidade de 20 litros), cujo funcionamento experimental, utiliza dejetos de bovinos, favorecendo a geração de biogás e biofertilizantes, em um período curto de tempo. Para aplicação na indústria, será necessário, redimensionar o tamanho do biodigestor, conforme a quantidade de resíduos do processo produtivo da indústria de laticínios. 0 biodigestor proposto, aplicado na produção de biogás metano - CH4, é ilustrado na figura 2:

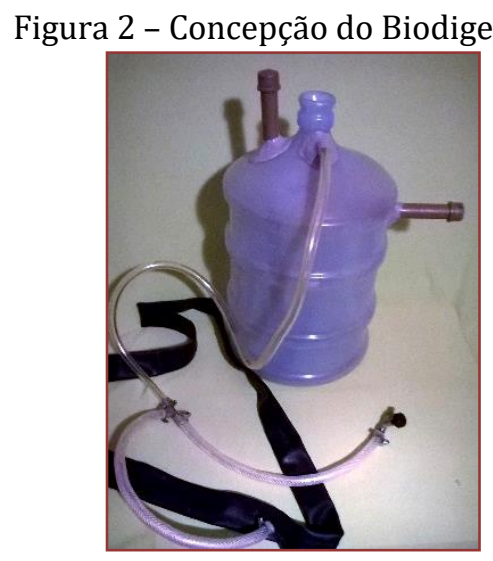

Fonte: O Autor

\subsection{CONCEPÇÃO MECÂNICA DO BIODIGESTOR EXPERIMENTAL}

A montagem do Biodigestor, aqui apresentado, é simples. Vejamos o passo-a-passo:

1. Corte a tubulação de $25 \mathrm{~mm}$ na mesma altura do gargalo do garrafão de 20 litros, deixando um espaço na parte inferior, de aproximadamente $5 \mathrm{~cm}$, para alimentação da carga do biodigestor; 
2. Na parte superior do garrafão de 20 litros, deverá ser feita a marcação do furo e a abertura do mesmo, onde será conectado a tubulação de PVC de $25 \mathrm{~mm}$. Este furo pode ser feito com um equipamento de solda quente, ou utilização de furadeira com broca chata;

3. Encaixe a tubulação de PVC de $25 \mathrm{~mm}$ a abertura, deixando um espaço entre a tubulação e o fundo, de $5 \mathrm{~cm}$;

4. Segure firme a tubulação e passe cola de PVC em torno da mesma, para fixa-la, após use cola quente para melhor vedação, em seguida utilize durepox, para maior resistência na fixação da tubulação;

5. Conecte um dos CAPS, de $25 \mathrm{~mm}$, na extremidade da tubulação que está fora do garrafão;

6. Na lateral do garrafão, do lado oposto a tubulação de entrada (10 $\mathrm{cm}$ abaixo do gargalo), faça outro furo para saída da matéria orgânica digerida. Corte o outro pedaço da tubulação de PVC, aproximadamente $25 \mathrm{~cm}$, e coloque-o na abertura até a metade do garrafão, após faça a fixação, do mesmo, conforme descrito no passo no $\mathbf{4}$;

7. Na lateral do gargalo faça um furo de aproximadamente $0,6 \mathrm{~cm}$ e encaixe a mangueira do gás (6mm), utilizando a fixação descrita no passo no 4 ;

8. Corte a mangueira do gás $(6 \mathrm{~mm})$ e encaixe na extremidade do Te $(6 \mathrm{~mm})$ e utilize uma abraçadeira para fixação (aperte abraçadeira utilizando as chaves de fenda ou Philips), após corte mais dois pedaços, aproximadamente $20 \mathrm{~cm}$ cada, e conecte as outras duas extremidades do Tê;

9. Conecte uma das extremidades da mangueira de gás na câmara de ar e fixe com abraçadeira (aperte abraçadeira utilizando as chaves de fenda ou Philips), repetindo posteriormente, os passos de vedação no 4 ;

10. Na outra extremidade restante da mangueira, conecte a válvula de registro $(6 \mathrm{~mm})$, fixando-a com uma abraçadeira (aperte abraçadeira utilizando as chaves de fenda ou Philips);

11. Feche o gargalo do garrafão com uma sacola plástica, utilizando a fita adesiva para vedação, ou utilize uma tampa apropriada, vedando com fita adesiva.

Figura 3 - Materiais utilizados para construção do Biodigestor

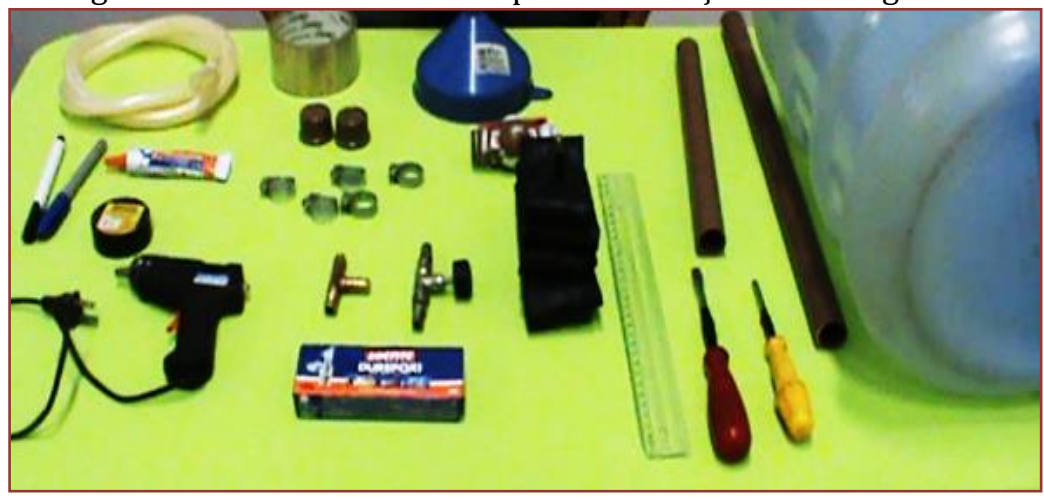

Fonte: O Autor (2018)

Após a montagem, o resultado final deverá ser como demonstrado na figura 4: 


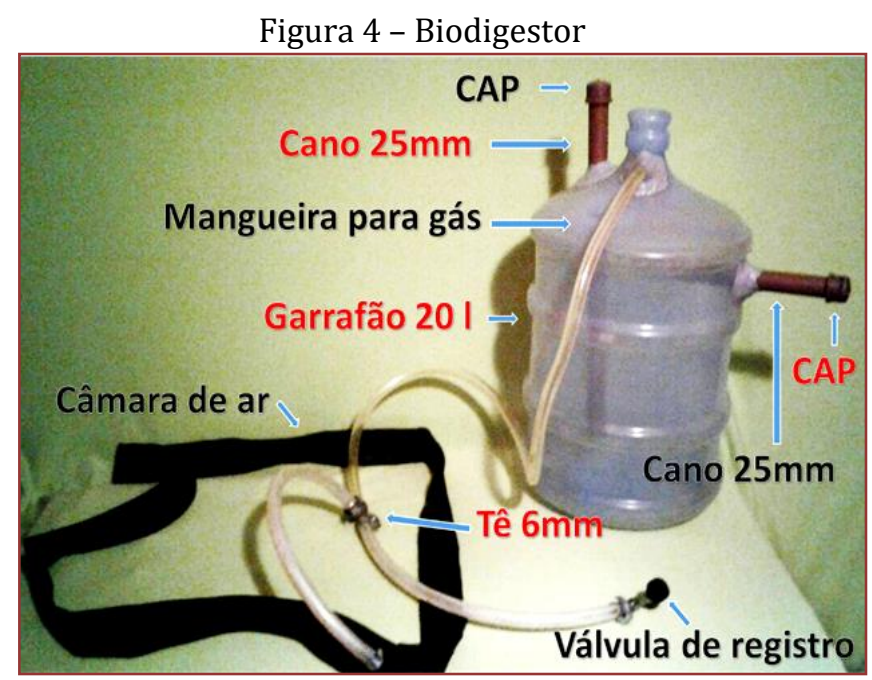

Fonte: O Autor (2018)

Para aumentar a temperatura no interior do biodigestor, utilize o pincel e a tinta preta, pintando toda a parte externa do garrafão, se necessário repita o procedimento até ficar uma pintura homogênea, demonstrado na figura 5 :

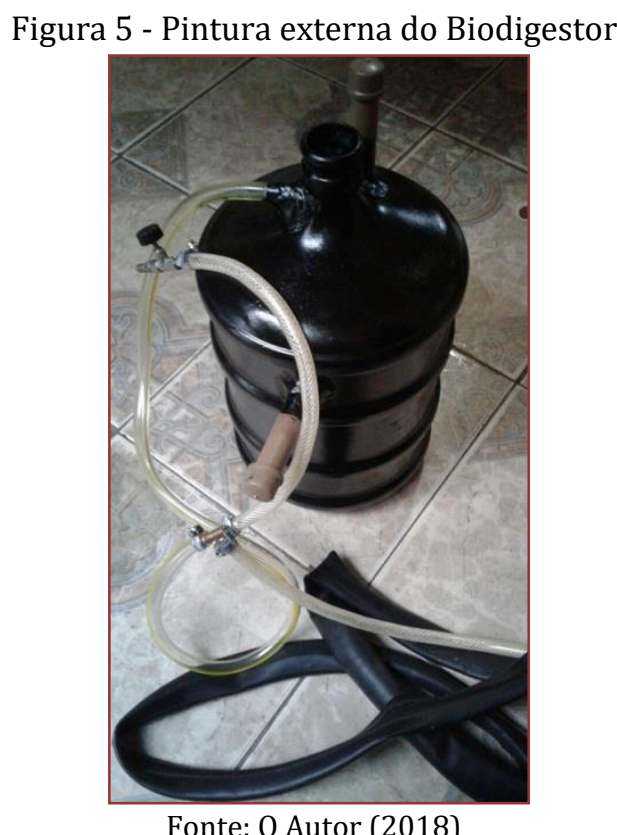

\subsection{AUTOMAÇÃO DAS VARIÁVEIS DE PROCESSO}

Na concepção do sistema de automação necessário para o controle das variáveis de processo, foi utilizado o kit de desenvolvimento baseado na plataforma Arduino UNO, considerando sua facilidade de aquisição, facilidade de programação e custo. A figura 6, ilustra o kit de desenvolvimento Arduino UNO, com destaque para os pinos de entrada e saída: 
Figura 6 - Kit de desenvolvimento Arduino UNO

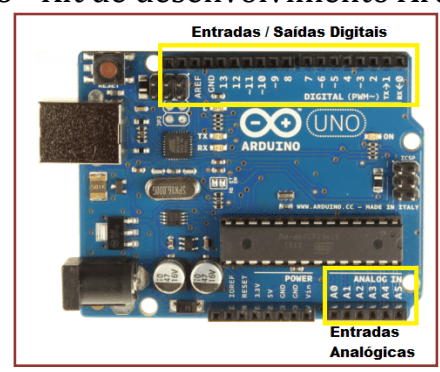

Fonte: Store Arduino, 2018

As variáveis de processo, importante para o sistema proposto, são temperatura e pressão, que são medidas a partir de sensores industriais e controladas por um programa desenvolvido em linguagem C. A temperatura no interior do biodigestor é controlada para permanecer na faixa recomendada pela literatura entre $30^{\circ} \mathrm{C} \mathrm{e} 36^{\circ} \mathrm{C}$, à qual será constantemente monitorada e corrigida. Para que o sistema seja seguro, a pressão no interior do Biodigestor também é monitorada, para que não ocorra sobrecarga no sistema ou risco de explosão.

Já os Alarmes sonoros e visuais foram utilizados para informar o operador do processo a alteração nos parâmetros que garantem uma produção contínua e segura, do Biogás. Os alarmes sonoros e visuais estão ilustrados na figura 7:

(a)

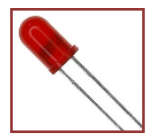

Figura 7 - Alarmes sonoros e visuais

$$
\text { (b) }
$$

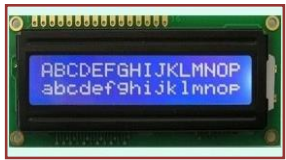

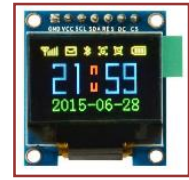

(d)

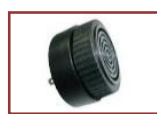

Fonte: INSTRUCTABLES, 2018

Os LEDs utilizados têm a função de avisar a faixa de pressão e quando a pressão ultrapassa o valor máximo permitido de 110PSI. A figura 7(a) ilustra o aspecto físico do LED. As figuras 7(b) e 7(c) ilustram os displays utilizados e a figura 7(d) ilustra o alarme sonoro. 0 display 7(b) tem a função de exibir os valores de temperatura e pressão, além dos dados do sistema. 0 display 7 (c) exibir mensagens para o operador em relação a pressão.

A figura 8, ilustra a estrutura em blocos do sistema de automação proposto para controle do biodigestor. 
Figura 8 - Estrutura em blocos do sistema de automação

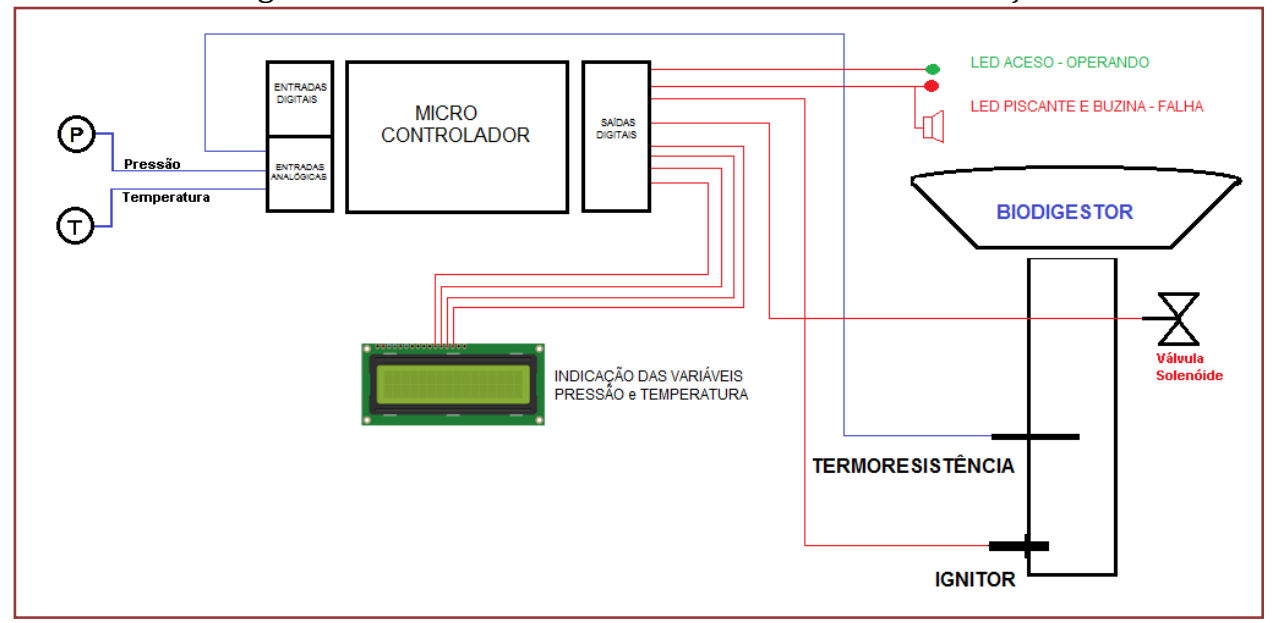

Fonte: 0 Autor

Para medir a temperatura, foi utilizado o sensor comercial DHT 11, que utiliza o protocolo $\mathrm{I}_{2} \mathrm{C}$ e pode medir com erro menor que $2 \%$, temperaturas na faixa de $-5^{\circ} \mathrm{C}$ a $80^{\circ} \mathrm{C}$. A figura 9 , ilustra o aspecto físico do sensor de temperatura utilizado:

Figura 9 - Sensor de temperatura

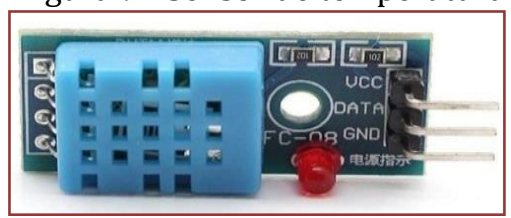

Fonte: ARDUINO\&ELETRÔNICA, 2018

Os dispositivos de entrada são utilizados para aquisição de informações do mundo externo. Para medir grandezas físicas como temperatura e pressão, foram utilizados os sensores ilustrados na figura 10 . A figura 10(a) ilustra o botão utilizado para iniciar o sistema de controle. Para medir a temperatura, foi utilizado o sensor comercial DHT 11, ilustrado em 10(b) que utiliza o protocolo I2C e pode medir com erro menor que $2 \%$ temperatura na faixa de $-5^{\circ} \mathrm{C}$ a $80^{\circ} \mathrm{C}$. A figura 10 (a) ilustra o aspecto físico do sensor de temperatura utilizado. A figura $10(C)$ ilustra o sensor e pressão, utilizado para medir a pressão do gás no biodigestor e limitar a pressão, abrindo a válvula de segurança quando a pressão passar do limite.

(a)

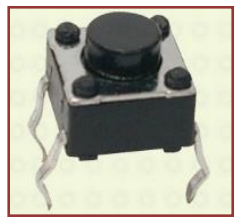

Figura 10 - Dispositivos de entrada

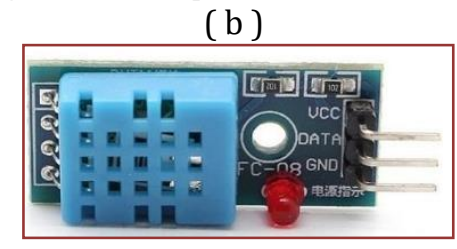

Fonte: INSTRUCTABLES, 2018

A resistência de aquecimento é mergulhada na solução orgânica, recebendo mais ou menos potência de acordo com a temperatura da solução, a fim de estabilizar a temperatura no valor determinado na programação, ou seja, $34^{\circ} \mathrm{C}$. A figura 11 ilustra o diagrama geral do sistema de automação proposto. Sempre que a pressão exceder o valor máximo definido, o LED1 pisca e o alarme sonoro emite um sinal para avisar o operador que existe o programa. Este problema comunicado por escrito no display OLED. Se o problema não for solucionado pelo operador, uma válvula de segurança é acionada. 
Figura 11 - Diagrama geral do sistema de automação

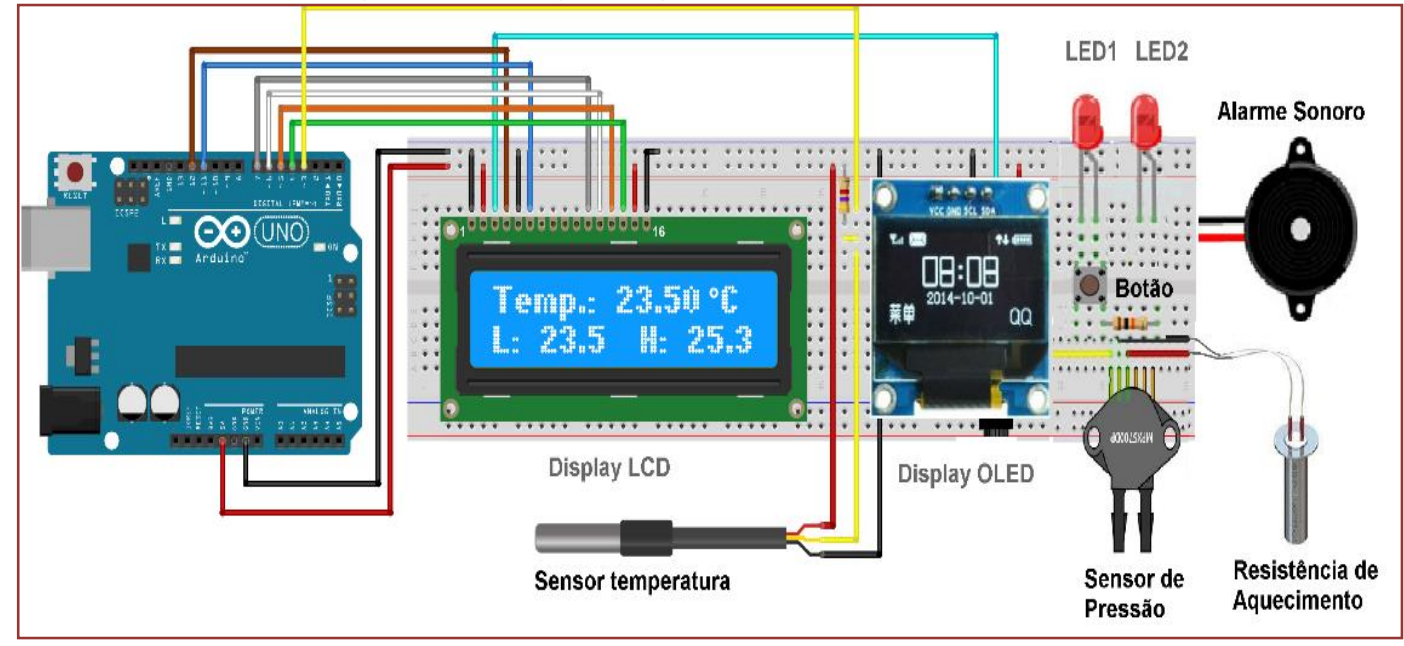

Fonte: O Autor (2018)

\subsection{TESTE DA PRODUÇÃO DE GÁS}

Após a concepção do biodigestor (20 litros), realizou-se o teste para verificação da produção de gás. Para isto iniciou-se procedimento de carga do biodigestor, conforme descrito abaixo.

1. Em um balde de 20 litros prepare o substrato (aproximadamente 1 a $2 \mathrm{~kg}$ de dejetos de bovinos), e dilua na mesma proporção com água, até obter uma mistura homogênea;

2. Retire a tampa do CAP da tubulação superior, acople um funil e despeje a matéria orgânica, após feche novamente a tubulação com o CAP;

3. Na próxima carga com o substrato o CAP da tubulação lateral deve ser retirado para que saia o material já digerido. Este material (matéria orgânica diluída), pode ser coletado e utilizado como biofertilizantes para adubação de plantas, exceto para vegetais de consumo humano.

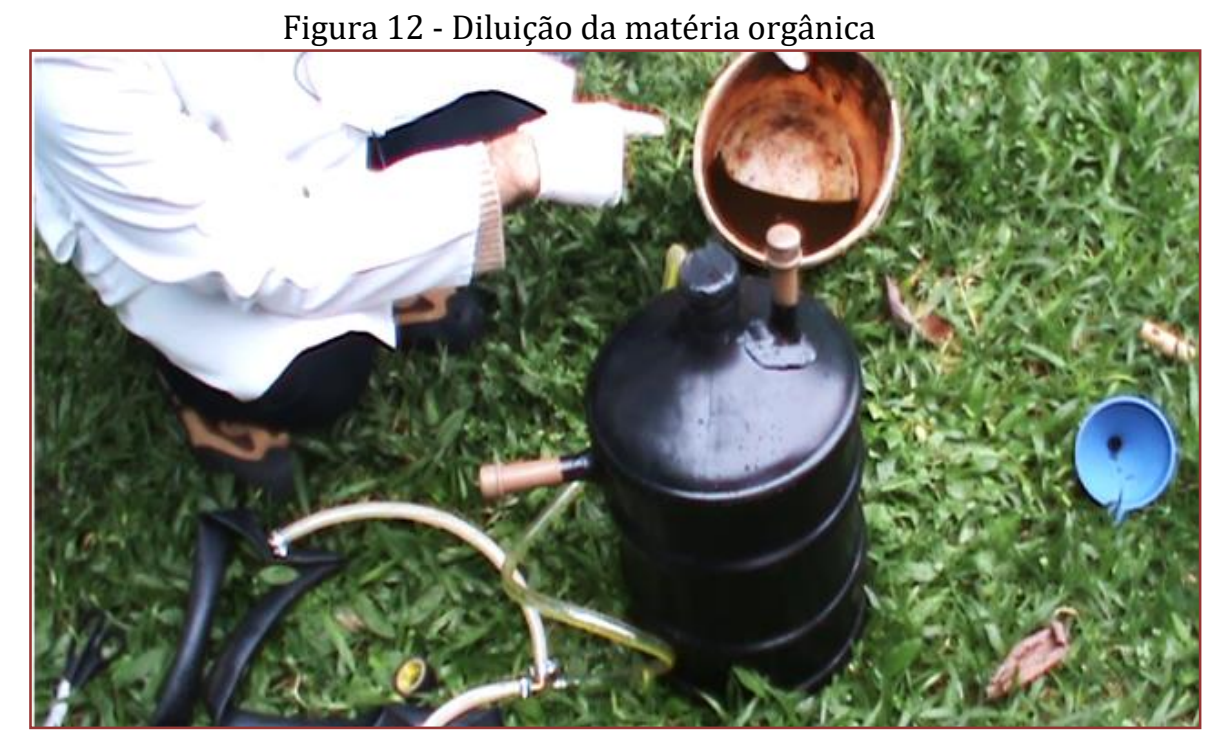

Fonte: 0 Autor (2018)

Após a primeira carga, o biodigestor (20 litros) deverá ser alimentado com $600 \mathrm{ml}$ de dejetos diluídos na mesma proporção de água, diariamente, para que a produção do gás seja constante. A produção de gás poderá ser de até 6 litros/semana.

Recomenda-se que o biodigestor, sem a automação das variáveis de processo, fique exposto ao sol para melhorar o rendimento da produção. Além disso, é importante que esteja localizado em local seguro e 
arejado, pois o gás produzido é altamente inflamável e alguns de seus componentes são tóxicos. Sempre que houver necessidade de recarregar o biodigestor é necessário a utilização de EPIs (máscara, luva e óculos de proteção). Nos testes realizados, utilizou-se dejetos de bovinos, favorecendo a geração de biogás e biofertilizantes, em um período de 2 semanas. A produção de gás sem a automação do processo é lenta e pode ficar ainda mais demorada nas baixas temperaturas do inverno.

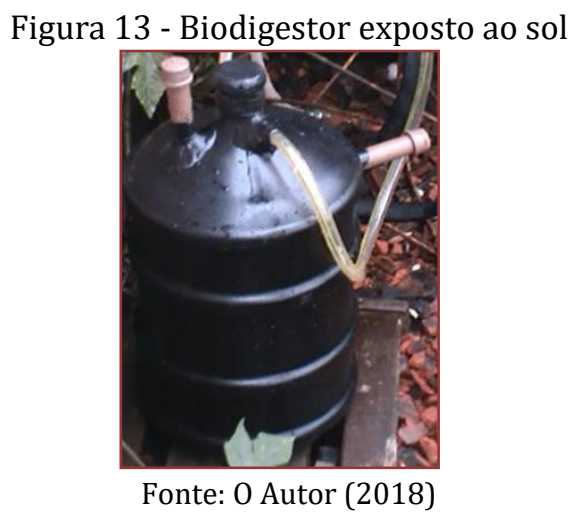

No modelo experimental, o biodigestor (20 litros), deverá ser agitado pelo menos uma vez na semana, sacudindo-o de um lado para o outro, este procedimento ajudará a manter o contato homogêneo das bactérias com os dejetos e mantendo a temperatura uniforme no interior do biodigestor.

\subsection{MONITORAMENTO E QUEIMA DO BIOGÁS NO MODELO EXPERIMENTAL}

A primeira produção de gás, sem o sistema de automação para controle das variáveis de processo, é mais lenta e depende de fatores como a temperatura (acima de $25^{\circ} \mathrm{C}$ ). 0 tempo aproximado é de 1 a 2 semanas, mas no inverno com temperaturas mais baixas, o período pode ser maior.

Para a verificação de produção de gás, além da parte visual do enchimento da câmara de ar, poderá ser instalado, na saída da mangueira do gargalo do garrafão, um medidor de vazão. Para purificação do gás, poderá ser instalado um filtro antes da válvula de registro.

Para a queima do biogás abra a válvula de registro e acenda um isqueiro ou fósforo, a chama é azul claro de difícil percepção, portanto é necessário ter cuidado para não se queimar. Caso a produção de metano ainda seja baixa, não produzirá chamas, então aguarde mais alguns dias e tente novamente.

\subsection{CONCEPÇÃO DO BIODIGESTOR PARA INDÚSTRIA DE LATICÍNIOS}

Para utilização na indústria de laticínios, utilizaremos o modelo de biodigestor, do tipo lagoa coberta, com capacidade de 16.000 litros, de armazenamento, que funcionará da seguinte forma:

1. Os resíduos de matéria orgânica, oriundos do processo produtivo, serão canalizados até a lagoa coberta, que não tem contato com o ar;

2. Sem oxigênio, a matéria orgânica passa por um processo bioquímico (hidrólise, fermentação acidogênico e metanogênica), realizado por milhares de bactérias, que se desenvolvem a partir da faixa de temperatura de 30 a $36^{\circ} \mathrm{C}$;

3. Como uma reciclagem natural, todo esse processo, resulta em uma parte líquida e outra gasosa, chamada de Biogás, que é composto de metano e gás carbônico;

4. No interior do biodigestor, serão instalados medidores de pressão e sensores de temperatura, acionados pela própria energia produzida pelo biogás, ou baterias movidas a energia solar.

Na Agroindústria a matéria orgânica será agitada pelo menos uma vez na semana, através de sistema interno automatizado. 
Figura 14 - Biodigestor Modelo Lagoa Coberta

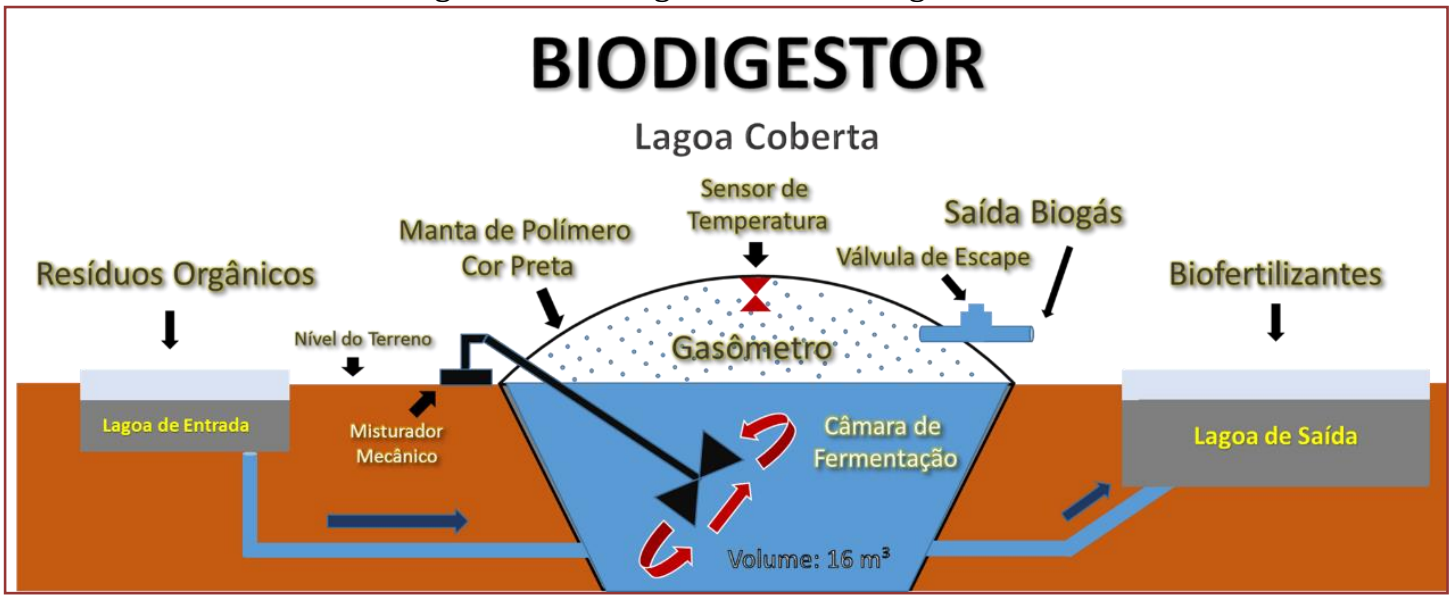

Fonte: O Autor (2018)

Figura 15 - Quantidade de Biogás produzido em um Biodigestor de 16.000litros

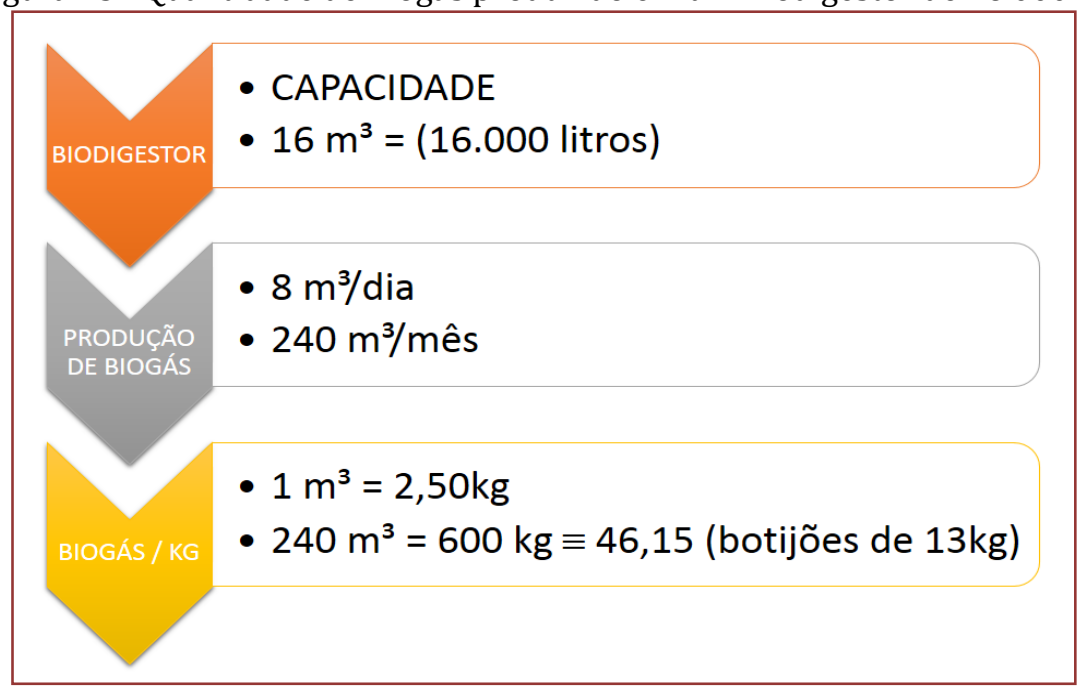

Fonte: O Autor (2018)

\subsection{TRANSFORMANDO BIOGÁS EM ENERGIA}

Para o reaproveitamento do Biogás na geração de energia elétrica, para uso na indústria de laticínios, o sistema utilizado é o mesmo do motor de um veículo. Dentro do motor, a mistura do gás com o ar gera calor, como os gases se expandem, quando aquecidos, é possível obter pressão suficiente para movimentar o motor, neste caso, o motor do gerador, que irá converter a energia mecânica em energia elétrica.

Toda energia excedente, na produção, poderá ser vendida, gerando lucros significativos a empresa, assim como o consumo zero de energia de fontes não-renováveis.

A Resolução Normativa № 482, de 17 de abril de 2012, da ANAEEL - Agência Nacional De Energia Elétrica, estabelece as condições gerais para o acesso de microgeração e minigeração distribuída aos sistemas de distribuição de energia elétrica, o sistema de compensação de energia elétrica, e dá outras providências (ANAEEL, 2012).

Por exemplo, uma empresa de médio porte, cuja produção de soro é de 45.000l/dia, pode gerar, aproximadamente, $7.200 \mathrm{kwh} /$ dia. Em um mês irá produzir o equivalente a $216.000 \mathrm{kwh}$, em um ano, o equivalente a $2.592 .000 \mathrm{kwh}$. Suponhamos que esta mesma empresa tenha um consumo mensal de $158.192 \mathrm{kwh}$, teremos uma produção excedente de energia, de $57.808 \mathrm{kwh}$, os quais poderão ser vendidos a companhia de energia elétrica, gerando lucros a agroindústria. Esta mesma indústria de médio porte produzindo 45.0001/dia de soro, em um ano produzirá energia suficiente para uma comunidade de 1389 habitantes, aproximadamente (O AUTOR, 2018). 


\section{RESULTADOS}

Após 30 dias da primeira carga do Biodigestor, sem o sistema de automação, a produção de biogás, sob temperaturas baixas do inverno, foram coletados os seguintes dados, conforme demonstra a figura 16:

Figura 16 - Produção de Biogás sem o Sistema de Automação

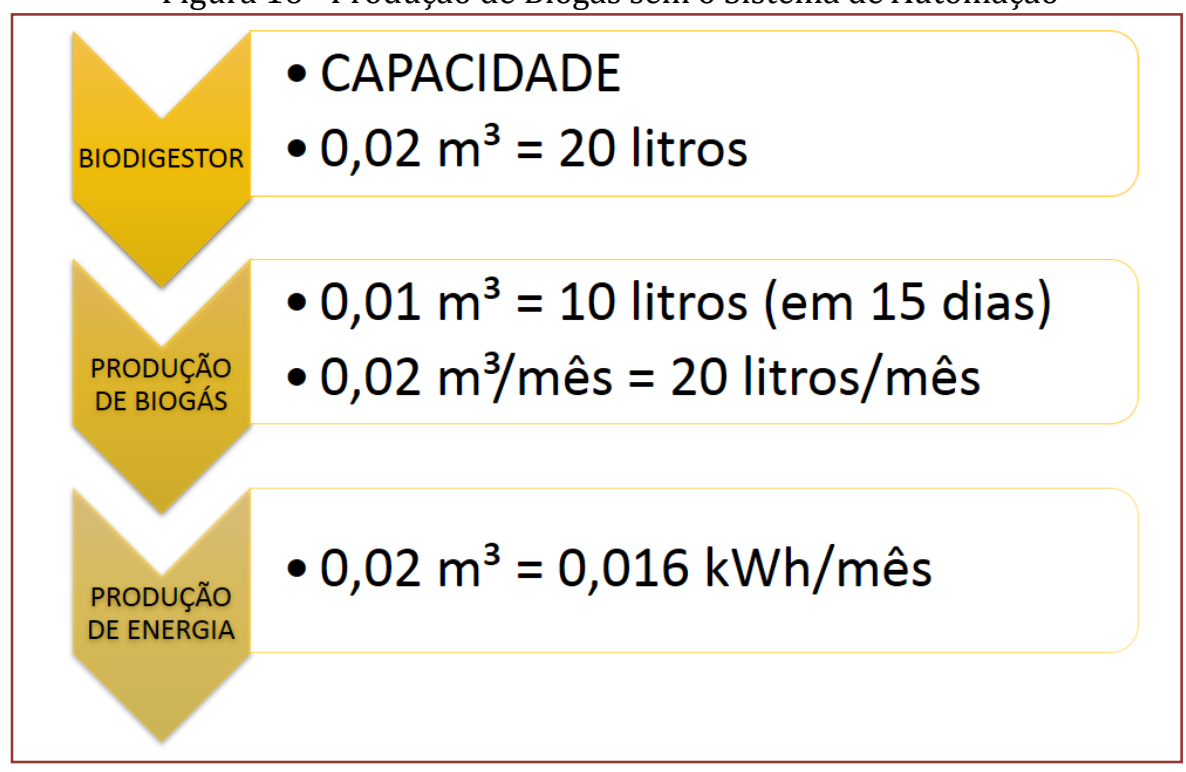

Fonte: O Autor (2018)

Após os resultados inciais, mostrados na figura 16 serem insatisfatórios, foi acoplado ao Biodigestor (20litros), o sistema de automação para controle das variáveis do processo. Para desenvolver o sistema de automação do biodigestor, foi utilizado o kit de desenvolvimento Arduino, o qual através de microcontroladores, monitoram e corrigem a temperatura e pressão, para obtenção da melhor performance do sistema. Indicadores de processo como LEDs, display e alarmes sonoros, foram adicionados para informar ao operador do sistema, quando houver alteração nos parâmetros, garantindo uma produção contínua e segura do Biogás. A figura 17 demonstra os indicadores do Processo:

Figura 17 - Indicadores de Processo - LEDs, Display e alarmes sonoros

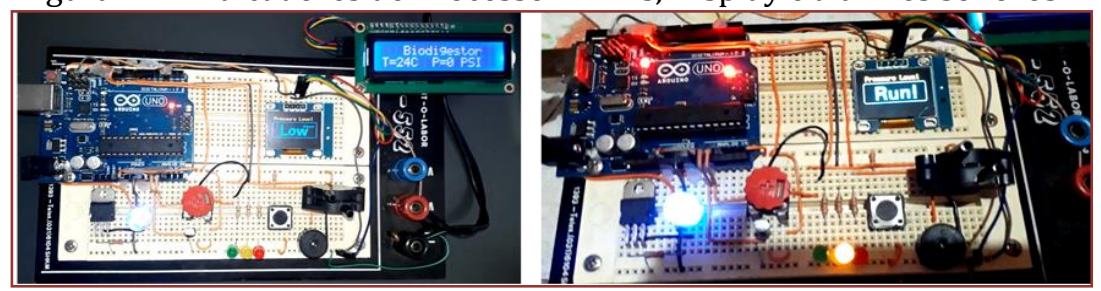

Fonte: O Autor (2018)

A resistência de aquecimento teve sua potencia modulada por PWM - Pulse Widht Modulation a fim de manter a temperatura no valor desejável de $34{ }^{\circ} \mathrm{C}$. A figura 18 ilustra o gráfico de variação de temperatura no período de $24 \mathrm{~h}$. 
Figura 18 - Sensor de temperatura

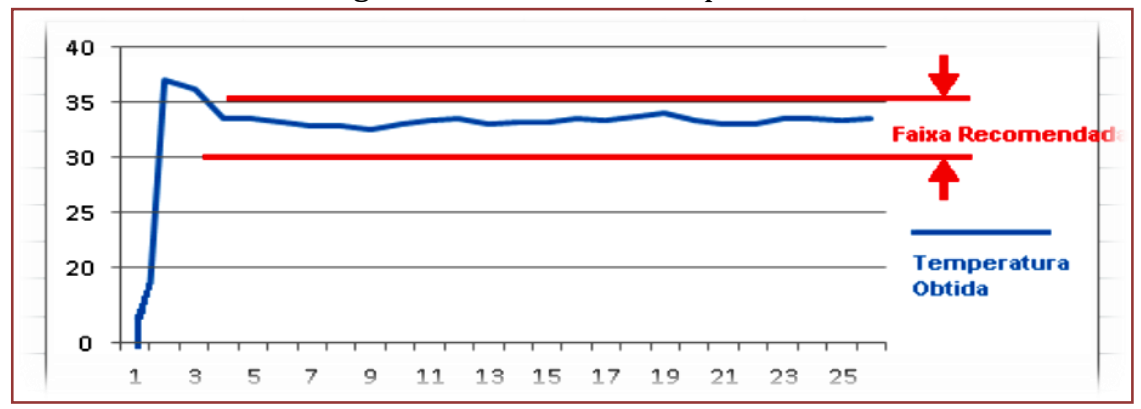

Fonte: O Autor (2018)

Assim, a temperatura foi mantida em $34^{\circ} \mathrm{C}$ no interior do biodigestor com um erro de $5 \%$. A pressão foi monitorada com notificações ao operador, nas etapas do processo, com alívio automático da pressão nos casos limite, mantendo a produção segura. A tabela 1 ilustra o status dos alarmes sonoros e visuais de acordo com a faixa de pressão. Uma válvula de alívio é utilizada para soltar o gás quando a pressão atinge o último limite da escala de segurança monitorada.

Tabela 1- Status dos alarmes sonoros e visuais de acordo com a faixa de pressão

\begin{tabular}{|cccccc|}
\hline Faixa de Pressão (PSI) & LED AM & LED VM & $\begin{array}{c}\text { Display OLED } \\
\text { Message }\end{array}$ & $\begin{array}{c}\text { Sound } \\
\text { Alarm }\end{array}$ & $\begin{array}{c}\text { Válvula de } \\
\text { Alívio }\end{array}$ \\
\hline$>50$ e $<70$ & Off & Off & Low & Off & Off \\
$>70$ e $<90$ & Off & Off & Mid & Off & Off \\
$>90$ e $<110$ & On & Off & High & Off & Off \\
\hline$>110$ & On & Blink & Danger & Blink & Off \\
\hline$>110$ after 30 s & On & Blink & RUN! & Blink & On \\
\hline \hline
\end{tabular}

Fonte: O Autor (2018)

Como resultado, a produção do biogás ocorreu dentro da faixa de temperatura de $30^{\circ} \mathrm{C}$ a $36^{\circ} \mathrm{C}$, que foi constantemente monitorada e corrigida pelo microcontrolador. Além disso, a pressão interna foi medida, não ultrapassando o limite $\geq 110$ (PSI), para que não ocorresse sobrecarga no sistema. 0 sistema automatizado se mostrou $60 \%$ mais eficiente que o sistema manual, produzindo os mesmo 10 litros de gás no período de 1 dia, conforme demonstrado na figura 19. Após os testes o gás produzido foi queimado.

Figura 19: Produção de Biogás utilizando o Sistema de Automação para Controle das Variáveis do Processo

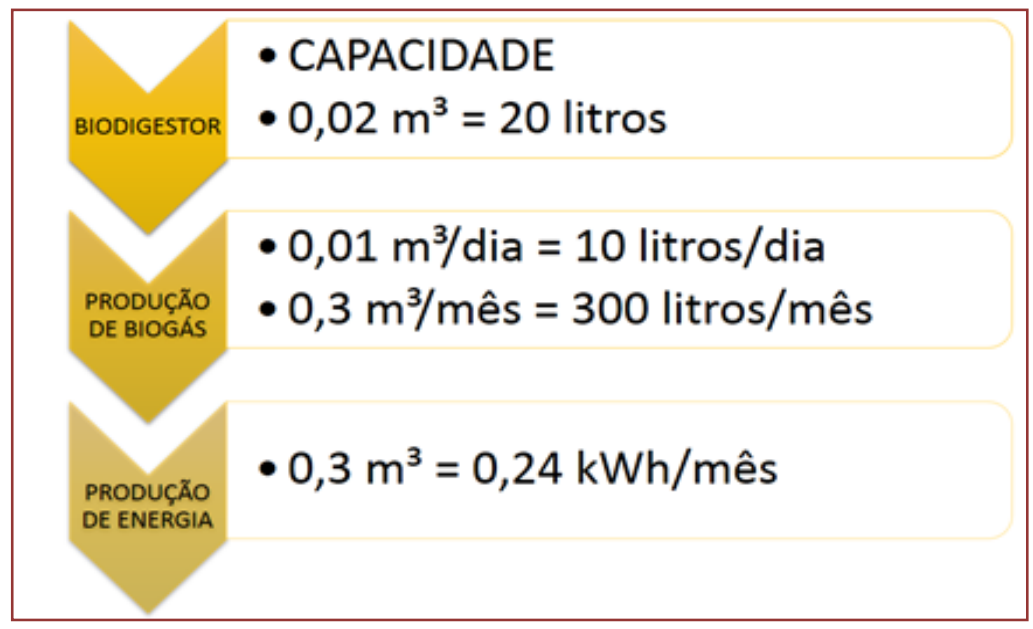

Fonte: O Autor (2018).

No modelo proposto para indústria de laticínios, o biodigestor tem capacidade de armazenamento de 16.000litros de resíduos orgânicos, porém a produção de biogás em 30 dias, vai gerar $192 \mathrm{kWh} / \mathrm{mês}$, 
abastecendo a indústria por 25 (vinte e cinco) dias, atingindo 82,65\% do consumo mensal, conforme demonstrado na figura 20.

Figura 20: Produção de Biogás e energia de um Biodigestor de 16.000litros

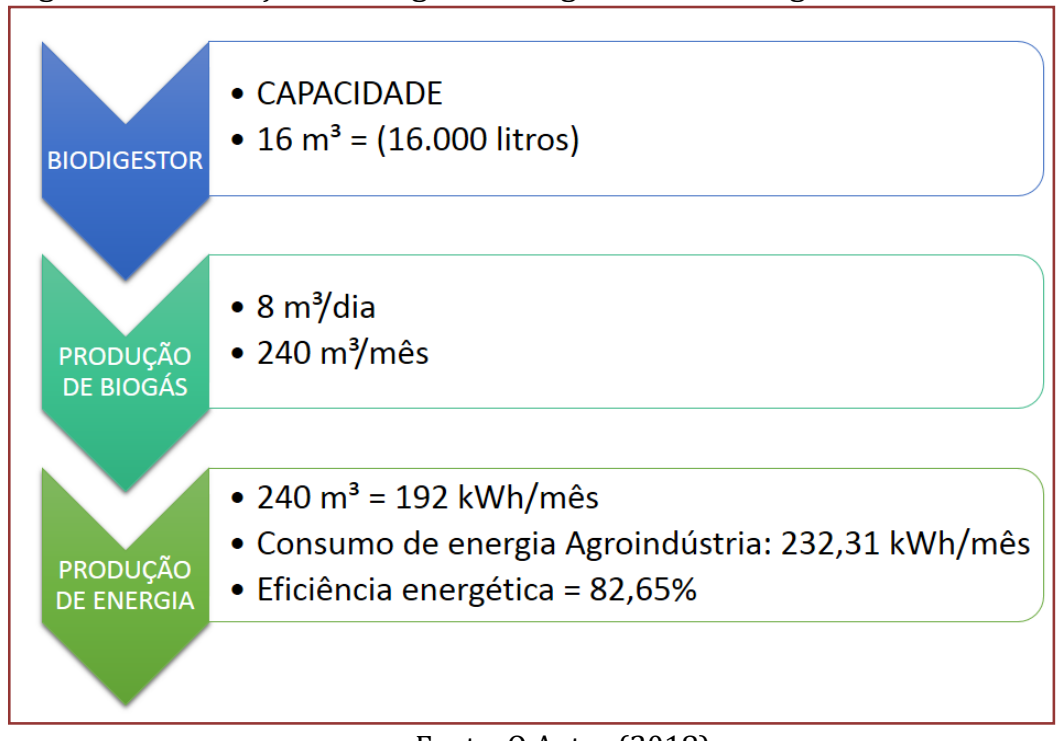

Fonte: O Autor (2018)

Para que a produção de biogás possa gerar energia suficiente, para abastecimento da indústria de laticínios durante 30 dias, será necessário redimensionar o projeto, aumentando a capacidade de armazenamento interno do biodigestor para 32.000litros, o qual possibilitará a produção de energia excedente, gerando economia e lucros para agroindústria, conforme demostrado na figura 21.

Figura 21: Produção de Biogás e Energia de um Biodigestor de 32.000litros

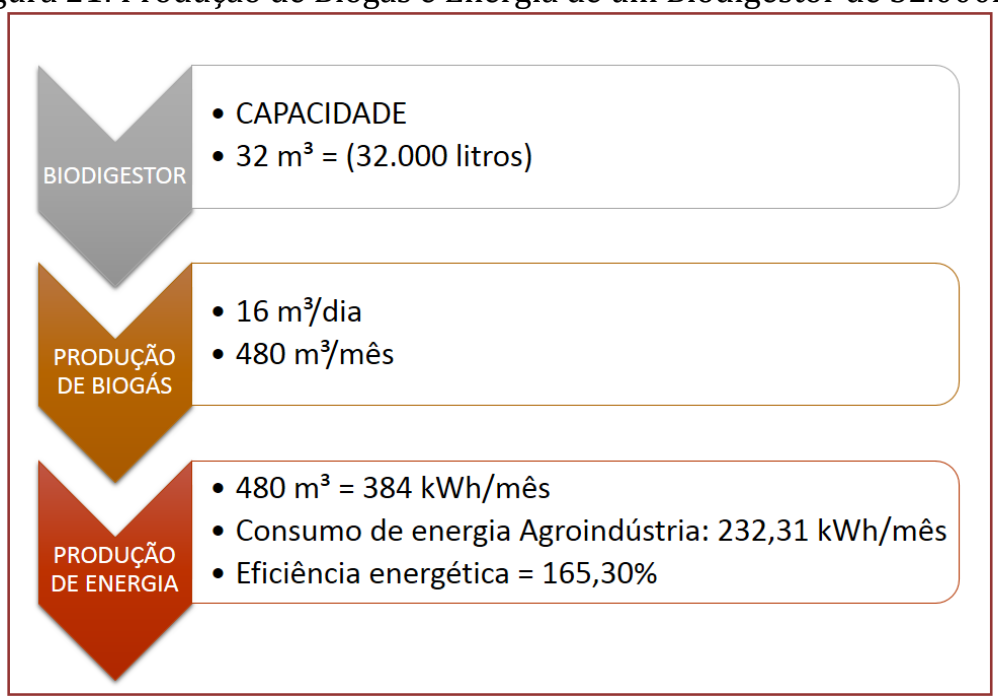

Fonte: O Autor (2018)

\section{CONSIDERAÇÕES FINAIS}

O sistema proposto permitiu o controle das variáveis de processo, temperatura e pressão, dentro da faixa recomendada. A temperatura foi mantida em $34^{\circ} \mathrm{C}$, com um erro de $5 \%$. A pressão foi monitorada com notificações ao operador, nas etapas do processo, com alívio automático da pressão nos casos limite, mantendo a produção segura. Embora a produção inicial de biogás, no protótipo do biodigestor (20litros), em um período de 15 dias, não tenha ultrapassado 10 litros de gás, devido as condições climáticas de um inverno rigoroso, foi possível realizar a queima do gás armazenado na câmara de ar. 
Ao ser acoplado o sistema de automação para controle das variáveis do processo, os resultados foram satisfatórios, produzindo em 30 dias, 300 litros de Biogás, os quais foram utilizados em um forno a lenha adaptado. Com a concepção deste protótipo experimental e seus resultados positivos, foi possível atingir o objetivo proposto de mostrar a viabilidade técnica e operacional do Biodigestor de Decomposição Anaeróbia.

O presente estudo, aponta para o Biodigestor Anaeróbio, como uma solução sustentável para indústrias de laticínios. Desta forma, resíduos que não têm tratamentos adequados e eficientes podem ser reaproveitados, reduzindo os impactos ambientais, além de proporcionar benefícios e lucros a agroindústria. É possível implantar este sistema em qualquer propriedade rural, pois tem baixo custo na montagem do equipamento, não precisa de manutenção, apenas observar os cuidados necessários de operação, os quais serão monitorados $24 \mathrm{~h}$ por equipamentos de automação industrial, instalados no interior do biodigestor, que controla os níveis das variáveis de processo, emitindo sinais luminosos e sonoros, caso haja sobrecarga do sistema ou divergência de temperaturas.

Na indústria de laticínios, com uso dos resíduos do soro do leite, por exemplo, a produção de biogás em lagoa coberta, conforme foi proposto no presente estudo, terá maior eficiência na produção de biogás, devido a sua alta concentração de matéria orgânica, mostrando que este método também é viável e ecologicamente correto, reduzindo custos e causando pouco e/ou nenhum impacto ambiental. 0 biogás é composto principalmente de metano e gás carbônico, ambos com ampla utilização na indústria.

Com base no estudo proposto, e em pesquisas sobre temas relacionados, recomenda-se para trabalhos futuros:

- $\quad$ Ajustar o pH do composto em função das diferentes fases da hidrólise: Acidogênese o pH ideal fica em torno de 5,2 a 6,3 e na Acetogênese e metanogênese o pH ideal fica entre 6,5 a 8;

- $\quad$ Recomenda-se a realização de testes com diferentes grupos de bactérias para verificar os ganhos na produção do Biogás;

- Estudos que abordam a comunicação do sistema de automação do biodigestor com dispositivos móveis, tais como celular e tabletes, recomendado para que a supervisão e controle do processo de produção de gás possa ser monitorada a distância;

- $\quad$ Analisar, em laboratório especializado, a qualidade do gás produzido.

\section{REFERÊNCIAS}

[1] Abnt NBR ISO 14001:2015. Sistemas da Gestão Ambiental - Requisitos com orientações para uso. Disponível em: <https://www.abntcatalogo.com.br/norma.aspx?ID=345116>. Acesso em: 6 jul. 2018.

[2] Anaeel. Agência Nacional de Energia Elétrica - Resolução Normativa no 482, de 17 de abril de 2012. Disponível em: <http://www2.aneel.gov.br/cedoc/ren2012482.pdf>. Acesso em: 19 maio de 2018.

[3] Andrade, Laura Hamdan de. Tratamento de efluente de indústria de laticínios por duas configurações de biorreator com membranas e nanofiltração visando o reuso [manuscrito] / Laura Hamdan de Andrade. - 2011. xii, 214 f., enc. : il.

[4] Arduino e Cia. Sensor de umidade e temperatura DHT11. Disponível em: <http://www.arduinoecia.com.br/2013/05/sensor-de-umidade-e-temperatura-dht11.html>. Acesso em: 19 maio de 2018.

[5] Arduino\&Eletrônica. Sensor de Umidade e Temperatura DHT11. Disponível em: <https://www.arduinoeeletronica.com.br/produto/sensor-de-umidade-e-temperatura-dht11/> Acesso em: 29 abr., 2018.

[6] Atra, R. et al. Investigation of ultr- and nanofiltration for utilization of whey protein and lactose. J. Food Eng., v. 67, p. 325-332, 2005.

[7] Brunozi Júnior, A.C.; Abrantes, L.A.; Ferreira, M.A.M.; Gomes, A.P. Mercado e Tributação: Uma Abordagem Teórica sob a Perspectiva de Estruturas de Mercado na Cadeia Agroindustrial do Leite. Revista Econômica do Nordeste, v.43, n.1, p.93-108, 2012.

[8] Carvalho, F.; Prazeres, A.R.; Rivas, J. (2013) Cheese whey wastewater: Characterization and treatment. Science of the Total Environment, v. 445-446, p. 385-396. Doi: 10.1016/j.scitotenv.2012.12.038.

[9] Furtado, M. R. Reuso de Água - Tarifas em alta incentivam os primeiros projetos na indústria. Revista Química e Derivados, n. 444, 2005. 
[10] Haupt, Alexandre G.; Dachi, Edison P. Eletrônica Digital. São Paulo: Blucher, 2016.Instructables. Disponível em: < https://www.instructables.com/> Acesso em: 29 abr., 2018.

[11] Kunz, A; Perdomo, C. C.; Oliveira, P. A. V. de. Biodigestores: avanços e retrocessos. Concórdia: Embrapa Cnpsa, 2004. p. 5.

[12] Machado, Edilson Eduardo Werneck; Suzart Neto, Eurico. Manual de Saneamento Básico. 3. ed. Fundação Nacional de Saúde: Ministério da Saúde, 2012. 373 p.

[13] Milkpoint. Ranking Leite Brasil: captação das maiores empresas cresce 5,9\% em 2014. Disponível em: <http://www.milkpoint.com.br/cadeia-do-leite/giro-lacteo/ranking-leite-brasil-captacao-das-maiores-empresascresce-59-em-2014-94625n.aspx>. Acesso em: 01 mai. 2018.

[14] Monk, S. Programação com Arduino: Começando com Sketches. 1. ed. Bookman, 2013.

[15] Moreira, M. S. Estratégia e Implantação do Sistema de Gestão Ambiental (Modelo ISO 14000). 3. ed., Nova Lima: IDG Tecnologia e Serviços Ltda., 2006.

[16] Mte. Ministério do Trabalho e Emprego. Relação Anual de Informações Sociais - Rais. Brasília: Rais. Disponível em: <http://bi.mte.gov.br/>. Acesso em: 24 jun. 2018.

[17] Notícias Agrícolas. Produção de leite aumentou 4,1\% em 2017, segundo o Ibge. Disponível em: <https://www.noticiasagricolas.com.br/noticias/leite/210365-producao-de-leite-aumentou-41-em-2017-segundo-oibge.html\#.W-3GuIdKjIV>. Acesso em: 04 jul. 2018.

[18] Portaldobiogás. Biodigestão anaeróbia. Disponível em: <https://www.portaldobiogas.com/biodigestaoanaerobia/>. Acesso em: 19 maio 2018.

[19] Ribeiro, Marco Antônio. Automação Industrial. Disponível em: <https://paulocrgomes.com.br/en/wpcontent/uploads/2017/08/Automacao-Industrial-Livro.pdf>. Acesso em: 19 maio 2018.

[20] Rodrigues, Kelly; Marinho, Glória. Fungos e Águas residuárias industriais: Nova Tecnologia. Recife: Imprima, 2012. 200 p.

[21] Silveira, W.B.; Produção de etano em permeado de queijo: efeito da concentração de substrato e do nível de oxigênio. Tese de Mestrado UFV, 2004.

[22] Store. Arduino Uno. Disponível em: <https://store.arduino.cc/usa/arduino-uno-rev3>. Acesso em: 19 maio, 2018.

[23] Tera. Por que resíduos da indústria de laticínios devem ser tratados? Disponível em: <https://www.teraambiental.com.br/blog-da-tera-ambiental/por-que-residuos-da-industria-de-laticinios-devem-sertratados>. Acesso em: 4 jul. 2018. 


\title{
Capítulo 18
}

Análise dos pré-tratamentos de resíduos vegetais na produção de metano em reatores de Biodigestão Anaeróbia

\author{
Arthur Ribeiro Torrecilhas \\ Marcio Ronald Sella \\ Flávio Augusto Carraro \\ Juliana Alberton Frias \\ Ana Carla Viotti
}

Resumo: A digestão anaeróbica de resíduos vegetais oferece uma excelente oportunidade para converter grandes recursos biológicos em energia renovável, como é o caso da conversão destes resíduos em biogás, com foco em altos teores de metano. Entretanto, estes resíduos vegetais apresentam uma estrutura de difícil biodegradabilidade por conta do elevado teor de lignina em suas estruturas, mantendo o material intracelular protegido da degradação por meio dos microorganismos da digestão anaeróbia. A capacidade de degradar substratos ricos em lignina pode ser realizada por meio de diversos tipos de pré-tratamentos, entre eles, os mais usuais, o pré-tratamento físico, químico e biológico. No entanto, ainda existem vários desafios que devem ser superados para a digestão eficiente da biomassa lignocelulósica com foco na maior produção de metano no processo de biodigestão, visando a eficiência energética. Um destes desafios é a não geração de subprodutos tóxicos ao meio biológico anaeróbio. Outro, é a ampliação no conhecimento de novas tecnologias e combinação destas, viabilizando o processo de biodigestão, tanto financeiramente quanto eficientemente falando. Este artigo de revisão destaca o estado atual da digestão de biomassa lignocelulósica e discute seus desafios. Para tal, foi necessário realizar uma extensa pesquisa em diferentes fontes bibliográficas, pesquisadores e revistas sobre a biodigestão anaeróbia e materiais lignocelulósicos para uso na biodigestão anaeróbia com foco na produção de metano. Além deste contexto, o artigo também discute as futuras necessidades de pesquisa da digestão de biomassa lignocelulósica, e sua importância no contexto sustentável e na busca pela melhoria de um processo de maior eficiência energética.

Palavras-chave: Biodigestão anaeróbia; Resíduos vegetais; Lignina; Produção de metano; eficiência energética. 


\section{INTRODUÇÃO}

A digestão anaeróbia (DA) faz parte de um processo bioquímico complexo, nele ocorre o tratamento de substratos orgânicos como, por exemplo, esgotos e efluentes industriais, adubos residuários e demais substratos sólidos (cultivos energéticos, resíduos agrícolas e alimentares). A DA recebeu maior atenção nos últimos anos pois, nesse período, esse processo teve uma elevada expansão. Esse processo envolve a estabilização da matéria orgânica complexa por um conjunto de microrganismos que, durante o processo, promovem como subproduto um gás com elevado potencial energético, o biogás, uma fonte de energia renovável capaz de substituir a fonte de energia fóssil (ANGELIDAKI et al., 2009).

Muitas pesquisas foram realizadas para verificação de melhores operabilidades no processo de DA, sempre visando a maior e melhor produção de metano no biogás (AMON et al., 2007).

Entre estas pesquisas, encontra-se a utilização de resíduos de poda vegetal, ricos em carbonos, mantendo o equilíbrio da relação C:N - Carbono: Nitrogênio, essa, fundamental para um excelente processo de biodegradação da matéria em vias anaeróbias. Estes resíduos são co-tratados juntamente com restos de alimentos, entretanto, os resíduos vegetais possuem uma proteção em sua composição que dificulta a penetração dos microrganismos anaeróbios na matéria orgânica do resíduo, complicando a degradação e consumo deste substrato (MATA-ALVAREZ, 2011).

Este trabalho consiste em uma pesquisa bibliográfica com foco na análise exploratória de resultados obtidos por experimentos relativos à produção de metano e tratamento de resíduos vegetais em processos de biodigestão anaeróbia. As buscas foram realizadas no banco de dados bibliográficos Sciencedirect e Portal periódicos CAPES. Foram selecionados artigos publicados entre 2007 e 2018, com exceção de alguns autores essenciais para o complemento deste trabalho que tiveram suas produções fora do período selecionado na metodologia, baseando-se no método descrito por Gerhardt e Silveira (2009).

Assim, este trabalho tem como objetivo realizar uma pesquisa bibliográfica com foco no pré-tratamento destes resíduos de poda vegetal visando a melhor produção de metano. E ainda, buscar o pré-tratamento de resíduos vegetais mais eficiente para o processo da digestão anaeróbia.

\section{REFERÊNCIAS BIBLIOGRÁFICAS}

\subsection{O BIOGÁS, O PROCESSO DE DIGESTÃO ANAERÓBIA E SUAS REAÇÕES BIOQUÍMICAS}

O biogás é o produto gerado pela degradação da biomassa sob condições anaeróbias, podendo existir, basicamente, três categorias de biomassa: (1) substratos de origem agrícola, como esterco líquido, resíduos alimentares e resíduos de colheitas; (2) resíduos municipais, como o lixo orgânico coletado e separado, restos de alimentos vencidos ou rejeitados; (3) e também a biomassa proveniente de resíduos industriais, como a glicerina, subprodutos industriais de alimentos ou resíduos de separadores de gordura. A digestão da parcela orgânica do substrato é convertida em biogás por bactérias contidas no interior de digestores herméticos (GOMEZ, 2013).

0 processo de degradação anaeróbica é um sistema altamente complexo e dinâmico, onde envolvem-se, intimamente, aspectos microbiológicos, bioquímicos e físico-químicos. As etapas de Biodigestão envolvem quatro principais etapas: hidrolise, acidogênese, acetogênese e metanogênese (ANGELIDAKI et al., 2009).

Na hidrólise, carboidratos, lipídios e/ou proteínas complexas de alto peso molecular, são degradados em polímeros solúveis por meio da ação enzimática de bactérias fermentativas hidrolíticas. Uma vez hidrolisados, estes materiais ficam disponíveis para serem transportados ao interior das bactérias fermentativas, onde, por meio da fermentação da matéria orgânica, serão convertidos em hidrogênio ou formiato, dióxido de carbono $\left(\mathrm{CO}_{2}\right)$, piruvato, ácido graxo volátil e outros produtos orgânicos tais como etanol, cetonas ou ácido láctico. Essa etapa é intitulada de acidogênese (ANGELIDAKI et al., 2009; MATAALVAREZ, 2011).

Na terceira etapa, a acetogênese, os produtos da acidogênese sofrem oxidação, sendo convertidos em ácidos acéticos, hidrogênio e $\mathrm{CO}_{2}$ pelas bactérias acetogênicas. Frequentemente, os três primeiros passos da digestão anaeróbia são agrupados como fermentação ácida (ANGELIDAKI et al., 2009; MATA-ALVAREZ, 2011). Posteriormente, na metanogênese, encontram-se dois grupos de Archaeas, as hidrogenotróficas (consumidoras de hidrogênio) e as acetoclásticas (consumidoras de acetato), as Archaeas são responsáveis pela conversão do acetato e do hidrogênio em $\mathrm{CH}_{4}$ (MATA-ALVAREZ, 2011).

Toda estabilidade deste processo depende do equilíbrio crítico existente entre o crescimento harmonioso dos principais grupos metabólicos de bactérias e Archaeas. 0 modelo pode ser simplificado conforme a 
Figura 1.

Figura 1 - Fluxograma das etapas da digestão anaeróbia

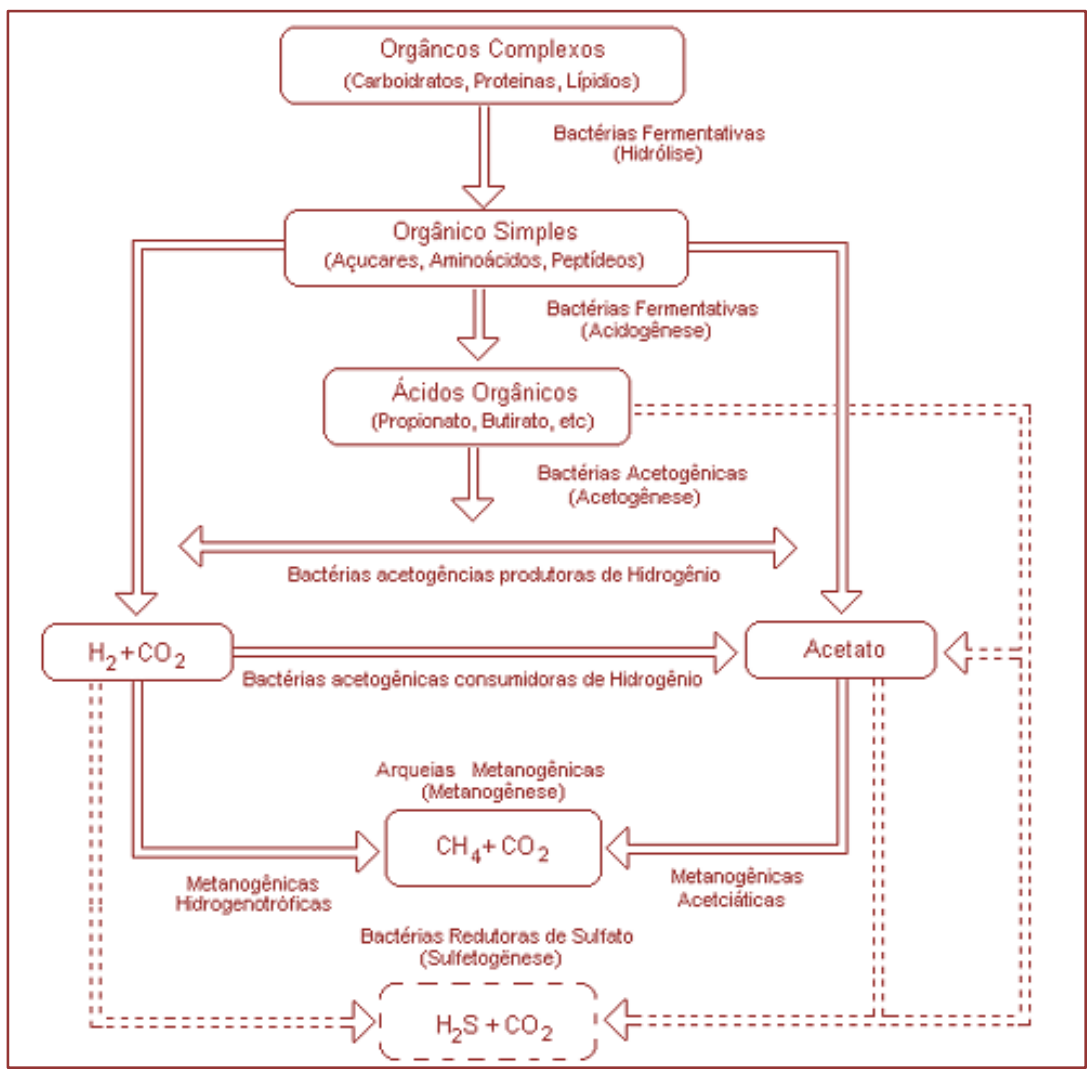

Fonte: Chernicharo (1997)

É evidente que o processo anaeróbio funciona bem, desde que cada classe subsequente de organismos processe a matéria orgânica tão rápido quanto é produzida, ou seja, um acúmulo de substrato pode resultar em sobrecarga dos organismos, comprometendo todo o processo de biodigestão anaeróbia.

\subsection{COMPOSIÇÃO DO BIOGÁS}

O biogás é composto principalmente por $\mathrm{CH}_{4}$ e $\mathrm{CO}_{2}$, a produção e a qualidade do gás estão diretamente relacionadas à quantidade e às características do tipo e concentração de matéria orgânica a ser digerida, população dos organismos presentes no reator e das condições físico-químicas do digestor (temperatura, agitação, alcalinidade e pH) (CONSTANT et al., 1989).

Para Mata-alvarez (2011) o biogás é composto por aproximadamente $65 \%$ de $\mathrm{CH}_{4}$ e $35 \%$ de $\mathrm{CO}_{2}$. Enquanto que Constant et al. (1989) afirma que, geralmente, o biogás é composto por 60 a $65 \%$ de $\mathrm{CH}_{4}, 35$ a $40 \%$ de $\mathrm{CO}_{2}$ e outros gases que em sua minoria constituem de sulfeto de hidrogênio $\left(\mathrm{H}_{2} \mathrm{~S}\right)$, nitrogênio $\left(\mathrm{N}_{2}\right)$, hidrogênio $\left(\mathrm{H}_{2}\right)$ e traços de oxigênio $\left(\mathrm{O}_{2}\right)$, monóxido de carbono (CO), amônia $\left(\mathrm{NH}_{3}\right)$ e outros compostos orgânicos voláteis.

Rosa et al. (2018), em sua pesquisa que buscou analisar o potencial energético dos subprodutos (lodo e biogás) de um reator UASB em escala real, verificou a composição média do biogás produzido pelo reator, chegando a valores médios de 78,2\% de $\mathrm{CH}_{4}, 6,7 \%$ de $\mathrm{CO}_{2}$, e 15,1\% de certa mistura de outros gases constituintes do tratamento.

\subsection{SUBSTRATO}

O substrato é a principal fonte de matéria orgânica utilizada para a produção de biogás por meio da digestão anaeróbia. As principais fontes de substratos para a biodigestão anaeróbia são resíduos agrícolas, resíduos industriais e urbanos. 
Substratos urbanos são a fração orgânica dos resíduos domésticos e comerciais, como por exemplo restos alimentares, resíduos de jardinagem, resíduos de escritório, entre outros. Os resíduos orgânicos recolhidos e selecionados são, muitas vezes, co-digeridos com estrume animal e/ou lodos de digestores anaeróbios. 0 volume de resíduos domésticos gerados na sociedade cresce cada vez mais, indicando uma fonte de potencial elevado para processos anaeróbios. Além de que estes resíduos, quando utilizados no processo de digestão anaeróbia, não competem pelo uso de terra, quando comparado aos aterros sanitários, assim acabam por não gerar impactos negativos sobre a sustentabilidade (RUTZ et al., 2011).

Indústrias de alimentos e bebidas, forragens, processamento de peixe, leite, amido, açúcar, produtos farmacêuticos, bioquímicos e cosméticos, papel e celulose, e até mesmo matadouros, acabam, por sua vez, gerando subprodutos, resíduos e desperdícios no decorrer do processamento da matéria-prima. Dentre estes resíduos industriais, existem diversos com potencial de geração de metano e, em sua grande maioria, são ricos em lipídios, proteínas ou açúcares. Muitos resíduos orgânicos industriais são co-digeridos com esterco animal, aumentando, assim, a produção de metano e uma melhor estabilidade no processo de digestão anaeróbia (BIOSANTECH et al., 2013).

\subsection{RESÍDUO VEGETAL}

Muitos pesquisadores estão realizando experimentos e estudos com o uso de materiais lignocelulósicos, ou seja, os resíduos vegetais ou de podas vegetais. Entre as fontes renováveis de energia, a biomassa lignocelulósa é reconhecida como a maior e mais sustentável fonte de energia em todo o mundo. $\mathrm{Na}$ natureza, a biomassa lignocelulósa é uma fonte orgânica abundante, incluindo resíduos agrícolas e culturas energéticas. Existe uma quantidade considerável de resíduos lignocelulósicos que se acumulam a partir de atividades agrícolas, florestais e outras atividades da humanidade, que contêm grandes quantidades de energia (ZHANG et al., 2010).

Porém, as estruturas destes vegetais são ricas em lignina, compondo as paredes celulares secundárias das plantas como a principal barreira para a conversão da biomassa em biogás (ZHANG et al., 2010).

\subsubsection{PRÉ-TRATAMENTO DE RESÍDUOS VEGETAIS}

0 pré-tratamento dos resíduos vegetais tem como principal foco a quebra da parede estrutural do vegetal, conhecida como lignina, conforme pode ser observado na Figura 2.

Figura 2 - Estrutura vegetal antes e após pré-tratamento para quebra da lignina

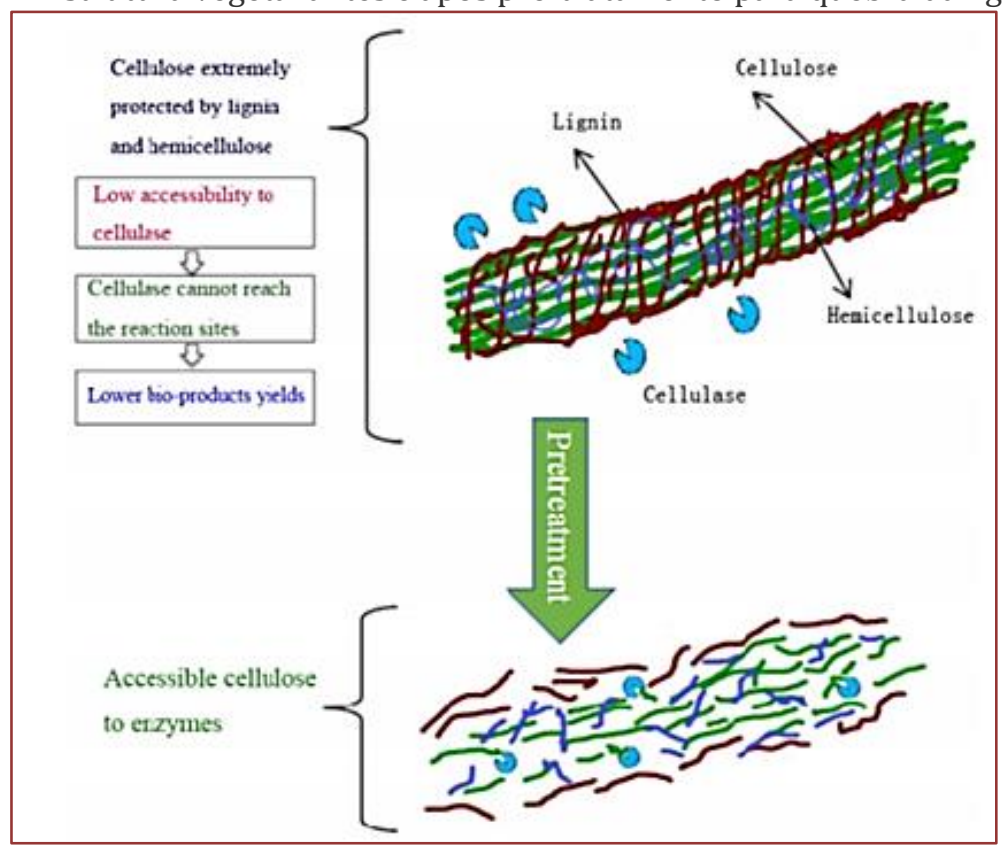

Fonte: Tian et al. (2018) 
Como observado na imagem, a quebra da lignina por meio de um pré-tratamento do vegetal facilita o acesso dos microrganismos responsáveis pela degradação do material orgânico do resíduo vegetal, aumentando, assim, os teores de metano na composição do biogás gerado (TIAN et al., 2018).

\subsubsection{PRÉ-TRATAMENTOS FÍSICOS}

Um dos tratamentos físicos mais utilizados é a redução do tamanho, grau ou cristais do resíduo vegetal. Pesquisas realizadas por Ghaffar e Fan (2013) apontam que ocorreu uma significante redução nos teores de lignina ao realizarem a trituração da palha de trigo (64\% de remoção). Portanto, os pré-tratamentos físicos podem aumentar a área acessível da biomassa lignocelulósa. No entanto, o subproduto de materiais tóxicos é geralmente insignificante no progresso do pré-tratamento, o que é uma vantagem importante do método de pré-tratamento físico.

Após a moagem por moinho, os materiais de palha de trigo são reduzidos e, consequentemente, têm sua área de superfície específica aumentada. A disponibilidade de celulase pode ser aumentada e a hidrólise da celulase pode ser mais completa. Além disso, a tecnologia de moagem de moinho pode tornar a estrutura de lignina solta, de modo que a estrutura e área do vegetal fique mais acessível à biodegradação. No entanto, o moinho é um método de pré-tratamento mecânico de alto consumo de energia, o que aumenta os custos de produção significativamente (COIMBRA, 2016).

\subsubsection{PRÉ-TRATAMENTOS QUÍMICOS}

Os métodos químicos são extremamente eficazes na destruição do composto lignocelulósicos. No entanto, a produção de produtos tóxicos, a perda de alguns compostos orgânicos e o alto custo do pré-tratamento são desvantagens comuns (AMON et al., 2007). Existem dois tipos principais de tratamentos químicos, os que ocorrem por vias ácidas e os por vias alcalinas.

Sobre o pré-tratamento químico da palha de trigo, a tecnologia de pré-tratamento ácido não é um método novo, entretanto os estudos sobre esse método ainda são realizados. Sabe-se que o efeito do prétratamento, quando combinado com outros pré-tratamentos, proporciona uma maior eficiência na remoção do material lignocelulósico (TIAN et al., 2018).

Os ácidos podem ser aplicados para pré-tratamento de matéria-prima lignocelulósica, em estudos realizados por Tian et al. (2018), a lignina de partícula vegetais, após tratamento com bases acidas, foi reduzida em até $70 \%$.

Nos experimentos de Brodeur et al. (2011), a palha de trigo foi moída e adicionada ao reator de prétratamento, onde aproximadamente $90 \%$ da lignina foi quebrada. Vale ressaltar que neste modelo, foi empregado dois tipos de tratamento, o físico devido a trituração dos resíduos e o químico.

Tian et. al. (2018) ressalta que no processo de degradação ácida da lignina pode ocorrer a geração de subprodutos tóxicos para as células do processo de biodigestão anaeróbia.

Por outro lado, existe também o pré-tratamento por meio alcalino, onde uma das principais vantagens dessa metodologia é a remoção eficiente da lignina, bem como a sua capacidade de aumentar a área das superfícies expostas. Entretanto, com um longo tempo de pré-tratamento ocorre a formação de sais, estes são relatadas como as desvantagens dos métodos de pré-tratamento alcalino (LI, KIM e NGHIEM, 2010).

Hidróxido de sódio e carbonato de sódio (sais) são as principais soluções alcalinas utilizadas para aplicação do pré-tratamento. Os efeitos do pré-tratamento da palha de trigo após o pré-tratamento com hidróxido de sódio foram estudados. A concentração ótima de tratamento alcalino da palha de trigo foi determinada e os principais componentes dos produtos de degradação foram analisados. A palha de trigo tratada com diferentes concentrações de hidróxido de sódio foi hidrolisada com eficiência, removendo altos teores de lignina e não gerando nenhum subproduto tóxico para o processo de biodigestão. Estudos apontam a redução de lignina em até 97\%, entretanto este processo deve ser observado, pois altas concentrações de sais em reatores de biodigestão podem influenciar negativamente na produção de metano (KUMAR, 2008). 


\subsubsection{PRÉ-TRATAMENTOS ORGÂNICOS}

Os métodos de pré-tratamento orgânicos podem eficientemente remover a ação de barreira dos materiais vegetais. No entanto, os principais problemas foram a recuperação dos microrganismos utilizados nestes processo, os enormes custos (em alguns casos), bem como a dificuldade de operação deste pré-tratamento podem ser considerados como desvantagens. Os métodos de pré-tratamento de soluções orgânicas podem reduzir as ligações internas da lignina em até 60\% (BENSAH e MENSAH, 2013).

Foi observado que fatores como a temperatura de reação, tempo e concentração de soluções são os principais parâmetros que afetam o processo de pré-tratamento. Soluções orgânicas como metanol, glicerol, acetona e etileno foram usadas para pré-tratar a palha de trigo (BENSAH e MENSAH, 2013).

\subsection{RESULTADOS DE REMOÇÃO PARA OS PRÉ-TRATAMENTO DE RESÍDUOS VEGETAIS}

Como resultado observado nos estudos analisados verifica-se na tabela da Figura 3, as informações de remoção de lignina conforme os trabalhos pesquisados.

\begin{tabular}{|c|c|c|c|c|}
\hline $\begin{array}{l}\text { Método } \\
\text { utilizado }\end{array}$ & $\begin{array}{l}\text { Residuo } \\
\text { vegetal }\end{array}$ & $\begin{array}{l}\text { Remoção } \\
\text { de lignina }\end{array}$ & Gerou subprodutos & Autor \\
\hline Físico & Palha de trigo & $64 \%$ & $\begin{array}{l}\text { sim, porém } \\
\text { insignificante para o } \\
\text { processo de DA }\end{array}$ & Ghaffar e Fan (2013) \\
\hline Químico - Acido & Palha de trigo & $70 \%$ & $\begin{array}{l}\text { Sim, agressivo para o } \\
\text { processo de DA }\end{array}$ & Tian et al. (2018) \\
\hline Físico e Químico & Palha de trigo & $90 \%$ & $\begin{array}{l}\text { Sim, agressivo para o } \\
\text { processo de DA }\end{array}$ & Brodeur et. al., (2011) \\
\hline Químico - Alcalino & Palha de trigo & $97 \%$ & $\begin{array}{c}\text { Sim, sais que podem } \\
\text { prejudicar o processo } \\
\text { de DA }\end{array}$ & Kumar (2008) \\
\hline Orgânicos & Palha de trigo & $60 \%$ & Não & Mensah (2013) \\
\hline
\end{tabular}

Fonte: os autores (2019)

Assim, nota-se que o processo de remoção mais eficiente é por meio físico e químico, porém a geração de subprodutos tóxicos ao processo de biodigestão pode acabar prejudicando a operação de reatores.

\subsection{PRODUÇÃO DE METANO COM O USO DE RESÍDUOS VEGETAIS PRÉ-TRATADOS}

O emprego da palha de trigo no processo de biodigestão anaeróbia é retratado por diversos autores, por ser um resíduo muito comum entre os resíduos vegetais. Por estas razões, tem-se como referência os resultados destes estudos com relação aos elevados teores de metano no processo de biodigestão anaeróbia.

Ghaffar e Fan (2013) compararam seus resultados com o de outros autores que utilizaram apenas resíduos orgânicos sem a adição de resíduos vegetais. Os resultados quanto a produção de metano foram $15 \%$ maiores quando empregados os resíduos de poda vegetal, e $45 \%$ maior quando realizado o prétratamento físico nestes resíduos vegetais.

Kumar (2008) buscou comparar seu experimento com a produção de metano de resíduos de um restaurante. Foi observado que no processo de biodigestão com resíduos vegetais pré-tratados com meios básicos de tratamento, onde foi empregado altas taxas de sódio, acabou prejudicando o processo de biodigestão anaeróbia, nestas condições, seu experimento com altas taxas de sódio produziu $20 \%$ menos metano que estudos sobre produção de metano com uso de resíduos orgânicos oriundos de restaurantes. Isso foi explicado devido à alta taxa de sódio em seu tratamento.

Corrigindo esta situação, Kumar (2008) aplicou um novo pré-tratamento em seu resíduo vegetal, desta vez com baixo teor de sódio, resultando em uma remoção de lignina $12 \%$ menor que no primeiro tratamento, obtendo resultados de $85,36 \%$ de remoção de lignina. Desta vez, quando aplicado no processo de biodigestão, obteve resultados satisfatórios, chegando em 55\% a mais de teores de metano quando comparado com a utilização de substratos apenas de resíduos de restaurantes no processo de DA. 
Bensah e Mensah (2013) não compararam seus resultados com outros trabalhos, porém quando comparado com os de Kumar (2008) obteve $24 \%$ menos produção de metano, e quando comparado com Ghaffar e Fan (2013) sua produção foi de $15 \%$ a mais de metano.

Melhores resultados foram obtidos com a pesquisa de Brodeur et al. (2011), com o emprego da adição de mais de um tratamento, porém seu sistema não durou muito tempo, pois o reator sofreu perda da biomassa microbiana devido ao elevado grau de toxicidade pelo processo de pré-tratamento.

\subsection{DEMAIS PROCESSOS DE PRÉ-TRATAMENTOS OBSERVADOS}

Existem outros tipos de tratamentos dos quais não foram abordados nesta pesquisa devida a dificuldade de encontrar resultados na literatura, principalmente relacionados com a co-digestão de resíduos vegetais com resíduos alimentares, e resíduos do tipo palha de trigo.

Existem outros pré-tratamentos com técnicas mais avançadas que ainda necessitam de maiores estudos para sua aplicabilidade, como por exemplo o uso de líquidos iônicos, uso de microrganismos próprios para rompimento de cadeias de vegetais lignocelulósicos e o emprego de diferentes tipos de fungos, como por exemplo, fungos brancos e marrons.

\section{CONCLUSÃO}

A conversão de materiais vegetais tais como a palha de trigo em produtos da biodigestão é altamente eficaz, desde que sejam aplicados métodos eficazes de pré-tratamento nestes resíduos. 0 surgimento de novas técnicas de pré-tratamento de resíduos vegetais tem apresentado um elevado crescimento no meio acadêmico, porém é fundamental o cuidado com a formação de subprodutos gerados após o prétratamentos, pois os mesmos podem afetar a biodigestão.

Fato estes que apresentam a necessidade de combinar diferentes estratégias de pré-tratamento como é o caso do uso do pré-tratamento físico com a sequência de um pré-tratamento químico com base alcalina.

A exploração eficiente de materiais de palha de trigo e outros vegetais, como biocombustível, pode atender às demandas por fontes de energia à medida que o desenvolvimento econômico cresce e, da mesma forma, fornece uma estratégia objetiva para a conservação ambiental e o crescimento sustentável.

Mais pesquisas e métodos efetivos de pré-tratamento devem ser realizados com relação a quebra de lignina para processos de biodigestão anaeróbia e sua contribuição para a degradação dos materiais de palha de trigo.

\section{REFERÊNCIAS}

[1] Amon, T., Amon, B., Kryvoruchko, V., Zollitsch, W., Mayer, K., Gruber, L., 2007. Biogas production from maize and dairy cattle manure-Influence of biomass composition on the methane yield. Agric. Ecosyst. Environ. 118, 17382.

[2] Angelidaki, I. et al. Defining the biomethane potential (BMP) of solid organic wastes and energy crops: a proposed protocol for batch assays. Water Science \& Technology, [s.l.], v. 59, n. 5, p.927-934, mar. 2009. IWA Publishing. http://dx.doi.org/10.2166/wst.2009.040.

[3] Brodeur G, Yau E, Badal K, Collier J, Ramachandran KB, Ramakrishnan S. Chemical and physicochemical pretreatment of lignocellulosic biomass: a review. Enzym Res 2011;2011:17.

[4] Biosantech, Teodorita Al Seadi et al. Biomass resources for biogas production. The Biogas Handbook, [s.l.], p.19-51, 2013. Elsevier. http://dx.doi.org/10.1533/9780857097415.1.19.

[5] Bensah EC, Mensah M. Chemical pretreatment methods for the production of cellulosic ethanol: technologies and innovations. Int J Chem Eng 2013;2013:21.

[6] Chernicharo, Carlos Augusto Lemos. Reatores Anaeróbios. Belo Horizonte: Departamento de Engenharia Sanitária e Ambiental - UFMF, 1997. Volume 5, 2ª ed. 588 p.

[7] Coimbra MC, Duque A, Saéz F, Manzanares P, Garcia-Cruz CH, Ballesteros M. Sugar production from wheat straw biomass by alkaline extrusion and Enzymatic hydrolysis. Renew Energy 2016;86:1060-8.

[8] Constant, M. et al. Biogas end-use in the European Community. Barking, Uk: Elsevier Science Publishers, 1989. 345 p. 
[9] Ghaffar SH, FAN M. Structural analysis for lignin characteristics in biomass straw. Biomass- Bioenergy 2013;57:264-79.

[10] Gomez, Claudius da Costa. Biogas as an energy option: an overview. The Biogas Handbook, [s.l.], p.1-16, 2013. Elsevier. http://dx.doi.org/10.1533/9780857097415.1.

[11] Kumar R, Singh S, Singh O. Bioconversion of lignocellulosic biomass: biochemical and molecular perspectives. J Ind Microbiol Biotechnol 2008;35:377-91.

[12] LI X, Kim TH, Nghiem NP. Bioethanol production from corn stover using aqueous ammonia pretreatment and two-phase simultaneous saccharification and fermentation (TPSSF). Bioresour Technol 2010;101:5910-6.

[13] Métodos de pesquisa / [organizado por] Tatiana Engel Gerhardt e Denise Tolfo Silveira; coordenado pela Universidade Aberta do Brasil - Uab/Ufrgs e pelo Curso de Graduação Tecnológica - Planejamento e Gestão para o Desenvolvimento Rural da Sead/Ufrgs. - Porto Alegre: Editora da UFRGS, 2009.

[14] Mata-Alvarez, J.. Biomethanization of the Organic Fraction of Municipal Solid Wastes. Department Of Chemical Engineering Of Barcelona, Barcelona, Spain: Iwa Publishing, 2011. 323 p.

[15] Rosa, A.p. et al. Assessing the potential of renewable energy sources (biogas and sludge) in a full-scale Uasbbased treatment plant. Renewable Energy, [s.l.], v. 124, p.21-26, ago. 2018. Elsevier BV. http://dx.doi.org/10.1016/j.renene.2017.09.025.

[16] Rutz D, et al. Organic waste for biogas production in urban areas. Proceedings of 19th European Biomass Conference and Exhibition, Berlin, Germany, 2125-2131, 2011. DOI:10.5071/19thEUBCE2011-VP3.4.27.

[17] Tian, Shuang-qi; Zhao, Ren-yong; Chen, Zhi-cheng. Review of the pretreatment and bioconversion of lignocellulosic biomass from wheat straw materials. Renewable And Sustainable Energy Reviews, [s.l.], v. 91, p.483489, ago. 2018. Elsevier BV. http://dx.doi.org/10.1016/j.rser.2018.03.113.

[18] Zhang L, XU CC, Champagne P. Overview of recent advances in thermo-chemical conversion of biomass. Energy Convers Manag 2010;51(5):969-82. 


\section{Capítulo 19}

Estudo bibliográfico sobre Estações de Recarga de Veículos Elétricos

\section{Matheus Binotto Francescatto \\ Anderson Felipe Habekost}

\section{Cristiano Roos}

Resumo: Com a crescente preocupação com os problemas ambientais, são constantes as buscas por soluções de engenharia em escala global. Neste contexto, volta-se a atenção para o setor automobilístico, o qual é responsável por uma grande parte das emissões prejudicais ao meio ambiente. Assim, os veículos elétricos aparecem como uma das soluções para este problema. Porém, não é possível ocorrer uma popularização destes automóveis sem haver uma estrutura de recarga que possa atender esta demanda. Neste contexto, o objetivo deste trabalho é apresentar estudos e pesquisas realizadas na área de viabilidade técnica e econômica voltados para a infraestrutura de recarga, de forma a proporcionar conhecimento e auxiliar futuros projetos de pesquisa nesta área.

Palavras Chave: Estações de Recarga, Veículos Elétricos, Engenharia Econômica. 


\section{INTRODUÇÃO}

Mediante a assinatura do acordo de Paris em 2015, um total de 189 países concordou em definir metas individuais de redução de Dióxido de carbono $\left(\mathrm{CO}_{2}\right)$ (Vital, 2018). Um dos setores mais afetados foi o setor automobilístico, pois possui uma influência muito elevada em relação à quantidade de emissões de poluentes na atmosfera. Segundo Deign (2016), países como Alemanha, Noruega e Índia buscam banir os veículos de combustão interna após 2030, desencadeando assim uma busca por substitutos aceitáveis. Entre os substitutos, surge o veículo elétrico, o qual se torna uma das melhores opções para a resolução destes problemas, devido aos benefícios que o mesmo apresenta no âmbito das emissões e seus danos. Contudo, junto ao crescente interesse pelos veículos elétricos, se torna importante atentar-se para a infraestrutura de recarga necessária para a introdução efetiva desses automóveis.

Com isto em mente, países como o Brasil, onde os incentivos e estudos sobre este tipo de tecnologia não são muito presentes, se torna importante à realização de uma pesquisa de viabilidade técnica e econômica voltada para a infraestrutura de recarga dos veículos elétricos. 0 presente trabalho se justifica e busca contribuir fornecendo mais uma pesquisa que trata sobre a implantação das estações de recarga no Brasil.

Neste contexto, o objetivo principal deste trabalho é identificar na literatura pesquisas na área de Engenharia Econômica que tratem sobre a infraestrutura de recarga dos veículos elétricos, contribuindo com uma revisão bibliográfica sobre o assunto. Junto a isso, este trabalho traz como objetivos secundários: apresentar informações técnicas básicas sobre os veículos elétricos e estações de recarga, apresentar trabalhos na área técnica relacionada a infraestrutura de recarga e determinar as melhores opções para a análise deste tipo de investimento.

\section{PROCEDIMENTOS METODOLÓGICOS}

Para este trabalho, foi utilizado o método de pesquisa bibliográfica (GIL, 2007). Inicialmente, baseou-se nos livros de Hirschfeld (1979), Casarotto e Kopittke (2010) e Hess et al. (1992). Após, o trabalho foi baseado em uma pesquisa em periódicos nacionais e internacionais, tendo a pesquisa internacional se concentrado na maior parte em publicações disponíveis pelo Portal de Periódicos da Capes, nas bases ScienceDirect e Emerald.

Seguindo as definições de Miguel (2012), esta pesquisa tem enfoque temático devido ao fato da mesma estar centrada em um foco específico, sendo este um tema da área das engenharias. Ainda segundo o autor, a função da pesquisa é classificada como de atualização, por trazer informações de estudos publicados recentemente. A abordagem escolhida pode ser considerada como uma bibliografia anotada, pois apresenta um conjunto de fontes sem trazer uma análise crítica, mostrando apenas uma gama de artigos e pesquisas que tratam sobre a análise da viabilidade técnica e econômica das estações de recarga.

\section{RESULTADOS: PESQUISA BIBLIOGRÁFICA}

Essa seção apresenta os resultados da pesquisa bibliográfica sobre os veículos elétricos e sobre as estações de recarga, juntamente com artigos aplicados envolvendo a viabilidade técnica e econômica de infraestruturas de recarga.

\subsection{VEÍCULOS ELÉTRICOS}

De acordo com Calçado (2015), os veículos elétricos surgiram com o objetivo de ser uma alternativa aos impactos danosos ao meio ambiente devido à contaminação do ar e à emissão de ruídos causados pelos motores de combustão interna. Segundo Xiong et al. (2019), atualmente, uma das obrigações dos veículos elétricos é conseguir obter um menor uso de energia, uma boa economia e uma forte praticidade, tudo isso ao mesmo tempo. Os veículos elétricos são uma proposta de otimização dos veículos convencionais, entretanto, envolvem os meios essenciais para a integração entre engenharia elétrica e mecânica, tendo também uma participação das engenharias eletrônica, de materiais e química (CALÇADO, 2015).

Em relação ao seu funcionamento, basicamente o veículo elétrico faz uso da propulsão por meio de motores elétricos para transportar pessoas, objetos ou uma carga específica, sendo composto por um sistema primário de energia, uma ou mais máquinas elétricas e um sistema de acionamento e controle de velocidade (ORNELLAS, 2013). Juntamente com esses princípios, existem outros componentes exclusivos 
dos veículos elétricos, como a transmissão de velocidade única, o carregador embarcado e o sistema de frenagem regenerativa (SOUSA, 2015).

Existem quatro tipos principais de veículos elétricos que estão entre os mais populares e mais utilizados na atualidade: veículos elétricos híbridos (HEV), veículos elétricos híbridos plug-in (PHEV), veículos elétricos plug-in (PEV) ou veículos elétricos a bateria (BEV) e os veículos elétricos a célula de combustível (FCEV).

O HEV utiliza em seu funcionamento um motor de combustão interna juntamente com baterias elétricas, fazendo uso da energia do freio para recarregar essas baterias, obtendo com isso vantagens econômicas e ambientais sobre os carros convencionais (RAHMANI e LOUREIRO, 2019). Segundo Doppstatd, Koberstein e Vigo (2016), com os problemas que os veículos elétricos apresentam em relação à autonomia e capacidade energética das baterias, o HEV acaba por se tornar uma opção mais segura e viável. Rahmani e Loureiro (2019), ressaltam que os HEVs são mais baratos que os veículos elétricos e os PHEVs, pois este tipo de automóvel não sofre de problemas de bateria ou falta de infraestrutura, apresentando benefícios de incentivos públicos em diversos países, fator que os tornam competitivos no mercado atual.

O PHEV possui dois motores: um de combustão interna e um puramente elétrico. Esses dois motores possuem a possibilidade de serem facilmente alternados permitindo a utilização de um ou outro dependendo da situação (PLÖTZ, FUNKE e JOCHEM, 2018). Devido a essa possibilidade de operação, segundo Hiermann et al. (2018), os PHEVs não tem a restrição de autonomia como os BEVs, devido à opção de serem recarregados, reduzindo o uso de combustíveis fósseis na viagem.

O BEV adota inteiramente o motor elétrico como motor principal, sem o apoio de um motor de combustão interna tradicional, podendo também, como todos os veículos elétricos, recarregar as baterias através de um processo conhecido como a frenagem regenerativa, que utiliza o motor elétrico para ajudar na desaceleração do veículo recuperando parte da energia normalmente convertida em calor pelos freios (CALÇADO, 2015).

o FCEV tem a capacidade de oferecer tanto a autonomia, quanto o curto tempo de recarga que o consumidor está acostumado com os outros tipos de automóveis, porém ele carece em infraestrutura (LANE et al. 2017). Ainda segundo a autora, o FCEV utiliza uma célula de combustível como motor e hidrogênio como combustível, obtendo como resultado um veículo com zero emissões e uma autonomia e tempo de recarga próxima a dos veículos convencionais a gasolina. Comparado com os outros tipos de veículos elétricos como o BEV e o HEV, o FCEV também apresenta mais vantagens como: eficiência de conversão energética muito maior que os motores de combustão tradicionais e nenhum poluente emitido (SONG et al. 2017).

\subsection{ESTAÇÕES DE RECARGA}

Segundo Gonzáles, Siavichay e Espinoza (2019), a principal função das estações de recarga para veículos elétricos (EVCS) é fornecer e controlar a energia que é transferida para a bateria do veículo. Com isso em mente, as estações de recarga tem uma participação crítica no desenvolvimento dos veículos elétricos, sendo no seu uso diário ou na sua interação com a rede elétrica (SBORDONE et al. 2014). Segundo Zhang et al. (2018), uma das principais barreiras para a disseminação do uso de veículos elétricos é a falta de infraestrutura de recarga pública. De acordo com Neiameh et al. (2017), uma infraestrutura de recarga apropriada pode ser o aspecto necessário para a adoção em massa dos veículos elétricos.

Para Sbordone et al. (2014), uma estação de recarga deve possuir a capacidade de carregar a bateria de um veículo elétrico rapidamente, detectar o estado da carga da bateria e se adaptar aos diferentes modelos de carros e baterias. Para os mesmos autores, em qualquer caso, o tempo de carregamento deve se adequar com as características da bateria do veículo a fim de garantir uma recarga ideal, prolongando a vida da bateria. Segundo Lokesh e Min (2017), o tempo de carregamento da bateria depende do tipo de estação de recarga que é utilizada e também da carga inicial presente na bateria.

Gonzáles, Siavichay e Espinoza (2019), classificam as estações de recarga com base nos níveis de energia juntamente com o tempo necessária para a recarga, obtendo assim três categorias:

a) Nível 1: esse nível é utilizado em residências com uma voltagem de até 120 Volts e capacidade energética de 3,7 kW. Nesse tipo de estação o carregamento do veículo elétrico demora um tempo elevado, podendo estar entre 6 a 24 horas. A conversão de energia deve ser feito pelo conversor do veículo elétrico; 
b) Nível 2: possui uma voltagem entre 208 a 240 Volts, capacidade de 3,7 kW até $22 \mathrm{~kW}$ e uma corrente que pode chegar a $32 \mathrm{~A}$. 0 tempo de carregamento pode ser menor que 6 horas dependendo do status atual do veículo. A conversão elétrica também deve ser feita pelo conversor do veículo elétrico;

c) Nível 3: nessa categoria estão os chamados fast chargers, o faixa de energia máxima que este tipo de estação de recarga consegue aguentar é de $50 \mathrm{~kW}$ até $240 \mathrm{~kW}$ com uma corrente elétrica chegando em até 400 A. Nesse nível as estações de recarga são responsáveis por fazer a conversão entre corrente alternada e corrente direta, a voltagem chega a até $600 \mathrm{~V}$ e é resultante da corrente direta.

Segundo Zhang et al. (2018), uma infraestrutura de recarga privada geralmente é acessível apenas a uma pessoa ou um pequeno grupo, uma infraestrutura pública é utilizada publicamente, tendo possiblidade de um maior número de veículos, e existem também a infraestrutura semi pública, que é reservada para locais de trabalhos e clubes. 0 tipo de carregamento realizado também dependerá da entrada (receptor) existente no veículo. Carregamentos de nível 1 ou 2 possuem compatibilidade com todos os veículos com conector e receptor padrões do tipo 1 (SAE J1772 ou conector Yazaki), usado nos EUA e Japão, e tipo 2 (VDE-AR-E 2623-2-2 ou conector Mennekes), usado na Europa e China (TUITE, 2012).

Por outro lado, segundo FGV Energia (2017), mesmo tendo-se um padrão para os conectores de níveis 1 e 2, para os carregamentos do tipo fast charger ainda não foi desenvolvido um padrão, fazendo com que esse tipo de recarga tenha até três modelos diferentes: SAE Combo ou CCS, CHAdeMO e Tesla Supercharger. Ainda segundo o autor, apesar da falta de uniformidade, as estações de recargas tendem a apresentar modelos que atendam tanto o CHAdeMO quando o SAE Combo.

Em relação ao tempo específico de recarga, cada veículo elétrico será diferente, pois dependem diretamente da capacidade de sua bateria. De acordo com Pelletier, Jabali e Laporte (2014), leva-se em conta também que o tempo anunciado para o carregamento geralmente é apenas considerando $80 \%$ da capacidade da bateria, isso ocorre porque a recarga não é linear durante todo o processo de carregamento. No Quadro 1, alguns dados técnicos sobre o carregamento de alguns veículos.

Quadro 1 - Dados técnicos de recarga de alguns veículos elétricos

\begin{tabular}{|c|c|c|c|c|c|c|c|c|c|}
\hline \multirow[b]{2}{*}{ Veículo } & \multirow{2}{*}{$\begin{array}{c}\text { Tipo de } \\
\text { Bateria e } \\
\text { Energia }\end{array}$} & \multirow[b]{2}{*}{ Autonomia } & \multirow[b]{2}{*}{ Conector } & \multicolumn{2}{|c|}{ Nivel 1} & \multicolumn{2}{|c|}{ Nivel 2} & \multicolumn{2}{|c|}{ Nível 3} \\
\hline & & & & Exigência & $\begin{array}{c}\text { Tempo de } \\
\text { recarga }\end{array}$ & Exigência & $\begin{array}{c}\text { Tempo de } \\
\text { recarga }\end{array}$ & Exigência & $\begin{array}{c}\text { Tempo de } \\
\text { recarga }\end{array}$ \\
\hline $\begin{array}{c}\text { Toyata } \\
\text { Prius PHEV } \\
(2012)\end{array}$ & $\begin{array}{c}\text { Li-Ion } 4.4 \\
\text { kWh }\end{array}$ & $22.6 \mathrm{Km}$ & SAE J1722 & $1.4 \mathrm{~kW}$ & 3 horas & $3.8 \mathrm{~kW}$ & 2.5 horas & $\mathrm{N} / \mathrm{A}$ & $\mathrm{N} / \mathrm{A}$ \\
\hline \begin{tabular}{|c|} 
Chevrolet \\
Volt PHEV
\end{tabular} & $\begin{array}{c}\text { Li-Ion } 16 \\
\mathrm{kWh}\end{array}$ & $65 \mathrm{Km}$ & SAE J1722 & $0.96-1.4 \mathrm{~kW}$ & 5-8 horas & $3.8 \mathrm{~kW}$ & $2-3$ horas & $\mathrm{N} / \mathrm{A}$ & N/A \\
\hline $\begin{array}{c}\text { Mitsubishi } \\
\text { i-MiEV }\end{array}$ & $\begin{array}{c}\text { Li-Ion } 16 \\
\text { kWh }\end{array}$ & $155 \mathrm{Km}$ & $\begin{array}{c}\text { SAE J1722 } \\
\text { JARI/TEPCO }\end{array}$ & $1.5 \mathrm{~kW}$ & 7 horas & $3 \mathrm{~kW}$ & 14 horas & $50 \mathrm{~kW}$ & 30 minutos \\
\hline $\begin{array}{l}\text { Nissan } \\
\text { Leaf EV }\end{array}$ & $\begin{array}{c}\text { Li-Ion } 24 \\
\text { kWh }\end{array}$ & $161 \mathrm{Km}$ & $\begin{array}{c}\text { SAE J1722 } \\
\text { JARI/TEPCO }\end{array}$ & $1.8 \mathrm{~kW}$ & $12-16$ horas & $3.3 \mathrm{~kW}$ & $6-8$ horas & $50+\mathrm{kW}$ & $\begin{array}{l}15-30 \\
\text { minutos }\end{array}$ \\
\hline \begin{tabular}{|l} 
Tesla \\
Roadster \\
Ev \\
\end{tabular} & $\begin{array}{c}\text { Li-Ion } 53 \\
\text { kWh }\end{array}$ & $395 \mathrm{Km}$ & SAE J1722 & $1.8 \mathrm{~kW}$ & $30+$ horas & $9.6-16.8 \mathrm{~kW}$ & 4-12 horas & $\mathrm{N} / \mathrm{A}$ & $\mathrm{N} / \mathrm{A}$ \\
\hline
\end{tabular}

Fonte: Adptado Yilmaz e Krein (2013).

Um nível de potência maior implica um menor tempo de carregamento, mas um maior custo de equipamento, geralmente um carregamento no nível 1 pode ser obtido em uma estação de recarga comum, já para o nível 2 ou 3 são necessárias estações de recarga dedicadas (YILMAZ e KREIN, 2013). Uma estação de recarga de nível 2, de acordo com Ference (2017), pode custar entre US\$1,200.00 até US\$ 2,000.00, enquanto uma estação de nível 3, segundo Ducharme e Kargas (2016), pode vir a custar entre US\$15,000.00 e US\$ 60,000.00.

\subsection{ESTUDOS TÉCNICOS APLICADOS ENVOLVENDO ESTAÇÕES DE RECARGA}

Xue e Gwee (2017), realizaram um estudo com o objetivo de dar uma visão global das considerações técnicas necessárias para a adoção de uma estação de recarga de nível 2, junto com o detalhamento das 
vantagens que a estação de recarga de nível 2 tem sobre as de nível 1. Para isso, os autores utilizam a referência de outras literaturas, estudos de caso e práticas globais, inserindo-as no cenário de Singapura. Os autores concluem que as estações de recarga de nível 2 possuem vantagens em aspectos como: menor range anxiety, maior retorno econômico e maior eficiência de recarga.

Gonzáles, Siavichay e Espinoza (2019), realizaram um estudo para analisar o efeito da implementação de estações de recargas do tipo fast chargers na rede de distribuição elétrica de uma cidade da América Latina. A fim de atingir esse objetivo, o estudo cobre aspectos sociais, geográficos e técnicos para determinar a infraestrutura de recarga mínima necessária. Os autores fizeram uso de métodos computacionais com um modelo de estação de $50 \mathrm{~kW}$ de potência. Os resultados obtidos mostram que o impacto da inclusão de estações de recargas do tipo fast charger no Equador é reduzido em termos de distorção harmônica e capacidade energética, gerando um benefício econômico e ambiental para a cidade.

O tamanho da carga necessária para carregar veículos elétricos plug-in pode causar um problema de baixa voltagem na rede de distribuição, a fim de mitigar esse problema, é necessário limitar o consumo de energia da estação de recarga (KIM et al. 2016). Assim, o operador da estação precisa de um método para distribuir a energia para os veículos apropriadamente, com isso em mente, Kim et al. (2016), propõem um método baseado em índices de prioridades para distribuir a energia corretamente entre os veículos elétricos. Os veículos elétricos são ranqueados por prioridade em tempo real utilizando um software de computador, obtendo uma solução quase ótima em um curto período de tempo. Como resultado, as simulações realizadas pelo autor comprovam a efetividade da implementação do método.

Zhang (2015), realizou um estudo para propor um modo de construção combinando as estações de recarga (nível 1, nível 2 e fast charger), gerando um modelo otimizado de localização. 0 objetivo deste modelo é não só determinar qual é a melhor localização, como também usar a teoria das filas para determinar o número apropriado de equipamentos de energia para atingir os custos mínimos. 0 resultado obtido pelo autor mostra que o lugar ideal para fazer a instalação da estação de recarga, estão localizados nas áreas urbanas.

\subsection{ENGENHARIA ECONÔMICA APLICADA NAS PESQUISAS}

Os estudos econômicos envolvendo diferentes estações de recarga são extremamente importantes porque ajudam a definir a melhor opção de investimento, além de analisar e obter conclusões sobre a viabilidade econômica do projeto. Com isso em mente, algumas bibliografias mostram diferentes aplicações da engenharia econômica relacionadas com a infraestrutura de recarga dos veículos elétricos.

Nesse contexto, Schroeder e Traber (2012), realizaram um estudo de viabilidade econômica sobre as estações de recarga classificadas como fast chargers, utilizando as condições econômicas da Alemanha como cenário de pesquisa. Nesse estudo, o Retorno sobre o Investimento (ROI) foi utilizado como o indicador de rentabilidade e assim, o autor pode concluir que, baseado no contexto econômico alemão, seria difícil obter uma infraestrutura de recarga classificada como fast charger que provesse lucro, visto que, o ROI para o valor inicial de 95 mil EUR necessários para implementar a estação de recarga, ficaria longe de viável economicamente. Os autores utilizaram parâmetros como CAPEX (custo de instalação e construção) e OPEX (custo de operação e manutenção) para determinar qual o custo relacionada com a infraestrutura de recarga estudada. Já para a receita gerada, foram levados em conta fatores como a porcentagem de utilização, potência da estação de recarga, a tarifa cobrada para a recarga, o número de veículos elétricos na região e a média de recarga dos mesmos.

Mazzeo (2018), abordou o problema econômico de forma diferente, realizando um estudo comparativo entre alguns cenários. Entretanto, devido a maior relevância para o presente trabalho, opta-se por analisar apenas o primeiro cenário gerado, o qual é composto por uma estação de recarga wall box privada de nível 1, instalada em uma casa obtendo energia somente da rede elétrica. Para realizar a análise econômica, o autor fez uso do Valor Presente Líquido (VPL). 0 resultado obtido foi um crescimento uniforme do VPL conforme o aumento da distância percorrida por dia pelo veículo elétrico, apresentando valores negativos em distâncias menores que $50 \mathrm{~km}$ por dia. Esses valores do VPL ficaram na faixa entre -4.084,00 EUR até 20.754,00 EUR para este cenário.

Um estudo de viabilidade realizado por NYSERDA (2015), na cidade de Nova Yorque, envolvendo uma estação de recarga de nível 2, fez uso de dois métodos: o payback simples e o VPL. As circunstâncias utilizadas levaram em conta uma premissa de crescimento anual em torno de 12\% na utilização das estações de recarga, um período de 20 anos, preço de recarga de US \$0,45/kWh e uma taxa mínima de 
atratividade de 7\% ao ano. O VPL obtido pelo autor foi de US\$ 7.482,00 juntamente com um payback de 8,71 anos, confirmando a viabilidade do investimento.

Outros autores como Vagropoulos, Kleidaras e Bakirtzis (2014), fizeram uso do VPL e da taxa interna de retorno (TIR) para analisar a lucratividade das estações de recarga de nível 2 no ambiente da Grécia. No estudo os autores consideraram dois tipos de estações, uma de 3,3 kW e outra de 7,2 kW, dentro de um período de 5 dias entre segunda-feira e sexta-feira e um período de 6 dias de segunda-feira até sábado. Os resultados obtidos seguem no Quadro 2.

Quadro 2 - Resultados Vagropoulos, Kleidaras e Bakirtzis.

\begin{tabular}{|c|c|c|c|c|}
\multicolumn{2}{c}{$\begin{array}{c}\text { Tipo de } \\
\text { carregador }\end{array}$} & \multicolumn{2}{c|}{ Segunda - Sexta } & \multicolumn{2}{c|}{ Segunda - Sábado } \\
\hline $3.3 \mathrm{~kW}$ & $11.7 \%$ & $1055 €$ & $22.4 \%$ & $4473 €$ \\
\hline $7.2 \mathrm{~kW}$ & $13.3 \%$ & $1453 €$ & $24.9 \%$ & $5180 €$ \\
\hline
\end{tabular}

Fonte: Adaptado Vagropoulos, Kleidaras e Bakirtzis (2014).

Do mesmo modo Liu et al. (2016), realizaram o estudo de viabilidade econômica de estrutura de recarga na China utilizando um cenário composto por um eletroposto com 4 unidades fast chargers e 16 unidades de recarga de nível 2. Nesse contexto, os autores fazem uso de métodos como VPL, ROI, payback e TIR. Dentre os resultados obtidos tem-se: 15,84 anos de payback, ROI de 7,55\%, TIR de 3,78\% ao ano e uma margem de lucro de 5,66\% para o investimento.

Por fim, com esta pesquisa bibliográfica foi possível verificar os métodos mais utilizados e por outros autores para se realizar os cálculos de viabilidade econômica aplicados às estações de recarga.

\section{CONSIDERAÇÕES FINAIS}

No presente trabalho foram identificadas e descritas definições sobre os veículos elétricos e as estações de recarga. Também foram apresentados trabalhos aplicados abordando estudos de viabilidade técnica e econômica da infraestrutura de recarga. A fim de que a pesquisa bibliográfica apresentada aqui venha a ser utilizada como referência para futuros trabalhos, teve-se como intuito agregar um número razoável de fontes bibliográficas.

De fato, este referencial teórico faz parte de um projeto de pesquisa que está em curso para ser aplicado no estacionamento do Centro de Tecnologia da Universidade Federal de Santa Maria. 0 trabalho está sendo desenvolvido em parceria com o Curso de Graduação em Engenharia de Produção e com o Curso de Graduação em Engenharia Mecânica da Universidade Federal de Santa Maria.

Com este trabalho pode-se verificar que, atualmente, para realizar todo o processo de instalação de uma estação de recarga no Brasil, existe ainda a presença de um custo elevado. Além disso, existem diversos modelos de estações de recarga disponíveis no mercado que apresentam uma grande variação, tanto tecnicamente quanto economicamente. Neste contexto, pode-se afirmar que a principal questão de pesquisa a ser resolvida é entender quais são as melhores opções de estações de recarga, tanto do ponto de vista técnico como econômico.

Assim, realizar uma comparação entre os diferentes modelos de estações de recarga é uma pesquisa importante, principalmente envolvendo métodos da Engenharia Econômica. Neste sentido, a partir da pesquisa bibliográfica apresentada neste trabalho, pode-se afirmar que métodos como o Valor Presente Líquido (VPL), o Payback e a Taxa Interna de Retorno (TIR) mostram-se adequados para este fim.

Pro último, cabe destacar que este trabalho cumpre com seu objetivo principal apresentando uma revisão bibliográfica básica sobre a aplicação da Engenharia Econômica na implementação de uma infraestrutura de recarga de veículos elétricos. 


\section{REFERÊNCIAS}

[1] Calçado, T. E. O. Estudo preliminar de implantação de estações de recarga de veículos elétricos no Centro de Tecnologia da UFRJ. Trabalho de Conclusão de Curso (Graduação em Engenharia Elétrica). Universidade Federal do Rio de Janeiro, Rio de Janeiro, RJ, 2015.

[2] Vital, M. Aquecimento global: acordos internacionais, emissões de CO2 e o surgimento dos mercados de carbono no mundo. Rio de Janeiro: Ed: Bndes, 2018. 77 p.

[3] Deign, J. Which country will become the first to ban internal combustion cars? And would such a goal be realistic or desirable. Barcelona, 2016. Disponível em: <https://www.greentechmedia.com/articles/read/whatcountry-will-become-the-first-to-ban-internal-combustion-cars\#gs.2ari1j>. Acesso em: 23 mar. 2019.

[4] Filho. N.; Kopittke, B. Análise dos Investimentos. 11. Ed. São Paulo: Atlas, 2010.

[5] Miguel, P. A. C. et al. Metodologia de pesquisa em Engenharia de Produção e gestão de operações. 2. ed. Rio de Janeiro: Elsevier, 2012.

[6] Gil, A. C. Como elaborar projetos de pesquisa. 4.ed. São Paulo: Atlas, 2007. 175 p.

[7] Hess, G et al. Engenharia Econômica. 21. Ed. Rio de Janeiro: Bertrand Brasil, 1992.

[8] Hirschfeld, H. Engenharia Econômica. 1. Ed. São Paulo: Atlas, 1979.

[9] Xiong, $\mathrm{H}$ et al. An energy matching method for battery electric vehicle and hydrogen fuel cell vehicle based on source energy consumption rate. International Journal of Hydrogen Energy, v. 44, p. 7737-7888, 2019.

[10] Ornelas, R. Impactos do consumo colaborativo de veículos elétricos na cidade de são Paulo. Future Studies Research Journal, v.5, p. 33 - 62, 2013.

[11] Sousa, M. Veículos elétricos: a rede de inovação da pesquisa e desenvolvimento do Brasil. 2015, 89 f. Trabalho de conclusão de curso (Graduação em Gestão de Empresas) - Faculdade de Ciências Aplicadas, Universidade Estadual de Campinas, Limeira, 2015.

[12] Rahmani, D.; Loureiro, M. Assesing drivers' preferences for hybrid electric vehicles (HEV) in Spain. Research in Transportation Economics, v. 73, 2019.

[13] Doppstadt, C.; Koberstein, A.; VIGO, D. The hybrid electric vehicle: traveling salesman problem. European Journal of Operational Research, v. 253, p. 825-842, 2016

[14] Hierman, G et al. Routing a mix of conventional, plug-in hybrid, and electric vehicles. European Journal of Operational Research, v. 272, p. 235-248, 2019.

[15] Plötz, P.; Funke, S.; Jochem, P. The impact of daily and annual driving on fuel economy and CO2 emissions of plug-in hybrid electric vehicles. Transportation Research Part A: Policy and Practice, v. 118, p. 331-340, 2018.

[16] Song, $\mathrm{K}$ et al. A comprehensive evaluation framework to evaluate energy managemt strategies of fuel cell electric vehicles. Electrochimica Acta, v. 292, p. 960-973, 2018.

[17] Lane, B et al. Plug-in fuel cell electric vehicles: A California case study. International Journal of Hydrogen Energy, v. 42, p. 14294-14300, 2017.

[18] González, L.; Siavichay, E.; Espinoza, J. Impact of EV fast charging stations on the power distribution network of a Latin American intermediate city. Renewable and Sustainable Energy Reviews, v. 107, p. 309-318, 2019.

[19] Sbordone, D et al. EV fast charging stations and energy storage technologies: A real implementation in the smart micro grid paradigma. Electric Power Systems Research, v. 120, p. 95-108, 2015.

[20] Nyserda. Review of New York State Electric Vehicle Charging Station Market and Policy, Finance, and Market Development Solutions. 2015.

[21] Neaimeh, M et al. Analysing the usage and evidencing the importance of fast chargers for the adoption of battery electric Vehicles. Energy Policy, v.108, p. 474-486, 2017.

[22] Lokesh, B.; MIN, J. A Framework for Electric Vehicle (EV) Charging in Singapore. Energy Procedia, v. 143, p. 15-20, 2017.

[23] Zhang, L et al. Charge pricing model for electric vehicle charging infrastructure public-private partnership projects in China: A system dynamics analysis. Journal of Cleaner Production, v. 199, p. 321-333, 2018.

[24] Tuite, D. Understanding U.S. and European Standards for Electric-Vehicle Charging. Electronic Design, 05 de março de 2012. Disponível em: <https://www.electronicdesign.com/power/understanding-us-and-europeanstandards-electric-vehicle-charging>. Acesso em: 14 de abril de 2019.

[25] FGV Energia. Carros elétricos. Rio de Janeiro, 2017. Disponível em: <http://www.fgv.br/fgvenergia/cadernocarros-eletricos/files/assets/basic-html/page-1.html\#>. Acesse em: 23 de mar. 2019. 
[26] Pelletier, S.; Jabali, O.; laporte, G. Battery electric vehicles for good distribution: A survey of vehicle technology, market penetration, incentives and practices. Cirrelt. 2014

[27] Yilmaz, M.; Krein, P. Review of Battery Charger Topologies, Charging Power Levels, and Infrastructure for Plug-In Electric and Hybrid Vehicles. Ieee transactions on power electronics, v. 28, p. 2151-2169, 2013.

[28] Ference, A. Electric Car Charger Installation in Your Home: True Costs and What You Need to Know. Realtor, 02 de nov. 2017. Disponível em: <https://www.realtor.com/advice/home-improvement/installing-electric-vehiclecharger/>. Acesso em: 15 de abril de 2019.

[29] Schroeder, A.; Traber, T. The economics of fast charging infrastructure for electric vehicles. Energy Policy, v.43, p. 136-144, 2012.

[30] Mazzeo, D. Nocturnal electric vehicle charging interacting with a residential photovoltaic-battery system: a 3E (energy, economic and environmental) analysis. Energy, v. 168, p. 310-331, 2019.

[31] Liu, C et al. Research on Economic Evaluation Method of Electric Vehicle Charging Station. MMME, v. 4, p. 689-693, 2016

[32] Vagropoulos, S.; Kleidaras, A.; Bakirtzis, A. Financial viability of investmentes on electric vehicle charging stations in workplaces with parking lots under flat rate retail tarrif scheme. International Universities Power Engineering Conference (UPEC), v. 49, p. 1-6, 2014.

[33] Xue, F.; Gwee,E. Electric Vehicle Development in Singapore and Technical Considerations for Charging Infrastructure. Energy Procedia, v. 143, p. 3-14, 2017.

[34] Kim, S.; et al. A Priority Index Method for Efficient Charging of PEVs in a Charging Station with Constrained Power Consumption. The Korean institute of Electrical Engineers, v. 11, p. 820-828, 2016.

[35] Zhang, L et al. The optimization of DC fast charging deployment in California. Applied Energy, v. 157, p. 111$122,2015$. 


\section{Capítulo 20}

\section{As dificuldades enfrentadas na concessão de crédito pelos empreendedores de Bonfinópolis de Minas}

\section{Jorge Luiz Andrade Ramos \\ Raquel Aparecida Alves \\ Gevair Campos \\ Rosimeire Fernandes Cruz Pereira}

Resumo: 0 empreendedor brasileiro tem opções de crédito para seu negócio como investimentos para implantação, ampliação, recuperação e modernização de instalações e/ou atividades nos setores de indústria, comércio, prestação de serviços, agropecuária, produção florestal, pesca e aquicultura. 0 acesso ao crédito constitui-se em uma ferramenta indispensável para que empreendedores e empresas consigam atender a sua capacidade produtiva e, sendo assim, estimular o crescimento econômico. Nesse sentido, o objetivo deste estudo foi averiguar os obstáculos enfrentados no que se refere à concessão de crédito para os empresários de Bonfinópolis de Minas manterem e expandirem seus empreendimentos. Este estudo se classifica como quantitativo e a coleta de dados foi realizada mediante a aplicação de questionários estruturados aos empresários do município em relação à concessão de crédito. Os resultados apontam dificuldades dos pequenos empreendedores em acessar o crédito para seus negócios devido a uma série de requisitos burocráticos a serem atendidos.

Palavras-chave: Empresas; Empreendedores; Concessão de Crédito. 


\section{INTRODUÇÃO}

As micro e pequenas empresas têm alta relevância quando se trata da economia do país e da contratação de funcionários no Brasil, é o setor que mais gera empregos. De acordo com um estudo de mercado feito pelo Sebrae em campo nacional, existem 6,4 milhões de estabelecimentos, desse total, $99 \%$ são micro e pequenas empresas (MPE). As MPEs respondem por 52\% dos empregos com carteira assinada no setor privado (16,1 milhões) (SEBRAE, 2000).

Contudo, como qualquer outra empresa, a exemplo das de médio e grande porte, as micro e pequenas também necessitam de capital de giro para fomentar suas atividades e oportunizar a sua permanência no mercado. Nesse sentido, os principais concessores de crédito no Brasil são os bancos estatais, sendo o principal o Banco de Desenvolvimento Nacional (BNDES).

Atualmente, o empreendedor brasileiro tem opções de crédito para seu negócio como investimentos para implantação, ampliação, recuperação e modernização de instalações e/ou atividades nos setores de indústria, infraestrutura, comércio, prestação de serviços, agropecuária, produção florestal, pesca e aquicultura. São financiáveis itens como estudos e projetos, obras civis, montagens e instalações, móveis e utensílios, treinamento, despesas pré-operacionais, máquinas e equipamentos nacionais novos credenciados no BNDES, aquisição ou licenciamento de softwares nacionais credenciados no BNDES e serviços correlatos. Esses são os incentivos utilizados para o crescimento da empresa, nos quais o empreendedor pode ser amparado (SEBRAE, 2000).

No entanto, existem duas grandes barreiras que dificultam essa liberação de crédito, sendo elas a burocracia e as altas taxas de juros. Isso dificulta o empreendedor a manter o seu negócio, muitas das vezes não conseguindo atuar da melhor forma em âmbito econômico devido às dificuldades encontradas.

Para expandir os negócios, micro e pequenas empresas podem acessar linhas de crédito específicas para o segmento ou para a finalidade que se quer alcançar com o recurso. É preciso tomar alguns cuidados, como, por exemplo, identificar a real necessidade de empréstimo/financiamento, pesquisar qual linha e banco melhor atende ao projeto, elaborar um plano de negócio etc.

Nesse contexto, este trabalho objetivou analisar a concessão de crédito para micro e pequenas empresas de Bonfinópolis de Minas a fim de investigar as barreiras enfrentadas no que se refere à concessão de crédito para que os empresários possam manter/expandir seus negócios.

Os resultados deste estudo são importantes uma vez que se identificaram os caminhos para a obtenção do crédito, as principais dificuldades e a relevância do crédito para a manutenção e crescimento das empresas. 0 trabalho também pode ser útil como fonte para pesquisas futuras que levem em conta o tema ou como instrumento de leitura para os interessados no assunto.

\section{EMPREENDEDORES, AS EMPRESAS E A QUESTÃO FINANCEIRA}

Palavras como negócios, inovação, criação e empreendedorismo são citadas constantemente no campo acadêmico quando se trata da área econômica, empresas e governo mostram graduais interesses tanto nacional como internacional pelos empreendedores. Mesmo com esse interesse, não se tem ainda uma definição precisa e totalmente aceita quando se trata do assunto empreendedorismo. No francês entrepreuner em sua fiel tradução significa "intermediário" ou "aquele que está entre" (HISRICH; PETERS; SHEPHERD, 2009).

Assim, apareceram algumas definições para o termo empreendedorismo bem como do processo empreendedor como também as características de quem se considerava um. Hisrich, Peter e Shepherd (2009) retratam o trajeto dessa definição indicando o período inicial que ocorreu ainda quando aconteciam as rotas comerciais, exploradas por Marco Polo, para o Extremo Oriente. Esse termo também foi usado na Idade Média para caracterização de um administrador de amplos projetos de criação (como castelos, fortificações e prédios públicos).

No século XVII, a palavra foi associada ao risco, sendo o empreendedor o que firmava um acordo com o governo para realizar um serviço ou produzir produtos, combinando uma quantia fixa para esse trato e admitindo todos os lucros ou danos decorrentes. Já no século XVIII o empreendedor teve o termo destoado do provedor de capital (atualmente chamado de investidor de risco), diferenciação decorrente da industrialização como resposta às modificações e produções da época. 
No próximo período, o final do século XIX e início do XX, não se diferenciavam empreendedores de administradores e tais eram vistos a partir de um ponto de vista econômico, e, na metade do século XX, surge a visão de empreendedor como inovador (PEREIRA, 1963).

Atualmente o empreendedorismo desenvolveu para mais que a ideia clássica de startup, incluindo empresas e instituições de vários modelos e fases. Diante disso, o empreendedorismo ocorre em empresas antigas e atuais, com menor e maior estrutura, com crescimento acelerado e retardado em vários setores (privativos, sem fins lucrativos ou comunitários), em ampla região e em totais etapas de progresso de uma nação (DORNELAS; SPINELLI; ADAMS JUNIOR, 2010).

A política de crédito, em uma instituição financeira, segundo Sant’anna, Borça Junior e Araújo (2009) deve observar as seguintes definições:

- mercado alvo - parâmetros que definem quais os tipos de clientes serão aceitos quanto ao porte, setor e ramo da economia, além da seleção da situação econômico- financeira dos clientes com quem se pretende trabalhar;

- critérios de aceitação de risco - devem existir parâmetros que visem produzir a lucratividade esperada pelos acionistas e mantenham a credibilidade da instituição junto ao mercado;

- critérios de impedimento - estabelecem restrições que impedem o cliente de operar com o crédito. Tais critérios estão dentro do que o mercado costuma chamar de "boa técnica bancária";

- critério de análise de clientes - estabelecem quais os pontos de análise relevantes para cada tipo de cliente;

- concessão de limite versus operações de crédito - separa a análise do cliente (limite de crédito) da análise da operação de crédito (capacidade de retornar o investimento).

Realizando algumas considerações a respeito da política ou modelos de crédito de um banco, percebe-se que são itens de referência para estudo, precavendo desentendimentos ou ausências pela parte de gerentes de crédito, englobando dúvidas relacionadas à dimensão dos empréstimos a serem liberados, por exemplo, níveis de risco admitidos, lucro mínimo das linhas de crédito, limiar de crédito, inclusive a condição de acompanhamento desses no tocante à verificação dos sistemas adotados, retomada de perdas e disposição para não cumprimento. Notadamente, de acordo com à provisão para devedores dúbios, recente normatização do Banco Central - Resolução no 2.682, de 21.12.1999 (ANEXO A) - normatizou o tema retirando a autocracia dos Bancos para solucionar o assunto, estabelecendo percentuais relacionados com o risco da operação de crédito contratada (DORNELAS; SPINELLI; ADAMS JUNIOR, 2010).

É indiscutível que as empresas se defrontem com inúmeras dificuldades, quando se busca recursos para investimentos ou empréstimos em instituições financeiras, tanto públicas quanto privadas. Essas dificuldades ganham dimensão especialmente para o segmento das micro e pequenas empresas. No Brasil as barreiras em obtenção de crédito sucedem principalmente dois pontos estruturais: o alto custo financeiro e as fortes restrições de acesso ao crédito. Comprova-se essa visão na baixa relação entre o Produto Interno Bruto Nacional (PIB) e o volume das operações de crédito do sistema financeiro em analogia a países com economias mais desenvolvidas ou semelhantes à brasileira (DORNELAS; SPINELLI; ADAMS JUNIOR, 2010).

A atividade de crédito implica risco significativo para as instituições financeiras, pois se trata de uma modalidade de risco que está presente em qualquer atividade comercial, caracterizada pela probabilidade de não recebimento dos recursos emprestados (DOUAT, 1994; SCHRICKEL, 1997 apud DORNELAS; SPINELLI; ADAMS JUNIOR, 2010).

$\mathrm{Na}$ gestão desse risco, as instituições financeiras desenvolveram vasto aparato de técnicas, visando minimizar suas perdas. Essas técnicas que vão desde o treinamento de especialistas até o uso de modelagens estatísticas que lhe conferiram maior robustez e eficácia na análise dos clientes. 
O avanço dessas técnicas foi fortemente influenciado por governos e por órgãos de supervisão bancária, tendo em vista a importância da concessão e crédito para o desenvolvimento de determinados segmentos da economia, em especial o das MPE's (DOUAT 1994; SCHRICKEL1997 apud DORNELAS; SPINELLI; ADAMS JUNIOR, 2010).

De acordo com Schrickel (1997apud ALVES; FERREIRA, 2009) a atividade de crédito provoca ameaças consideráveis às instituições financeiras, já que se trata de uma categoria de risco que está corrente em qualquer ação comercial, descrita pela provável falta de recebimento dos fundos emprestados. Devido a esse risco, as companhias financeiras elaboraram amplo mecanismo estratégico, planejando reduzir seus males. Essas táticas que vão desde a capacitação de entendedores, até a utilização de modelagens estatísticas proporcionam uma maior força e êxito na análise dos clientes.

Conforme pesquisas desenvolvidas pelo SEBRAE (2000) o crédito é fator determinante para o desempenho econômico-financeiro das Micro e Pequenas Empresas (MPE's). Em pesquisa realizada em 2000, constatou-se que existe uma inadequação do crédito para esse segmento, sinalizando que as principais dificuldades para obtenção de financiamento são a burocracia elevada (59\%) e juros elevados (40,7\%) (ALMEIDA, 2000 apud CAMARGOS; LIMA 2008).

Em complemento a isso, conforme destacam Camargos e Lima (2008), existem recursos financeiros disponíveis em várias instituições, mas o custo é alto para as empresas desse segmento, pois há percepção de risco elevado por parte das instituições financeiras.

O desenvolvimento de políticas voltadas para a promoção do empreendedorismo deve ser precedido pela construção de um sistema de apoio financeiro, frequentemente mais importante que a própria expectativa de sucesso do negócio (SHAPERO; SOKOL,1982 apud BUENO, 2003).

Refere-se à chance de perdas que é o resultado da falta de certeza em relação ao recebimento de uma quantia contratada, adequado pelo titular de um empréstimo ou emissor de um título. Sendo uma falha de uma contraparte no cumprimento de compromissos contratuais. De acordo com Duarte Júnior (1996, p. 5) a chance de perdas está ligada ao "recebimento de um valor contratado, a ser pago por um tomador de empréstimo, contraparte de um contrato ou emissor de um título, descontadas as expectativas de recuperação e realização de garantias".

A permissão de empréstimos é a ação essencial da maior parte dos bancos. Para que sejam desenvolvidos seus serviços de empréstimos necessitam fazer avaliações sobre o cliente contratante, para se ter as possibilidades de crédito dos fornecedores (BUENO, 2003).

Como uma forma de classificação o SEBRAE (2000) organizou uma forma de agrupar as empresas que é relacionada com a quantidade de funcionários e seu setor de atuação, determinados em relação à receita bruta anual e ao número de empregados. Quanto à Receita Bruta Anual do Microempreendedor Individual, ela vai até $R \$ 60.000,00$, já a microempresa tem receita de até $R \$ 360.000,00$ e a empresa de Pequeno Porte de $\mathrm{R} \$ 360.000,01$ até $\mathrm{R} \$ 3.600 .000,00$. Já quanto ao número de colaboradores o SEBRAE utiliza o critério por número de empregados do IBGE como critério de ordenação do porte dos empreendimentos para fins bancários, ações de tecnologia, exportação, entre outros. Para a indústria têm-se os micros com até 19 empregados, as pequenas de 20 a 99 empregados, as médias de 100 a 499 empregados e as grandes com mais de 500 empregados. Para o comércio e serviços para micros com até 9 empregados, para pequenas de 10 a 49 empregados, para médias de 50 a 99 empregados e para grandes com mais de 100 empregados.

\section{MÉTODO}

Conforme o objetivo deste estudo, que foi investigar as barreiras enfrentadas no que se refere à concessão de crédito para que os empresários de Bonfinópolis de Minas possam manter ou expandir os seus negócios, ele se classifica como quantitativo uma vez que intencionou-se coletar informações dos empresários do município acerca do processo de concessão de crédito para uma compreensão mais consistente do objeto pesquisado e descrevê-las utilizando-se de técnicas estatísticas.

Em relação ao campo da pesquisa, a zona urbana de Bonfinópolis de Minas possui 494 (quatrocentos e noventa e quatro) empresas ativas nos ramos de comércio em geral e uma população de 5.865 (cinco mil, oitocentos e sessenta e cinco) habitantes. No dia 10 de março de 1963, o município recebeu o nome de Bonfinópolis de Minas. Foram muitos obstáculos a transpor, pois nesta época não havia infraestrutura suficiente no município para promover o desenvolvimento. 
Muitos homens e mulheres anônimos, alguns nascidos na própria região e outros imigrantes, se destacaram e se empenharam na construção do município, doando terras para loteamentos, construindo igrejas, pontes, estradas, criando escolas e desbravando o vasto cerrado (BONFINÓPOLIS DE MINAS, 2018).

Para a coleta de dados utilizou-se um questionário estruturado contendo questões construídas a partir do objetivo da pesquisa. Os participantes da pesquisa foram todos os empresários da zona urbana do município. Ressalta-se que muito embora existam quatrocentas e noventa e quatro empresas registradas, nem todas estão em funcionamento efetivo e que boa parte dos empresários não devolveram o questionário, assim, conseguiu-se recolher 42 (quarenta e dois) questionários efetivamente respondidos.

A coleta de dados aconteceu no mês de abril de 2019. A codificação dos dados foi feita no Microsoft Excel e os dados transformados em média aritmética simples. Os resultados da pesquisa são apresentados na seção seguinte.

\section{RESULTADOS E DISCUSSÃO}

Quanto ao perfil dos respondentes, investigou-se o gênero, a faixa etária, a formação, o ramo de negócios e a atuação no mercado. Quanto ao gênero, a prevalência de empresários é do gênero masculino (76\%) e os dados revelam que prevalecem pessoas mais maduras: 28,5\% respondentes com idade entre 41 e 50 anos e 33,3\% com idade entre 31 e 40 anos. No que se refere à formação escolar, 16,6\% possuem formação apenas no ensino fundamental, 35,7\% possuem formação no ensino médio completo, 23,8\% não completaram o ensino médio, 11,9\% possuem ensino superior completo e 11,9\% possuem ensino superior incompleto.

Os campos de atuação dos entrevistados são variados, sendo eles perfumaria, contabilidade, lojas agropecuárias, lojas de calçados e vestuário, hortifrúti, postos de combustíveis, mercearias e mercados, autopeças e serviços mecânicos, restaurantes, advocacias, bares, farmácias, papelaria e salões de beleza. Quanto ao tempo de atuação no mercado a maioria deles $(76,1 \%)$ possuem menos do que 10 anos de atuação, 19\% possuem de 11 a 20 anos e os demais um maior tempo de atuação.

É importante ressaltar, a princípio, que o empresário precisa compreender e ter um bom entendimento sobre as características, elementos e necessidades do mercado em que atua para usufruir de vários aspectos positivos, tais como visão estratégica do negócio, bom desempenho nas diversas fases do negócio, identificação de cenários e tendências e conhecer melhor a clientela e características de consumo (MORAIS, 2019).

Foi questionado aos entrevistados sobre como eles percebem o seu nível de conhecimento sobre o contexto financeiro ao qual sua empresa está inserida. As respostas foram variadas, 23,8\% percebem como ótimo, 47,6\% como bom, 16,6\% como regular, 4,7\% como ruim e 7,1\% não souberam responder. Os dados revelam que a maioria parece ter conhecimento acerca do seu contexto financeiro, ainda que uma pequena parcela dissesse não conhecer e/ou não soube responder.

Ao serem questionados sobre já terem precisado de crédito para sua empresa, $90 \%$ responderam já terem precisado e $10 \%$ não precisaram, ou seja, ao que tudo indica, a maior parte dos pesquisados já sentiu alguma necessidade relacionada ao capital para alguma finalidade e, sobre a finalidade do pedido de crédito, 38\% utilizaram para capital de giro de sua empresa, 36\% para quitação de dívidas, 17\% para ampliar a empresa e 9\% relataram nunca terem pedido crédito junto a instituições financeiras, como pode-se observar na Figura 1. 


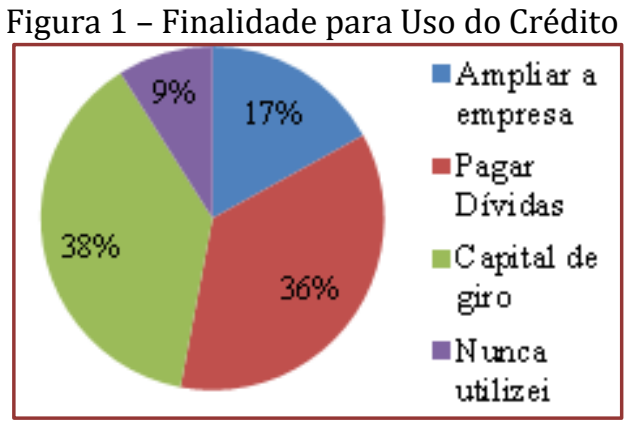

Fonte: Dados da pesquisa.

O processo de concessão de crédito pode ser enxergado como uma tática de atração de clientes e melhora nas vendas das pequenas empresas com o objetivo de aumentar o faturamento, nesse sentido, quitar dívidas ou ampliar o negócio pode ser entendido como uma reorganização e, consequentemente, aquecimento do negócio (POTRICH et al. 2012 apud AMORIM, 2019).

Contudo, o acesso ao crédito não se tem mostrado algo fácil ou acessível a todos na medida em que é um processo cujos caminhos são difíceis e burocráticos. Nesse contexto, a análise das Figuras 2 e 3 permite observar as principais burocracias e dificuldades encontradas pelos participantes da pesquisa ao pleitearem o crédito.

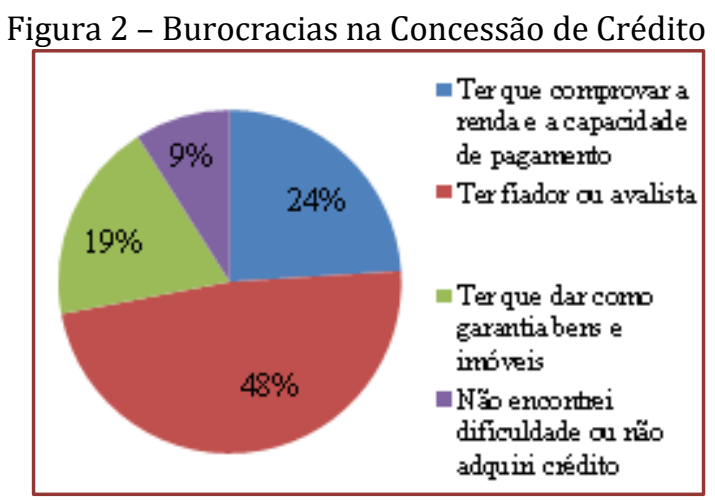

Fonte: Dados da pesquisa.

Conforme os dados da Figura 2, 48\% dos questionados acreditam que ter um avalista é a parte mais burocrática no processo de concessão de crédito, seguida da necessidade de comprovação da renda e da capacidade de pagamento (24\%) e de ter que dar em garantia bens (19\%). Nove por cento dos respondentes disseram não terem precisado de crédito.

Figura 3 - Dificuldades no Processo de Concessão de Crédito

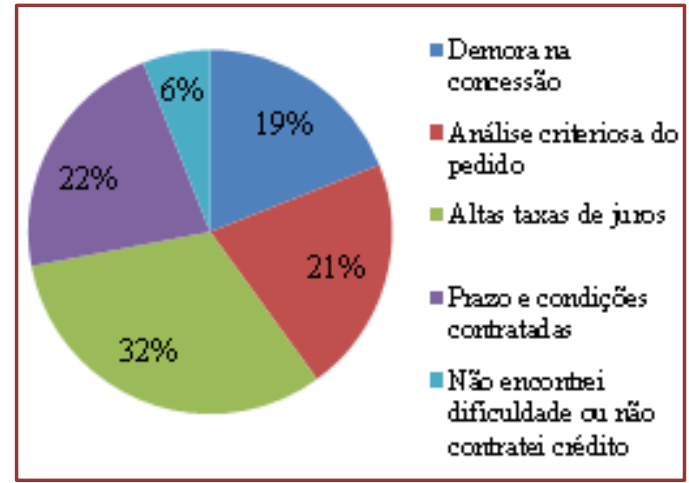

Fonte: Dados da pesquisa. 
Quanto às dificuldades enfrentadas no processo de concessão, as altas taxas de juros foram indicadas como uma das maiores (32\%). No entanto, os prazos para pagamento e as condições contratuais (22\%) juntamente com a análise criteriosa do pedido (21\%) e a demora na concessão também foram apontadas como dificuldades expressivas. Fagnani (2011) ressalta que as elevadas taxas de juros no mercado dificultam a atuação dos empreendedores em todos os sentidos, podendo colocar seu negócio em risco.

Os serviços de atendimento e atenção ao cliente no momento de concessão também foram questionados pelos empresários bonfinopolitanos, 11,9\% deles relatam como sendo um serviço muito bom, 23,8\% como bom, 33,3\% como regular, 14,2\% como ruim, 7,1\% como muito ruim e 9,5\% não souberam responder. Com relação à opinião dos entrevistados em relação à dificuldade de conseguir empréstimos em tempos de crise, $71 \%$ relatam sentir maior dificuldade e $29 \%$ relatam não verem dificuldade.

É relevante que antes de ir a uma empresa de concessão de crédito, o empresário pesquise para saber das particularidades de cada uma. Assim sendo, 52,4\% dos empreendedores declararam não terem feito nenhuma pesquisa, 47,6\% declararam que fizeram pesquisas na Internet, em diferentes instituições, entre pessoas que já adquiriram crédito e por indicações.

No que se refere a expectativa para o atual cenário econômico brasileiro e a nova gestão do país em relação a concessão de crédito, 23,8\% dos empreendedores possuem expectativas muito boas, 16,7\% boas, $33,3 \%$ regulares, $14,2 \%$ ruins, $2,3 \%$ muito ruins e $9,5 \%$ não souberam responder.

A pesquisa foi finalizada com um questionamento sobre a visão de futuro que cada empresário tem de sua empresa baseado na situação atual e na mudança econômica; 23,8\% deles disseram que enxergam a empresa ampliada na sua área de atuação, 52,4\% veem a empresa gerando mais lucros, 7,1\% veem a empresa estagnada, 7,1\% enxergam uma baixa no ramo de atuação no futuro e 9,5\% não souberam responder.

As dificuldades encontradas pelos empresários da cidade como altas taxas de juros, burocracias, demora na análise do pedido, garantia de bens e condições contratuais foram comentadas pelos autores referenciados neste artigo, confirmando que tais fatos atrapalham os empreendedores a expandirem ou manterem seus pequenos empreendimentos. Essas mesmas dificuldades relatadas pelos autores foram as principais reclamações apontadas pelos entrevistados.

\section{CONSIDERAÇÕES FINAIS}

O empreendedorismo é um ramo no qual não se tem uma classe social padrão ou pré-requisito, todas as pessoas podem empreender desde que possuam os recursos financeiros suficientes para tal. Essa acaba sendo a primeira dificuldade do empreendedor. Na tentativa de facilitar a abertura de novos negócios foi criado o microcrédito. Os obstáculos que surgem para os pequenos empreendedores resultam numa empresa com alto custo e baixo lucro, consequentemente, baixa produtividade, sendo o principal fator de falência das MPE's.

Diante da pesquisa aqui apresentada e os estudos feitos na literatura conclui-se que há uma maior dificuldade dos micro e pequenos empreendedores de conseguir concessão de crédito para seus negócios devido a quantidade de requisitos a serem preenchidos para a concessão. Além disso, os investidores precisam analisar e pesquisar sobre o novo negócio para concluir se devem ou não investir.

Percebeu-se também que o empresário deve ter um conhecimento sobre o ramo que pretende atuar, pesquisar o mercado, estudar seus concorrentes, estudar seus produtos e ter clareza dos pontos cruciais para ter um bom embasamento teórico e colocá-lo em prática.

Constatou-se que grande parte do fechamento das novas empresas não depende apenas de capital para abertura, mas também de capital de giro, baixa lucratividade, alto custo, problemas financeiros, pouca clientela, baixo conhecimento de campo e déficit de crédito bancário.

Em relação aos micro e pequenos empreendedores de Bonfinópolis de Minas pode-se concluir, através da pesquisa, que a maioria relata ter dificuldade em conseguir crédito para seus negócios. Apontam também a necessidade de avalista e análise criteriosa do pedido como uma das principais dificuldades. 
Recomenda-se que outras pesquisas sobre o assunto sejam realizadas, principalmente pesquisas que abranjam um número maior de empresas, tanto micro, pequenas e grandes para fins de comparação e melhor compreensão dos processos de concessão de crédito.

\section{REFERÊNCIAS}

1] Alves, R. F.; Ferreira, J. A. L. A. Análise de crédito: um fator potencial de rentabilidade nos negócios. 2009. Disponível em: <http://twixar.me/45jK>. Acesso em 17 abr. 2019.

2] Amorim. G. Concessão de crédito e receita financeira: Uma ferramenta de análise econômico-gerencial. Revista de empreendedorismo e Gestão de Pequenas Empresas, v.8, n.2, 2019. Disponível em: <http://www.regepe.org.br/regepe/article/view/1339/pdf>. Acesso em: 05 jun. 2019.

3] Bonfinopolis de Minas. Prefeitura Municipal. História: origem e formação. Disponível em: <http://twixar.me/XzjK>. Acesso em: 28 nov. 2018.

4] Bueno, V. de F. F. Avaliação de risco na concessão de crédito bancário para micros e pequenas empresas. 2003. 187 f. Dissertação (Mestrado em Engenharia de Produção) - Programa de Pós-Graduação em Engenharia de Produção, Universidade Federal de Santa Catarina, Florianópolis, 2003.

5] Camargos, M. A. de; Lima, J. de O. Previsão de Inadimplência em Processos de Concessão de Crédito a Micro e Pequenas Empresas do Estado de Minas Gerais. In: Encontro da ANPAD, 32., 2008, Rio de Janeiro. Anais... Rio de Janeiro: Anpad, 2008.

6] Dornelas, J.; Spinelli, S.; Adams Junior, R. Criação de negócios: empreendedorismo para o século XXI. Rio de Janeiro: Campus, 2010.

7] Duarte Júnior, Antonio Marcos. Risco: Definições, Tipos Medição e Recomendações para o seu Gerenciamento. 1996,

8] Fagnani, M. M. de A. Sociedade de garantia de crédito: mecanismo de inclusão financeira para empreendedores com projetos economicamente viáveis. 2011. 50 p. Trabalho de Conclusão de Curso de Especialização (Especialização em Gestão de Negócios) - Escola de Administração, Universidade Federal do Rio Grande do Sul, Porto Alegre, 2011.

9] Hisrich; R. D.; Peters M. P.; Shepherd, D. A. Empreendedorismo. 7. ed. Porto Alegre: Bookman, 2009.

10] Morais, J. G. P. A Importância do estudo de mercado. Sebrae. 2019. Disponível em: <http://www.sebrae.com.br/sites/PortalSebrae/ufs/ap/artigos/a-importancia-do-estudo-demercado,92e9812ca826e510VgnVCM 1000004c00210aRCRD> Acesso em: 05/06/2019.

11] Pereira, L. C. B. O empresário industrial e a revolução brasileira. São Paulo: Atlas, 1963. Disponível em: <http://twixar.me/JzjK>. Acesso em: 08 out. 2018.

12] Sant'anna, A. A.; Borça Junior, G. R.; Araujo, P. Q. de. Mercado de crédito no Brasil: evolução recente e o papel do BNDES (2004-2008). Rio de Janeiro: Atlas, 2009.

13] Sebrae. Fatores intervenientes no desempenho econômico-financeiro das micro e pequenas empresas. Relatório de Pesquisa. Belo Horizonte, 2000. 


\section{Capítulo 21}

Um estudo comparativo entre as diferentes propostas metodológicas no desenvolvimento de um Sistema de Mobilidade para Equoterapia

\section{Guilherme Neto Ferrari}

Paula Conceição Rocha de Oliveira

Bruno Isamu Obana

Maria de Lourdes Santiago Luz

Resumo: 0 presente artigo expõe o processo de desenvolvimento de um sistema de mobilidade para praticantes equoterapia em que foram utilizadas metodologias projetuais de quatro autores diferentes, levando em consideração as necessidades particulares do projeto em questão. Foram levantadas as orientações metodológicas de cada autor e as convergentes foram sintetizadas em uma orientação comum. Desse modo, foi possível elaborar um consenso entre os aspectos metodológicos distintos e com isso gerar uma estrutura de base para dar suporte a proposta metodológica utilizada neste projeto. Em cada etapa do projeto foram utilizadas orientações de autores diferentes, considerando aquelas que melhor se enquadram na necessidade da situação em que aplicada. Sendo assim, esse artigo irá descrever e apresentar a seleção e utilização das diferentes metodologias de projeto de produto e a importância do levantamento desse referencial na seleção dos métodos que melhor se adequem aos objetivos de cada projeto.

Palavras-chave: Desenvolvimento de Produto, Metodologias de Projeto, Ergonomia, 


\section{INTRODUÇÃO}

A equoterapia é um método utilizado por profissionais ocupacionais, fisioterapeutas e fonoaudiólogos, que utiliza o movimento tridimensional do cavalo como ferramenta terapêutica (LÉVEILLÉ; ROCHETTE; MAINVILLE, 2017). No atendimento, o terapeuta recepciona o paciente, posiciona-o no cavalo, e acompanha durante a prática, interagindo o tempo todo. Em uma análise das atividades dos profissionais de um centro de equoterapia, diagnosticou-se os esforços biomecânicos indicando riscos de DORT e desconfortos principalmente, na transferência do praticante até o cavalo, evidenciando necessidade de intervenção ergonômica (LUZ; BOARETTO; RODRIGUES, 2017).

Soluções para reduzir riscos no manuseio de pacientes e diminuir o estresse físico dos profissionais de saúde podem ser por meio de sistemas de elevação assistivos, reduzindo esforços e lesões músculo esqueléticas (EVANOFF et al., 2003). Desse modo, percebeu-se a possibilidade de desenvolvimento de um equipamento minimizador dos esforços dos equoterapeutas. Esse artigo apresenta a breve descrição desse desenvolvimento, desde o planejamento, coleta de dados, concepção de ideias, até a validação da solução final, atendendo as necessidades, restrições dos usuários e do centro de equoterapia que fez parceria com a universidade.

Para organizar a seleção dos integrantes da equipe de desenvolvimento do equipamento, considerou-se o desenvolvimento de produtos como um processo complexo, devendo envolver diversos profissionais (IIDA e GUIMARÃES, 2016). Desse modo, a equipe consolidou-se com oito integrantes: quatro alunos de graduação de engenharia de produção, engenharia mecânica e design de produtos, três professores das respectivas áreas de conhecimento dos graduandos e um profissional da área de engenharia. Essa configuração proporcionou uma leitura multidisciplinar do problema, amparando o processo por meio de diferentes perspectivas.

Considerando o número de integrantes e a diversificação de perspectivas, iniciaram-se debates sobre a melhor metodologia a ser utilizada, encaminhando para o constructo teórico por meio de um levantamento de abordagens conceituadas na área de projetos em engenharia e design. É interessante que o profissional domine diversas técnicas, podendo escolher aquela que mais se adapte ao seu problema (BAXTER, 2011), por isso as metodologias e autores levantados foram aqueles que os integrantes obtinham afinidade.

Foi feito um levantamento teórico da metodologia de Rozenfeld et al. (2006) - da área de engenharia de produção; de Pahl et al. (2007) - utilizada na área de engenharia mecânica; e de Baxter (2011) - mais utilizada por profissionais de design. Considerando a motivação inicial do projeto oriunda de um diagnóstico ergonômico e que o equipamento que será projetado deve ser pautado em conceitos da ergonomia, adicionou-se ao projeto as perspectivas da ergonomia de Iida e Guimarães (2016).

Foi possível realizar uma comparação de possibilidades de métodos e abordagens já reconhecidos cientificamente e também constatar que alguns não se enquadram, fazendo assim uma seleção compatível com as necessidades do projeto.

\section{REFERENCIAL TEÓRICO}

Esse tópico busca expor os autores que serviram de referência bibliográfica e base para a organização da metodologia do projeto, fornecendo a área de conhecimento deles e justificando seu levantamento.

\subsection{ROZENFELD ET AL. (2006)}

O livro Gestão de Desenvolvimento de Produtos, escrito por sete professores engenheiros, Rozenfeld et al. (2006), traz uma perspectiva do Processo de Desenvolvimento de Produto (PDP) estendida e mais complexa, no qual o produto era idealizado para vender em grande quantidade e visando o lucro. É levantada a importância do PDP como um gerador de valor, entendendo o mercado e como um novo produto pode competir no cenário empresarial, mas também se preocupando com o futuro do produto, seu ciclo de vida e retirada do mercado. 0 livro apresenta visões anteriores e posteriores ao processo de desenvolvimento, que muitas vezes não são mencionadas ou consideradas relevantes por outros autores. 


\subsection{PAHL ET AL. (2007)}

Pahl et al. (2007) apresentam uma abordagem sistemática que pode ser aplicada para qualquer tipo de produto ou fase do projeto, apresentando diversos métodos intuitivos e discursivos. 0 modelo, composto por quatro principais etapas, se inicia já numa ideia de PDP definida que será incrementada para a elaboração de requisitos. É evidenciada a importância da resolução de problemas e criação de alternativas, possibilitando a geração de diferentes soluções que serão refinadas e alteradas até atingir um conceito final adequado. Boa parte do livro é dedicada ao detalhamento do conceito, de forma a realizar as especificações técnicas para direcionar o produto final diretamente à produção. De forma geral, os autores evidenciam a importância de destrinchar a ideia do produto em etapas, desenvolver e resolver seus principais problemas, sempre considerando as especificações e medidas, visando otimizar a produção, aumentar a satisfação dos clientes e a competitividade no mercado.

\subsection{BAXTER (2011)}

Mike Baxter é um autor estrangeiro, professor e diretor de Design e de Engenharia, mundialmente conhecido na área de projetos de produto (BAXTER, 2011). Em seu livro ele abrange planejamentos estratégicos, construção de protótipos/modelos e projetos detalhados para engenharia. Um diferencial do Baxter em relação aos outros autores é que ele trata sobre princípios da criatividade e de estilo dentro da sua metodologia, que são perspectivas mais abordadas na área do Design.

\subsection{IIDA E GUIMARÃES (2016)}

Iida e Guimarães (2016) é autor do livro nacionalmente conhecido "Ergonomia: projeto e produção", onde discorre sobre aspectos da ergonomia não só dentro do desenvolvimento de produtos, mas também expõe a importância em situações ambientais e industriais. Ele não descreve uma metodologia específica, comenta sobre como inserir a ergonomia para melhorar produtos, processos, ambientes e atividades.

É citado por Iida e Guimarães (2016) que o ergonomista lida com a análise das tarefas, carateriza os usuários, propõe melhorias de usabilidade, avaliando o produto ergonomicamente. Ele cita que é necessário inserir esses profissionais desde o início do desenvolvimento de produtos e também comenta que o processo não é linear, cada etapa pode ser retomada em algum momento se necessário, mas a visão da ergonomia deve estar presente em todas elas.

\section{METODOLOGIA}

O presente estudo realizou um levantamento bibliográfico dos autores mais relevantes das áreas de engenharia de produção, engenharia mecânica, design e ergonomia, buscando adotar uma metodologia de desenvolvimento de produto que melhor se adeque e supra as necessidades do projeto. A partir do levantamento procurou-se explorar e evidenciar suas recomendações, ferramentas e métodos de (PDP) mais pertinentes ao desenvolvimento do sistema de elevação.

Os conceitos de ergonomia foram utilizados principalmente na fase de geração de requisitos, para que as alternativas de solução fossem geradas com parâmetros ergonômicos. As etapas de testes com usuário, desenvolvimento e análise da interface do equipamento também tiveram uma participação maior dos conceitos de ergonomia.

Uma vez levantados os tópicos relevantes de cada uma das metodologias, foi elaborado um quadro comparativo para facilitar a visualização e entendimento. Constatou-se que as metodologias se assemelham e compartilham tópicos análogos, dessa forma, foi possível gerar etapas para o desenvolvimento do projeto em questão. A metodologia desenvolvida, é composta por quatro etapas principais (Figura 1), que serão apresentadas e detalhadas neste trabalho, evidenciando as atividades exigidas em cada uma das etapas e como elas foram influenciadas pelas bibliografias levantadas - quais recomendações e ferramentas de cada autor foram aplicadas. 
Figura 1 - Etapas do processo de desenvolvimento do produto

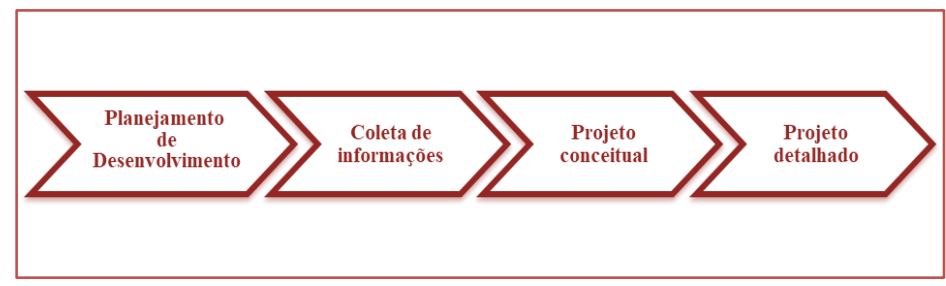

Fonte: Autores (2019)

\section{DESENVOLVIMENTO}

A partir do estudo aprofundado dos métodos de desenvolvimento de produto pelos autores elencados, elaborou-se um Quadro convergindo as visões de projeto de cada um deles, apresentado na Figura 2, possibilitando uma ampla comparação, gerando uma convergência de orientações encontradas entre os três autores.

No esquema visualizado na Figura 2, os conceitos da ergonomia, conforme apresentado por Iida e Guimarães (2016) permeiam e são absorvidos nas etapas durante todo processo projetual.

Figura 2 - Esquema comparativo das metodologias entre Rozenfeld et al. (2006), Baxter (2011), Pahl et al. (2007) e Iida e Guimarães (2016).

\begin{tabular}{|c|c|c|c|c|}
\hline Rozenfeld et al (2006) & Pahl et al (2007) & Baxter (2011) & Etapas & \multirow{2}{*}{ 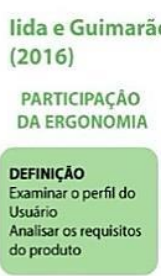 } \\
\hline 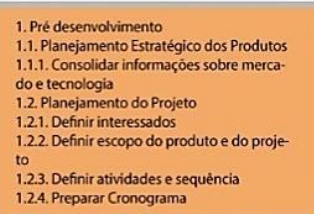 & 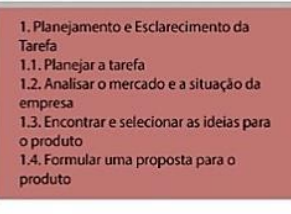 & 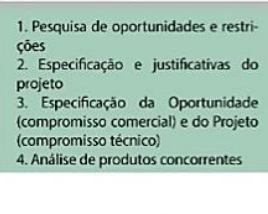 & $\begin{array}{l}\text { Planejamento } \\
\text { de } \\
\text { Desenvolvimento }\end{array}$ & \\
\hline 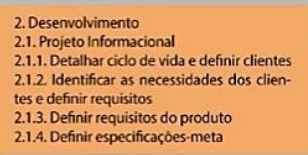 & $\begin{array}{l}\text { 15. Elaborar a lista de } \\
\text { requisitos }\end{array}$ & 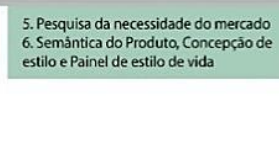 & $\begin{array}{l}\text { Coletade } \\
\text { informacioes }\end{array}$ & \\
\hline $\begin{array}{l}\text { 2.2. Projetto Conceitual } \\
\text { 2.21. Modelar funcionalmente oproduto }\end{array}$ & 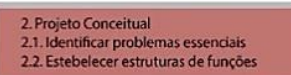 & \multirow{2}{*}{ 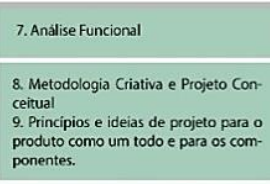 } & \multirow{4}{*}{$\begin{array}{l}\text { Projeto } \\
\text { Conceitual }\end{array}$} & \multirow{4}{*}{ 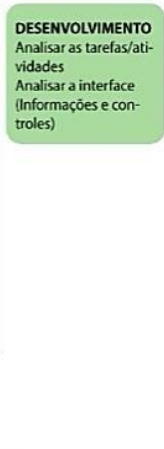 } \\
\hline $\begin{array}{l}\text { 2.2.2. Desernvolver principios de soluçò } \\
\text { para as surnóes } \\
\text { 2.23. Deserviver alternativas de soluç̧o } \\
\text { para o produto }\end{array}$ & 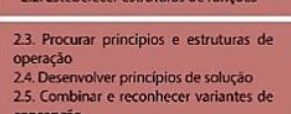 & & & \\
\hline \multirow{2}{*}{ 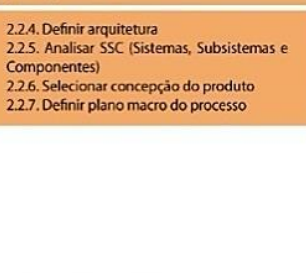 } & 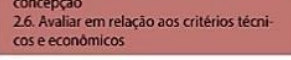 & \multirow{2}{*}{ 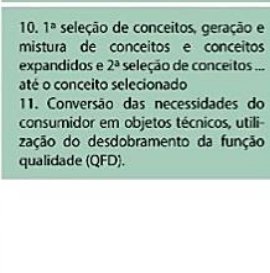 } & & \\
\hline & 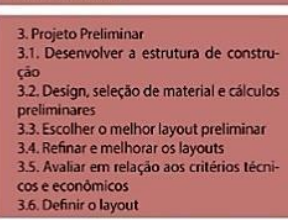 & & & \\
\hline $\begin{array}{l}\text { 23. Projetoto Detalhado } \\
\text { 23.1. Detallara os SSC } \\
\text { 23.2. Especiricar toleranncia } \\
\text { 2.3.3. Decidif fazer ou comprar os SSC }\end{array}$ & \multirow{2}{*}{ 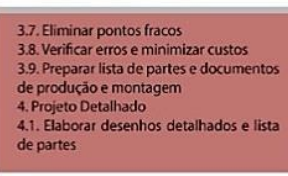 } & \multirow{4}{*}{ 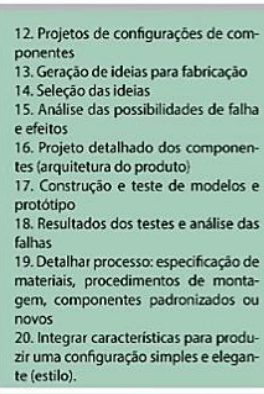 } & \multirow{5}{*}{$\begin{array}{l}\text { Projeto } \\
\text { Detalhado }\end{array}$} & $\begin{array}{l}\text { DEtALHAMENTO } \\
\text { Acompanhar os } \\
\text { detalhamentos }\end{array}$ \\
\hline $\begin{array}{l}\text { 2.3.4. Planejar processso de fabricaç̧o e mon- } \\
\text { tagem } \\
\text { 2.4. Preparaçăo Produçăo }\end{array}$ & & & & $\begin{array}{l}\text { AVALLACAO } \\
\text { Testara interface } \\
\text { como oususurio }\end{array}$ \\
\hline \multirow[t]{3}{*}{$\begin{array}{l}\text { 25. Lancamento do Produto } \\
\text { 3. Pos Desenvolvimentuto } \\
\text { 3.1. Acompanhar Produto/Processo } \\
\text { 3.2. Descontinuar Produto }\end{array}$} & \multirow[t]{3}{*}{ 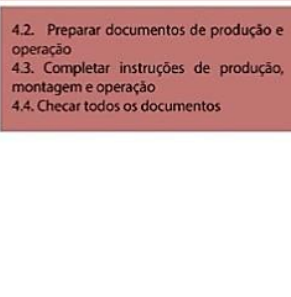 } & & & \multirow[t]{3}{*}{$\begin{array}{l}\text { PRODUTO EM USO } \\
\text { EEtudos de campo } \\
\text { junto as usuriose } \\
\text { consumidores }\end{array}$} \\
\hline & & & & \\
\hline & & $\begin{array}{l}\text { 21. Atender requistos do mercado, } \\
\text { requistos de produço, requisitos de } \\
\text { funcionamento. }\end{array}$ & & \\
\hline
\end{tabular}

Fonte: Autores (2019). 
A síntese das bibliografias foi idealizada pela equipe do projeto de forma a combinar etapas semelhantes dos autores, consolidando quatro etapas, conforme apresentadas na quarta coluna da Figura 2, que servirão de guia no desenvolvimento do sistema de mobilidade, podendo ser observadas na Figura 3 . De forma a explicitar como cada um dos autores influenciou na definição dessas etapas, utilizou-se uma legenda que demonstra a participação das bibliografias no desenvolvimento.

Figura 3 - Etapas de Desenvolvimento e Referências Utilizadas

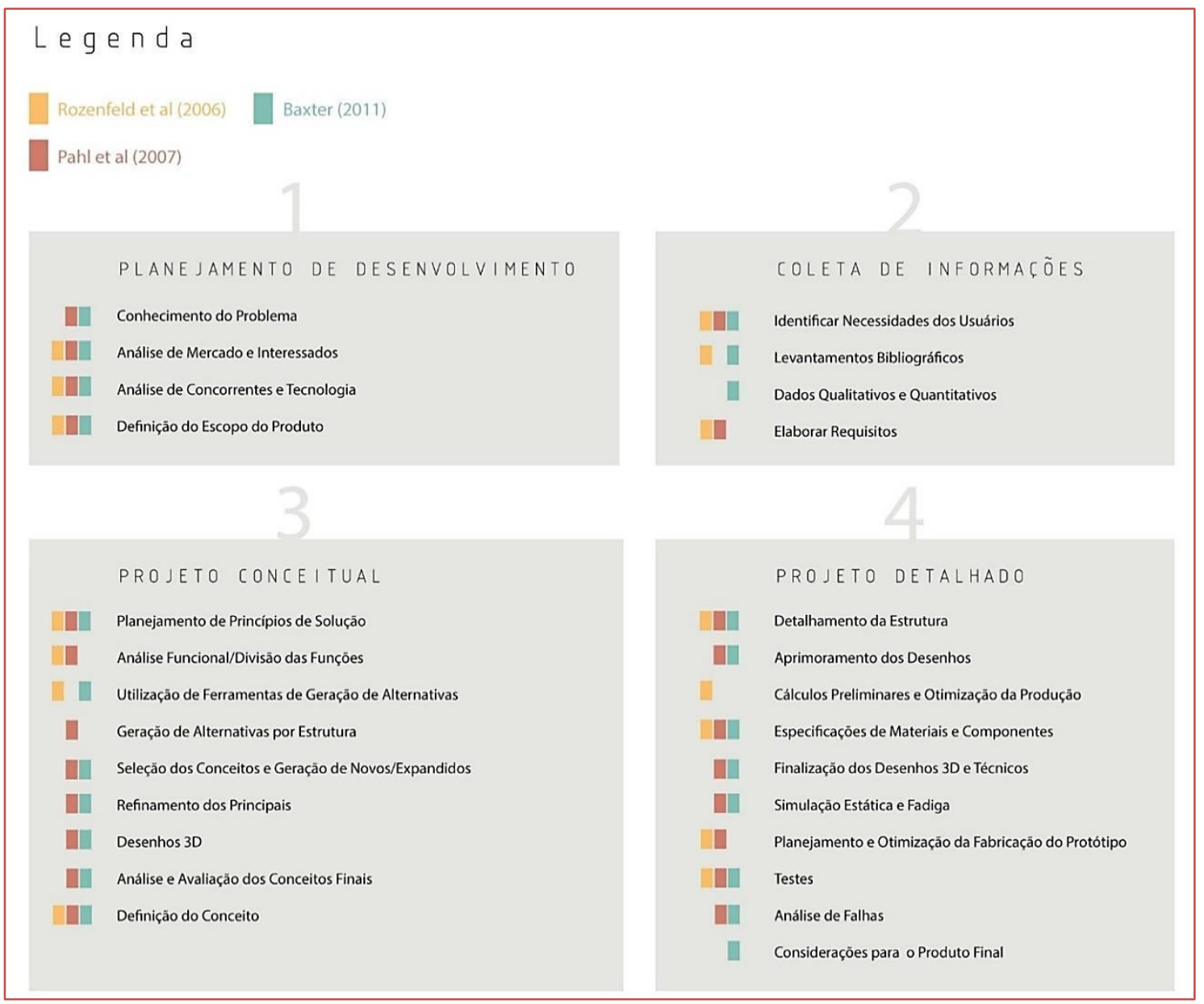

Fonte: Autores (2019).

A seguir, essas macro etapas serão detalhadas evidenciando como as referências influenciaram no desenvolvimento do sistema de mobilidade para equoterapia.

\subsection{ETAPAS}

Serão descritas detalhadamente as etapas de desenvolvimento desse projeto e o que cada um dos autores recomendou para cada fase. Ao final de cada etapa, serão mencionadas as atividades realizadas pela equipe seguindo as recomendações utilizadas, de forma que as decisões tomadas tenham fundamentação teórica, motivação técnica e agregando valor às ações de projeto.

\subsubsection{PLANEJAMENTO DE DESENVOLVIMENTO}

Na etapa de planejamento do desenvolvimento, Baxter (2011) indica que devem ser especificadas as características que o produto deve apresentar para que a oportunidade seja aproveitada, expondo justificativas para o seu desenvolvimento. Aqui também é sugerido a apresentação de restrições técnicas mínimas, criando fronteiras, mas permitindo a inovação. 0 projeto utilizou a recomendação de Baxter 
(2011) como método de Conhecimento do Problema, onde elencamos o que já foi pesquisada em relação a necessidade de uma intervenção ergonômica para diminuir esforços de profissionais de equoterapia.

A etapa definida por Baxter (2011) como "pesquisa e análise da oportunidade" orienta sobre conhecer a demanda de consumidores por meio de levantamento de informações quantitativas e/ou qualitativas, analisar sistematicamente a concorrência vinda de outros produtos que já estão no mercado e pesquisar as possíveis oportunidades tecnológicas. Dessa forma, essa orientação foi utilizada na Análise de Mercado e Interessados e também na Análise de Concorrentes e Tecnologia.

Por último, na Descrição do Escopo do Produto foi adaptada de Baxter (2011) a sugestão de realização de uma análise das funções do produto, começando pela sua função principal e desdobrando para as secundárias, isso permite um conhecimento prévio do sistema de uso e funcionamento.

Para Rozenfeld et al. (2006), a etapa inicial se dá através de um planejamento estratégico do produto e uma análise estratégica da empresa, porém, muitas informações recomendadas pelos autores têm maior relevância para organizações já consolidadas no mercado e com produtos lançados. Como o presente estudo não se trata de um lançamento para competição mercadológica, essas informações estratégicas não foram levadas em consideração.

Informações recomendadas e utilizadas no estudo foram, por exemplo, a coleta de informações sobre o mercado e tecnologias, através de pesquisas, entrevistas, dados de uso comum e revisões bibliográficas; também, a definição dos interessados do projeto, ou seja, todos aqueles envolvidos ou afetados pelo produto, para que fosse possível entender suas individualidades e exigências e, assim, elencar suas necessidades de forma a desenvolver uma lista de requisitos adequada para todos na etapa seguinte.

Para Pahl et al. (2007), a etapa inicial é de extrema importância pois são definidos não apenas as informações sobre as funcionalidades e performance do produto, mas também informações sobre o projeto em si, como cronograma e custos. De acordo com os autores, essa etapa é para esclarecimento daquilo que será realizado, respondendo perguntas como: qual o problema que se pretende satisfazer com o produto, quais as propriedades que o mesmo deve possuir, quais as características indesejáveis para o mesmo, entre outras. Com essas informações é possível desenvolver a lista de requisitos do produto na etapa seguinte.

Utilizando os métodos dos autores supracitados, foi possível entender como realizar o planejamento inicial do desenvolvimento do produto em questão. A equipe pôde visualizar de forma crítica e estratégica o problema a ser resolvido e entender o que é exigido e esperado do produto, de forma que na etapa seguinte se designou a coleta de todas as informações necessárias para a fundamentação da resolução desses problemas, adquirindo os dados dos usuários e suas necessidades para a elaboração dos requisitos.

\subsubsection{COLETA DE INFORMAÇÕES}

Baxter (2011) aponta para algumas fontes de informações sobre as necessidades do usuário: pesquisa bibliográfica, levantamentos qualitativos e quantitativos do mercado. Suas orientações serviram para guiar a etapa de Identificar Necessidades do Usuário, de Levantamentos Bibliográficos e Dados Qualitativos e Quantitativos.

Na etapa de levantamento de informações, Rozenfeld et al. (2006) destaca a importância do detalhamento de todas as etapas do ciclo de vida, porém, o presente projeto busca desenvolver um sistema único e pontual, dessa forma as preocupações com a descontinuidade do produto e outras atividades do pósdesenvolvimento não foram consideradas no momento. Outras atividades importantes estão relacionadas à definição dos requisitos, obtidos através da identificação das necessidades dos clientes - por meio de entrevistas, grupos de foco, observação, etc - que serão interpretados e convertidos em expressões mensuráveis de engenharia, recebendo valores que guiarão a geração de soluções e alternativas ao desenvolvimento.

Pahl et al. (2007) também citam sobre a importância da elaboração dos requisitos, sendo que inicialmente eles serão definidos e registrados e, posteriormente, refinados e estendidos. Os requisitos devem ser quantificados e definidos da forma mais clara possível e toda adição ou modificação deve ser registrada. Não se espera que a primeira coleta de requisitos seja perfeita, a quantidade e qualidade da lista gerada depende da técnica utilizada e pode ser melhorada. Busca-se entender do que se trata o problema a ser resolvido, quais as expectativas, quais as limitações existentes e quais os caminhos conhecidos para o desenvolvimento. Essas informações devem sofrer refinamentos e extensão, ou seja, buscar cenários não 
explorados, entender como o produto reage em determinados momentos e, com isso, melhorar ou gerar novos requisitos. 0 resultado dessa etapa é uma lista com todos os requisitos gerados reunidos.

Uma das técnicas apresentadas por Pahl et al. (2007) e utilizada pela equipe foi a de refinamento de requisitos, sendo possível identificar novas necessidades, e até alterar alguns requisitos. Por exemplo, a necessidade do equipamento ser montado e desmontado por somente uma pessoa não havia sido coletada na primeira geração dos requisitos.

A equipe buscou identificar as necessidades dos usuários através do estudo bibliográfico, visitas ao local, a observação das atividades, conversas com os envolvidos, transformando essas informações em uma lista de requisitos iniciais como pode ser verificado na Figura 4. Eles foram inseridos dentro das esferas de usabilidade e agradabilidade, citadas por Iida e Guimarães (2016) como conceitos importantes para o desenvolvimento de produtos ergonômicos. Em que a Usabilidade tem relação com a eficiência, conforto e segurança e a Agradabilidade com aspectos estéticos e simbólicos para o usuário.

Figura 4 - Requisitos do Produto conforme as Esferas Ergonômicas

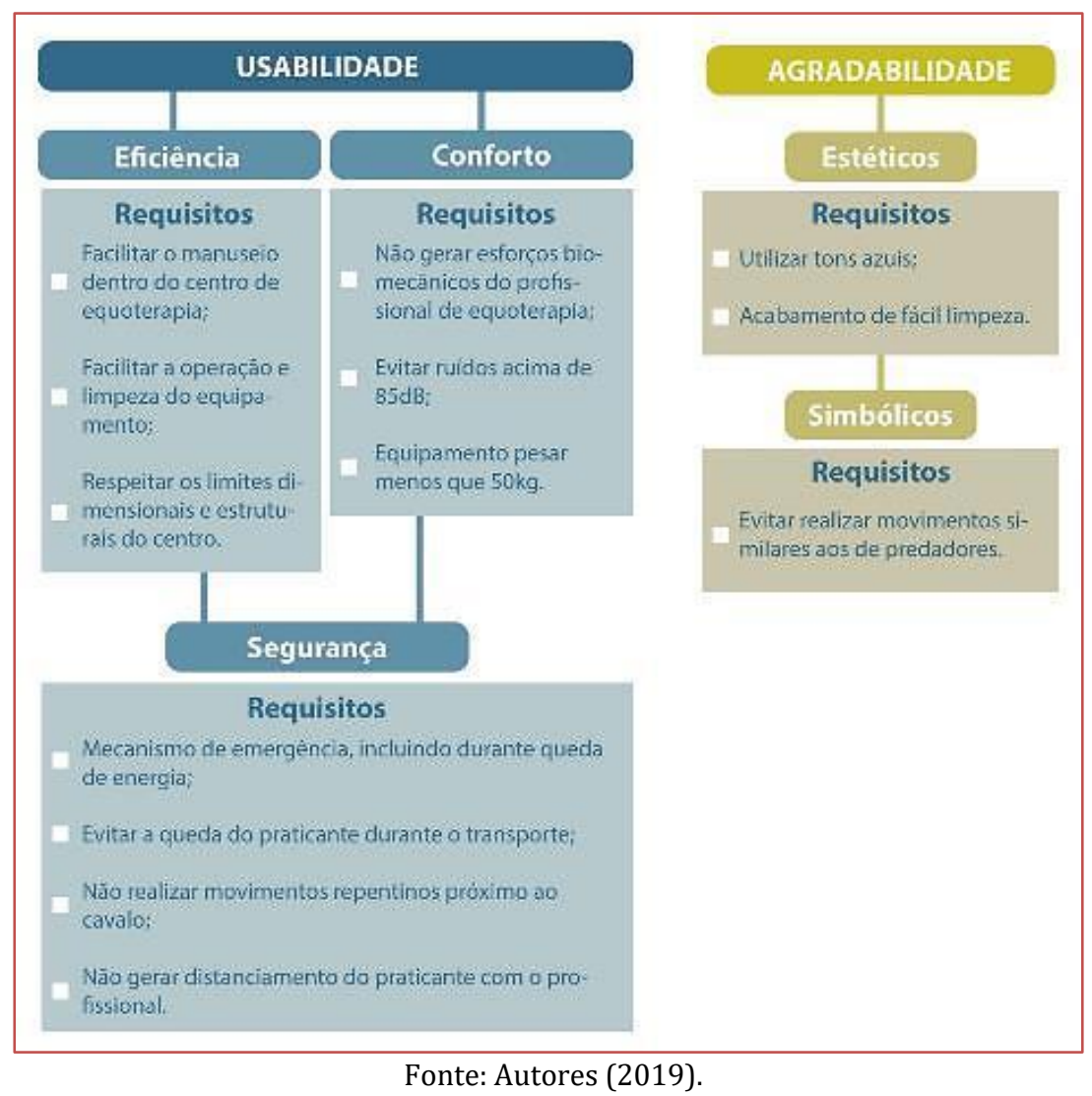

A partir da obtenção dos requisitos, foi possível partir para a etapa seguinte, iniciando o desenvolvimento dos conceitos.

\subsubsection{PROJETO CONCEITUAL}

Para guiar o processo criativo, utilizou-se como fonte os elementos chaves citados por Baxter (2011), onde ele indica o que deve ser considerado durante todas as fases criativas (Figura 5), em que se encontram as orientações iniciais que devem ser consideradas para melhoria do processo. 
Figura 5 - Elementos-chaves das diversas fases do processo criativo

\begin{tabular}{|c|c|}
\hline \multicolumn{2}{|c|}{$\begin{array}{l}\text { ELEMENTOS- CHAVES DAS DIVERSAS FASES DO PROCESSO CRIATIVO } \\
\text { (Baxter, 2011) }\end{array}$} \\
\hline 1. PREPARAÇÄO & 3. SELEÇÃO DE IDEIAS \\
\hline $\begin{array}{l}\text { Explore, expanda e defina o problema. } \\
\text { Levante todas as soluçōes existentes. }\end{array}$ & $\begin{array}{l}\text { Considere tanto os bons como os maus } \\
\text { aspectos de todas as ideias; } \\
\text { Combine ideias aproveitando as partes } \\
\text { boas de cada uma. }\end{array}$ \\
\hline 2. GERAÇÃO DE IDEIAS & 4. REVISÄO DO PROCESSO CRIATIVO \\
\hline $\begin{array}{l}\text { Pense somente nas ideias - deixe as restri- } \\
\text { çöes prátivas para uma etapa posterior; } \\
\text { Procure ideias fora do domínio normal do } \\
\text { problema; } \\
\text { Use técnicas para: Redução, Expansăo e } \\
\text { Digressão do problema. }\end{array}$ & $\begin{array}{l}\text { Avalie o processo de soluçăo de proble- } \\
\text { mas. }\end{array}$ \\
\hline
\end{tabular}

Fonte: Adaptado de Baxter (2011).

Na etapa de Projeto Conceitual, Baxter (2011) recomenda a fixação de princípios sobre o funcionamento do produto e estilo, para isso é necessário realizar uma imersão no problema, explicitar as restrições que foram definidas no planejamento do projeto e compilar as informações, configurando uma síntese coerente para guiar a geração de alternativas. Segundo ele, isso deve gerar princípios básicos de forma e função do produto. Essa recomendação foi utilizada no planejamento de princípios de soluções, onde foi possível dividir inicialmente em dois vieses de forma e funcionamento para a solução: um pórtico/ponte rolante e uma coluna articulada, conforme apresentado na Figura 6.

Figura 6 - Princípios de soluções em duas formas de funcionamento do equipamento: coluna e pórtico

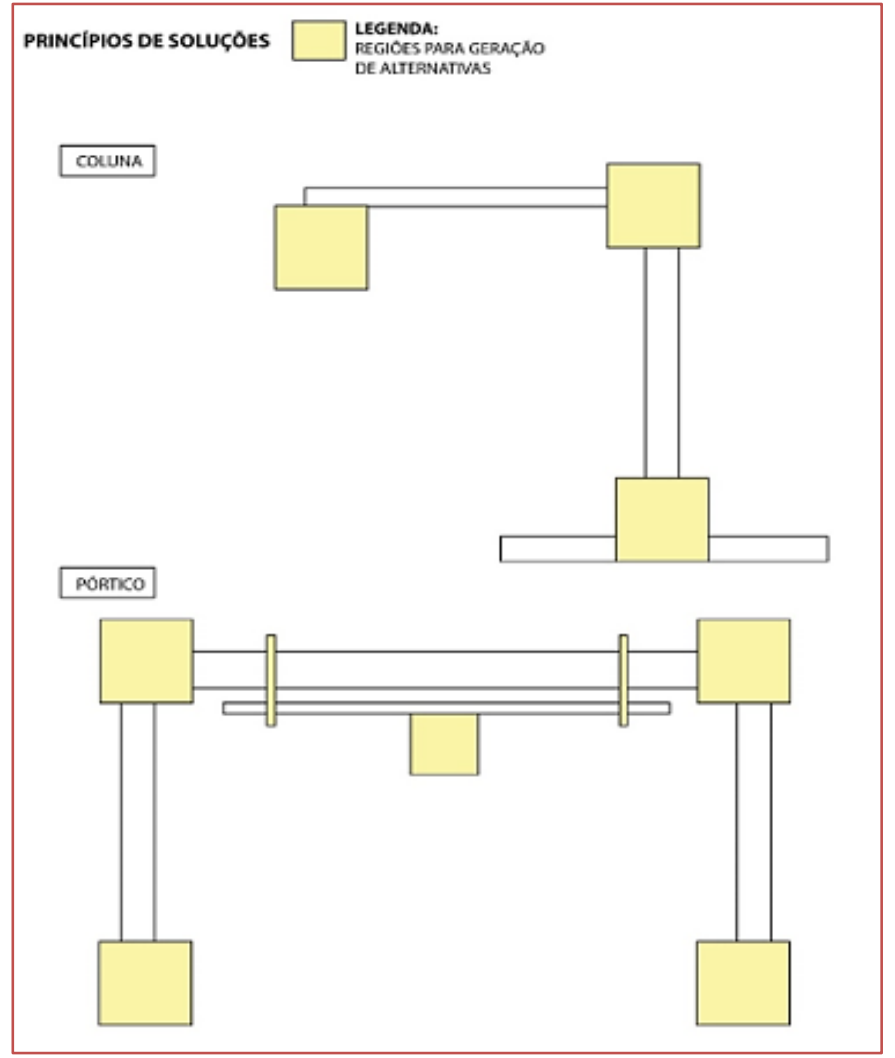

Fonte: Autores (2019). 
Após definir os dois princípios de solução, utilizou-se um esquema de segmentação das partes do equipamento com intuito de melhorar a geração de alternativas (Figura 7), possibilitando a utilização da ferramenta de análise morfológica (BAXTER, 2011) para combinar alguns componentes buscando alternativas melhores. Também foi utilizada a ferramenta MESCRAI (Modifique, Elimine, Substitua, Combine, Rearranje, Adapte, Inverta) (BAXTER, 2011), onde os integrantes foram estimulados a misturar os componentes, baseando-se nas alternativas geradas pela equipe, fazendo combinações para novas.

Figura 7 - Geração de alternativas

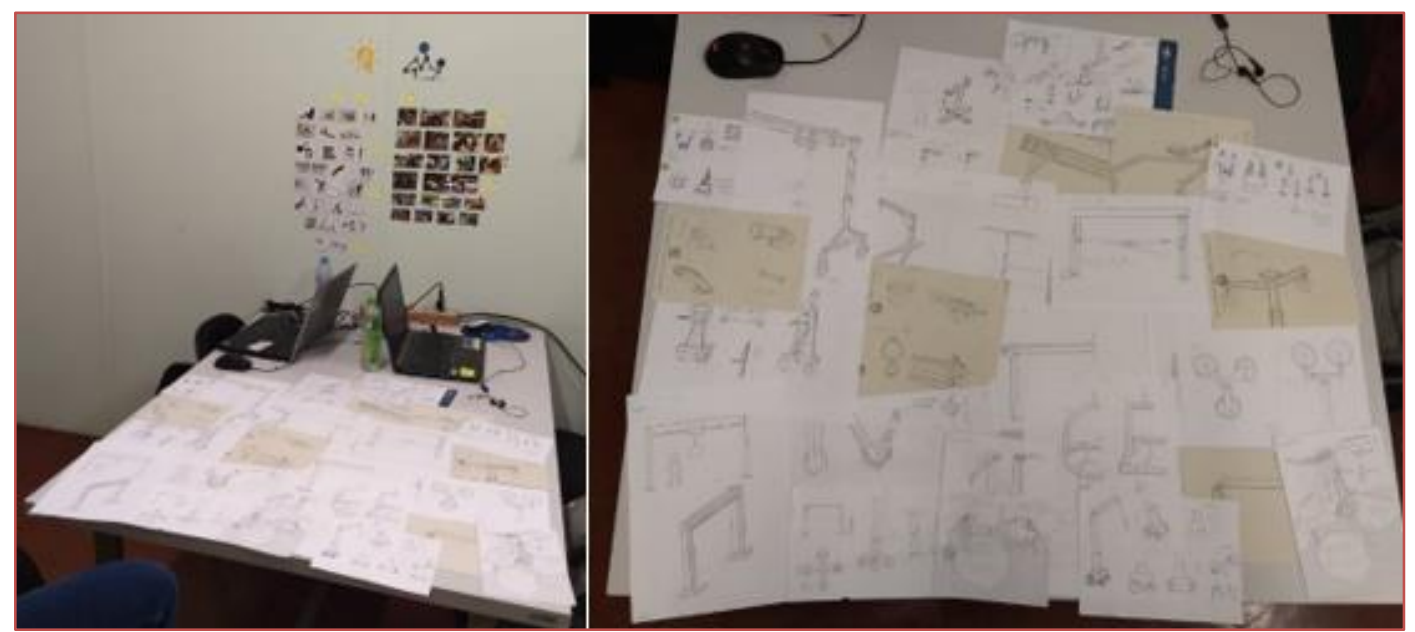

Fonte: Autores (2019).

No decorrer do processo, a equipe observou a necessidade de comparar as alternativas com os produtos já existentes, levando em conta o desejo de gerar uma patente e também de analisar similares que funcionam ou não no mercado. Para isso foi realizada uma análise paramétrica (BAXTER, 2011). Dentro dessa ferramenta foi utilizada uma avaliação dos aspectos de classificação, citado por Baxter (2011) como indicações para comparação das características existentes ou ausentes de produtos. A equipe se reuniu para analisar vídeos de equipamentos de transporte de paciente, em que cada integrante da equipe preencheu uma tabela elencando aspectos positivos e negativos, fazendo uma comparação com as alternativas geradas e levando em consideração sua área do conhecimento, conforme apresentado no Quadro 1. Dessa forma, obteve-se uma avaliação multidisciplinar e de mercado.

Quadro 1 - Exemplo da Planilha Utilizada para Analisar Similares

\begin{tabular}{|c|c|c|}
\hline Nome & Guilherme & \\
\hline Área & Engenharia de Produção & \\
\hline vídeo & Comentário positivo & Comentário negativo \\
\hline \multirow{4}{*}{ 08:36 } & Sustentação das pernas do paciente, boa posição ergonômica & $\begin{array}{l}\text { Elevaçăo de uma criança, não dá pra saber se funciona com uma } \\
\text { pessoa maior }\end{array}$ \\
\hline & $\begin{array}{l}\text { Equipamento de sustentação firme e parece se adequar ao } \\
\text { corpo do praticante }\end{array}$ & $\begin{array}{l}\text { A criança parece ter controle do tronco e dos braços, não dá pra } \\
\text { saber como funcionaria com uma pessoa sem controle, se ela } \\
\text { conseguiria se manter firme no equipamento }\end{array}$ \\
\hline & Facilidade de tirar o equipamento do praticante & \\
\hline & Equoterapeuta faz o movimento & \\
\hline \multirow{3}{*}{ 08:38 } & $\begin{array}{l}\text { Estrutura incluindo uma rampa, semelhante ao que é desejado } \\
\text { no centro de equoterapia }\end{array}$ & $\begin{array}{l}\text { A demonstração foi feita com alguem que tem controle do } \\
\text { tronco e das pernas, não dá para saber como funciona com uma } \\
\text { pessoa que näo tenha esse controle }\end{array}$ \\
\hline & $\begin{array}{l}\text { Demonstração realizada com uma pessoa adulta, identificando } \\
\text { que o equipamento funciona para pessoas maiores }\end{array}$ & \\
\hline & $\begin{array}{l}\text { Suporte para as pernas é apenas encaixe, sem velcro ou botão, } \\
\text { facilitando a retirada em caso de emergencia }\end{array}$ & \\
\hline \multirow{4}{*}{ 08:40 } & $\begin{array}{l}\text { Superficie de sustentaçăo não precisa levantar a pessoa, coloca } \\
\text { atrás das costas e por baixo das pernas e fica cruzado }\end{array}$ & Cavalo tem que entrar em um local muito pequeno e fechado \\
\hline & $\begin{array}{l}\text { Movimento de levar o paciente até o cavalo é feito pelo } \\
\text { terapeuta }\end{array}$ & $\begin{array}{l}\text { Cavalo fica preso à estrutura, năo da pra saber como seria a } \\
\text { reaçăo do mesmo caso contrário }\end{array}$ \\
\hline & $\begin{array}{l}\text { Estrutura para segurar a superficie de sustentaçäo mantém o } \\
\text { paciente sentado }\end{array}$ & $\begin{array}{l}\text { Equipamento para simular a equoterapia, por isso o cavalo deve } \\
\text { ficar confinado }\end{array}$ \\
\hline & $\begin{array}{l}\text { O paciente é retirado deitado e volta à posiçăo sentado graças a } \\
\text { estrutura de sustentaçăa }\end{array}$ & \\
\hline
\end{tabular}

Fonte: Autores (2019). 
Devido a equipe do projeto constar com 5 integrantes envolvidos na geração de alternativas, observou-se a ferramenta de votação (BAXTER, 2011) como a mais democrática e precisa para selecionar os melhores conceitos. Desse modo, foram estabelecidos 4 critérios de avaliação: segurança, ergonomia, fabricação e manuseio. Cada integrante teve que pontuar as alternativas entre 0 (não atende o critério) até 10 (atende totalmente o critério), a avaliação e imagem das alternativas estão presentes na Figura 8. As alternativas com maiores pontuações sofreram refinamentos, como é sugerido por Baxter (2011) sobre a seleção dos conceitos e geração de novos expandidos com base nos selecionados.

Figura 8 - Avaliação de Alternativas

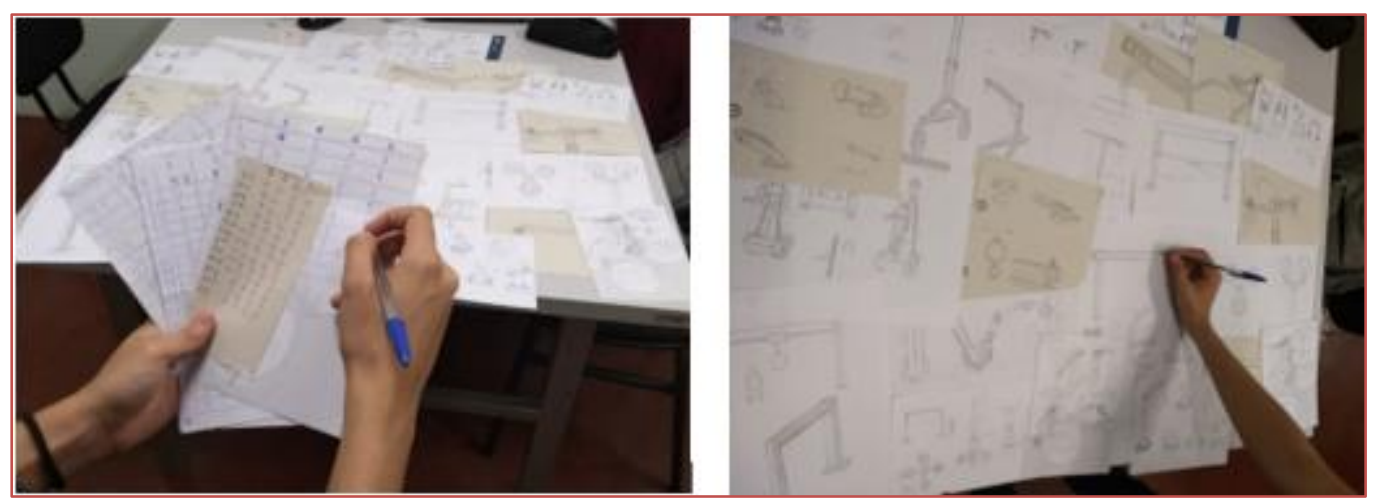

Fonte: Autores (2019).

Rozenfeld et al. (2006) menciona a importância de se desenvolver princípios de solução para cada uma das partes e funções isoladas do produto, sendo necessário a decomposição do mesmo em funcionalidades de menor complexidade. São citados diferentes métodos e ferramentas para geração de alternativas de solução, como por exemplo brainstorming e matriz morfológica, e, a partir da geração das diferentes soluções deve-se selecionar a melhor concepção do produto para ser produzida.

Para Pahl et al. (2007) a lista de requisitos fornece as informações necessárias para a geração de conceitos do que será desenvolvido, iniciando com a identificação dos principais problemas que precisam ser resolvidos. Uma vez definido os pontos cruciais, fica muito mais fácil a formulação das soluções. Pode-se também identificar a principal função e decompô-la, de forma a facilitar o desenvolvimento de soluções para as subfunções. Então, pode-se utilizar ferramentas como a matriz morfológica para combinar os princípios gerados e, a partir disso, realizar a seleção da melhor opção (PAHL et al., 2007).

A equipe realizou as recomendações dos autores, utilizando ferramentas de geração de alternativa, de forma que as partes do proposto sistema puderam ter seu conceito desenvolvido. Posteriormente, as concepções geradas foram analisadas, votadas e escolhida a que a equipe julgou ser melhor, conforme detalhamento na etapa seguinte.

\subsubsection{PROJETO DETALHADO}

Segundo Baxter (2011) depois da definição do conceito selecionado ele deve passar por uma especificação de projeto e seu refinamento deve conter informações mais detalhadas sobre a arquitetura do produto, seus processos de fabricação, componentes, montagem e materiais. Para isso, devem ser feitos desenhos mais detalhados sobre os componentes e os materiais, manualmente ou em softwares de modelagem 3D. 0 autor também cita a importância da utilização da ferramenta de análise das falhas, que visa prever os erros potenciais do equipamento e minimizar ou anular a ocorrência deles. Dessa forma, foi realizado um modelo volumétrico em escala real para teste de risco com o cavalo e simulações de resistência dos materiais e componentes em um software.

Nessa etapa, Rozenfeld et al. (2006) fala sobre a definição da arquitetura do produto, ou seja, quais são os seus componentes e elementos funcionais e a maneira como estão arranjados e interagem entre si, proporcionando um entendimento de aspectos de funcionamento, montagem e fabricação. Esses componentes devem ser detalhados, calculados, terem suas tolerâncias definidas e desenhados pela equipe. Além disso, o processo de fabricação e montagem deve ser bem pensado e planejado, decidindo o 
que será produzido e o que será comprado, buscando otimizar o processo produtivo. Os autores falam também sobre a realização de testes até a exaustão do produto.

Para os autores Pahl et al. (2007), o princípio de solução elaborado na etapa conceitual anterior e suas ideias subjacentes agora podem ser consolidadas, sendo definidos: o layout geral - arranjos dos componentes e as compatibilidades estruturais; o design preliminar do produto - definindo formatos e materiais das estruturas; e os processos de produção. Ou seja, essa etapa consiste em pegar a ideia gerada na etapa anterior e estabelecer as definições finais de formato, arranjo, aparência, material e toda informação necessária para que o processo produtivo se inicie. Devem ser levados em consideração fatores tecnológicos e econômicos, e o desenvolvimento deve ser auxiliado através de desenhos em escala, revisões críticas, testes e avaliações.

Essa etapa é a que a equipe atualmente se encontra, foram realizadas as especificações do conceito definido na etapa anterior, detalhando os componentes e partes através de desenhos 2D e 3D, definindo suas tolerâncias e medidas através de cálculos e simulações. Está sendo realizado o desenvolvimento do protótipo, através do qual serão feitas as avaliações com o usuário, os testes, o desenvolvimento de manuais de uso e manutenção e análise de riscos.

\section{RESULTADOS}

Diante do exposto, foi possível ter uma visão ampla das diferentes perspectivas e metodologias de projeto de produto, utilizando métodos cientificamente comprovados. Esse processo possibilitou a elaboração de uma metodologia personalizada levando em consideração as necessidades específicas, sendo possível abranger áreas multidisciplinares e aumentando o entendimento do problema. Consequentemente permitiu sistematizar o planejamento do processo de desenvolvimento do produto, possibilitando diferentes métodos criativos e auxiliando na eliminação do bloqueio mental.

Entretanto, percebeu-se a importância da experiência em projeto de produtos e do entendimento amplo sobre o processo de desenvolvimento e suas etapas, de forma que possibilita lidar com os diversos aportes teóricos dos autores e discernir quais métodos ou etapas que devem ser utilizados ou descartados. Constatou-se que por meio das particularidades de cada projeto, pode não haver um único método que satisfará e abrangerá as necessidades a serem atendidas.

\section{CONCLUSÃO}

Esse artigo pretendeu explicitar de forma prática a importância de conhecer e compreender diversas metodologias e buscar confrontá-las a fim de selecionar o que há de mais adequado para as necessidades de um projeto. Ainda, foi possível apresentar a vantagem de configurar uma equipe com profissionais de conhecimento multidisciplinar, de forma a estimular o debate entre diferentes perspectivas de desenvolvimento de produto.

\section{REFERÊNCIAS}

[1] BAXTER, Mike. Projeto de Produto: guia prático para o design de novos produtos. 3ạ edição. Blucher. São Paulo, 2011.

[2] BOARETTO, Marcelo Dondelli et al. Equoterapy center at a glance for ergonomic activity: Epidemiological prolife versus therapeutical practices. 20th Congress Of International Ergnomics Association, Florence, v. 20, n. 1, p.759-764, ago. 2018. Anual.

[3] EVANOFF, B.; WOLF, L.; ATON, E.; CANOS, J.; COLLINS, James. Reduction in Injury Rates in Nursing Personnel Through Introduction of mechanical lifts in the workplace. American Journal of Industrial Medicine. 2003. DOI: 10.1002/ajim.10294.

[4] IIDA, Itiro; GUIMARÃES, Lia Buarque de Macedo. Ergonomia - Projeto e Produção. 3. ed. São Paulo: Edgard Blücher, 2016. 850 p.

[5] LUZ, Maria de Lourdes Santiago; BOARETTO, Marcelo Dondelli; RODRIGUES, Jullia Maria Zullim. 0 trabalho em um Centro de Equoterapia sob a compreensão da ergonomia da atividade. [s.l.], v. 1, n. 37, p.1-19, 15 nov. 2017. Anual. ENEGEP 2017 - Encontro Nacional de Engenharia de Produção. http://dx.doi.org/10.14488/enegep2017_tn_sto_241_397_34518. 
[6] PAHL, G; BEITZ, W; FELDHUSEN, J; GROTE, K.H. Engineering Design: A systematic Approach. 3rd ed. Springer. London, UK.

[7] ROZENFELD, H. et al. Gestão de desenvolvimento de produtos: uma referência para a melhoria do processo. São Paulo: Saraiva, 2006. 


\section{Capítulo 22}

Um estudo comparativo da eficiência do desempenho acadêmico à luz da aplicação de metodologias inovadoras

Ivonalda Brito de Almeida Morais

Eldelita Aguida Porfírio Franco

Genyvana Criscya Garcia Carvalho

Manoel Eulálio Neto

Oduvaldo Vendrametto

Resumo: Na busca da eficiência e da qualidade em educação, o presente artigo trata de um estudo comparativo entre diferentes metodologias de ensino utilizadas no curso de Engenharia Civil da Cristo Faculdade do Piauí - CHRISFAPI. Neste estudo, foi comparado o desempenho dos alunos submetidos à metodologia tradicional, no semestre 2018.2, e a metodologias inovadoras, no semestre 2019.1. 0 objetivo da pesquisa foi identificar, entre as metodologias adotadas pelos docentes, a que produz indicadores de qualidade mais eficientes a fim de melhorar o uso dos recursos e auxiliar na tomada de decisão. Utilizou-se metodologia baseada em pesquisa documental, através de relatórios de aulas com aplicação de metodologias inovadoras e de planilhas de resultado acadêmico dos alunos, considerando seu desempenho em três disciplinas, tendo como parâmetro as notas obtidas na primeira avaliação de cada um dos semestres sob análise. Como resultado, a pesquisa mostrou que a utilização de metodologias consideradas inovadoras, sobretudo as ferramentas que utilizam tecnologias digitais, é um dos fatores que, além de melhorar o desempenho dos alunos, gera comportamentos proativos e de engajamento, tanto nos discentes quanto nos docentes e, partindo dessa experiência, esse novo modelo deve ser testado nos demais cursos da instituição para melhorar a qualidade dos serviços prestados, uma vez que os experimentos realizados vão ao encontro de mudanças curriculares definitivas, no que permite o estado da arte para ocupações já previsíveis da Indústria 4.0, tanto na indústria, como na agricultura, na saúde e em outras atividades.

Palavras chave: Metodologias inovadoras. Eficiência. Indústria 4.0. 


\section{INTRODUÇÃO}

A Quarta Revolução Industrial, termo cunhado a partir do lançamento do projeto Plattform Industrie 4.0, na Feira de Hannover, na Alemanha, em 2011 (SACOMANO e SÁTYRO, 2018), vem alterando de forma nunca antes vista a forma como as pessoas vivem, convivem e se relacionam com o mundo do trabalho, tendo as tecnologias digitais, com a Internet das Coisas- IdC, assumido papel preponderante na conjuntura social hodierna. Frente a essa sociedade em constante transformação, a educação precisa evoluir, com a reavaliação de seus currículos, metodologias, tempo e espaços (MORAN, 2015), preparando as novas gerações para um mercado de trabalho no qual as tecnologias digitais serão as novas ferramentas do profissional de qualquer área.

A Educação já está sofrendo o impacto das tecnologias digitais. A atividade docente tornou- se um grande desafio para grande parte dos professores em todos os níveis e modalidades de ensino.

Neste estudo, será enfocado o Ensino Superior, mais especificamente o curso de Engenharia Civil, que apresenta um alto índice de evasão e reprovação escolar, no qual a utilização de metodologias inovadoras surge como uma alternativa para despertar o engajamento desses alunos bem como promover a sua autonomia diante de sua própria aprendizagem, buscando desenvolver neles uma atitude ativa em seu processo de aprendizagem, integrando o espaço da sala de aula com os demais espaços onde ele atua, incluindo-se o virtual.

Essas novas estratégias buscam melhorar os indicadores de qualidade da educação e auxiliar as Instituições de Ensino Superior na tomada de decisão, na melhoria de seus processos e na oferta de serviços de qualidade.

Este artigo, portanto, busca responder ao seguinte questionamento: A aplicação de metodologias inovadoras pode melhorar o desempenho acadêmico dos alunos do curso de Engenharia Civil e auxiliar no processo de tomada de decisão das instituições de ensino superior?

O objetivo geral da pesquisa foi identificar, entre as metodologias adotadas pelos docentes, a que produz indicadores de qualidade mais eficientes a fim de melhorar o uso dos recursos e auxiliar na tomada de decisão.

A escolha do tema em estudo se deu por conta do contexto de atuação dos professores de ensino superior no curso de Engenharia Civil, o qual está cada vez mais complexo, exigindo uma formação que vai além do campo científico, exigindo conhecimentos teóricos e práticos relacionados à docência, que desperte nos estudantes sua capacidade questionadora, inventiva e criativa.

Sendo o ambiente acadêmico um campo extremamente fértil para experiências didático-pedagógicas inovadoras, importante buscar novas ferramentas para conectar o ambiente da sala de aula ao mundo das tecnologias digitais. Logo, esse estudo poderá contribuir para um processo de ensino mais dinâmico, inovador, incentivando professores de ensino superior a utilizarem ferramentas que estimulem o desenvolvimento intelectual dos alunos, oferecendo condições para que eles se apropriem do saber sistematizado, tornando-se sujeitos ativos na busca do conhecimento e aptos a atuarem no mercado de trabalho da Quarta Revolução Industrial.

\section{METODOLOGIAS ATIVAS: UM NOVO CAMINHO PARA UMA APRENDIZAGEM COLABORATIVA}

Ao longo das últimas décadas, observou-se uma mudança nos paradigmas econômicos e sociais, quando as tecnologias digitais passam a influenciar o modo como o homem vive e interage com seu contexto social. Nesse novo modelo de sociedade, que começa a se consolidar no século XXI, com a presença indissociável dos computadores pessoais, tablets, smartphones, Internet acessível a todos, concentração das mídias de comunicação para a forma digital, na qual a própria organização do trabalho se transforma com a crescente implantação de sistemas de automação, há a necessidade urgente do enfrentamento de desafios na área da educação, com a reestruturação do ensino de tecnologia e engenharia e a otimização da qualidade da educação (SILVA, 2018).

Há, portanto, uma necessidade de se reavaliar o processo educacional numa sociedade cada vez mais colaborativa, na qual a aprendizagem também passa a ser uma experiência colaborativa haja vista que o conhecimento passa a ser compartilhado de forma pública (RIFKIN, 2016). 
Importante considerar ainda que a crescente automação da força de trabalho, com a fusão de várias tecnologias, trazem como desdobramento o aumento do trabalho e da cognição do ser humano, tornando imprescindível que as lideranças preparem os novos profissionais para o mercado de trabalho, que surge como resultado da Indústria 4.0, criando um novo paradigma de formação acadêmica que prepare estes profissionais para interagir com máquinas inteligentes, conectadas e eficientes (SCHWAB, 2016).

Assim, as buscas por materiais e novas estratégias de ensino têm sido constantes na tentativa de melhorar as práticas docentes atuais, destacando- se as metodologias inovadoras que, neste estudo, serão tratadas como metodologias ativas, que são estratégias importantes para manter o aluno na sala de aula bem como melhorar seu desempenho acadêmico.

Para Pereira (2012), a metodologia ativa pode ser entendida como qualquer estratégia didática centrada no aluno, deixando o protagonismo do professor e o uso do livro didático como únicas ferramentas do conhecimento em sala de aula.

As metodologias ativas são técnicas de ensino nas quais o aluno assume a responsabilidade individual e colaborativa para buscar o conhecimento, dedicando-se a um estudo prévio e contínuo, estabelecendo uma rotina própria que seja capaz de preencher as lacunas no seu processo de aprendizagem, saindo de uma posição passiva, centrada no professor, para se tornar um agente ativo.

Diversas técnicas de ensino podem ser classificadas como metodologias ativas, desde as mais tradicionais, como a aula expositiva dialogada, o debate, o estudo dirigido, estudo de caso, a visita técnica e a exibição de filmes, até as técnicas consideradas mais modernas e inovadoras, como a aprendizagem baseada em problemas (ABP), a aprendizagem baseada em times (ABE), a utilização das tecnologias da informação e comunicação (Tic's) e a aula invertida.

\subsection{AULA EXPOSITIVA DIALOGADA}

A aula expositiva dialogada é uma técnica de ensino onde o processo de aprendizagem é um procedimento compartilhado entre os sujeitos envolvidos, ou seja, professores e alunos realizam um diálogo, respeitando a realidade, o contexto e as experiências de cada um. Essa estratégia envolve passos que norteiam a prática da ação docente. 0 primeiro deles é a inspiração, onde o educador traz algo que mobilize para determinado conhecimento. 0 segundo passo é a problematização, momento em que se relaciona o conteúdo à realidade por meio de questões que o problematizem. 0 terceiro passo é a reflexão, onde se exige um movimento individual e coletivo para que o educando e o educador possam pensar juntos. 0 quarto passo é a transpiração, que é o momento do estudo propriamente dito sobre tema, conteúdo e conhecimento. 0 quinto e último passo é a síntese, ou seja, momento de compartilhar o aprendido, seja de forma escrita, oral ou de ambas (LEAL; MIRANDA; NOVA, 2018).

\subsection{DEBATE}

O debate é uma estratégia de ensino onde se discute formalmente duas ou mais opiniões sobre um tema polêmico, ou seja, representa uma análise de um ponto de vista. Para Castanho (1998 apud Leal; Miranda; Nova, 2018), tem como finalidade fomentar diversificadas opiniões, posicionamentos com a utilização da competitividade cognitiva. Para a realização do debate é necessário fazer uma apresentação do tema, dos participantes e das normas. Cada debatedor deve explanar o tema, expor suas controvérsias e pontos de vista, envolvendo comentários por parte da oposição e réplicas.

\subsection{ESTUDO DIRIGIDO}

Estudo dirigido significa o ato de estudar sob a orientação do professor (VEIGA, 2001). Nele, os alunos desenvolvem em sala de aula, ou fora dela, atividades selecionadas pelo professor, o qual fica responsável por orientá-los e acompanhá-los na sua realização. Para desenvolver essa metodologia, o professor deverá estabelecer um roteiro para direcionar o estudo, que pode ser ler um texto e depois responder perguntas repassadas pelo professor, observar fatos e depois fazer observações ou realizar experiências e fazer relatórios. 


\subsection{ESTUDO DE CASO}

O estudo de caso é considerado uma ferramenta pedagógica que se desenvolve através da participação dos estudantes na reflexão e solução da situação exposta pelo professor, o qual pode descrever casos reais ou fictícios, com problema mal estruturado ou sem uma solução predefinida. Para Masetto (2003), o estudo de caso desenvolve a capacidade de analisar problemas, apresentar soluções e preparar-se para enfrentar situações reais e complexas, aproximando o estudante da realidade profissional.

\subsection{VISITA TÉCNICA}

A visita técnica permite que os alunos ouçam, vejam e sintam as práticas de uma organização, o que torna o processo motivador e significativo para a aprendizagem (MONEZI; ALMEIDA FILHO, 2005). Essa atividade oferece uma aprendizagem experiencial fora da sala de aula, pela qual a experiência do aluno é refletida, fazendo surgir novos aprendizados, podendo ser aplicada em qualquer graduação.

\subsection{FILMES}

O filme é um instrumento de aprendizagem utilizado nos mais diversos níveis de ensino que traz ritmo e envolve os alunos em uma conexão do mundo real coma ciência aplicada. Moram (1995) aduz que filmes podem ser utilizados em sala de aula para sensibilização, para ilustrações, para simulações, ensino, produção e avaliação. Devem ser utilizados de acordo com os objetivos da aprendizagem.

\subsection{APRENDIZAGEM BASEADA EM PROBLEMAS (ABP)}

Na aplicação do Problem - Based learning (PBL) ou Aprendizagem Baseada em Problemas (ABP), os alunos são colocados em contato com problemas reais que surgem na prática da profissão, desenvolvendo no aluno agilidade para solucionar problemas e criatividade para explorar novos métodos de organização profissional (RODRIGUES, 2007). O PBL é realizado por etapas, onde cada etapa vai formando os sete passos para a resolução do problema proposto.

\subsection{APRENDIZAGEM BASEADA EM EQUIPE (ABE)}

A Team-Based Learning (TBL) ou Aprendizagem Baseada em Equipe (ABE) é uma estratégia de ensino composta por uma série de práticas sequenciadas de ensino-aprendizagem (PARMELEE D, MICHAELSEN LK, COOK S, HUDES PD, 2012). É apropriada para ser aplicada em turmas numerosas. Desenvolve o estudo colaborativo com alto desempenho, possibilitando-lhes situações de aprendizagem significativa (MICHAELSEN LK, SWEET M, 2008).

\subsection{TECNOLOGIAS DA INFORMAÇÃO E DA COMUNICAÇÃO- TIC'S}

As tecnologias da informação e comunicação (TIC's) são ferramentas tecnológicas por meio de hardware, software e telecomunicações que podem ser utilizadas em sala de aula para facilitar o processo de ensino aprendizagem. Essas tecnologias permitem ao professor e aos docentes experimentar a utilização da Internet através de celular, tablet ou computador pessoal e são muito valorizadas pelos alunos. Dentre as mais utilizadas, destacam-se o livro digital, que permite aos seus leitores complementos com vídeos, áudios, animações, links, entre outros; a formação continuada online, ou seja, cursos e palestras a distância para complementar o ensino presencial; a gamificação, com a utilização de desafios por meio de jogos de competição, mantendo o foco em tarefas; as redes sociais, como o whatsapp, através do qual são criados grupos envolvendo professores e alunos para troca de informações, envio de materiais complementares, esclarecimento de dúvidas e realização de debates sobre acontecimentos importantes relacionados à profissão; a avaliação online, através da qual os alunos realizam testes de conhecimento por meio de aplicativos como socratives ou formulários google, os quais já oferecem relatórios prontos com os resultados obtidos pelos alunos e Google Classroom plataforma que facilita a comunicação entre alunos e professores, com troca de materiais e informações. 


\subsection{SALA DE AULA INVERTIDA}

A sala de aula invertida é uma estratégia de ensino onde as atividades que tradicionalmente seriam feitas em sala de aula, são executadas em casa, ou seja, materiais são lidos em casa e discutidos em sala, vídeos com pequenas aulas são assistidos em casa e atividades respondidas em sala, entre outros. A aula não mais gira em torno do professor e sim dos alunos, pois o professor está presente unicamente para prover feedback especializado, amparando os alunos e não transmitindo informações. A inversão fala a língua dos estudantes dos dias atuais principalmente por se utilizar de recursos digitais, ajuda estudantes que se encontram sobrecarregados por alternar diversas atividades, cria condições para que os professores conheçam melhor seus alunos por meio de interações e torna a aula mais transparente (BERGMANN, 2018).

\section{APLICAÇ̃̃O DAS METODOLOGIAS ATIVAS NO CURSO DE ENGENHARIA CIVIL}

A partir da observação do baixo desempenho dos alunos do curso de Engenharia, sobretudo nas disciplinas do primeiro ano do curso, a Direção de Ensino e a Coordenação Pedagógica da CHRISFAPI, montaram um plano estratégico, no qual definiram a implantação do uso de metodologias ativas em três disciplinas do primeiro período do curso, com o objetivo de elevar os resultados dos alunos bem como utilizar esse modelo como auxiliar no uso dos recursos disponíveis e na tomada de decisão.

A gestão optou por uma busca de mudança progressiva, na qual cada docente bem como os alunos envolvidos não experimentassem uma ruptura brusca de um modelo essencialmente tradicional para um modelo inovador.

Assim, no início do semestre de 2019.1, os professores das disciplinas Cálculo Diferencial e Integral I; Química Geral e Experimental e Homem, Sociedade e Cultura, participaram de oficinas pedagógicas nas quais foram repassadas algumas das ferramentas das metodologias ativas, começando a aplicá-las a partir da primeira semana desse mesmo semestre.

Foi criado um grupo em um aplicativo de interação virtual para que cada experiência fosse compartilhada entre os professores e houvesse um compartilhamento de ideias e procedimentos. Cada atividade aplicada pelo professor era detalhada num relatório que era entregue ao Núcleo de Apoio Pedagógico- NUAPE para análise e intervenções, quando necessárias.

Os relatórios apresentados ao NUAPE pelos professores participantes da experiência mostravam a cada nova aula, o surgimento de um ambiente colaborativo em que as experiências e ferramentas eram compartilhadas.

\section{METODOLOGIA}

Para a realização desse estudo, foi feita uma pesquisa documental, através da qual foram analisados relatórios de desempenhos acadêmicos de alunos na primeira avaliação do semestre 2018.2, em 3 (três) disciplinas nas quais foram aplicadas atividades envolvendo metodologias consideradas inovadoras e confrontados tais resultados com o desempenho de alunos nessas mesmas disciplinas, no semestre 2019.1. Importante ressaltar que os professores das referidas disciplinas, nos dois semestres, permaneceram os mesmos.

Além da análise dos percentuais de rendimento acadêmico, levaram-se em consideração os relatórios das atividades desenvolvidas a fim de encontrar fatores que poderiam ter favorecido os resultados ou os estagnado. Como resultado, observou-se o que o gráfico abaixo demonstra: 
Figura 1 - Desempenho acadêmico dos alunos do curso de Engenharia Civil

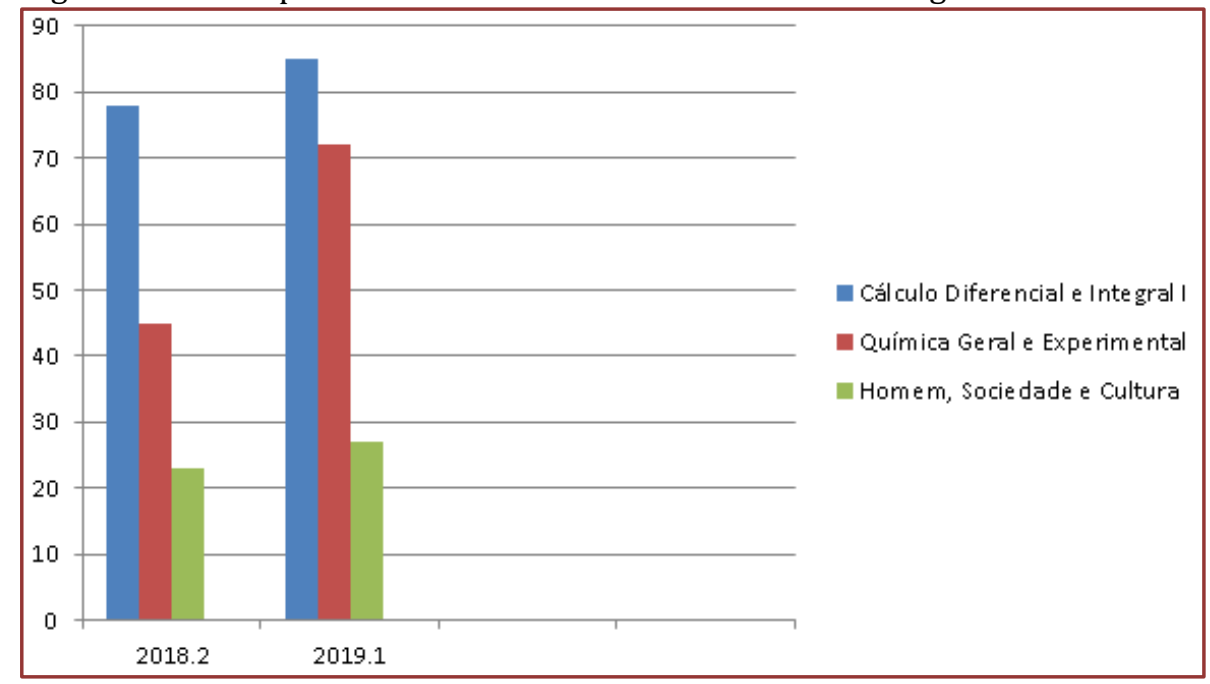

Fonte: Dados coletados relatórios NUAPE CHRISFAPI.

Pode-se perceber, pelo gráfico, que houve um aumento no percentual de rendimento dos alunos em todas as disciplinas. Observando-se que na disciplina Química Geral e Experimental esse resultado foi mais significativo, 27\%. Enquanto que nas disciplinas Homem, Cultura e Sociedade e Cálculo Diferencial e Integral I, foi insignificante, tendo somente $4 \%$ de aumento no percentual de aproveitamento dos alunos na primeira e $7 \%$ na segunda.

Para buscar uma justificativa para a disparidade dos resultados de desempenho, verificou-se que na disciplina Química Geral e Experimental, o relatório do professor demonstrou que os alunos participaram da atividade e mostraram-se bastante engajados com a utilização das TIC's. Já na disciplina Homem, Cultura e Sociedade e Cálculo Diferencial e Integral I, os relatórios mostram que embora tenha havido adesão dos alunos, as ferramentas empregadas foram debate, estudo de caso e filmes, técnicas que, embora consideradas metodologias ativas, são menos inovadoras e não utilizam tecnologias digitais.

A utilização de tecnologias digitais, como aplicativos no desenvolvimento das atividades e o compartilhamento dos conhecimentos fomentou um ambiente colaborativo e de compartilhamento, o que gerou uma mudança de postura tanto de discentes como de docentes, que desenvolveram um engajamento maior frente ao processo pedagógico, observando-se um comprometimento com o desenvolvimento daqueles que apresentavam maior dificuldade no uso das ferramentas digitais e na aprendizagem dos conteúdos.

\section{CONSIDERAÇÕES FINAIS}

A pesquisa buscou fazer um estudo comparativo entre os resultados de desempenho obtidos por alunos do curso de Engenharia Civil para os quais o professor utilizou apenas aulas tradicionais, no semestre 2018.2, e resultados nos quais houve a aplicação de metodologias ativas, no semestre 2019.1.

Observou-se, após a análise dos documentos que mostravam o desempenho acadêmico dos alunos nas disciplinas selecionadas nos semestre 2018.2 e 2019.1, bem como dos relatórios dos professores sobre a aplicação das metodologias ativas, que houve uma melhoria nos índices de notas aprovativas, sendo que a disciplina Química Geral e Experimental destacou-se pelo aumento significativo do desempenho dos alunos e a disciplina Homem, Cultura e Sociedade apresentou um aumento de desempenho bem insignificante, o que ficou comprovado pela análise dos relatórios de aplicação das metodologias ativas que as atividades que utilizam as TIC's são mais motivadoras e proporcionam uma atividade mais colaborativa e significativa.

Dessa forma, conclui-se que a aplicação das metodologias ativas em sala de aula promove inovação e desperta o interesse dos alunos, colaborando para que estes não só melhorem o seu desempenho acadêmico, mas gerando comportamentos proativos e de engajamento. Essa mudança de postura foi observada em discentes e docentes. 
Partindo dessa experiência, os indicadores de qualidade gerados possibilitaram obter informações que auxiliaram na tomada de decisão a fim de que a faculdade, através de seu Núcleo de Apoio Pedagógico, possa melhorar a qualidade do serviço prestado, ampliando a utilização desse modelo do curso de Engenharia Civil e nos demais cursos da instituição, uma vez que os experimentos realizados vão ao encontro de mudanças curriculares definitivas, no que permite o estado da arte para ocupações já previsíveis da Quarta Revolução Industrial, tanto na indústria, como na agricultura, na saúde e em outras atividades.

\section{REFERÊNCIAS}

[1] Bergmann, J. Sala de aula invertida: uma metodologia ativa de aprendizagem. 1aㅡ Ed. Rio de Janeiro: LTC, 2018.

[2] Leal, E. A.; Miranda, G. J.; Nova, S. P. de C. C.. Revolucionando a sala de aula: como envolver o estudante aplicando as técnicas de metodologias ativas de aprendizagem. 1. ed. São Paulo: Atlas, 2018.

[3] Michaelsen LK, Sweet M. Fundamental principles and practices of Team-Based Learning. In: Michaelsen LK, Parmelee D, MacMahon KK, Levine RE. Team-Based Learning for health professions education: a guide to using small groups for improving learning. Sterling, VA: Stylus Publishing; 2008. 9-34. 9. Searle NS, Haidet P, Kelly

[4] Monezi, C. A.; Almeida Filho, C. O. C. de. A visita técnica como recurso metodológico aplicado ao curso de engenharia. Congresso Brasileiro de Ensino de Engenharia, 33, 2005. Campina Grande, PB. Anais Congresso brasileiro de ensino de engenharia, Campina Grande, 2005.

[5] Moran, J. M. O vídeo na sala de aula. Comunicação e educação. São Paulo, v.2, p. 27-35, jan./abr.1995.

[6] Moran, J. M. Mudando a educação com metodologias ativas. In: Coleção Mídias Contemporâneas. Convergências Midiáticas, Educação e Cidadania: aproximações jovens. Vol. II, p. 15 -33 2015. Disponível em: http://uepgfocafoto.wordpress.com.Acesso em: 14 abr. 2019.

[7] Parmelee D, Michaelsen LK, Cook S, Hudes PD. Team-based learning: a practical guide: AMEE guide no. 65. Med Teach 2012;34(5): e 275-e7.

[8] Pereira, R. Método Ativo: Técnicas de Problematização da Realidade aplicada à Educação Básica e ao Ensino Superior. In: VI Colóquio internacional. Educação e Contemporaneidade. São Cristóvão, SE. 20 a 22 setembro de 2012.

[9] Rifkin, J. Sociedade de custo marginal zero. São Paulo: M. Books do Brasil Editora Ltda., 2016.

[10] Rodrigues, E. A.; Araújo, A. M. P. O ensino da contabilidade: aplicação do método PBL nas disciplinas de contabilidade em uma instituição de ensino superior particular. Revista de educação, v.10, n. 10, p. 166-176, 2007.

[11] Sacomano, J. B.; Satyro, W. C. Indústria 4.0: conceitos e elementos formadores. In: Sacomano, J. B. et al. Indústria 4.0: conceitos e fundamentos. São Paulo: Blucher, 2018.

[12] Schwab, K. A quarta revolução industrial. São Paulo: Edipro, 2016.

[13] Silva, M. T. Organização e Trabalho 4.0. In: Sacomano, J. B. et al. Indústria 4.0: conceitos e fundamentos. São Paulo: Blucher, 2018.

[14] Veiga, I. P. A. (org.). Técnicas de ensino: por quê não? Campinas, São Paulo: Papirus, 2001. 


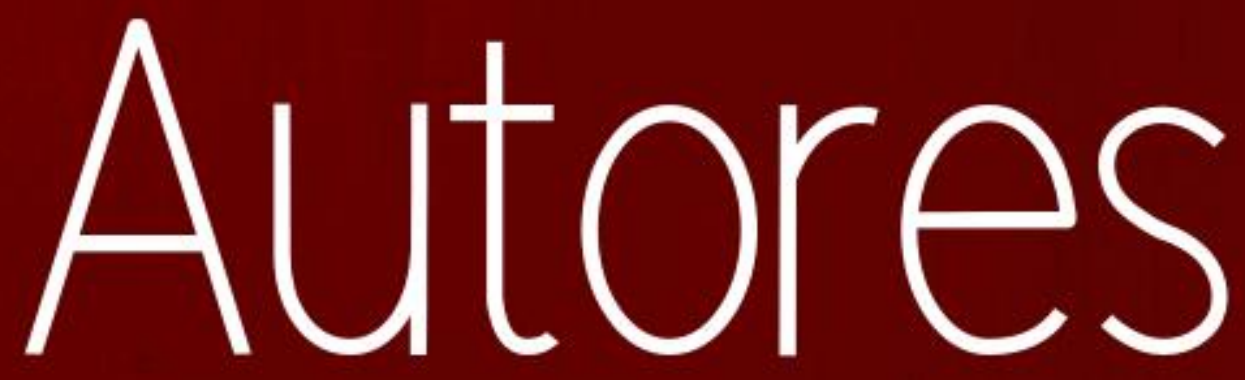




\section{ADÃO ROBSON VIEIRA DA CRUZ}

Especialista em Engenharia de Produção (IERGS/UNIASSELVI), MBA in Project Management (IERGS/UNIASSELVI), Pós-Graduando em Biotecnologia (FAVENI), Pós-Graduando em Auditoria e Perícia Ambiental (FAVENI), graduado em Gestão Ambiental (IERGS/UNIASSELVI, 2017). Funcionário Público a 19 anos, atuou como Auditor Fiscal da Vigilância em Saúde, Vigilância Ambiental, Supervisor de Controle de Endemias e Laboratorista Entomológico, na Prefeitura Municipal de Minas do Leão/RS. Atualmente é Servidor Público Federal na Empresa Brasileira de Infraestrutura Aeroportuária - INFRAERO, desenvolvendo atividades no Setor Administrativo / Finanças / Licitações / Agente de GRC - Governança, Riscos e Compliance; Pesquisa temas relacionados a Tecnologias Ambientais e Biotecnologias, Fontes Renováveis de Energia Limpa, visando a Sustentabilidade, o Desenvolvimento Econômico e Social, mitigando os Impactos Ambientais. Autor de Artigos de Iniciação Cientifica, Anais de Eventos de Engenharia de Produção e Engenharia da Sustentabilidade, Palestrante de Seminários e Conferências de Saúde Pública e Ambiental.

\section{ALEXANDRE GASPARY HAUPT}

Doutorando em Engenharia Elétrica (UFRGS), mestre em Engenharia Elétrica (UFRGS, 2004), graduado em Engenharia Elétrica (PUCRS, 1992) e graduado em Licenciatura (Cefet, 1996). Atuou como docente/coordenador no curso de Engenharia de Telecomunicações e Engenharia da Computação na universidade La Salle. Atualmente é coordenador dos cursos de Automação Industrial e Sistemas Embarcados na Faculdade de Tecnologia Senai Porto Alegre. É professor titular das disciplinas de Eletrônica Digital, Eletrônica Analógica, Microprocessadores, Processamento de Imagens, Sistemas de Controle, Inteligência Artificial e Introdução aos Sistemas Embarcados. Pesquisa temas relacionados a processamento de imagens, inteligência artificial, automação industrial e sistemas embarcados. Autor do livro Eletrônica Digital editado pelo editora Blucher em 2016.

\section{ALFREDO IAROZINSKI NETO}

Possui graduação em Engenharia Mecânica pela Universidade Federal do Paraná (1985), Mestrado em Engenharia de Produção pela Universidade Federal de Santa Catarina (1989), DEA em Engenharia de Sistemas Industriais e Inovação pelo INPL de Nancy (1993) e Doutorado em Ciências pela Universidade Paul Cezánne (1996). Atualmente é professor associado da Universidade Tecnológica Federal do Paraná (UTFPR) no Programa de Pós-graduação em Engenharia Civil e na Graduação de Engenharia Civil. Atua nos seguintes temas de pesquisa: concepção de sistemas de gestão, gestão integrada da produção, modelagem de sistemas, gestão da construção e teoria da complexidade.

\section{ALINE DOS REIS CORDEIRO}

Graduação em Engenharia de Produção pela Universidade de Araraquara. Especialização em Gestão de Pessoas e Liderança pela Faculdade Dom Bosco. Cursando Mestrado Profissional em Engenharia de Produção pela Universidade de Araraquara. Linha de Pesquisa - Gestão da Produção e Pesquisa Operacional

\section{ANA CARLA VIOTTI}

Graduada em Engenharia Civil, especialista em Engenharia de Segurança do Trabalho. Desde o início da carreira atuou no segmento de análises orçamentárias e projetuais de obras públicas, atualmente atua no desenvolvimento de projetos, planejamento e orçamentos de obras de artes especiais (pontes e viadutos) e obras civis, com projetos ao longo dos estados de Paraná e Mato Grosso do Sul. 


\section{ANDERSON FELIPE HABEKOST}

É Engenheiro de Produção, Especialista em Gestão Empresarial e Mestre em Engenharia de Produção e Sistemas pela Universidade do Rio dos Sinos. Também atua como gestor de projetos na Universidade do Vale do Taquari e como professor do colégio técnico CT Teutônia, no departamento de administração.

\section{ANTONILTON SERRA SOUSA JUNIOR}

Graduado em Engenharia de Produção e Técnico em Meio Ambiente pela Universidade Ceuma. Graduando em Processos Gerenciais pelo Instituto de Ciência e Tecnologia do Maranhão (IFMA). Pós-graduando no MBA em Engenharia de Produção e Gestão da Qualidade pelo IPOG. Participação em capítulos nos livros de Engenharia de Produção com autoria dos alunos e professores da Universidade Ceuma. Membro da Oficina de Escrita da Universidade Ceuma, atuando como autor, tutor e organizador. Desenvolvedor de artigos científicos com aprovações em periódicos e congressos nacionais. Atualmente, é responsável pelo departamento de logística da Dimensão Indústria de Tubos e Forros (DI-PVC).

\section{ARI MELO MARIANO}

Cientista de Dados, Pós-doutor em Data Science, Pós Doutor em Metodologia Científica e Métodos Quantitativos, Doutor em Administração, Mestre em Administração, e Graduado em Administração. Possui também um MBA em Direito do Consumidor Europeu. Atualmente é Professor/Pesquisador de Engenharia da Produção na Universidade de Brasília (UNB). Professor do Mestrado Profissional de Computação Aplicada, no Departamento de Ciências da Computação. Professor no Mestrado de Gestão da Informação e Tecnologia, na Universidade Católica do Norte, no Chile. Professor do Doutorado de Gestão Empresarial e do Doutorado de Ciências Sociais da Universidade San Francisco Xavier, na Bolívia e do Doutorado de Ciências Empresariais da Universidade de San Simon, também na Bolívia.

\section{ARTHUR RIBEIRO TORRECILHAS}

Graduado em Engenharia Civil (2015), especialista em Perícia e Auditoria Ambiental (2016) e Engenharia de Segurança do Trabalho (2017), Mestre em Engenharia Civil pelo Programa de Pós Graduação em Engenharia Civil na Universidade Estadual de Londrina - UEL (2018) com foco na área de Engenharia Sanitária e ênfase no Tratamento de Resíduos Sólidos. Trabalhou como engenheiro civil atuando nas áreas de perícia e avaliação de imóveis; planejamento e gerenciamento de obras de infraestrutura e saneamento. Presentemente, atua como docente, com experiência em diversas áreas da Engenharia.

\section{BERNARDO DUARTE TOFANO}

Atualmente Técnico de Planejamento e Controle da Produção (PCP) em ITAMIL Itapemirim Mecânica Industrial LTDA. Graduado em Engenharia de Produção pela Universidade Estadual do Norte Fluminense - UENF (2018).

\section{BRENDA BAUMANN GEWEHR}

Graduanda em Engenharia de Produção pela Universidade de Brasília (UnB). Atualmente participa de projeto de pesquisa entre a UnB e uma organização pública das Forças Armadas, atuando com mapeamento do fluxo de valor da organização. Tem experiência na área de Engenharia de Produção.

\section{BRUNO ISAMU OBANA}

Graduando em Engenharia de Produção com ênfase em Software pela Universidade Estadual de Maringá, bolsista no projeto de extensão intitulado Projeto SIMOPE: Sistema de Mobilidade para 
Portadores de Necessidades Especiais aplicado às práticas de Equoterapia, atuando na equipe multidisciplinar para o desenvolvimento de um equipamento de tecnologia assistiva.

\section{CAIO VINICIUS DE ARAUJO FERREIRA GOMES}

Graduando em Engenharia de Produção Mecânica pela Universidade Regional do Cariri - URCA. Atualmente é Bolsista de Iniciação Científica (PIBIC -URCA) na área de Recursos Hídricos

\section{CARLOS ALBERTO CHAVES}

Professor Adjunto IV da Escola de Engenharia Industrial Metalúrgica de Volta Redonda da Universidade Federal Fluminense, lotado no Departamento de Engenharia de Produção. Tem experiência na área de Engenharia de Produção, Materiais e Metalúrgica, com ênfase em Gerenciamento de Projetos, Gestão da Tecnologia, Controle de Qualidade, Siderurgia, implantação de empreendimentos e reciclagem de resíduos industriais.

\section{CÁSSIO RICELLY SOUZA COSTA}

Graduado em Engenharia de Produção pela Universidade Ceuma. Desenvolvedor de artigos científicos com aprovações em congresso nacional. Obtive uma breve experiência em uma indústria de bebidas na área de supervisão produção e na área administrativa e alocação de insumos em uma empresa de telecomunicações.

\section{CEZAR AUGUSTO ROMANO}

Doutor em Engenharia de Produção pela Universidade Federal de Santa Catarina, graduado em Engenharia Civil pela Universidade Federal do Paraná. É Professor Titular da Universidade Tecnológica Federal do Paraná (UTFPR) onde atua desde 1979. Foi Diretor-Geral do Campus Medianeira (1992-1996), Vice-Reitor da UTFPR (1996-2002) e Diretor-Geral do Campus Curitiba (2014-2017). Foi Conselheiro eleito do Conselho Universitário (COUNI) e do Conselho de Planejamento e Administração (COPLAD) da UTFPR. Atualmente é Professor Permanente do Programa de Pós-Graduação em Engenharia Civil (PPGEC), do Programa de Pós-Graduação em Sustentabilidade Ambiental Urbana (PPGSAU) e do Mestrado Profissional em Administração Pública (PROFIAP), atuando nas áreas de estratégia, planejamento e gestão, com foco na produtividade organizacional.

\section{CHRISTIANE WAGNER MAINARDES KRAINER}

Possui graduação em Engenharia Civil pela Universidade Federal do Paraná (1994), Mestrado em Engenharia Civil pela Universidade Tecnológica Federal do Paraná (2012), Doutoranda em Engenharia Civil pela Universidade Tecnológica Federal do Paraná (2017), MBA em Marketing pela Fundação Getúlio Vargas (FGV). Professor colaborador de Engenharia Civil da Universidade Federal do Paraná e pesquisadora da Universidade Tecnológica Federal do Paraná. Atua nos seguintes temas de pesquisa: supply chain, logística, gestão integrada da produção, relacionamento interorganizacional, gestão da construção com foco na produtividade organizacional e gestão do conhecimento.

\section{CRISTIANO ROOS}

Professor do Departamento de Engenharia de Produção e Sistemas no Centro de Tecnologia da Universidade Federal de Santa Maria. É Engenheiro de Produção, Especialista em Engenharia de Produção pela Universidade Federal do Rio Grande do Sul, Mestre em Engenharia de Produção pela Universidade Federal de Santa Maria, e Doutor em Engenharia de Produção pela Universidade Federal de Santa Catarina. 


\section{DAISY APARECIDA DO NASCIMENTO REBELATTO}

Possui graduação em Engenharia Civil pela Universidade Federal de São Carlos (1984), mestrado em Engenharia de Produção pela Universidade de São Paulo (1992), doutorado em Engenharia Mecânica pela Universidade de São Paulo (1999), pós-doutorado pela Universidad Complutense de Madrid (2004) e pela Universidad de Salamanca (2008), livre-docência pela Universidade de São Paulo (2005). Atualmente é professor associado da Universidade de São Paulo, membro do corpo editorial dos periódicos: - Revista de Engenharia e Ciências Aplicadas , - Produção (São Paulo) (0103-6513), - Revista Produção Online, - RAP. Revista Brasileira de Administração Pública e Gestão e Produção (UFSCar). Tem experiência na área de Engenharia de Produção, com ênfase em Engenharia Econômica, atuando principalmente nos seguintes temas: análise de investimento, competitividade, inovação tecnológica, sustentabilidade, capital privado e capital público.

\section{DANIEL GETÚLIO FERNANDES RIBEIRO}

Mestrando em Engenharia Civil pela Universidade Tecnológica Federal do Paraná (2019), possui Bacharelado em Engenharia Civil pela Universidade do Planalto Catarinense (2018). Atua nos seguintes temas de pesquisa: construção civil, gestão da construção, desempenho, processo de padronização de processos nos canteiros de obra, supply chain, logística, gestão integrada da produção, relacionamento interorganizacional, gestão da construção com foco na produtividade organizacional e gestão do conhecimento.

\section{DAVID DE ALMEIDA MOYSÉS}

Possui graduação em Engenharia de Produção pela Universidade de Brasília (2018). Atualmente é assistente de projeto de pesquisa da Fundação de Empreendimentos Científicos e Tecnológicos (FINATEC) atuando com um a proposição de um modelo de Gestão do Conhecimento aplicado aos processos do Sistema de Pessoal do Exército Brasileiro. Tem experiência na área de Engenharia de Produção, com ênfase em Gestão de Projetos, atuando principalmente nos seguintes temas: qualidade de serviço, gerenciamento de projetos ágil, gerenciamento de processos e equações estruturais.

\section{DIOGO FERRAZ}

Doutor em Engenharia de Produção pela Universidade de São Paulo (USP). Ph.D. candidate em Economia da Inovação na Universität Hohenheim. Economista. Possui experiência em indicadores sociais, modelos econométricos e Data Envelopment Analysis (DEA). Utiliza dados do Banco Mundial, PNAD/IBGE e RAIS/CAGED (MTE) por meio dos softwares Stata e Matlab. A área de pesquisa relaciona questões sobre Bioeconomia, Desenvolvimento Humano, Complexidade Econômica e Inovação. Em 2019, recebeu o prêmio Lions-Club-Förderpreis na Alemanha. Membro dos grupos de pesquisa: Análise de Desempenho de Sistemas Produtivos (USP), Sustentabilidade e Desenvolvimento Humano (UNESP-Bauru), Gestão e Tecnologia (GeTec/UFSCar) e Grupo de Estudos em Finanças (GeFin/UFSCar).

\section{DIOGO LÔNDERO DA SILVA}

Possui doutorado e mestrado (2008) em Engenharia Mecânica e graduação em Engenharia de Alimentos pela Universidade Federal de Santa Catarina. Em 2011, participou do programa de doutorado sanduíche na Brunel University, Inglaterra, onde desenvolveu parte da sua pesquisa sobre a formação de gelo em trocadores de calor e seus impactos sobre a eficiência energética de sistemas de refrigeração. É autor de patentes, tem experiência com o desenvolvimento e validação experimental de modelos matemáticos de sistemas de refrigeração e como engenheiro de P\&D em empresas da área de refrigeração e produção de alimentos. Atualmente, é professor na Universidade Federal de Santa Catarina e desenvolve atividades de pesquisa e extensão na área de refrigeração e condicionamento de ar.

\section{EDGARD COSTA OLIVEIRA}


Professor Adjunto IV do Departamento de Engenharia de Produção da Universidade de Brasília, EPR/FT/UnB desde 2017. De 2008 a 2017 foi professor da Faculdade UnB Gama FGA/Engenharia de Software. Pós-doutorado em Ciência da Computação CIC/UnB (2017), sob orientação da Brunel University London. Doutor e Mestre em Ciência da Informação pela UnB/FCI (2006 e 2001). Doutorado Sanduíche na Vrije Universiteit Amsterdam, Dept. de Ciência da Computação (20042005). Coordenador de Linha de Pesquisa e professor do Mestrado Profissional em Computação Aplicada/ Governança e Gestão de Riscos do CIC/UnB. Pesquisador e professor em disciplinas: Sistemas de Informação, Gerenciamento de Projetos, Web Semântica e Ontologias, Projeto Integrador de Engenharias, Introdução à Engenharia, Governança e Gestão de Riscos, Normas e Padrões de Segurança da Informação, Humanidades e Cidadania para Engenharias.

\section{ELDELITA ÁGUIDA PORFÍRIO FRANCO}

Possui graduação em Engenharia Agronômica pela Universidade Federal do Piauí (1993), graduação em Processamento de Dados pela Universidade Estadual do Piauí (1999), Especialização em Ciência Ambiental, pela Universidade Federal do Piauí (2002), Mestrado em Desenvolvimento e Meio Ambiente pela Universidade Federal do Piauí (2005) e Especialização em Docência do Ensino Superior, pela Faculdade Santo Agostinho (2014). Atualmente é Coordenadora e Docente do Curso de Bacharelado em Engenharia de Produção no Centro Universitário Santo Agostinho.

\section{ESTEFÂNIA PAULA DA SILVA}

Professora no IFMG-Campus Bambuí. Pós-graduanda em Engenharia de Segurança no Trabalho (UNIMAIS). Especialista em Gestão Pública (UFLA). Engenheira de Produção (IFMG-Campus Bambuí). Tecnóloga em Sistemas para Internet (IFMG-Campus Bambuí)

\section{ETHEL CRISTINA CHIARI DA SILVA}

Graduada em Engenharia de Produção e Materiais pela Universidade Federal de São Carlos (UFSCar) em 1990; Mestre em Engenharia (área de concentração: Engenharia Mecânica) pela Escola de Engenharia de São Carlos/Universidade de São Paulo (EESC/USP) em 1994 e Doutora em Engenharia (área de concentração: Engenharia Mecânica) pela mesma instituição em 1999. Atuou por cinco anos em empresa de médio porte do setor metal mecânico, sendo consultora interna nas áreas de planejamento e controle da produção e gestão de pessoas. É coordenadora do Curso de Graduação em Engenharia de Produção da Universidade de Araraquara (UNIARA) e, na mesma instituição, está vinculada ao Programa de Mestrado Profissional em Engenharia de Produção.

\section{FLÁVIO AUGUSTO CARRARO}

Arquiteto e Urbanista, Grad. pela Universidade Estadual de Londrina (UEL-2003). Engenheiro Civil, Grad. Pela Pitágoras. (2019) Esp. Eng. Seg. Trabalho pela Universidade Tecnológica Federal do Paraná (UTFPR-CP-2011). Mestre em Eng. de Edificações e Saneamento (bolsista CNPQ - UEL 2012). Assessor de Planejamento Físico (Arquiteto) Universidade Estadual de Londrina (UEL2012/13) . Professor da Universidade Norte do Paraná (UNOPAR) e Centro Universitário Filadélfia (2013/2014_UNIFIL). Instrutor do Curso Técnico em Design de Interiores SENAC (2013/2014 Londrina-Uep02). Coordenador do Curso Superior de Tecnologia em Segurança do Trabalho EaD KROTON (2014-2018 ) Atualmente: Coordenador do Curso Bacharelado em Arquitetura e Urbanismo KROTON \& Coordenador do Curso Superior de Tecnologia em Design de Interiores KROTON. Áreas maior atuação profissional Arquitetura/projetos: Industrial e Institucional. Área maior atuação Seg. Trab: Industrial e Institucional, programas e treinamentos. Área de interesse em pesquisa acadêmica: Gestão do projeto de edificações, projetos, meio ambiente e saneamento ambiental.

\section{GABRIEL ALEXANDRE MÜLLER}

Graduando em Engenharia de Transportes e Logística pela Universidade Federal de Santa Catarina. 


\section{GENYVANA CRISCYA GARCIA CARVALHO}

Autora possui graduação em Direito pela Faculdade CEUT (2010) e Graduação em Pedagogia pela Universidade Federal do Piauí -UFPI (2010). Mestrado em Educação pela Universidade Federal do Piauí - UFPI (2013). Doutoranda UNIP/São Paulo. Especialização em Direito Previdenciário pela Faculdade Estácio de Teresina e Especialização em Docência do Ensino Superior pela Faculdade Ítalo Brasileira - FIB. Atualmente é Advogada. Professora e Coordenadora do Curso de Bacharelado em Direito da Faculdade CHRISFAPI e Pedagoga da Secretaria Municipal de Saúde de Piripiri.

\section{GEVAIR CAMPOS}

Mestre em Agronegócios pelo Programa de pós Graduação em Agronegócios (PROPAGA) da Universidade de Brasília (UnB); Especialista em Gestão do Agronegócio e Legislação Ambiental pela Universidade Cândido Mendes (UCAM); Docente pela Faculdade CNEC Unaí

\section{GUILHERME NETO FERRARI}

Graduando em Engenharia de Produção com ênfase em Software pela Universidade Estadual de Maringá, bolsista no projeto de extensão intitulado Projeto SIMOPE: Sistema de Mobilidade para Portadores de Necessidades Especiais aplicado às práticas de Equoterapia, foi bolsista também no Programa Institucional de Bolsas de Iniciação em Desenvolvimento Tecnológico e Inovação (PIBITI), tem experiência nas áreas de planejamento e desenvolvimento de software, processo de desenvolvimento de produtos e ergonomia.

\section{GUSTAVO DE SOUZA}

Atualmente Doutorando em Materiais Derivados de Fontes Renováveis pelo Programa da PósGraduação em Ciência e Engenharia de Materiais (PGrCEM) - Universidade de São Paulo. Engenheiro de Materiais e Manufatura pela Escola de Engenharia de São Carlos EESC-USP (2016). ORCID: https://orcid.org/0000-0002-9056-8550

\section{ISABEL CRISTINA RAVAZZI FERNANDES NOGUEIRA}

Graduação em Administração de Empresas pela Faculdades Integradas Antônio Eufrásio de Toledo e Especialização em Desenvolvimento Gerencial e Marketing pela mesma instituição. Especialização em Psicopedagogia Institucional e Especialização em Administração Hospitalar pela UNIVALE. Atualmente é professora titular da Universidade do Oeste Paulista. Tem experiência na área administrativa, atuando principalmente nos seguintes temas: empreendedorismo, marketing e logística

\section{ISABELLA HELENA TAVARES DE MORAIS}

Graduanda em Engenharia de Produção pela Universidade de Brasília (UnB). Atualmente é estagiária na Empresa de Planejamento e Logística participando da equipe de desenvolvimento do Boletim de Logística do Observatório Nacional de Transporte e Logística (ONTL). Tem experiência na área de Engenharia de Produção.

\section{ISOTILIA COSTA MELO}

Doutorado em Engenharia de Produção (em andamento). Mestrado em Engenharia de Produção (concluído). Experiência no setor automotivo como engenheira do produto e de qualidade (5 anos). Especialização em Engenharia de Soldagem. Graduação em Engenharia Mecânica. 


\section{IVONALDA BRITO DE ALMEIDA MORAIS}

A autora é Diretora de Ensino e professora do curso de Direito da Christus Faculdade do PiauíCHRISFAPI; Advogada e Procuradora Geral do Município de Piracuruca-PI. Doutoranda pela Universidade Paulista - UNIP, Mestra em Administração (Linha de pesquisa Gestão de Sistemas Educacionais) pela Faculdade de Estudos Administrativos de Minas Gerais, graduada em LETRAS/ Português (1997) e em Direito (2007), pela Universidade Estadual do Piauí- UESPI. Especialista em Docência do Ensino Superior, pela Universidade Cândido Mendes; em Gestão Escolar, pela Universidade Federal do Piauí-UFPI e em DIREITO PENAL, pela Faculdades Integradas de Jacarepaguá- FIJ.

\section{JEFFERSON AUGUSTO KRAINER}

Doutorando em Engenharia Civil pela Universidade Tecnológica Federal do Paraná (2017), Mestre em Ciência, Gestão e Tecnologia da Informação pela Universidade Federal do Paraná (2013), possui Bacharelado em Direito pela Faculdade de Direito de Curitiba (1995). Professor colaborador da Universidade Estadual do Paraná nos cursos de Ciências Sociais e pesquisador da Universidade Tecnológica Federal do Paraná. Atua nos seguintes temas de pesquisa: construção civil, supply chain, logística, gestão integrada da produção, relacionamento interorganizacional, gestão da construção com foco na produtividade organizacional e gestão do conhecimento.

\section{JESSICA ALVES JUSTO MENDES}

Formada em engenharia de produção pela Universidade Federal Fluminense (UFF, Capus Volta Redonda). Iniciação cientifica na área de produção de energia através de resíduos de lactose, com ênfase em estudo de viabilidade técnica e ambiental. Experiência internacional: Intercambio no Canadá, em Vancouver, onde cursou um módulo de Business, na Pacific Gateway Internacional College (PGIC). Pós-graduação concluída na Universidade Paulista (Unip, Campus: São José dos Campos), em Qualidade e Produtividade, com certificação Green Belt. Atualmente cursando mestrado na Universidade Federal de Pernambuco (UFPE), conceito CAPES 7. Tem interesse nas áreas de decisão multicritério, gestão da qualidade, energias renováveis e controle estatístico da produção.

\section{JORGE LUIZ ANDRADE RAMOS}

Bacharel em Administração pela Faculdade CNEC Unaí.

\section{JULIA ESTEFANE GONÇALVES}

Acadêmica de Engenharia de Produção no Centro Universitário Adventista de São Paulo (campus Engenheiro Coelho). Atualmente, auxilio como voluntária no curso, ministrando monitorias da matéria de Física I e sou integrante de grupos de iniciação científica. Visando a importância do constante aprendizado, possuo amplo interesse em buscar novos conhecimentos e compartilhá-los, beneficiando a sociedade na qual estou inserida.

\section{JULIANA ALBERTON FRIAS}

Engenheira Ambiental, graduada pela Pontifícia Universidade Católica do Paraná - PUCPR (2010), com especialização em Engenharia de Segurança do Trabalho pela Universidade Paranaense UNIPAR (2014) e mestra pela Universidade Estadual de Londrina - UEL na área de Engenharia de Edificações e Saneamento (2015). Possui experiência em: gestão de cursos na Educação Superior, com atuação na docência e coordenação na modalidade à Distância, bem como projetos para segurança do trabalho; e Licenciamento ambiental. Nomeada membro da Comissão Assessora de Área de Tecnologia em Segurança do Trabalho, do Enade 2019, no Instituto Nacional de Estudos e Pesquisas Educacionais Anísio Teixeira (INEP). 


\section{KAROLINE ARGUELHO DA SILVA}

Possui graduação em Engenharia de Produção pela Universidade Federal da Grande Dourados. Tem experiência na área de Engenharia de Produção, atuando principalmente nos seguintes temas: planejamento e controle da produção, custos, rentabilidade, análise de viabilidade, projetos industriais, engenharia da qualidade, vivência em gerenciamentos de rotina, desenvolvimento de processos, gestão de resultados, gestão de pessoas. Mestre em Engenharia Agrícola pela Universidade Federal da Grande Dourados. Doutoranda no programa de Pós Graduação em Engenharia de Produção pela Escola de Engenharia de São Carlos (EESC-USP).

\section{KELLY ALONSO COSTA}

Possui graduação em Engenharia Civil pela Universidade Federal Fluminense, mestrado em Engenharia Civil pela Universidade Federal Fluminense e doutorado em Engenharia Civil. Atualmente é professor Adjunto da Universidade Federal Fluminense, Polo de Volta Redonda, pertencente ao Departamento de Engenharia de Produção. Tem experiência e pesquisa na área de Engenharia Civil, com ênfase em Materiais, Avaliação em ciclo de vida, cálculo e em Engenharia de Produção em Sistemas de Informação, Indústria 4.0 e Estatística.

\section{KELLY VANESSA BARBOSA CONCEIÇÃO}

Graduada em Engenharia de Produção pela Universidade Ceuma, tendo artigos científicos aprovados em congressos nacionais e, atualmente, participando como autora na Oficina de Escrita da Universidade Ceuma.

\section{LAÍNE DE CÁSSIA TEIXEIRA}

Graduanda de Engenharia de Produção do Instituto Federal de Minas Gerais - campus Bambuí. Tutora de Eletromagnetismo (2017/2019). Representante Discentes no Conselho de Orientação Disciplinar da Moradia Estudantil (CODIME) (2018/2019). Presidente do Grupo de Estudos de Sinais de Processos (2018/2019). Tesoureira do Diretório Acadêmico da Engenharia de Produção (2019/2020).

\section{LENITA DUARTE}

Possui graduação em Engenharia de Produção pela Universidade Luterana do Brasil - ULBRA (2019). Atua na área de Engenharia de Produção.

\section{LISLEY PANFILO SANTOS}

Cursando Engenharia de Produção no Centro Universitário Adventista de São Paulo (Campos Engenheiro Coelho). Atualmente monitora voluntaria de calculo II para alunos de engenharia de produção. Monitora voluntária de Calculo I e SOLIDWORKS. Sempre em busca do envolvimento em projetos de pesquisa e outros projetos de voluntariado que promovam o desenvolvimento profissional e pessoal, visando agregar valores que me permitam ajudar a sociedade.

\section{LUIDSON COELHO FERNANDES}

Graduado em Engenharia de Produção pela Universidade Ceuma. Participação em capítulos nos livros de Engenharia de Produção com autoria dos alunos e professores da Universidade Ceuma. Membro da Oficina de Escrita da Universidade Ceuma, atuando como autor. Desenvolvedor de artigos científicos com aprovações em periódicos e congressos nacionais. Atualmente, é responsável pelo departamento de suprimentos do hospital UDI de São Luís. 


\section{LUIS GABRIEL DE ALENCAR ALVES}

Graduando em Engenharia de Produção Mecânica pela Universidade Regional do Cariri - URCA. Foi Bolsista de Iniciação Científica (CNPq) entre 2017 a 2019. trabalhando na área de Recursos Hídricos e desenvolvimento de softwares.

\section{LUIS MANOEL BORGES GOUVEIA}

É Professor Catedrático na Universidade Fernando Pessoa (UFP) desde Janeiro de 2017, onde se encontra desde 1994. Desde 2006, é coordenador do Doutoramento em Ciência da Informação, especialidade de Sistemas, Tecnologia e Gestão da Informação. Colaborou com diversas instituições de ensino superior nacionais e estrangeiras. É autor de 18 livros de caráter técnico e especializado sobre temas associados com o uso e exploração do digital na atividade humana. Possui cerca de 400 publicações em revistas, capítulos de livros e conferências de natureza científica. Colaborou em projetos como coordenador ou responsável técnico, envolvendo o uso e aplicação de tecnologias em contexto organizacional no setor público (governo central e local, administração pública local) e privado (em diversos setores de atividade e dimensões de empresas) em áreas como as cidades digitais, os sistemas de informação, o elearning e a gestão do conhecimento. Os seus interesses estão associados com o uso e exploração do digital e as suas aplicações, nomeadamente em sistemas de informação e na gestão do conhecimento. Possui página na Web: http://homepage.ufp.pt/lmbg/.

\section{MACÁLISTON GONÇALVES DA SILVA}

Doutorando em Engenharia de Produção e Sistemas pela Universidade do Vale do Rio dos Sinos UNISINOS, possui mestrado em Engenharia de Produção e Sistemas (2010) e graduação em Engenharia de Produção Mecânica pela UNISINOS (2003). É professor pesquisador em Engenharia de Produção pela Universidade Luterana do Brasil - ULBRA. http://orcid.org/0000-0002-74466909

\section{MANOEL EULÁLIO NETO}

O autor possui graduação em Bacharelado em Ciências Contábeis pelo Centro de Ensino SUPERIOR do Vale do Parnaíba (1992) e Mestrado em Economia pela Universidade Federal do Ceará (2007). Pós-Graduação em Administração Financeira (Universo-1996). Pós-Graduação em Docência do Ensino Superior (FSA -2008). Atualmente é professor da Faculdade Santo Agostinho, e professor efetivo da Universidade Estadual do Piauí - UESPI. Tem experiência na área de Auditoria, Administração Bancaria, Economia e Administração e Gestão Financeira. É Doutorando em Engenharia de Produção na Universidade Paulista - UNIP.

\section{MANUEL ANTONIO MOLINA PALMA}

Professor Associado lotado no Laboratório de Engenharia de Produção, Centro de Ciência e Tecnologia da Universidade Estadual do Norte Fluminense Darcy Ribeiro - UENF. Doutorado em Administração pela Faculdade de Economia, Administração e Contabilidade da Universidade de São Paulo - FEA/USP; Mestrado em Administração de Empresas pelo Instituto Centroamericano de Administración de Empresas - INCAE Business School (Alajuela, Costa Rica), Bacharel em Administração pela Universidade Federal de Viçosa, Viçosa, MG. Diretor da Agência UENF de Inovação (gestão 2016-2019), Pró-Reitor de Graduação (gestão 2020-2023).

\section{MARCELO FRANCA ALVES JÚNIOR}

Graduando de Engenharia de Produção no UNASP. Voluntário no Núcleo de Tecnologia de Engenharia e Arquitetura na operação de cortadora a laser CNC e impressora 3D. Possui conhecimento Intermediário em SOLIDWORKS. Participante ativo de grupos de pesquisa nos campos de: Otimização Matemática; Conforto Térmico; Estratégia da Indústria Siderúrgica no Brasil; Custos Industriais. Aluno, em 2017, de programa de intercâmbio linguístico e cultural no Kingsway College, Canadá. 


\section{MARCIO RONALD SELLA}

Aluno do programa de Doutorado em Metodologias para o Ensino de Linguagens e suas Tecnologias pela UNOPAR, Mestre em Engenharia de Produção pela UNIARA (Universidade de Araraquara), Especialista em Administração Industrial pela UEL (Universidade Estadual de Londrina) e Bacharel em Engenharia de Produção Mecânica pela FEI (Faculdade de Engenharia Industrial). Atua como docente do ensino superior desde 2011 e como Coordenador de curso de graduação EaD desde 2015. Possui experiência de mais de 20 anos nas áreas de produção e logística conduzindo equipes de trabalho em empresas de médio a grande porte nos setores de varejo nacional e industrial. Reconhecido ao longo da carreira pelo profissionalismo, rápido aprendizado e pelos resultados obtidos.

\section{MARCO ANDRÉ MATOS CUTRIM}

Graduado em Engenharia de Produção pela Universidade Ceuma. Pós-graduando do MBA em Gestão da Qualidade e Engenharia de Produção pelo IPOG. Participação em capítulos de livros voltados para a Engenharia de Produção, com autoria dos alunos e professores da Universidade Ceuma. Membro da Oficina de Escrita da Universidade Ceuma, atuando como autor, tutor e organizador. Desenvolvedor de artigos científicos com aprovações em periódicos e congressos nacionais. Atualmente, é auxiliar de operações da Localiza Rent a Car.

\section{MARIA DE LOURDES SANTIAGO LUZ}

Graduada como Engenheira Eletricista e Engenheira de Produção Eletricista pelo Centro Universitário da FEI. Possue pós-graduação em Especialização de Alimentos, Mestrado em Agronomia pela Universidade Estadual de Maringá e Doutorado em Engenharia de Produção pela Universidade Federal de São Carlos.. Atualmente é Professora de Ensino Superior, na classe de Professor Adjunto do curso de Engenharia de Produção, da Universidade Estadual de Maringá. Desenvolve atividades de ensino e pesquisa nas áreas de conhecimento relacionadas à Gestão de Produção, Segurança do Trabalho e Ergonomia. Pesquisadora integrante do Grupo de Pesquisa em Ergonomia: Organização e Sociedade (GEOS).

\section{MATHEUS BINOTTO FRANCESCATTO}

É estudante de Engenharia Mecânica pela Universidade Federal de Santa Maria. Atuou como Estagiário na empresa Indutar Tecno Metal. Participou como monitor durante um ano na disciplina de Mecânica para a Engenharia Mecânica.

\section{NELSON ANTONIO DE MELLO SILVA JUNIOR}

Mestrando no Programa de Engenharia de Alimentos na Universidade Estadual de Maringá (UEM). Bacharel em Engenharia de Produção pela Universidade do Grande Rio. Projeto final do curso de título Gestão por Processos na Área de Planejamento de Call Center, ênfase em Forecasting. Atualmente é analista de planejamento e professor de engenharia no EAD, na Instituição de Ensino UNICESUMAR, atuando na docência do ensino superior no curso de Engenharia de Produção. Tem experiência de cinco anos na área de planejamento de Call Center, e posteriormente no setor bancário, onde atuou por quase dois anos na empresa Bradesco S/A.

\section{NICOLAS ANDRÉ ALVES DA SILVA}

Mestrando no Programa de Engenharia de Sistemas e Computação (PESC) da COPPE/UFRJ. Bacharel em Engenharia Eletrônica pelo CEFET/RJ). Intercâmbio pelo programa Ciência sem Fronteiras em Budapeste, Hungria, cursando disciplinas do curso de Engenharia Elétrica da Óbuda University e estágios de férias realizados nos laboratórios da própria instituição. Atuação profissional como estagiário na empresa PETROBRAS, na área de projeto, onde foi possível desenvolver o projeto de um laboratório para a empresa, projeto que definiu o trabalho de conclusão de curso; estágio na empresa GLOBOSAT, na área de produção externa, onde era feita 
montado todo o sistema de TV, que inclui captação de imagem, audio e comunicação interna; entre outros.

\section{ODUVALDO VENDRAMETTO}

O autor possui graduação em Fisica pela Universidade de São Paulo (1970), mestrado em Física pela Universidade de São Paulo (1987) e doutorado em Engenharia (Engenharia de Produção) pela Universidade de São Paulo (1994).

\section{PAULA CONCEIÇÃO ROCHA DE OLIVEIRA}

Graduanda em Design de Produto pela Universidade Estadual de Maringá, bolsista no projeto SIMOPE (Sistema de Mobilidade para Portadores de Necessidades Especiais aplicado às práticas de Equoterapia), participou do projeto de pesquisa LEAD (learning experiences for approaching design). Experiência profissional com modelagem 3D e desenho técnico de produto.

\section{PEDRO EUGÊNIO SABIÁ}

Empreendedor na área de Logística e Meio Ambiente, pesquisador voluntário do Laboratório de Águas, Efluentes e Metais Pesados (LAEMP) da Universidade Regional do Cariri, administrador de empresas e graduando em Advocacia.

\section{RAFAEL MACIEL DA SILVA}

Possui graduação em Engenharia de Produção pela Universidade Luterana do Brasil - ULBRA (2019). Atua na área de Engenharia de Produção.

\section{RAQUEL APARECIDA ALVES}

Mestre em Agronegócios pelo Programa de pós Graduação em Agronegócios (PROPAGA) da Universidade de Brasília (UnB); Especialista em Gestão de Pessoas pelo Instituto de Ensino Superior Cenecista (INESC); Docente pela Faculdade CNEC Unaí

\section{RAYMUNDO JORGE DE SOUSA MANÇÚ}

Auditor Líder em Sistemas de Gestão do SGI e dos Regulamentos Técnicos da ANP. Doutorando em Ciência da Informação pela Universidade Fernando Pessoa (UFP) - Cidade do Porto - Portugal (2018-Atual). Mestrado em Administração Estratégica pela Universidade Salvador (UNIFACS) Salvador-Ba (2006-2008). Especialista em Sistemas de Gestão Integrados (SGI) pelo Centro Universitário Jorge Amado (UNIJORGE) - Salvador-Ba (2005-2006). Graduação em Administração com Habilitação em Gestão de Negócio pela Faculdade Santíssimo Sacramento (FSSS) - AlagoinhasBa (2001-2004). Professor de Engenharia e de Administração (2009-Atual). Coordenador da PósGraduação de Gestão de Petróleo e Gás Natural da Faculdade Santíssimo Sacramento.

\section{ROBERTA PINHEIRO BORTOLASSI}

Formada em Engenharia de Produção pela Universidade de Araraquara. Mestre em Engenharia de Produção pela Universidade de Araraquara. Linha de pesquisa na área da Educação em Engenharia de Produção

\section{ROBERTO GUZMAN SANCHEZ}

Mestre Em Engenharia. Bacharel em Engenharia Metalúrgica. Bacharel em Administração. 32 anos de experiência profissional técnica e de gestão em empresa siderúrgica integrada Cosipa/Usiminas- Área de Planejamento e controle da produção e Engenharia de produção. 19 anos de experiência docente. 


\section{RODOLFO JOSÉ SABIÁ}

Possui graduação em Agronomia pela Universidade Federal do Ceará (1993), mestrado em Engenharia Civil (Recursos Hídricos) pela Universidade Federal do Ceará (2000), doutorado em Engenharia Civil (Saneamento Ambiental) pela Universidade Federal do Ceará (2008) E Pós Doutorado em Engenharia de Produção pela Universidade Estadual Paulista- Unesp (2015). Atualmente é professor associado 0 do Departamento de Engenharia de Produção da Universidade Regional do Cariri, tem experiência nas áreas de Gestão Ambiental, Gestão de Recursos Hídricos, Gestão de Resíduos Sólidos e Líquidos , Análise de Metais Pesados em Águas e Decision making. Coordenador do Laboratório de Águas, Efluentes e Metais Pesados da Universidade Regional do Cariri. Pesquisador do CNPq desenvolvendo Projeto Universal intitulado: "SISTEMA DE SUPORTE A DECISÃO COMBINADO A PEGADA HÍDRICA PARA À ANÁLISE DA SUSTENTABILIDADE EM REGIÃO SEMIÁRIDA".

\section{ROSIMEIRE FERNANDES CRUZ PEREIRA}

Mestre em Agronegócios pelo Programa de pós Graduação em Agronegócios (PROPAGA) da Universidade de Brasília (UnB); Docente pela Faculdade do Noroeste de Minas (FINOM)

\section{SHIRLEY LIMA SILVA}

Graduanda de Engenharia de Produção do Instituto Federal de Minas Gerais - campus Bambuí. Representante Discentes no Conselho de Orientação Disciplinar da Moradia Estudantil (CODIME) (2019/2020). Estagiária no Instituto Federal de Minas Gerais - campus Bambuí (2019/2020). VicePresidente Grupo de Estudos de Sinais de Processos (2018).

\section{SILVÉRIO DOS SANTOS BRUNHOSO CORDEIRO}

É Professor Associado da Universidade Fernando Pessoa (UFP). Possui o Doutoramento em Ciências da Administração, área de conhecimento em Políticas Públicas e Administração Aplicada, pela Universidade do Minho. O Mestrado em Administração Pública, também pela Universidade do Minho e a Licenciatura em Direito pela Universidade Portucalense. Ocupou diversos cargos de direção e alta direção em grupos económicos privados e em instituições públicas, como o Centro Hospitalar Conde Ferreira (CHCF) e Centro Hospitalar de Vila Nova de Gaia / Espinho.

\section{THAIS APARECIDA RIBEIRO CLEMENTINO}

Possui formação no curso Técnico de nível médio em Edificações pela EEEP Raimundo Saraiva Coelho (2015). Graduanda em Engenharia de Produção Mecânica pela Universidade Regional do Cariri - URCA (2016). Foi Bolsista de Iniciação Científica (CNPq) entre 2017 a 2019. Atualmente é Bolsista de Iniciação Científica (PIBIC -URCA) na área de Recursos Hídricos.

\section{VANINA MACOWSKI DURSKI SILVA}

Possui graduação em Engenharia de Produção Agroindustrial pela Faculdade Estadual de Ciências e Letras de Campo Mourão e especialização em Gestão de Agronegócios pela Fesurv . Possui o título de mestre e doutora em Eng. de Produção na área de Logística e Transporte pela Universidade Federal de Santa Catarina. Em 2010 participou do programa de doutorado sanduíche no BIBA-Bremer Institut für Produktion und Logistik, Universidade de Bremen. Realizou Pós Doutorado pelo Programa Nacional de Pós Doutorado (PNPD-CAPES) no Depto. de Eng. de Produção da UFSC. Atualmente é professora Adjunto IV do Departamento de Engenharias da Mobilidade da Universidade Federal de Santa Catarina (UFSC), sendo também Coordenadora do Grupo de Pesquisa em Logística Dinâmica e Autônoma que atua em trabalhos de pesquisa e extensão voltados à logística autônoma e à dinamicidade dos sistemas logísticos. É membro da MIT Global SCALE Network: Supply Chain and Logistics Excellence. Atuou como engenheira de produção na área de Planejamento e Controle da Produção em empresas de grande porte como Perdigão Agroindustrial S.A. e Macedo Agroindustrial S.A. Lecionou em cursos de graduação bem como de pós-graduação do tipo lato sensu, além de atuar como consultora. Tem experiência na 
área de Engenharia de Produção, com ênfase em Logística e Transporte, Logística Portuária, Pesquisa Operacional e Planejamento e Controle da Produção, atuando como referee de periódicos nacionais e internacionais relacionados à tais áreas, participando de projetos com diversas universidades, além de possuir uma produção bibliográfica ativa.

\section{VINÍCIUS PIMENTEL MARTINS}

Atualmente aluno de Mestrado Profissional em Engenharia de Produção pela Universidade Federal Fluminense. Possui graduação em Engenharia de Produção pela Universidade Estadual do Norte Fluminense (2018), com bolsa de Iniciação Científica na área de Economia - CNPq (2014 - 2015). Período de graduação sanduíche fomentada pela CAPES em Manufacturing and Systems Engineering and Management - California State University Northridge (2015 - 2016), com estágio de Pesquisa Acadêmica na área de Systems Engineering - Stevens Institute of Technology (2016). Tem experiência como estagiário de Engenharia na área de Planejamento e Controle de Projetos Companhia Siderúrgica Nacional (2017 - 2018), como Analista de Logística Internacional Companhia Siderúrgica Nacional (2018 - 2019), atua como Assistente de Engenharia ll pela mesma empresa (2019).

\section{YURI FARO}

Pós Graduado no MBA de Engenharia de Manutenção da Universidade Federal do Rio de Janeiro (UFRJ). Bacharel em Engenharia de Produção pela Universidade do Grande Rio. Especialista em planejamento e gestão da manutenção com experiência de mais de 5 anos na área e projetos aplicados envolvendo métodos e conceitos da MCC, Reliability-centered maintenance, TPM, Total Productive Maintenance, Gestão de Ativos, entre outros. Atualmente é planejador de manutenção na Sotrel Equipamentos S/A, empresa de grande porte da área de movimentação de cargas pesadas, localizada no Rio de janeiro. 
Agência Brasileira do ISBN ISBN 978-85-7042-205-7

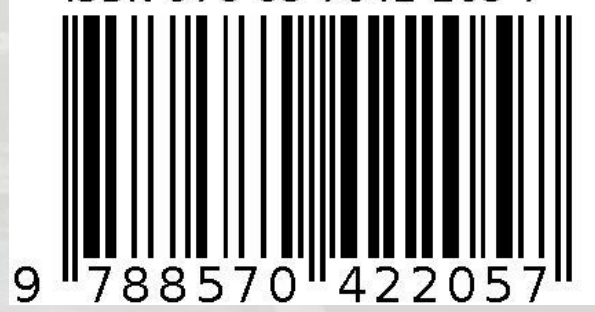

